\title{
VARIABILIDADE DAS LEITURAS DE TENSIOMETROS E SONDA DE NÊUTRONS EM EXPERIMENTOS DE MANEJO DE IRRIGAÇĀO
}

\author{
CLÁUDIO ROBERTO MARCIANO \\ Engenheiro Agrônomo
}

Orientador: Prof. Dr. SERGIO OLIVEIRA MORAES

Dissertação apresentada à Escola Superior de Agricultura "Luiz de Queiroz", da Universidade de São Paulo, para obtenção do título de Mestre em Agronomia. Área de concentração: Solos e Nutrição de Plantas.

P I R A C I C A B A

Estado de São Paulo - Brasil

Novembro - 1995 
Dados Internacionais de Catalogação na Publicação (CIP)

DIVISÃO DE BIBLIOTECA E DOCUMENTAÇAO - Campus "Luiz de Que iroz"/USP

\section{Marciano, Cláudio Roberto}

Variabilidade das leituras de tensiómetros e sonda de nêutrons em experimentos de manejo de irrigaçåo. Piracicaba, 1995.

149. ilus.

Diss. (Mestre) - ESALQ

Bibl iografia.

1. Irrigação - Mane jo 2. Milho - Irrigação 3. Solo - Unidade - Avą liação 4. Sonda de neutron 5. Tensiómetro 1. Escola superior de Agri cultura Luiz de Queiroz, Piracicabo

CDD 631.432

631.7 


\title{
VARIABILIDADE DAS LEITURAS DE TENSIÔMETROS E SONDA DE NÊUTRONS EM EXPERIMENTOS DE MANEJO DE IRRIGAÇĀO
}

\author{
CLÁUDIO ROBERTO MARCIANO
}

Aprovada em: 19/01/1996

Comissão julgadora:

Prof. Dr. Sergio Oliveira Moraes

ESALQ/USP

Prof. Dr. Paulo Leonel Libardi ESALQ/USP

Prof. Dr ${ }^{a}$. Marlene Cristina Alves FEIS/UNESP

\author{
beurees
}

Prof. Dr. SERGIO OLIVEIRA MORAES

Orientador 


\section{AGRADECIMENTOS}

- À Comissão de Pós-Graduação em Solos e Nutrição de Plantas, pela oportunidade de realização do curso de Mestrado;

- Ao Prof. Dr. Sergio Oliveira Moraes, pela orientação, dedicação e amizade;

- Ao Prof. Dr. Paulo Leonel Libardi, pelos ensinamentos recebidos e pelo exemplo de trabalho e dedicação à vida acadêmica;

- Ao CNPq, Conselho de Desenvolvimento Científico e Tecnológico, pela bolsa de estudos concedida;

- Ao DFM/ESALQ/USP e ao Sr. Antônio de Oliveira Lima, proprietário da Fazenda Recanto da Barcelona, em Guaira/SP, pela concessão das áreas experimentais;

- À Agência Internacional de Energia Atômica (IAEA), através do Contrato de Pesquisa $n^{0}$ 6405/R1/RB, e ao Departamento de Ciência e Tecnologia (DCET) da Secretaria de Ciência, Tecnologia e Desenvolvimento Econômico do Governo do Estado de São Paulo, através do Processo $\mathrm{n}^{\mathrm{o}}$ 01173/92, pelo apoio financeiro recebido;

- Aos técnicos José Aparecido Silvério dos Santos e Sebastião Fernandes da Silva Júnior, do IPT, pela dedicação nos trabalhos de campo;

- Aos técnicos Luiz Fernando Novello e Francisco Bernardo Dias, do DFM/ESALQ/USP, pelos trabalhos de campo e digitação dos resultados;

- Ao geólogo Antonio Melhem Saad, do IPT, ao Prof. Dr. Quirijn de Jong van Lier, da UFRGS, e ao engenheiro agrônomo Oscar Vieira, pelo auxilio nos trabalhos de campo e imprescindíveis sugestões;

- Às bibliotecárias Kátia M. de Andrade Ferraz e Eliana M. Garcia Sabino, da DIBD/ESALQ/USP, pela revisão das referências bibliográficas;

- Aos professores do Curso de Engenharia Agronômica da Faculdade de Engenharia de Tha Solteira/UNESP, pela iniciação na vida agronômica;

- A todos que colaboraram para a realização deste trabalho, sinceramente agradeço. 


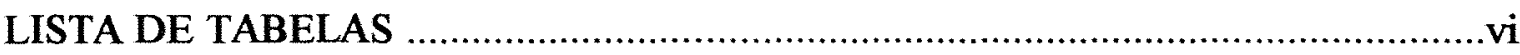

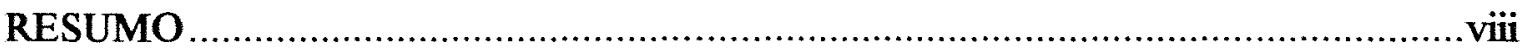

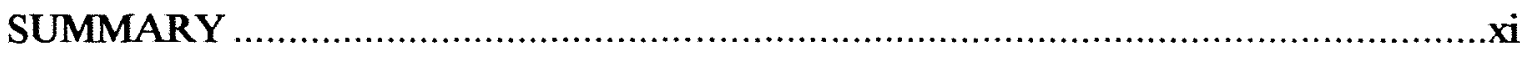

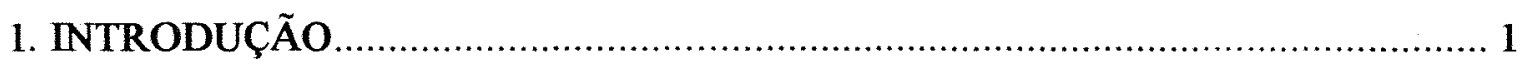

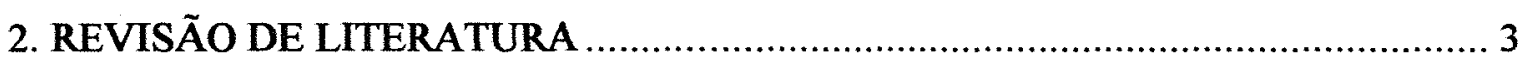

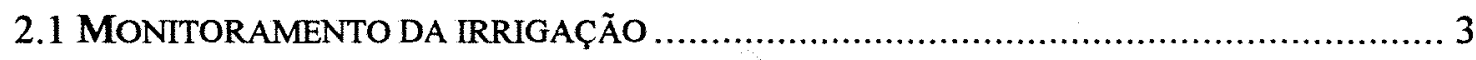

2.2 MÉTODOS DE DETERMINAÇÃo DA UMIDADE DO SOLO ........................................ 6

2.2.1 O tensiômetro: descrição e funcionamento................................................. 7

2.2.2 Leitura do tensiômetro "versus" umidade …................................................ 9

2.2.3 A sonda de nêutrons: descrição e funcionamento ........................................ 11

2.2.4 Leitura da sonda de nêutrons "versus" umidade ........................................ 12

2.3 VARIABILIDADE DA UMIDADE E DA ARMAZENAGEM DE ÁGUA NO SOLO............... 13

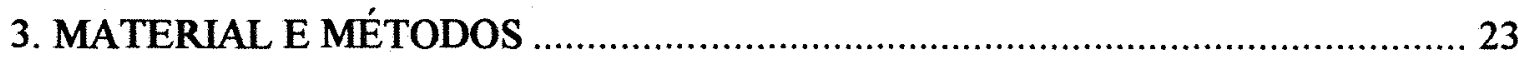

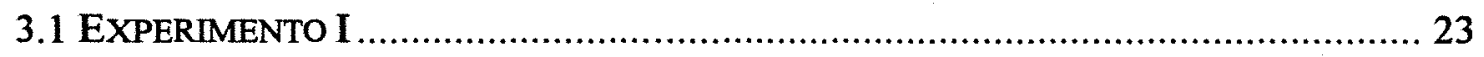

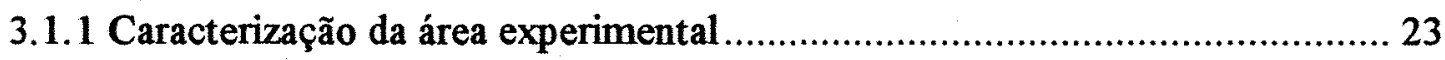

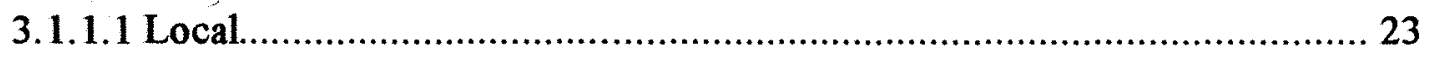

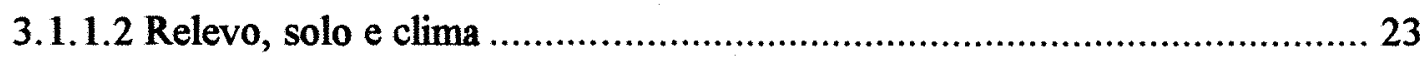

3.1.2 Tratamentos, dimensões das parcelas e delineamento experimental .............. 24

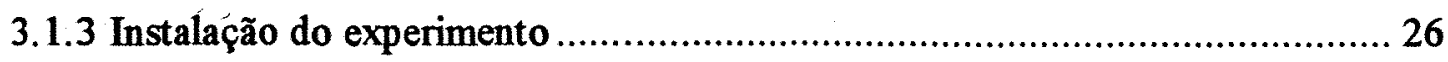

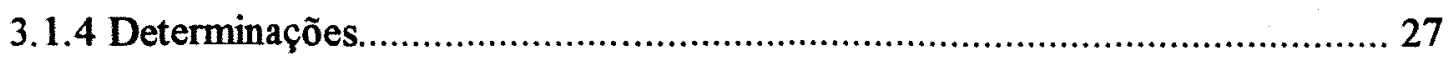




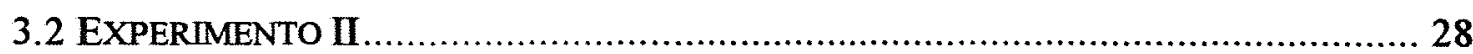

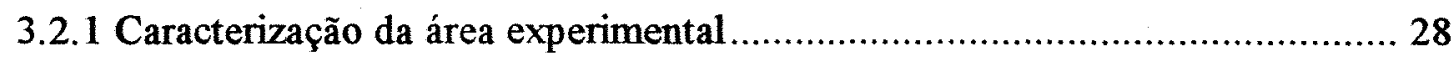

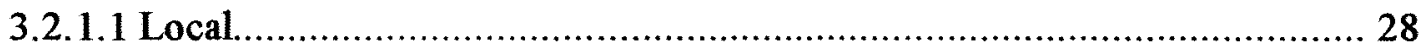

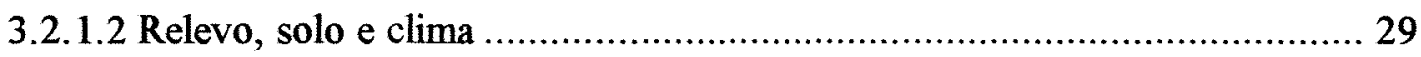

3.2.2 Tratamentos, dimensões das parcelas e delineamento experimental .............. 29

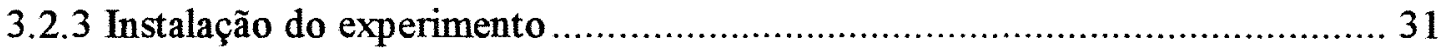

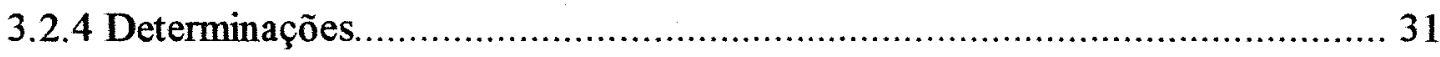

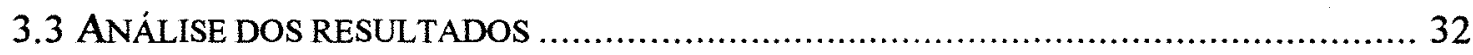

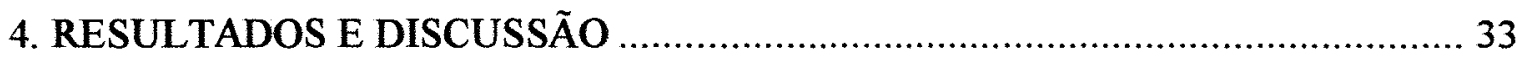

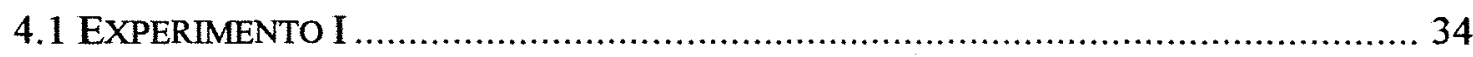

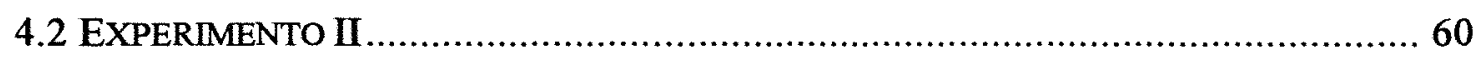

5. CONCLUSÕES

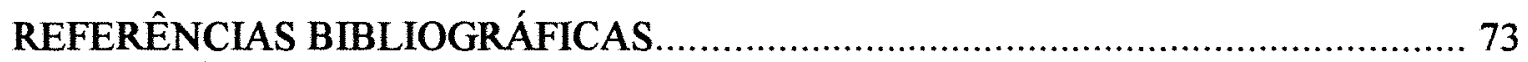

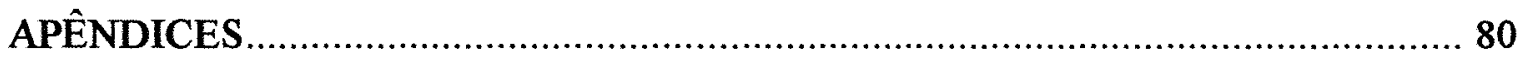

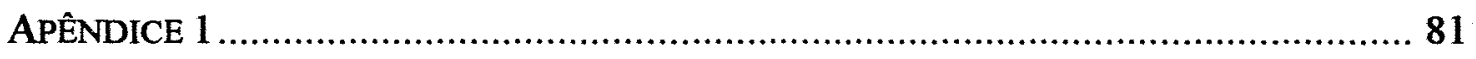

APÊNDICE 2

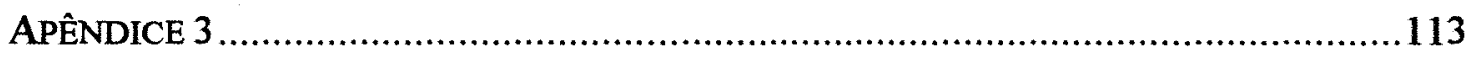

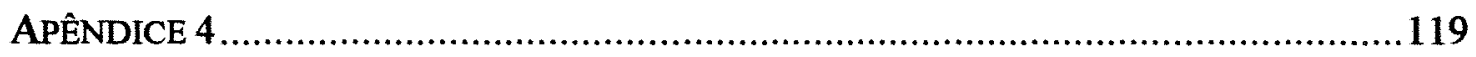

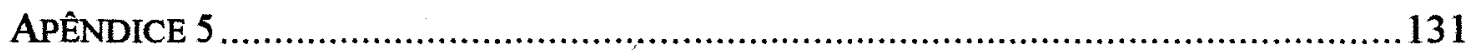

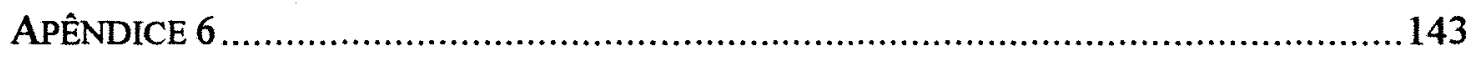


Figura 1 - Esquema da área experimental I.

Figura 2 - Esquema da área experimental II

Figura 3 - Potencial mátrico $\left(\phi_{\mathrm{m}}\right.$, em $\left.\mathrm{kPa}\right)$ e lâminas de água precipitadas ou irrigadas $\left(P+I\right.$, em $\left.\mathrm{m}^{3} / \mathrm{m}^{2}\right)$, ao longo do tempo (DAS, dias após a semeadura): tratamento tr0I0, profundidade $0,10 \mathrm{~m}$

Figura 4 - Variabilidade do potencial mátrico, expressa em termos de desvio padrão (dp), em função do valor desse potencial mátrico $\left(\phi_{\mathrm{m}}\right)$, em $\mathrm{kPa}$ (profundidade $0,20 \mathrm{~m})$

Figura 5 - Relação entre potencial mátrico $\left(\phi_{\mathrm{m}}\right.$, em $\left.\mathrm{kPa}\right)$ e umidade do solo $\left(\theta, \mathrm{em} \mathrm{m}^{3} / \mathrm{m}^{3}\right)$ da área, para profundidade $0,30 \mathrm{~m}$

Figura 6 - Variabilidade da contagem relativa de nêutrons lentos (CR) ao longo do tempo (DAS, dias após a semeadura) e lâminas de água precipitadas ou irrigadas $\left(P+I, \mathrm{~m}^{3} / \mathrm{m}^{2}\right)$ : tratamento $\mathrm{tr} 2$, profundidade $0,30 \mathrm{~m}$.

Figura 7 - Variabilidade da contagem relativa de nêutrons lentos, expressa em termos de desvio padrão (dp), em função do valor dessa contagem (CR): profundidades 0,20 e $0,30 \mathrm{~m}$. 
Tabela 1 - Teste de uniformidade do equipamento de irrigação: lâminas de água e desvio padrão (dp), em $10^{3} \cdot \mathrm{m}^{3} / \mathrm{m}^{2}$; coeficiente de variação (CV) e coeficiente de uniformidade de Christiansen (CUC), em \%; pressão nos tubos na entrada das parcelas, em $\mathrm{kPa}$

Tabela 2 - Resultados referentes às precipitações e irrigações durante o ciclo da cultura: dias após a semeadura (DAS); horário do início das irrigações e precipitações $(\mathrm{H})$ e duração das irrigações (D), em h:min; lâminas de água precipitadas $(P)$, irrigadas (I) e a soma de ambas $(P+I)$, em $\mathrm{m}^{3} / \mathrm{m}^{2}$.

Tabela 3 - Média aritmética (m) e desvio padrão (dp) do potencial mátrico para todo o ciclo da cultura, para cada profundidade e tratamento estudados, e a média aritmética dos desvios padrões diários (mdp) desses potenciais, em kPa.

Tabela 4 - Volumes de água recomendados, $\mathrm{em} \mathrm{m}^{3} / \mathrm{ha}$, calculadas pelo método 1 (média dos potenciais mátricos, substituída na equação) e pelo método 2 (média das umidades para cada potencial mátrico), e os parâmetros da equação de VAN GENUCHTEN (1980).

Tabela 5 - Exemplo de uniformidade no aumento do potencial mátrico (em kPa) das 4 repetições após irrigação (I, em $\left.\mathrm{m}^{3} / \mathrm{m}^{2}\right)$ : tratamento troI0, profundidade $0,20 \mathrm{~m}$.

Tabela 6 - Exemplo de desuniformidade de aumento do potencial mátrico (em $\mathrm{kPa}$ ) das 4 repetições após irrigação (I, em $\left.\mathrm{m}^{3} / \mathrm{m}^{2}\right)$ : tratamento troI0, profundidade $0,20 \mathrm{~m}$. 
Tabela 7 - Exemplo de desuniformidade de aumento do potencial mátrico (em kPa) das 4 repetições após irrigação ( $\mathrm{I}, \mathrm{em} \mathrm{m}^{3} / \mathrm{m}^{2}$ ): tratamento trol0, profundidade $0,30 \mathrm{~m}$.

Tabela 8 - Exemplo de desuniformidade de aumento do potencial mátrico (em $\mathrm{kPa}$ ) após precipitação $\left(\mathrm{P}, \mathrm{em} \mathrm{m} \mathrm{m}^{3} / \mathrm{m}^{2}\right)$ : tratamento troI0, profundidade $0,10 \mathrm{~m}$. 51

Tabela 9 - Parâmetros das regressões lineares entre cada repetição e a média. 55

Tabela 10 - Valores de desvio padrão diário e a média desses desvios para o ciclo da cultura, para o tratamento trIII, considerando as 4 repetições (dp) e descartando-se a repetição mais discrepante da média (dp2), em kPa.

Tabela 11 - Parâmetros das regressões lineares entre cada repetição e a média, para o tratamento trIII, quando descartou-se a repetição mais discrepante da média.

Tabela 13 - Média (m) e desvio padrão (dp) da contagem relativa de nêutrons lentos e a média dos desvios padrões diários (mdp) dessas contagens, para todo o ciclo da cultura.

Tabela 14 - Resultados das regressões lineares entre cada repetição e a média.

Tabela 15 - Médias diárias de contagem relativa (CR) e de umidade a base de massa, e os coeficientes de variação para esses parâmetros, para as profundidades 0,20 e $1,20 \mathrm{~m}$ do tratamento trIII. 


\title{
VARIABILIDADE DAS LEITURAS DE TENSIÔMETROS E SONDA DE NÊUTRONS EM EXPERIMENTOS DE MANEJO DE IRRIGAÇÃO
}

\author{
Autor: CLÁUDIO ROBERTO MARCIANO \\ Orientador: PROF. DR. SERGIO OLIVEIRA MORAES
}

\section{RESUMO}

Neste trabalho foram utilizados dois equipamentos pelos quais se chega indiretamente ao valor da umidade do solo: o tensiômetro e a sonda de nêutrons. $\mathrm{O}$ enfoque dado foi o da avaliação da variabilidade de suas leituras em experimentos com planejamento convencional, para avaliar manejo de irrigação. $\mathbf{O}$ objetivo foi identificar em quais faixas de valores dessas leituras essa variabilidade se manifesta mais acentuadamente, e inferir, com base nos resultados, conseqüências para o manejo da irrigação. Essa avaliação foi realizada em dois experimentos de manejo de irrigação, na cultura do milho, nos municípios de Guaíra e Piracicaba, Estado de São Paulo. No experimento I (Guaíra) avaliou-se a variabilidade do potencial mátrico obtido com o tensiômetro em um Latossolo Roxo. Esse experimento contou de 3 tratamentos (tr000: aplicação de metade da lâmina de água recomendada durante todo o ciclo da cultura; troI0: aplicação da lâmina recomendada somente na fase II da cultura e metade nas 
fases I e III; e trIII: aplicação da lâmina recomendada durante todo o ciclo da cultura), com 4 repetições. Para cada parcela determinou-se o potencial mátrico de 0,10 a $1,00 \mathrm{~m}$ de profundidade, de $0,10 \mathrm{em} 0,10 \mathrm{~m}$. No experimento II (Piracicaba) avaliou-se a variabilidade da contagem relativa de nêutrons lentos em uma Terra Roxa Estruturada Latossólica. Neste caso, o experimento consistiu de 4 tratamentos (trbs: tratamento sem planta; tro, tr1 e tr2: três níveis de Nitrogênio aplicado em cobertura, respectivamente 0,75 e $150 \mathrm{~kg} / \mathrm{ha}$ ), com 3 repetições. Pelos resultados pôde-se concluir que:

1 - A variabilidade do potencial mátrico mostrou-se dependente do valor médio desse potencial, sendo crescente da saturação até aproximadamente $-50 \mathrm{kPa}$ e decrescente desse valor até o potencial mátrico limite de funcionamento do tensiômetro. Considerando valores aproximados de potencial mátrico, a variabilidade foi baixa entre 0 e $-15 \mathrm{kPa}$ e -70 e $-85 \mathrm{kPa}$, média entre -15 e $-40 \mathrm{kPa}$ e -60 e $-70 \mathrm{kPa}$, e variou de média a alta entre -40 e $-60 \mathrm{kPa}$.

2 - Em diversas situações, para as primeiras leituras realizadas após a ocorrência de irrigação ou precipitação pluvial, o potencial mátrico mostrou acréscimo considerável em sua variabilidade, o que só teria importância em termos práticos se o manejo da irrigação fosse baseado no avanço da frente de molhamento no solo.

3 - A variabilidade da contagem relativa de nêutrons lentos foi baixa, não se mostrando claramente dependente do valor dessa contagem. Fica evidenciada a maior estabilidade da sonda de nêutrons quando comparada às do tensiômetro, o que é 
explicado basicamente pelo maior volume de solo por ela amostrado, menos sujeitas a variações pontuais.

4 - Para os parâmetros analisados nos dois experimentos (potencial mátrico e contagem relativa de nêutrons lentos) foi possível identificar repetições que se mostraram excessivamente discrepantes da média para o ciclo da cultura, o que nos permite concluir que seria aconselhável a execução de experimentos que talvez contenham menos tratamentos, porém com um número maior de repetições, todas instrumentadas. 


\title{
VARIABILITY OF READING OF TENSIOMETERS AND NEUTRON PROBE IN IRRIGATION MANAGEMENT EXPERIMENTS
}

\author{
Author: CLÁUDIO ROBERTO MARCIANO \\ Adviser: PROF. DR. SERGIO OLIVEIRA MORAES
}

\section{SUMMARY}

In this work two equipments that measure indirectly the soil water content was studied: the tensiometer and the neutron probe. The main idea was to evaluate the variability of the results of both equipments in conventionaly planned experiments, to evaluate irrigation management. The objective was to identify in which value ranges of these measurements, this variability is higher, and deduce, based on the results, the consequences to the irrigation management. This evaluation was achieved in two irrigation management experiments, in maize crop, in the conties of Guaira and Piracicaba, State of São Paulo, Brasil. In experiment I (Guaíra) the matric potential obtained with the tensiometer was evaluated in a Typic Haphustox, with three treatments ( tr000 - application of half the recommended amount of water along the crop cycle; tr0I0 - application of the total recommended amount of water recomended only in the intermediate stage, and the half of it during the initial and the final stages; and trIII application of the total recommended amount of water during the whole crop cycle), and 
four repetitions. For each plot the matric potential was determined from 0,10 to $1,00 \mathrm{~m}$ deep, every $0,10 \mathrm{~m}$. In experiment II (Piracicaba) the count ratio of thermal neutrons (CR) was evaluated in the Rhodic Kanhapludalf, with four treatments (trbs - treatment without plants - or bare soil; and tro, tr 1 and tr2, three levels of suplementary Nitrogen application $-0 ; 75$ and $150 \mathrm{~kg} / \mathrm{ha}$, respectivity), and 3 repetitions. From the results, the following could be concluded:

1 - The matric potential variability was high and dependent upon the value of this potential. It increased from saturation to aproximetely $-50 \mathrm{kPa}$, and decreased from $-50 \mathrm{kPa}$ to the matric potential limit value of the tensiometer functioning.

2 - In several situations, the first measurements after irrigations or rains, the matric potential showed a considerable increase in its variability, which would only be important if the irrigation management had been based on the advance of wetting front in the soil.

3 - The variability of CR was small, and it did not clearly depend on the CR value. This dependence only occurred in some situations. It was evident that the neutron probe is less sensitive than the tensiometer, what is explained basicaly by the larger soil volume that the probe samples.

4 - In both experiments it was possible to identify plots in which both (matric potential and CR) showed excessive diferences from the mean value along the crop cycle; this allows us to conclude that it would be more convenient to carry out experiments with less treatments, but with more repetitions all of them instrumented. 


\section{INTRODUÇÃO}

A água é indispensável para a produção vegetal, sendo consumida em grande quantidade e, para a maioria das plantas, obtida a partir do solo. $\mathrm{O}$ solo é o meio poroso que primeiramente serve de substrato às plantas e que, recebendo a água das chuvas, fica parcial ou totalmente preenchido por esta. Dai surge o conceito de umidade do solo, que é a razão entre as quantidades de água e de solo.

A água deixa constantemente o solo, percolando para o lençol freático, evaporando para a atmosfera ou sendo absorvida pelas plantas. Naturalmente, a única maneira imaginável pela qual seria possível a manutenção de um teor de água no solo estável e adequado às plantas seria o seu fornecimento pela chuva em quantidades equivalentes às que deixam o solo por percolação, evaporação e absorção pelas plantas. Porém a chuva não é um evento contínuo, mas fornece água ao solo com freqüência indefinida e em quantidades variáveis. Esse fornecimento instável faz com que algumas vezes o solo se tome saturado, e outras seu teor de água se reduza a valores que provocam restrições ao desenvolvimento adequado das plantas. $\mathbf{A}$ irrigação é a técnica que permite fornecer água ao solo quando sua umidade se reduz a baixos patamares, evitando-se que as culturas tenham suas produções afetadas. Sua utilização faz com que 
se tenha incrementos consideráveis na produção, mesmo onde a deficiência de água não é facilmente visualizada. É, porém, uma técnica financeiramente onerosa, tanto em sua instalação quanto em sua execução. O custo de instalação do sistema de irrigação é inevitável, mas os custos com as irrigações podem ser minimizados mediante a otimização da aplicação da água. $O$ aumento do tempo entre irrigações ou mesmo a diminuição de alguns milímetros em uma irrigação justificariam um certo investimento visando obter essa otimização. Em se tratando de áreas extensas, isso poderia significar uma grande economia, tanto de água quanto de energia. Essa economia deve ser buscada mediante a utilização de técnicas adequadas, como o monitoramento do teor de água no solo até a profundidade de absorção pelo sistema radicular, já que numa agricultura tecnificada como é a irrigada, os objetivos principais devem ser a maximização da produção e a minimização dos custos.

Esse monitoramento pode ser feito por diversas técnicas. Neste trabalho foram utilizadas duas delas, pelas quais se chega indiretamente ao valor da umidade do solo: o emprego do tensiômetro e o da sonda de nêutrons. $O$ enfoque dado foi o da avaliação da variabilidade das leituras desses equipamentos em experimentos com planejamento convencional de manejo da irrigação, não necessariamente planejados para esse estudo. $\mathrm{O}$ objetivo foi identificar em quais faixas de valores dessas leituras essa variabilidade se manifesta mais acentuadamente, e inferir, com base nos resultados, conseqüências para o manejo da irrigação. Essa avaliação foi realizada em dois experimentos de manejo de irrigação, na cultura do milho, nos municípios de Guaíra e Piracicaba, ambos no Estado de São Paulo. 


\section{REVISÃO DE LITERATURA}

\subsection{Monitoramento da irrigação}

JENSEN (1981) enfatizou que os principais objetivos do controle da irrigação são racionalizar o uso da energia, otimizar a umidade do solo para a colheita da cultura, estabelecer a umidade adequada para o plantio da safra agrícola e otimizar a capacidade de armazenagem de água do solo entre duas precipitações pluviais. A necessidade de irrigação pode ser monitorada de diversas maneiras: (1) com base nos parâmetros físico-hídricos do solo; (2) com base na fisiologia das plantas; (3) com base no comportamento do balanço de água na zona radicular e (4) com base em modelos climatológicos (SAAD, 1991). Segundo BERNARDO (1986), a deficiência de água na planta medida ou evidenciada por sintomas, a disponibilidade de água no solo, a evapotranspiração real, o tumo de rega e o balanço de água no solo, podem ser colas derados para a definição da lâmina de água a ser aplicada e do momento da irrigação.

Diversas técnicas são estudadas e recomendadas por inúmeros autores. Assim, AZEVEDo et al (1986), para a região do cerrado, MARQUELLI (1986), para hortaliças no Brasil central, e ARRUDA (1987), para diversos cereais em São Paulo, 
indicam os métodos do tanque classe A e do tensiômetro. SCALOPPI (1985) apresentou critérios para racionalizar a irrigação com base no índice de estresse hídrico, definido por HILER et al. (1974). FOLEGATTI (1988) monitorou a cultura do feijoeiro com um aparelho portátil denominado "scheduler", o qual por meio de medidas do ambiente ao redor das plantas, calcula o índice de estresse, indicando, com base nesse índice, o momento de irrigar. BRONER (1990) sugeriu que a irrigação pode ser monitorada por um equipamento denominado atmômetro modificado, que se constitui de uma cápsula de cerâmica porosa coberta com uma lona verde rugosa, que simula as perdas de água através da parede superficial de folhas de alfafa em pleno crescimento. LAMBERT et al. (1981), para milho irrigado por pivô central em solos com baixa capacidade de água disponível, no sudeste dos Estados Unidos, observaram incrementos médios de produção de 89,2 \%, 79,3\% e 70,4 \% para os métodos de controle de irrigação por tensiômetro, tanque de evaporação e balanço de água no solo, respectivamente, quando comparados à testemunha.

ZUR et al. (1994) propõem um método para estimar e controlar a quantidade de água aplicada em uma irrigação. Essa seria interrompida quando a frente de molhamento atingisse uma profundidade critica $\left(Z_{\mathrm{L}}\right)$, a qual dependendo da taxa de aplicação de água e da umidade inicial do solo, faria com que a umidade se tornasse adequada até uma profundidade desejada $\left(Z_{F}\right)$. Os autores desenvolveram uma sonda para determinar o avanço da frente de molhamento, e trabalhando com colunas de solo verificaram que quando a umidade do perfil é uniforme, a equação desenvolvida para estimar $Z_{\mathrm{L}}$ foi bem sucedida. Porém para condições de campo, onde a umidade é 
desuniforme, os autores propõem mudanças e fatores de correção para o modelo desenvolvido.

Obtendo-se a lâmina de água a ser aplicada, por qualquer dos métodos anteriormente descritos, torna-se necessário conhecer não só a eficiência de aplicação, mas também a variabilidade da distribuição de água pelo sistema de irrigação. O primeiro índice introduzido para a avaliação da uniformidade de distribuição de água em um sistema de irrigação por aspersores foi o coeficiente de uniformidade de Christiansen (CUC), que apresenta-se ainda hoje como o mais difundido. ScalopPI (1984) recomendou sua utilização a partir de resultados de ensaios de campo, onde se utiliza um número representativo de coletores, regularmente espaçados. DOURADo NETO (1989), trabalhando em uma área experimental de $6500 \mathrm{~m}^{2}(125 \mathrm{~m} \times 50 \mathrm{~m})$, instalou 250 pluviômetros em intervalos regulares de $5 \mathrm{~m}$, formando uma malha quadriculada ("grid"). Foram coletados os volumes de irrigação de 6 dias e os de 11 dias de chuva. As alturas de chuva apresentaram baixa variação, sem estrutura espacial, e as alturas de irrigação apresentaram alta variação, com estrutura indicando periodicidade espacial, a qual foi atribuída à posição relativa dos aspersores e dos pluviômetros na área experimental.

Sabendo-se que a variabilidade da lâmina de água a ser aplicada depende da variabilidade instrumental para determinação do parâmetro utilizado para sua recomendação e daquela intrínseca a esse parâmetro, e sabendo que os equipamentos de irrigação não distribuem essa lâmina de água uniformemente na área (essa uniformidade depende de diversos fatores, como o vento, a inclinação do terreno, o tipo de 
equipamento de irrigação, entre outros), toma-se necessário analisar conjuntamente a variabilidade de ambos. Isso é necessário para que não haja discrepância de exigências entre uma e outra, pois pouco adiantaria se esta fosse baixa para uma delas se é alta para a outra.

\subsection{Métodos de determinação da umidade do solo}

Das técnicas de controle de irrigação, sumariadas por SILVA (1988a, b), as que se baseiam no monitoramento direto ou indireto da umidade do solo têm proporcionado excelentes resultados. $\mathrm{O}$ método direto de determinação da umidade do solo a base de volume é o gravimétrico (KIEHL 1979). Essa técnica é trabalhosa e exige que se possua uma estufa, uma balança e, no mínimo, um tempo de 24 horas para a secagem da amostra. Alguns autores têm citado a utilização do forno de microondas como método promissor para a secagem da amostra quando se deseja determinar a umidade do solo pelo método gravimétrico, pois reduz-se consideravelmente esse tempo de secagem (MILLER et al., 1974; OLIVEIRA et al., 1980). Mais detalhes sobre a determinação gravimétrica da umidade do solo podem ser vistos em textos de física de solos, como KIEHL (1979), REICHARDT (1987) e BRADY (1989).

A determinação indireta se baseia no fato de que diversos parâmetros do solo apresentam dependência da umidade. Assim, conhecendo-se um desses parâmetros e conhecendo-se a maneira pela qual se relaciona com a umidade, essa pode ser estimada. Diversos equipamentos também descritos nos textos de KIEHL (1979), REICHARDT (1987) e BRADY (1989) podem ser utilizados, tais como: (1) o bloco de 
resistência elétrica, que se beneficia do fato de certos materiais porosos, como o gesso, o "nylon" e a fibra de vidro, apresentarem correlações entre a resistência elétrica e a umidade; (2) o tensiômetro, que mede a tensão da água no solo e se aproveita da relação entre tensão e umidade, previamente estabelecida pela curva de retenção da água no solo; (3) a sonda de nêutrons, que emite nêutrons rápidos e faz contagem de nêutrons lentos moderados pelos núcleos de hidrogênio presentes na molécula de água, sendo a relação entre as leituras da sonda e a umidade do solo dada por uma curva de calibração. Além de mais práticos e rápidos que a determinação gravimétrica, esses métodos indiretos, entre outros, possuem a vantagem de não serem destrutivos, podendo-se amostrar o mesmo volume de solo inúmeras vezes.

\subsubsection{O tensiômetro: descrição e funcionamento}

O tensiômetro consiste de uma cápsula porosa de cerâmica ligada a um manômetro por meio de um tubo de PVC. Para a compreensão do seu funcionamento toma-se importante o conhecimento do conceito de potencial mátrico, que se refere à energia da água contida no solo. Ele surge da interação da água com as partículas sólidas, mediante os fenồmenos de adsorsão e capilaridade. Considerando-se determinado volume de solo, a energia da água nele contida aumenta quando aumenta sua umidade. A existência dessa relação faz com que o valor da umidade do solo possa ser inferido a partir do valor dessa energia. Como a água se desloca de regiões de maior para de menor energia, podemos considerar como implicação prática que, para solos mais secos, além da 
quantidade de água disponível às plantas ser menor, aumenta a dificuldade de sua absorção devido ao seu baixo nível de energia.

No ato da instalação do tensiômetro no campo é necessário que a cápsula esteja saturada e que se promova um bom contato cápsula-solo. Após a instalação, o conjunto tubo de PVC mais manômetro deve ser totalmente preenchido por água. Seu princípio de funcionamento pode ser descrito como em KIEHL (1979): quando a cápsula porosa é enterrada no solo, a água de seu interior, inicialmente sob pressão atmosférica, entra em contato com a água do solo, geralmente sob pressão sub-atmosférica (tensão). Como conseqüência, haverá a transferência da água do interior da cápsula e do tubo de PVC para o solo que envolve a cápsula, causando uma queda de pressão no interior do instrumento, queda esta que será registrada e equilibrada pelo manômetro.

O tipo mais comum de manômetro é um tubo de "nylon", com uma de suas extremidades ligada ao tubo de PVC e a outra livre. O funcionamento desse tipo de tensiômetro é discutido com detalhes em LiBARDI (1995). Por ocasião da instalação, estando o tubo de PVC e o manômetro preenchidos por água, a extremidade livre do manômetro é colocada em contato com o mercúrio de uma cuba, formando-se no manômetro um "continuum" água-mercúrio, da forma como é descrito a seguir.

A tensão da água do solo $(\tau)$ é transmitida para a água do interior do conjunto tubo de PVC mais manômetro e para o mercúrio. A pressão atmosférica, atuando na superficie do mercúrio da cuba, faz com que ele se eleve no manômetro, até que o equilibrio seja atingido. Sendo conhecidas as densidades da água 
$\left(\rho_{\mathrm{a}}=1000 \mathrm{~kg} / \mathrm{m}^{3}\right)$ e do mercúrio $\left(\rho_{\mathrm{Hg}}=13600 \mathrm{~kg} / \mathrm{m}^{3}\right)$, e também a profundidade de instalação do tensiômetro (z) e a altura da superficie do mercúrio na cuba (h), ambos em relação à superficie do solo, podemos deduzir as equações pertinentes. A coluna de mercúrio resultante terá uma altura $(\mathrm{H})$ que proporciona uma determinada pressão $\left(\mathbf{P}_{\mathrm{Hg}}\right)$.

$$
P_{\mathrm{Hg}}=\rho_{\mathrm{Hg}} \cdot H
$$

A pressão da coluna de água entre a cápsula e a altura da interface águamercúrio no manômetro $P_{a}$ será

$$
P_{z}=\rho_{\mathbf{z}} \cdot(H+h+z)
$$

Como no equilíbrio a pressão $P_{\mathrm{Hg}}$ será igual à tensão da água no solo $\tau$ somada à pressão $P_{\mathrm{a}}$, o valor dessa tensão $\tau$ será igual à pressão $P_{\mathrm{Hg}}$ menos a pressão $P_{a}$

$$
\tau=12600 . \mathrm{H}-1000 . \mathrm{h}-1000 . \mathrm{z}
$$

sendo a tensão $\tau$ expressa em mm de água e as alturas $\mathrm{H}, \mathrm{h}$ e $\mathrm{z}$ expressas em $\mathrm{m}$. Como o potencial mátrico da água no solo é equivalente à tensão com sinal trocado, considerando-se a aceleração da gravidade igual a $10 \mathrm{~m} / \mathrm{s}^{2}$ e expressando-se as alturas em $\mathbf{m m}$, podemos determinar o potencial mátrico $\left(\phi_{\mathrm{m}}\right)$, em $\mathrm{kPa}$.

$$
\phi \mathrm{m}=\frac{-12,6 \cdot \mathrm{H}+\mathrm{h}+\mathrm{z}}{100}
$$

\subsubsection{Leitura do tensiômetro "versus" umidade}

De posse das leituras do manômetro, e subtraindo-se a pressão da coluna de água entre a cápsula porosa e a altura da interface água-mercúrio no manômetro, tem-se 
a tensão da água no solo. Porém, para a obtenção do valor da umidade, é necessário estar de posse da curva de retenção da água no solo. Esta é conseguida submetendo-se uma amostra de solo indeformada, inicialmente saturada com água, a crescentes diferenças de pressão entre suas faces. Essas diferenças de pressão expulsarão água da amostra fazendo com que essa atinja uma umidade equivalente àquela em que o potencial mátrico é igual à diferença de pressão utilizada, porém com o sinal negativo. Aumentando-se essas diferenças, chega-se a umidades da amostra cada vez menores, equivalentes a potenciais mátricos também cada vez menores. Ter-se-á pares de potencial mátrico $\left(\phi_{\mathrm{m}}\right)$ e umidade $(\theta)$, que podem ser utilizados para a confecção de um gráfico ou serem ajustados a divervos modelos propostos na literatura, alguns citados em BRUCE \& LUXMOORE (1986). Um de uso freqüente é o modelo de VAN GENUCHTEN (1980), cuja equação segue:

$$
\theta=\theta \mathrm{r}+\frac{\theta \mathrm{s}-\theta \mathrm{r}}{\left[1-\left(\left|\phi_{\mathrm{m}}\right| \cdot \alpha\right)^{\mathrm{n}}\right]^{\mathrm{m}}}
$$

onde $\theta$ s e $\theta$ r são as umidades à base de volume $\left(\mathrm{m}^{3} / \mathrm{m}^{3}\right)$ correspondentes respectivamente à saturação e à $-1500 \mathrm{kPa}$ de potencial mátrico, $\phi_{\mathrm{m}}$ é o potencial mátrico $(\mathrm{kPa})$, e $\alpha(1 / \mathrm{kPa})$ e m e n (adimensionais) são os parâmetros empíricos da equação. A umidade $\theta$ correspondente à leitura do tensiômetro é obtida, então, substituindo-se o valor do potencial mátrico na equação de VAN GENUCHTEN (1980). 


\subsubsection{A sonda de nêutrons: descrição e funcionamento}

A sonda de nêutrons consta de um cilindro metálico selado de 3 a $4 \mathrm{~cm}$ de diâmetro e 20 a $30 \mathrm{~cm}$ de comprimento, que contém uma fonte radioativa emissora de nêutrons rápidos, um detector para nêutrons lentos e um pré-amplificador. Um cabo liga o pré-amplificador a um sistema eletrônico de contagem, na caixa da sonda. Este consiste basicamente de um amplificador, fonte de alta voltagem, contador, relógio, bateria recarregável, microprocessador e demais partes opcionais. GREACEN (1981) e BACCHI \& REICHARDT (1990) descrevem com mais detalhes esse equipamento. Além desses, autores como Beltrame \& TAYLOR (1980), BURMAN et al (1983), BRADY (1989), REICHARDT (1993), entre outros, descrevem o procedimento para a obtenção das leituras. Assenta-se a caixa da sonda sobre o tubo de acesso de alumínio, previamente instalado, abaixa-se o cilindro que contém em seu interior a sonda e o sensor até a profundidade desejada e aciona-se o sistema de contagem. Os nêutrons rápidos oriundos da fonte irão colidir com os núcleos dos elementos presentes no solo, sendo moderados, capturados ou desintegrando-se. Esses nêutrons somente perdem quantidade significativa de energia, tornando-se térmicos, quando colidem com elementos de baixa massa atômica. Sendo o hidrogênio o único elemento com baixa massa atômica em quantidade significativa no solo, ele será o principal responsável pela termalização (moderação) dos nêutrons. Como a quase totalidade do hidrogênio presente no solo se encontra na forma de água, a densidade da nuvem de nêutrons lentos que se forma ao redor da fonte reflete a umidade do solo. 


\subsubsection{Leitura da sonda de nêutrons "versus" umidade}

Como já citado, a contagem de nêutrons lentos está diretamente relacionada com a concentração de hidrogênio no solo. A partir dessa contagem, o valor da umidade do solo pode ser inferido por uma curva de calibração. Essa curva de calibração é obtida mediante regressão linear de pares de contagem relativa de nêutrons lentos e umidade do solo, sendo a umidade do solo a variável dependente e a contagem relativa a variável independente. Esses pares são obtidos da maneira como é descrito no próximo parágrafo, e com mais detalhes em GREACEN (1981) e BACCHI \& REICHARDT (1990).

Instala-se tubos de acesso de alumínio e faz-se as leituras de contagem nas profundidades desejadas para a calibração. A contagem relativa é a razão entre esses valores e a média de algumas leituras padrões. A leitura padrão é realizada com o cilindro imerso em um tambor com água ou dentro da própria blindagem da sonda, que contém um elemento moderador de nêutrons, com alto teor de hidrogênio (geralmente parafina). A cada profundidade de obtenção de leitura coleta-se amostras para a determinação da umidade pelo método gravimétrico, que é considerado padrão. A regressão linear entre as contagens relativas (CR) e as umidades $(\theta)$ determinadas pelo método gravimétrico fornece-nos a curva de calibração, expressa pela equação

$$
\theta=a+b \cdot C R \pm e
$$

onde a é o coeficiente linear, b é o coeficiente angular e $e$ é o erro de regressão.

O uso da contagem relativa e não da contagem propriamente dita se torna importante quando se deseja comparar resultados de sondas diferentes para um mesmo 
solo, pois padroniza as leituras. Além disso, como a contagem relativa considera a leitura padrão, sua utilização é bastante aconselhável, pois pode ajudar a identificar problemas no sistema eletrônico de contagem. Cabe ressaltar ainda que a obtenção desses pares de contagem relativa e umidade deve ser realizada em vários dias, tentando-se abranger um amplo espectro de valores de umidade do solo, para que a calibração seja representativa. Para BACCHI \& REICHARDT (1990), a amostragem é o principal problema da calibração da sonda, isso porque na obtenção dos valores de umidade pelo método clássico se amostra um pequeno volume de solo, 20 a 50 vezes menor do que o volume de solo amostrado pelos nêutrons, o qual não é bem definido, pois se assume uma esfera de 20 a $30 \mathrm{~cm}$ de diâmetro, ou maior. Estudos do IAEA $(1970)^{1}$, citados por BACCHI \& REICHARDT (1990), mostram que o diâmetro dessa esfera é mínimo em materiais com alto conteúdo de hidrogênio, como a água pura, atingindo cerca de 0,10 a $0,15 \mathrm{~m}$, e aumenta para materiais com baixo conteúdo de hidrogênio, atingindo para solos muito $\operatorname{secos}\left(0,10 \mathrm{~cm}^{3}\right.$ de água $/ \mathrm{cm}^{3}$ de solo) até $0,80 \mathrm{~m}$ ou mais.

\subsection{Variabilidade da umidade e da armazenagem de água no solo}

A primeira consideração a ser feita a respeito da variabilidade da umidade do solo é que ela é, intrinsecamente, um parâmetro variável no tempo e no espaço. Sua variabilidade temporal existe e é, em primeiro lugar, conforme já dito, resultado do fato do solo receber água da chuva de maneira descontínua, em quantidades variáveis e com

\footnotetext{
${ }^{1}$ IAEA. Neutron moisture gauges. Viena, 1970. 137p. (Technical report series, 112).
} 
freqüência indefinida. Além disso, estando o solo com um determinado teor de água, ela o deixa por percolação, evaporação ou sendo absorvida pelas plantas. Sendo a própria matéria descontínua, a variação no espaço da umidade do solo, assim como qualquer parâmetro do solo, também existe, podendo ter um caráter aleatório (variação ao acaso) ou assumir algum padrão de variação ao longo de uma direção.

Para a variação ao acaso, tendo o parâmetro considerado distribuição normal, o instrumento de análise dos resultados mais indicado é a estatística clássica ou de Gauss, cujos principais parâmetros são a média, a variância, o desvio padrão e o coeficiente de variação (SPIEGEL, 1961). A média (m) é calculada pela fórmula:

$$
\mathbf{m}=\frac{\sum_{\mathrm{i}=1}^{\mathrm{n}} \mathrm{x}_{\mathrm{i}}}{\mathrm{n}}
$$

sendo $\mathrm{n}$ o número de valores da série e $\mathrm{x}_{\mathrm{i}}$ cada valor da série, com $\mathrm{i}$ variando de 1 a $\mathrm{n}$.

Para efeito de comparação da variabilidade de um parâmetro do solo a utilização da variância $\left(\sigma^{2}\right)$ não permite uma interpretação física clara, pois seu valor é expresso em unidades do parâmetro avaliado elevado ao quadrado.

$$
\sigma^{2}=\frac{\left(\sum_{i=1}^{n}\left(x_{i}-m\right)^{2}\right)}{n-1}
$$

O desvio padrão (dp) é a raiz quadrada da variância, expresso em unidades do parâmetro avaliado, ambos dizendo respeito à dispersão absoluta dos resultados.

$$
d p=\sqrt{\sigma^{2}}
$$


O coeficiente de variação (CV), expresso em porcentagem, padroniza os resultados de desvio padrão dividindo-os pela média, dizendo respeito à sua dispersão relativa.

$$
\mathrm{CV}=\frac{\mathrm{dp} .100}{\mathrm{~m}}
$$

Exemplificando, um desvio padrão de $1 \mathrm{kPa}$ para um potencial mátrico médio de $-10 \mathrm{kPa}$ significa $10 \%$ de variação com relação à media, da mesma forma que um desvio padrão de $7 \mathrm{kPa}$ para um potencial mátrico médio de $-70 \mathrm{kPa}$. A utilização do coeficiente de variação para a comparação não evidenciaria variabilidade diferenciada, pois seria de $10 \%$ para as duas médias, ao passo que a utilização do desvio padrão detectaria variabilidades diferenciadas. Quando a variabilidade é acentuada ela pode se manifestar quando analisada por qualquer desses parâmetros, porém sendo sempre mais pronunciada quando se utiliza o desvio padrão. WARRICK \& NIELSEN (1980), analisando resultados da literatura para diversos parâmetros do solo, encontraram coeficientes de variação desde inferiores a $10 \%$ até superiores a $1000 \%$. Classificaram essas variabilidades encontradas nos níveis baixo (abaixo de $12 \%$ ), médio (entre $12 \%$ e $80 \%$ ) e alto (acima de $80 \%$ ).

CAMeron (1978), trabalhando com amostras de solo indeformadas para obtenção da curva de retenção, identificou que a umidade do solo na saturação apresentou-se com distribuição normal de seus desvios. WESENBEECK \& KACHANOSKI (1988) utilizaram sondas TDR ('time domain reflectometry") para determinar a umidade da camada de zero a $0,20 \mathrm{~m}$ em um "transect" de $20 \mathrm{~m}$, 
perpendicular às linhas de milho. Determinaram essa umidade na linha $\left(\theta_{\mathrm{L}}\right)$, na entrelinha $\left(\theta_{E}\right)$, e entre essas duas posições $\left(\theta_{I}\right)$. Verificaram distribuição normal dos resultados no início e no final do ciclo da cultura. Para a fase intermediária, quando a cultura absorve mais água, os valores de assimetria indicaram distribuição não normal dos resultados. O fato de que os autores utilizaram valores de umidade provenientes de posições diferentes em relação a linha de plantio provavelmente foi a causa desse resultado. Sendo a absorção pelas plantas diferenciada nessas posições e o fluxo da água precipitada ocorrer preferencialmente pelo caule, isso provavelmente promoveu um padrão de variação não normal dos resultados. Deve-se então tomar o cuidado de que os tensiômetros utilizados para manejo de irrigação sejam instalados na mesma posição com relação às limhas da cultura, pois desde que nas mesmas condições de extração e fornecimento de água ao solo, os valores de umidade têm se mostrado normalmente distribuídos. Já para o caso da tensão da água no solo, HENDRICKX et al. (1990) identificaram distribuição log-normal dos resultados, recomendando o uso dos valores log-transformados dessa tensão para que inferências estatísticas possam ser feitas com maior segurança.

Quando os resultados são espacialmente dependentes, a ferramenta indicada para se trabalhar com os dados é a teoria das variáveis regionalizadas (geoestatística), a qual considera essa dependência. Os trabalhos de Es \& Es (1993) e REICHARDT et al. (1986) discutem a variabilidade espacial em solos e a experimentação de campo. De qualquer modo, mesmo para parâmetros que apresentam variabilidade espacial, o conhecimento dos parâmetros da estatística clássica é importante, não para a 
determinação da estrutura de variação no espaço, mas para a determinação da amplitude de variação. Além dessa variabilidade intrínseca ao parâmetro umidade do solo, no ato de sua determinação inclui-se ainda uma outra fonte de variação para o valor da umidade do solo obtida, que é a variabilidade instrumental ou metodológica.

Conforme SILVA (1988a), a determinação da lâmina de água para a irrigação a partir do monitoramento da umidade do solo deve considerar esta umidade ao longo da profundidade explorada pelo sistema radicular da cultura. De posse desse perfil de umidade do solo calcula-se, por técnicas numéricas de integração, a quantidade de água contida no solo, ou seja, a armazenagem. A lâmina de água a ser aplicada pode ser determinada pela diferença entre a armazenagem desejada e a armazenagem considerada mínima, e traz consigo os erros propagados da estimativa da armazenagem. Nessa estimativa somam-se os erros decorrentes da variabilidade da umidade do solo e aqueles decorrentes do método de integração utilizado. HAVERKAMP et al. (1984) identificaram a contribuição da variância devida às medidas de umidade e da variância devida a dois métodos de integração (trapezoidal e regra de Simpson) na variância total. Para isso se utilizaram dos resultados obtidos das leituras de duas sondas de nêutrons, e estimaram a armazenagem pelos dois métodos de integração. Obtiveram que as variâncias devidas às medidas de umidade, no geral, mostraram-se maiores do que as variâncias dos métodos de integração. Na comparação desses métodos observaram que o uso da regra de Simpson propiciou variâncias menores do que as obtidas quando se utilizou do método trapezoidal, o que é teoricamente mais aceitável, pois ela fornece uma curva do perfil de 
umidade suave, sem arestas ou mudanças bruscas de direção, o mesmo não acontecendo com o método trapezoidal. Recomendam que, sempre que possível, a regra de Simpson deve ser preferida em relação ao método trapezoidal, devendo esse fato ser levado em consideração desde o momento de planejamento do experimento. TURATTI \& REICHARDT (1991) fizeram estudo semelhante e concluíram que os erros devidos à integração são muito menores do que aqueles devidos à determinação do valor da umidade, e que, para os mesmos métodos de integração, a técnica de Simpson conduz à obtenção de valores de armazenamento de água pelo solo mais precisos que a técnica trapezoidal, minimizando os erros devidos tanto às medidas de umidade quanto ao método de integração.

BACCHI \& REICHARDT (1990) descrevem, assim como GREACEN (1981), os erros envolvidos na determinação da umidade e da armazenagem de água no solo com a sonda de nêutrons. $O$ conjunto de incertezas envolvidas nos processos físicos desse método, desde a produção de nêutrons até a sua contagem, passando pela deteç̧ão, fotomultiplicação, amplificação de pulsos, contagem de pulsos, etc., é denominado erro instrumental. $\mathrm{Na}$ calibração, erros próprios da regressão são incorporados, que dependem da qualidade e da representatividade dos valores de umidade. A qualidade e representatividade dos valores medidos pelo método padrão na esfera de influência da sonda são, conforme já foi dito, bastante variáveis dependendo da umidade do solo, atividade da fonte, variabilidade espacial do solo (estratificação dos horizontes e variações horizontais), modo de instalação dos tubos de acesso, etc., e esses são os erros 
de calibração. Como uma única curva de calibração da sonda de nêutrons é utilizada na medição da umidade de diferentes tubos de acesso numa área, e até mesmo de áreas diferentes, introduz-se os erros locais, devidos a variabilidade espacial do solo e diferenças nos procedimentos de instalação dos tubos.

MARANHO et al. (1995) afirmam que uma das dificuldades apresentadas pelo método da moderação de nêutrons é a obtenção de curvas de calibração, pois essas podem variar entre as várias camadas do perfil e numa mesma camada, ao longo do tempo, dependendo do manejo do solo. Num experimento com milho utilizaram sonda de nêutrons para comparar o comportamento da umidade volumétrica ao longo do tempo obtidas a partir de curvas de calibração de profundidades crescentes de $0,1 \mathrm{~m}$, desde $0,2 \mathrm{~m}$ até $1,00 \mathrm{~m}$, e a partir de uma curva de calibração geral para o perfil. Verificaram que na profundidade de $0,20 \mathrm{~m}$ a curva geral subestimou a umidade do solo devido, provavelmente, à interferência da atmosfera na esfera de influência da medida, e na camada entre 0,50 e $0,70 \mathrm{~m}$, a curva geral também sub-estimou a umidade, possivelmente devido as diferenças estruturais do solo nessa camada (Bt) e, conseqüentemente, maior atenuação de nêutrons e maior contagem relativa. Verificaram ainda que a curva de calibração geral superestimou a umidade para as demais profundidades, o que pode ser atribuído à influência dos dados das camadas citadas anteriormente, que levaram a média a valores maiores de contagem relativa. Concluíram assim que não é recomendável a utilização de uma curva de calibração geral para solos que apresentem diferenças estruturais ao longo do perfil, como para o presente caso. 
HAVERKAMP et al. (1984), no mesmo trabalho citado anteriormente, utilizaram-se de duas curvas de calibração para cada uma das sondas de nêutrons, uma curva diferindo da outra pela correção dos erros das medidas pela técnica dos quadrados mínimos. Verificaram que o uso das curvas corrigidas não propiciou diferenças no valor da armazenagem, mas reduziram a variância devida às medidas de umidade.

TURATTI et al. (1990) verificaram que a variabilidade espacial do solo é um fator importante na calibração de sondas de nêutrons, a ponto de não permitir que o método da moderação de nêutrons forneça valores precisos e absolutos de umidade do solo. Mostraram porém, com os resultados de uma transeção de 25 tubos de acesso de sonda, que o método é consistente para ser utilizado com segurança em medidas de variações temporais de umidade do solo ou mesmo de armazenamento de água no perfil.

KIRDA \& REICHARDT (1992), comparando a sonda de nêutrons com métodos não nucleares de estimativa da água no solo em condições de campo, obtiveram que a variância das medidas de umidade do solo obtidas por sonda de nêutrons foi menor do que para a amostragem gravimétrica, que requer um número de amostras 2 a 6 vezes maior em relação à sonda de nêutrons, dentro de um mesmo nível de significância.

Da mesma forma que a obtenção do valor da umidade do solo a partir da sonda de nêutrons, a obtenção de seu valor pelo uso do tensiômetro inclui a variabilidade intrínseca à umidade e a variabilidade instrumental ou metodológica. MORAEs (1991) discute com detalhes aspectos da curva de retenção, enfatizando sua variabilidade, a qual se propaga para os valores de umidade obtidos com o tensiômetro. $\mathbf{O}$ autor, trabalhando 
com uma Terra Roxa Estruturada Latossólica e utilizando-se de parâmetros da estatística clássica, observou que o solo utilizado apresentou variabilidade para os pontos da curva de retenção. Identificou ainda, mediante interpretação fisica dos resultados, problemas metodológicos na obtenção da curva. Eliminando-se os valores discrepantes identificados nessa interpretação fisica, e reduzindo-se o número de curvas obtidas, diminui-se também os coeficientes de variação correspondentes a cada potencial mátrico considerado. Discutiu-se o conceito de água disponível para vários valores de capacidade de campo assumidos, tentando se beneficiar da variabilidade do solo encontrada. Assim foi mostrado que tanto a variabilidade metodológica de obtenção da curva quanto a do solo podem tornar sem sentido a discussão sobre os valores a serem assumidos para a capacidade de campo e para o ponto de murcha permanente, evidenciando-se, portanto, a necessidade de mais cuidados na elaboração das curvas de retenção, a fim de que pelo menos essa variabilidade seja reduzida.

SILVA (1988), trabalhando com amostragem a duas profundidades em uma malha de 63 pontos distanciados de 20 metros, determinou o número de amostras necessário para se estimar a média com variação permitida de $10 \%$ para diversos parâmetros do solo. Para a água retida às tensões de $10,33,100$ e $1500 \mathrm{kPa}$, pontos esses comumente utilizados na obtenção da curva de retenção, 5 amostras seriam suficientes.

Com o objetivo de caracterizar a variabilidade do potencial mátrico e estimar o número de tensiômetros necessários para a determinação do nível de irrigação do 
pimentão por gotejamento, HENDRICKX \& WIERENGA (1990) utilizaram-se de 200 tensiômetros. Os resultados indicaram grande variabilidade espacial e pouca estabilidade temporal das leituras. O desvio padrão do potencial mátrico aumentava de 3 para $18 \mathrm{kPa}$, quando o potencial mátrico variava de -5 para $-45 \mathrm{kPa}$, respectivamente. Para a determinação do potencial mátrico em que a cultura perde rendimento os autores recomendaram a utilização de sete tensiômetros por campo de cultivo.

VILLAGRA et al. (1988) se utilizaram da tensiometria para estudar a variabilidade espacial do potencial mátrico da água no solo. Os autores decompuseram a variância total em variância instrumental e variância local (ou do solo), concluindo que a última é muito mais importante que a primeira. Os coeficientes de variação totais do potencial mátrico podem ir além de $40 \%$. De qualquer modo, a variância instrumental somar-se-á à variância total das leituras, e não deixa de ter importância. Afirmam ainda que o tempo de resposta do tensiômetro será tanto maior quanto mais negativo for o potencial mátrico da água no solo, não ultrapassando, porém, oito horas. A variabilidade do tempo de resposta das cápsulas porosas pode ser um fator que contribui na variabilidade total do valor da umidade do solo obtido por esse método. Deve-se então, quando se planeja um experimento, utilizar cápsulas porosas o mais uniformes possível quanto à condutância, e, nos casos de molhamento do solo ou fluxagem do tensiômetro, aguardar o tempo necessário para que o equilibrio se restabeleça antes de fazer as leituras, visando minimizar o efeito dessa variabilidade. 


\section{MATERIAL E MÉTODOS}

O trabalho constou de dois experimentos de manejo de irrigação na cultura do milho, cujas áreas experimentais, roteiro de implantação e condução dos experimentos são descritos nos sub-ítens 3.1 e 3.2. O sub-ítem 3.3 consta da descrição da maneira pela qual os resultados coletados nos experimentos foram analisados.

\subsection{Experimento I}

\subsubsection{Caracterização da área experimental}

\subsubsection{Local}

A área se encontra localizada a $20^{\circ} 28^{\prime}$ de latitude sul e a $48^{\circ} 20^{\prime}$ de longitude oeste, a uma altitude de $495 \mathrm{~m}$ acima do nível do mar. Situa-se na vertente da margem esquerda do córrego Santa Cruz, na fazenda "Recanto da Barcelona", no município de Guaíra, Estado de São Paulo, Brasil.

\subsubsection{Relevo, solo e clima}

A área apresenta relevo plano a suave ondulado, com declividades menores que $3 \%$. O solo foi classificado como Latossolo Roxo distrófico, A moderado, textura 
muito argilosa, correspondente ao Typic Haphustox da classificação americana. É derivado do intemperismo de rochas eruptivas básicas da formação Serra Geral (Oliveira \& PRADO, 1991).

O clima, segundo a classificação de Köeppen, é do tipo Cwa: subtropical com inverno seco, com temperatura média do mês mais frio superior a $18^{\circ} \mathrm{C}$ e do mês mais quente superior a $22^{\circ} \mathrm{C}$. Os parâmetros climáticos, conforme $\operatorname{SAAD}(1991)$, obtidos na Estação Climatológica de Barretos, do Instituto Nacional de Meteorologia (INEMET), apresentam as seguintes médias anuais: (i) precipitação: $1330 \mathrm{~mm}$; (ii) temperatura: $24^{\circ} \mathrm{C}$; (iii) umidade relativa do ar: $64 \%$; (iv) velocidade do vento: $2,6 \mathrm{~m} / \mathrm{s}$, com direção predominante NE.

\subsubsection{Tratamentos, dimensões das parcelas e delineamento experimental}

A definição dos tratamentos considerou a distinção de três fases de desenvolvimento da cultura. A fase I foi equivalente à fase vegetativa descrita em FANCELLI (1991), e as fases II e III foram equivalentes à fase reprodutiva também descrita, sendo que a fase II prolonga-se do início da fase reprodutiva ao estádio de grãos pastosos-farináceos, e fase III, do estádio de grãos farináceos (duros) e morfologicamente maduros ao final da fase reprodutiva. $O$ experimento constou de três tratamentos, sendo tr000 a aplicação de metade da lâmina de água recomendada durante todo o ciclo da cultura; troI0 a aplicação da lâmina recomendada somente na fase II da cultura, aplicando-se metade dessa lâmina nas fases I e III; e trIII a aplicação da lâmina recomendada durante todo o ciclo da cultura. Os três tratamentos foram repetidos em 
quatro blocos ( blocos A, B, C e D), totalizando 12 parcelas experimentais. Cada parcela constou de 9 linhas de milho de $10 \mathrm{~m}$ de comprimento, espaçadas $0,8 \mathrm{~m}$ entre si ( $72 \mathrm{~m}^{2}$ por parcela). A área total em que o experimento foi conduzido é de $1000 \mathrm{~m}^{2}$ (20 m $\times 50 \mathrm{~m}$ ), estando ainda instaladas no local as estruturas metálicas que teriam suportado duas estufas de cobertura plástica, que embora não estivessem cobertas no período do experimento), aqui foram chamadas estufas 1 e 2. Assim os blocos A e B referem-se àqueles sob a estufa 1 , e os blocos $\mathrm{C}$ e $\mathrm{D}$, àqueles sob a estufa 2 , conforme Figura 1.

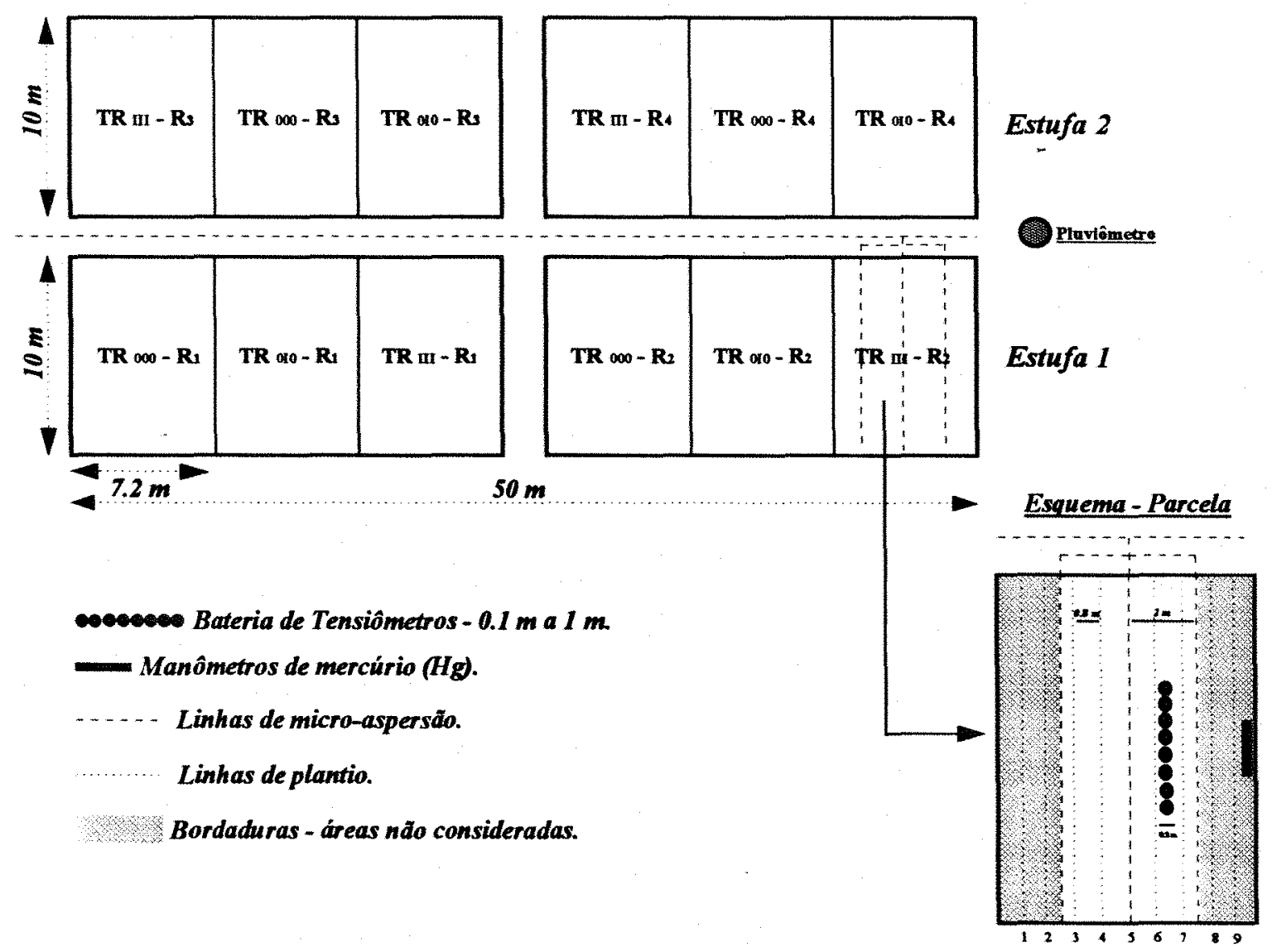

Figura 1 - Esquema da área experimental I. 


\subsubsection{Instalação do experimento}

Utilizou-se irrigação por microaspersores, que foram instalados na área utilizando como suporte para o sistema as estruturas metálicas das estufas 1 e 2 . Cada parcela possuía um registro para interromper a entrada de água quando necessário, e a tubulação era constituída de três tubos espaçados $2 \mathrm{~m}$ entre si, com os microaspersores espaçados $1 \mathrm{~m}$. Foi realizado um teste para verificar a intensidade de aplicação e a uniformidade de distribuição da lâmina de água aplicada. Inicialmente se considerou a situação em que todas as parcelas estavam sendo irrigadas ao mesmo tempo. Para as situações em que se mantinha o sistema funcionando somente para irrigar as parcelas dos tratamentos troI0 e trIII ou somente as do tratamento trIII, fez-se ajuste da pressão na tubulação regulando-se a abertura do registro no conjunto moto-bomba, mantendo-a nos mesmos patamares anteriores a fim de conseguir a mesma distribuição de água. Instalouse também ao lado da área um pluviômetro para que as lâminas das precipitações no local durante o período do experimento fossem coletadas.

O solo da área foi preparado com uma passagem de arado escarificador e duas gradagens, conseguindo-se assim um bom destorroamento. A semeadura foi realizada manualmente, em 29/07/1994, visando a obtenção de uma densidade de semeadura de 62500 plantas por hectare ( 5 plantas por metro de linha).

Os tensiômetros para leitura do potencial mátrico da água no solo e monitoramento da irrigação foram instalados a $0,20 \mathrm{~m}$ ao lado da $6^{\mathrm{a}}$ linha de cada 
parcela, aproximadamente em seu centro, nas profundidades de 0,$10 ; 0,20 ; 0,30 ; 0,40$; 0,$50 ; 0,60 ; 0,70 ; 0,80 ; 0,90$ e $1,00 \mathrm{~m}$. Os tensiômetros utilizados foram de manômetro de mercúrio, conforme descrito no sub-ítem 2.2.1, e a altura da superficie do mercúrio em relação à superfície do solo foi $0,30 \mathrm{~m}$ para todos os tensiômetros.

\subsubsection{Determinações}

As lâminas de água recomendadas foram estipuladas tomando por base as leituras dos tensiômetros instalados nas parcelas do tratamento trIII, que receberam essa lâmina durante todo o ciclo, e também a fase da cultura, visando elevar a umidade do solo à capacidade de campo. Assim, para a fase I, a lâmina recomendada foi determinada pela média das leituras dos tensiômetros instalados a $0,20 \mathrm{~m}$ de profundidade; para as fases II e III, pela média das leituras a $0,30 \mathrm{~m}$ de profundidade. Os tempos de funcionamento do sistema de irrigação para que as lâminas recomendadas fossem efetivamente aplicadas foram determinados com base no teste de aplicação de água, e as lâminas de água das precipitações no local durante o período do experimento foram coletadas no pluviômetro instalado na área.

As leituras de altura da coluna de mercúrio nos tensiômetros foram realizadas diariamente às $17: 00 \mathrm{hs}$, servindo como base para tomada de decisão do momento de irrigação e sendo utilizadas para se obter o potencial mátrico, calculado pela equação

$$
\phi \mathrm{m}=(-12,6 \mathrm{H}+\mathrm{z}+300) / 100
$$


sendo $\phi_{\mathrm{m}}$ o potencial mátrico, em $\mathrm{kPa} ; \mathrm{H}$ a altura do mercúrio no manômetro, em mm de Hg; 300 a altura da superficie do mercúrio na cuba em relação à superficie do solo, em mm; e z a profundidade de instalação do tensiômetro, em mm.

Quando a altura da coluna de mercúrio atingia aproximadamente $0,70 \mathrm{~m}$ era feito o desligamento dos tensiômetros, o que evitava que ocorresse o rompimento da coluna e que parte do mercúrio fosse para o interior da cápsula porosa. Isso muitas vezes também fez com que, principalmente nos períodos e tratamentos em que a cultura foi submetida a défice hídrico, não estejam disponiveis os valores de potencial mátrico para todas as repetições, ocasionado a ocorrência de células vazias nas tabelas que contém os resultados, conforme pode ser verificado.

\subsection{Experimento II}

\subsubsection{Caracterização da área experimental}

\subsubsection{Local}

A área se encontra localizada a $22^{\circ} 43^{\prime}$ de latitude sul e a $47^{\circ} 25^{\prime}$ de longitude oeste, a uma altitude de $580 \mathrm{~m}$ acima do nível do mar. Situa-se no campo experimental do Departamento de Física e Meteorologia, Campus da Escola Superior de Agricultura 'Luiz de Queiroz", Universidade de São Paulo, município de Piracicaba, Estado de São Paulo, Brasil. 


\subsubsection{Relevo, solo e clima}

A área apresenta relevo suave ondulado. O solo foi classificado como Terra Roxa Estruturada Latossólica, correspondente ao Rhodic Kanhapludalf da classificação americana (VIDAL-TORRADO \& SPAROVEK, 1993).

O clima, segundo a classificação de Köeppen, é do tịpo Cwa, com as seguintes médias anuais (média de 71 anos: 1917 a 1987): (i) precipitação: $1253 \mathrm{~mm}$; (ii) temperatura: $21,1^{\circ} \mathrm{C}$; (iii) umidade relativa: $74 \%$; (iv) velocidade do vento: $2,2 \mathrm{~m} / \mathrm{s}$, com direção E/SE (VILLA NoVA, 1989).

\subsubsection{Tratamentos, dimensões das parcelas e delineamento experimental}

O experimento foi planejado de forma que pudesse cumprir também outros objetivos que não os especificados para este trabalho. Assim, tratou-se de um grupo de três experimentos, cada qual conduzido em uma condição de aplicação de água, para o estudo do manejo de irrigação. Cada experimento teve o delineamento de blocos ao acaso, num esquema fatorial $3 \times 3$, sendo três híbridos de milho: $\mathrm{XL}-520, \mathrm{XL}-380$ e XL-678, e três níveis de nitrogênio em cobertura: 0,75 e $150 \mathrm{~kg} / \mathrm{ha}$, parcelados em duas aplicações, constituindo 9 tratamentos. Cada tratamento foi repetido em 3 blocos, totalizando 27 parcelas experimentais, e cada parcela foi constituída de 8 linhas de milho de $5 \mathrm{~m}$ de comprimento, espaçadas de $0,85 \mathrm{~m}$ entre si ( $34 \mathrm{~m}^{2}$ por parcela).

Para o cumprimento dos objetivos aqui propostos, foram efetuadas leituras com sonda de nêutrons somente nas parcelas cultivadas com o híbrido XL-380 do experimento que recebeu a lâmina total de água recomendada para a irrigação. Houve, 
dessa forma, para nossa análise, três tratamentos cultivados com o milho hibrido XL-380, correspondentes às três doses de nitrogênio (tro, tr1 e tr2), e mais um tratamento com solo nú, em que não houve planta (trbs), também com três repetições, localizado ao lado da área. No total foram 4 tratamentos e 3 repetições, totalizando 12 parcelas, conforme Figura 2.

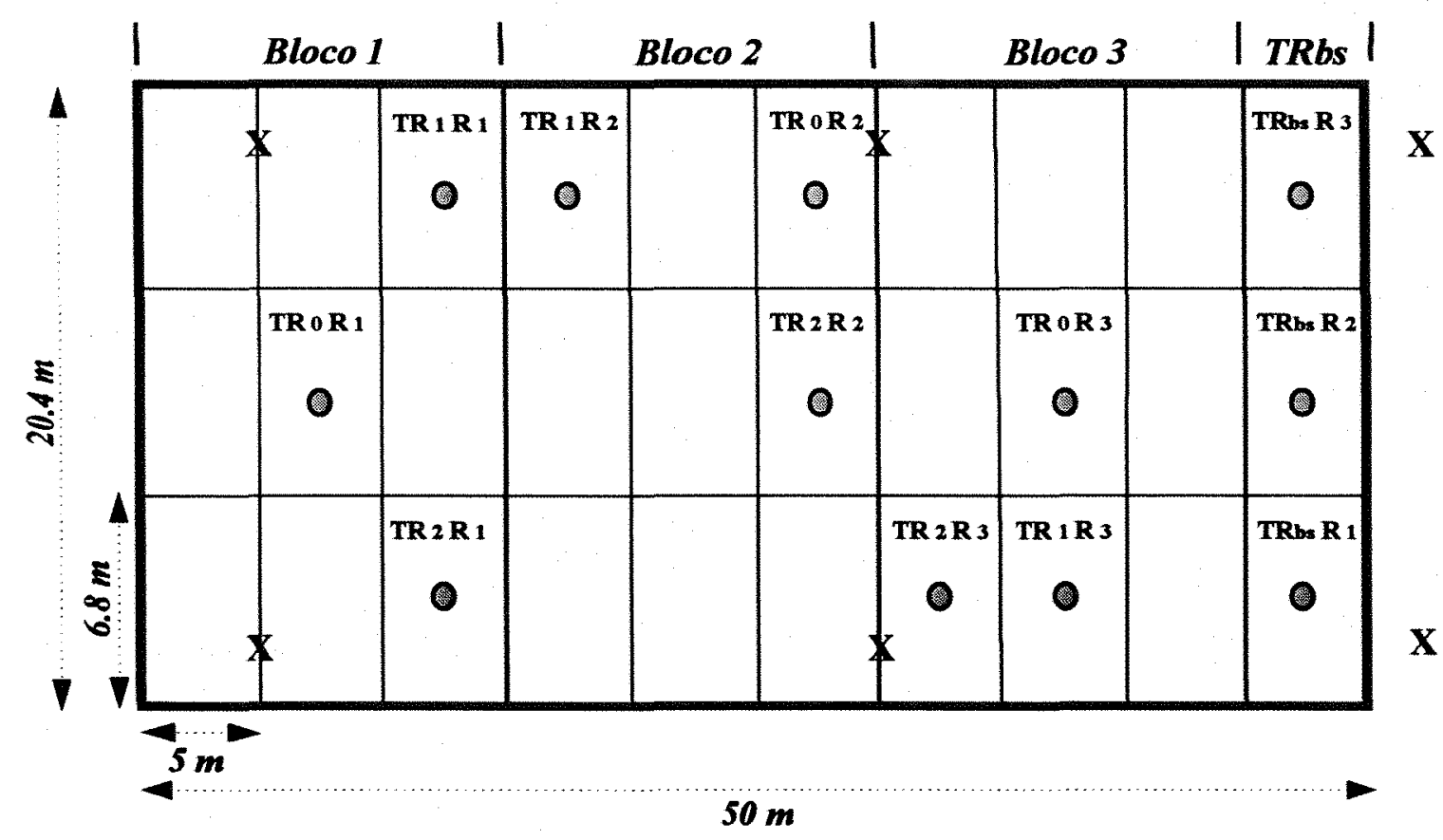

$\mathbf{X}$ Aspersores.

- Tubos de acesso da Sonda de Nêutrons.

Figura 2 - Esquema da área experimental II. 


\subsubsection{Instalação do experimento}

O solo da área foi preparado convencionalmente com uma aração e duas gradagens, obtendo-se assim um bom destorroamento. Um sistema de irrigação convencional foi instalado na área, realizando-se posteriormente um teste para verificar a intensidade de aplicação da lâmina de água e a uniformidade de distribuição dessa lâmina.

A semeadura do milho foi realizada manualmente com o auxilio de uma régua, objetivando a obtenção de uma densidade de semeadura de 58800 plantas por hectare ( 5 plantas por metro de linha). Após a semeadura do milho foram instalados, no centro de cada uma das 12 parcelas, tubos de alumínio para acesso da sonda de nêutrons, até a profundidade de $1,50 \mathrm{~m}$.

Baterias de tensiômetros para controle da irrigação foram instaladas nas parcelas do hibrido XL-380, que receberam a dose de $150 \mathrm{Kg} / \mathrm{ha}$, às profundidades de 0,$20 ; 0,40 ; 0,60$ e $0,80 \mathrm{~m}$

\subsubsection{Determinações}

No início do ciclo a aplicação de água elevou a umidade do solo e a manteve próxima à capacidade de campo, para que houvesse um bom estabelecimento da cultura e para que o manejo da irrigação fosse iniciado a partir da mesma condição de umidade do solo. Estabelecida a cultura, as irrigações passaram a ser feitas visando a aplicação da lâmina de água recomendada, determinada com base nas leituras dos tensiômetros, realizadas diariamente às $8: 00$ horas, e com base na fase da cultura. Assim, toda vez que 
o potencial mátrico da água no solo atingia $-8 \mathrm{~m}$ de água à $0,20 \mathrm{~m}$ para o período inicial, ou à $0,35 \mathrm{~m}$ com o desenvolvimento do sistema radicular, efetuava-se a irrigação da cultura para elevar o teor de água no solo ao valor correspondente à capacidade de campo.

Da mesma forma que para o experimento I, o tempo de funcionamento do equipamento de irrigação para a aplicação da lâmina de água recomendada foi estipulado com base no teste de aplicação de água. As lâmina de água das chuvas foram coletadas no posto meteorológico do Departamento de Física e Meteorologia, localizado aproximadamente a $100 \mathrm{~m}$ da área.

Foram realizadas leituras de contagem de nêutrons lentos três vezes por semana, às segundas, quartas e sextas-feiras, nas profundidades 0,$20 ; 0,30 ; 0,40 ; 0,50$; 0,$60 ; 0,70 ; 0,80 ; 0,90,1,00 ; 1,10$ e $1,20 \mathrm{~m}$, tendo sido o tempo de contagem 33 segundos. O modelo de sonda nêutrons utilizada foi a HYDROPROBE-503, de fabricação americana, que emite nêutrons com alta energia de uma fonte de Amerício/Berilio e contabiliza nêutrons com baixa energia no detector, de Trifluoreto de Boro $\left(\mathrm{BF}_{3}\right)$.

\subsection{Análise dos resultados}

Os resultados foram analisados utilizando-se os métodos da estatística descritiva, baseados na medida de posição e de dispersão (média, desvio padrão e coeficiente de variação). Foram construídos tabelas e gráficos utilizando-se do programa Microsoft Excel versão 5.0 (MICROSOFT CORPORATION, 1994), que serviram para a visualização da variação dos parâmetros no tempo. 


\section{RESULTADOS E DISCUSSÃo}

Os resultados diários para cada profundidade estudada do potencial mátrico, para o experimento I, e da contagem relativa de nêutrons lentos, para o experimento II, bem como as lâminas diárias de água das chuvas ou aplicadas nas irrigações, para ambos os experimentos, estão expressos na forma de tabelas e gráficos em anexo. Os Apêndices 1, 2 e 3 são referentes ao experimento I, e os Apêndices 4, 5 e 6, ao experimento II. O Apêndice 1 consta das tabelas com o valor por parcela do potencial mátrico, de seu valor médio por tratamento e das lâminas de água recebidas pelo solo. As lâminas de água e os valores médios e de desvio padrão para cada tratamento estão nos gráficos do Apêndice 2, e os gráficos mostrando a variação do desvio padrão com a média estão no Apêndice 3. Os Apêndices 4, 5 e 6 são respectivamente análogos aos Apêndices 1, 2 e 3, mostrando os resultados de contagem relativa de nêutrons lentos do experimento II. Para os dois experimentos os resultados foram interpretados primeiramente com base nessas tabelas e gráficos, mas para efeito de sua discussão serão utilizados somente alguns trechos deles extraidos ou deles adaptados, suficientes para explicar ou evidenciar as possíveis inferências. 
O conhecimento prévio tanto da amplitude quanto da possível estrutura espacial de variação dos parâmetros avaliados nas áreas experimentais seria de grande valia, pois permitiria que se pudesse comparar a variabilidade real estimada para as áreas com a variabilidade medida entre as parcelas dos experimentos convencionais conduzidos, planejados no caso para avaliar manejo de irrigação. Porém a dificuldade para a caracterização detalhada da variabilidade desses parâmetros para as referidas áreas a impossibilitou, pois exigiria uma quantidade bastante grande de instrumentação a ser instalada, bem como da disponibilidade de tempo e mão-de-obra para tal.

\subsection{Experimento I}

Os resultados do teste para verificar a intensidade de aplicação e a uniformidade de distribuição da lâmina de água aplicada pelo equipamento de irrigação instalado na área experimental estão expressos na Tabela 1. Com base nesse teste foram estabelecidos os tempos de funcionamento do equipamento de irrigação para a aplicação das lâminas de água recomendadas.

Tabela 1 - Teste de uniformidade do equipamento de irrigação: lâminas de água e desvio padrão (dp), em $10^{3} \cdot \mathrm{m}^{3} / \mathrm{m}^{2}$; coeficiente de variação (CV) e coeficiente de uniformidade de Christiansen (CUC), em \%; pressão nos tubos na entrada das parcelas, em kPa.

\begin{tabular}{|c|c|c|c|c|c|c|c|c|c|c|c|c|c|c|c|}
\hline \multirow{2}{*}{$\begin{array}{l}\text { parâ- } \\
\text { metro }\end{array}$} & \multicolumn{5}{|c|}{ troon } & \multicolumn{5}{|c|}{ tro10 } & \multicolumn{5}{|c|}{ trin } \\
\hline & $\pi 1$ & $\sqrt{2}$ & r3 & $\mathrm{r} 4$ & média & r1 & r2 & r3 & $r 4$ & métia & r1 & r2 & r3 & r4 & média \\
\hline lâmina & 13.8 & 14.8 & 12.5 & 13.4 & 13.6 & 13.7 & 14.2 & 14.3 & 12.9 & 13.8 & 14 & 13.8 & 12.9 & 14.8 & 13.9 \\
\hline dp & 2.0 & 2.6 & 1.1 & 1.1 & 1.7 & 1.8 & 1.4 & 1.3 & 1.1 & 1.4 & 2.5 & 1.5 & 1.9 & 1.9 & 2.0 \\
\hline $\mathrm{CV}$ & 14.3 & 17.5 & 8.9 & 8.4 & 12.3 & 12.8 & 9.9 & 9.1 & 8.8 & 10.2 & 17.6 & 10.7 & 14.5 & 13.1 & 14.0 \\
\hline CUC & 90.4 & 87.1 & 93 & 94.2 & 91.2 & 90.3 & 91.9 & 92.5 & 92.7 & 91.9 & 87.9 & 91.3 & 88.2 & 90.8 & 89.6 \\
\hline pressão & 200 & 190 & 195 & 185 & 193 & 195 & 185 & 190 & 185 & 189 & 190 & 185 & 200 & 190 & 191 \\
\hline
\end{tabular}


Os horários disponíveis do início das irrigações ou precipitações, os tempos de funcionamento do sistema de irrigação, as lâminas de água aplicadas e de precipitações pluviais verificadas no período estão representadas na Tabela 2 . Conforme pode ser observado, as lâminas de água das irrigações aplicadas no período inicial da cultura, até o $30^{\circ}$ DAS (dia após a semeadura), foram as mesmas para todos os tratamentos, visando o estabelecimento adequado da cultura e o início do manejo da irrigação a partir da umidade do solo na capacidade de campo, uniforme para todo o experimento. Assim, para os tratamentos tr000 e troI0, quando se diz que na fase I houve aplicação de metade da lâmina recomendada, entenda-se que houve aplicação de metade dessa lâmina a partir do início do manejo da irrigação.

A mudança da fase I para a fase II da cultura ficou caracterizada no $71^{\circ}$ DAS, a mudança da fase II para a fase III no $113^{\circ}$ DAS, e a colheita foi realizada no $139^{\circ}$ DAS. Para a fase I, a lâmina recomendada era aplicada toda vez que a média das leituras dos tensiômetros instalados a $0,20 \mathrm{~m}$ de profundidade no tratamento trIII ultrapassava $500 \mathrm{~mm}$ de $\mathrm{Hg}$ (aproximadamente $58 \mathrm{kPa}$ de potencial mátrico da água no solo); para a fase II, quando a média das leituras a $0,30 \mathrm{~m}$ ultrapassava $300 \mathrm{~mm} \mathrm{de} \mathrm{Hg}$ (aproximadamente $32 \mathrm{kPa}$ ); e para a fase III, quando essa média a $0,30 \mathrm{~m}$ ultrapassava $700 \mathrm{~mm}$ de $\mathrm{Hg}$ (aproximadamente $82 \mathrm{kPa}$ ). 
Tabela 2 - Resultados referentes às precipitações e irrigações durante o ciclo da cultura: dias após a semeadura (DAS); horário do início das irrigações e precipitações (H) e duração das irrigações (D), em h:min; lâminas de água precipitadas (P), irrigadas (I) e a soma de ambas (P+I), $\mathrm{em} \mathrm{m}^{3} / \mathrm{m}^{2}$.

\begin{tabular}{|c|c|c|c|c|c|c|c|c|c|c|c|}
\hline \multirow[b]{2}{*}{ DAS } & \multirow[b]{2}{*}{ H } & \multirow[b]{2}{*}{$\mathbf{P}$} & \multicolumn{3}{|c|}{ TRATAMENTO } & \multicolumn{3}{|c|}{ TRATAMENTO } & \multicolumn{3}{|c|}{ TRATAMENTO II } \\
\hline & & & $\mathrm{I}$ & $\mathrm{D}$ & $P+1$ & I & D & $\mathrm{P}+\mathrm{I}$ & I & D & $\mathrm{P}+\mathrm{I}$ \\
\hline 0 & $16: 30$ & 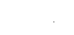 & 0.020 & $0: 30$ & 0.020 & 0.021 & $0: 30$ & 0.021 & 0.021 & $0: 30$ & 0.021 \\
\hline 1 & $8: 00$ & & 0.014 & $1: 00$ & 0.014 & 0.014 & $1: 00$ & 0.014 & 0.014 & $1: 00$ & 0.014 \\
\hline 2 & $16: 00$ & & 0.027 & $2: 00$ & 0.027 & 0.028 & $2: 00$ & 0.028 & 0.028 & $2: 00$ & 0.028 \\
\hline 4 & $21: 30$ & & 0.027 & $2: 00$ & 0.027 & 0.028 & $2: 00$ & 0.028 & 0.028 & $2: 00$ & 0.028 \\
\hline 5 & $21: 30$ & & 0.020 & $1: 30$ & 0.020 & 0.021 & $1: 30$ & 0.021 & 0.021 & $1: 30$ & 0.021 \\
\hline 7 & $21: 30$ & & 0.027 & $2: 00$ & 0.027 & 0.028 & $2: 00$ & 0.028 & 0.028 & $2: 00$ & 0.028 \\
\hline 8 & $18: 30$ & & 0.020 & $1: 30$ & 0.020 & 0.021 & $1: 30$ & 0.021 & 0.021 & $1: 30$ & 0.021 \\
\hline 9 & $19: 00$ & & 0.020 & $1: 30$ & 0.020 & 0.021 & $1: 30$ & 0.021 & 0.021 & $1: 30$ & 0.021 \\
\hline 13 & $12: 30$ & & 0.027 & $2: 00$ & 0.027 & 0.028 & $2: 00$ & 0.028 & 0.028 & $2: 00$ & 0.028 \\
\hline 16 & $21: 30$ & & 0.020 & $1: 30$ & 0.020 & 0.021 & $1: 30$ & 0.021 & 0.021 & $1: 30$ & 0.021 \\
\hline 18 & $17: 00$ & & 0.014 & $1: 00$ & 0.014 & 0.014 & $1: 00$ & 0.014 & 0.014 & $1: 00$ & 0.014 \\
\hline 20 & $21: 05$ & & 0.019 & $1: 25$ & 0.019 & 0.020 & $1: 25$ & 0.020 & 0.020 & $1: 25$ & 0.020 \\
\hline 21 & $16: 50$ & & 0.011 & $0: 50$ & 0.011 & 0.011 & $0: 50$ & 0.011 & 0.011 & $0: 50$ & 0.011 \\
\hline 23 & $17: 00$ & & 0.027 & $2: 00$ & 0.027 & 0.028 & $2: 00$ & 0.028 & 0.028 & $2: 00$ & 0.028 \\
\hline 28 & $11: 15$ & & 0.024 & $1: 45$ & 0.024 & 0.024 & $1: 45$ & 0.024 & 0.024 & $1: 45$ & 0.024 \\
\hline 29 & $17: 00$ & & 0.027 & $2: 00$ & 0.027 & 0.028 & $2: 00$ & 0.028 & 0.028 & $2: 00$ & 0.028 \\
\hline 30 & $17: 00$ & & 0.027 & $2: 00$ & 0.027 & 0.028 & $2: 00$ & 0.028 & 0.028 & $2: 00$ & 0.028 \\
\hline 43 & $10: 00$ & & 0.020 & $1: 30$ & 0.020 & 0.021 & $1: 30$ & 0.021 & 0.036 & $2: 58$ & 0.036 \\
\hline 44 & $9: 42$ & & 0.014 & $1: 00$ & 0.014 & 0.014 & $1: 00$ & 0.014 & 0.028 & $2: 00$ & 0.028 \\
\hline 50 & $16: 35$ & & 0.014 & $1: 00$ & 0.014 & 0.014 & $1: 00$ & 0.014 & 0.028 & $2: 00$ & 0.028 \\
\hline 54 & $17: 50$ & & 0.014 & $1: 00$ & 0.014 & 0.014 & $1: 00$ & 0.014 & 0.028 & $2: 00$ & 0.028 \\
\hline 57 & $17: 23$ & & 0.014 & $1: 00$ & 0.014 & 0.014 & $1: 00$ & 0.014 & 0.028 & $2: 00$ & 0.028 \\
\hline 61 & $18: 00$ & & 0.014 & $1: 00$ & 0.014 & 0.014 & $1: 00$ & 0.014 & 0.028 & $2: 00$ & 0.028 \\
\hline 65 & $19: 30$ & & 0.014 & $1: 00$ & 0.014 & 0.014 & $1: 00$ & 0.014 & 0.028 & $2: 00$ & 0.028 \\
\hline 71 & $7: 05$ & & 0.014 & $1: 00$ & 0.014 & 0.014 & $1: 00$ & 0.014 & 0.028 & $2: 00$ & 0.028 \\
\hline 74 & $18: 35$ & & 0.020 & $1: 30$ & 0.020 & 0.041 & $3: 00$ & 0.041 & 0.041 & $3: 00$ & 0.041 \\
\hline 78 & $7: 30$ & & 0.020 & $1: 30$ & 0.020 & 0.041 & $3: 00$ & 0.041 & 0.041 & $3: 00$ & 0.041 \\
\hline 85 & 18:00 & 0.014 & & & 0.014 & 0.014 & $1: 00$ & 0.028 & 0.014 & $1: 00$ & 0.028 \\
\hline 88 & $7: 00$ & 0.047 & & & 0.047 & & & 0.047 & & & 0.047 \\
\hline 90 & & 0.019 & & & 0.019 & & & 0.019 & & & 0.019 \\
\hline 91 & & 0.017 & & & 0.017 & & & 0.017 & & & 0.017 \\
\hline 92 & & 0.045 & & & 0.045 & & & 0.045 & & & 0.045 \\
\hline 100 & $17 ; 00$ & 0.003 & 0.020 & $1: 30$ & 0.023 & 0.041 & $3: 00$ & 0.044 & 0.041 & $3: 00$ & 0.044 \\
\hline 106 & $7: 40$ & & 0.020 & $1: 30$ & 0.020 & 0.041 & $3: 00$ & 0.041 & 0.041 & $3: 00$ & 0.041 \\
\hline 107 & $16: 00$ & 0.031 & & & 0.031 & & & 0.031 & & & 0.031 \\
\hline 109 & $14: 00$ & 0.038 & & & 0.038 & & & 0.038 & & & 0.038 \\
\hline 113 & $6: 00$ & 0.055 & & & 0.055 & & & 0.055 & & & 0.055 \\
\hline 121 & & 0.006 & & & 0.006 & & & 0.006 & & & 0.006 \\
\hline 123 & & 0.035 & & & 0.035 & & & 0.035 & & & 0.035 \\
\hline 129 & $16: 00$ & 0.008 & & & 0.008 & & & 0.008 & & & 0.008 \\
\hline 130 & $17: 00$ & 0.007 & & & 0.007 & & & 0.007 & & & 0.007 \\
\hline 131 & $20: 00$ & 0.021 & & & 0.021 & & & 0.021 & & & 0.021 \\
\hline 134 & $18: 00$ & 0.015 & & & 0.015 & & & 0.015 & & & 0.015 \\
\hline 139 & $17: 00$ & 0.008 & & & 0.008 & & & 0.008 & & & 0.008 \\
\hline 141 & 7:00 & 0.020 & & & 0.020 & & & 0.020 & & & 0.020 \\
\hline 142 & $17: 00$ & 0.025 & & & 0.025 & & & 0.025 & & & 0.025 \\
\hline 143 & $6: 00$ & 0.015 & & & 0.015 & & & 0.015 & & & 0.015 \\
\hline 146 & $12: 00$ & 0.043 & & & 0.043 & & & 0.043 & & & 0.043 \\
\hline 147 & $17: 30$ & 0.070 & & & 0.070 & & & 0.070 & & & 0.070 \\
\hline
\end{tabular}


A Tabela 3 contém os valores da média aritmética e desvio padrão do potencial mátrico para todo o ciclo da cultura, para cada profundidade e tratamento estudados, bem como a média aritmética dos desvios padrões diários desses potenciais. Pode-se verificar que de maneira geral o potencial mátrico aumenta em profundidade, o que indica aumento da umidade do solo, podendo isso ser atribuído ao fato de que na camada superficial do solo ocorre maior extração de água pelas plantas e maior perda por evaporação. Também de maneira geral ocorreu a redução dos desvios padrões desses potenciais, para todos os tratamentos, o que evidencia maior estabilidade temporal do potencial mátrico com a profundidade. A mesma redução aconteceu para a média dos desvios padrões diários, mostrando também menor variabilidade espacial em profundidade.

Tabela 3 - Média aritmética (m) e desvio padrão (dp) do potencial mátrico para todo o ciclo da cultura, para cada profundidade e tratamento estudados, e a média aritmética dos desvios padrões diários (mdp) desses potenciais, em $\mathrm{kPa}$.

\begin{tabular}{|c|c|c|c|c|c|c|c|c|c|}
\hline \multirow{2}{*}{$\begin{array}{l}\text { prof. } \\
\text { (m) }\end{array}$} & \multicolumn{3}{|c|}{ tro00 } & \multicolumn{3}{|c|}{ tr0I0 } & \multicolumn{3}{|c|}{ trIII } \\
\hline & $\mathbf{m}$ & $\mathrm{dp}$ & mdp & m & $\mathrm{dp}$ & mdp & $\mathbf{m}$ & $d p$ & mdp \\
\hline 0,10 & -38.7 & 27.7 & 7.6 & -36.1 & 28.5 & 7.1 & -22.8 & 17.4 & 7.3 \\
\hline 0,20 & -30.6 & 24.0 & 7.5 & -33.7 & 27.6 & 5.6 & -22.1 & 16.7 & 5.5 \\
\hline 0,30 & -30.9 & 25.4 & 5.9 & -31.5 & 25.3 & 7.6 & -21.4 & 14.4 & 6.5 \\
\hline 0,40 & -29.4 & 25.5 & 4.0 & -29.0 & 24.7 & 5.0 & -22.9 & 16.6 & 7.7 \\
\hline 0,50 & -28.1 & 23.8 & 5.1 & -26.8 & 23.2 & 4.9 & -22.3 & 16.5 & 7.5 \\
\hline 0,60 & -27.8 & 23.5 & 4.2 & -29.6 & 24.5 & 5.4 & -21.0 & 14.3 & 7.8 \\
\hline 0,70 & -27.6 & 22.9 & 4.8 & -25.7 & 22.2 & 5.1 & -19.8 & 13.3 & 6.9 \\
\hline 0,80 & -24.9 & 18.7 & 7.2 & -27.2 & 22.9 & 5.4 & -18.4 & 10.7 & 6.1 \\
\hline 0,90 & -27.3 & 21.9 & 4.6 & -25.9 & 21.6 & 6.0 & -18.4 & 10.6 & 6.2 \\
\hline 1,00 & -27.3 & 20.7 & 4.6 & -24.3 & 20.0 & 5.6 & -18.2 & 9.5 & 6.2 \\
\hline média & -29.3 & 23.4 & 5.6 & -29.0 & 24.1 & 5.8 & -20.7 & 14.0 & 6.8 \\
\hline
\end{tabular}


Conforme exemplificado pela Figura 3, extraída do Apêndice 2, e analisando ainda a Figura 4, extraída do Apêndice 3, vertifica-se que o desvio padrão diário dos potenciais mátricos se mostrou variável em função do valor desse potencial, comportamento esse idêntico ao ocorrido quando os resultados foram tratados em termos de coeficiente de variação. De maneira geral, pode-se observar que o desvio padrão aumenta quando o potencial mátrico se torna mais negativo, até certo ponto, e volta a diminuir a partir desse ponto, até o potencial mátrico mínimo limite para o funcionamento do tensiômetro, aproximadamente $-85 \mathrm{kPa}$. Analisando a variabilidade nas faixas de potencial mátrico e comparando-as com a tabela de WARRICK \& NIELSEN (1980), que classifica a variabilidade em termos de coeficiente de variação (baixa, média e alta variação), vê-se que ela pode ser considerada baixa quando nas faixas de 0 a $-15 \mathrm{kPa}$ e -70 a $-85 \mathrm{kPa}$, média quando nas faixas de -15 a $-40 \mathrm{kPa}$ e -60 a $-70 \mathrm{kPa}$, e variando entre média e alta quando entre -40 e $-60 \mathrm{kPa}$.

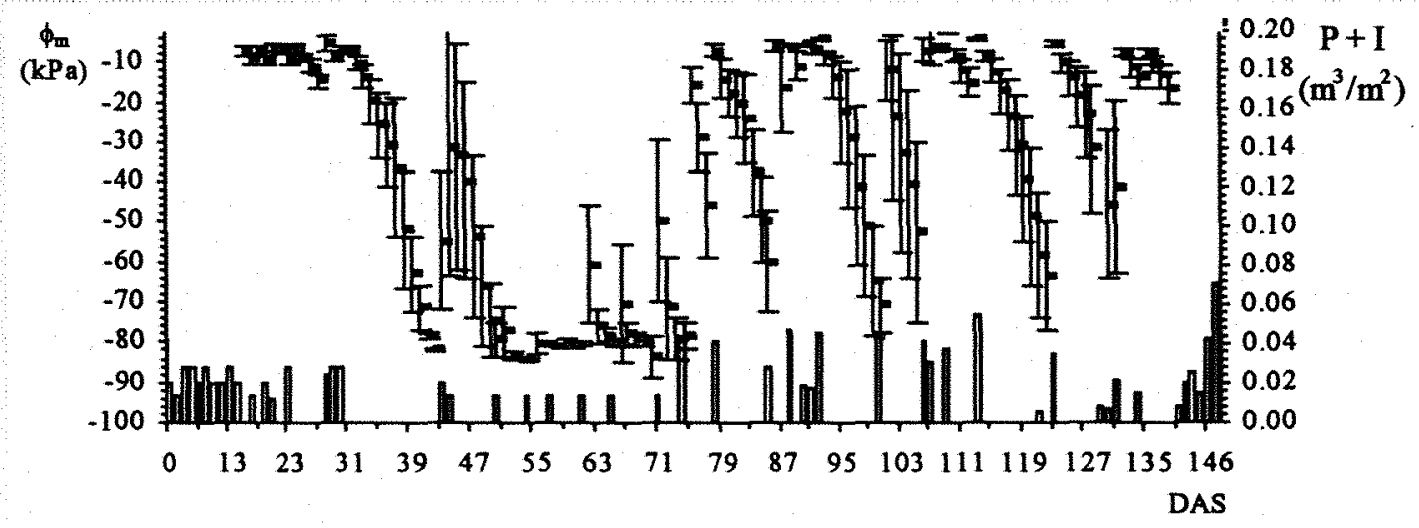

Figura 3 - Potencial mátrico $\left(\phi_{\mathrm{m}}\right.$, em $\left.\mathrm{kPa}\right)$ e lâminas de água precipitadas ou irrigadas $\left(P+I\right.$, em $\left.\mathrm{m}^{3} / \mathrm{m}^{2}\right)$, ao longo do tempo (DAS, dias após a semeadura): tratamento trol0, profundidade $0,10 \mathrm{~m}$. 


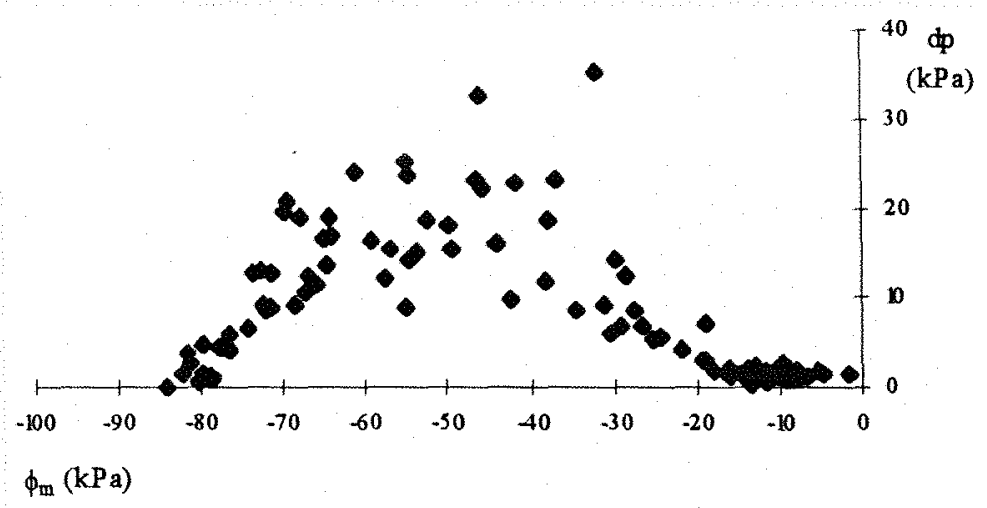

Tratamento tro00

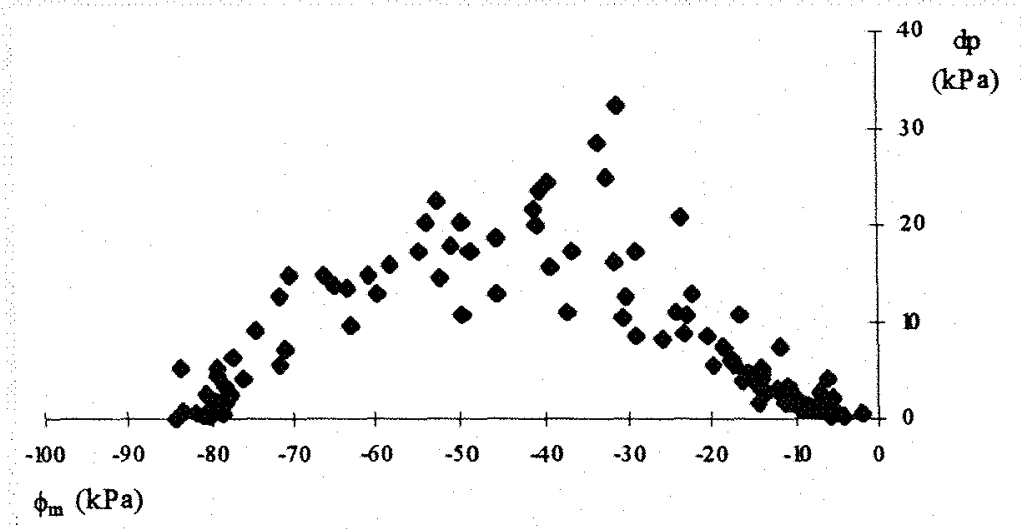

Tratamento tr0I0

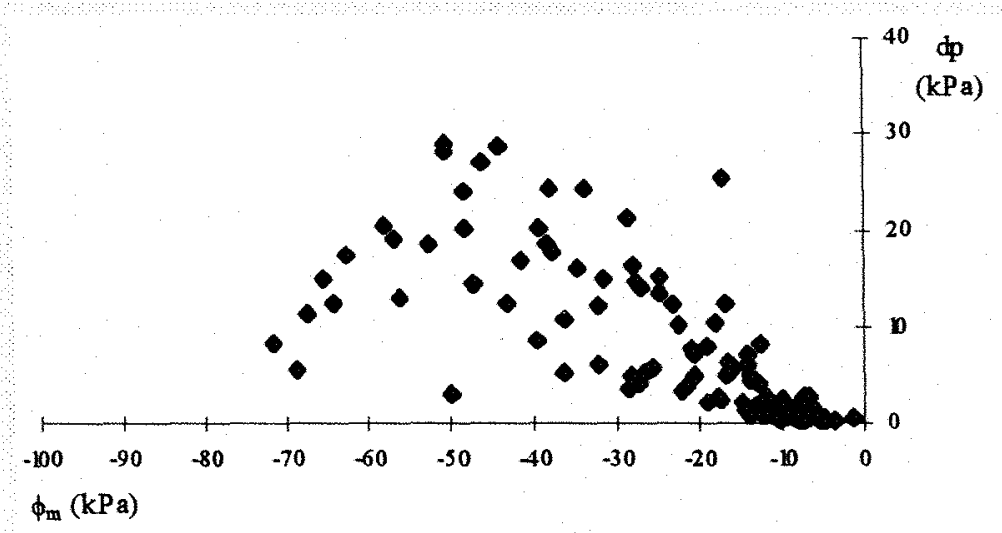

Tratamento trIII

Figura 4 - Variabilidade do potencial mátrico, expressa em termos de desvio padrão (dp), em função do valor desse potencial mátrico $\left(\phi_{\mathrm{m}}\right)$, em $\mathrm{kPa}$ (profundidade $0,20 \mathrm{~m})$. 
Verifica-se assim a ocorrência do efeito proporcional para o potencial mátrico da água no solo, o que é estatisticamente indesejável, pois evidencia a ocorrência de heterogeneidade de variâncias. Ou seja, uma comparação dos resultados deve-se considerar que a confiabilidade dos resultados é diferente dependendo do valor da média. Assim, por exemplo, se a tomada de decisão para irrigar fosse feita quando o potencial mátrico médio fosse de $-30 \mathrm{kPa}$, ela exigiria que se tivesse um número de repetições diferente daquele em que a tomada de decisão para irrigar fosse feita quando o potencial mátrico médio fosse de $-50 \mathrm{kPa}$, para que um mesmo nível de significância seja mantido. A transformação dos dados poderia ser usada em certos casos para resolver este problema, como recomendado por HENDRICKX et al (1990) para a tensão da água no solo.

Estudando a variabilidade do potencial mátrico obtido com o tensiômetro, HENDRICKX \& WIERENGA (1990) verificaram para valores compreendidos aproximadamente entre -10 e $-50 \mathrm{kPa}$, a mesma tendência de aumento do desvio padrão, inclusive tendo sido possível o ajuste por regressão linear de retas de dependência entre eles. Esse aumento da variabilidade poderia ser conseqüência de um aumento de variabilidade da umidade do solo com o seu secamento. HENDRICKX et al. (1990) verificaram que essa tendência se propagou para os resultados de umidade do solo obtidos a partir do potencial mátrico. Porém mesmo que a variabilidade da umidade do solo permaneça estável para qualquer ordem de grandeza, como a relação entre o potencial mátrico e a umidade do solo não é linear, o aumento da variabilidade para o 
potencial mátrico poderia se manifestar. Ou seja, para uma variabilidade da umidade do solo estável para qualquer ordem de grandeza, poder-se-ia esperar que para o potencial mátrico a variabilidade não fosse estável, mas aumente a medida que ele se torne mais negativo. Assim, uma pequena variação na umidade do solo pode significar uma variação também pequena nos valores de potencial mátrico se estes forem, por exemplo, da ordem de $-10 \mathrm{kPa}$, e uma variação exponencialmente maior se estes forem, por exemplo, da ordem de $-50 \mathrm{kPa}$.

CAMERON (1978) identificou que a umidade do solo na saturação apresenta-se com distribuição normal de seus desvios. WESENBEECK \& KACHANOSKI (1988) verificaram distribuição normal dos resultados no início e no final do ciclo da cultura (para a fase intermediária os valores de assimetria indicaram distribuição não normal dos resultados, o que provavelmente ocorreu devido ao fato de que os autores utilizaram valores de umidade provenientes de posições diferentes em relação a linha de plantio). Assim, a utilização do valor médio e dos desvios para representar um conjunto de valores, conforme prescrito pela estatística clássica, toma-se adequado. Apresentando a umidade distribuição normal, espera-se também que qualquer parâmetro do solo que se apresente linearmente dependente dela também seja normalmente distribuído. Para o caso do potencial mátrico, como a relação entre esse e a umidade do solo não é linear, poder-se-ia esperar uma distribuição não normal dos resultados. HENDRICKX et al. (1990) identificaram distribuição log-normal de resultados de tensão da água no solo, recomendando o uso dos valores log-transformados dessa 
tensão, para que inferências estatísticas possam ser feitas com maior segurança. Nesse caso a aplicação dos parâmetros da estatística clássica diretamente aos valores de tensão (ou potencial mátrico), especialmente a média e o desvio padrão, devem ser vistos com cautela, pois podem ter conseqüências indesejáveis.

Para verificar essas possíveis conseqüências considerou-se a situação em que estão disponíveis quatro repetições do potencial mátrico para a determinação da umidade do solo. A umidade pode ser determinada de duas maneiras: a primeira (método 1), calculando-se a média dos potenciais mátricos e substituindo-a na equação de VAN GENUCHTEN (1980), e a segunda (método 2), determinando-se essa umidade para cada valor de potencial mátrico, também por essa equação, e então calculando-se o seu valor médio. Devido a não linearidade da relação entre o potencial mátrico e umidade do solo, cuja forma aproximada da curva para a faixa de atuação do tensiômetro está expressa na Figura 5, o valor dessa umidade calculada pelo método 1 será menor do que aquele calculado pelo método 2. Assumindo que o método 2 seja o correto (pois considera a umidade média e não o potencial mátrico médio), o uso do método 1 traria como conseqüência a superestimação das lâminas de água recomendadas para a irrigação, fazendo com que a armazenagem atingida seja superior àquela desejada, e possivelmente fazendo com que parte da água aplicada na irrigação seja drenada.

Conhecendo-se os valores de $\theta r, \theta$ s e os parâmetros $\alpha, \mathbf{m}$ e $\mathbf{n}$ da equação de VAN GENUCHTEN (1980) representativos para a área, na profundidade de $0,30 \mathrm{~m}$, com os 
quais foi construído o gráfico da Figura 5 e cujos valores constam na equação 12, pôde-se calcular a umidade pelas duas maneiras.

$$
\theta=0,247+\frac{0,570-0,247}{\left[1+\left(\left|\phi_{m}\right| \cdot 3,36172\right)^{1,21843}\right]^{0,21124}}
$$

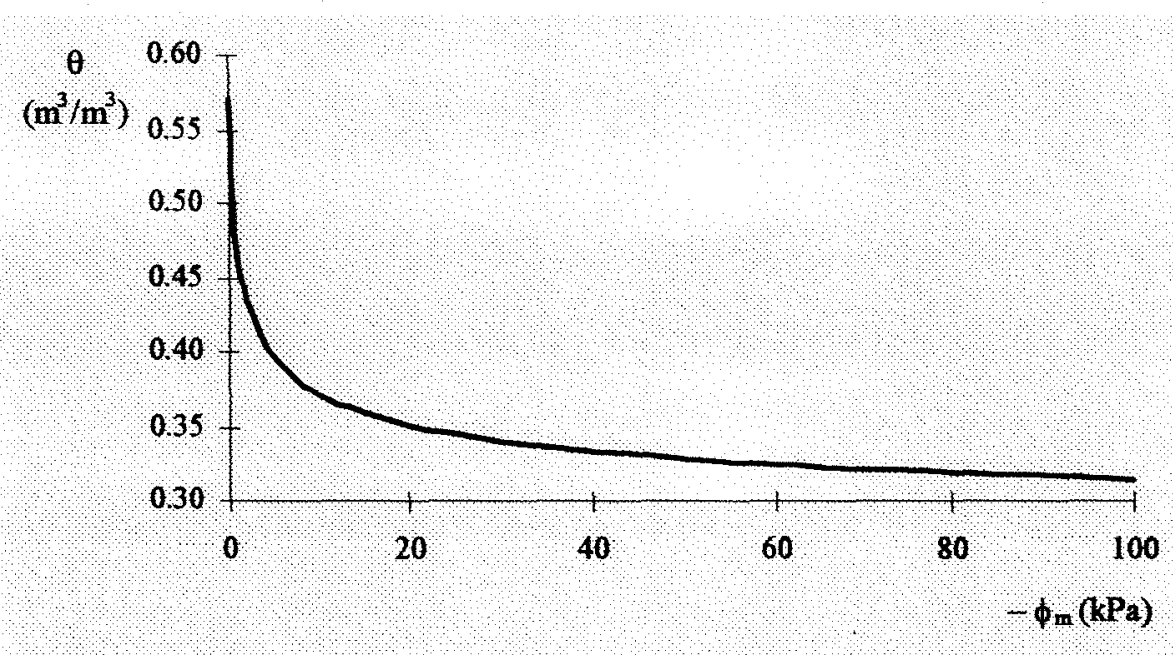

Figura 5 - Relação entre potencial mátrico $\left(\phi_{\mathrm{m}}, \mathrm{em} \mathrm{kPa}\right)$ e umidade do solo $\left(\theta, \mathrm{em} \mathrm{m}^{3} / \mathrm{m}^{3}\right)$ $\mathrm{da}$ área, para profundidade $0,30 \mathrm{~m}$.

Escolheu-se para o tratamento trIII diversas situações em que foi necessário a recomendação da aplicação de água, coincidentemente quando o potencial mátrico se mostrava com variabilidade elevada, e calculou-se a diferença entre as lâminas de irrigação recomendadas a partir das duas maneiras de determinação da umidade. Para isso calculou-se a armazenagem até $0,30 \mathrm{~m}$, considerando que a umidade é uniforme até essa profundidade. Sendo a umidade a ser atingida considerada equivalente àquela na qual o potencial mátrico é de $-10 \mathrm{kPa}$, calculou-se também a armazenagem desejada. Pela 
diferença entre a armazenagem e a armazenagem desejada obteve-se o volume a ser aplicado, para os dois métodos de cálculo da umidade. Os resultados estão expressos na Tabela 4 a seguir.

Tabela 4 - Volumes de água recomendados, em $\mathrm{m}^{3} / \mathrm{ha}$, calculadas pelo método 1 (média dos potenciais mátricos, substituída na equação) e pelo método 2 (média das umidades para cada potencial mátrico),e os parâmetros da equação de VAN GENUCHTEN (1980).

\begin{tabular}{|c|c|c|c|c|}
\hline \multirow[b]{2}{*}{ parâmetros } & \multirow{2}{*}{$\begin{array}{c}\text { tempo } \\
\text { DAS }\end{array}$} & \multicolumn{2}{|c|}{ volume recomendado $\left(\mathrm{m}^{3} / \mathrm{ha}\right)$} & \multirow[b]{2}{*}{ diferença $\left(\mathrm{m}^{3} / \mathrm{ha}\right)$} \\
\hline & & método 1 & método 2 & \\
\hline$\theta r=0.247 \mathrm{~m}^{3} / \mathrm{m}^{3}$ & 50 & 154.5 & 154.3 & 0.2 \\
\hline$\theta s=0.570 \mathrm{~m}^{3} / \mathrm{m}^{3}$ & 54 & 132.6 & 129.5 & 3.1 \\
\hline$\alpha=3.36172 \mathrm{kPa}^{-1}$ & 57 & 143.3 & 140.2 & 3.1 \\
\hline$n=1.26843$ & 61 & 133.7 & 128.8 & 5.0 \\
\hline \multirow[t]{3}{*}{$m=0.211624$} & 65 & 133.9 & 126.8 & 7.1 \\
\hline & 70 & 153.2 & 152.5 & 0.8 \\
\hline & soma & 851.3 & 832.0 & 19.3 \\
\hline
\end{tabular}

Pelos resultados pode-se perceber que os volumes de água que seriam aplicados a cada irrigação calculados pelas duas maneiras não são muito diferentes. A maior diferença obtida foi da ordem de $7 \mathrm{~m}^{3} / \mathrm{ha}$, para o $65^{\circ} \mathrm{DAS}$, que corresponde a uma lâmina de água de $0,7 \mathrm{~mm}$. Porém quando se observa o período total considerado, o volume de água por hectare nos 20 dias chega a $19 \mathrm{~m}^{3}$, o que segundo SERVIço MuNICIPAl De ÁGUA E ESGOTo (SEMAe/Piracicaba) ${ }^{2}$ é comparável ao consumo médio mensal de uma familia de 4 pessoas. Extrapolando-se para áreas mais extensas comumente encontradas na agricultura, poder-se-ia conchuir que se trata de um excesso

\footnotetext{
${ }^{2}$ SeRviço Municipal de Água E Esgoto, Piracicaba, SP. Informação por telefone, 1995.
} 
de aplicação de água considerável, ainda mais tendo em vista a eminente crise de fornecimento de água prevista para diversos locais.

O mesmo comportamento de aumento de variabilidade do potencial mátrico verificado entre -10 e $-50 \mathrm{kPa}$ não foi verificado para os valores de potencial mátrico entre -50 e $-80 \mathrm{kPa}$. A falta de resultados na literatura que analisem a variabilidade do potencial mátrico nessa faixa de valores dificulta a realização de comparações. Para o presente caso houve diminuição da variabilidade, a qual porém não contradiz a relação não linear entre potencial mátrico e umidade, mas possivelmente evidencia que houve diminuição da variabilidade do teor de água ao ponto de reduzir também a variabilidade do potencial mátrico. Essa uniformização da umidade do solo far-se-ia presente provavelmente devido ao fato que quando o potencial mátrico da água no solo diminui além de $-50 \mathrm{kPa}$ o solo passaria a perder água mais lentamente, seja pela diminuição da percolação ou da evaporação da superficie, seja pela diminuição do ritmo de sua absorção pelas plantas. Uma outra observação que deve ser considerada é que os resultados obtidos com o tensiômetro quando esse se aproxima de seu potencial mátrico limite de funcionamento perdem a confiabilidade, uma vez que é freqüente a formação de bolhas no interior do tubo de "nylon" utilizado como manômetro, a partir do ar dissolvido na água e do próprio vapor de água. Porém mesmo descartando-se os potenciais mais próximos a esse limite de funcionamento, a tendência de redução dos desvios padrões abaixo de $-50 \mathrm{kPa}$ ainda se mantém, reforçando a hipótese de uniformização da umidade do solo. 
Os resultados evidenciam um outro tipo de variabilidade do potencial mátrico da água, que é aquele que se manifesta após uma irrigação ou chuva. Essa variabilidade pode parecer a princípio, não ter influência relevante para o manejo da irrigação, justamente pelo momento em que ocorre, mas pode permitir que dela sejam extraídas algumas inferências de aplicação geral ou mesmo para o manejo da irrigação. Além disso teria grande importância para a utilização de métodos de controle de irrigação baseados no avanço da frente de molhamento, como o sugerido por ZUR et al (1994). Porém para condições de campo, onde a umidade é desuniforme, alguns dos problemas que podem ser enfrentados foram evidenciados no presente experimento, e são discutidos a seguir.

A água recebida pelo solo se infiltra e se distribui, alterando a umidade do solo e os valores de potencial mátrico da água. Poder-se-ia idealizar uma distribuição uniforme de água, num solo com umidade inicial e condutividade hidráulica uniformes, e em que a condutância de água das cápsulas porosas dos tensiômetros instalados fossem também uniformes. Nesta situação seria esperado que um certo tempo após uma chuva ou irrigação, idêntico para todas as repetições, a frente de molhamento atingisse a profundidade em questão. Como as cápsulas porosas também seriam uniformes quanto à condutância, a respostas dos tensiômetros também ocorreriam ao mesmo tempo. Numa situação real isso dificilmente ocorreria, pois somar-se-iam as variabilidades de todos os fatores envolvidos. Fosse este estudo planejado para cumprir esse fim, as variabilidades de cada um desses fatores deveriam ser individualizadas ao máximo, fazendo-se leituras 
dos tensiômetros com intervalos de tempo o mais curto possíveis. Não tendo sido planejado para isso, ainda assim algumas inferências podem ser extraidas.

Os resultados de precipitação pluvial e irrigação e os valores médios e de desvio padrão do potencial mátrico na tabela 5 mostram uma situação referente ao tratamento troI0 na profundidade $0,20 \mathrm{~m}$, bastante encontrada durante $\mathrm{o}$ experimento, que é aquela na qual a primeira leitura realizada após uma irrigação ou precipitação mostrou elevação do potencial mátrico para todas as repetições de um tratamento. Nessas situações a água da frente de molhamento do solo já atingiu a profundidade em questão e a condutância da cápsula porosa já permitiu a resposta do equipamento à diminuição do potencial mátrico devido ao aumento de umidade. Para a maioria dos casos, esse tempo entre a irrigação e a primeira leitura após ela foi de cerca de 24 horas, pois a irrigação era realizada imediatamente após uma leitura, e aproximadamente 24 horas antes da seguinte. Para o caso dos resultados da Tabela 5 a irrigação foi realizada no mesmo dia da leitura seguinte, tendo sido esse tempo ainda menor, cerca de 10 horas (obs.: os horários disponíveis das aplicações de água e precipitações constam na Tabela 2).

Tabela 5 - Exemplo de uniformidade no aumento do potencial mátrico das 4 repetições $(\mathrm{kPa})$ após irrigação $\left(\mathrm{I}, \mathrm{em} \mathrm{m} \mathrm{m}^{3} / \mathrm{m}^{2}\right)$ : tratamento trol0, profundidade $0,20 \mathrm{~m}$.

\begin{tabular}{ccccccccc}
\hline tempo & \multicolumn{6}{c}{ repetição } & média & \multicolumn{1}{c}{ desvio } \\
DAS & $\mathrm{r} 1$ & $\mathrm{r} 2$ & $\mathrm{r} 3$ & $\mathrm{r} 4$ & aritmética & padrão & 1 \\
\hline 77 & -61.5 & -34.6 & -34.6 & -48.8 & -44.9 & 12.9 & \\
78 & -6.9 & -6.5 & -8.2 & -12.5 & -8.5 & 2.7 & 0.041 \\
79 & -12.0 & -11.7 & -11.8 & -19.5 & -13.8 & 3.8 & \\
\hline
\end{tabular}


Diversas vezes, porém, verificou-se que mesmo quando o tempo entre a irrigação e a primeira leitura após foi de $\mathbf{2 4}$ horas ou maior, algumas repetições não responderam a aplicação de água. Ainda considerando o exemplo da Tabela 6 (também referente ao tratamento troI0 na profundidade $0,20 \mathrm{~m}$ ), verifica-se que no $85^{\circ} \mathrm{DAS}$ a média foi $-60,1 \mathrm{kPa}$ e o desvio padrão $6,7 \mathrm{kPa}$. Tendo ocorrido uma irrigação no $85^{\circ}$ DAS, pode-se perceber pelo aumento do potencial mátrico médio no $86^{\circ}$ DAS que houve aumento da umidade do solo, para o tratamento e profundidade em questão. Porém vê-se que houve aumento considerável no valor do desvio padrão com esse aumento do potencial mátrico médio, de $6,7 \mathrm{kPa}$ no $85^{\circ}$ DAS para $33,3 \mathrm{kPa}$ no $86^{\circ} \mathrm{DAS}$. Analisando-se os valores dos potenciais mátricos para cada repetição vê-se que a causa do aumento de variabilidade foi a repetição $\mathrm{r} 4$, que não respondeu a irrigação, não tendo havido aumento do potencial mátrico da água.

Tabela 6 - Exemplo de desuniformidade de aumento do potencial mátrico (kPa) das 4 repetições após irrigação $\left(\mathrm{I}, \mathrm{em} \mathrm{m}^{3} / \mathrm{m}^{2}\right)$ : tratamento trol0, profundidade $0,20 \mathrm{~m}$.

\begin{tabular}{|c|c|c|c|c|c|c|c|}
\hline \multirow{2}{*}{$\begin{array}{c}\text { tempo } \\
\text { DAS }\end{array}$} & \multicolumn{4}{|c|}{ repetição } & \multirow{2}{*}{$\begin{array}{c}\text { média } \\
\text { aritmética }\end{array}$} & \multirow{2}{*}{$\begin{array}{l}\text { desvio } \\
\text { padrão }\end{array}$} & \multirow[b]{2}{*}{ I } \\
\hline & r1 & $\mathrm{r2}$ & r3 & 14 & & & \\
\hline 85 & -63.0 & -56.8 & -52.7 & -68.0 & -60.1 & 6.7 & 0.028 \\
\hline 86 & -5.7 & -5.5 & -7.7 & -72.9 & -23.0 & 33.3 & \\
\hline 87 & -10.6 & -10.6 & -12.3 & -59.2 & -23.2 & 24.0 & \\
\hline
\end{tabular}

Por esse fato poder-se-ia formular algumas hipóteses. A primeira seria quanto a variabilidade no tempo de resposta das cápsulas porosas dos tensiômetros, tendo a da repetição $\mathrm{r} 4$ um tempo de resposta maior, não tendo sido atingido ainda o equilíbrio. Tendo sido a água proveniente de irrigação, a segunda seria que houve desuniformidade 
na aplicação dessa lâmina de água, ao ponto dela não ter atingido a profundidade em questão para essa repetição, e tê-la atingido para as demais. A terceira seria que mesmo que a lâmina de água aplicada tenha sido uniforme, a diferença na umidade inicial do solo devida à variabilidade espacial fez com que a repetição menos úmida tenha retido mais água nas camadas superficiais, restando pouca água para o umedecimento de camadas inferiores. Uma quarta seria que há variabilidade na condutividade hidráulica do solo, sendo esta menor para a repetição $\mathrm{r} 4$, não permitindo que a água já tenha atingido a profundidade considerada.

Porém analisando-se os resultados obtidos agora para o $87^{\circ}$ DAS, expressos na mesma tabela, verifica-se que houve redução considerável no desvio padrão. Esta deve-se ao fato de que o valor do potencial mátrico nas repetições $r 1, r 2$ e r3 começaram a diminuir e o da repetição $\mathrm{r} 4$ a se tornar menos negativo, seja porque a cápsula porosa tenha finalmente equilibrado o potencial mátrico da água no solo, seja porque a água tenha agora atingido a profundidade em questão para essa repetição $\mathbf{r} 4$. Como para a instalação dos tensiômetros utilizou-se como critério principal a uniformidade de condutância das cápsulas porosas, e tendo-se em vista os resultados obtidos por VILLAGRA et al. (1988), que obtiveram que o tempo de resposta do tensiômetro não excede 8 horas, pode-se considerar bastante improvável a possibilidade de que a variabilidade do potencial mátrico seja, nesse caso, conseqüência do tempo de resposta diferenciado das cápsulas. Além disso, para a profundidade subseqüente, cujos resultados estão expressos na Tabela 7, analisando-a da mesma forma que foi feito para a 
profundidade anterior, percebe-se que o mesmo comportamento se repete exatamente para a repetição $\mathbf{r}$. A diferença na umidade inicial do solo parece ter existido, pois tanto pela Tabela 6 quanto pela Tabela 7 o potencial mátrico antes da aplicação de água era mais negativo para a repetição $r 4$, porém essa diferença não seria suficiente para proporcionar uma variabilidade tão grande como a encontrada no $86^{\underline{a}}$ DAS. A possibilidade de desuniformidade na aplicação da água parece também evidente, pois na Tabela 6 mesmo para o $87^{\circ}$ DAS o aumento do potencial mátrico foi muito menor para r4 que para as outras repetições. Além disso percebe-se pela Tabela 7 que a profundidade subseqüente não foi atingida pela frente de molhamento mesmo no $87^{\circ}$ DAS. Porém essa desuniformidade não pode ser assumida como explicativa para a alta variabilidade do potencial mátrico encontrado, pois essa ocorreu diversas vezes também onde a lâmina de água era tida como uniforme, pois era proveniente da chuva, como no exemplo do $8^{\circ}$ DAS da Tabela 8 (referente ao tratamento tr000 na profundidade $0,10 \mathrm{~m}$ ), em que a precipitação ocorreu cerca de 10 horas antes da leitura.

Tabela 7 - Exemplo de desuniformidade de aumento do potencial mátrico (kPa) das 4 repetições após irrigação $\left(\mathrm{I}, \mathrm{em} \mathrm{m} / \mathrm{m}^{2}\right)$ : tratamento trol0, profundidade $0,30 \mathrm{~m}$.

\begin{tabular}{cccccccc}
\hline tempo & \multicolumn{9}{c}{ repetição } & \multicolumn{2}{c}{ média } & \multicolumn{2}{c}{ desvio } \\
DAS & $\mathrm{r} 1$ & $\mathrm{r} 2$ & $\mathrm{r} 3$ & $\mathrm{r} 4$ & aritmética & padrão & I \\
\hline 855 & -56.1 & -50.2 & -39.8 & -78.4 & -56.1 & 16.2 & 0.028 \\
86 & -5.5 & -6.7 & -8.2 & -79.4 & -25.0 & 36.3 & \\
87 & -10.3 & -10.8 & -11.6 & -77.1 & -27.5 & 33.1 & \\
\hline
\end{tabular}


Tabela 8 - Exemplo de desuniformidade de aumento do potencial mátrico (kPa) após precipitação $\left(P, \mathrm{em} \mathrm{m} / \mathrm{m}^{2}\right)$ : tratamento trol0, profundidade $0,10 \mathrm{~m}$.

\begin{tabular}{|c|c|c|c|c|c|c|c|}
\hline \multirow{2}{*}{$\begin{array}{c}\text { tempo } \\
\text { DAS }\end{array}$} & \multicolumn{4}{|c|}{ repetição } & \multirow{2}{*}{$\begin{array}{c}\text { média } \\
\text { aritmética }\end{array}$} & \multirow{2}{*}{$\begin{array}{l}\text { desvio } \\
\text { padrão }\end{array}$} & \multirow[b]{2}{*}{$\mathbf{P}$} \\
\hline & $\mathrm{rl}$ & $\mathrm{r} 2$ & r3 & r4 & & & \\
\hline 86 & -79.1 & -81.6 & -38.4 & -78.5 & -69.4 & 20.7 & \\
\hline 87 & -80.5 & -80.4 & -40.6 & -77.2 & -69.7 & 19.4 & \\
\hline 88 & -6.5 & -80.5 & -5.7 & -36.1 & -32.2 & 35.1 & 0.047 \\
\hline 89 & -13.6 & -14.5 & -12.8 & -13.2 & -13.5 & 0.7 & \\
\hline
\end{tabular}

Uma hipótese mais completa seria aquela que envolve as três últimas possibilidades, pois sabe-se que a condutividade é principalmente função da umidade do solo. Parece então adequado atribuir a variabilidade do potencial mátrico à variabilidade da umidade inicial do solo, à variabilidade da aplicação de água e à variabilidade da condutividade hidráulica do solo. Essa ultima é função da desuniformidade da umidade inicial do solo ou da desuniformidade de umidade devida à aplicação de água diferenciada para as repetições, e da própria variabilidade espacial do solo.

Por inúmeras situações que podem ser verificadas no Apêndice 1 pode-se ainda avaliar que as repetições próximas não mostram tendências de apresentarem valores mais próximos de potencial mátrico. Verifica-se por exemplo pela Tabela 5 que no $77^{\circ}$ DAS os potenciais mátricos de r2 e r3 são idênticos entre si e discrepantes de rl e r4. Porém pela Figura 1 verifica-se que r 2 e r3 estão mais distanciados que r 3 de r1 e que r2 de r4. O mesmo acontece por exemplo no $87^{\circ}$ DAS com a repetição $\mathrm{r} 2$ da Tabela 6 , que pela Figura 1 está mais próxima de $\mathrm{r} 4$, mas mostra valores mais próximos de r1 e r2 do que de r4. Esta variação por vezes elevada e aparentemente sem estrutura espacial toma condenável situações em que há um número reduzido de repetições ou em que apenas uma repetição de tratamento recebe instrumentação, por exemplo para o controle da 
irrigação. Diante da dificuldade de se instrumentar um grande número de parcelas no campo seria aconselhável a execução de experimentos que talvez contenham menos tratamentos, porém com um número maior de repetições, todas intrumentadas. Es \& Es (1993) já haviam verificado que repetições próximas não necessariamente apresentam valores mais próximos do parâmetro em questão, e salientaram a importância de se utilizar um número adequado de repetições.

Para os tipos de variabilidade observadas tentou-se verificar a possibilidade de atribuição de parte dessas à existência de repetições discrepantes das demais. Para tal fez-se regressões lineares entre os valores de cada repetição e a média do tratamento, para o período total do experimento, cujos resultados obtidos estão expressos na Tabela 9. Numa situação ideal, onde o estudo tivesse sido planejado visando uma avaliação mais precisa da variabilidade do solo para o parâmetro em questão, dever-se-ia estabelecer um número maior de repetições, fazendo com que a média estimada pelas repetições pudesse representar com mais confiança a média verdadeira desse parâmetro para a área de estudo. Considerando então essa média como uma boa estimativa do valor médio verdadeiro, poder-se-ia, então, fazer regressões entre cada repetição e a média, preferencialmente utilizando uma média das repetições que não incluisse a repetição que estava sendo avaliada. No caso em discussão, em que o experimento foi planejado para extrair informações da variabilidade em um experimento convencional, esse tipo de análise não é o mais adequado, pois tendo-se somente quatro repetições, não seria possível retirar do cálculo da média estimada uma repetição. Além disso a média utilizada 
para a regressão não representa com necessária confiança a média verdadeira. Ainda assim os resultados mostraram-se como bons indicativos de se verificar tendências, pois sendo o período do experimento longo, a idéia foi verificar se a tendência de divergir da média é algo que se repete no tempo. Pôde-se então identificar repetições que se mostraram excessivamente discrepantes da média, e que provavelmente interferiram decisivamente no manejo da irrigação, retardando ou antecipando o momento da irrigação ou mesmo fazendo com que se aplicasse lâminas de água maiores ou menores do que aquelas pretendidas. Numa situação em que estivesse disponível um número maior de repetições o erro proporcionado pela repetição discrepante seria diluído, ou mesmo haveria a possibilidade de que fosse descartada.

Numa situação ideal, em que cada repetição representasse perfeitamente a média, os coeficientes de correlação e determinação seriam 1. Como não se trata de uma regressão entre um parâmetro e outro que com ele se relaciona, mas sim de um parâmetro com ele mesmo (repetição e média), nesta situação ideal poder-se-ia esperar que o coeficiente linear da reta de regressão fosse zero, e que o coeficiente angular dessa reta também fosse 1 (ângulo de inclinação de $45^{\circ}$ ). Pelos resultados expressos na Tabela 9 pode-se dizer que para os tratamentos tr000 e tr0I0 as repetições não se apresentaram muito discrepantes da média, porém para o tratamento trIII observa-se que a repetição $\mathrm{rl}$ representou bem $\mathrm{o}$ valor médio diário somente para as profundidades 0,10 e $0,20 \mathrm{~m}$, sendo bastante discrepante para as demais profundidades. Cabe ressaltar que esta maior variabilidade ocorreu justamente no tratamento trIII, o qual recebeu maior 
aplicação de água. Conforme a Tabela 10 , a computação dessa repetição rl no cálculo do desvio padrão diário dos resultados faz com que em média esses sejam maiores do que quando feitos sem a sua inclusão, para todas as profundidades exceto para 0,10 e $0,30 \mathrm{~m}$. Como pode ser verificado na Tabela 11, a sua exchusão do cálculo do valor médio diário melhorou os resultados das regressões entre as demais repetições e essa nova média, para todas as profundidades, inclusive $0,10,0,20$ e $0,30 \mathrm{~m}$

A Tabela 12 traz os valores de umidade do solo para o tratamento trIII, nas profundidades 0,50 e $0,90 \mathrm{~m}$, calculados pela equação 12 , utilizando-se a média das 4 repetições $\left(\theta_{1}\right)$, a média de 3 repetições $\left(\theta_{2}\right.$, onde se excluiu a repetição $\left.\mathrm{r} 1\right)$, e somente a repetição rl $\left(\theta_{3}\right)$. Vê-se que a utilização da repetição discrepante (r1)não proporcionou grandes diferenças nos valores de umidade obtidos, mesmo tendo sido consideradas as profundidades que apresentaram os piores ajustes nas regressões lineares e a fase que apresentou a maior variabilidade ( $99^{\circ}$ ao $\left.106^{\circ} \mathrm{DAS}\right)$. Além disso, a grande sensibilidade verificada quando se analisou o potencial mátrico se manifesta de maneira muito menos intensa quando os resultados são transformados para umidade do solo. Isso permite-nos afirmar que essa alta variabilidade encontrada não necessariamente compromete sua utilização para manejo de irrigação, que é feita com base na variação de armazenagem calculada através da umidade do solo. 
Tabela 9 - Parâmetros das regressões lineares entre cada repetição e a média.

\begin{tabular}{|c|c|c|c|c|c|c|c|}
\hline profund. & tratirep. & no. obs. & Interserso & coef. ang. & R mültiplo & R-Quadr. & $R-Q$ ajust \\
\hline $0,10 \mathrm{~m}$ & 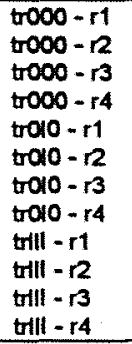 & $\begin{array}{l}113 \\
114 \\
111 \\
101 \\
119 \\
121 \\
119 \\
119 \\
119 \\
119 \\
110 \\
119 \\
\end{array}$ & $\begin{array}{r}-3.57003 \\
-6.04485 \\
-1.48136 \\
-5.03387 \\
-2.25894 \\
-6.88625 \\
-2.33906 \\
1.75480 \\
-3.12130 \\
-3.61833 \\
-2.18953 \\
-4.01071 \\
\end{array}$ & $\begin{array}{l}0.88209 \\
0.86539 \\
0.97085 \\
0.84925 \\
0.96502 \\
0.92999 \\
0.99964 \\
0.85287 \\
1.13076 \\
0.68558 \\
0.76703 \\
0.98505 \\
\end{array}$ & $\begin{array}{l}0.98013 \\
0.91701 \\
0.95293 \\
0.92290 \\
0.98380 \\
0.96294 \\
0.98408 \\
0.94008 \\
0.91673 \\
0.93946 \\
0.92400 \\
0.91609 \\
\end{array}$ & $\begin{array}{l}0.96066 \\
0.84091 \\
0.90807 \\
0.85174 \\
0.96786 \\
0.92725 \\
0.96842 \\
0.88375 \\
0.84040 \\
0.88259 \\
0.85377 \\
0.83922 \\
\end{array}$ & $\begin{array}{l}0.96030 \\
0.83949 \\
0.90723 \\
0.85024 \\
0.96758 \\
0.92664 \\
0.96815 \\
0.88276 \\
0.83903 \\
0.88159 \\
0.85242 \\
0.83784 \\
\end{array}$ \\
\hline $0,20 \mathrm{~m}$ & 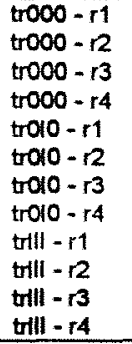 & $\begin{array}{l}91 \\
95 \\
85 \\
91 \\
117 \\
117 \\
117 \\
105 \\
121 \\
121 \\
121 \\
121 \\
\end{array}$ & $\begin{array}{l}-3.98866 \\
-2.32411 \\
-2.75335 \\
-3.83631 \\
-2.33879 \\
-3.54406 \\
-3.67301 \\
0.77339 \\
-3.22734 \\
-2.23002 \\
-1.84749 \\
-1.18839 \\
\end{array}$ & $\begin{array}{l}0.88879 \\
0.93231 \\
0.96829 \\
0.79935 \\
0.92935 \\
0.94208 \\
0.92598 \\
0.92736 \\
1.03255 \\
0.77046 \\
0.79701 \\
1.10444 \\
\end{array}$ & $\begin{array}{l}0.98193 \\
0.91385 \\
0.95099 \\
0.92887 \\
0.96547 \\
0.98500 \\
0.96785 \\
0.94264 \\
0.92910 \\
0.92389 \\
0.98142 \\
0.96754 \\
\end{array}$ & $\begin{array}{l}0.96418 \\
0.83512 \\
0.90438 \\
0.86280 \\
0.93214 \\
0.97022 \\
0.93673 \\
0.88858 \\
0.86322 \\
0.85358 \\
0.96319 \\
0.93613 \\
\end{array}$ & $\begin{array}{l}0.96378 \\
0.83335 \\
0.90323 \\
0.86126 \\
0.93155 \\
0.96996 \\
0.93618 \\
0.88750 \\
0.86208 \\
0.85235 \\
0.96289 \\
0.93560 \\
\end{array}$ \\
\hline $0,30 \mathrm{~m}$ & 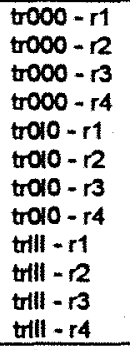 & $\begin{array}{c}95 \\
92 \\
94 \\
92 \\
114 \\
114 \\
114 \\
107 \\
121 \\
121 \\
121 \\
121 \\
\end{array}$ & $\begin{array}{l}-1.68644 \\
-1.15098 \\
-3.60412 \\
-2.89820 \\
-3.61900 \\
-5.18628 \\
-5.93883 \\
-1.23569 \\
-0.80323 \\
-5.51185 \\
-2.18302 \\
-3.48968 \\
\end{array}$ & $\begin{array}{l}0.97065 \\
0.99655 \\
0.90369 \\
0.83215 \\
0.91260 \\
0.95912 \\
0.90654 \\
0.73020 \\
1.27102 \\
0.56307 \\
0.89456 \\
0.90834 \\
\end{array}$ & $\begin{array}{l}0.98093 \\
0.94250 \\
0.94182 \\
0.97344 \\
0.94691 \\
0.97461 \\
0.95413 \\
0.88785 \\
0.83340 \\
0.91420 \\
0.95557 \\
0.92821 \\
\end{array}$ & $\begin{array}{l}0.96222 \\
0.88831 \\
0.88703 \\
0.94759 \\
0.89664 \\
0.94987 \\
0.91037 \\
0.78828 \\
0.69455 \\
0.83576 \\
0.91312 \\
0.86157 \\
\end{array}$ & $\begin{array}{l}0.96181 \\
0.88707 \\
0.88581 \\
0.94701 \\
0.89571 \\
0.94942 \\
0.90957 \\
0.78626 \\
0.69199 \\
0.83438 \\
0.91239 \\
0.86040 \\
\end{array}$ \\
\hline $0,40 \mathrm{~m}$ & 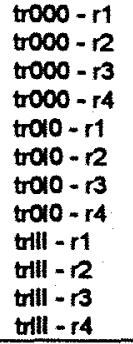 & $\begin{array}{c}98 \\
97 \\
98 \\
94 \\
113 \\
115 \\
115 \\
115 \\
121 \\
121 \\
121 \\
121 \\
\end{array}$ & $\begin{array}{l}-1.11688 \\
-0.53398 \\
-1.86132 \\
-1.80554 \\
-2.82714 \\
-3.00959 \\
-3.16931 \\
0.71344 \\
-2.64959 \\
-5.78826 \\
-3.50906 \\
-3.27313 \\
\end{array}$ & $\begin{array}{l}0.89839 \\
1.03527 \\
0.97015 \\
0.92047 \\
0.95748 \\
0.92057 \\
0.98454 \\
0.86886 \\
1.19404 \\
0.55067 \\
0.80813 \\
1.00387 \\
\end{array}$ & $\begin{array}{l}0.96301 \\
0.98225 \\
0.97542 \\
0.98728 \\
0.98145 \\
0.97985 \\
0.96773 \\
0.93119 \\
0.81762 \\
0.90782 \\
0.96691 \\
0.88702 \\
\end{array}$ & $\begin{array}{l}0.92738 \\
0.96482 \\
0.95144 \\
0.97472 \\
0.96325 \\
0.96011 \\
0.93650 \\
0.86711 \\
0.66851 \\
0.82413 \\
0.93492 \\
0.78680 \\
\end{array}$ & $\begin{array}{l}0.92663 \\
0.96445 \\
0.95094 \\
0.97445 \\
0.96292 \\
0.95975 \\
0.93593 \\
0.86594 \\
0.66572 \\
0.82266 \\
0.93437 \\
0.78501 \\
\end{array}$ \\
\hline $0,50 \mathrm{~m}$ & 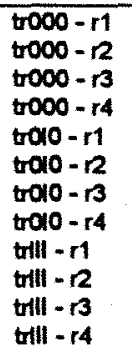 & $\begin{array}{l}95 \\
98 \\
96 \\
96 \\
97 \\
108 \\
108 \\
103 \\
121 \\
121 \\
121 \\
121\end{array}$ & $\begin{array}{l}-3.34854 \\
-1.65935 \\
-3.08056 \\
-1.79285 \\
2.66325 \\
-1.88253 \\
-2.77060 \\
0.80071 \\
-3.27705 \\
-5.18108 \\
-3.12660 \\
-4.01239\end{array}$ & $\begin{array}{l}0.77183 \\
1.03866 \\
0.92057 \\
0.92920 \\
1.42392 \\
0.87051 \\
0.92430 \\
0.81832 \\
1.21168 \\
0.58741 \\
0.81280 \\
0.87909\end{array}$ & $\begin{array}{l}0.90628 \\
0.97881 \\
0.95248 \\
0.98458 \\
0.90490 \\
0.98248 \\
0.97450 \\
0.98272 \\
0.74938 \\
0.94803 \\
0.93771 \\
0.90168\end{array}$ & $\begin{array}{l}0.82131 \\
0.95807 \\
0.90725 \\
0.96941 \\
0.81885 \\
0.98527 \\
0.94984 \\
0.96574 \\
0.58154 \\
0.89875 \\
0.87930 \\
0.81302\end{array}$ & $\begin{array}{l}0.81938 \\
0.95764 \\
0.90828 \\
0.86909 \\
0.81694 \\
0.96494 \\
0.94917 \\
0.96540 \\
0.55786 \\
0.89790 \\
0.87829 \\
0.81145\end{array}$ \\
\hline
\end{tabular}

(continua). 
Tabela 9 (continuação) - Parâmetros das regressões lineares entre cada repetição e a média.

\begin{tabular}{|c|c|c|c|c|c|c|c|}
\hline profund & tratirep. & no. obs. & Intersecĩo & coof. ang. & R múltiplo & R-Quadr. & $R-Q$ ajust \\
\hline $0,60 \mathrm{~m}$ & 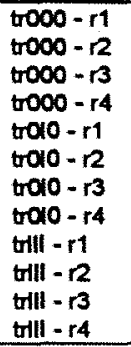 & $\begin{array}{c}97 \\
101 \\
99 \\
97 \\
111 \\
117 \\
117 \\
111 \\
121 \\
117 \\
121 \\
121 \\
\end{array}$ & $\begin{array}{l}-0.70874 \\
-2.11657 \\
-2.19524 \\
-1.22795 \\
-4.03647 \\
-1.11813 \\
-3.00728 \\
-0.04845 \\
-0.04120 \\
-6.38296 \\
-3.33306 \\
-3.33263\end{array}$ & $\begin{array}{l}0.90255 \\
1.02439 \\
0.91803 \\
0.92740 \\
1.05694 \\
0.93510 \\
0.93507 \\
0.83522 \\
1.48445 \\
0.52094 \\
0.80847 \\
0.86674 \\
\end{array}$ & $\begin{array}{l}0.97164 \\
0.96470 \\
0.96474 \\
0.98736 \\
0.93025 \\
0.98918 \\
0.97898 \\
0.94308 \\
0.72109 \\
0.94930 \\
0.90295 \\
0.89461 \\
\end{array}$ & $\begin{array}{l}0.94409 \\
0.93065 \\
0.93073 \\
0.97488 \\
0.86537 \\
0.97848 \\
0.95840 \\
0.88940 \\
0.51997 \\
0.90117 \\
0.81531 \\
0.80033 \\
\end{array}$ & $\begin{array}{l}0.94350 \\
0.92995 \\
0.93002 \\
0.97461 \\
0.86413 \\
0.97829 \\
0.95803 \\
0.88839 \\
0.51594 \\
0.90031 \\
0.81376 \\
0.79865 \\
\end{array}$ \\
\hline $0.70 \mathrm{~m}$ & 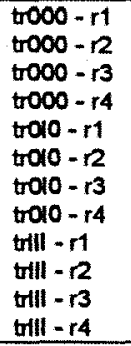 & $\begin{array}{c}98 \\
100 \\
100 \\
97 \\
105 \\
108 \\
108 \\
104 \\
121 \\
115 \\
121 \\
121 \\
\end{array}$ & $\begin{array}{l}-0.84336 \\
-3.74189 \\
-1.15183 \\
-1.97710 \\
-2.81395 \\
-0.89833 \\
-2.92202 \\
-1.01992 \\
-0.77801 \\
-5.68305 \\
-3.12954 \\
-1.88923 \\
\end{array}$ & $\begin{array}{l}0.92602 \\
1.04477 \\
0.91874 \\
0.85221 \\
1.10023 \\
0.94643 \\
0.90820 \\
0.79533 \\
1.45603 \\
0.53651 \\
0.81806 \\
0.89527 \\
\end{array}$ & $\begin{array}{l}0.98160 \\
0.92245 \\
0.98291 \\
0.96988 \\
0.94452 \\
0.98860 \\
0.98102 \\
0.92738 \\
0.65329 \\
0.96259 \\
0.91272 \\
0.93754 \\
\end{array}$ & $\begin{array}{l}0.96353 \\
0.85092 \\
0.96611 \\
0.94062 \\
0.89212 \\
0.97733 \\
0.96240 \\
0.86003 \\
0.42679 \\
0.92658 \\
0.83306 \\
0.87897 \\
\end{array}$ & $\begin{array}{l}0.96315 \\
0.84940 \\
0.96577 \\
0.94000 \\
0.89108 \\
0.97711 \\
0.96204 \\
0.85865 \\
0.42198 \\
0.92593 \\
0.83166 \\
0.87795 \\
\end{array}$ \\
\hline $0,80 \mathrm{~m}$ & 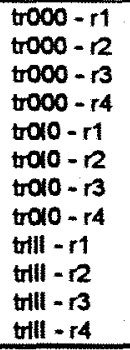 & $\begin{array}{c}94 \\
98 \\
98 \\
96 \\
93 \\
111 \\
111 \\
111 \\
121 \\
109 \\
121 \\
121 \\
\end{array}$ & $\begin{array}{l}-1.73132 \\
-5.12056 \\
-4.12409 \\
-4.24953 \\
3.98181 \\
-0.80963 \\
-1.88101 \\
-1.60346 \\
-2.53047 \\
-4.57147 \\
-6.91315 \\
-1.53749 \\
\end{array}$ & $\begin{array}{l}1.08495 \\
0.92391 \\
0.75285 \\
0.71520 \\
1.75600 \\
0.94174 \\
0.97754 \\
0.79038 \\
1.23080 \\
0.62466 \\
0.53545 \\
0.92318 \\
\end{array}$ & $\begin{array}{l}0.88298 \\
0.88437 \\
0.90568 \\
0.94469 \\
0.78151 \\
0.98490 \\
0.97720 \\
0.91328 \\
0.59296 \\
0.98273 \\
0.86005 \\
0.92556 \\
\end{array}$ & $\begin{array}{l}0.77965 \\
0.78210 \\
0.82022 \\
0.89244 \\
0.61076 \\
0.97002 \\
0.95491 \\
0.83408 \\
0.35160 \\
0.96576 \\
0.73968 \\
0.85663 \\
\end{array}$ & $\begin{array}{l}0.77726 \\
0.77983 \\
0.81835 \\
0.89129 \\
0.60548 \\
0.05975 \\
0.95450 \\
0.83256 \\
0.34615 \\
0.95544 \\
0.73749 \\
0.85545 \\
\end{array}$ \\
\hline $0,90 \mathrm{~m}$ & 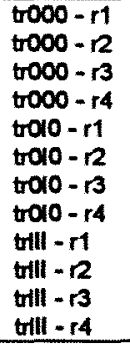 & $\begin{array}{l}100 \\
101 \\
101 \\
96 \\
97 \\
111 \\
111 \\
111 \\
121 \\
115 \\
121 \\
121 \\
\end{array}$ & $\begin{array}{l}-1.27931 \\
-2.00255 \\
-3.45307 \\
-1.19035 \\
6.29925 \\
-1.28381 \\
-3.13378 \\
-1.39385 \\
-0.07137 \\
-4.91307 \\
-7.11136 \\
-0.13209 \\
\end{array}$ & $\begin{array}{l}0.99670 \\
1.00565 \\
0.82737 \\
0.89053 \\
2.02008 \\
0.95120 \\
0.90585 \\
0.75598 \\
0.76553 \\
0.61320 \\
0.53089 \\
0.96365 \\
\end{array}$ & $\begin{array}{l}0.98046 \\
0.93861 \\
0.95836 \\
0.97375 \\
0.82874 \\
0.98449 \\
0.97385 \\
0.89563 \\
0.30873 \\
0.97617 \\
0.81504 \\
0.90257 \\
\end{array}$ & $\begin{array}{l}0.95130 \\
0.88099 \\
0.91463 \\
0.94819 \\
0.68848 \\
0.05923 \\
0.94839 \\
0.80215 \\
0.09531 \\
0.95291 \\
0.83729 \\
0.81464\end{array}$ & $\begin{array}{l}0.80091 \\
0.87979 \\
0.91377 \\
0.94764 \\
0.68520 \\
0.95895 \\
0.94792 \\
0.80033 \\
0.08771 \\
0.95249 \\
0.83593 \\
0.81308\end{array}$ \\
\hline $1,00 \mathrm{~m}$ & 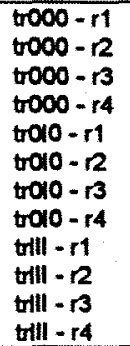 & $\begin{array}{l}103 \\
103 \\
103 \\
102 \\
97 \\
111 \\
111 \\
111 \\
120 \\
115 \\
121 \\
121\end{array}$ & $\begin{array}{l}-3.72268 \\
-3.49143 \\
-3.72268 \\
-1.47050 \\
-3.01608 \\
-0.73424 \\
-2.23585 \\
-2.08517 \\
-10.88982 \\
-3.24968 \\
-8.92187 \\
4.48900\end{array}$ & $\begin{array}{l}0.87355 \\
0.95968 \\
0.87355 \\
0.84324 \\
1.18998 \\
1.00215 \\
0.85397 \\
0.71778 \\
0.56425 \\
0.70396 \\
0.42546 \\
1.31531\end{array}$ & $\begin{array}{l}0.97254 \\
0.91148 \\
0.97254 \\
0.94509 \\
0.81050 \\
0.98216 \\
0.07912 \\
0.87446 \\
0.26791 \\
0.98270 \\
0.91929 \\
0.92801\end{array}$ & $\begin{array}{l}0.94584 \\
0.83075 \\
0.84584 \\
0.89433 \\
0.65691 \\
0.89464 \\
0.85887 \\
0.76467 \\
0.07178 \\
0.92696 \\
0.84510 \\
0.85750\end{array}$ & $\begin{array}{l}0.94530 \\
0.82908 \\
0.94530 \\
0.89327 \\
0.05329 \\
0.96431 \\
0.95829 \\
0.76251 \\
0.06391 \\
0.82631 \\
0.84380 \\
0.85630\end{array}$ \\
\hline
\end{tabular}


Tabela 10 - Valores de desvio padrão diário e a média desses desvios para o ciclo da cultura, para o tratamento trIII, considerando as 4 repetições (dp) e descartando-se a repetição mais discrepante da média (dp2), em kPa.

\begin{tabular}{|c|c|c|c|c|c|c|c|c|c|c|c|c|c|c|c|c|c|c|c|c|}
\hline \multirow[b]{2}{*}{ DAS } & \multicolumn{2}{|c|}{$0,10 \mathrm{~m}$} & \multicolumn{2}{|c|}{$0,20 \mathrm{~m}$} & \multicolumn{2}{|c|}{$0,30 \mathrm{~m}$} & \multicolumn{2}{|c|}{$0,40 \mathrm{~m}$} & \multicolumn{2}{|c|}{$0,50 \mathrm{~m}$} & \multicolumn{2}{|c|}{$0,60 \mathrm{~m}$} & \multicolumn{2}{|c|}{$0,70 \mathrm{~m}$} & \multicolumn{2}{|c|}{$0,80 \mathrm{~m}$} & \multicolumn{2}{|c|}{$0,90 \mathrm{~m}$} & \multicolumn{2}{|c|}{$1,00 \mathrm{~m}$} \\
\hline & $d p$ & $d p 2$ & $d p$ & $d p 2$ & $d p$ & $d p 2$ & $d p$ & $d p 2$ & $d p$ & $d p 2$ & $d p$ & $d p 2$ & $d p$ & $d p 2$ & $d p$ & $d p 2$ & $d p$ & $1 p 2$ & p & $d p 2$ \\
\hline 17 & 0.37 & 0.44 & 0.76 & 0.74 & 0.64 & 0.77 & 0.78 & 0.91 & 0.83 & 1.01 & 1.76 & 2.02 & 0.97 & 1.17 & 0.85 & 0.95 & 0.89 & 1.08 & 0.77 & $\overline{0.93}$ \\
\hline 18 & 0.45 & 0.45 & 0.60 & 0.60 & 0.53 & 0.65 & 0.52 & 0.62 & 0.68 & 0.82 & 1.77 & 2.03 & 0.90 & 1.07 & 0.99 & 1.14 & 1.11 & 1.33 & 1.18 & 1.45 \\
\hline 19 & 0.28 & 0.32 & 0.69 & 0.69 & 0.61 & 0.72 & 0.58 & 0.69 & 0.72 & 0.88 & 1.77 & 2.08 & 1.00 & 1.21 & 1.03 & 1.21 & 1.15 & 1.40 & 1.19 & 1.46 \\
\hline 20 & 0.22 & 0.25 & 0.54 & 0.60 & 0.47 & 0.51 & 0.49 & 0.58 & 0.62 & 0.76 & 1.83 & 2.15 & 0.90 & 1.09 & 0.93 & 1.08 & 1.15 & 1.40 & 1.29 & 1.59 \\
\hline 21 & 2.19 & 2.52 & 2.38 & 2.68 & 2.16 & 2.56 & 1.71 & 1.94 & 1.40 & 1.53 & 0.80 & 0.96 & 0.95 & 0.63 & 1.02 & 0.95 & 0.95 & 1.14 & 1.14 & 1.39 \\
\hline 22 & 0.83 & 0.91 & 1.32 & 1.42 & 1.30 & 1.56 & 1.27 & 1.47 & 1.22 & 1.34 & 0.69 & 0.84 & 1.04 & 0.79 & 1.03 & 0.60 & 0.73 & 0.52 & 1.29 & 1.31 \\
\hline 23 & 0.81 & 0.88 & 1.03 & 1.16 & 0.91 & 1.10 & 0.86 & 1.02 & 0.84 & 0.95 & 0.95 & 1.14 & 0.81 & 0.60 & 0.73 & 0.45 & 0.68 & 0.52 & 1.32 & 1.40 \\
\hline 24 & 0.49 & 0.45 & 0.71 & 0.69 & 0.62 & 0.76 & 0.59 & 0.72 & 0.76 & 0.88 & 0.79 & 0.95 & 0.92 & 0.88 & 0.98 & 0.82 & 0.88 & 0.73 & 1.84 & 1.82 \\
\hline 25 & 1.37 & 1.67 & 0.64 & 0.74 & 0.48 & 0.51 & 0.61 & 0.74 & 0.67 & 0.80 & 0.72 & 0.88 & 0.69 & 0.74 & 0.57 & 0.41 & 0.80 & 0.84 & 0.80 & 0.74 \\
\hline 26 & 1.74 & 2.13 & 0.45 & 0.55 & 0.51 & 0.52 & 0.45 & 0.55 & 0.52 & 0.63 & 1.43 & 1.70 & 0.74 & 0.80 & 0.60 & 0.69 & 0.86 & 0.95 & 0.92 & 1.09 \\
\hline 27 & & & 0.28 & 0.33 & 0.31 & 0.38 & 0.43 & 0.52 & 0.58 & 0.70 & 1.93 & 2.28 & 0.71 & 0.84 & 0.80 & 0.95 & 0.96 & 1.14 & 1.15 & 1.32 \\
\hline 28 & & & 1.28 & 0.77 & 0.52 & 0.63 & 0.38 & 0.44 & 0.49 & 0.58 & 1.85 & 2.17 & 0.66 & 0.77 & 0.84 & 0.95 & 0.96 & 1.14 & 1.11 & 1.32 \\
\hline 29 & & & 1.05 & 1.22 & 0.83 & 1.00 & 0.57 & 0.69 & 0.65 & 0.77 & 2.16 & 2.48 & 0.95 & 1.10 & 0.90 & 1.02 & 1.05 & 1.26 & 1.03 & 1.26 \\
\hline 30 & 0.39 & 0.38 & 0.71 & 0.69 & 0.39 & 0.45 & 0.53 & 0.65 & 0.67 & 0.77 & 2.24 & 2.56 & 0.90 & 1.00 & 1.04 & 1.03 & 1.12 & 1.26 & .46 & 1.71 \\
\hline 31 & 0.59 & 0.51 & 0.60 & 0.63 & 0.53 & 0.65 & 0.57 & 0.69 & 0.69 & 0.84 & 2.12 & 2.47 & 0.74 & 0.83 & 0.76 & 0.72 & 0.83 & 0.89 & 1.29 & 1.40 \\
\hline 32 & 1.02 & 0.88 & 0.45 & 0.55 & 0.55 & 0.65 & 0.53 & 0.65 & 0.69 & 0.84 & 1.10 & 1.31 & 0.72 & 0.86 & 0.62 & 0.65 & 0.82 & 0.96 & 1.16 & 1.36 \\
\hline 33 & 0.93 & 0.65 & 0.42 & 0.51 & 0.61 & 0.69 & 0.67 & 0.80 & 0.71 & 0.82 & 0.83 & 1.01 & 0.70 & 0.84 & 0.67 & 0.77 & 1.02 & 17 & 94 & 1.14 \\
\hline 34 & & & 0.28 & 0.33 & 0.51 & 0.48 & 0.42 & 0.51 & 0.63 & 0.77 & 0.67 & 0.82 & 0.77 & 0.93 & 0.75 & 0.86 & 0.93 & 1.14 & 0.88 & 1.07 \\
\hline 35 & & & 0.24 & 0.29 & 0.45 & 0.36 & 0.42 & 0.51 & 3 & 0.77 & $0.64^{\circ}$ & 0.76 & 10 & 0.98 & 89 & 1.08 & 99 & 1.21 & 98 & 1.20 \\
\hline 36 & 5.07 & 6.13 & 0.16 & 0.15 & 0.42 & 0.32 & 0.42 & 0.45 & 0.60 & 0.73 & 0.60 & 0.74 & 0.38 & 0.36 & 0.88 & 1.07 & 1.06 & 1.29 & 1.13 & 1.39 \\
\hline 37 & 8.52 & 10.38 & 0.53 & 0.58 & 0.94 & 1.15 & 0.49 & 0.55 & 0.72 & 0.86 & 1.10 & 1.20 & 0.93 & 1.13 & 0.98 & 1.20 & 1.16 & 1.42 & 1.25 & 1.51 \\
\hline 38 & 13.04 & 15.96 & 1.12 & 1.36 & 0.78 & 0.80 & 0.60 & 0.72 & 3.14 & 0.95 & 0.62 & 0.72 & 0.90 & 1.08 & 99 & 1.21 & 23 & 1.50 & .25 & 1.53 \\
\hline 39 & 12.40 & 15.02 & 3.35 & 3.95 & 0.30 & 0.07 & 0.88 & 1.02 & 1.17 & 1.42 & 0.47 & 0.51 & 1.02 & 1.17 & 1.02 & 1.24 & 1.25 & 1.52 & 1.29 & 1.56 \\
\hline - & - & - & . & - & . & . & . & - & - & • & . & . & . & 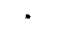 & - & - & - & - & . & - \\
\hline • & - & - & • & • & - & • & . & - & • & - & . & - & . & . & - & - & - & - & - & - \\
\hline - & • & • & - & • & - & • & - & . & - & - & . & - & • & . & - & • & - & • & • & - \\
\hline - & . & - & - & - & . & - & - & - & - & - & - & - & - & - & • & - & - & - & $\cdot$ & - \\
\hline - & - & - & - & - & . & - & • & . & - & - & - & - & - & 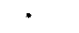 & - & - & - & - & - & . \\
\hline 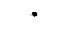 & - & - & ${ }^{\circ}$ & 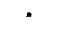 & - & 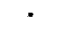 & 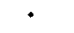 & 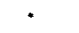 & 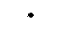 & 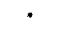 & 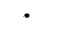 & 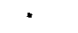 & ${ }^{*}$ & 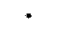 & $\cdot$ & 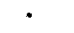 & 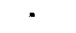 & - & ${ }^{\circ}$ & - \\
\hline 121 & 10.67 & 12.76 & 6.05 & 5.74 & 4.91 & 5.05 & 0.96 & 1.06 & 0.51 & 0.62 & 0.92 & 1.07 & 1.12 & 1.29 & 1.67 & 1.95 & 1.34 & 1.64 & 1.84 & 2.24 \\
\hline 122 & 12.46 & 14.08 & 7.00 & 6.85 & 5.99 & 6.12 & 1.04 & 1.22 & 0.59 & 0.73 & 0.98 & 1.17 & 0.84 & 0.93 & 1.75 & 2.09 & 1.42 & 1.72 & 1.97 & 2.40 \\
\hline 123 & 0.40 & 0.48 & 1.25 & 1.15 & 0.74 & 0.81 & 2.05 & 1.58 & 3.71 & 4.04 & 1.82 & 2.01 & 0.79 & 0.96 & 2.38 & 2.82 & 1.46 & 1.78 & 2.27 & 2.77 \\
\hline 124 & 0.43 & 0.52 & 1.22 & 1.26 & 0.51 & 0.19 & 0.57 & 0.44 & 1.76 & 1.84 & 2.63 & 2.75 & 2.57 & 2.29 & 1.74 & 1.55 & 1.39 & 1.65 & 3.28 & 4.00 \\
\hline 125 & 1.17 & 1.24 & 1.74 & 1.64 & 1.06 & 0.52 & 0.84 & 0.2 & 1.34 & 1.14 & 2.51 & 2.44 & 2.36 & 2.00 & 1.80 & 1.58 & 1.43 & 1.58 & 3.67 & 4.39 \\
\hline 126 & 2.10 & 2.20 & 2.11 & 2.02 & 1.57 & 0.80 & 1.23 & 0.33 & 1.38 & 1.09 & 2.22 & 2.06 & 1.84 & 1.35 & 1.84 & 1.20 & 1.53 & 1.56 & 4.04 & 4.83 \\
\hline 127 & 2.47 & 2.41 & 3.12 & 2.96 & 2.53 & 1.65 & 1.58 & 0.36 & 1.59 & 0.91 & 2.37 & 2.21 & 1.98 & 1.20 & 1.70 & 1.10 & 1.64 & 1.67 & 4.42 & 5.23 \\
\hline 128 & 3.27 & 3.24 & 4.74 & 4.59 & 4.04 & 3.21 & 2.18 & 0.69 & 2.10 & 1.17 & 2.65 & 2.27 & 2.05 & 1.13 & 1.65 & 0.88 & 2.19 & 2.40 & 4.93 & 5.87 \\
\hline 130 & 3.57 & 3.15 & 6.12 & 6.31 & 4.70 & 3.82 & 2.78 & 1.20 & 2.50 & 1.09 & 2.17 & 1.39 & 1.79 & 0.78 & 1.46 & 0.69 & 2.39 & 2.52 & 3.86 & 4.69 \\
\hline 131 & 4.94 & 4.84 & 5.05 & 3.15 & 4.76 & 3.33 & 2.57 & 1.13 & 2.21 & 0.81 & 2.10 & 1.51 & 1.62 & 0.57 & 1.62 & 1.24 & 3.27 & 2.52 & 3.97 & 4.73 \\
\hline 132 & 0.42 & 0.22 & 1.23 & 1.24 & 0.99 & 0.81 & 3.61 & 3.98 & 4.65 & 5.17 & 4.03 & 4.35 & 2.51 & 1.80 & 1.77 & 1.39 & 3.43 & $2 \pi$ & 4.01 & 4.79 \\
\hline 133 & 0.75 & 0.81 & 1.17 & 1.10 & 0.57 & 0.44 & 1.03 & 0.69 & 2.04 & 2.03 & 2.82 & 3.08 & 2.93 & 2.62 & 2.18 & 1.71 & 3.16 & 2.43 & 3.68 & 4.37 \\
\hline 134 & 0.92 & 0.98 & 0.92 & 0.77 & 0.57 & 0.36 & 0.87 & 0.48 & 1.52 & 1.24 & 1.96 & 1.86 & 2.02 & 1.52 & 1.78 & 1.15 & 1.86 & 1.79 & 2.95 & 3.40 \\
\hline 135 & 0.30 & 0.36 & 0.80 & 0.63 & 0.76 & 0.86 & 1.00 & 1.07 & 1.56 & 1.77 & 2.14 & 2.41 & 1.78 & 1.51 & 1.54 & 1.08 & $1 . \infty 0$ & 1.57 & 2.54 & 2.85 \\
\hline 136 & 0.67 & 0.81 & 0.87 & 0.76 & 0.57 & 0.58 & 0.74 & 0.67 & 1.17 & 1.20 & 1.53 & 1.72 & 1.33 & 1.10 & 1.79 & 1.64 & 1.81 & 1.22 & 2.14 & 2.27 \\
\hline 137 & 0.76 & 0.38 & 0.93 & 0.76 & 0.63 & 0.67 & 0.79 & 0.58 & 1.03 & 0.91 & 1.31 & 1.35 & 1.25 & 0.91 & 0.88 & 0.68 & 0.97 & 0.98 & 1.78 & 1.95 \\
\hline 138 & 1.43 & 0.51 & 0.96 & 0.68 & 0.51 & 0.52 & 0.70 & 0.50 & 0.86 & 0.79 & 1.17 & 1.17 & 0.90 & 0.76 & 0.88 & 0.36 & 0.70 & 0.88 & 1.51 & 1.75 \\
\hline di & 7.56 & 7.69 & 5.48 & 35 & .53 & 5.69 & 7.66 & 7,05 & 7.48 & 6.26 & 7.49 & 6.66 & 6.28 & 4.97 & 3.91 & 3.14 & 5.02 & 3.49 & 4.93 & 4.49 \\
\hline
\end{tabular}


Tabela 11 - Parâmetros das regressões lineares entre cada repetição e a média, para o tratamento trIII, quando descartou-se a repetição mais discrepante da média.

\begin{tabular}{|c|c|c|c|c|c|c|}
\hline prof. - repet. & no. obs. & Interseçāo & coef. angular & R múliplo & R-Quadrado & R-q. ajust. \\
\hline $0,10 m-12$ & 110 & 3.41998 & 0.76172 & 0.95674 & 0.91535 & 0.91456 \\
\hline $0.10 m-13$ & 110 & -1.60390 & 0.85624 & 0.94647 & 0.89580 & 0.89483 \\
\hline $0,10 m-r 4$ & 110 & -5.30029 & 1.02508 & 0.87805 & 0.77097 & 0.76885 \\
\hline $0,20 m-r 2$ & 121 & -1.62113 & 0.84357 & 0.95387 & 0.90086 & 0.90910 \\
\hline $0,20 m-13$ & 121 & -2.04290 & 0.83951 & 0.97480 & 0.95023 & 0.94982 \\
\hline $0,20 m-14$ & 121 & -1.46910 & 1.15606 & 0.95575 & 0.91345 & 0.91272 \\
\hline $0,30 m-12$ & 121 & -4.47464 & 0.66130 & 0.92759 & 0.86042 & 0.85925 \\
\hline $0,30 m-13$ & 121 & -0.84647 & 1.03750 & 0.95746 & 0.91673 & 0.91603 \\
\hline $0,30 m-14$ & 121 & -2.50745 & 1.04600 & 0.92352 & 0.85288 & 0.85164 \\
\hline $0,40 m-r 2$ & 121 & -4.56360 & 0.65309 & 0.93410 & 0.87255 & 0.87148 \\
\hline $0,40 m-13$ & 121 & -253965 & 0.92894 & 0.96534 & 0.93188 & 0.93131 \\
\hline $0,40 m-r 4$ & 121 & -2.77680 & 1.13070 & 0.86559 & 0.74925 & 0.74715 \\
\hline $0,50 m-r 2$ & 121 & -3.90887 & 0.70674 & 0.96113 & 0.92378 & 0.92314 \\
\hline $0,50 m-13$ & 121 & -1.35702 & 0.98143 & 0.96398 & 0.91009 & 0.90933 \\
\hline $0,50 \mathrm{~m}$ - r4 & 121 & -3.18384 & 1.02487 & 0.88579 & 0.78463 & 0.78282 \\
\hline $0,60 m-12$ & 117 & -5.19180 & 0.64507 & 0.96222 & 0.92586 & 0.92522 \\
\hline $0,60 m-13$ & 117 & -0.56318 & 1.06938 & 0.93833 & 0.88046 & 0.87942 \\
\hline $0,60 m-r 4$ & 117 & -1.95250 & 1.03211 & 0.87475 & 0.76519 & 0.76314 \\
\hline $0,70 m-12$ & 115 & -4.36220 & 0.66987 & 0.97053 & 0.94193 & 0.94141 \\
\hline $0,70 m-13$ & 115 & 1.61000 & 1.22691 & 0.98507 & 0.97036 & 0.97000 \\
\hline $0,70 m-14$ & 115 & 0.86655 & 1.11534 & 0.94635 & 0.89558 & 0.89466 \\
\hline $0,80 m-R$ & 100 & -3.27296 & 0.75318 & 0.98210 & 0.96451 & 0.96418 \\
\hline $0,80 m-13$ & 100 & -2.26326 & 0.91889 & 0.92677 & 0.85890 & 0.85758 \\
\hline $0,80 m-r 4$ & 100 & 2.23853 & 1.17214 & 0.95906 & 0.91979 & 0.91904 \\
\hline $0,90 m-12$ & 115 & -2.93752 & 0.79547 & 0.98338 & 0.96704 & 0.96675 \\
\hline $0,90 m-13$ & 115 & -4.23110 & 0.79662 & 0.94233 & 0.88798 & 0.88690 \\
\hline $0,90 \mathrm{~m}$ - r4 & 115 & 2.10711 & 1.16027 & 0.88145 & 0.77695 & 0.77498 \\
\hline $1, \infty m-12$ & 114 & -0.81808 & 0.89774 & 0.95469 & 0.91143 & 0.91063 \\
\hline $1,00 m-13$ & 114 & -7.13301 & 0.59388 & 0.93755 & 0.87900 & 0.87792 \\
\hline $1,00 m-r 4$ & 114 & 7.63466 & 1.57401 & 0.89125 & 0.79433 & 0.79249 \\
\hline
\end{tabular}


Tabela 12 - Coeficiente de variação, em \%, para 4 repetições do potencial mátrico (cv- $\phi \mathrm{m})$ e para 4 repetições da umidade (cv- $\theta$ ): tratamento trIII, profundidade 0,50 . Umidade do solo, em $\mathrm{m}^{3} / \mathrm{m}^{3}$, calculada pela média das 4 repetições $\left(\theta_{1}\right)$, calculada pela média de 3 repetições $\left(\theta_{2}\right)$ - onde se excluiu a repetição $\mathrm{rl}$, e calculada apenas pela repetição $\mathrm{rl}\left(\theta_{3}\right)$ : tratamento trIII, profundidades 0,50 e $0,90 \mathrm{~m}$.

\begin{tabular}{|c|c|c|c|c|c|c|c|c|}
\hline \multirow[b]{2}{*}{ DAS } & \multicolumn{5}{|c|}{$0.50 \mathrm{~m}$} & \multicolumn{3}{|c|}{$0.90 \mathrm{~m}$} \\
\hline & $c v-\phi m$ & $c v-\theta$ & $\theta_{1}$ & $\theta_{2}$ & $\theta_{3}$ & $\theta_{1}$ & $\theta_{2}$ & $\theta_{3}$ \\
\hline 17 & 8.955 & 0.842 & 0.380 & 0.380 & 0.381 & 0.386 & 0.385 & 0.387 \\
\hline 18 & 6.742 & 0.618 & 0.377 & 0.377 & 0.378 & 0.384 & 0.383 & 0.387 \\
\hline 19 & 7.658 & 0.707 & 0.379 & 0.379 & 0.380 & 0.384 & 0.383 & 0.385 \\
\hline 20 & 6.135 & 0.562 & 0.377 & 0.377 & 0.377 & 0.384 & 0.383 & 0.385 \\
\hline 21 & 16.551 & 1.493 & 0.383 & 0.382 & 0.388 & 0.384 & 0.384 & 0.386 \\
\hline 22 & 15.120 & 1.382 & 0.385 & 0.384 & 0.389 & 0.392 & 0.390 & 0.399 \\
\hline 23 & 9.206 & 0.855 & 0.381 & 0.380 & 0.383 & 0.392 & 0.390 & 0.398 \\
\hline 24 & 11.109 & 1.118 & 0.391 & 0.390 & 0.393 & 0.404 & 0.400 & 0.414 \\
\hline • & • & • & • & • & • & . & • & \\
\hline - & • & - & - & - & - & - & - & \\
\hline • & • & • & • & • & . & • & • & \\
\hline • & - & • & • & . & 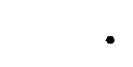 & . & . & \\
\hline • & • & - & • & • & - & - & $\cdot$ & \\
\hline $9 \dot{9}$ & $11.544^{\circ}$ & $0.82 \dot{4}^{\circ}$ & $0.36 \overline{7}^{\circ}$ & $0.36 \dot{5}^{\circ}$ & $0.360^{\circ}$ & $0.348^{\circ}$ & $0.34 \dot{2}^{\circ}$ & $0.375^{\circ}$ \\
\hline 100 & 35.845 & 2.779 & 0.360 & 0.359 & 0.354 & 0.342 & 0.339 & 0.355 \\
\hline 101 & 13.128 & 1.223 & 0.355 & 0.354 & 0.347 & 0.341 & 0.335 & 0.368 \\
\hline 102 & 10.768 & 0.957 & 0.350 & 0.349 & 0.340 & 0.339 & 0.330 & 0.410 \\
\hline 103 & 10.208 & 0.886 & 0.367 & 0.362 & 0.381 & 0.340 & 0.331 & 0.402 \\
\hline 104 & 7.937 & 0.638 & 0.371 & 0.368 & 0.371 & 0.342 & 0.332 & 0.419 \\
\hline 105 & 9.015 & 0.681 & 0.391 & 0.390 & 0.365 & 0.402 & 0.390 & 0.471 \\
\hline 106 & 42.353 & 4.672 & 0.419 & 0.418 & 0.358 & 0.412 & 0.410 & 0.417 \\
\hline • & - & - & • & • & - & . & • & \\
\hline • & • & • & • & • & - & • & - & \\
\hline - & • & • & • & • & - & • & • & \\
\hline • & . & . & . & - & - & . & - & \\
\hline - & • & • & • & - & . & : & : & \\
\hline $132^{\circ}$ & $35.58 \mathrm{i}$ & $2.95 \dot{2}^{\circ}$ & $0.37 \dot{2}^{\circ}$ & $0.370^{\circ}$ & $0.37 \dot{8}$ & $0.35 \mathrm{i}$ & $0.347^{\circ}$ & $0.365^{\circ}$ \\
\hline 133 & 17.481 & 1.533 & 0.371 & 0.369 & 0.376 & 0.353 & 0.351 & 0.359 \\
\hline 134 & 12.442 & 1.111 & 0.377 & 0.376 & 0.381 & 0.357 & 0.355 & 0.362 \\
\hline 135 & 15.572 & 1.443 & 0.377 & 0.376 & 0.380 & 0.364 & 0.361 & 0.375 \\
\hline 136 & 11.426 & 1.051 & 0.374 & 0.373 & 0.377 & 0.365 & 0.364 & 0.368 \\
\hline 137 & 9.300 & 0.842 & 0.372 & 0.371 & 0.374 & 0.365 & 0.365 & 0.364 \\
\hline 138 & 7.215 & 0.640 & 0.353 & 0.350 & 0.363 & 0.350 & 0.345 & 0.370 \\
\hline média & 24.553 & 2.070 & 0.360 & 0.359 & 0.001 & 0.361 & 0.358 & 0.003 \\
\hline
\end{tabular}




\subsection{Experimento II}

O teste para verificar a intensidade de aplicação e a uniformidade de distribuição da lâmina de água aplicada pelo equipamento de irrigação foi realizado com um único aspersor em funcionamento. Com base nesse teste estabeleceu-se o espaçamento entre os aspersores de $18 \mathrm{~m}$ x $12 \mathrm{~m}$, visando boa distribuição dessa lâmina de água. A intensidade de aplicação obtida foi $5 \mathrm{~mm} / \mathrm{h}$, pela qual se pôde calcular o tempo de funcionamento do equipamento de irrigação para que a lâmina de irrigação fosse efetivamente aplicada.

O início do manejo da irrigação ocorreu no $23^{\circ}$ DAS, após o período inicial de estabelecimento da cultura em que a irrigação manteve a umidade próxima à capacidade de campo. Da semeadura até o $49^{\circ}$ DAS as lâminas de água foram provenientes exclusivamente das irrigações, e daí até o final do ciclo da cultura provenientes exclusivamente de precipitações. As lâminas de água aplicadas ou as irrigações ocorridas durante o experimento constam nas tabelas do Apêndice 4. A colheita foi feita no $134^{\circ}$ DAS.

As leituras com a sonda de nêutrons começaram a ser realizadas no $23^{\circ}$ DAS, e logo no início pode ser notado que algum tipo de problema estava ocorrendo na parcela da repetição $r 3$ do tratamento tr2. Leituras muito inferiores às observadas nas outras parcelas e repetições estavam ocorrendo nas profundidades de 0,70 a $1,00 \mathrm{~m}$. Instalou-se então um outro tubo de acesso para a sonda, no qual obteve-se leituras condizentes com as outras parcelas. Durante todo o ciclo da cultura as leituras continuaram a ser 
realizadas também no tubo que apresentou o problema, e seus valores de contagem relativa estão apresentados nas tabelas do Apêndice 4, sob a denominação de r3-p. Estas baixas leituras obtidas podem ter sido conseqüência de problemas durante a instalação do tubo de acesso, tendo ficado uma camada de ar considerável entre a parede do tubo e o solo, ou serem próprias do local de instalação, ocorrendo devido a presença de camada com baixíssima densidade, conseqüência, por exemplo, da presença de um formigueiro. Este problema só pôde ser detectado porque os valores foram extremamente discrepantes em relação aos outros pontos de amostragem. Pode-se ressaltar então a importância de se ter um número adequado de tubos de acesso, bem como de se ter conhecimento do processo físico envolvido, para que problemas como esse possam ser contornados mesmo que as diferenças sejam mais sutis do que as encontradas.

A Tabela 13 contém os valores de contagem relativa por profundidade de cada tratamento para todo o ciclo da cultura, bem como o desvio padrão dessas contagens e a média dos desvios padrões diários. Pode-se verificar que a contagem relativa aumentou da superficie até $0,60-0,70 \mathrm{~m}$, e diminuiu a partir dessa profundidade. Essa contagem relativa mais elevada nessa camada intermediária provavelmente significa também umidade mais elevada, pois coincide com a presença do horizonte B textural, que pressupõe maior proporção de microporos, e portanto maior retenção de água, quando comparado ao horizonte A superficial ou ao horizonte B latossólico, mais profundo. Além disso essa camada estaria menos sujeita tanto aos ganhos de água por irrigação ou precipitação quanto às perdas devidas à evaporação ou absorção pelas plantas, quando 
Tabela 13 - Média (m) e desvio padrão (dp) da contagem relativa de nêutrons lentos e a média dos desvios padrões diários (mdp) dessas contagens, para todo o ciclo da cultura.

\begin{tabular}{|c|c|c|c|c|c|c|c|c|c|c|c|c|}
\hline \multirow{2}{*}{$\begin{array}{l}\text { prof. } \\
\text { (m) }\end{array}$} & \multicolumn{3}{|c|}{ TR0 } & \multicolumn{3}{|c|}{ TR1 } & \multicolumn{3}{|c|}{ TR2 } & \multicolumn{3}{|c|}{ TRbs } \\
\hline & $\mathrm{m}$ & $\phi p$ & adp & $\mathrm{m}$ & $d p$ & mdp & $\mathrm{m}$ & dp & mdp & $\mathrm{m}$ & 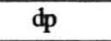 & mdp \\
\hline 0,20 & 1.4482 & 0.1422 & 0.0582 & 1.5472 & 0.1362 & 0.0540 & 1.5478 & 0.1269 & 0.0544 & 1.5248 & 0.0924 & 0.1436 \\
\hline 0,30 & .6606 & 0.0881 & 0.0619 & 1.7420 & 0.0939 & 0.0643 & $1 . @ 997$ & 0.0955 & 0.0869 & 1.6686 & 0.0666 & 0.0976 \\
\hline, 40 & & 0.0743 & 0.0404 & 1.8148 & 0.0875 & 0.0661 & 1.7897 & 0.0840 & & 1.7456 & 0.0465 & 0.0538 \\
\hline 0,50 & 1.8495 & 0.0648 & 0.0388 & 1.8393 & 0.0845 & 0.0629 & 1.8542 & 0.0782 & 0.0692 & 1.8030 & 0.0429 & 0.0390 \\
\hline, 60 & .8464 & 0.0610 & 0.0719 & 1.8051 & 0.0860 & 0.0416 & 1.8752 & 0.0765 & 0.0286 & 1.8343 & 0.0431 & 0.0477 \\
\hline & & 0.0560 & & & 0.0807 & & & & & & & \\
\hline, 80 & 1.7682 & 0.0614 & 0.0795 & 1.6995 & 0.0755 & 0.0702 & 1.7487 & 0.0639 & 0.0418 & 1.8128 & 0.0382 & 0.0362 \\
\hline 0,90 & 1.6979 & 0.0645 & 0.0818 & 1.5797 & 0.0704 & 0.0690 & 1.6908 & 0.0578 & 0.0432 & 1.7807 & 0.0359 & 0.0272 \\
\hline 1,00 & 1.6368 & 0.0631 & 0.0578 & 1.5586 & 0.0676 & 0.0537 & 1.6444 & 0.0518 & 0.0408 & 1.7006 & 0.0255 & 0.0721 \\
\hline 1,10 & 1.6192 & 0.0587 & 0.0373 & 1.5434 & 0.0634 & 0.0319 & 1.6186 & 0.0470 & 0.0352 & 1.6199 & 0.0244 & 0.1186 \\
\hline 1,20 & 1.6561 & 0.0584 & 0.0693 & 1.5561 & 0.0654 & 0.0953 & 1.6237 & 0.0418 & 0.0358 & 1.5943 & 0.0189 & 0.1316 \\
\hline média & 1.7080 & 0.0721 & 0.0611 & 1.6778 & 0.0828 & 0.0612 & 1.7195 & 0.0717 & 0.0526 & 1.7216 & 0.0432 & 0.0738 \\
\hline
\end{tabular}

comparada às camadas mais superficiais. Há no entanto um outro fator a considerar, que é a densidade do solo mais elevada nessa camada intermediária, o que poderia aumentar a contagem relativa pela moderação de nêutrons por outros núcleos que não os de hidrogênio. Este fato poderia justificar a necessidade de se utilizar uma curva de calibração específica para cada camada uniforme do solo, principalmente quando se deseja chegar a valores confiáveis de umidade do solo, o que concorda com MARANHO et al. (1995). Porém, conforme verificado por TURATTI et al. (1988), quando se trata da determinação da variação da armazenagem a utilização de uma curva geral para um perfil não representaria problema. Isso também foi comprovado pelo estudo de KIRDA \& REICHARDT (1992), que verificaram que as medidas da sonda de nêutrons apresentaram alta estabilidade temporal, isto é, os valores mínimo, máximo e médio ocorrem sempre nas mesmas posições no campo experimental, o que foi atribuído ao fato 
do tamanho da amostra ser elevado, representando bem um valor médio da camada, menos sujeito a variações pontuais.

Os valores de desvio padrão dessas contagens raramente atingiriam $10 \%$ se transformados para coeficiente de variação, podendo ser considerados baixos por exemplo quando comparados com a tabela de classificação sugerida por WARRICK \& NIELSEN (1980). Mostraram-se predominantemente decrescentes com a profundidade, para todos os tratamentos, o que evidencia a maior estabilidade temporal da contagem relativa em profundidade. Na profundidade de $0,20 \mathrm{~m}$ os valores médios das contagens relativas foram consideravelmente menores e os valores de desvio padrão maiores do que nas profundidades subseqüentes, o que pode ser atribuído em parte ao aumento da esfera de influência da medida com o secamento do solo, a qual teria atingido a atmosfera acima da superficie, proporcionando contagens menores do que seriam aquelas em camadas mais profundas com uma umidade equivalente. Essa hipótese é bastante plausível, principalmente levando em conta as informações de IEAE $(1970)^{3}$, citadas por BACCHI \& REICHARDt (1990), que consideram que o diâmetro pode atingir até $0,80 \mathrm{~m}$ ou mais, para solos com $10 \%$ de umidade à base de volume. Para o presente caso a ocorrência de diâmetro da esfera de influência maior que $0,40 \mathrm{~m}$ seria suficiente para que a atmosfera fosse atingida. Diante dessa possibilidade é aconselhável a utilização de uma curva de calibração específica para a profundidade em questão, conforme verificado por MARANHO et al (1995).

${ }^{3}$ IAEA. Neutron moisture gauges. Viena, 1970. 137p. (Technical report series, 112). 
Quanto à média dos desvios padrões diários por tratamento, ainda pela Tabela 13, verifica-se que esses não apresentam nenhuma tendência clara de variação com a profundidade. Apenas para o tratamento trbs pode-se observar que esses valores são menos elevados nas profundidades intermediárias quando comparados com as mais superficiais $(0,20$ e $0,30 \mathrm{~m})$ ou mais profundas $(1,10 \mathrm{~m}$ ou $1,20 \mathrm{~m})$.

Numa análise da Figura 6, extraída dos gráficos apresentados no Apêndice 5, é perceptível a elevação do valor médio e a diminuição dos desvios padrões da segunda metade do ciclo da cultura em relação à primeira, podendo-se diferenciar essas fases pela ocorrência da estação chuvosa no segundo período. Verifica-se também que a tendência de variação dos desvios padrões com o valor médio das contagens relativas não fica claramente evidenciada. Este fato identifica a não ocorrência do efeito proporcional para a contagem relativa de nêutrons, diferentemente do que foi verificado para o potencial mátrico. Analisando-se a Figura 7, extraídas do Apêndice 6, percebe-se que apenas para algumas profundidades e tratamentos parece existir tendência de aumento da

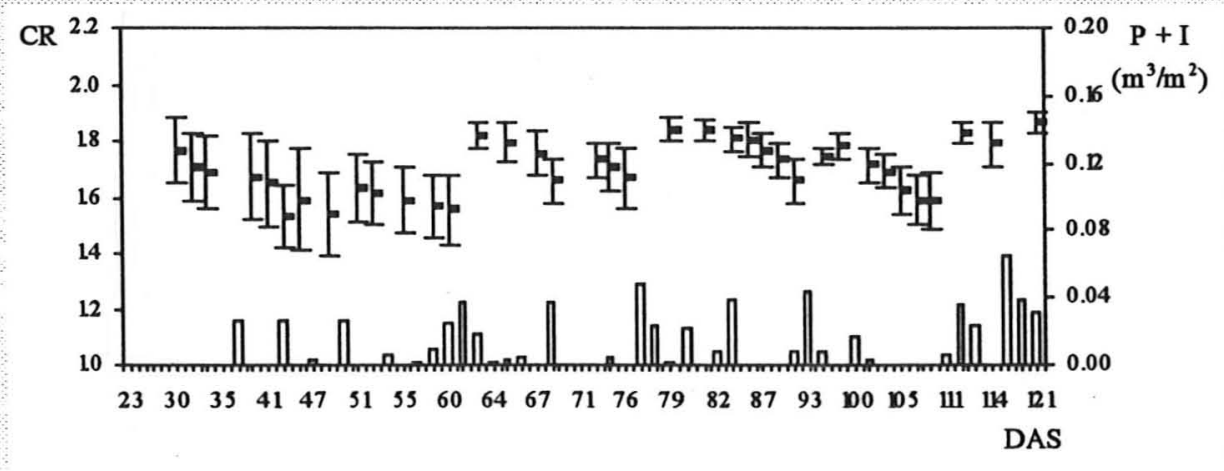

Figura 6 - Variabilidade da contagem relativa de nêutrons lentos (CR) ao longo do tempo (DAS, dias após a semeadura) e lâminas de água precipitadas ou irrigadas $\left(P+I, \mathrm{~m}^{3} / \mathrm{m}^{2}\right)$ : tratamento $\mathrm{tr} 2$, profundidade $0,30 \mathrm{~m}$. 


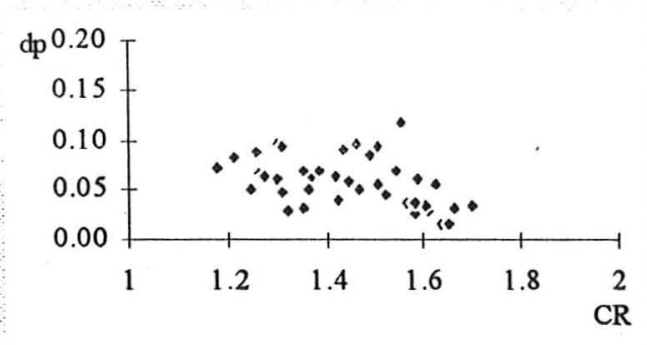

Tratamento tro

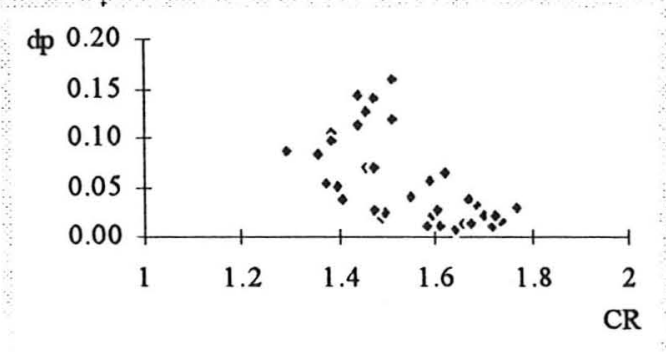

Tratamento tr2

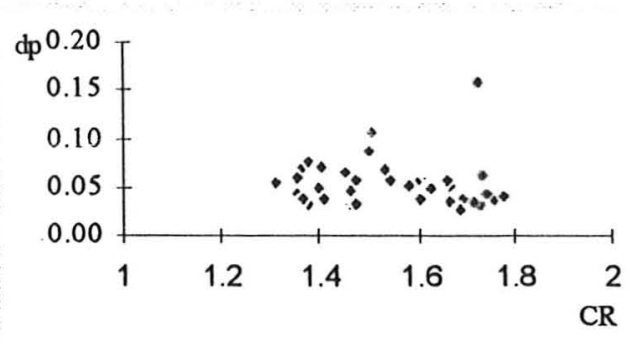

Tratamento trl

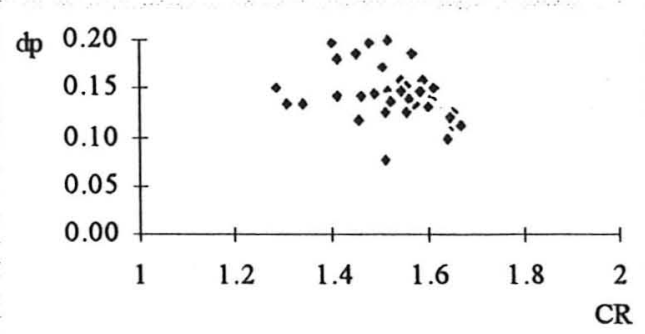

Tratamento trbs

PROFUNDIDADE $0,20 \mathrm{~m}$

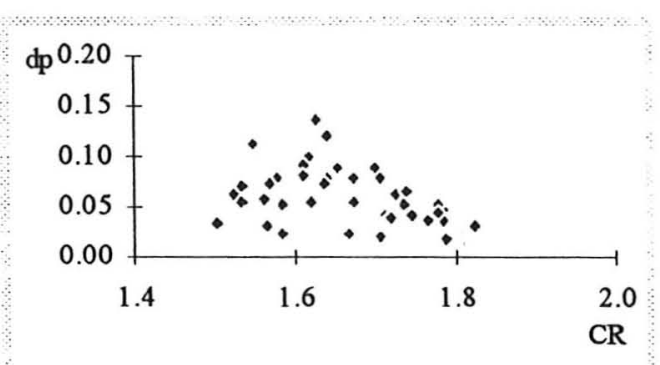

Tratamento tro

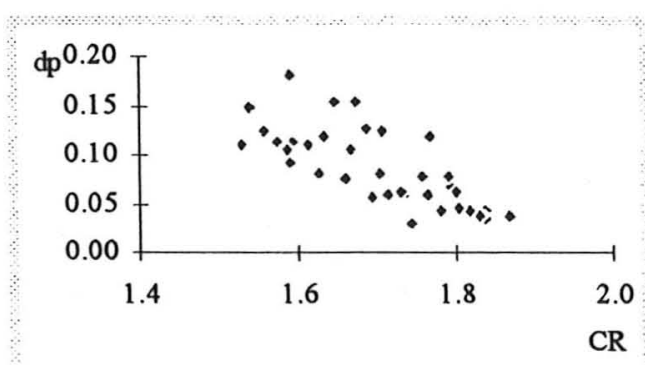

Tratamento tr2

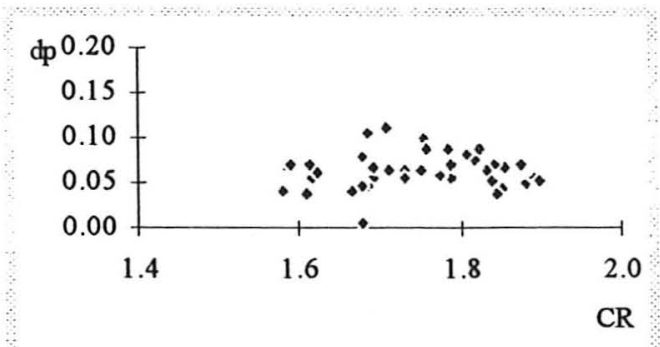

Tratamento tr1

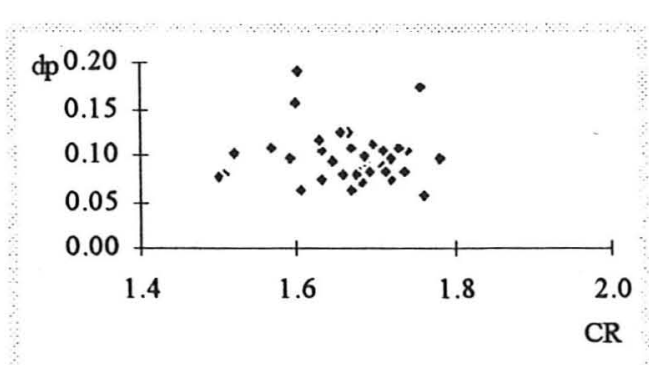

Tratamento trbs

PROFUNDIDADE $0,30 \mathrm{~m}$

Figura 7 - Variabilidade da contagem relativa de nêutrons lentos, expressa em termos de desvio padrão (dp), em função do valor dessa contagem (CR): profundidades 0,20 e $0,30 \mathrm{~m}$. 
variabilidade com a diminuição do valor médio da contagem relativa, manifestando-se essa variabilidade tanto em termos de desvio padrão quanto em termos de coeficiente de variação. Resultados obtidos por HENDRYCKX et al. (1990) mostraram desvio padrão crescente com a diminuição dos valores de umidade do solo, porém obtida com o tensiômetro. A tendência de variabilidade crescente com o decréscimo da contagem relativa, onde esta foi verificada, se propagaria para a umidade, pois se obtém a umidade a partir da contagem relativa de nêutrons lentos pela equação de uma reta.

Da mesma forma que para o experimento I, e valendo-se das mesmas considerações feitas quanto ao que seria a situação ideal para esse tipo de análise, foram feitas regressões lineares entre cada repetição e a média, com o objetivo de verificar a ocorrência de repetições excessivamente discrepantes dessa média. Os resultados constam da Tabela 14. Pode-se perceber que somente para o tratamento trbs os ajustes entre cada repetição e a média não foram bons, porém a menor sensibilidade das leituras da sonda quando comparadas às do tensiômetro e o fato de haver apenas três repetições dificultaram a percepção da repetição mais discrepante em relação à média. Os piores ajustes foram verificados para a repetição $\mathrm{r} 1$ do tratamento trbs, nas profundidades 0,50 ; 0,$60 ; 0,70$ e $0,80 \mathrm{~m}$, e para a repetição r2 do mesmo tratamento, nas profundidades 0,30 ; 0,$40 ; 0,90 ; 1,00 ; 1,10$ e $1,20 \mathrm{~m}$. Essa maior variabilidade para o tratamento trbs já havia sido identificada pela análise da Tabela 13, em que se apresentavam desvios padrões diários maiores que para os outros tratamentos, principalmente na superfície e nas camadas mais profundas. 
Tabela 14 - Resultados das regressões lineares entre cada repetição e a média.

\begin{tabular}{|c|c|c|c|c|c|c|c|}
\hline profund. & trat./rep. & no. obs. & Interseção & coef. angular & $\mathrm{R}$ múltiplo & R-Quadrado & $R-Q$ ajust. \\
\hline \multirow[t]{12}{*}{$0,20 \mathrm{~m}$} & tror1 & 40 & 0.16859 & 0.87994 & 0.96820 & 0.93741 & 0.93577 \\
\hline & tror 2 & 40 & 0.12514 & 0.94792 & 0.98146 & 0.96326 & 0.96230 \\
\hline & tror3 & 40 & -0.12954 & 1.05559 & 0.98467 & 0.96957 & 0.96877 \\
\hline & $\operatorname{tr} 1 \mathrm{r} 1$ & 40 & 0.12572 & 0.90082 & 0.95461 & 0.91128 & 0.90894 \\
\hline & $\operatorname{tr} 12$ & 40 & 0.10163 & 0.96565 & 0.98774 & 0.97562 & 0.97498 \\
\hline & $\operatorname{tr} 1 \mathrm{r} 3$ & 40 & 0.01310 & 0.97923 & 0.97865 & 0.95776 & 0.95665 \\
\hline & $\operatorname{tr} 2 \mathrm{r} 1$ & 37 & 0.49101 & 0.70224 & 0.97319 & 0.94709 & 0.94558 \\
\hline & $\operatorname{tr} 2 \sqrt{2}$ & 37 & -0.35915 & 1.20325 & 0.92752 & 0.86029 & 0.85629 \\
\hline & $\mathrm{tr} 2 \mathrm{r} 3$ & 37 & -0.07650 & 1.04545 & 0.98940 & 0.97891 & 0.97831 \\
\hline & trbsr 1 & 40 & 0.01164 & 0.90023 & 0.92950 & 0.86398 & 0.86040 \\
\hline & trbsr 2 & 40 & -0.09629 & 1.09534 & 0.93462 & 0.87352 & 0.87019 \\
\hline & trbsr 3 & 40 & 0.47554 & 0.74229 & 0.96047 & 0.92251 & 0.92047 \\
\hline \multirow[t]{12}{*}{$0,30 \mathrm{~m}$} & tror1 & 40 & -0.09177 & 1.01764 & 0.94144 & 0.88632 & 0.88332 \\
\hline & tror2 & 40 & 0.29236 & 0.85454 & 0.96050 & 0.92256 & 0.92052 \\
\hline & tror3 & 40 & 0.11647 & 0.93096 & 0.98843 & 0.97699 & 0.97638 \\
\hline & $\operatorname{tr} 1 \mathrm{r} 1$ & 40 & 0.15680 & 0.87557 & 0.96147 & 0.92443 & 0.92244 \\
\hline & $\operatorname{tr} 1 \mathrm{r} 2$ & 40 & -0.02119 & 1.02917 & 0.97572 & 0.95203 & 0.95077 \\
\hline & $\operatorname{tr} 1 \mathrm{r} 3$ & 40 & 0.19928 & 0.90625 & 0.96104 & 0.92361 & 0.92160 \\
\hline & $\operatorname{tr} 2 \mathrm{r} 1$ & 37 & 0.54952 & 0.71755 & 0.97545 & 0.95150 & 0.95012 \\
\hline & $\operatorname{tr} 2 \pi$ & 37 & -0.42212 & 1.19996 & 0.93685 & 0.87769 & 0.87420 \\
\hline & $\operatorname{tr} 2 \mathrm{r} 3$ & 37 & -0.10744 & 1.04583 & 0.99284 & 0.98572 & 0.98532 \\
\hline & trbsr1 & 40 & 0.30247 & 0.77034 & 0.87968 & 0.77383 & 0.76788 \\
\hline & trbsr 2 & 40 & -0.27428 & 1.19987 & 0.85702 & 0.73448 & 0.72750 \\
\hline & trbsr3 & 40 & 0.62201 & 0.64879 & 0.94736 & 0.89748 & 0.89479 \\
\hline \multirow[t]{12}{*}{$0,40 \mathrm{~m}$} & tror1 & 40 & -0.18087 & 1.07848 & 0.92574 & 0.85700 & 0.85324 \\
\hline & tron 2 & 40 & 0.35723 & 0.81567 & 0.94575 & 0.89445 & 0.89167 \\
\hline & tror3 & 40 & 0.25719 & 0.85842 & 0.97560 & 0.95179 & 0.95053 \\
\hline & $\operatorname{tr} 1 \mathrm{r} 1$ & 40 & 0.29665 & 0.82387 & 0.94455 & 0.89218 & 0.88935 \\
\hline & $\operatorname{tr} 12$ & 40 & 0.22293 & 0.86090 & 0.87634 & 0.76798 & 0.76187 \\
\hline & tr1r 3 & 40 & 0.32362 & 0.85084 & 0.93388 & 0.87214 & 0.86877 \\
\hline & $\operatorname{tr} 2 \mathrm{r} 1$ & 37 & 0.51884 & 0.75714 & 0.97191 & 0.94461 & 0.94303 \\
\hline & tr2r2 & 37 & -0.28540 & 1.10028 & 0.95209 & 0.90648 & 0.90380 \\
\hline & $t+2 r^{3}$ & 37 & -0.10853 & 1.05187 & 0.98828 & 0.97670 & 0.97604 \\
\hline & trbsr 1 & 40 & 0.67572 & 0.60165 & 0.72506 & 0.52572 & 0.51323 \\
\hline & trbsr & 40 & 0.92301 & 0.48143 & 0.57280 & 0.32810 & 0.31041 \\
\hline & trbsr3 & 40 & 0.70404 & 0.59519 & 0.92730 & 0.85988 & 0.85619 \\
\hline \multirow[t]{12}{*}{$0,50 \mathrm{~m}$} & tror1 & 40 & -0.35000 & 1.16433 & 0.92832 & 0.86179 & 0.85815 \\
\hline & tror2 & 40 & 0.40855 & 0.78836 & 0.94432 & 0.89173 & 0.88888 \\
\hline & tror3 & 40 & 0.28324 & 0.85511 & 0.98243 & 0.96518 & 0.96426 \\
\hline & $\operatorname{tr} 1 \mathrm{r} 1$ & 40 & 0.39304 & 0.78717 & 0.92615 & 0.85775 & 0.85401 \\
\hline & $\operatorname{tr} 12$ & 40 & -0.06542 & 1.00564 & 0.96533 & 0.93187 & 0.93007 \\
\hline & $\operatorname{tr} 1 \mathrm{r}$ & 40 & 0.21132 & 0.91123 & 0.94677 & 0.89637 & 0.89365 \\
\hline & tr2r1 & 37 & 0.38200 & 0.82076 & 0.95237 & 0.90702 & 0.90436 \\
\hline & tr2n & 37 & -0.08323 & 1.00546 & 0.94938 & 0.90133 & 0.89851 \\
\hline & tr2r3 & 37 & 0.09963 & 0.95254 & 0.97523 & 0.95108 & 0.94968 \\
\hline & trbar1 & 40 & 0.66926 & 0.62650 & 0.63921 & 0.40858 & 0.39302 \\
\hline & trbar2 & 40 & 0.48990 & 0.73435 & 0.80660 & 0.65060 & 0.64141 \\
\hline & trbsr3 & 40 & 0.78463 & 0.56225 & 0.90661 & 0.82194 & 0.81725 \\
\hline \multirow[t]{12}{*}{$0,60 \mathrm{~m}$} & tror1 & 40 & -0.19731 & 1.06212 & 0.86832 & 0.75398 & 0.74750 \\
\hline & tror & 40 & 0.57821 & 0.70706 & 0.90600 & 0.82084 & 0.81613 \\
\hline & tror3 & 40 & 0.34770 & 0.82282 & 0.96391 & 0.92912 & 0.92726 \\
\hline & $\operatorname{tr} 1 \mathrm{r} 1$ & 40 & 0.60355 & 0.67897 & 0.91063 & 0.82924 & 0.82474 \\
\hline & $\operatorname{tr} 12$ & 40 & -0.04951 & 1.01407 & 0.95008 & 0.90265 & 0.90009 \\
\hline & tr1r3 & 40 & -0.01420 & 1.00140 & 0.94329 & 0.88980 & 0.88690 \\
\hline & $\operatorname{tr} 2 \mathrm{r} 1$ & 37 & 0.19598 & 0.90599 & 0.94673 & 0.89630 & 0.89333 \\
\hline & $\mathrm{t} 2 \sqrt{2}$ & 37 & 0.10294 & 0.93298 & 0.95020 & 0.90289 & 0.90011 \\
\hline & $\operatorname{tr} 2 \sqrt{3}$ & 37 & 0.12975 & 0.93211 & 0.98598 & 0.97215 & 0.97135 \\
\hline & trbsr 1 & 40 & 0.58708 & 0.67556 & 0.53836 & 0.28983 & 0.27114 \\
\hline & trbsr2 & 40 & 0.41906 & 0.78680 & 0.89264 & 0.79681 & 0.79146 \\
\hline & trbar3 & 39 & 0.82875 & 0.54152 & 0.92667 & 0.85871 & 0.85489 \\
\hline
\end{tabular}

(continua) 
Tabela 14 (continuação) - Resultados das regressões lineares.

\begin{tabular}{|c|c|c|c|c|c|c|c|}
\hline profund. & trat./rep. & no. obs. & Interseção & coef. angular & R múltiplo & R-Quadrado & $R-Q$ ajust. \\
\hline $0,70 \mathrm{~m}$ & $\begin{array}{l}\text { tror1 } \\
\text { tror2 } \\
\text { tror3 } \\
\text { tr1r1 } \\
\text { tr112 } \\
\text { tr1r3 } \\
\text { tr2r1 } \\
\text { tr2 } 2 \\
\text { tr2r3 } \\
\text { trbsr1 } \\
\text { trbsr2 } \\
\text { trbsr3 } \\
\end{array}$ & $\begin{array}{l}40 \\
40 \\
40 \\
40 \\
40 \\
40 \\
37 \\
37 \\
37 \\
40 \\
40 \\
40 \\
\end{array}$ & $\begin{array}{c}-0.25151 \\
0.76400 \\
0.47042 \\
0.78578 \\
0.02226 \\
-0.17810 \\
0.58088 \\
0.28104 \\
0.16670 \\
0.29748 \\
0.27002 \\
0.83827 \\
\end{array}$ & $\begin{array}{l}1.09782 \\
0.60336 \\
0.73808 \\
0.57134 \\
0.99227 \\
1.06668 \\
0.69349 \\
0.83839 \\
0.90028 \\
0.83889 \\
0.86824 \\
0.53925 \\
\end{array}$ & $\begin{array}{l}0.79902 \\
0.87816 \\
0.91742 \\
0.91156 \\
0.91408 \\
0.86631 \\
0.86682 \\
0.86886 \\
0.95643 \\
0.62540 \\
0.90422 \\
0.92656 \\
\end{array}$ & $\begin{array}{l}0.63843 \\
0.77116 \\
0.84166 \\
0.83094 \\
0.83555 \\
0.75049 \\
0.75138 \\
0.75491 \\
0.91476 \\
0.39113 \\
0.81762 \\
0.85852 \\
\end{array}$ & $\begin{array}{l}0.62891 \\
0.76514 \\
0.83750 \\
0.82649 \\
0.83122 \\
0.74392 \\
0.74428 \\
0.74791 \\
0.91233 \\
0.37511 \\
0.81282 \\
0.85480 \\
\end{array}$ \\
\hline $0,80 \mathrm{~m}$ & $\begin{array}{l}\text { tror1 } \\
\text { tror2 } \\
\text { tror3 } \\
\operatorname{tr} 1 \mathrm{r} 1 \\
\operatorname{tr} 122 \\
\operatorname{tr} 1 \mathrm{r} 3 \\
\operatorname{tr} 2 \mathrm{r} 1 \\
\operatorname{tr} 2 \mathrm{r} 2 \\
\operatorname{tr} 2 \mathrm{r} 3 \\
\operatorname{trbsr1} \\
\text { trbsr2 } \\
\text { trbsr3 }\end{array}$ & $\begin{array}{l}40 \\
40 \\
40 \\
40 \\
40 \\
40 \\
37 \\
37 \\
37 \\
40 \\
40 \\
40 \\
\end{array}$ & $\begin{array}{c}0.14384 \\
0.75167 \\
0.54300 \\
0.78604 \\
0.03481 \\
-0.18181 \\
0.67540 \\
0.29841 \\
0.05287 \\
0.34540 \\
0.05295 \\
0.82533 \\
\end{array}$ & $\begin{array}{l}0.89361 \\
0.60392 \\
0.67931 \\
0.54809 \\
0.99457 \\
1.07007 \\
0.61329 \\
0.82375 \\
0.97719 \\
0.81878 \\
0.97364 \\
0.53704 \\
\end{array}$ & $\begin{array}{l}0.77329 \\
0.87307 \\
0.85202 \\
0.91163 \\
0.89427 \\
0.85279 \\
0.87417 \\
0.83016 \\
0.94680 \\
0.73725 \\
0.85685 \\
0.92176 \\
\end{array}$ & $\begin{array}{l}0.59798 \\
0.76226 \\
0.72594 \\
0.83106 \\
0.79973 \\
0.72724 \\
0.76417 \\
0.68917 \\
0.89643 \\
0.54354 \\
0.73419 \\
0.84964\end{array}$ & $\begin{array}{l}0.58740 \\
0.75600 \\
0.71872 \\
0.82662 \\
0.79446 \\
0.72006 \\
0.75743 \\
0.68029 \\
0.89348 \\
0.53153 \\
0.72719 \\
0.84569\end{array}$ \\
\hline $0,90 \mathrm{~m}$ & $\begin{array}{l}\text { tror1 } \\
\text { tr0r2 } \\
\text { tror3 } \\
\operatorname{tr} 1 \mathrm{r} 1 \\
\operatorname{tr} 1 \mathrm{r} 2 \\
\operatorname{tr} 1 \mathrm{r} 3 \\
\operatorname{tr} 2 \mathrm{r} 1 \\
\operatorname{tr} 2 \mathrm{r} 2 \\
\operatorname{tr} 2 \mathrm{r} 3 \\
\text { trbsr1 } \\
\text { trbs } 2 \\
\text { trbs } 3\end{array}$ & $\begin{array}{l}40 \\
40 \\
40 \\
40 \\
40 \\
40 \\
37 \\
37 \\
37 \\
40 \\
40 \\
40 \\
\end{array}$ & $\begin{array}{c}0.39619 \\
0.63215 \\
0.34296 \\
0.68128 \\
0.00061 \\
-0.16998 \\
0.77702 \\
0.35890 \\
0.09507 \\
-0.02260 \\
-0.19508 \\
0.84908\end{array}$ & $\begin{array}{l}0.75297 \\
0.66123 \\
0.77285 \\
0.56132 \\
1.03466 \\
1.08520 \\
0.53933 \\
0.78393 \\
0.95035 \\
1.01294 \\
1.11273 \\
0.52156 \\
\end{array}$ & $\begin{array}{l}0.82267 \\
0.86204 \\
0.86911 \\
0.92787 \\
0.89905 \\
0.86219 \\
0.84986 \\
0.80439 \\
0.89103 \\
0.85455 \\
0.80579 \\
0.94039 \\
\end{array}$ & $\begin{array}{l}0.67679 \\
0.74310 \\
0.75535 \\
0.86094 \\
0.80829 \\
0.74337 \\
0.72227 \\
0.64704 \\
0.79394 \\
0.73026 \\
0.64931 \\
0.88433 \\
\end{array}$ & $\begin{array}{l}0.66829 \\
0.73634 \\
0.74891 \\
0.85728 \\
0.80324 \\
0.73662 \\
0.71433 \\
0.63696 \\
0.78805 \\
0.72316 \\
0.64008 \\
0.88129 \\
\end{array}$ \\
\hline $0,100 \mathrm{~m}$ & $\begin{array}{l}\text { tror1 } \\
\text { tror2 } \\
\text { tr0r3 } \\
\text { tr1r1 } \\
\text { tr112 } \\
\text { tr1r3 } \\
\text { tr2r1 } \\
\text { tr2r2 } \\
\text { tr2r3 } \\
\text { trbsr1 } \\
\text { trbs } 2 \\
\text { trbsr3 }\end{array}$ & $\begin{array}{l}40 \\
40 \\
40 \\
40 \\
40 \\
40 \\
37 \\
37 \\
37 \\
40 \\
40 \\
40 \\
\end{array}$ & $\begin{array}{c}0.45469 \\
0.54763 \\
0.20485 \\
0.57738 \\
0.20051 \\
-0.18039 \\
0.77080 \\
0.15919 \\
0.25184 \\
0.44384 \\
0.84689 \\
0.95276\end{array}$ & $\begin{array}{l}0.70577 \\
0.68819 \\
0.86634 \\
0.62344 \\
0.89385 \\
1.09888 \\
0.52969 \\
0.90607 \\
0.84671 \\
0.71550 \\
0.52518 \\
0.43482 \\
\end{array}$ & $\begin{array}{l}0.85376 \\
0.86680 \\
0.87089 \\
0.92330 \\
0.89227 \\
0.90291 \\
0.87641 \\
0.77804 \\
0.86407 \\
0.76367 \\
0.41961 \\
0.89681\end{array}$ & $\begin{array}{l}0.72890 \\
0.75134 \\
0.75844 \\
0.85249 \\
0.79615 \\
0.81525 \\
0.76810 \\
0.60534 \\
0.74662 \\
0.58319 \\
0.17607 \\
0.80428\end{array}$ & $\begin{array}{l}0.72177 \\
0.74480 \\
0.75209 \\
0.84861 \\
0.79079 \\
0.81039 \\
0.76148 \\
0.59407 \\
0.73938 \\
0.57222 \\
0.15439 \\
0.79913\end{array}$ \\
\hline $1,10 \mathrm{~m}$ & $\begin{array}{l}\text { tror1 } \\
\text { tror2 } \\
\text { tror3 } \\
\text { tr1r1 } \\
\text { tr12 } \\
\text { tr1r3 } \\
\text { tr2r1 } \\
\text { tr2r2 } \\
\text { tr2r3 } \\
\text { trbsr1 } \\
\text { trbsr } 2 \\
\text { trbsr3 }\end{array}$ & $\begin{array}{l}40 \\
40 \\
40 \\
40 \\
40 \\
40 \\
37 \\
37 \\
37 \\
40 \\
40 \\
40 \\
\end{array}$ & $\begin{array}{c}0.38830 \\
0.46815 \\
-0.01844 \\
0.39461 \\
0.05205 \\
-0.24322 \\
0.75270 \\
0.19414 \\
0.19594 \\
0.15756 \\
0.66197 \\
0.75165 \\
\end{array}$ & $\begin{array}{l}0.75787 \\
0.72330 \\
0.99732 \\
0.75679 \\
0.96664 \\
1.13841 \\
0.53882 \\
0.87214 \\
0.88064 \\
0.85310 \\
0.64359 \\
0.52394 \\
\end{array}$ & $\begin{array}{l}0.88345 \\
0.91276 \\
0.90340 \\
0.96848 \\
0.97667 \\
0.94167 \\
0.87526 \\
0.76845 \\
0.89084 \\
0.94800 \\
0.55157 \\
0.87874 \\
\end{array}$ & $\begin{array}{l}0.78048 \\
0.83313 \\
0.81613 \\
0.93408 \\
0.95388 \\
0.88675 \\
0.76607 \\
0.59052 \\
0.79359 \\
0.89871 \\
0.30423 \\
0.77219 \\
\end{array}$ & $\begin{array}{l}0.77471 \\
0.82873 \\
0.81129 \\
0.93234 \\
0.95267 \\
0.88377 \\
0.75939 \\
0.57882 \\
0.78769 \\
0.89605 \\
0.28592 \\
0.76619 \\
\end{array}$ \\
\hline $1,20 \mathrm{~m}$ & $\begin{array}{l}\text { tror1 } \\
\text { tror2 } \\
\text { tror3 } \\
\text { tr1r1 } \\
\text { tr112 } \\
\text { tr1r3 } \\
\text { tr2r1 } \\
\text { tr2 } 22 \\
\text { tr2 } 3 \\
\text { trbsr1 } \\
\text { trbsr2 } \\
\text { trbsr3 }\end{array}$ & $\begin{array}{l}40 \\
40 \\
40 \\
40 \\
40 \\
40 \\
37 \\
37 \\
37 \\
40 \\
40 \\
40 \\
\end{array}$ & $\begin{array}{c}0.40253 \\
0.35514 \\
-0.12713 \\
0.26852 \\
0.09240 \\
-0.09645 \\
0.71299 \\
-0.08979 \\
0.28225 \\
0.57513 \\
0.67898 \\
0.80740\end{array}$ & $\begin{array}{l}0.78454 \\
0.75333 \\
1.08530 \\
0.87135 \\
0.95638 \\
0.99547 \\
0.56826 \\
1.03788 \\
0.82966 \\
0.59820 \\
0.63177 \\
0.48323 \\
\end{array}$ & $\begin{array}{l}0.92376 \\
0.91251 \\
0.93586 \\
0.97264 \\
0.98342 \\
0.94815 \\
0.89303 \\
0.81324 \\
0.89210 \\
0.84672 \\
0.61886 \\
0.76000 \\
\end{array}$ & $\begin{array}{l}0.85332 \\
0.83268 \\
0.87582 \\
0.94603 \\
0.86712 \\
0.89898 \\
0.79750 \\
0.68136 \\
0.79585 \\
0.71694 \\
0.38299 \\
0.57760 \\
\end{array}$ & $\begin{array}{l}0.84946 \\
0.82827 \\
0.87256 \\
0.94461 \\
0.96625 \\
0.89632 \\
0.79172 \\
0.65169 \\
0.79001 \\
0.70949 \\
0.36675 \\
0.56649 \\
\end{array}$ \\
\hline
\end{tabular}


Escolhendo-se por exemplo as profundidades 0,20 e $1,20 \mathrm{~m}$, as quais pela Tabela 13 apresentaram as maiores variabilidades, e utilizando as equações de calibração 13 e 14, respectivamente para as profundidades acima descritas, calculou-se os valores de umidade para cada contagem relativa. Comparando-se os valores de coeficiente de variação obtidos para a contagem relativa e para a umidade do solo obtida, expressos na Tabela 15, verifica-se que apesar dessa variabilidade ser baixa, esta se manifestou nos mesmos níveis quando os resultados foram transformados para umidade do solo.

$$
\theta=-0,02776+0,25011 . \mathrm{CR}
$$

$$
\theta=0,1149+0,14693 . \mathrm{CR}
$$


Tabela 15 - Médias diárias de contagem relativa (CR) e de umidade a base de massa, e os coeficientes de variação para esses parâmetros, para as profundidades $0,20 \mathrm{e}$ $1,20 \mathrm{~m}$ do tratamento trIII.

\begin{tabular}{|c|c|c|c|c|c|c|c|c|}
\hline \multirow[b]{3}{*}{ DAS } & \multicolumn{4}{|c|}{$0,20 \mathrm{~m}$} & \multicolumn{4}{|c|}{$1,20 \mathrm{~m}$} \\
\hline & \multicolumn{2}{|c|}{$\mathrm{CR}$} & \multicolumn{2}{|c|}{ TETA } & \multicolumn{2}{|c|}{$\mathrm{CR}$} & \multicolumn{2}{|c|}{ TETA } \\
\hline & MÉDIA & $\mathrm{CV}$ & MÉDIA & $\mathrm{CV}$ & MÉDIA & $\mathrm{CV}$ & MÉDIA & $\mathrm{CV}$ \\
\hline $\begin{array}{l}23 \\
25\end{array}$ & $\begin{array}{l}1.587 \\
1.568\end{array}$ & $\begin{array}{l}10.088 \\
11.861\end{array}$ & $\begin{array}{l}0.369 \\
0.365\end{array}$ & $\begin{array}{l}10.846 \\
12.765\end{array}$ & & & & \\
\hline 27 & 1.505 & 11.481 & 0.349 & 12.395 & & & & \\
\hline 30 & 1.450 & 12.818 & 0.335 & 13.88 & 1.651 & 4.707 & 0.385 & 5.046 \\
\hline 32 & 1.410 & 12.82 & 0.325 & 13.916 & 1.602 & 3.863 & 0.373 & 4.150 \\
\hline 34 & 1.401 & 14.117 & 0.323 & 15.332 & 1.621 & 3.173 & 0.378 & 3.406 \\
\hline 38 & 1.637 & 5.9879 & 0.382 & 6.4235 & 1.619 & 3.545 & 0.377 & 3.806 \\
\hline 41 & 1.531 & 9.5444 & 0.355 & 10.29 & 1.620 & 3.610 & 0.377 & 3.875 \\
\hline 44 & 1.459 & 9.807 & 0.337 & 10.614 & 1.609 & 4.147 & 0.375 & 4.454 \\
\hline 46 & 1.572 & 9.1141 & 0.366 & 9.8063 & 1.601 & 3.048 & 0.373 & 3.275 \\
\hline 48 & 1.514 & 9.7077 & 0.351 & 10.476 & 1.568 & 5.721 & 0.364 & 6.157 \\
\hline 51 & 1.648 & 6.8646 & 0.385 & 7.3602 & 1.605 & 3.259 & 0.374 & 3.501 \\
\hline 53 & 1.584 & 9.3604 & 0.368 & 10.066 & 1.590 & 3.212 & 0.370 & 3.453 \\
\hline 55 & 1.574 & 8.4957 & 0.366 & 9.1403 & 1.578 & 2.456 & 0.367 & 2.641 \\
\hline 58 & 1.542 & 10.288 & 0.358 & 11.086 & 1.587 & 2.829 & 0.369 & 3.042 \\
\hline 60 & 1.554 & 9.9543 & 0.361 & 10.72 & 1.584 & 2.970 & 0.368 & 3.194 \\
\hline 62 & 1.666 & 6.8051 & 0.389 & 7.2907 & 1.569 & 2.643 & 0.365 & 2.845 \\
\hline 65 & 1.615 & 8.1467 & 0.376 & 8.7478 & 1.623 & 2.214 & 0.378 & 2.376 \\
\hline 67 & 1.607 & 8.6175 & 0.374 & 9.257 & 1.622 & 1.993 & 0.378 & 2.140 \\
\hline 69 & 1.516 & 9.0301 & 0.352 & 9.7432 & 1.578 & 2.506 & 0.367 & 2.696 \\
\hline 72 & 1.557 & 8.0944 & 0.362 & 8.7159 & 1.576 & 1.587 & 0.367 & 1.707 \\
\hline 74 & 1.543 & 9.5361 & 0.358 & 10.275 & 1.603 & 1.229 & 0.373 & 1.321 \\
\hline 76 & 1.489 & 9.6796 & 0.345 & 10.459 & 1.607 & 1.134 & 0.374 & 1.218 \\
\hline 79 & 1.651 & 7.5999 & 0.385 & 8.1477 & 1.638 & 1.363 & 0.382 & 1.462 \\
\hline 81 & 1.643 & 7.3862 & 0.383 & 7.9213 & 1.673 & 1.518 & 0.391 & 1.626 \\
\hline 83 & 1.606 & 8.2443 & 0.374 & 8.8563 & 1.673 & 0.408 & 0.391 & 0.437 \\
\hline 85 & 1.596 & 8.2816 & 0.371 & 8.9005 & 1.714 & 0.548 & 0.401 & 0.586 \\
\hline 87 & 1.560 & 8.9821 & 0.362 & 9.6701 & 1.690 & 0.936 & 0.395 & 1.002 \\
\hline 89 & 1.524 & 9.0575 & 0.353 & 9.769 & 1.686 & 0.554 & 0.394 & 0.593 \\
\hline 92 & 1.461 & 7.9335 & 0.338 & 8.5856 & 1.667 & 2.209 & 0.389 & 2.367 \\
\hline 94 & 1.509 & 5.039 & 0.350 & 5.439 & 1.621 & 0.183 & 0.378 & 0.196 \\
\hline 96 & 1.509 & 8.4007 & 0.350 & 9.0678 & 1.668 & 1.147 & 0.389 & 1.229 \\
\hline 101 & 1.458 & 8.1084 & 0.337 & 8.7766 & 1.649 & 1.266 & 0.385 & 1.357 \\
\hline 103 & 1.411 & 10.151 & 0.325 & 11.018 & 1.649 & 2.108 & 0.385 & 2.260 \\
\hline 105 & 1.341 & 10.022 & 0.308 & 10.926 & 1.624 & 1.616 & 0.378 & 1.735 \\
\hline 107 & 1.308 & 10.352 & 0.299 & 11.312 & 1.604 & 1.435 & 0.373 & 1.542 \\
\hline 109 & 1.284 & 11.768 & 0.293 & 12.882 & 1.608 & 1.467 & 0.374 & 1.576 \\
\hline 112 & 1.515 & 13.236 & 0.351 & 14.282 & 1.590 & 1.165 & 0.370 & 1.252 \\
\hline 114 & 1.475 & 13.338 & 0.341 & 14.424 & 1.587 & 1.970 & 0.369 & 2.118 \\
\hline 121 & 1.612 & 9.3473 & 0.375 & 10.038 & 1.734 & 1.609 & 0.406 & 1.719 \\
\hline média & 1.525 & 9.487 & 0.354 & 10.241 & 1.624 & 2.199 & 0.378 & 2.361 \\
\hline
\end{tabular}




\section{CONCLUSÕES}

1 - A variabilidade do potencial mátrico mostrou-se dependente do valor médio desse potencial, sendo crescente da saturação até aproximadamente $-50 \mathrm{kPa}$ e decrescente desse patamar até o potencial mátrico limite de funcionamento do tensiômetro. Considerando valores aproximados de potencial mátrico, a variabilidade foi baixa entre 0 e $-15 \mathrm{kPa}$ e -70 e $-85 \mathrm{kPa}$, média entre -15 e $-40 \mathrm{kPa}$ e -60 e $-70 \mathrm{kPa}$, e variou de média a alta entre -40 e $-60 \mathrm{kPa}$.

2 - Em diversas situações, para as primeiras leituras realizadas após a ocorrência de irrigação ou precipitação, o potencial mátrico mostrou acréscimo considerável em sua variabilidade, o que teria importância em termos práticos se o manejo da irrigação fosse baseado no avanço da frente de molhamento no solo.

3 - A variabilidade da contagem relativa de nêutrons lentos foi baixa, não se mostrando claramente dependente do valor dessa contagem. Fica evidenciada a maior estabilidade das leituras da sonda de nêutrons quando comparada às do tensiômetro, o que é explicado basicamente pelo maior volume de solo por ela amostrado, menos sujeitas a variações pontuais.

4 - Para os parâmetros analisados nos dois experimentos (potencial mátrico e contagem relativa de nêutrons lentos) foi possível identificar repetições que se mostraram 
excessivamente discrepantes da média para o ciclo da cultura, o que nos permite concluir que seria aconselhável a execução de experimentos que talvez contivessem menos tratamentos, porém com um número maior de repetições, todas instrumentadas. 


\section{REFERÊNCIAS BIBLIOGRÁFICAS}

ARRUDA, F.B. Uso da água na produção agrícola. In: SIMPÓsIO SOBRE MANEJO DE ÁGUa NA Agricultura, Campinas, 1987. Anais. Campinas, Fundação Cargill, 1987. p.177-99.

AzeVedo, J.A. de; Silva, E.M. da; Morethson, R.; Guerra, A.F. Aspectos sobre o manejo da irrigação por aspersão para o cerrado. 2.ed. Planaltina, EMBRAPA/CPAC, 1986. 52p. (EMBRAPA/CPAC. Circular Técnica, 16).

BACCHI, O.O.S. \& REICHARDT, K. A sonda de nêutrons e seu uso na pesquisa agronômica. Piracicaba, CENA, 1990. 84p. (CENA. Boletim Didático, 22).

Beltrame, L. \& TAYLOR, J.C. Uso da sonda de nêutrons para a determinação da umidade do solo no campo. Revista Brasileira de Ciência do Solo, Campinas, 4(1):57-61, 1980.

BERNARDO, S. Manual de irrigação. 4.ed. Viçosa, Impr. Univ., 1986. 488p.

BRADY, N.C. Natureza e propriedades dos solos. 7.ed. Rio de Janeiro, Freitas Bastos, 1989. 898p.

BRONER, I. Irrigation scheduling with atmometers. In: INTERNATIONAL CONFERENCE ON IRrigation, 5, Tel Aviv, 1990. Proceedings. Tel Aviv, 1990. p.99-107. 
BRUCE, R.R. \& LUXMOORE, R.J. Water Retention: Field Methods. In: Methods of Soil Analysis, Part 1:Physical and mineralogical methods. A. Klute (ed.), American Society of Agronomy, Inc. of Soil Science Society of America, Inc., Madison, Wisconsin (USA), Agronomy Series Number 9, Cap. 27, p.663-86. 1986.

BURMAN, R.D. ; CUENCA, R.H. ; WeISS, A. Techniques for estimating irrigation water requeriments. In: HILLEL, D., ed. Advances in irrigation. New York, Academic Press, 1983. v.3, p.335-94.

CAMERON, D.R. Variability of soil water retention curves and predicted hydraulic condutivies on a small plot. Soil Science. Baltimore, 126(6):364-71, 1978.

DOURADO NETO, D. Variabilidade espacial das alturas de chuva de irrigação e de potenciais da solução do solo. Piracicaba, 1989. 180p. (Mestrado - Escola Superior de Agricultura 'Luiz de Queiroz"/USP).

Es, H.M. van \& ES, C.L. van Spatial nature of randomization and its effect on the outcome of field experiments. Agronomy Journal, Madison, 85:420-8, 1993.

FANCELLI, A.L. Milho e feijão: elementos de manejo em agricultura irrigada. In: Dourado Neto, D.; SAAD, A.M.; Jong van LIER, Q. de, ed. Curso de agricultura irrigada. Piracicaba, ESALQ/Depto. Agricultura. 1991. p.156-67.

Folegatti, M.V. Avaliação do desempenho de um "scheduler" na detecção de um estresse hídrico em cultura do feijoeiro (Phaseolus vulgaris L.) irrigada com diferentes lâminas. Piracicaba, 1988. 197p. (Doutorado - Escola Superior de Agricultura "Luiz de Queiroz"/USP). 
GREACEN, E.L. Soil water assessment by neutron method. Adelaide, CSIRO/Division of Soils, 1981. 140p.

HAVerKamP, R.; Vauclin, M.; Vachaud, G. Error analysisin estimating soil water content from netron probe measurements: 1. Local standpoint. Soil Science, Baltimore, 137(2): 78-90, 1984.

HENDRICKX, J.M.H. \& WIERENGA, P.J. Variability of soil water tension in a trickle irrigated Chile pepper field. Irrigation Science, St. Joseph, 11:23-30, 1990.

HENDRICKX, J.M.H.; WIERENGA, P.J.; NASH, M.S. Variability of soil water tension and soil water content. Agricultural Water Management, Amsterdam, 18:135-48, 1990.

HILER, E.A. ; HOWELL, T.A. ; LEWIS, R.B. ; Boss, R.P. Irrigation timing by the stress day index methods. Transactions of the ASAE, St. Joseph, 17(3):393-8, 1974.

JENSEN, M.E. Summary and challengers. In: IRRIGATION SCHEDULING CONFERENCE, Chicago, 1981. Irrigation scheduling for water energy conservation in the 80's; proceedings. St. Joseph, ASAE, 1981. p.225-31.

KIEHL, E.J. Manual de edafologia: relações solo planta. São Paulo, Ceres, 1979. 264p.

KIRDA, C. \& REICHARDT, K. Comparison of neutron moiture ganges with non-nuclear methods to measure field soil water status. Scientia Agricola, Piracicaba, 49(1):111-21, 1992. 
LAMBERT, J.R.; DOTY, C.W.; QUISENBERRY, V.L. Irrigation scheduling in humid areas. In: IRRIGATION SCHEDULING CONFERENCE, Chicago, 1981. Irrigation scheduling for water energy conservation in the 80's; proceedings. St. Joseph, ASAE, 1981. p.133-43.

LIBARDI, P.L. Dinâmica da água no solo. Piracicaba: O Autor, 1995. 497p.

Maranho, M.F.; Marciano, C.R.; Vieira, O.; Moraes, S.O., Libardi, P.L. O correto uso da curva de calibração da sonda de nêutrons para medida da umidade de solos. In: SIMPÓSIO DE INICIAÇÃo CIENTífICA DA USP, 3, Resumos. São Paulo, USP, 1995. (No prelo).

MARQUELLI, W.A. Manejo da irrigação em hortaliças. Anápolis, EMBRAPA/CNPH, 1986. 12 p. (EMBRAPA/CNPH. Circular Técnica, 2).

Microsoft Corporation. Microsoft Excel v. 5.0. Redmond, 1994.

MILLER, R.J.; SMITH, R.B.; BIGGAR, J.W. Soil water content - microwave oven method. Soil Science Society of America Proceedings, Madison, 38:535-7, 1974.

MORAES, S.O. Heterogeneidade hidráulica de uma terra roxa estruturada. Piracicaba, 1991. 141p. (Doutorado - Escola Superior de Agricultura "Luiz de Queiroz"/USP).

Oliveira, G.R. de, Carvalho, H.O., Gheyi, H. R. Uso do forno de microondas na determinação do conteúdo de água do solo. Revista Brasileira de Ciência do Solo, Campinas, 4:114-7, 1980.

Oliveira, J.B. \& Prado, H. Plano cartográfico do Estado de São Paulo: Guaíra. São Paulo, SAA/Instituto Agronômico, 1991. Escala 1:100.000. 
REICHARDT, K. A água em sistemas agrícolas. São Paulo, Ed. Manole, 1987. 188 p.

REICHARDT, K. Dinâmica da matéria e da energia em ecossistemas. Piracicaba, ESALQ/Depto. de Física e Meteorologia, 1993. 505p.

Reichardt, K.; VieIRA, S.R.; Libardi, P.L. Variabilidade espacial de solos e experimentação de campo. Revista Brasileira de Ciência do Solo, Campinas, 10:1-6, 1986.

SAAD, A.M. Uso de tensiômetro no controle da irrigação por pivô central em cultura do feijoeiro (Phaseolus vulgaris L.). Piracicaba, 1991. 144 p. (Mestrado - Escola Superior de Agricultura "Luiz de Queiroz"/USP)

SCALOPPI, E.J. Eficiência de aplicação de água em sistemas de irrigação por aspersão. Item. Irrigação e Tecnologia Moderna, Brasília, (16):37-40, 1984.

SCALOPPI, E.J. Otimização da produção em função dos recursos hídricos disponíveis. Item. Irrigação e Tecnologia Moderna, Brasília, (20):2-5, 1985.

SILVA, A.P. da Variabilidade espacial de atributos físicos do solo. Piracicaba, 1988. 98p. (Doutorado - Escola Superior de Agricultura "Luiz de Queiroz"/USP)

SILVA, A.R. da Aconselhamento de irrigação - Primeira parte: tecnologia disponível no manejo da irrigação por aspersão. Item. Irrigação e Tecnologia Moderna, Brasília, (32):28-30, 1988a.

SLVA, A.R. da Aconselhamento de irrigação - Segunda parte: necessidade e possibilidades. Item. Irrigação e Tecnologia Moderna, Brasília, (33):18-20, 1988b. 
SpIEGEL, M.R. Theory and problems of statistics. New York, McGraw Hill, 1961. 374p. (Schaum's Outlines Series).

TURATTI, A.L. \& REICHARDT, K. Variabilidade do armazenamento de água em terra roxa estruturada. Revista Brasileira de Ciência do Solo, Campinas, 13(3):253-7, 1991.

Turatti, A.L.; Villagra, M.M.; Ponce, J.E.; Bacchi, O.O.S.; ReichardT, K. Variabilidade espacial de solo e sua implicação na calibração de sondas de neutrons. Revista Brasileira de Ciência do Solo, Campinas, 14:259-62, 1990.

VAN Genuchten, M.T. A closed form equation for predicting the hidraulic condutivity of unsaturated soils. Soil Science Society of America Journal, Madison, 44:892-7, 1980.

VIDAL-ToRrado, P. \& SpaRoveK. G. Mapa pedológico detalhado do Campus "Luiz de Queiroz". Piracicaba, ESALQ/Depto. de Ciência do Solo, 1993. (Escala 1:10.000).

Villagra, M.M.; Matsumoto, O.M.; BACChI, O.O.S.; MORAES, S.O.; LIBARDI, P.L.; REICHARDT, K. Tensiometria e variabilidade espacial em terra roxa estruturada. Revista Brasileira de Ciência do Solo, Campinas, 12:205-10, 1988.

Villa nova, N.A. Dados meteorológicos do município de Piracicaba. Piracicaba, ESALQ/Depto. de Física e Meteorologia, 1989.

WARRICK, A.W. \& NIELSEN, D.R. Spatial Variability of Soil Physical Properties in the field. In: HrLlel, D.,ed. Aplications of Soil Physics. New York, Academic Press, 1980. p.319-44. 
WESENBEECK, I.J. van \& KACHANOSKI, R.G. Spatial and temporal distribuition of soil water in tilled layer under a corn crop. Soil Science Society of America Journal, Madison, 52:363-8, 1988.

Zur, B.; Ben-Hanan, U.; RIMMER, A.; Yardeni, A. Control of irrigation amounts using velocity and position of wetting front. Irrigation Science, Berlin, 14:207-12, 1994. 


\section{APÊNDICES}




\section{APENDICE 1}

Potenciais mátricos para cada repetição (r1, r2, r3 e r4) e a média por tratamento, em $\mathrm{kPa}$, e as quantidades estimadas de água das chuvas ou aplicadas nas irrigações $(\mathrm{P}+\mathrm{I})$, em $\mathrm{m}^{3} / \mathrm{m}^{2}$, em função do tempo (DAS), em dias após a semeadura, para cada profundidade estudada. 
Profundidade $0,10 \mathrm{~m}$.

\begin{tabular}{|c|c|c|c|c|c|c|c|c|c|c|c|c|c|c|c|c|c|c|}
\hline \multirow[b]{2}{*}{ DAS } & \multicolumn{6}{|c|}{ trat -000} & \multicolumn{6}{|c|}{ trat 0I0 } & \multicolumn{6}{|c|}{ trat III } \\
\hline & r1 & 12 & $\mathrm{r} 3$ & 14 & média & $\mathrm{P}+\mathrm{I}$ & $\mathrm{r} 1$ & 12 & r3 & $\mathrm{r} 4$ & média & $\mathrm{P}+\mathrm{I}$ & r1 & 12 & $\mathrm{r} 3$ & $\mathrm{r} 4$ & média & $\mathrm{P}+\mathrm{I}$ \\
\hline 0 & & & & & & 0.020 & & & & & & 0.021 & & & & & & 0.021 \\
\hline 1 & & & & & & 0.014 & & & & & & 0.014 & & & & & & 0.014 \\
\hline 2 & & & & & & 0.027 & & & & & & 0.028 & & & & & & 0.028 \\
\hline 4 & & & & & & 0.027 & & & & & & 0.028 & & & & & & 0.028 \\
\hline 5 & & & & & & 0.020 & & & & & & 0.021 & & & & & & 0.021 \\
\hline 7 & & & & & & 0.027 & & & & & & 0.028 & & & & & & 0.028 \\
\hline 8 & & & & & & 0.020 & & & & & & 0.021 & & & & & & 0.021 \\
\hline 9 & & & & & & 0.020 & & & & & & 0.021 & & & & & & 0.021 \\
\hline 13 & & & & & & 0.027 & & & & & & 0.028 & & & & & & 0.028 \\
\hline 16 & & & & & & 0.020 & & & & & & 0.021 & & & & & & 0.021 \\
\hline 17 & -6.96 & -8.47 & -9.10 & -7.34 & -7.97 & & -8.47 & -6.08 & -7.97 & -6.08 & -7.15 & & -7.97 & -7.72 & -8.60 & -8.10 & -8.10 & \\
\hline 18 & -9.23 & -10.87 & -11.50 & -9.10 & -10.18 & 0.014 & -10.49 & -8.22 & -10.49 & -8.35 & -9.39 & 0.014 & -10.11 & -10.24 & -11.12 & -10.49 & -10.49 & 0.014 \\
\hline 19 & -7.09 & -8.35 & -9.23 & -7.21 & -7.97 & & -8.47 & -5.70 & -7.72 & -6.08 & -6.99 & & -8.10 & -7.59 & -8.22 & -7.84 & -7.94 & \\
\hline 20 & -9.23 & -11.12 & -11.75 & -9.61 & -10.43 & 0.019 & -10.24 & -8.10 & -10.62 & -9.23 & -9.55 & 0.020 & -10.36 & -10.49 & -10.74 & -10.24 & -10.46 & 0.020 \\
\hline 21 & -9.36 & -7.34 & -8.60 & -5.83 & -7.78 & 0.011 & -7.21 & -5.32 & -6.84 & -5.32 & -6.17 & 0.011 & -6.71 & -6.58 & -11.12 & -6.96 & -7.84 & 0.011 \\
\hline 22 & -7.34 & -7.84 & -8.85 & -6.33 & -7.59 & & -7.59 & -5.83 & -7.84 & -5.83 & -6.77 & & -7.09 & -7.09 & -8.85 & -7.59 & -7.66 & \\
\hline 23 & -10.24 & -9.86 & -11.25 & -8.47 & -9.95 & 0.027 & -9.86 & -7.72 & -10.11 & -8.35 & -9.01 & 0.028 & -9.48 & -9.61 & -11.25 & -9.86 & -10.05 & 0.028 \\
\hline 24 & -10.24 & -7.59 & -8.60 & -6.08 & -8.13 & & -7.34 & -5.58 & -7.34 & -5.70 & -6.49 & & -6.84 & -7.09 & -7.97 & -7.34 & -7.31 & \\
\hline 25 & -6.58 & -9.61 & -11.50 & -8.73 & -9.10 & & -9.23 & -7.47 & -10.36 & -8.60 & -8.92 & & -9.23 & -7.09 & -10.24 & -9.61 & -9.04 & \\
\hline 26 & -9.36 & -11.62 & -13.77 & -11.12 & -11.47 & & -11.12 & -9.10 & -12.88 & -11.12 & -11.06 & & -11.12 & -8.73 & -12.88 & -11.62 & -11.09 & \\
\hline 27 & -13.39 & -14.65 & -16.41 & -14.14 & -14.65 & & -13.39 & -12.88 & -16.29 & -15.53 & -14.52 & & -14.14 & -11.25 & & -14.77 & -13.39 & \\
\hline 28 & -7.72 & -7.09 & -13.14 & -10.24 & -9.55 & 0.024 & -8.35 & -3.43 & -5.32 & -4.57 & -5.42 & 0.024 & -5.83 & -10.49 & & -5.70 & -7.34 & 0.024 \\
\hline 29 & -10.36 & -9.23 & -13.14 & -9.86 & -10.65 & 0.027 & -9.10 & -6.96 & -9.61 & -8.98 & -8.66 & 0.028 & -9.36 & -10.62 & & -9.10 & -9.69 & 0.028 \\
\hline 30 & -6.84 & -7.59 & -9.36 & -6.96 & -7.69 & 0.027 & -7.72 & -5.83 & -8.10 & -6.58 & -7.06 & 0.028 & -7.34 & -7.72 & -8.22 & -7.47 & -7.69 & 0.028 \\
\hline 31 & -6.71 & -7.47 & -9.23 & -6.84 & -7.56 & & -7.47 & -5.83 & -8.35 & -6.21 & -6.96 & & -7.09 & -7.84 & -8.47 & -7.47 & -7.72 & \\
\hline 32 & -10.11 & -10.11 & -12.51 & & -10.91 & & -9.86 & -8.10 & -12.38 & -10.49 & -10.21 & & -10.11 & -12.38 & -11.62 & -10.62 & -11.18 & \\
\hline 33 & -13.14 & -12.25 & -16.29 & & -13.89 & & -11.75 & -10.74 & -16.41 & -15.28 & -13.55 & & -12.76 & -13.89 & -15.03 & -13.89 & -13.89 & \\
\hline 34 & -17.80 & -15.53 & -22.84 & -19.56 & -18.93 & & -14.52 & -15.40 & -24.98 & -24.22 & -19.78 & & -16.66 & -21.20 & & -19.69 & -19.18 & \\
\hline 35 & -23.47 & -19.31 & -31.66 & -27.75 & -25.55 & & -17.80 & -20.44 & -28.63 & -36.07 & -25.74 & & -23.34 & -31.66 & & -27.12 & -27.37 & \\
\hline 36 & -28.51 & -23.34 & -36.70 & -34.30 & -30.71 & & -21.83 & -24.85 & -31.28 & -45.14 & -30.78 & & -27.25 & -32.92 & -21.83 & -31.91 & -28.48 & \\
\hline 37 & -39.60 & -30.27 & -52.07 & 48.04 & -42.49 & & -28.26 & -18.55 & -40.98 & -58.62 & -36.60 & & -38.46 & -47.53 & -28.38 & -44.89 & -39.82 & \\
\hline 38 & -56.48 & -40.73 & -68.07 & -64.54 & -57.46 & & -39.72 & -42.49 & -54.34 & -71.35 & -51.98 & & -55.22 & -69.08 & -38.34 & -61.14 & -55.94 & \\
\hline 39 & -68.45 & 48.92 & -74.25 & -72.23 & -65.96 & & -52.07 & -61.27 & -63.79 & -75.13 & -63.06 & & -66.81 & -73.49 & -45.90 & -69.96 & -64.04 & \\
\hline 40 & -77.02 & -58.12 & -76.77 & -76.51 & -72.10 & & -64.54 & -71.98 & -71.35 & -77.77 & -71.41 & & -74.25 & -77.77 & -59.50 & -75.13 & -71.66 & \\
\hline 41 & -81.68 & -71.22 & -79.03 & -79.03 & -77.74 & & -77.90 & -78.40 & & -79.03 & -78.45 & & -78.78 & & & -78.66 & & \\
\hline 42 & -86.72 & -77.77 & -81.05 & -81.30 & -81.71 & & -81.43 & -82.31 & & -81.81 & -81.85 & & -81.93 & & & -82.06 & & \\
\hline 43 & -73.24 & -65.93 & -42.49 & 44.89 & -56.64 & 0.020 & -56.86 & 45.52 & -38.59 & -77.90 & -54.72 & 0.021 & -8.98 & -3.81 & & -7.97 & -6.92 & 0.036 \\
\hline 44 & -48.67 & -13.01 & -62.53 & -61.52 & 46.43 & 0.014 & -14.02 & -5.45 & -27.25 & -77.90 & -31.15 & 0.014 & -4.82 & -4.82 & -5.45 & -5.45 & -5.14 & 0.028 \\
\hline 45 & -30.02 & -17.17 & -52.95 & -67.82 & 41.99 & & -23.72 & -12.38 & -22.59 & -75.38 & -33.52 & & -11.12 & -9.86 & -14.52 & -10.99 & -11.62 & \\
\hline 46 & -55.60 & -23.85 & -52.70 & -65.93 & -49.52 & & -38.59 & -17.55 & -28.26 & -73.99 & -39.60 & & -16.16 & -10.24 & -23.34 & -15.28 & -16.25 & \\
\hline 47 & -73.11 & -35.94 & -71.73 & -76.39 & -64.29 & & -57.99 & -28.13 & -51.57 & -77.14 & -53.71 & & -23.59 & -23.85 & -34.30 & -21.70 & -25.86 & \\
\hline 48 & -79.54 & -52.32 & -76.01 & -77.90 & -71.44 & & -72.10 & 44.38 & -69.96 & -78.03 & -66.12 & & -36.32 & -35.31 & -43.75 & -31.28 & -36.67 & \\
\hline 49 & -80.92 & -67.57 & -78.53 & -78.53 & -76.39 & & -77.65 & -61.14 & -77.90 & -81.68 & -74.59 & & -49.93 & -51.94 & -52.07 & -45.77 & -49.93 & \\
\hline 50 & -81.68 & -77.90 & -84.20 & -81.68 & -81.37 & 0.014 & -79.16 & -73.74 & -80.42 & -84.20 & -79.38 & 0.014 & -64.29 & -73.49 & -73.11 & -63.66 & -68.64 & 0.028 \\
\hline 51 & -82.94 & -79.92 & -82.94 & -82.69 & -82.12 & & -82.94 & -68.70 & -80.42 & -76.89 & -77.24 & & -9.48 & -18.68 & -16.16 & -10.99 & -13.83 & \\
\hline 52 & -84.20 & -84.20 & -84.20 & -84.20 & -84.20 & & -82.94 & -82.18 & -83.82 & -84.20 & -83.29 & & -16.16 & -18.05 & -31.66 & -17.55 & -20.85 & \\
\hline 53 & -84.20 & -83.95 & -84.20 & & -84.12 & & -84.20 & -84.20 & -84.20 & -84.20 & -84.20 & & -28.38 & -22.33 & -50.18 & -29.01 & -32.48 & \\
\hline 54 & -84.20 & -84.20 & -84.20 & & -84.20 & 0.014 & -84.20 & -84.20 & -84.20 & -84.20 & -84.20 & 0.014 & -47.66 & -27.00 & -60.26 & -54.21 & 47.28 & 0.028 \\
\hline 55 & -72.23 & -80.42 & -63.41 & & -72.02 & & & -81.05 & -82.94 & -77.90 & -80.63 & & -11.88 & -32.04 & -35.69 & -13.26 & -23.22 & \\
\hline 56 & -77.65 & -79.66 & -71.60 & & -76.30 & & & -80.42 & -80.42 & -79.79 & -80.21 & & -21.96 & -47.53 & -57.61 & -23.72 & -37.71 & \\
\hline 57 & & -81.30 & -57.49 & -78.53 & -72.44 & 0.014 & -81.30 & -80.80 & -81.05 & -80.42 & -80.89 & 0.014 & -38.46 & -76.26 & -69.46 & 41.99 & -56.54 & 0.028 \\
\hline 58 & -79.79 & -81.18 & & -80.42 & -80.46 & & -81.30 & -80.67 & -81.30 & -80.67 & -80.99 & & -9.99 & -31.91 & -21.07 & -9.73 & -18.18 & \\
\hline 59 & -78.28 & -80.17 & & -77.90 & -78.78 & & -80.17 & -79.92 & -79.79 & -79.16 & -79.76 & & -16.29 & 46.27 & -33.17 & -15.53 & -27.82 & \\
\hline 60 & -79.79 & -81.05 & & -80.42 & -80.42 & & -81.05 & -80.42 & -81.05 & -80.42 & -80.74 & & -22.08 & -62.78 & -49.80 & -22.71 & -39.34 & \\
\hline 61 & -80.17 & -80.17 & & & & 0.014 & -80.42 & -79.92 & -80.55 & -79.41 & -80.07 & 0.014 & -28.13 & -71.60 & -58.24 & -34.81 & -48.20 & 0.028 \\
\hline 62 & -60.26 & -63.41 & -52.07 & 43.88 & -54.91 & & -57.11 & -69.08 & -41.36 & -74.75 & -60.58 & & -10.11 & -24.98 & -13.01 & -9.48 & -14.40 & \\
\hline 63 & -77.90 & -75.00 & -59.63 & -56.48 & -67.25 & & -77.52 & -77.27 & -69.71 & -79.16 & -75.92 & & -15.40 & -46.90 & -22.46 & -14.27 & -24.76 & \\
\hline 64 & -77.90 & -77.90 & -66.56 & & -74.12 & & -79.16 & -78.53 & -76.01 & -79.79 & -78.37 & & -19.31 & -68.45 & -33.17 & -15.28 & -34.05 & \\
\hline 65 & -79.03 & -80.67 & -72.48 & & -77.40 & 0.014 & -80.55 & -81.05 & -79.29 & -79.79 & -80.17 & 0.014 & -32.54 & -76.14 & -59.76 & -24.73 & -48.29 & 0.028 \\
\hline 66 & -53.33 & -31.28 & -78.78 & & -54.46 & & -50.05 & -81.81 & -68.32 & -81.30 & -70.37 & & -9.73 & -17.80 & -14.52 & -9.23 & -12.82 & \\
\hline 67 & -75.51 & -60.89 & -77.14 & & -71.18 & & -75.13 & -80.17 & -75.51 & -79.29 & -77.52 & & -14.40 & -35.56 & -25.74 & -14.65 & -22.59 & \\
\hline 68 & -78.91 & -79.79 & -77.90 & & -78.87 & & -77.65 & -80.55 & -77.90 & -80.92 & -79.25 & & -24.22 & -62.53 & -43.88 & -23.72 & -38.59 & \\
\hline 69 & -79.54 & -81.05 & -78.28 & & -79.62 & & -78.91 & -80.92 & -79.16 & & -79.66 & & -35.69 & -75.13 & -59.88 & -39.09 & -52.45 & \\
\hline 70 & -81.55 & -81.43 & & & -81.49 & & -81.05 & -89.49 & -80.17 & & -83.57 & & -53.08 & -80.42 & -70.09 & -65.05 & -67.16 & \\
\hline 71 & -50.05 & -75.38 & -28.51 & -28.76 & -45.68 & 0.014 & -35.69 & -69.46 & -28.76 & -64.67 & -49.64 & 0.014 & -6.71 & -24.48 & -11.75 & -6.96 & -12.47 & 0.028 \\
\hline 7 & -77.27 & -81.05 & -52.07 & 48.92 & -64.83 & & -77.65 & -78.78 & -52.70 & -76.77 & -71.47 & & -13.77 & -58.37 & -30.40 & -13.01 & -28.89 & \\
\hline 73 & -82.56 & -82.56 & -74.12 & & -79.75 & & -81.68 & -81.68 & -71.60 & -82.56 & -79.38 & & -24.98 & -80.42 & -70.34 & -26.24 & -50.50 & \\
\hline 74 & -79.79 & -80.04 & & & & 0.020 & -80.17 & -80.42 & -73.49 & -79.16 & -78.31 & 0.041 & -47.53 & -80.80 & -73.74 & 47.66 & -62.43 & 0.041 \\
\hline 75 & 47.03 & -32.29 & -27.88 & -12.76 & -29.99 & & -13.64 & -16.66 & -10.49 & -21.33 & -15.53 & & -9.23 & -21.20 & -17.92 & -9.10 & -14.36 & \\
\hline
\end{tabular}


Profundidade $0,10 \mathrm{~m}$ (continuação).

\begin{tabular}{|c|c|c|c|c|c|c|c|c|c|c|c|c|c|c|c|c|c|c|}
\hline \multirow[b]{2}{*}{ DAS } & \multicolumn{6}{|c|}{ trat -000} & \multicolumn{6}{|c|}{ trat $0 \mathrm{IO}$} & \multicolumn{6}{|c|}{ trat III } \\
\hline & $\mathrm{rl}$ & 12 & r3 & $\mathrm{r} 4$ & média & $\mathrm{P}+\mathrm{I}$ & rl & 12 & $r^{3}$ & $\mathrm{r} 4$ & média & $\mathrm{P}+\mathrm{I}$ & $\mathrm{rl}$ & 12 & r3 & 14 & média & $\mathrm{P}+\mathrm{I}$ \\
\hline 76 & -75.38 & -76.01 & 41.74 & -25.74 & -54.72 & & -31.91 & -31.66 & -16.54 & -35.56 & -28.92 & & -14.90 & 45.77 & -38.71 & -13.64 & -28.26 & \\
\hline 77 & -76.64 & -77.90 & -57.74 & -42.62 & -63.73 & & -57.74 & 48.92 & -27.50 & 49.17 & -45.83 & & -18.68 & -76.14 & -60.76 & -21.70 & -44.32 & \\
\hline 78 & -27.12 & -83.19 & -62.65 & -12.13 & -46.27 & 0.020 & -7.21 & -5.70 & -6.33 & -9.48 & -7.18 & 0.041 & -4.57 & -8.22 & -7.59 & -5.70 & -6.52 & 0.041 \\
\hline 79 & -68.83 & -81.43 & -67.82 & -26.24 & -61.08 & & -13.01 & -11.62 & -10.87 & -20.95 & -14.11 & & -9.48 & -18.81 & -17.29 & -9.48 & -13.77 & \\
\hline 80 & -77.65 & -81.18 & -72.61 & -40.10 & -67.88 & & -14.90 & -15.15 & -13.77 & -26.87 & -17.67 & & -10.99 & -22.46 & -21.96 & -11.12 & -16.63 & \\
\hline 81 & -81.05 & -81.68 & -76.39 & -54.59 & -73.43 & & -16.79 & -16.16 & -16.16 & -33.17 & -20.57 & & -11.75 & -26.87 & -24.98 & -12.88 & -19.12 & \\
\hline 82 & & & & -65.30 & & & -18.43 & -18.68 & -19.31 & 40.86 & -24.32 & & -12.38 & -34.81 & -38.21 & -14.27 & -24.92 & \\
\hline 83 & & & & -73.49 & & & -32.79 & -34.56 & -28.89 & -53.20 & -37.36 & & -15.53 & -59.00 & -59.63 & -19.06 & -38.30 & \\
\hline 84 & & & & -75.38 & & & -40.10 & -50.18 & 43.25 & -64.42 & -49.49 & & -19.69 & -69.08 & -69.71 & -26.24 & 46.18 & \\
\hline 85 & & & & -77.27 & & 0.014 & -50.18 & -57.24 & -53.46 & -78.53 & -59.85 & 0.028 & -21.70 & -73.87 & -75.38 & -31.28 & -50.56 & 0.028 \\
\hline 86 & -79.16 & -81.68 & -38.46 & -78.53 & -69.46 & & -5.58 & -4.57 & -5.20 & -7.72 & -5.77 & & -3.81 & 4.57 & -55.22 & 4.57 & -17.04 & \\
\hline 87 & -80.55 & -80.42 & 40.60 & -77.27 & -69.71 & & -11.50 & -11.12 & -10.99 & -32.54 & -16.54 & & -8.60 & -15.40 & -34.93 & -8.60 & -16.88 & \\
\hline 88 & -6.58 & -80.55 & -5.70 & -36.19 & -32.26 & 0.047 & -5.95 & -5.32 & -5.58 & -5.58 & -5.61 & 0.047 & 4.69 & 4.82 & -6.08 & 4.95 & -5.14 & 0.047 \\
\hline 89 & -13.64 & -14.52 & -12.88 & -13.26 & -13.58 & & -9.73 & -8.35 & -9.73 & -15.91 & -10.93 & & -8.22 & -10.49 & -13.01 & -7.97 & -9.92 & \\
\hline 90 & -5.95 & -8.10 & -7.84 & -5.45 & -6.84 & 0.019 & -6.21 & 4.95 & -5.58 & -5.45 & -5.54 & 0.019 & -5.58 & -5.45 & -6.21 & -5.32 & -5.64 & 0.019 \\
\hline 91 & -7.72 & -9.48 & -8.60 & -6.96 & -8.19 & 0.017 & -7.34 & -5.70 & -6.96 & -7.97 & -6.99 & 0.017 & -6.21 & -6.84 & -8.22 & -6.08 & -6.84 & 0.017 \\
\hline 92 & -4.32 & -5.83 & -6.08 & -2.80 & 4.76 & 0.045 & 4.57 & -3.94 & -3.81 & 4.19 & 4.13 & 0.045 & -3.31 & -3.31 & -3.31 & -3.69 & -3.40 & 0.045 \\
\hline 93 & -9.23 & -9.99 & -9.86 & -8.10 & -9.29 & & -8.73 & -7.09 & -8.60 & -10.62 & -8.76 & & -7.72 & -8.35 & -10.24 & -7.34 & -8.41 & \\
\hline 94 & -13.77 & -13.64 & -13.14 & -14.14 & -13.67 & & -12.13 & -9.86 & -12.38 & -21.45 & -13.96 & & -9.99 & -12.38 & -15.66 & -9.86 & -11.97 & \\
\hline 95 & -24.98 & -18.18 & -18.43 & -25.99 & -21.89 & & -18.05 & -13.14 & -17.17 & 41.36 & -22.43 & & -13.14 & -17.04 & -23.72 & -13.01 & -16.73 & \\
\hline 96 & -36.45 & -21.96 & -18.68 & -33.80 & -27.72 & & -24.98 & -15.03 & -22.08 & -53.96 & -29.01 & & -14.52 & -21.70 & -31.41 & -16.16 & -20.95 & \\
\hline 97 & -57.87 & -27.50 & -33.42 & -57.74 & 44.13 & & -39.09 & -21.96 & -33.80 & -69.08 & -40.98 & & -19.56 & -31.66 & -52.43 & -22.59 & -31.56 & \\
\hline 98 & -59.38 & -37.20 & 45.90 & -71.35 & -53.46 & & -48.16 & -30.78 & -50.56 & -73.99 & -50.87 & & -25.11 & 46.65 & -63.28 & -32.16 & 41.80 & \\
\hline 99 & -76.14 & 49.55 & -55.85 & -76.14 & -64.42 & & -72.61 & 45.14 & -65.30 & -76.01 & -64.76 & & -33.80 & -72.10 & -77.14 & 48.29 & -57.83 & \\
\hline 100 & -76.89 & -60.89 & -60.39 & -75.63 & -68.45 & 0.023 & -75.13 & -60.64 & -71.60 & -75.76 & -70.78 & 0.044 & 46.90 & -68.83 & -82.69 & -63.41 & -65.46 & 0.044 \\
\hline 101 & -13.39 & -15.28 & -18.18 & -17.55 & -16.10 & & -8.98 & -6.84 & -8.73 & -22.96 & -11.88 & & -7.59 & -10.36 & -8.35 & -7.47 & -8.44 & \\
\hline 102 & -29.14 & -22.08 & -27.75 & -38.39 & -29.39 & & -15.66 & -10.49 & -14.14 & -54.59 & -23.72 & & -11.25 & -18.68 & & -11.25 & -13.72 & \\
\hline 103 & -61.65 & -30.78 & -43.88 & -73.24 & -52.39 & & -25.36 & -15.28 & -20.57 & -69.71 & -32.73 & & -14.27 & -28.26 & & -14.52 & -19.02 & \\
\hline 104 & -71.35 & -39.60 & -51.69 & -73.99 & -59.16 & & 40.73 & -19.31 & -29.01 & -73.24 & 40.57 & & -18.05 & -43.25 & & -20.32 & -27.21 & \\
\hline 105 & -77.02 & -52.07 & -61.52 & -77.02 & -66.91 & & -64.42 & -27.25 & 41.23 & -77.27 & -52.54 & & -22.84 & -58.12 & -32.04 & -26.87 & -34.97 & \\
\hline 106 & -20.57 & -58.37 & -55.22 & -13.64 & -36.95 & 0.020 & -6.46 & 4.69 & -5.83 & -10.87 & -6.96 & 0.041 & 4.37 & -5.58 & 4.32 & -5.20 & 4.91 & 0.041 \\
\hline 107 & -30.65 & 43.00 & -61.52 & -17.29 & -38.12 & 0.031 & -8.85 & -6.96 & -8.35 & 0.22 & -5.99 & 0.031 & -7.34 & -10.24 & -7.84 & -7.59 & -8.25 & 0.031 \\
\hline 108 & -7.34 & -8.60 & -9.73 & -6.58 & -8.06 & & -6.58 & -5.07 & -5.45 & -6.96 & -6.02 & & -5.95 & -5.70 & -5.07 & -6.08 & -5.70 & \\
\hline 109 & -1.67 & -1.29 & -3.69 & -0.41 & -1.76 & 0.038 & -2.30 & -2.55 & -1.67 & -1.67 & -2.05 & 0.038 & -1.04 & -0.41 & -1.29 & -2.05 & -1.20 & 0.038 \\
\hline 110 & -8.35 & -8.98 & -10.24 & -7.72 & -8.82 & & -9.10 & -6.33 & -8.10 & -9.73 & -8.32 & & -7.34 & -8.22 & -6.71 & -6.96 & -7.31 & \\
\hline 111 & -11.25 & -11.37 & -12.76 & -11.50 & -11.72 & & -12.63 & -8.60 & -11.12 & -15.78 & -12.03 & & -9.86 & -11.62 & -10.49 & -9.48 & -10.36 & \\
\hline 112 & -13.64 & -12.88 & -15.78 & -14.77 & -14.27 & & -15.53 & -11.12 & -13.26 & -19.31 & -14.81 & & -11.75 & -14.02 & -14.27 & -11.50 & -12.88 & \\
\hline 11 & 4.44 & -5.45 & -6.08 & -2.80 & 4.69 & 0.055 & 4.57 & -3.81 & 4.06 & 4.06 & 4.13 & 0.055 & -3.81 & -3.56 & -3.31 & 4.19 & -3.72 & 0.055 \\
\hline 114 & -8.35 & -9.23 & -10.11 & -7.97 & -8.92 & & -9.61 & -6.84 & -8.60 & -9.86 & -8.73 & & -8.10 & -8.73 & -7.97 & -7.72 & -8.13 & \\
\hline 11 & -10.62 & -11.37 & -12.88 & -11.50 & -11.59 & & -13.14 & -8.47 & -11.62 & -15.78 & -12.25 & & -10.11 & -11.50 & -12.00 & -10.36 & -10.99 & \\
\hline 1 & -13.51 & -13.64 & -15.91 & -16.16 & -14.81 & & -18.18 & -11.12 & -15.40 & -24.35 & -17.26 & & -12.13 & -14.90 & -16.16 & -13.39 & -14.14 & \\
\hline 1 & -17.17 & -16.54 & -20.70 & -23.09 & -19.37 & & -25.48 & -14.02 & -19.31 & -34.43 & -23.31 & & -14.65 & -18.05 & -21.20 & -16.79 & -17.67 & \\
\hline 11 & -21.20 & -19.06 & -25.48 & -31.91 & -24.41 & & 3.80 & -17.42 & -24.48 & 46.27 & -30.49 & & -16.92 & -21.20 & -26.62 & -21.70 & -21.61 & \\
\hline & -27.75 & -22.46 & -30.65 & 43.88 & -31.19 & & 44.26 & -21.83 & -32.79 & -58.50 & -39.34 & & -20.57 & -24.98 & -32.79 & -29.52 & -26.96 & \\
\hline 12 & -37.58 & -26.24 & -35.69 & -54.59 & -38.53 & & 18 & -27.12 & 43.88 & -67.19 & -48.67 & & -25.61 & -29.14 & -39.22 & -35.69 & -32.41 & \\
\hline 12 & -52.07 & -32.54 & 43.63 & -69.08 & -49.33 & 0.006 & -66.56 & -37.58 & -54.34 & -74.12 & -58.15 & 0.006 & -33.17 & -33.80 & -27.50 & -52.07 & -36.64 & 0.00 \\
\hline & -56.23 & -38.84 & 49.80 & -72.86 & -54.43 & & -71.60 & -45.14 & -61.02 & -75.38 & -63.28 & & -36.07 & -47.53 & -30.78 & -58.75 & -43.28 & \\
\hline & -4.57 & -6.21 & -7.34 & -3.69 & -5.45 & 0.035 & -6.08 & -4.32 & 4.95 & 4.82 & -5.04 & 0.03 & 4.57 & 4.44 & -4.57 & -5.32 & -4.73 & 0.03 \\
\hline 12 & -8.73 & -9.99 & -10.49 & -8.35 & -9.39 & & -10.36 & -7.34 & -9.73 & -12.76 & -10.05 & & -8.85 & -9.36 & -8.60 & -8.35 & -8.79 & \\
\hline 12 & -10.74 & -13.14 & -13.51 & -12.13 & -12.38 & & -13.14 & -9.86 & -13.26 & -19.81 & -14.02 & & -11.12 & -12.88 & -13.14 & -10.87 & -12.00 & \\
\hline 12 & -14.27 & -16.66 & -17.04 & -16.66 & -16.16 & & -16.41 & -12.38 & -16.29 & -29.14 & & & -13.14 & -16.66 & -17.17 & -13.14 & -15.03 & \\
\hline 12 & -16.16 & -18.55 & -17.67 & -20.07 & -18 & & & -14.27 & -19.94 & -38.59 & -23 & & -15.15 & -19.06 & -19.94 & -15.40 & -1 & \\
\hline 128 & -20.95 & -35.82 & -22.33 & -28.13 & -26.81 & & -25.61 & -18.81 & -26.87 & -55.09 & -31.60 & & -19.31 & -25.11 & -24.98 & -19.44 & -22.21 & \\
\hline 129 & & & & & & 0.008 & & & & & & & & & & & & .00 \\
\hline 130 & 50 & 4 & -29 & -46.78 & -34 & 0.00 & & & & -72.61 & & & 3 & 80 & -28.76 & -28.00 & 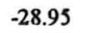 & 0 \\
\hline 13 & -17.42 & -33.17 & -19.94 & -43.88 & -28.60 & 0.021 & -25.61 & -26.87 & 40.10 & -72.23 & 41.20 & 0.021 & -15.91 & -18.68 & -27.50 & -20.57 & -20.66 & 0.0 \\
\hline 132 & -6.71 & -8.60 & -8.73 & -6.58 & -7.66 & & -7.97 & -5.83 & -7.84 & -8.10 & -7.43 & & -7.34 & -6.46 & -6.46 & -6.84 & -6.77 & \\
\hline 133 & -9.61 & -12.25 & -11.50 & -10.11 & -10.87 & & -10.74 & -8.73 & -11.75 & -14.65 & -11.47 & & -9.86 & -9.36 & -10.62 & -8.85 & -9.67 & \\
\hline 13 & -10.36 & -15.78 & -13 & -12.51 & -13.01 & 0.015 & -11.88 & -10.87 & -14.02 & -17.17 & -13.48 & 0.015 & -11.50 & -11.88 & -13.51 & -11.75 & -12.16 & 0.0 \\
\hline 13 & -7.34 & -9.86 & & -7.34 & -8.76 & & -8.47 & -6.33 & -8.60 & -8.73 & & & -7.59 & -7.97 & -7.34 & -7.34 & -7.56 & \\
\hline 136 & -8.85 & -12.38 & -11.75 & -9.73 & -10.68 & & -9.86 & -8.35 & -11.62 & -12.00 & -10.46 & & -9.73 & -8.60 & -9.86 & -10.11 & -9.58 & \\
\hline 137 & -10.49 & -15.40 & -14.40 & -12.38 & -13 & & 11.75 & -10.87 & -13.89 & -17.17 & -13 & & -11.37 & -12.76 & -13.14 & -12.38 & -12.41 & \\
\hline 138 & -13.14 & -18.55 & -29.26 & -15.15 & -19.03 & & -13.77 & -13.51 & -16.66 & -21.58 & -16.38 & & -12.38 & -15.40 & -15.40 & -14.52 & -14.43 & \\
\hline 139 & & & & & & 0.008 & & & & & & 0.00 & & & & & & 0.0 \\
\hline 141 & & & & & & 0.02 & & & & & & & & & & & & \\
\hline 142 & & & & & & 0.0 & & & & & & 0.025 & & & & & & 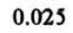 \\
\hline 143 & & & & & & 0.015 & & & & & & 0.015 & & & & & & 0.0 \\
\hline 146 & & & & & & 0.043 & & & & & & 0.043 & & & & & & 0.0 \\
\hline 147 & & & & & & 0.070 & & & & & & 0.070 & & & & & & 0.0 \\
\hline
\end{tabular}


Profundidade $0,20 \mathrm{~m}$.

\begin{tabular}{|c|c|c|c|c|c|c|c|c|c|c|c|c|c|c|c|c|c|c|}
\hline \multirow[b]{2}{*}{ DAS } & \multicolumn{6}{|c|}{ trat -000} & \multicolumn{6}{|c|}{ trat $0 \mathrm{IO}$} & \multicolumn{6}{|c|}{ trat III } \\
\hline & $\mathrm{r} 1$ & 12 & r3 & $\mathrm{r} 4$ & média & $\mathrm{P}+\mathrm{I}$ & $\mathrm{rl}$ & 12 & r3 & $\mathrm{r} 4$ & média & $\mathrm{P}+\mathrm{I}$ & r1 & 12 & r3 & $\mathrm{r} 4$ & média & $\mathrm{P}+\mathrm{I}$ \\
\hline 0 & & & & & & 0.020 & & & & & & 0.021 & & & & & & 0.021 \\
\hline 1 & & & & & & 0.014 & & & & & & 0.014 & & & & & & 0.014 \\
\hline 2 & & & & & & 0.027 & & & & & & 0.028 & & & & & & 0.028 \\
\hline 4 & & & & & & 0.027 & & & & & & 0.028 & & & & & & 0.028 \\
\hline 5 & & & & & & 0.020 & & & & & & 0.021 & & & & & & 0.021 \\
\hline 7 & & & & & & 0.027 & & & & & & 0.028 & & & & & & 0.028 \\
\hline 8 & & & & & & 0.020 & & & & & & 0.021 & & & & & & 0.021 \\
\hline 9 & & & & & & 0.020 & & & & & & 0.021 & & & & & & 0.021 \\
\hline 13 & & & & & & 0.027 & & & & & & 0.028 & & & & & & 0.028 \\
\hline 16 & & & & & & 0.020 & & & & & & 0.021 & & & & & & 0.021 \\
\hline 17 & -6.97 & -9.62 & -9.24 & -7.98 & -8.45 & & -8.73 & -9.11 & -10.12 & -7.60 & -8.89 & & -8.10 & -8.48 & -9.87 & -8.73 & -8.80 & \\
\hline 18 & -9.11 & -11.25 & -11.00 & -9.36 & -10.18 & 0.014 & -10.12 & -10.62 & -11.51 & -7.73 & -9.99 & 0.014 & -10.12 & -10.62 & -11.51 & -10.37 & -10.66 & 0.014 \\
\hline 19 & -6.84 & -9.11 & -9.62 & -7.98 & -8.39 & & -8.36 & -8.86 & -10.12 & -6.97 & -8.58 & & -8.48 & -8.48 & -9.62 & -9.74 & -9.08 & \\
\hline 20 & -9.49 & -11.13 & -11.38 & -9.62 & -10.40 & 0.019 & -9.99 & -10.62 & -11.51 & -6.09 & -9.55 & 0.020 & -10.25 & -10.50 & -11.38 & -10.25 & -10.59 & 0.020 \\
\hline 21 & -9.24 & -7.85 & -8.48 & -6.47 & -8.01 & 0.011 & -6.97 & -7.35 & -7.98 & -6.84 & -7.29 & 0.011 & -6.72 & -7.22 & -11.76 & -7.10 & -8.20 & 0.011 \\
\hline 22 & -7.22 & -8.23 & -8.61 & -6.84 & -7.73 & & -7.35 & -7.98 & -8.61 & -7.73 & -7.92 & & -7.22 & -7.73 & -10.12 & -7.60 & -8.17 & \\
\hline 23 & -9.11 & -10.12 & -10.12 & -8.86 & -9.55 & 0.027 & -9.36 & -9.62 & -10.12 & -9.99 & -9.77 & 0.028 & -9.36 & -9.49 & -11.51 & -9.49 & -9.96 & 0.028 \\
\hline 24 & -9.11 & -7.85 & -8.10 & -6.72 & -7.95 & & -7.22 & -7.60 & -8.23 & -7.35 & -7.60 & & -6.84 & -7.22 & -8.48 & -7.35 & -7.47 & \\
\hline 25 & -6.34 & -9.74 & -9.87 & -8.99 & -8.73 & & -8.86 & -8.61 & -9.99 & -9.24 & -9.18 & & -9.11 & -8.99 & -10.37 & -9.24 & -9.43 & \\
\hline 26 & -7.98 & -11.13 & -11.63 & -10.37 & -10.28 & & -10.25 & -10.25 & -11.51 & & -10.67 & & -10.88 & -10.50 & -11.51 & -10.62 & -10.88 & \\
\hline 27 & -10.88 & -13.14 & -13.65 & -11.76 & -12.36 & & -11.88 & -12.26 & -13.14 & & -12.43 & & -12.39 & -12.26 & -12.89 & -12.39 & -12.48 & \\
\hline 28 & -6.97 & -9.99 & -11.88 & -7.60 & -9.11 & 0.024 & -10.75 & -8.10 & -13.14 & & -10.67 & 0.024 & -7.47 & -8.86 & -10.37 & -9.87 & -9.14 & 0.024 \\
\hline 29 & -8.48 & -10.37 & -12.14 & -8.99 & -9.99 & 0.027 & -8.73 & -8.23 & -11.88 & -7.60 & -9.11 & 0.028 & -9.62 & -9.99 & -11.63 & -9.24 & -10.12 & 0.028 \\
\hline 30 & -6.21 & -8.10 & -8.48 & -7.73 & -7.63 & 0.027 & -7.47 & -7.85 & -8.61 & -7.98 & -7.98 & 0.028 & -7.10 & -7.47 & -8.73 & -7.60 & -7.73 & 0.028 \\
\hline 31 & -6.09 & -7.85 & -8.36 & -7.35 & -7.41 & & -7.22 & -7.73 & -8.48 & -7.35 & -7.69 & & -6.84 & -6.84 & -8.10 & -7.35 & -7.29 & \\
\hline 32 & -8.73 & -9.99 & -10.62 & & -9.78 & & -9.24 & -9.49 & -10.62 & -9.99 & -9.84 & & -9.74 & -9.36 & -10.37 & -9.49 & -9.74 & \\
\hline 33 & -10.50 & -11.63 & -12.64 & & -11.59 & & -10.75 & -10.37 & -12.64 & -12.64 & -11.60 & & -11.51 & -11.38 & -12.26 & -11.38 & -11.63 & \\
\hline 34 & -12.77 & -13.40 & -15.66 & -13.52 & -13.84 & & -12.89 & -12.14 & -15.29 & -16.29 & -14.15 & & -13.65 & -13.27 & -13.90 & -13.40 & -13.55 & \\
\hline 35 & -15.16 & -15.16 & -31.16 & -16.42 & $-19,48$ & & -14.78 & -14.91 & -18.18 & -17.30 & -16.29 & & -15.54 & -15.29 & -15.79 & -15.29 & -15.48 & \\
\hline 36 & -17.43 & -17.05 & -20.33 & -18.69 & -18.37 & & -17.05 & -17.30 & -19.32 & -18.56 & -18.06 & & -17.68 & -17.55 & -17.55 & -17.30 & -17.52 & \\
\hline 37 & -21.84 & -20.20 & -26.50 & -24.99 & -23.38 & & -20.45 & -23.60 & -26.63 & -20.70 & -22.85 & & -20.58 & -20.70 & -21.71 & -20.70 & -20.92 & \\
\hline 38 & -29.65 & -23.10 & -35.82 & -35.07 & -30.91 & & -25.62 & -36.71 & -36.83 & -26.25 & -31.35 & & -25.49 & -25.24 & -27.38 & -24.86 & -25.74 & \\
\hline 39 & -26.50 & -28.01 & -50.82 & -47.79 & -38.28 & & -33.18 & -56.74 & -50.06 & -31.54 & -42.88 & & -31.54 & -32.30 & -37.71 & -30.03 & -32.89 & \\
\hline 40 & -51.20 & -33.56 & -59.64 & -60.65 & -51.26 & & -43.13 & -68.08 & -61.40 & -39.98 & -53.15 & & -40.74 & -40.99 & -52.08 & -37.21 & -42.75 & \\
\hline 41 & -67.45 & -39.10 & -75.77 & -74.38 & -64.17 & & -55.98 & -77.15 & -74.88 & -54.98 & -65.75 & & -54.22 & -52.71 & -68.58 & 45.78 & -55.32 & \\
\hline 42 & -75.77 & -47.29 & -79.29 & -78.03 & -70.10 & & -67.58 & -80.68 & -76.52 & -63.17 & -71.99 & & -65.43 & -62.79 & -75.01 & -55.10 & -64.58 & \\
\hline 43 & -76.77 & -48.30 & 42.25 & -76.77 & -61.02 & 0.020 & -72.87 & -75.01 & -77.40 & -66.06 & -72.84 & 0.021 & -46.66 & 47.92 & -59.76 & -57.75 & -53.02 & 0.036 \\
\hline 44 & -37.46 & -30.91 & 40.36 & -72.74 & 45.37 & 0.014 & -38.85 & -79.42 & -78.92 & -64.30 & -65.37 & 0.014 & 4.83 & -7.10 & -7.47 & -5.71 & -6.28 & 0.028 \\
\hline 45 & -27.76 & -20.20 & -38.72 & -56.74 & -35.86 & & -25.87 & -35.32 & -81.69 & -64.05 & -51.73 & & -11.38 & -12.89 & -14.28 & -10.50 & -12.26 & \\
\hline 46 & 46.66 & -24.74 & -39.73 & -66.19 & 44.33 & & -37.71 & -52.96 & -78.16 & -59.51 & -57.09 & & -18.94 & -16.04 & -23.98 & -13.40 & -18.09 & \\
\hline 47 & -67.20 & -31.67 & -41.75 & -75.26 & -53.97 & & -53.46 & -68.84 & -79.04 & -68.84 & -67.54 & & -29.27 & -20.83 & -33.81 & -17.81 & -25.43 & \\
\hline 48 & -75.14 & -41.37 & -69.34 & -76.90 & -65.69 & & -68.71 & -72.49 & -79.42 & -72.36 & -73.25 & & -45.40 & -27.13 & -51.45 & -22.85 & -36.71 & \\
\hline 49 & -76.90 & -52.96 & -79.42 & -78.03 & -71.83 & & -75.64 & -77.53 & -80.43 & -75.64 & -77.31 & & -56.24 & -34.69 & -64.93 & -31.16 & 46.75 & \\
\hline 50 & -76.90 & -64.93 & -83.20 & -80.43 & -76.36 & 0.014 & -76.90 & -80.05 & -81.69 & -79.42 & -79.51 & 0.014 & -68.84 & 44.64 & -72.87 & 44.64 & -57.75 & 0.028 \\
\hline 51 & -80.05 & -74.25 & -83.20 & -81.94 & -79.86 & & -79.17 & -81.94 & -82.57 & -78.03 & -80.43 & & -13.65 & -17.05 & -25.24 & -21.08 & -19.26 & \\
\hline 52 & -83.20 & -76.02 & -83.20 & -83.20 & -81.40 & & -80.43 & -82.57 & -83.20 & -83.20 & -82.35 & & -30.91 & -26.50 & 43.01 & -28.14 & -32.14 & \\
\hline 53 & -83.20 & -77.28 & -83.20 & & -81.23 & & -81.94 & -83.20 & -83.20 & -83.20 & -82.89 & & -54.22 & -39.10 & -65.06 & -43.64 & -50.50 & \\
\hline 54 & -83.20 & -83.20 & -83.20 & & -83.20 & 0.014 & -83.20 & -83.20 & -83.20 & -83.20 & -83.20 & 0.014 & -71.23 & -54.22 & -73.75 & -61.15 & -65.09 & 0.028 \\
\hline 55 & -79.17 & -81.94 & & & & & & & & -83.20 & & & -17.05 & -25.62 & -37.71 & -22.47 & -25.71 & \\
\hline 56 & -72.87 & -78.79 & & & & & & -81.31 & -79.42 & & & & 44.39 & 44.14 & -68.08 & 42.88 & 49.87 & \\
\hline 57 & & -79.55 & & -70.60 & & 0.014 & -80.30 & -80.55 & -78.66 & -71.86 & -77.85 & 0.014 & -64.30 & -66.06 & -77.40 & -66.95 & -68.68 & 0.028 \\
\hline 58 & & & & -74.88 & & & -80.55 & -81.44 & -78.79 & -74.13 & -78.73 & & -10.75 & -20.33 & -20.45 & -13.77 & -16.33 & \\
\hline 59 & & & & -74.63 & & & -79.42 & -79.17 & -78.03 & -73.25 & -77.47 & & -19.70 & -32.80 & -34.69 & -23.10 & -27.57 & \\
\hline 60 & & & & -77.66 & & & -80.30 & -80.05 & -79.42 & -75.39 & -78.79 & & -25.87 & -50.44 & -53.34 & -35.32 & -41.24 & \\
\hline 61 & & -78.79 & & & & 0.014 & -79.67 & -79.80 & -78.54 & & -79.34 & 0.014 & -38.47 & -65.18 & -68.08 & -54.22 & -56.49 & 0.028 \\
\hline 62 & & -41.37 & & -38.34 & & & -72.24 & -59.26 & -64.93 & & -65.48 & & -10.12 & -23.10 & -15.16 & -12.01 & -15.10 & \\
\hline 63 & & -78.16 & & -56.74 & & & -78.16 & -69.34 & -69.09 & & -72.20 & & -15.79 & -39.48 & -24.36 & -11.25 & -22.7 & \\
\hline 64 & & -78.79 & & & & & -79.42 & -73.75 & -71.23 & & -74.80 & & -20.83 & -56.49 & -33.81 & -26.50 & -34.41 & \\
\hline 65 & -65.31 & -78.66 & & & & 0.014 & -79.55 & -77.40 & -79.29 & -68.84 & -76.27 & 0.014 & -25.62 & -71.61 & -57.87 & -42.50 & -49.40 & 0.028 \\
\hline 66 & -49.68 & -43.13 & & & & & -80.30 & -78.03 & -80.68 & -76.14 & -78.79 & & -9.49 & -19.57 & -13.27 & -10.50 & -13.21 & \\
\hline 67 & -53.34 & -72.24 & & & & & -79.04 & -77.78 & -79.17 & -75.39 & -77.85 & & -14.53 & -32.55 & -21.59 & -16.92 & -21.40 & \\
\hline 68 & -69.34 & -79.42 & & -77.40 & -75.39 & & -79.04 & -79.04 & -79.17 & & -79.08 & & -22.09 & -54.22 & -35.07 & -27.38 & -34.69 & \\
\hline 69 & -74.38 & -80.05 & & & & & -79.04 & -79.04 & -79.67 & & -79.25 & & -30.91 & -71.23 & -55.48 & -41.62 & -49.81 & \\
\hline 70 & & -80.43 & & & & & -80.55 & -80.05 & -79.92 & & -80.18 & & -46.03 & -76.65 & -73.12 & -62.54 & -64.58 & \\
\hline 71 & & -80.43 & & & & 0.014 & -68.08 & -79.55 & -78.16 & & -75.26 & 0.014 & -6.72 & -23.73 & -11.63 & -7.73 & -12.45 & 0.028 \\
\hline$n$ & & -80.43 & & & & & -76.27 & -79.42 & & & & & -14.40 & -47.92 & -23.98 & -14.78 & -25.27 & \\
\hline 73 & & & & & & & -80.05 & -80.05 & & & & & -26.63 & -78.79 & -54.22 & -27.76 & -46.85 & \\
\hline 74 & & & & & & 0.020 & -79.17 & -76.90 & -74.38 & & -76.82 & 0.041 & -45.40 & -79.29 & -75.01 & -48.17 & -61.97 & 0.041 \\
\hline 75 & -27.76 & -41.62 & & -15.54 & -28.31 & & -13.52 & -14.78 & -12.89 & -24.23 & -16.36 & & -8.61 & -21.46 & -13.40 & -9.24 & -13.18 & \\
\hline
\end{tabular}


Profundidade 0,20 m (continuação).

\begin{tabular}{|c|c|c|c|c|c|c|c|c|c|c|c|c|c|c|c|c|c|c|}
\hline \multirow[b]{2}{*}{ DAS } & \multicolumn{6}{|c|}{ trat -000} & \multicolumn{6}{|c|}{ trat $0 \mathrm{IO}$} & \multicolumn{6}{|c|}{ trat III } \\
\hline & $\mathrm{r1}$ & 12 & r3 & $\mathrm{r} 4$ & média & $\mathrm{P}+\mathrm{I}$ & $\mathrm{rl}$ & 2 & r3 & $\mathrm{r} 4$ & média & $\mathrm{P}+\mathrm{I}$ & rl & 2 & t3 & $\mathrm{r} 4$ & média & $\mathrm{P}+\mathrm{I}$ \\
\hline 76 & -56.74 & -61.78 & & -34.56 & -51.03 & & -32.80 & -24.61 & -20.58 & -31.54 & -27.38 & & -13.40 & -39.10 & -22.72 & -13.90 & -22.28 & \\
\hline$\pi 7$ & -69.97 & -70.60 & & -51.70 & -64.09 & & -61.53 & -34.69 & -34.69 & -48.80 & 44.93 & & -18.56 & -65.56 & -40.11 & -20.20 & -36.11 & \\
\hline 78 & -51.45 & -77.78 & & -13.77 & -47.67 & 0.020 & -6.97 & -6.59 & -8.23 & -12.51 & -8.58 & 0.041 & 4.20 & -9.74 & -6.59 & -5.84 & -6.59 & 0.041 \\
\hline 79 & -54.22 & -78.16 & & -30.03 & -54.14 & & -12.01 & -11.76 & -11.88 & -19.57 & -13.81 & & -9.11 & -16.80 & -13.65 & -9.74 & -12.33 & \\
\hline 80 & -71.23 & -77.78 & & 46.16 & -65.06 & & -13.90 & -15.03 & -15.29 & -26.25 & -17.62 & & -11.00 & -20.45 & -17.68 & -11.51 & -15.16 & \\
\hline 81 & -76.27 & -78.16 & & -57.75 & -70.73 & & -16.42 & -17.05 & -17.68 & -35.32 & -21.62 & & -12.14 & -23.35 & -20.83 & -13.14 & -17.37 & \\
\hline 82 & & & & -63.67 & & & -20.45 & -19.95 & -21.46 & -45.27 & -26.78 & & -13.90 & -28.39 & -27.76 & -15.16 & -21.30 & \\
\hline 83 & & & & -69.34 & & & -37.21 & -30.91 & -30.53 & -56.99 & -38.91 & & -17.93 & -41.62 & 44.64 & -19.70 & -30.97 & \\
\hline 84 & & & & & & & -59.26 & -45.65 & -42.25 & -64.68 & -52.96 & & -22.34 & -59.89 & -67.07 & -25.87 & 43.79 & \\
\hline 85 & & & & & & 0.014 & -63.04 & -56.87 & -52.71 & -68.08 & -60.17 & 0.028 & -25.62 & -68.08 & -72.87 & -31.54 & 49.53 & 0.028 \\
\hline 86 & -71.48 & & & & & & -5.71 & -5.58 & -7.73 & -72.99 & -23.00 & & -3.57 & -6.97 & -11.00 & -4.58 & -6.53 & \\
\hline 87 & -71.61 & & & -45.40 & & & -10.62 & -10.62 & -12.39 & -59.26 & -23.22 & & -8.86 & -14.28 & -20.45 & -9.11 & -13.18 & \\
\hline 88 & & & -33.81 & & & 0.047 & -5.84 & -5.96 & -7.10 & -7.22 & -6.53 & 0.047 & 4.58 & -5.96 & -5.71 & -4.83 & -5.27 & 0.047 \\
\hline 89 & -11.63 & -12.64 & -14.78 & -15.54 & -13.65 & & -9.24 & -8.99 & -10.25 & -15.29 & -10.94 & & -8.61 & -9.62 & -8.86 & -8.36 & -8.86 & \\
\hline 90 & -5.58 & -6.34 & -7.60 & -5.71 & -6.31 & 0.019 & -5.96 & -6.34 & -7.35 & -8.10 & -6.94 & 0.019 & -5.33 & -6.21 & -8.10 & -5.21 & -6.21 & 0.019 \\
\hline 91 & -6.59 & -8.36 & -8.23 & -7.22 & -7.60 & 0.017 & -7.10 & -6.97 & -8.23 & -9.62 & -7.98 & 0.017 & -6.34 & -7.35 & -7.60 & -5.96 & -6.81 & 0.017 \\
\hline 92 & -3.44 & -2.81 & -5.21 & -3.44 & -3.73 & 0.045 & -4.70 & -4.45 & -6.09 & -5.84 & -5.27 & 0.045 & -3.32 & -4.58 & -5.71 & -3.06 & -4.17 & 0.045 \\
\hline 93 & -7.60 & -4.83 & -8.86 & -7.85 & -7.29 & & -8.23 & -8.23 & -9.62 & -10.37 & -9.11 & & -7.85 & -8.36 & -9.49 & -7.35 & -8.26 & \\
\hline 94 & -11.38 & -6.09 & -12.14 & -13.52 & -10.78 & & -11.25 & -10.75 & -12.01 & -14.28 & -12.07 & & -10.50 & -11.13 & -12.14 & -10.12 & -10.97 & \\
\hline 95 & & -15.92 & -16.80 & -26.88 & -19.86 & & -15.79 & -14.91 & -14.91 & -21.46 & -16.77 & & -13.77 & -14.78 & -15.66 & -13.14 & -14.34 & \\
\hline 96 & & -19.44 & -20.83 & -44.14 & -28.14 & & -21.33 & -17.68 & -17.81 & -33.93 & -22.69 & & -15.92 & -18.18 & -10.12 & -15.16 & -14.85 & \\
\hline 97 & & -25.62 & -27.51 & -65.56 & -39.56 & & -33.56 & -26.12 & -22.97 & -51.70 & -33.59 & & -19.57 & -24.61 & -21.96 & -20.70 & -21.71 & \\
\hline 98 & & -36.08 & -37.08 & -71.23 & -48.13 & & -57.75 & -40.49 & -30.03 & -62.41 & -47.67 & & -25.24 & -35.70 & -33.43 & -28.89 & -30.82 & \\
\hline 99 & -62.79 & -49.81 & -45.40 & -73.12 & -57.78 & & -70.60 & -58.88 & -39.10 & -68.71 & -59.32 & & -34.06 & -52.71 & -43.51 & 40.36 & -42.66 & \\
\hline 100 & -73.62 & -60.52 & -53.21 & -73.25 & -65.15 & 0.023 & -73.50 & -67.70 & -51.07 & -72.36 & -66.16 & 0.044 & -44.27 & -66.95 & -58.13 & -57.62 & -56.74 & 0.044 \\
\hline 101 & -20.07 & -23.22 & -16.42 & -34.56 & -23.57 & & -9.11 & -8.48 & -9.62 & -15.79 & -10.75 & & -7.73 & -11.38 & -10.25 & -7.85 & -9.30 & \\
\hline 102 & -28.77 & -34.82 & -24.23 & -72.74 & 40.14 & & -15.16 & -13.27 & -13.52 & -27.76 & -17.43 & & -11.51 & -18.06 & -14.91 & -12.01 & -14.12 & \\
\hline 103 & -59.89 & -51.70 & -35.07 & -74.76 & -55.35 & & -24.61 & -18.44 & -16.42 & -48.55 & -27.00 & & -14.78 & -27.00 & -20.45 & -15.54 & -19.44 & \\
\hline 104 & -63.92 & -60.52 & -53.84 & -73.62 & -62.98 & & -47.54 & -27.13 & -21.33 & -54.85 & -37.71 & & -17.81 & -40.36 & -26.50 & -21.08 & -26.44 & \\
\hline 105 & -71.61 & -71.23 & -70.60 & -75.14 & -72.14 & & -70.35 & -39.48 & -25.24 & -66.82 & -50.47 & & -22.34 & -59.64 & -35.07 & -27.26 & -36.08 & \\
\hline 106 & -16.80 & -62.41 & & -27.13 & -35.45 & 0.020 & -6.84 & -5.84 & -7.22 & -10.12 & -7.51 & 0.041 & -4.32 & -8.36 & -7.35 & -3.95 & -5.99 & 0.041 \\
\hline 107 & -25.62 & -53.97 & & -30.53 & -36.71 & 0.031 & -8.23 & -7.85 & -9.11 & -14.53 & -9.93 & 0.031 & -7.22 & -11.63 & -9.74 & -6.97 & -8.89 & 0.031 \\
\hline 108 & -5.84 & -9.87 & -14.53 & -9.49 & -9.93 & & -6.47 & -5.96 & -7.60 & -8.10 & -7.03 & & -5.84 & -6.72 & -7.60 & -5.71 & -6.47 & \\
\hline 109 & 0.09 & -6.72 & -7.60 & -0.92 & -3.79 & 0.038 & -1.93 & -2.18 & -4.07 & -1.93 & -2.53 & 0.038 & -0.67 & -1.55 & -3.19 & -1.05 & -1.62 & 0.038 \\
\hline 110 & -6.97 & -8.36 & -12.64 & -8.61 & -9.14 & & -8.48 & -7.98 & -9.11 & -9.74 & -8.83 & & -7.60 & -8.23 & -8.99 & -7.10 & -7.98 & \\
\hline 111 & -10.12 & -13.02 & -11.00 & -14.28 & -12.10 & & -11.00 & -10.50 & -11.00 & -10.37 & -10.72 & & -9.74 & -11.13 & -11.38 & -9.49 & -10.44 & \\
\hline 112 & -12.39 & -15.29 & -13.40 & -17.30 & -14.59 & & -14.15 & -12.01 & -12.64 & -13.90 & -13.18 & & -10.12 & -13.14 & -12.89 & -11.25 & -11.85 & \\
\hline 113 & -3.69 & -5.33 & -5.08 & -3.32 & -4.36 & 0.055 & -4.83 & -4.70 & -5.96 & -2.81 & 4.58 & 0.055 & -3.69 & 4.70 & -3.19 & -3.44 & -3.76 & 0.055 \\
\hline 114 & -6.97 & -10.12 & -8.73 & -8.23 & -8.51 & & -9.11 & -8.36 & -9.99 & -7.85 & -8.83 & & -8.10 & -8.61 & -9.74 & -7.85 & -8.58 & \\
\hline 115 & -9.49 & -13.02 & -10.75 & -11.88 & -11.29 & & -12.26 & -10.37 & -11.00 & -11.25 & -11.22 & & -9.99 & -11.38 & -11.88 & -9.87 & -10.78 & \\
\hline 116 & -12.14 & -16.80 & -13.27 & -17.18 & -14.85 & & -17.05 & -12.77 & -13.02 & -14.53 & -14.34 & & -11.88 & -14.53 & -13.65 & -12.51 & -13.14 & \\
\hline 117 & -15.92 & -21.08 & -15.79 & -23.98 & -19.19 & & -24.48 & -15.66 & -15.29 & -18.94 & -18.59 & & -14.03 & -17.30 & -15.66 & -14.78 & -15.44 & \\
\hline 118 & -19.57 & -25.24 & -18.44 & -31.29 & -23.63 & & -34.31 & -18.06 & -17.05 & -23.98 & -23.35 & & -15.54 & -20.45 & -17.55 & -17.05 & -17.65 & \\
\hline 119 & -25.87 & -33.30 & -20.96 & -37.71 & -29.46 & & 46.91 & -21.84 & -19.32 & -29.78 & -29.46 & & -17.68 & -24.99 & -20.07 & -20.58 & -20.83 & \\
\hline 120 & -32.67 & -42.38 & -23.35 & -45.90 & -36.08 & & -58.76 & -26.12 & -21.59 & -35.07 & -35.38 & & -20.20 & -32.17 & -23.35 & -24.61 & -25.08 & \\
\hline 121 & -77.78 & -49.43 & -26.63 & -54.47 & -52.08 & 0.006 & -63.80 & -29.40 & -24.23 & -42.88 & -40.08 & 0.006 & -23.35 & -37.46 & -26.50 & -29.02 & -29.08 & 0.006 \\
\hline 122 & -45.15 & -54.98 & -29.15 & -58.76 & 47.01 & & -67.95 & -32.30 & -26.12 & -47.29 & -43.42 & & -26.00 & -42.25 & -29.02 & -32.55 & -32.45 & \\
\hline 123 & -3.44 & -7.73 & -6.34 & -5.33 & -5.71 & 0.035 & -6.34 & -5.46 & -7.22 & 4.83 & -5.96 & 0.035 & 4.45 & -6.34 & -7.10 & -4.83 & -5.68 & 0.035 \\
\hline 124 & -8.10 & -12.51 & -9.49 & -9.74 & -9.96 & & -9.74 & -9.11 & -10.25 & -11.00 & -10.03 & & -8.61 & -10.88 & -10.37 & -8.48 & -9.58 & \\
\hline 125 & -11.25 & -16.80 & -11.88 & -13.40 & -13.33 & & -12.51 & -11.38 & -12.26 & -15.54 & -12.92 & & -10.50 & -14.28 & -12.89 & -11.00 & -12.17 & \\
\hline 126 & -15.54 & -22.09 & -14.28 & -18.06 & -17.49 & & -16.55 & -13.65 & -14.28 & -21.84 & -16.58 & & -12.77 & -17.43 & -15.41 & -13.40 & -14.75 & \\
\hline 127 & -17.30 & -27.00 & -15.41 & -21.59 & -20.33 & & -19.95 & -15.29 & -15.66 & -26.50 & -19.35 & & -13.77 & -20.96 & -17.05 & -15.16 & -16.74 & \\
\hline 128 & -24.36 & -37.84 & -18.06 & -29.65 & -27.48 & & -27.76 & -18.56 & -18.18 & -38.22 & -25.68 & & -16.17 & -27.26 & -19.57 & -19.07 & -20.52 & \\
\hline 129 & & & & & & 0.008 & & & & & & 0.008 & & & & & & 0.008 \\
\hline 130 & -34.06 & -54.22 & -21.84 & -41.87 & -38.00 & 0.007 & -38.47 & -23.10 & -22.59 & -54.60 & -34.69 & 0.007 & -21.46 & -35.32 & -23.98 & -24.86 & -26.41 & 0.007 \\
\hline 131 & -30.28 & -56.74 & -19.32 & 41.62 & -36.99 & 0.021 & -34.69 & -23.98 & -23.35 & -55.48 & -34.38 & 0.021 & -17.30 & -29.52 & -23.48 & -24.99 & -23.82 & 0.021 \\
\hline 132 & -6.34 & -13.27 & -7.73 & -7.98 & -8.83 & & -7.85 & -8.10 & -9.99 & -8.73 & -8.67 & & -6.97 & -8.73 & -9.36 & -6.97 & -8.01 & \\
\hline 133 & -9.36 & -17.05 & -10.12 & -11.25 & -11.95 & & -10.25 & -10.12 & -11.51 & -13.27 & -11.29 & & -9.49 & -11.51 & -11.76 & -9.74 & -10.62 & \\
\hline 134 & -11.25 & -20.70 & -11.76 & -13.27 & -14.25 & 0.015 & -11.51 & -11.13 & -13.27 & -16.67 & -13.14 & 0.015 & -11.13 & -12.64 & -13.14 & -11.63 & -12.14 & 0.015 \\
\hline 135 & -6.59 & -13.65 & -8.73 & -7.98 & -9.24 & & -8.10 & -8.48 & -10.12 & -10.12 & -9.21 & & -7.60 & -8.73 & -9.49 & -8.23 & -8.51 & \\
\hline 136 & -8.10 & -15.79 & -10.75 & -10.12 & -11.19 & & -9.49 & -10.12 & -11.25 & -12.77 & -10.91 & & -9.24 & -10.37 & -11.25 & -9.74 & -10.15 & \\
\hline 137 & -10.12 & -18.69 & -12.26 & -12.01 & -13.27 & & -10.88 & -11.38 & -12.89 & -3.19 & -9.58 & & -10.88 & -12.26 & -13.02 & -11.51 & -11.92 & \\
\hline 138 & -12.01 & -21.46 & -14.40 & -13.90 & -15.44 & & -12.77 & -13.14 & -14.28 & -17.81 & -14.50 & & -12.01 & -13.52 & -14.28 & -12.89 & -13.18 & \\
\hline 139 & & & & & & 0.008 & & & & & & 0.008 & & & & & & 0.008 \\
\hline 141 & & & & & & 0.020 & & & & & & 0.020 & & & & & & 0.020 \\
\hline 142 & & & & & & 0.025 & & & & & & 0.025 & & & & & & 0.025 \\
\hline 143 & & & & & & 0.015 & & & & & & 0.015 & & & & & & 0.015 \\
\hline 146 & & & & & & 0.043 & & & & & & 0.043 & & & & & & 0.043 \\
\hline 147 & & & & & & 0.070 & & & & & & 0.070 & & & & & & 0.070 \\
\hline
\end{tabular}


Profundidade $0,30 \mathrm{~m}$.

\begin{tabular}{|c|c|c|c|c|c|c|c|c|c|c|c|c|c|c|c|c|c|c|}
\hline \multirow[b]{2}{*}{ DAS } & \multicolumn{6}{|c|}{ trat -000} & \multicolumn{6}{|c|}{ trat $0 \mathrm{IO}$} & \multicolumn{6}{|c|}{ trat III } \\
\hline & r1 & 12 & r3 & $\mathrm{r} 4$ & média & $\mathrm{P}+\mathrm{I}$ & $\mathrm{rl}$ & 2 & r3 & $\mathrm{r} 4$ & média & $\mathrm{P}+\mathrm{I}$ & $\mathrm{rl}$ & 2 & r3 & $\mathrm{r} 4$ & média & $\mathrm{P}+\mathrm{I}$ \\
\hline 0 & & & & & & 0.020 & & & & & & 0.021 & & & & & & 0.021 \\
\hline 1 & & & & & & 0.014 & & & & & & 0.014 & & & & & & 0.014 \\
\hline 2 & & & & & & 0.027 & & & & & & 0.028 & & & & & & 0.028 \\
\hline 4 & & & & & & 0.027 & & & & & & 0.028 & & & & & & 0.028 \\
\hline 5 & & & & & & 0.020 & & & & & & 0.021 & & & & & & 0.021 \\
\hline 7 & & & & & & 0.027 & & & & & & 0.028 & & & & & & 0.028 \\
\hline 8 & & & & & & 0.020 & & & & & & 0.021 & & & & & & 0.021 \\
\hline 9 & & & & & & 0.020 & & & & & & 0.021 & & & & & & 0.021 \\
\hline 13 & & & & & & 0.027 & & & & & & 0.028 & & & & & & 0.028 \\
\hline 16 & & & & & & 0.020 & & & & & & 0.021 & & & & & & 0.021 \\
\hline 17 & -7.73 & -9.50 & -9.25 & -7.73 & -8.55 & & -8.11 & -8.99 & -10.76 & -10.25 & -9.53 & & -8.99 & -8.36 & -9.75 & -9.62 & -9.18 & \\
\hline 18 & -9.50 & -10.88 & -10.76 & -8.49 & -9.91 & 0.014 & -9.75 & -10.38 & -11.51 & -11.14 & -10.70 & 0.014 & -10.76 & -10.00 & -11.26 & -10.88 & -10.73 & 0.014 \\
\hline 19 & -7.61 & -9.50 & -9.88 & -7.86 & -8.71 & & -8.62 & -9.25 & -12.27 & -10.13 & -10.07 & & -9.50 & -8.36 & -9.75 & -9.37 & -9.25 & \\
\hline 20 & -9.25 & -10.88 & -10.76 & -8.87 & -9.94 & 0.019 & -9.75 & -9.88 & -11.64 & -11.26 & -10.63 & 0.020 & -10.88 & -9.88 & -10.76 & -10.76 & -10.57 & 0.020 \\
\hline 21 & -9.62 & -8.11 & -8.49 & -5.97 & -8.05 & 0.011 & -6.47 & -7.48 & -8.36 & -8.11 & -7.61 & 0.011 & -7.61 & -6.98 & -11.64 & -7.48 & -8.43 & 0.011 \\
\hline 22 & -7.99 & -8.24 & -8.24 & -5.84 & -7.58 & & -7.10 & -7.86 & -8.74 & -8.24 & -7.99 & & -7.86 & -7.10 & -10.13 & -7.99 & -8.27 & \\
\hline 23 & -9.37 & -10.00 & -9.75 & -7.48 & -9.15 & 0.027 & -8.62 & -9.37 & -10.13 & -10.13 & -9.56 & 0.028 & -9.62 & -9.12 & -11.14 & -9.37 & -9.81 & 0.028 \\
\hline 24 & -9.37 & -7.61 & -7.61 & -5.47 & -7.51 & & -6.60 & -7.48 & -8.24 & -7.86 & -7.55 & & -7.48 & -6.60 & -8.11 & -7.36 & -7.39 & \\
\hline 25 & -6.60 & -9.37 & -9.37 & -7.36 & -8.18 & & -8.24 & -9.12 & -8.24 & -9.50 & -8.77 & & -8.36 & -8.24 & -9.12 & -9.12 & -8.71 & \\
\hline 26 & -8.11 & -10.63 & -10.51 & -8.62 & -9.47 & & -9.62 & -10.38 & -10.25 & -10.88 & -10.29 & & -10.51 & -9.37 & -10.13 & -10.38 & -10.10 & \\
\hline 27 & -10.25 & -12.14 & -12.14 & -10.51 & -11.26 & & -10.63 & -11.77 & -12.27 & -11.89 & -11.64 & & -11.26 & -10.88 & -11.26 & -11.64 & -11.26 & \\
\hline 28 & -9.50 & -11.39 & -12.52 & -10.51 & -10.98 & 0.024 & -11.39 & -10.76 & -12.14 & -12.52 & -11.70 & 0.024 & -11.39 & -10.88 & -12.14 & -11.64 & -11.51 & 0.024 \\
\hline 29 & -8.87 & -10.51 & -11.64 & -9.25 & -10.07 & 0.027 & -10.13 & -9.75 & -11.64 & -11.39 & -10.73 & 0.028 & -10.51 & -9.50 & -11.39 & -9.88 & -10.32 & 0.028 \\
\hline 30 & -6.35 & -7.86 & -7.86 & -5.59 & -6.92 & 0.027 & -7.36 & -7.61 & -8.36 & -8.36 & -7.92 & 0.028 & -7.61 & -6.85 & -7.48 & -7.73 & -7.42 & 0.028 \\
\hline 31 & -5.59 & -7.61 & -7.61 & -5.59 & -6.60 & & -7.10 & -7.61 & -8.24 & -7.86 & -7.70 & & -7.23 & -6.47 & -7.61 & -7.61 & -7.23 & \\
\hline 32 & -8.36 & -9.37 & -9.50 & & -9.08 & & -9.37 & -9.25 & -9.88 & -9.75 & -9.56 & & -9.37 & -8.36 & -9.62 & -9.25 & -9.15 & \\
\hline 33 & -9.75 & -10.76 & -11.26 & & -10.59 & & -10.38 & -10.76 & -10.63 & -11.14 & -10.73 & & -10.88 & -9.62 & -10.88 & -10.76 & -10.54 & \\
\hline 34 & -11.39 & -12.14 & -13.03 & -11.26 & -11.96 & & -12.02 & -12.14 & -12.90 & -12.65 & -12.43 & & -12.27 & -11.26 & -11.39 & -12.14 & -11.77 & \\
\hline 35 & -12.14 & -13.28 & -15.04 & -13.03 & -13.37 & & -13.03 & -13.53 & -14.16 & -13.78 & -13.62 & & -13.28 & -12.40 & -12.40 & -13.03 & -12.77 & \\
\hline 36 & -13.78 & -14.79 & -16.68 & -14.54 & -14.95 & & -14.54 & -15.04 & -15.55 & -15.17 & -15.07 & & -14.79 & -14.16 & -13.78 & -14.41 & -14.29 & \\
\hline 37 & -15.17 & -16.55 & -20.21 & -17.06 & -17.25 & & -16.30 & -16.93 & -17.94 & -17.06 & -17.06 & & -16.55 & -15.55 & -17.81 & -16.30 & -16.55 & \\
\hline 38 & -17.56 & -18.07 & -37.34 & -21.72 & -23.67 & & -18.32 & -19.83 & -20.96 & -19.70 & -19.70 & & -18.32 & -17.94 & -16.55 & -17.94 & -17.69 & \\
\hline 39 & -20.21 & -20.59 & -33.69 & -27.64 & -25.53 & & -21.09 & -22.98 & -25.25 & -24.11 & -23.36 & & -21.09 & -20.46 & -20.46 & -20.59 & -20.65 & \\
\hline 40 & -24.37 & -23.99 & 46.29 & -37.85 & -33.12 & & -25.50 & -28.02 & -32.05 & -31.55 & -29.28 & & -25.50 & -24.24 & -23.86 & -24.11 & -24.43 & \\
\hline 41 & -29.28 & -26.63 & -58.26 & -53.60 & -41.94 & & -30.16 & -34.32 & -40.75 & -44.40 & -37.41 & & -30.04 & -28.02 & -28.40 & -28.02 & -28.62 & \\
\hline 42 & -35.20 & -31.17 & -67.96 & -66.20 & -50.13 & & -36.71 & 42.51 & -52.34 & -57.63 & 47.30 & & -36.71 & -33.56 & -35.45 & -33.44 & -34.79 & \\
\hline 43 & -39.74 & -34.70 & -70.73 & -72.37 & -54.39 & 0.020 & -39.74 & 49.82 & -58.01 & -63.30 & -52.72 & 0.021 & -41.38 & -37.85 & -35.58 & -37.22 & -38.01 & 0.036 \\
\hline 44 & 43.52 & -34.32 & -71.87 & -74.26 & -55.99 & 0.014 & -43.27 & -47.30 & -64.56 & -67.71 & -55.71 & 0.014 & -9.25 & -9.75 & -10.38 & -6.85 & -9.06 & 0.028 \\
\hline 45 & -35.58 & -24.24 & -74.39 & -77.66 & -52.97 & & -33.94 & -33.69 & -69.22 & -73.38 & -52.56 & & -11.14 & -12.40 & -13.15 & -10.51 & -11.80 & \\
\hline 46 & -37.97 & -26.51 & -71.87 & -74.64 & -52.75 & & -37.85 & -42.13 & -67.84 & -72.75 & -55.14 & & -13.53 & -14.66 & -16.68 & -12.52 & -14.35 & \\
\hline 47 & 46.54 & -31.93 & -74.77 & -78.55 & -57.95 & & 44.02 & -55.99 & -75.52 & -75.52 & -62.76 & & -16.30 & -31.30 & -19.70 & -15.67 & -20.74 & \\
\hline 48 & -55.87 & -38.86 & -75.52 & -79.93 & -62.54 & & -51.96 & -67.58 & -75.90 & -76.15 & -67.90 & & -20.71 & -23.23 & -25.75 & -19.70 & -22.35 & \\
\hline 49 & -68.34 & -47.42 & -78.42 & -79.05 & -68.31 & & -62.17 & -74.89 & -76.53 & -78.92 & -73.13 & & -25.25 & -29.28 & -34.07 & -25.75 & -28.59 & \\
\hline 50 & -75.90 & -58.89 & -81.57 & -79.55 & -73.98 & 0.014 & -70.48 & -76.78 & -79.55 & -80.56 & -76.85 & 0.014 & -32.43 & -37.22 & 44.02 & -36.59 & -37.56 & 0.028 \\
\hline 51 & -78.42 & -69.22 & -82.20 & -81.44 & -77.82 & & -74.26 & -78.92 & -81.95 & -76.40 & -77.88 & & -12.27 & -27.89 & -31.67 & -33.56 & -26.35 & \\
\hline 52 & -80.94 & -74.14 & -82.20 & -82.20 & -79.87 & & -75.65 & -80.94 & -82.20 & -82.20 & -80.25 & & -18.44 & -34.19 & -38.48 & -35.71 & -31.71 & \\
\hline 53 & -82.20 & -75.65 & -82.20 & & -80.02 & & -80.94 & -82.20 & -82.20 & -82.20 & -81.89 & & -26.13 & -44.15 & -49.69 & -47.05 & 41.75 & \\
\hline 54 & -82.20 & -78.42 & -82.20 & & -80.94 & 0.014 & -82.20 & -82.20 & -82.20 & -82.20 & -82.20 & 0.014 & -36.84 & -56.75 & -61.79 & 48.68 & -51.02 & 0.028 \\
\hline 55 & -75.90 & -79.68 & & & & & & & & -82.20 & & & -16.05 & -54.98 & -55.74 & -50.20 & -44.24 & \\
\hline 56 & & -78.42 & & & & & & -78.80 & -78.42 & & & & -23.61 & -62.04 & -65.82 & -62.42 & -53.47 & \\
\hline 57 & & -79.43 & -78.80 & -78.80 & -79.01 & 0.014 & -79.68 & -78.67 & -79.30 & -79.18 & -79.21 & 0.014 & -35.96 & -75.52 & -75.14 & -74.39 & -65.25 & 0.028 \\
\hline 58 & -77.79 & -79.43 & -78.42 & -78.80 & -78.61 & & -79.05 & -78.67 & -79.05 & -79.18 & -78.99 & & -13.78 & 45.91 & -38.10 & -28.40 & -31.55 & \\
\hline 59 & -77.79 & & -77.54 & -78.42 & -77.92 & & -78.42 & -78.42 & -78.04 & -79.18 & -78.51 & & -16.68 & -49.82 & -47.68 & -41.63 & -38.95 & \\
\hline 60 & -79.05 & & -79.18 & -79.43 & -79.22 & & -79.55 & -80.31 & -79.43 & -79.55 & -79.71 & & -23.61 & -67.46 & -61.41 & -59.77 & -53.06 & \\
\hline 61 & -78.67 & -78.55 & -79.05 & -79.43 & -78.92 & 0.014 & -79.05 & -79.68 & -79.18 & -79.68 & -79.40 & 0.014 & -30.54 & -73.38 & -67.71 & -67.33 & -59.74 & 0.028 \\
\hline 62 & -68.59 & -83.46 & -65.82 & -61.41 & -69.82 & & & -70.86 & -55.74 & & & & -11.64 & -65.82 & -19.83 & -16.43 & -28.43 & \\
\hline 63 & -75.02 & -79.68 & -70.23 & -70.86 & -73.95 & & & -75.27 & -63.30 & & & & -15.42 & -63.68 & -28.52 & -24.49 & -33.03 & \\
\hline 64 & & -79.68 & -72.12 & & & & -69.60 & -76.53 & -66.45 & & -70.86 & & -19.20 & -71.49 & -36.08 & -33.69 & -40.12 & \\
\hline 65 & & -78.92 & -78.17 & & & 0.014 & -74.77 & -77.92 & -76.53 & -69.35 & -74.64 & 0.014 & -26.26 & -76.03 & -49.44 & -54.98 & -51.68 & 0.028 \\
\hline 66 & & -80.06 & -79.18 & & & & -77.29 & -79.30 & -79.81 & & -78.80 & & -11.26 & -75.02 & -20.08 & -11.89 & -29.56 & \\
\hline 67 & & -78.80 & -77.54 & & & & -77.41 & -77.79 & -77.79 & & -77.66 & & -14.54 & -57.88 & -19.96 & -17.69 & -27.52 & \\
\hline 68 & & -78.42 & -77.79 & & & & -79.05 & -78.55 & -78.17 & & -78.59 & & -19.96 & -72.12 & -29.03 & -27.26 & -37.09 & \\
\hline 69 & & -79.05 & -79.05 & & & & -78.67 & -78.04 & -79.05 & & -78.59 & & -26.13 & -76.53 & -38.73 & -38.98 & -45.09 & \\
\hline 70 & & -79.30 & & & & & -80.18 & -78.92 & -78.55 & & -79.22 & & -36.34 & -78.17 & -51.58 & -58.64 & -56.18 & \\
\hline 71 & & -79.18 & & & & 0.014 & -80.31 & -78.42 & -78.92 & & -79.22 & 0.014 & -17.31 & -77.16 & -18.19 & -9.50 & -30.54 & 0.028 \\
\hline 72 & & -79.18 & & & & & -79.05 & -78.92 & & & & & -20.08 & -77.79 & -25.37 & -16.68 & -34.98 & \\
\hline 73 & & & & & & & -79.05 & -79.43 & & & & & -35.45 & -79.05 & 46.54 & -29.91 & -47.74 & \\
\hline 74 & & & & & & 0.020 & & & & & & 0.041 & -47.68 & -76.53 & -56.24 & -51.08 & -57.88 & 0.041 \\
\hline 75 & -50.45 & & & -29.28 & -39.86 & & -12.27 & -12.65 & -12.14 & -32.43 & -17.37 & & -10.13 & -41.88 & -12.90 & -9.62 & -18.63 & \\
\hline
\end{tabular}

(continua) 
Profundidade $0,30 \mathrm{~m}$ (continuação).

\begin{tabular}{|c|c|c|c|c|c|c|c|c|c|c|c|c|c|c|c|c|c|c|}
\hline \multirow[b]{2}{*}{ DAS } & \multicolumn{6}{|c|}{ trat -000} & \multicolumn{6}{|c|}{ trat 0IO } & \multicolumn{6}{|c|}{ trat III } \\
\hline & r1 & 12 & r3 & $\mathrm{r4}$ & média & $\mathrm{P}+\mathrm{I}$ & $\mathrm{rl}$ & 12 & r3 & $\mathrm{r} 4$ & média & $\mathrm{P}+\mathrm{I}$ & rl & 2 & r3 & $\mathrm{r} 4$ & média & $\mathrm{P}+\mathrm{I}$ \\
\hline 76 & -58.76 & & & 40.87 & 49.82 & & -20.46 & -21.09 & -17.94 & -44.27 & -25.94 & & -14.16 & -57.63 & -19.20 & -13.91 & -26.22 & \\
\hline 77 & & & & & & & -31.80 & -32.18 & -26.13 & -60.40 & -37.63 & & -18.57 & -73.38 & -27.77 & -20.46 & -35.04 & \\
\hline 78 & & & & -32.93 & & 0.020 & -8.11 & -7.73 & -8.49 & -54.10 & -19.61 & 0.041 & -6.35 & -15.04 & -8.24 & -6.98 & -9.15 & 0.041 \\
\hline 79 & & & & -39.11 & & & -11.14 & -12.52 & -12.77 & -36.46 & -18.22 & & -10.00 & -21.34 & -12.65 & -10.13 & -13.53 & \\
\hline 80 & & & & 44.40 & & & -14.03 & -15.17 & -15.42 & -43.39 & -22.00 & & -11.39 & -25.12 & -16.55 & -12.02 & -16.27 & \\
\hline 81 & & & & -46.16 & & & -16.81 & -17.44 & -17.31 & -51.96 & -25.88 & & -12.52 & -27.26 & -19.83 & -13.53 & -18.29 & \\
\hline 82 & & & & & & & -20.46 & -20.08 & -20.46 & -61.41 & -30.60 & & -14.79 & -33.69 & -23.61 & -16.05 & -22.04 & \\
\hline 83 & & & & & & & -30.04 & -27.77 & -26.00 & -70.86 & -38.67 & & -19.45 & 48.18 & -31.17 & -20.59 & -29.85 & \\
\hline 84 & & & & & & & -43.14 & -38.10 & -31.80 & -75.90 & -47.24 & & -25.00 & -65.82 & -41.12 & -26.13 & -39.52 & \\
\hline 85 & & & & & & 0.014 & -56.12 & -50.20 & -39.86 & -78.42 & -56.15 & 0.028 & -29.91 & -72.12 & -51.46 & -31.30 & 46.20 & 0.028 \\
\hline 86 & & & & & & & -5.59 & -6.73 & -8.24 & -79.43 & -25.00 & & -5.34 & -12.02 & -28.27 & -6.35 & -12.99 & \\
\hline 87 & & & & -64.56 & & & -10.38 & -10.88 & -11.64 & -77.16 & -27.52 & & -9.88 & -16.43 & -25.12 & -9.62 & -15.26 & \\
\hline 88 & & & & & & 0.047 & -5.59 & -6.10 & -7.10 & -9.75 & -7.14 & 0.047 & -6.10 & -5.59 & -6.98 & -6.60 & -6.32 & 0.047 \\
\hline 89 & -8.87 & -10.38 & -16.43 & -10.63 & -11.58 & & -9.25 & -7.23 & -9.75 & -14.16 & -10.10 & & -9.37 & -9.12 & -9.75 & -9.25 & -9.37 & \\
\hline 90 & -5.34 & -6.85 & -8.62 & -6.85 & -6.92 & 0.019 & -6.10 & -6.85 & -7.73 & -7.86 & -7.14 & 0.019 & -6.60 & -5.84 & -7.36 & -6.85 & -6.66 & 0.019 \\
\hline 91 & -5.72 & -7.23 & -8.62 & -5.97 & -6.88 & 0.017 & -7.23 & -7.48 & -8.24 & -9.12 & -8.02 & 0.017 & -7.48 & -6.60 & -7.86 & -7.73 & -7.42 & 0.017 \\
\hline 92 & -3.58 & -4.71 & -5.47 & -3.32 & 4.27 & 0.045 & -5.09 & -4.96 & -6.22 & -5.97 & -5.56 & 0.045 & -5.21 & -4.08 & -5.84 & -5.59 & -5.18 & 0.045 \\
\hline 93 & -6.98 & -8.24 & -8.87 & -6.85 & -7.73 & & -8.49 & -8.74 & -9.25 & -9.88 & -9.09 & & -8.62 & -7.61 & -8.99 & -8.62 & -8.46 & \\
\hline 94 & -9.12 & -10.51 & -11.77 & -9.37 & -10.19 & & -11.26 & -11.01 & -11.14 & -13.53 & -11.73 & & -11.39 & -10.38 & -10.76 & -10.88 & -10.85 & \\
\hline 95 & -12.14 & -13.66 & -15.17 & -12.65 & -13.40 & & -15.80 & -13.53 & -12.90 & -19.83 & -15.51 & & -15.04 & -13.91 & -13.28 & -13.78 & -14.00 & \\
\hline 96 & -19.83 & -17.81 & -18.19 & -19.45 & -18.82 & & -19.83 & -15.80 & -12.90 & -28.15 & -19.17 & & -15.42 & -16.68 & -14.92 & -16.05 & -15.77 & \\
\hline 97 & -25.25 & -22.48 & -22.98 & -31.42 & -25.53 & & -30.04 & -20.08 & -17.18 & -55.74 & -30.76 & & -22.35 & -22.35 & -17.69 & -21.09 & -20.87 & \\
\hline 98 & -36.97 & -32.81 & -29.91 & 48.94 & -37.16 & & -49.06 & -25.75 & -20.33 & -72.12 & 41.82 & & -29.91 & -32.81 & -21.72 & -3.58 & -22.00 & \\
\hline 99 & -50.07 & -44.15 & -36.59 & -62.42 & 48.31 & & -65.32 & -33.94 & -24.24 & -74.64 & 49.53 & & -40.62 & -39.99 & -27.39 & -41.25 & -37.31 & \\
\hline 100 & -59.02 & -54.23 & -43.52 & -70.23 & -56.75 & 0.023 & -70.86 & 43.27 & -29.53 & -75.40 & -54.76 & 0.044 & -51.71 & -46.16 & -34.45 & -35.96 & -42.07 & 0.044 \\
\hline 101 & -28.40 & -39.11 & -17.94 & -55.99 & -35.36 & & -9.50 & -9.12 & -9.37 & -25.50 & -13.37 & & -9.62 & -11.64 & -9.75 & -9.50 & -10.13 & \\
\hline 102 & 43.14 & -47.55 & -25.37 & -70.10 & -46.54 & & -16.05 & -12.65 & -12.02 & -59.77 & -25.12 & & -13.15 & -17.69 & -13.78 & -13.28 & -14.48 & \\
\hline 103 & -60.78 & -62.04 & -34.32 & -75.52 & -58.17 & & -24.87 & -16.81 & -14.54 & -77.66 & -33.47 & & -16.68 & -26.00 & -18.19 & -17.31 & -19.55 & \\
\hline 104 & -67.46 & -67.84 & 41.75 & -76.15 & -63.30 & & 43.77 & -21.09 & -17.06 & -77.16 & -39.77 & & -20.08 & -37.60 & -22.35 & -24.49 & -26.13 & \\
\hline 105 & -72.25 & -73.13 & -50.70 & -78.04 & -68.53 & & -67.46 & -27.64 & -19.58 & -78.42 & -48.27 & & -25.25 & -55.49 & -28.27 & -32.05 & -35.27 & \\
\hline 106 & -74.39 & -76.91 & -51.58 & -78.42 & -70.32 & 0.020 & -7.61 & -6.73 & -7.10 & -77.54 & -24.74 & 0.041 & -6.22 & -10.00 & -6.85 & -7.48 & -7.64 & 0.041 \\
\hline 107 & -76.15 & -79.68 & 43.14 & -80.06 & -69.76 & 0.031 & -8.62 & -8.49 & -9.25 & -26.13 & -13.12 & 0.031 & -7.86 & -11.39 & -9.62 & -8.49 & -9.34 & 0.031 \\
\hline 108 & -31.04 & -12.27 & -10.76 & -12.14 & -16.55 & & -6.73 & -6.73 & -7.73 & -9.50 & -7.67 & & -6.35 & -6.22 & -7.48 & -7.36 & -6.85 & \\
\hline 109 & -2.19 & -6.60 & -3.83 & -2.44 & -3.77 & 0.038 & -2.82 & -3.07 & -4.08 & -3.58 & -3.39 & 0.038 & -4.08 & -2.19 & -3.83 & -4.08 & -3.54 & 0.038 \\
\hline 110 & -8.74 & -7.99 & -8.74 & -8.11 & -8.40 & & -8.74 & -8.36 & -9.12 & -9.75 & -8.99 & & -8.24 & -7.73 & -8.62 & -8.62 & -8.30 & \\
\hline 111 & -11.51 & -12.40 & -9.12 & -11.26 & -11.07 & & -11.64 & -10.51 & -10.63 & -12.90 & -11.42 & & -10.13 & -10.13 & -10.63 & -10.76 & -10.41 & \\
\hline 112 & -13.78 & -14.16 & -11.01 & -13.53 & -13.12 & & -14.03 & -12.27 & -12.02 & -14.54 & -13.22 & & -11.64 & -11.89 & -11.77 & -12.02 & -11.83 & \\
\hline 113 & -4.84 & -5.84 & -5.84 & -4.08 & -5.15 & 0.055 & -5.21 & -5.09 & -6.10 & -5.84 & -5.56 & 0.055 & -5.09 & 4.08 & -5.72 & -5.72 & -5.15 & 0.055 \\
\hline 114 & -8.74 & -9.75 & -6.60 & -8.24 & -8.33 & & -9.37 & -8.49 & -9.37 & -8.74 & -8.99 & & -8.74 & -7.99 & -8.87 & -9.12 & -8.68 & \\
\hline 115 & -10.88 & -12.14 & -8.62 & -10.76 & -10.60 & & -12.52 & -10.76 & -11.01 & -12.40 & -11.67 & & -10.51 & -10.51 & -10.88 & -11.26 & -10.79 & \\
\hline 116 & -13.40 & -14.66 & -12.77 & -13.15 & -13.50 & & -17.06 & -13.03 & -12.52 & -15.04 & -14.41 & & -12.40 & -13.15 & -11.89 & -13.53 & -12.74 & \\
\hline 117 & -16.30 & -17.94 & -14.79 & -16.55 & -16.40 & & -22.48 & -14.92 & -14.29 & -18.32 & -17.50 & & -14.41 & -15.67 & -14.16 & -15.80 & -15.01 & \\
\hline 118 & -19.58 & -21.09 & -16.68 & -19.20 & -19.14 & & -31.17 & -17.06 & -15.55 & -21.59 & -21.34 & & -15.67 & -18.32 & -15.55 & -17.94 & -16.87 & \\
\hline 119 & -24.24 & -25.50 & -18.82 & -22.73 & -22.82 & & 46.16 & -19.83 & -17.31 & -25.88 & -27.30 & & -17.56 & -22.35 & -17.18 & -21.09 & -19.55 & \\
\hline 120 & -30.04 & -32.43 & -21.34 & -26.13 & -27.48 & & -65.19 & -21.59 & -18.82 & -31.17 & -34.19 & & -19.70 & -27.89 & -19.20 & -24.87 & -22.92 & \\
\hline 121 & -35.45 & -37.85 & -23.23 & -30.54 & -31.77 & 0.006 & -66.83 & -23.99 & -20.84 & -36.97 & -37.16 & 0.006 & -21.72 & -31.30 & -21.47 & -28.40 & -25.72 & 0.006 \\
\hline 122 & -39.74 & -42.89 & -24.49 & -31.93 & -34.76 & & -67.96 & -25.88 & -22.10 & 41.50 & -39.36 & & -23.11 & -34.95 & -22.98 & -31.17 & -28.05 & \\
\hline 123 & -6.73 & -10.63 & -7.10 & -6.35 & -7.70 & 0.035 & -11.01 & -6.60 & -7.61 & -8.62 & -8.46 & 0.035 & -6.60 & -6.35 & -7.86 & -7.61 & -7.10 & 0.035 \\
\hline 124 & -10.38 & -13.03 & -9.88 & -10.25 & -10.88 & & -11.77 & -9.62 & -10.13 & -13.15 & -11.17 & & -9.25 & -10.25 & -10.00 & -10.38 & -9.97 & \\
\hline 125 & -13.15 & -16.55 & -11.89 & -13.28 & -13.72 & & -14.92 & -11.77 & -12.14 & -17.56 & -14.10 & & -10.88 & -13.40 & -12.40 & -12.65 & -12.33 & \\
\hline 126 & -16.93 & -20.46 & -13.91 & -16.81 & -17.03 & & -20.33 & -13.78 & -13.66 & -22.60 & -17.59 & & -12.77 & -16.55 & -15.17 & -15.17 & -14.92 & \\
\hline 127 & -20.21 & -24.87 & -15.29 & -19.20 & -19.89 & & -26.26 & -14.16 & -15.29 & -27.77 & -20.87 & & -13.66 & -19.70 & -16.43 & -17.69 & -16.87 & \\
\hline 128 & -27.89 & -33.94 & -17.56 & -24.49 & -25.97 & & -42.13 & -17.06 & -17.44 & -38.86 & -28.87 & & -15.80 & -25.12 & -18.70 & -21.97 & -20.40 & \\
\hline 129 & & & & & & 0.008 & & & & & & 0.008 & & & & & & 0.008 \\
\hline 130 & -39.99 & -47.55 & -20.84 & -32.81 & -35.30 & 0.007 & 45.03 & -21.72 & -21.09 & -56.37 & -36.05 & 0.007 & -19.20 & -29.66 & -22.10 & -26.89 & -24.46 & 0.007 \\
\hline 131 & -43.14 & -49.69 & -20.33 & -33.69 & -36.71 & 0.021 & 42.26 & -21.97 & -21.47 & -58.39 & -36.02 & 0.021 & -18.32 & -28.65 & -22.35 & -27.39 & -24.18 & 0.021 \\
\hline 132 & -10.38 & -17.56 & -8.36 & -10.00 & -11.58 & & -9.62 & -8.87 & -10.88 & -13.91 & -10.82 & & -8.49 & -8.74 & -10.38 & -10.25 & -9.47 & \\
\hline 133 & -12.40 & -18.07 & -10.38 & -12.65 & -13.37 & & -11.26 & -10.88 & -11.89 & -18.19 & -13.06 & & -10.25 & -10.88 & -11.64 & -10.88 & -10.92 & \\
\hline 134 & -14.03 & -19.96 & -11.77 & -14.79 & -15.14 & 0.015 & -12.65 & -12.27 & -13.15 & -21.09 & -14.79 & 0.015 & -11.51 & -12.27 & -12.90 & -12.27 & -12.24 & 0.015 \\
\hline 135 & -9.50 & -13.91 & -9.50 & -9.75 & -10.66 & & -8.74 & -9.50 & -10.63 & -13.91 & -10.70 & & -8.87 & -8.49 & -10.13 & -9.75 & -9.31 & \\
\hline 136 & -10.63 & -15.17 & -10.51 & -11.64 & -11.99 & & -10.25 & -10.63 & -11.39 & -15.80 & -12.02 & & -9.88 & -9.88 & -11.01 & -10.63 & -10.35 & \\
\hline 137 & -12.27 & -17.44 & -12.02 & -13.28 & -13.75 & & -12.02 & -12.27 & -12.77 & -17.81 & -13.72 & & -11.26 & -11.39 & -12.65 & -11.64 & -11.73 & \\
\hline 138 & -14.03 & -18.82 & -13.40 & -15.04 & -15.33 & & -13.53 & -13.66 & -14.03 & -19.83 & -15.26 & & -12.40 & -12.52 & -13.53 & -12.77 & -12.81 & \\
\hline 139 & & & & & & 0.008 & & & & & & 0.008 & & & & & & .008 \\
\hline 141 & & & & & & 0.020 & & & & & & 0.020 & & & & & & 0.020 \\
\hline 142 & & & & & & 0.025 & & & & & & 0.025 & & & & & & 0.025 \\
\hline 143 & & & & & & 0.015 & & & & & & 0.015 & & & & & & 0.015 \\
\hline 146 & & & & & & 0.043 & & & & & & 0.043 & & & & & & 0.043 \\
\hline 147 & & & & & & 0.070 & & & & & & 0.070 & & & & & & 0.070 \\
\hline
\end{tabular}


Profundidade $0,40 \mathrm{~m}$.

\begin{tabular}{|c|c|c|c|c|c|c|c|c|c|c|c|c|c|c|c|c|c|c|}
\hline \multirow[b]{2}{*}{ DAS } & \multicolumn{6}{|c|}{ trat -000} & \multicolumn{6}{|c|}{ trat 0I0 } & \multicolumn{6}{|c|}{ trat III } \\
\hline & r1 & 12 & r3 & $\mathrm{m}$ & média & $\mathrm{P}+\mathrm{I}$ & rl & 12 & r3 & $\mathrm{r} 4$ & média & $\mathrm{P}+\mathrm{I}$ & $\mathrm{rl}$ & 12 & r3 & $\mathrm{r} 4$ & média & $\mathrm{P}+\mathrm{I}$ \\
\hline 0 & & & & & & 0.020 & & & & & & 0.021 & & & & & & 0.021 \\
\hline 1 & & & & & & 0.014 & & & & & & 0.014 & & & & & & 0.014 \\
\hline 2 & & & & & & 0.027 & & & & & & 0.028 & & & & & & 0.028 \\
\hline 4 & & & & & & 0.027 & & & & & & 0.028 & & & & & & 0.028 \\
\hline 5 & & & & & & 0.020 & & & & & & 0.021 & & & & & & 0.021 \\
\hline 7 & & & & & & 0.027 & & & & & & 0.028 & & & & & & 0.028 \\
\hline 8 & & & & & & 0.020 & & & & & & 0.021 & & & & & & 0.021 \\
\hline 9 & & & & & & 0.020 & & & & & & 0.021 & & & & & & 0.021 \\
\hline 13 & & & & & & 0.027 & & & & & & 0.028 & & & & & & 0.028 \\
\hline 16 & & & & & & 0.020 & & & & & & 0.021 & & & & & & 0.021 \\
\hline 17 & -7.87 & -8.75 & -9.38 & -8.25 & -8.56 & & -8.50 & -9.13 & -10.64 & -9.88 & -9.54 & & -8.88 & -8.37 & -9.63 & -10.14 & -9.25 & \\
\hline 18 & -9.38 & -9.88 & -10.39 & -9.13 & -9.70 & 0.014 & -9.51 & -10.26 & -11.27 & -10.26 & -10.33 & 0.014 & -10.39 & -9.88 & -11.02 & -10.89 & -10.55 & 0.014 \\
\hline 19 & -7.62 & -9.00 & -10.14 & -8.25 & -8.75 & & -8.62 & -9.51 & -10.89 & -10.01 & -9.76 & & -9.63 & -8.62 & -9.76 & -9.88 & -9.47 & \\
\hline 20 & -9.13 & -10.01 & -10.77 & -9.13 & -9.76 & 0.019 & -9.38 & -10.39 & -11.65 & -10.77 & -10.55 & 0.020 & -10.64 & -9.76 & -10.51 & -10.89 & -10.45 & 0.020 \\
\hline 21 & -9.38 & -7.74 & -9.00 & -6.23 & -8.09 & 0.011 & -6.61 & -7.62 & -8.62 & -8.37 & -7.81 & 0.011 & -7.62 & -7.62 & -11.14 & -7.99 & -8.59 & 0.011 \\
\hline 22 & -8.12 & -7.62 & -8.37 & -6.61 & -7.68 & & -6.99 & -7.62 & -8.75 & -8.25 & -7.90 & & -7.62 & -7.11 & -10.01 & -8.12 & -8.21 & \\
\hline 23 & -9.13 & -9.00 & -9.76 & -7.87 & -8.94 & 0.027 & -8.37 & -9.13 & -9.88 & -9.51 & -9.22 & 0.028 & -9.13 & -8.62 & -10.64 & -9.38 & -9.44 & 0.028 \\
\hline 24 & -9.13 & -6.73 & -7.49 & -6.10 & -7.36 & & -6.61 & -7.24 & -7.87 & -7.36 & -7.27 & & -7.11 & -6.36 & -7.74 & -7.36 & -7.14 & \\
\hline 25 & -6.36 & -8.37 & -8.88 & -7.62 & -7.81 & & -7.87 & -8.62 & -9.51 & -9.00 & -8.75 & & -8.62 & -7.99 & -9.38 & -9.13 & -8.78 & \\
\hline 26 & -5.98 & -9.51 & -10.01 & -8.88 & -8.59 & & -9.13 & -9.88 & -10.64 & -10.26 & -9.98 & & -10.01 & -9.38 & -10.39 & -10.26 & -10.01 & \\
\hline 27 & -9.88 & -11.02 & -11.40 & -9.88 & -10.55 & & -10.39 & -11.14 & -11.77 & -11.40 & -11.18 & & -11.02 & -10.39 & -11.14 & -11.40 & -10.99 & \\
\hline 28 & -10.39 & -11.14 & -11.90 & -10.39 & -10.96 & 0.024 & -10.89 & -11.65 & -12.28 & -11.65 & -11.62 & 0.024 & -11.40 & -11.14 & -11.90 & -11.90 & -11.59 & 0.024 \\
\hline 29 & -9.00 & -9.88 & -11.65 & -9.38 & -9.98 & 0.027 & -9.88 & -9.88 & -11.65 & -11.27 & -10.67 & 0.028 & -10.39 & -9.88 & -11.27 & -10.51 & -10.51 & 0.028 \\
\hline 30 & -6.36 & -7.11 & -7.99 & -6.23 & -6.92 & 0.027 & -6.48 & -7.49 & -9.13 & -7.87 & -7.74 & 0.028 & -7.36 & -6.73 & -7.99 & -7.62 & -7.43 & 0.028 \\
\hline 31 & -6.10 & -6.73 & -7.24 & -5.98 & -6.51 & & -6.36 & -7.24 & -7.87 & -7.24 & -7.18 & & -6.99 & -6.23 & -7.36 & -7.49 & -7.02 & \\
\hline 32 & -8.25 & -8.25 & -9.00 & & -8.50 & & -8.25 & -9.00 & -9.63 & -9.00 & -8.97 & & -8.75 & -7.99 & -9.13 & -9.13 & -8.75 & \\
\hline 33 & -9.25 & -9.63 & -10.26 & & -9.72 & & -9.63 & -10.14 & -10.77 & -10.01 & -10.14 & & -9.63 & -9.00 & -10.39 & -10.39 & -9.85 & \\
\hline 34 & -10.64 & -10.89 & -11.65 & -10.01 & -10.80 & & -10.89 & -11.52 & -12.15 & -11.14 & -11.43 & & -11.27 & -10.64 & -11.27 & -11.65 & -11.21 & \\
\hline 35 & -11.27 & -12.03 & -12.78 & -11.14 & -11.81 & & -11.90 & -12.66 & -12.91 & -12.15 & -12.40 & & -12.15 & -11.52 & -11.90 & -12.53 & -12.03 & \\
\hline 36 & -12.53 & -13.03 & -13.92 & -12.40 & -12.97 & & -12.78 & -13.54 & -14.17 & -13.54 & -13.51 & & -13.41 & -12.66 & -12.91 & -13.54 & -13.13 & \\
\hline 37 & -13.79 & -14.42 & -15.43 & -13.66 & -14.33 & & -14.29 & -15.43 & -15.68 & -14.92 & -15.08 & & -14.67 & -14.04 & -13.92 & -14.92 & -14.39 & \\
\hline 38 & -15.05 & -15.81 & -17.19 & -15.68 & -15.93 & & -15.68 & -17.07 & -17.07 & -16.69 & -16.63 & & -15.93 & -15.43 & -15.05 & -16.44 & -15.71 & \\
\hline 39 & -16.94 & -17.95 & -19.46 & -17.95 & -18.07 & & -15.81 & -19.96 & -19.21 & -19.33 & -18.58 & & -17.95 & -17.57 & -16.31 & -18.33 & -17.54 & \\
\hline 40 & -19.59 & -7.62 & -22.61 & -21.35 & -17.79 & & -19.96 & -23.74 & -21.85 & -22.61 & -22.04 & & -20.34 & -20.09 & -18.20 & -20.72 & -19.84 & \\
\hline 41 & -22.48 & -22.48 & -26.14 & -26.26 & -24.34 & & -22.99 & -28.03 & -37.23 & -27.15 & -28.85 & & -23.24 & -22.86 & -20.09 & -23.74 & -22.48 & \\
\hline 42 & -26.64 & -25.51 & -30.67 & -35.59 & -29.60 & & -27.40 & -35.71 & -28.66 & -33.70 & -31.37 & & -28.15 & -27.02 & -22.48 & -29.41 & -26.77 & \\
\hline 43 & -29.04 & -28.41 & -33.45 & -38.61 & -32.38 & 0.020 & -28.78 & -39.62 & -32.56 & -36.22 & -34.30 & 0.021 & -29.67 & -26.64 & -24.75 & -30.80 & -27.97 & 0.036 \\
\hline 44 & -31.93 & -30.17 & -38.74 & -45.29 & -36.53 & 0.014 & -29.67 & 43.78 & -36.22 & -39.24 & -37.23 & 0.014 & -28.78 & -28.03 & -19.46 & -27.40 & -25.92 & 0.028 \\
\hline 45 & -32.69 & -25.51 & 43.53 & -48.57 & -37.57 & & -33.07 & 40.88 & -38.74 & -43.15 & -38.96 & & -10.64 & -12.03 & -12.91 & -10.77 & -11.59 & \\
\hline 46 & -35.71 & -26.52 & 47.56 & -54.36 & -41.04 & & -34.96 & 47.94 & -42.39 & -46.30 & -42.90 & & -11.02 & -15.68 & -15.30 & -12.78 & -13.70 & \\
\hline 47 & -38.99 & -30.30 & -55.75 & -64.32 & -47.34 & & -37.48 & -55.12 & 47.31 & -53.86 & -48.44 & & -15.05 & -19.21 & -18.07 & -14.67 & -16.75 & \\
\hline 48 & -45.16 & -34.83 & -65.20 & -70.24 & -53.86 & & 42.77 & -63.81 & -54.61 & -61.54 & -55.69 & & -18.58 & -24.25 & -20.97 & -17.57 & -20.34 & \\
\hline 49 & -54.11 & -42.27 & -71.75 & -74.27 & -60.60 & & -50.71 & -71.12 & -63.94 & -68.60 & -63.59 & & -22.74 & -28.78 & -25.13 & -21.10 & -24.44 & \\
\hline 50 & -64.19 & -52.85 & -73.39 & -77.17 & -66.90 & 0.014 & -61.04 & -73.64 & -71.25 & -72.13 & -69.51 & 0.014 & -29.16 & -35.21 & -30.42 & -27.40 & -30.55 & 0.028 \\
\hline 51 & -71.12 & -64.32 & -74.77 & -79.69 & -72.47 & & -70.11 & -76.41 & -74.52 & -74.14 & -73.80 & & -23.11 & 40.50 & -25.63 & -29.92 & -29.79 & \\
\hline 52 & -74.90 & -71.75 & -77.42 & -81.20 & -76.32 & & -74.02 & -78.55 & -74.90 & -76.16 & -75.91 & & -24.12 & -44.03 & -29.54 & -30.55 & -32.06 & \\
\hline 53 & -78.68 & -74.65 & -79.18 & & -77.50 & & -78.43 & -81.20 & -77.04 & -78.43 & -78.77 & & -35.46 & -51.97 & -38.74 & -36.72 & -40.72 & \\
\hline 54 & -81.20 & -77.42 & -81.20 & & -79.94 & 0.014 & -81.20 & -81.20 & -81.20 & -81.20 & -81.20 & 0.014 & -45.29 & -61.04 & -50.83 & -47.18 & -51.09 & 0.028 \\
\hline 55 & -81.20 & -79.94 & & & & & & & & -81.20 & & & -45.04 & -69.86 & -66.84 & -49.20 & -57.73 & \\
\hline 56 & & -76.66 & & & & & & -77.80 & -78.05 & & & & -48.44 & -70.87 & -66.21 & -54.74 & -60.06 & \\
\hline 57 & & -78.30 & -77.80 & -77.80 & -77.97 & 0.014 & -78.43 & -75.53 & -77.04 & -77.04 & -77.01 & 0.014 & -57.51 & -75.28 & -73.26 & -64.19 & -67.56 & 0.028 \\
\hline 58 & -77.80 & -78.18 & -77.67 & -80.32 & -78.49 & & -78.55 & -75.66 & -78.55 & -76.92 & -77.42 & & -33.32 & -76.79 & -74.52 & -66.71 & -62.84 & \\
\hline 59 & -76.66 & & -76.92 & -77.29 & -76.96 & & -77.67 & -75.28 & -76.92 & -76.29 & -76.54 & & -27.78 & -74.65 & -73.14 & -66.33 & -60.47 & \\
\hline 60 & -77.42 & & -77.80 & -78.05 & -77.76 & & -78.68 & -77.92 & -78.43 & -78.81 & -78.46 & & -34.33 & -75.53 & -74.65 & -68.35 & -63.21 & \\
\hline 61 & -78.18 & -78.55 & -78.05 & -78.68 & -78.37 & 0.014 & -77.67 & -78.55 & -78.18 & -78.68 & -78.27 & 0.014 & -43.40 & -74.90 & -74.02 & -69.61 & -65.48 & 0.028 \\
\hline 62 & -79.94 & -64.82 & -77.42 & -77.67 & -74.96 & & & -77.42 & -63.56 & -77.92 & -72.97 & & -13.41 & -79.31 & -71.50 & -53.48 & -54.43 & \\
\hline 63 & -71.12 & -70.49 & -77.80 & -79.69 & -74.77 & & & -77.42 & -68.60 & -78.05 & -74.69 & & -13.79 & -79.31 & -50.08 & -40.25 & -45.86 & \\
\hline 64 & -74.90 & -72.38 & -77.42 & -76.79 & -75.37 & & -71.12 & -77.42 & -70.49 & -77.42 & -74.11 & & -17.32 & -79.31 & -53.61 & -44.16 & -48.60 & \\
\hline 65 & -77.17 & -77.42 & -77.67 & -77.29 & -77.39 & 0.014 & -77.80 & -77.92 & -77.92 & -75.15 & -77.20 & 0.014 & -28.28 & -77.55 & -70.99 & -54.61 & -57.86 & 0.028 \\
\hline 66 & -79.06 & -78.18 & -79.06 & -78.81 & -78.77 & & -77.42 & -79.06 & -79.56 & -77.42 & -78.37 & & -10.89 & -78.68 & -33.95 & -13.54 & -34.27 & \\
\hline 67 & -77.55 & -76.79 & -77.67 & -77.29 & -77.33 & & -77.04 & -77.67 & -77.29 & -76.79 & -77.20 & & -15.05 & -78.18 & -24.63 & -17.57 & -33.86 & \\
\hline 68 & -78.43 & -77.42 & -78.43 & & -78.09 & & -77.80 & -77.92 & -77.80 & -77.55 & -77.77 & & -20.09 & -78.68 & -32.82 & -23.87 & -38.86 & \\
\hline 69 & & -78.30 & -78.18 & & & & -78.55 & -78.68 & -78.05 & -77.42 & -78.18 & & -25.13 & -78.68 & -53.73 & -30.80 & -47.09 & \\
\hline 70 & & -78.43 & & & & & -78.68 & -78.81 & -77.80 & -78.68 & -78.49 & & -33.82 & -78.55 & -61.04 & -40.25 & -53.42 & \\
\hline 71 & & -78.30 & & & & 0.014 & & -78.68 & -77.42 & & & 0.014 & -35.08 & -77.17 & -66.08 & -19.46 & -49.45 & 0.028 \\
\hline$n$ & & -76.16 & & & & & & -78.05 & & & & & -28.28 & -78.30 & -59.78 & -19.46 & 46.46 & \\
\hline 73 & & & & & & & & -78.30 & & & & & -40.25 & -79.06 & -67.97 & -31.43 & -54.68 & \\
\hline 74 & & & & & & 0.020 & & -78.05 & & & & 0.041 & -50.96 & -76.79 & -70.49 & -37.10 & -58.84 & 0.041 \\
\hline 75 & & & -78.05 & -45.29 & & & -28.66 & -76.16 & -21.48 & 40.88 & 41.79 & & -7.62 & -77.17 & -16.18 & -9.51 & -27.62 & \\
\hline
\end{tabular}

(continua) 
Profundidade $0,40 \mathrm{~m}$ (continuação).

\begin{tabular}{|c|c|c|c|c|c|c|c|c|c|c|c|c|c|c|c|c|c|c|}
\hline \multirow[b]{2}{*}{ DAS } & \multicolumn{6}{|c|}{ trat -000} & \multicolumn{6}{|c|}{ trat $0 \mathrm{IO}$} & \multicolumn{6}{|c|}{ trat III } \\
\hline & r1 & 12 & r3 & $\mathrm{r} 4$ & média & $\mathrm{P}+\mathrm{I}$ & $\mathrm{rl}$ & 2 & r3 & $\mathrm{r} 4$ & média & $\mathrm{P}+\mathrm{I}$ & rl & 12 & r3 & $\mathrm{r} 4$ & média & $\mathrm{P}+\mathrm{I}$ \\
\hline 76 & & & & & & & 49.70 & -52.22 & -27.78 & -48.06 & -44.44 & & -12.53 & -77.42 & -21.35 & -12.91 & -31.05 & \\
\hline 77 & & & & & & & -70.49 & -62.93 & -38.74 & -59.65 & -57.95 & & -16.31 & -76.79 & -30.30 & -16.69 & -35.02 & \\
\hline 78 & & & & -34.45 & & 0.020 & -7.99 & -11.65 & -9.63 & -22.36 & -12.91 & 0.041 & -5.47 & -78.05 & -10.01 & -6.99 & -25.13 & 0.041 \\
\hline 79 & & & & & & & -12.78 & -14.04 & -13.16 & -31.43 & -17.85 & & -9.13 & -75.40 & -13.16 & -9.76 & -26.86 & \\
\hline 80 & & & & & & & -16.31 & -17.19 & -16.06 & -40.00 & -22.39 & & -10.89 & -43.53 & -16.94 & -11.52 & -20.72 & \\
\hline 81 & & & -77.29 & & & & -19.21 & -19.21 & -18.20 & -46.93 & -25.89 & & -12.15 & -39.37 & -20.09 & -13.03 & -21.16 & \\
\hline 82 & & & & & & & -27.02 & -24.12 & -22.23 & -54.74 & -32.03 & & -14.04 & 47.81 & -24.37 & -14.67 & -25.22 & \\
\hline 83 & & & & & & & -44.16 & -33.95 & -28.78 & -62.93 & -42.46 & & -17.57 & -63.06 & -32.06 & -17.44 & -32.53 & \\
\hline 84 & & & & & & & -65.45 & -46.55 & -35.84 & -67.21 & -53.76 & & -21.73 & -71.12 & -42.64 & -20.72 & -39.05 & \\
\hline 85 & & & & & & 0.014 & -71.12 & -56.76 & -16.44 & -76.16 & -55.12 & 0.028 & -26.01 & -72.00 & -52.09 & -23.87 & -43.49 & 0.028 \\
\hline 86 & & & & & & & -7.99 & -11.90 & -9.76 & -77.17 & -26.71 & & -6.10 & -76.66 & -58.90 & -6.61 & -37.07 & \\
\hline 87 & & & & & & & -10.77 & -12.40 & -12.03 & -74.65 & -27.46 & & -9.38 & -21.85 & 44.16 & -9.63 & -21.26 & \\
\hline 88 & & & & & & 0.047 & -5.47 & -6.48 & -6.99 & -7.99 & -6.73 & 0.047 & -5.98 & -3.84 & -7.11 & -6.61 & -5.88 & 0.047 \\
\hline 89 & -8.37 & -10.14 & -17.95 & -8.75 & -11.30 & & -8.75 & -4.97 & -9.38 & -12.15 & -8.81 & & -4.97 & -8.75 & -10.26 & -9.00 & -8.25 & \\
\hline 90 & -6.23 & -7.49 & -13.16 & -11.02 & -9.47 & 0.019 & -6.23 & -5.35 & -7.62 & -7.36 & -6.64 & 0.019 & -5.22 & -6.36 & -7.62 & -7.62 & -6.70 & 0.019 \\
\hline 91 & -5.35 & -6.61 & -8.62 & -8.62 & -7.30 & 0.017 & -6.61 & -5.47 & -7.87 & -7.99 & -6.99 & 0.017 & 4.97 & -6.61 & -7.74 & -7.49 & -6.70 & 0.017 \\
\hline 92 & -3.71 & -5.35 & -5.98 & -3.08 & -4.53 & 0.045 & -4.97 & -5.73 & -6.10 & -5.35 & -5.54 & 0.045 & -5.22 & -4.09 & -5.60 & -5.85 & -5.19 & 0.045 \\
\hline 93 & -6.61 & -6.10 & -7.11 & -6.10 & -6.48 & & -7.99 & -8.37 & -9.00 & -9.00 & -8.59 & & -5.22 & -7.36 & -8.50 & -8.62 & -7.43 & \\
\hline 94 & -9.13 & -9.00 & -9.51 & -8.37 & -9.00 & & -10.51 & -10.39 & -10.89 & -11.52 & -10.83 & & -7.49 & -9.76 & -10.39 & -10.64 & -9.57 & \\
\hline 95 & -12.03 & -11.77 & -12.28 & -9.63 & -11.43 & & -14.04 & -12.78 & -12.66 & -14.80 & -13.57 & & -11.52 & -12.53 & -12.53 & -12.66 & -12.31 & \\
\hline 96 & -16.56 & -14.92 & -14.55 & -13.03 & -14.77 & & -15.18 & -15.30 & -14.17 & -18.58 & -15.81 & & -12.91 & -14.67 & -13.92 & -14.17 & -13.92 & \\
\hline 97 & -21.98 & -18.83 & -17.57 & -16.31 & -18.67 & & -19.71 & -16.31 & -16.44 & -30.17 & -20.66 & & -20.09 & -18.83 & -16.81 & -16.81 & -18.14 & \\
\hline 98 & -32.82 & -24.37 & -21.35 & -20.72 & -24.82 & & -26.39 & -19.71 & -18.83 & -31.43 & -24.09 & & -26.14 & -24.00 & -20.47 & -20.34 & -22.74 & \\
\hline 99 & 45.92 & -30.80 & -25.51 & -25.38 & -31.90 & & -36.85 & -24.50 & -21.98 & -42.77 & -31.52 & & -35.84 & -31.68 & -25.76 & -25.13 & -29.60 & \\
\hline 100 & -55.75 & -37.23 & -30.17 & -31.30 & -38.61 & 0.023 & -47.31 & -29.16 & -27.15 & -59.65 & -40.82 & 0.044 & -51.59 & -28.28 & -34.45 & -31.68 & -36.50 & 0.044 \\
\hline 101 & -45.67 & -38.61 & -20.97 & -31.81 & -34.27 & & -9.38 & -9.88 & -9.13 & -17.32 & -11.43 & & -9.38 & -11.90 & -10.14 & -10.51 & -10.48 & \\
\hline 102 & -63.31 & -39.62 & -24.75 & -38.11 & 41.45 & & -13.16 & -12.53 & -11.65 & -25.76 & -15.77 & & -12.91 & -16.31 & -14.04 & -13.16 & -14.11 & \\
\hline 103 & -69.73 & 46.93 & -30.55 & 44.91 & 48.03 & & -18.58 & -15.68 & -13.79 & -36.47 & -21.13 & & -15.93 & -21.35 & -17.82 & -16.69 & -17.95 & \\
\hline 104 & -70.49 & -50.20 & -34.83 & 48.69 & -51.05 & & -23.24 & -18.20 & -16.31 & -51.97 & -27.43 & & -19.59 & -29.79 & -22.48 & -19.84 & -22.93 & \\
\hline 105 & -72.63 & -57.13 & -40.75 & -55.50 & -56.50 & & -29.92 & -21.73 & -18.58 & -62.93 & -33.29 & & -23.62 & -37.48 & -27.78 & -24.50 & -28.34 & \\
\hline 106 & -76.54 & -66.08 & 44.16 & -61.42 & -62.05 & 0.020 & -9.25 & -8.75 & -7.36 & -76.79 & -25.54 & 0.041 & -9.76 & -20.59 & -10.26 & -8.25 & -12.22 & 0.041 \\
\hline 107 & -79.06 & -69.10 & -46.30 & -66.08 & -65.14 & 0.031 & -9.13 & -9.00 & -8.75 & -18.20 & -11.27 & 0.031 & -9.88 & -13.29 & -10.14 & -8.88 & -10.55 & 0.031 \\
\hline 108 & -77.29 & -14.55 & -14.42 & -18.45 & -31.18 & & -5.98 & -6.86 & -7.62 & -8.50 & -7.24 & & -6.48 & -6.48 & -7.24 & -7.11 & -6.83 & \\
\hline 109 & -5.73 & 4.09 & 4.72 & -2.32 & -4.21 & 0.038 & -3.08 & -3.84 & -4.09 & -3.71 & -3.68 & 0.038 & -3.84 & -2.58 & -3.96 & -4.21 & -3.65 & 0.038 \\
\hline 110 & -7.99 & -7.87 & -8.25 & -6.86 & -7.74 & & -7.49 & -8.12 & -8.62 & -8.50 & -8.18 & & -8.12 & -7.24 & -8.25 & -8.25 & -7.96 & \\
\hline 111 & -10.77 & -10.14 & -10.26 & -6.48 & -9.41 & & -9.00 & -10.01 & -10.39 & -10.64 & -10.01 & & -6.23 & -9.63 & -9.88 & -10.01 & -8.94 & \\
\hline 112 & -12.91 & -11.90 & -11.90 & -10.01 & -11.68 & & -11.40 & -11.52 & -11.90 & -12.53 & -11.84 & & -10.26 & -10.89 & -11.27 & -11.52 & -10.99 & \\
\hline 113 & 4.72 & -4.97 & -5.47 & -6.23 & -5.35 & 0.055 & 4.84 & -5.60 & -6.10 & -5.35 & -5.47 & 0.055 & -7.11 & -4.09 & -5.60 & -5.85 & -5.66 & 0.055 \\
\hline 114 & -8.12 & -8.12 & -8.50 & -6.86 & -7.90 & & -8.12 & -7.24 & -9.25 & -8.88 & -8.37 & & -7.49 & -7.62 & -8.50 & -8.75 & -8.09 & \\
\hline 115 & -10.14 & -10.14 & -10.14 & -9.38 & -9.95 & & -10.14 & -10.14 & -10.64 & -11.14 & -10.51 & & -10.51 & -9.88 & -10.14 & -10.64 & -10.29 & \\
\hline 116 & -12.03 & -12.15 & -11.77 & -11.14 & -11.77 & & -12.28 & -11.90 & -12.40 & -13.16 & -12.44 & & -12.28 & -11.90 & -11.65 & -12.28 & -12.03 & \\
\hline 117 & -14.80 & -15.18 & -13.66 & -13.29 & -14.23 & & -14.55 & -13.66 & -14.04 & -15.68 & -14.48 & & -13.79 & -13.54 & -13.29 & -14.17 & -13.70 & \\
\hline 118 & -17.32 & -16.31 & -15.05 & -15.05 & -15.93 & & -16.56 & -15.05 & -15.43 & -17.82 & -16.22 & & -15.18 & -15.30 & -14.67 & -15.68 & -15.21 & \\
\hline 119 & -33.70 & -18.58 & -16.44 & -17.32 & -21.51 & & -19.08 & -16.56 & -16.81 & -20.59 & -18.26 & & -16.81 & -17.07 & -15.93 & -18.58 & -17.10 & \\
\hline 120 & -26.39 & -21.35 & -19.84 & -19.08 & -21.67 & & -21.98 & -18.45 & -18.58 & -25.00 & -21.00 & & -19.08 & -19.71 & -17.95 & -19.46 & $-19,05$ & \\
\hline 121 & -29.79 & -24.25 & -19.84 & -21.48 & -23.84 & 0.006 & -24.75 & -20.09 & -19.84 & -27.78 & -23.11 & 0.006 & -20.09 & -21.48 & -19.71 & -21.60 & -20.72 & 0.006 \\
\hline 122 & -33.70 & -26.52 & -20.97 & -23.24 & -26.11 & & -26.64 & -21.60 & -20.72 & -30.93 & -24.97 & & -21.48 & -22.61 & -20.72 & -22.99 & -21.95 & \\
\hline 123 & -8.25 & -10.39 & -9.38 & -9.13 & -9.29 & 0.035 & -12.78 & -9.13 & -8.50 & -9.13 & -9.88 & 0.035 & -6.86 & -8.50 & -10.01 & -11.65 & -9.25 & 0.035 \\
\hline 124 & -10.14 & -10.64 & -9.63 & -10.26 & -10.17 & & -8.75 & -9.76 & -10.14 & -12.53 & -10.29 & & -9.51 & -10.14 & -10.14 & -10.89 & -10.17 & \\
\hline 125 & -12.03 & -13.29 & -11.40 & -12.91 & -12.40 & & -10.26 & -11.65 & -11.77 & -15.93 & -12.40 & & -10.77 & -12.28 & -12.28 & -12.66 & -11.99 & \\
\hline 126 & -16.18 & -16.06 & -13.29 & -15.43 & -15.24 & & -13.92 & -13.79 & -13.29 & -19.59 & -15.14 & & -12.40 & -15.05 & -14.42 & -14.92 & -14.20 & \\
\hline 127 & -18.70 & -18.33 & -14.42 & -17.44 & -17.22 & & -15.55 & -14.42 & -14.55 & -23.49 & -17.00 & & -13.03 & -16.31 & -15.68 & -16.31 & -15.33 & \\
\hline 128 & -24.88 & -22.61 & -16.44 & -20.97 & -21.22 & & -18.83 & -16.69 & -16.69 & -30.93 & -20.78 & & -14.80 & -19.33 & -18.20 & -19.46 & -17.95 & \\
\hline 129 & & & & & & 0.008 & & & & & & 0.008 & & & & & & 0.008 \\
\hline 130 & -34.33 & -29.54 & -19.21 & -26.52 & -27.40 & 0.007 & -23.24 & -20.47 & -20.09 & -42.14 & -26.48 & 0.007 & -17.32 & -22.36 & -21.35 & -23.74 & -21.19 & 0.007 \\
\hline 131 & -36.09 & -31.43 & -18.83 & -26.89 & -28.31 & 0.021 & -23.37 & -18.70 & -20.59 & -45.04 & -26.93 & 0.021 & -17.82 & -22.61 & -21.48 & -23.74 & -21.41 & 0.021 \\
\hline 132 & -15.68 & -17.95 & -9.25 & -14.04 & -14.23 & & -10.14 & -10.64 & -11.14 & -15.55 & -11.87 & & -9.38 & -9.25 & -11.27 & -16.94 & -11.71 & \\
\hline 133 & -13.79 & -15.05 & -10.14 & -13.54 & -13.13 & & -10.64 & -11.27 & -12.91 & -17.82 & -13.16 & & -10.01 & -11.02 & -11.77 & -12.40 & -11.30 & \\
\hline 134 & -14.55 & -16.18 & -11.40 & -15.05 & -14.29 & 0.015 & -11.52 & -12.53 & -12.91 & -20.09 & -14.26 & 0.015 & -11.02 & -12.03 & -12.91 & -12.78 & -12.18 & 0.015 \\
\hline 135 & -10.14 & -12.53 & -9.38 & -10.39 & -10.61 & & -8.50 & -10.01 & -10.77 & -12.91 & -10.55 & & -9.00 & -8.75 & -10.39 & -10.77 & -9.73 & \\
\hline 136 & -10.77 & -12.66 & -10.14 & -11.52 & -11.27 & & -9.51 & -10.89 & -11.40 & -14.80 & -11.65 & & -9.51 & -9.76 & -11.02 & -10.77 & -10.26 & \\
\hline 137 & -11.90 & -14.29 & -11.40 & -13.16 & -12.69 & & -10.39 & -12.40 & -12.40 & -16.81 & -13.00 & & -10.51 & -11.14 & -12.28 & -11.90 & -11.46 & \\
\hline 138 & -13.66 & -15.93 & -12.66 & -14.67 & -14.23 & & -12.15 & -13.66 & -13.54 & -18.45 & -14.45 & & -11.65 & -12.28 & -13.29 & -12.78 & -12.50 & \\
\hline 139 & & & & & & 0.008 & & & & & & 0.008 & & & & & & 0.008 \\
\hline 141 & & & & & & 0.020 & & & & & & 0.020 & & & & & & 0.020 \\
\hline 142 & & & & & & 0.023 & & & & & & 0.025 & & & & & & 0.025 \\
\hline 143 & & & & & & 0.015 & & & & & & 0.015 & & & & & & 0.015 \\
\hline 146 & & & & & & 0.043 & & & & & & 0.043 & & & & & & 0.043 \\
\hline 147 & & & & & & 0.070 & & & & & & 0.070 & & & & & & 0.070 \\
\hline
\end{tabular}


Profundidade $0,50 \mathrm{~m}$.

\begin{tabular}{|c|c|c|c|c|c|c|c|c|c|c|c|c|c|c|c|c|c|c|}
\hline \multirow[b]{2}{*}{ DAS } & \multicolumn{6}{|c|}{ trat -000} & \multicolumn{6}{|c|}{ trat $0 \mathrm{IO}$} & \multicolumn{6}{|c|}{ trat III } \\
\hline & rl & 2 & $\mathrm{r} 3$ & $\mathrm{r} 4$ & média & $\mathrm{P}+\mathrm{I}$ & $\mathrm{Il}$ & 12 & r3 & $\mathrm{r} 4$ & média & $\mathrm{P}+\mathrm{I}$ & $\mathrm{rl}$ & 12 & $\mathrm{r} 3$ & $\mathrm{r} 4$ & média & $\mathrm{P}+\mathrm{I}$ \\
\hline 0 & & & & & & 0.020 & & & & & & 0.021 & & & & & & 0.021 \\
\hline 1 & & & & & & 0.014 & & & & & & 0.014 & & & & & & 0.014 \\
\hline 2 & & & & & & 0.027 & & & & & & 0.028 & & & & & & 0.028 \\
\hline 4 & & & & & & 0.027 & & & & & & 0.028 & & & & & & 0.028 \\
\hline 5 & & & & & & 0.020 & & & & & & 0.021 & & & & & & 0.021 \\
\hline 7 & & & & & & 0.027 & & & & & & 0.028 & & & & & & 0.028 \\
\hline 8 & & & & & & 0.020 & & & & & & 0.021 & & & & & & 0.021 \\
\hline 9 & & & & & & 0.020 & & & & & & 0.021 & & & & & & 0.021 \\
\hline 13 & & & & & & 0.027 & & & & & & 0.028 & & & & & & 0.028 \\
\hline 16 & & & & & & 0.020 & & & & & & 0.021 & & & & & & 0.021 \\
\hline 17 & -7.62 & -9.64 & -9.39 & -8.63 & -8.82 & & -8.76 & -9.26 & -10.27 & -10.52 & -9.70 & & -9.14 & -8.25 & -9.39 & -10.27 & -9.26 & \\
\hline 18 & -9.51 & -10.14 & -10.27 & -9.26 & -9.80 & 0.014 & -9.77 & -10.14 & -10.14 & -10.02 & -10.02 & 0.014 & -9.89 & -9.26 & -10.14 & -10.90 & -10.05 & 0.014 \\
\hline 19 & -8.51 & -9.77 & -10.14 & -8.63 & -9.26 & & -8.88 & -9.64 & -10.52 & -10.14 & -9.80 & & -9.39 & -8.63 & -9.39 & -10.40 & -9.45 & \\
\hline 20 & -9.26 & -10.14 & -10.52 & -9.26 & -9.80 & 0.019 & -9.64 & -10.27 & -11.28 & -10.52 & -10.43 & 0.020 & -10.14 & -9.39 & -10.02 & -10.90 & -10.11 & 0.020 \\
\hline 21 & -9.51 & -8.25 & -9.01 & -6.74 & -8.38 & 0.011 & -6.99 & -7.88 & -8.76 & -8.63 & -8.07 & 0.011 & -7.50 & -7.37 & -10.40 & -8.51 & -8.44 & 0.011 \\
\hline 22 & -8.51 & -8.00 & -8.38 & -6.62 & -7.88 & & -7.25 & -7.88 & -8.51 & -8.13 & -7.94 & & -7.25 & -7.12 & -9.77 & -8.13 & -8.07 & \\
\hline 23 & -9.14 & -9.01 & -9.39 & -7.75 & -8.82 & 0.027 & -8.38 & -9.14 & -9.64 & -9.01 & -9.04 & 0.028 & -8.63 & -8.25 & -10.14 & -9.39 & -9.10 & 0.028 \\
\hline 24 & -9.14 & -6.74 & -7.12 & -5.99 & -7.25 & & -6.74 & -7.12 & -7.62 & -6.99 & -7.12 & & -6.49 & -5.99 & -7.37 & -7.62 & -6.87 & \\
\hline 25 & -6.36 & -8.25 & -8.51 & -7.25 & -7.59 & & -7.88 & -8.25 & -8.25 & -8.51 & -8.22 & & -8.13 & -7.50 & -8.88 & -8.88 & -8.35 & \\
\hline 26 & -7.88 & -9.39 & -9.51 & -8.51 & -8.82 & & -8.88 & -9.51 & -9.39 & -9.64 & -9.36 & & -9.26 & -8.76 & -9.51 & -10.02 & -9.39 & \\
\hline 27 & -9.89 & -10.65 & -10.90 & -9.39 & -10.21 & & -10.02 & -11.03 & -11.28 & -10.90 & -10.81 & & -10.52 & -9.77 & -10.27 & -11.15 & -10.43 & \\
\hline 28 & -10.52 & -11.15 & -11.40 & -10.02 & -10.77 & 0.024 & -10.52 & -11.28 & -11.03 & -11.28 & -11.03 & 0.024 & -10.77 & -10.52 & -10.90 & -11.66 & -10.96 & 0.024 \\
\hline 29 & -9.77 & -10.27 & -11.28 & -9.51 & -10.21 & 0.027 & -10.14 & -10.02 & -11.28 & -11.15 & -10.65 & 0.028 & -10.02 & -9.51 & -10.77 & -10.90 & -10.30 & 0.028 \\
\hline 30 & -6.62 & -6.99 & -7.88 & -6.36 & -6.96 & 0.027 & -6.74 & -7.37 & -9.01 & -7.88 & -7.75 & 0.028 & -6.74 & -6.36 & -7.62 & -7.75 & -7.12 & 0.028 \\
\hline 31 & -6.49 & -6.36 & -6.87 & -5.73 & -6.36 & & -6.36 & -6.87 & -7.50 & -6.99 & -6.93 & & -6.49 & -5.73 & -6.87 & -7.37 & -6.62 & \\
\hline 32 & -8.13 & -8.38 & -8.63 & & -8.38 & & -8.00 & -8.63 & -8.88 & -8.38 & -8.47 & & -8.13 & -7.25 & -8.38 & -8.88 & -8.16 & \\
\hline 33 & -9.14 & -8.88 & -9.77 & & -9.26 & & -9.01 & -9.89 & -9.14 & -9.64 & -9.42 & & -8.88 & -8.51 & -9.39 & -10.14 & -9.23 & \\
\hline 34 & -10.14 & -10.65 & -11.03 & -8.88 & -10.18 & & -10.14 & -11.15 & -10.40 & -10.65 & -10.59 & & -10.40 & -9.77 & -10.27 & -11.28 & -10.43 & \\
\hline 35 & -10.77 & -11.40 & -12.03 & -9.14 & -10.84 & & -10.90 & -12.03 & -11.78 & -11.53 & -11.56 & & -11.28 & -10.65 & -10.77 & -12.03 & -11.18 & \\
\hline 36 & -11.78 & -12.54 & -13.17 & -11.40 & -12.22 & & -11.78 & -13.17 & -12.92 & -12.66 & -12.63 & & -12.29 & -11.66 & -11.66 & -12.92 & -12.13 & \\
\hline 37 & -12.66 & -13.67 & -14.55 & -12.54 & -13.36 & & -12.79 & -14.05 & -13.92 & -13.55 & -13.58 & & -13.42 & -12.79 & -12.41 & -14.05 & -13.17 & \\
\hline 38 & -13.42 & -14.55 & -16.07 & -13.92 & -14.49 & & -13.42 & -15.44 & -16.44 & -14.81 & -15.03 & & -8.13 & -14.18 & -13.29 & -15.18 & -12.70 & \\
\hline 39 & -14.55 & -16.07 & -18.33 & -15.06 & -16.00 & & -14.68 & -16.57 & -18.21 & -16.19 & -16.41 & & -15.94 & -15.94 & -14.05 & -16.82 & -15.69 & \\
\hline 40 & -15.81 & -17.83 & -21.61 & -17.07 & -18.08 & & -16.32 & -18.59 & -20.60 & -18.08 & -18.40 & & -18.08 & -18.21 & -15.31 & -18.71 & -17.58 & \\
\hline 41 & -16.70 & -19.09 & -26.02 & -19.72 & -20.38 & & -17.33 & -20.22 & -23.25 & -20.60 & -20.35 & & -20.60 & -21.36 & -16.95 & -20.60 & -19.88 & \\
\hline 42 & -18.33 & -21.11 & -18.96 & -23.12 & -20.38 & & -18.84 & -23.00 & -27.28 & -23.50 & -23.15 & & -23.12 & -25.26 & -18.84 & -23.63 & -22.71 & \\
\hline 43 & -19.59 & -23.00 & -33.83 & -24.38 & -25.20 & 0.020 & -20.22 & -25.52 & -29.55 & -28.16 & -25.86 & 0.021 & -23.75 & -26.52 & -19.85 & -23.75 & -23.47 & 0.036 \\
\hline 44 & -20.98 & -24.63 & -35.85 & -28.41 & -27.47 & 0.014 & -21.23 & -28.29 & -32.32 & -28.54 & -27.60 & 0.014 & -28.16 & -28.04 & -20.73 & -24.51 & -25.36 & 0.028 \\
\hline 45 & -23.25 & -25.64 & -36.48 & -29.80 & -28.79 & & -22.87 & -30.81 & -32.95 & -31.69 & -29.58 & & -10.52 & -14.68 & -13.17 & -12.16 & -12.63 & \\
\hline 46 & -24.38 & -26.40 & 44.54 & -36.35 & -32.92 & & -36.60 & -34.46 & -36.48 & -35.97 & -35.88 & & -12.54 & -16.19 & -14.81 & -12.16 & -13.92 & \\
\hline 47 & -25.01 & -27.91 & -52.10 & -42.90 & -36.98 & & -25.39 & -39.00 & -40.13 & -42.27 & -36.70 & & -12.79 & -18.84 & -16.57 & -14.30 & -15.63 & \\
\hline 48 & -29.04 & -30.68 & -61.30 & -51.85 & -43.22 & & -27.91 & -46.43 & -44.79 & -51.22 & -42.59 & & -15.31 & -22.62 & -18.71 & -15.94 & -18.15 & , \\
\hline 49 & -34.34 & -34.84 & -68.48 & -60.92 & 49.65 & & -31.56 & -57.52 & -51.85 & -60.67 & -50.40 & & -20.85 & -26.52 & -20.98 & -17.83 & -21.55 & \\
\hline 50 & -43.03 & 40.89 & -72.39 & -67.98 & -56.07 & 0.014 & -32.70 & -66.34 & -60.42 & -68.86 & -57.08 & 0.014 & -25.77 & -32.57 & -23.88 & -20.73 & -25.74 & 0.028 \\
\hline 51 & -53.36 & 48.07 & -73.90 & -72.64 & -61.99 & & -33.08 & -73.90 & -68.10 & -72.14 & -61.80 & & -28.41 & -36.98 & -21.61 & -22.74 & -27.44 & \\
\hline 52 & -65.08 & -56.26 & -75.16 & -73.40 & -67.47 & & -33.45 & -75.16 & -72.26 & -72.64 & -63.38 & & -27.28 & -40.89 & -23.25 & -23.88 & -28.82 & \\
\hline 53 & -71.38 & -66.84 & -76.55 & -76.17 & -72.73 & & -34.84 & -77.43 & -72.89 & -73.90 & -64.77 & & -31.44 & -47.82 & -26.65 & -26.78 & -33.17 & \\
\hline 54 & -77.68 & -71.38 & -79.95 & -78.94 & -76.99 & 0.014 & -36.73 & -79.82 & -76.42 & -78.94 & -67.98 & 0.014 & -37.36 & -56.01 & -31.69 & -31.69 & -39.19 & 0.028 \\
\hline 55 & -76.42 & -73.63 & & -78.94 & -76.34 & & -37.11 & & & -79.95 & & & 43.16 & -65.33 & -36.73 & -37.74 & 45.74 & \\
\hline 56 & & -74.15 & & -76.42 & & & -37.74 & -76.42 & -75.16 & -75.79 & -66.28 & & -44.67 & -68.36 & -41.14 & -42.90 & -49.27 & \\
\hline 57 & & -77.05 & -76.67 & -77.05 & -76.92 & 0.014 & -39.25 & -74.91 & -76.04 & & -63.40 & 0.014 & -51.22 & -74.03 & -51.35 & -52.48 & -57.27 & 0.028 \\
\hline 58 & & -77.18 & -76.42 & -77.05 & -76.88 & & -37.99 & -69.99 & -75.79 & -76.92 & -65.17 & & 49.96 & -74.15 & -56.51 & -58.78 & -59.85 & \\
\hline 59 & & & -74.91 & -75.66 & & & -37.99 & -74.91 & -74.28 & -75.92 & -65.77 & & -24.89 & -73.40 & -56.89 & -59.66 & -53.71 & \\
\hline 60 & & & -77.43 & -77.68 & & & & -75.79 & -76.17 & -77.05 & -76.34 & & -34.71 & -74.53 & -61.30 & -64.32 & -58.72 & \\
\hline 61 & -76.67 & -76.29 & -76.55 & -77.18 & -76.67 & 0.014 & -36.98 & -77.55 & -75.92 & -77.43 & -66.97 & 0.014 & -38.37 & -74.15 & -63.19 & -65.71 & -60.36 & 0.028 \\
\hline 62 & -76.42 & -82.72 & -76.17 & -76.17 & -77.87 & & & & -76.42 & -77.05 & -76.46 & & -17.70 & -73.90 & -68.61 & -70.12 & -57.58 & \\
\hline 63 & -76.55 & -77.05 & -75.16 & -75.79 & -76.14 & & & -76.80 & -78.06 & -77.05 & -77.30 & & -17.58 & -73.65 & -61.55 & -72.64 & -56.35 & \\
\hline 64 & -76.42 & -77.05 & -76.80 & -75.66 & -76.48 & & & -76.42 & -73.40 & -76.67 & -75.50 & & -17.83 & -73.40 & -54.12 & -71.00 & -54.09 & \\
\hline 65 & -75.41 & -75.03 & -75.29 & -76.55 & -75.57 & 0.014 & & -76.80 & -76.92 & -76.55 & -76.76 & 0.014 & -24.26 & -74.40 & -59.66 & -72.14 & -57.61 & 0.028 \\
\hline 66 & -78.56 & -77.81 & -76.92 & -77.81 & -77.77 & & & -77.68 & -78.06 & -77.93 & -77.89 & & -13.29 & -77.05 & -48.95 & -54.12 & -48.35 & \\
\hline 67 & -76.80 & -76.67 & -75.41 & -76.17 & -76.26 & & & -76.92 & -76.55 & -77.43 & -76.97 & & -14.43 & -76.55 & -27.15 & -29.17 & -36.82 & \\
\hline 68 & -78.18 & -77.05 & -75.92 & & & & & -76.67 & -76.17 & -77.30 & -76.71 & & -17.96 & -77.43 & -33.33 & -32.82 & -40.38 & \\
\hline 69 & & -77.18 & -76.04 & & & & & -77.68 & -76.17 & -77.18 & -77.01 & & -21.86 & -77.43 & -41.39 & -39.25 & -44.98 & \\
\hline 70 & & -77.55 & & & & & & -78.18 & -76.92 & & & & -27.78 & -77.81 & -53.74 & -49.08 & -52.10 & \\
\hline 71 & & -76.92 & & & & 0.014 & & -78.06 & -75.66 & & & 0.014 & -31.06 & -77.55 & -60.04 & -51.85 & -55.13 & 0.028 \\
\hline 72 & & -75.66 & & & & & & -77.68 & & & & & -30.18 & -77.30 & -67.60 & -54.24 & -57.33 & \\
\hline 73 & & & & & & & & -78.18 & & & & & -36.35 & -78.06 & -74.40 & -65.46 & -63.57 & \\
\hline 74 & & & & & & 0.020 & & -77.05 & & & & 0.041 & -43.66 & -75.66 & -72.64 & -58.15 & -62.53 & 0.041 \\
\hline 75 & -76.42 & & & -76.17 & & & & -73.02 & -61.30 & -60.67 & -65.00 & & -6.62 & -76.80 & -76.42 & -10.90 & -42.68 & \\
\hline
\end{tabular}

(continua). 
Profundidade $0,50 \mathrm{~m}$ (continuação).

\begin{tabular}{|c|c|c|c|c|c|c|c|c|c|c|c|c|c|c|c|c|c|c|}
\hline \multirow[b]{2}{*}{ DAS } & \multicolumn{6}{|c|}{ trat -000} & \multicolumn{6}{|c|}{ trat $0 \mathrm{IO}$} & \multicolumn{6}{|c|}{ trat III } \\
\hline & rl & 12 & 13 & $\mathrm{r}$ & média & $\mathrm{P}+\mathrm{I}$ & rl & 2 & r3 & $\mathrm{r} 4$ & média & $\mathrm{P}+\mathrm{I}$ & $\mathrm{r} 1$ & 12 & r3 & $\mathrm{r} 4$ & média & $\mathrm{P}+\mathrm{I}$ \\
\hline 76 & -76.42 & & & -76.17 & & & & -73.65 & -34.84 & -66.34 & -58.28 & & -11.03 & -77.30 & -41.52 & -13.80 & -35.91 & \\
\hline 77 & & & & -74.53 & & & & -73.27 & -43.41 & & & & -14.05 & -76.04 & -49.20 & -17.58 & -39.22 & \\
\hline 78 & -75.66 & & & -76.42 & & 0.020 & & -74.66 & -14.30 & & & 0.041 & 4.73 & -76.80 & -35.72 & -7.25 & -31.12 & 0.041 \\
\hline 79 & -75.54 & & & -76.80 & & & & -19.97 & -14.55 & & & & -8.88 & -67.47 & -17.33 & -9.51 & -25.80 & \\
\hline 80 & -75.41 & & & -76.92 & & & & -21.61 & -17.20 & & & & -8.76 & -45.05 & -19.97 & -11.53 & -21.33 & \\
\hline 81 & & & -77.30 & & & & & -23.37 & -19.59 & & & & -10.27 & -42.27 & -18.84 & -12.79 & -21.04 & \\
\hline 82 & & & & & & & & -31.69 & -22.74 & & & & -10.40 & -44.29 & -28.16 & -14.30 & -24.29 & \\
\hline 83 & & & & & & & & -45.68 & -27.53 & & & & -15.31 & -53.74 & -36.73 & -16.57 & -30.59 & \\
\hline 84 & & & & & & & -56.51 & -59.41 & -33.33 & & 49.75 & & -18.21 & -63.57 & 49.08 & -19.09 & -37.49 & \\
\hline 85 & & & & & & 0.014 & -66.34 & -65.71 & -35.60 & & -55.88 & 0.028 & -20.48 & -68.23 & -59.66 & -21.61 & -42.49 & 0.028 \\
\hline 86 & & & & & & & -19.09 & -71.38 & -21.23 & & -37.23 & & -5.36 & -70.12 & -65.46 & -7.75 & -37.17 & \\
\hline 87 & & & & & & & -13.29 & -16.07 & -12.54 & & -13.97 & & -8.38 & -20.85 & -68.10 & -9.64 & -26.74 & \\
\hline 88 & & -76.42 & & -76.55 & -76.48 & 0.047 & -5.73 & -6.11 & -6.24 & -19.34 & -9.36 & 0.047 & -5.61 & -5.10 & -9.26 & -6.62 & -6.65 & 0.047 \\
\hline 89 & -47.44 & -19.85 & -19.72 & -55.00 & -35.50 & & -8.51 & -8.51 & -5.36 & -12.16 & -8.63 & & -5.23 & -7.88 & -10.40 & -8.63 & -8.03 & \\
\hline 90 & -15.18 & -10.65 & -23.50 & -20.22 & -17.39 & 0.019 & -6.62 & -7.25 & -5.61 & -9.77 & -7.31 & 0.019 & -5.10 & -6.11 & -7.75 & -8.13 & -6.77 & 0.019 \\
\hline 91 & -9.89 & -8.00 & -9.01 & -8.88 & -8.95 & 0.017 & -6.87 & -7.25 & -6.24 & -9.77 & -7.53 & 0.017 & -6.87 & -5.99 & -7.37 & -7.75 & -6.99 & 0.017 \\
\hline 92 & -4.85 & -5.10 & -4.98 & 4.10 & 4.76 & 0.045 & -5.10 & -4.98 & -5.61 & -7.37 & -5.77 & 0.045 & -4.98 & -3.84 & -5.23 & -5.86 & -4.98 & 0.045 \\
\hline 93 & -7.75 & -7.75 & -6.74 & -6.74 & -7.25 & & -8.00 & -7.88 & -8.38 & -7.50 & -7.94 & & -7.62 & -6.87 & -7.88 & -8.51 & -7.72 & \\
\hline 94 & -10.65 & -10.02 & -9.01 & -8.63 & -9.58 & & -10.02 & -10.27 & -9.64 & -9.64 & -9.89 & & -9.89 & -8.88 & -9.64 & -10.40 & -9.70 & \\
\hline 95 & -14.43 & -12.16 & -11.03 & -10.77 & -12.10 & & -12.66 & -12.92 & -11.91 & -12.29 & -12.44 & & -12.29 & -11.03 & -11.53 & -12.03 & -11.72 & \\
\hline 96 & -17.58 & -13.80 & -13.29 & -12.16 & -14.21 & & -14.18 & -15.69 & -13.17 & -15.31 & -14.59 & & -14.18 & -12.54 & -12.79 & -13.42 & -13.23 & \\
\hline 97 & -26.90 & -16.95 & -15.44 & -14.68 & -18.49 & & -16.95 & -22.11 & -15.18 & -19.09 & -18.33 & & -17.20 & -15.31 & -14.93 & -15.69 & -15.78 & \\
\hline 98 & 48.32 & -19.72 & -18.46 & -17.83 & -26.08 & & -20.22 & -21.86 & -17.20 & -24.89 & -21.04 & & -21.23 & -18.21 & -18.08 & -18.08 & -18.90 & \\
\hline 99 & -66.34 & -23.50 & -20.60 & -21.61 & -33.01 & & -24.26 & -41.77 & -19.85 & -30.81 & -29.17 & & -27.28 & -22.24 & -22.11 & -21.48 & -23.28 & \\
\hline 100 & -71.13 & -28.16 & -23.88 & -27.41 & -37.64 & 0.023 & -29.80 & -58.02 & -23.50 & -37.99 & -37.33 & 0.044 & -37.36 & -22.74 & -15.44 & -26.40 & -25.48 & 0.044 \\
\hline 101 & -74.28 & -30.30 & -24.76 & -32.07 & 40.35 & & -11.40 & -14.05 & -9.26 & -24.26 & -14.74 & & -9.14 & -10.27 & -11.91 & -12.16 & -10.87 & \\
\hline 102 & -75.29 & -31.69 & -25.77 & -35.85 & -42.15 & & -13.42 & -15.56 & -11.28 & -27.03 & -16.82 & & -11.91 & -13.55 & -14.68 & -15.31 & -13.86 & \\
\hline 103 & -76.42 & -33.58 & -28.92 & -41.14 & -45.01 & & -17.20 & -18.46 & -13.04 & -34.21 & -20.73 & & -14.68 & -17.70 & -18.71 & -17.83 & -17.23 & \\
\hline 104 & -76.42 & -36.73 & -31.69 & 45.93 & -47.69 & & -20.22 & -22.11 & -15.31 & -38.37 & -24.00 & & -18.33 & -20.98 & -22.24 & -20.48 & -20.51 & \\
\hline 105 & -76.42 & 40.38 & -36.48 & -54.24 & -51.88 & & -23.88 & -25.64 & -17.33 & -46.43 & -28.32 & & -21.99 & -25.26 & -27.28 & -24.00 & -24.63 & \\
\hline 106 & -77.18 & 44.04 & -40.89 & -57.52 & -54.91 & 0.020 & -21.61 & -15.81 & -8.88 & -45.55 & -22.96 & 0.041 & -6.11 & -14.55 & -20.10 & -13.55 & -13.58 & 0.041 \\
\hline 107 & -77.43 & -45.80 & 41.39 & -61.05 & -56.42 & 0.031 & -12.16 & -11.40 & -8.88 & -27.28 & -14.93 & 0.031 & -7.37 & -14.81 & -13.29 & -12.16 & -11.91 & 0.031 \\
\hline 108 & -76.42 & -42.15 & -35.09 & -63.57 & -54.31 & & -12.79 & -6.74 & -6.99 & -10.02 & -9.14 & & -6.11 & -5.86 & -7.75 & -7.75 & -6.87 & \\
\hline 109 & -75.79 & -4.35 & -8.76 & -4.85 & -23.44 & 0.038 & -3.34 & -7.25 & -4.10 & -3.84 & -4.63 & 0.038 & -3.34 & -2.21 & -4.10 & -4.60 & -3.56 & 0.038 \\
\hline 110 & -7.75 & -7.62 & -8.00 & -6.74 & -7.53 & & -7.37 & -7.37 & -8.00 & -7.88 & -7.66 & & -7.37 & -6.49 & -7.88 & -8.25 & -7.50 & \\
\hline 111 & -10.02 & -9.39 & -9.64 & -8.63 & -9.42 & & -9.14 & -9.39 & -9.39 & -5.48 & -8.35 & & -9.26 & -8.38 & -9.14 & -9.89 & -9.17 & \\
\hline 112 & -12.16 & -10.90 & -11.40 & -10.40 & -11.22 & & -10.77 & -10.77 & -11.15 & -11.40 & -11.03 & & -10.40 & -9.77 & -10.52 & -11.28 & -10.49 & \\
\hline 113 & -12.16 & -5.10 & -5.23 & -3.97 & -6.62 & 0.055 & -4.85 & -4.98 & -9.26 & -5.10 & -6.05 & 0.055 & -4.85 & -3.97 & -5.10 & -5.73 & 4.92 & 0.055 \\
\hline 114 & -7.75 & -7.75 & -8.38 & -6.74 & -7.66 & & -7.88 & -7.88 & -9.39 & -8.51 & -8.41 & & -7.88 & -6.62 & -7.88 & -8.63 & -7.75 & \\
\hline 115 & -9.51 & -9.51 & -9.77 & -8.38 & -9.29 & & -9.51 & --9.51 & -10.02 & -10.27 & --9.83 & & -9.51 & -8.63 & -9.39 & -10.40 & -9.48 & \\
\hline 116 & -11.03 & -11.15 & -11.28 & -10.02 & -10.87 & & -11.28 & -11.28 & -11.40 & -12.03 & -11.50 & & -11.15 & -10.27 & -10.65 & -12.03 & -11.03 & \\
\hline 117 & -13.17 & -12.79 & -12.92 & -11.91 & -12.70 & & -12.79 & -12.92 & -13.04 & -13.67 & -13.11 & & -12.54 & -11.66 & -12.29 & -13.17 & -12.41 & \\
\hline 118 & -14.68 & -14.18 & -14.18 & -13.17 & -14.05 & & -14.18 & -14.30 & -14.18 & -15.31 & -14.49 & & -13.80 & -13.04 & -13.42 & -14.43 & -13.67 & \\
\hline 119 & -16.95 & -15.69 & -15.31 & -14.81 & -15.69 & & -15.81 & -15.94 & -15.56 & -17.33 & -16.16 & & -15.44 & -14.43 & -14.68 & -15.81 & -15.09 & \\
\hline 120 & -19.09 & -17.45 & -16.95 & -16.57 & -17.52 & & -17.20 & -17.70 & -16.95 & -19.47 & -17.83 & & -17.20 & -15.94 & -16.19 & -17.20 & -16.63 & \\
\hline 121 & -21.48 & -18.84 & -18.21 & -18.84 & -19.34 & 0.006 & -18.71 & -19.22 & -18.21 & -21.61 & -19.44 & 0.006 & -17.83 & -17.58 & -17.70 & -18.71 & -17.96 & 0.006 \\
\hline 122 & -23.12 & -20.35 & -18.71 & -19.22 & -20.35 & & -19.85 & -20.48 & -19.22 & -22.87 & -20.60 & & -18.84 & -18.46 & -18.46 & -19.72 & -18.87 & \\
\hline 123 & -20.60 & -11.78 & -11.91 & -19.34 & -15.91 & 0.035 & -16.57 & -14.05 & -11.03 & -11.91 & -13.39 & 0.035 & -9.64 & -8.88 & -13.29 & -16.95 & -12.19 & 0.035 \\
\hline 124 & -11.66 & -10.52 & -9.64 & -12.41 & -11.06 & & -10.27 & -10.40 & -9.64 & -12.66 & -10.74 & & -8.76 & -8.88 & -10.27 & -12.54 & -10.11 & \\
\hline 125 & -12.92 & -12.16 & -11.15 & -13.55 & -12.44 & & -11.15 & -11.78 & -11.15 & -14.93 & -12.25 & & -10.14 & -10.90 & -12.16 & -13.17 & -11.59 & \\
\hline 126 & -15.56 & -14.18 & -12.66 & -15.44 & -14.46 & & -13.04 & -13.55 & -12.66 & -17.70 & -14.24 & & -11.66 & -12.54 & -14.43 & -14.43 & -13.26 & \\
\hline 127 & -17.45 & -15.69 & -13.67 & -17.07 & -15.97 & & -14.05 & -14.81 & -13.80 & -19.72 & -15.59 & & -12.16 & -13.92 & -15.44 & -15.56 & -14.27 & \\
\hline 128 & -21.11 & -18.21 & -15.56 & -20.10 & -18.74 & & -16.32 & -17.07 & -15.81 & -23.50 & -18.18 & & -13.67 & -16.07 & -18.21 & -17.96 & -16.48 & \\
\hline 129 & & & & & & 0.008 & & & & & & 0.008 & & & & & & 0.008 \\
\hline 130 & -27.28 & -22.11 & -17.96 & -24.13 & -22.87 & 0.007 & -19.72 & -20.35 & .84 & & 05 & 0.007 & & -19.09 & -20.98 & -20.98 & -19.18 & 0.007 \\
\hline 131 & -27.91 & -22.87 & -17.83 & -24.38 & -23.25 & 0.021 & -19.97 & -20.48 & -19.34 & -30.18 & -22.49 & 0.021 & -16.32 & -19.47 & -20.73 & -21.23 & -19.44 & 0.021 \\
\hline 132 & -28.41 & -19.85 & -9.89 & -24.00 & -20.54 & & -14.30 & -12.79 & -11.40 & -18.33 & -14.21 & & -10.14 & -9.01 & -13.80 & -19.34 & -13.07 & \\
\hline 133 & -20.60 & -15.56 & -10.40 & -18.59 & -16.29 & & -12.16 & -11.91 & -11.28 & -18.08 & -13.36 & & -9.89 & -10.14 & -12.54 & -14.18 & -11.69 & \\
\hline 134 & -18.84 & -15.56 & -11.28 & -17.83 & -15.88 & 0.015 & -12.54 & -12.79 & -12.41 & -19.47 & -14.30 & 0.015 & -10.52 & -11.40 & -13.17 & -13.80 & -12.22 & 0.015 \\
\hline 135 & -14.68 & -13.80 & -9.26 & -14.55 & -13.07 & & -9.89 & -10.65 & -12.03 & -15.31 & -11.97 & & -9.14 & -8.38 & -10.90 & -11.78 & -10.05 & \\
\hline 136 & -12.79 & -12.92 & -10.14 & -13.04 & -12.22 & & -9.89 & -10.65 & -10.77 & -15.44 & -11.69 & & -9.26 & -9.14 & -11.15 & -11.28 & -10.21 & \\
\hline 137 & -13.67 & -13.92 & -11.28 & -14.05 & -13.23 & & -10.90 & -11.91 & -11.78 & -16.70 & -12.82 & & -10.02 & -10.40 & -11.91 & -12.03 & -11.09 & \\
\hline 138 & -14.68 & -15.06 & -12.41 & -15.06 & -14.30 & & -12.16 & -12.92 & -12.79 & -17.70 & -13.89 & & -11.03 & -11.28 & -12.79 & -12.41 & -11.88 & \\
\hline 139 & & & & & & 0.008 & & & & & & 0.008 & & & & & & 0.008 \\
\hline 141 & & & & & & 0.020 & & & & & & 0.020 & & & & & & 0.020 \\
\hline 142 & & & & & & 0.025 & & & & & & 0.025 & & & & & & 0.025 \\
\hline 143 & & & & & & 0.015 & & & & & & 0.015 & & & & & & 0.015 \\
\hline 146 & & & & & & 0.043 & & & & & & 0.043 & & & & & & 0.043 \\
\hline 147 & & & & & & 0.070 & & & & & & 0.070 & & & & & & 0.070 \\
\hline
\end{tabular}


Profundidade $0,60 \mathrm{~m}$.

\begin{tabular}{|c|c|c|c|c|c|c|c|c|c|c|c|c|c|c|c|c|c|c|}
\hline \multirow[b]{2}{*}{ DAS } & \multicolumn{6}{|c|}{ trat -000} & \multicolumn{6}{|c|}{ trat $0 \mathrm{IO}$} & \multicolumn{6}{|c|}{ trat III } \\
\hline & r1 & 12 & r3 & $\mathrm{r4}$ & média & $\mathrm{P}+\mathrm{I}$ & $\mathrm{rl}$ & $\mathrm{r} 2$ & 13 & $\mathrm{r}$ & média & $\mathrm{P}+\mathrm{I}$ & $\mathrm{rl}$ & $\sqrt{2}$ & $\mathrm{r} 3$ & $\mathrm{r} 4$ & média & $\mathrm{P}+\mathrm{I}$ \\
\hline 0 & & & & & & 0.020 & & & & & & 0.021 & & & & & & 0.021 \\
\hline 1 & & & & & & 0.014 & & & & & & 0.014 & & & & & & 0.014 \\
\hline 2 & & & & & & 0.027 & & & & & & 0.028 & & & & & & 0.028 \\
\hline 4 & & & & & & 0.027 & & & & & & 0.028 & & & & & & 0.028 \\
\hline 5 & & & & & & 0.020 & & & & & & 0.021 & & & & & & 0.021 \\
\hline 7 & & & & & & 0.027 & & & & & & 0.028 & & & & & & 0.028 \\
\hline 8 & & & & & & 0.020 & & & & & & 0.021 & & & & & & 0.021 \\
\hline 9 & & & & & & 0.020 & & & & & & 0.021 & & & & & & 0.021 \\
\hline 13 & & & & & & 0.027 & & & & & & 0.028 & & & & & & 0.028 \\
\hline 16 & & & & & & 0.020 & & & & & & 0.021 & & & & & & 0.021 \\
\hline 17 & -8.64 & -9.40 & -9.65 & -7.88 & -8.89 & & -10.78 & -9.77 & -10.78 & -9.77 & -10.28 & & -9.65 & -8.26 & -6.50 & -10.53 & -8.73 & \\
\hline 18 & -9.14 & -9.40 & -10.28 & -8.26 & -9.27 & 0.014 & -9.65 & -10.28 & -10.78 & -9.65 & -10.09 & 0.014 & -10.03 & -9.02 & -6.62 & -10.66 & -9.08 & 0.014 \\
\hline 19 & -8.77 & -9.27 & -10.78 & -8.14 & -9.24 & & -9.27 & -10.78 & -10.40 & -9.90 & -10.09 & & -9.77 & -8.89 & -6.62 & -10.78 & -9.02 & \\
\hline 20 & -9.27 & -9.90 & -10.40 & -8.51 & -9.52 & 0.019 & -9.65 & -10.53 & -10.91 & -10.28 & -10.34 & 0.020 & -10.15 & -9.27 & -6.88 & -11.16 & -9.36 & 0.020 \\
\hline 21 & -9.65 & -8.14 & -9.52 & -6.62 & -8.48 & 0.011 & -7.63 & -8.64 & -9.14 & -8.77 & -8.55 & 0.011 & -8.26 & -7.76 & -7.13 & -9.02 & -8.04 & 0.011 \\
\hline 22 & -8.89 & -7.51 & -8.64 & -5.99 & -7.76 & & -7.51 & -8.01 & -8.39 & -8.14 & -8.01 & & -7.51 & -7.00 & -6.88 & -8.39 & -7.44 & \\
\hline 23 & -9.14 & -8.77 & -9.14 & -7.00 & -8.51 & 0.027 & -8.39 & -9.14 & -9.40 & -9.02 & -8.99 & 0.028 & -8.51 & -8.01 & -7.13 & -9.40 & -8.26 & 0.028 \\
\hline 24 & -9.14 & -6.37 & -7.13 & -5.49 & -7.03 & & -6.62 & -7.38 & -7.25 & -6.75 & -7.00 & & -6.62 & -5.87 & -7.00 & -7.76 & -6.81 & \\
\hline 25 & -6.37 & -7.51 & -8.39 & -5.99 & -7.07 & & -7.63 & -8.39 & -8.51 & -8.14 & -8.17 & & -7.88 & -7.13 & -7.38 & -8.77 & -7.79 & \\
\hline 26 & -7.51 & -8.77 & -9.40 & -7.13 & -8.20 & & -8.64 & -9.65 & -9.65 & -9.14 & -9.27 & & -9.02 & -8.26 & -6.62 & -10.03 & -8.48 & \\
\hline 27 & -9.77 & -9.90 & -10.66 & -8.77 & -9.77 & & -9.77 & -10.78 & -10.91 & -10.28 & -10.44 & & -10.15 & -9.52 & -6.50 & -10.91 & -9.27 & \\
\hline 28 & -10.15 & -10.53 & -10.91 & -8.77 & -10.09 & 0.024 & -10.15 & -11.29 & -11.41 & -10.78 & -10.91 & 0.024 & -10.53 & -9.90 & -7.13 & -11.41 & -9.74 & 0.024 \\
\hline 29 & -9.77 & -10.15 & -11.16 & -8.89 & -9.99 & 0.027 & -10.28 & -10.53 & -11.29 & -10.91 & -10.75 & 0.028 & -10.28 & -9.52 & -14.44 & -11.41 & -11.41 & 0.028 \\
\hline 30 & -6.75 & -6.88 & -8.39 & -5.74 & -6.94 & 0.027 & -7.13 & -7.63 & -7.88 & -8.01 & -7.66 & 0.028 & -7.00 & -6.37 & -11.41 & -8.14 & -8.23 & 0.028 \\
\hline 31 & -6.50 & -7.38 & -6.75 & 4.99 & -6.40 & & -6.25 & -6.88 & -7.00 & -6.50 & -6.66 & & -6.37 & -5.36 & -10.28 & -7.38 & -7.35 & \\
\hline 32 & -7.76 & -7.76 & -8.14 & & -7.88 & & -7.63 & -8.51 & -8.64 & -8.26 & -8.26 & & -7.88 & -6.88 & -9.40 & -8.77 & -8.23 & \\
\hline 33 & -8.77 & -8.89 & -9.27 & & -8.98 & & -8.64 & -9.40 & -9.90 & -9.14 & -9.27 & & -9.02 & -7.88 & -9.02 & -9.90 & -8.96 & \\
\hline 34 & -9.77 & -9.90 & -10.40 & -7.25 & -9.33 & & -9.77 & -10.66 & -10.78 & -10.40 & -10.40 & & -10.15 & -9.27 & -10.03 & -10.91 & -10.09 & \\
\hline 35 & -10.40 & -10.66 & -11.16 & -9.02 & -10.31 & & -10.28 & -11.41 & -11.66 & -11.03 & -11 & & -11 & -10 & -10.66 & -11.54 & -10.81 & \\
\hline 36 & -11.16 & -11.66 & -12.29 & -10.03 & -11.29 & & -11.03 & -12.55 & -12.80 & -12.17 & -12.14 & & -11.92 & -11.03 & -12.42 & -12.17 & -11.88 & \\
\hline 37 & -11.92 & -12.80 & -13.18 & -10.66 & -12.14 & & -11.66 & -13.43 & -13.81 & -12.80 & -12.92 & & -13.05 & -11.92 & -10.91 & -13.30 & -12.29 & \\
\hline 38 & -12.55 & -13.55 & -14.18 & -11.79 & -13.02 & & -12.29 & -14.31 & -14.94 & -13.68 & -13.81 & & -13.68 & -13.05 & -12.67 & -14.06 & -13.37 & \\
\hline 39 & -13.55 & -14.81 & -15.57 & -12.67 & -14.15 & & -13.05 & -15.44 & -16.20 & -15.95 & -15.16 & & -14.81 & -14.69 & -13.81 & -14.69 & -14.50 & \\
\hline 40 & -14.44 & -16.20 & -16.33 & -13.68 & -15.16 & & -13.93 & -16.83 & -17.84 & -18.47 & -16.77 & & -16.07 & -16.45 & -15.07 & -16.20 & -15.95 & \\
\hline 41 & -15.19 & -18.47 & -19.73 & -16.58 & -17.49 & & -14.81 & -17.59 & -19.60 & -20.36 & -18.09 & & -17.71 & -18.47 & -15.19 & -17.46 & -17.21 & \\
\hline 42 & -16.58 & -18.72 & -23.00 & -18.59 & -19.22 & & -14.81 & -18.97 & -21.62 & -23.38 & -19.70 & & -19.60 & -21.62 & -15.44 & -18.72 & -18.85 & \\
\hline 43 & -17.71 & -19.98 & -24.89 & -18.97 & -20.39 & 0.020 & -15.70 & -20.61 & -23.76 & -23.76 & -20.96 & 0.021 & -21.37 & -22.25 & -16.83 & -20.11 & -20.14 & 0.036 \\
\hline 44 & -18.85 & -21.24 & -26.91 & -20.74 & -21.93 & 0.014 & -16.70 & -22.25 & -25.40 & -25.52 & -22.47 & 0.014 & -22.88 & -24.52 & -16.83 & -21.11 & -21.33 & 0.028 \\
\hline 45 & -20.86 & -22.25 & -27.04 & -24.39 & -23.63 & & -17.71 & -24.01 & -27.29 & -26.03 & -23.76 & & -12.17 & -17.46 & -15.07 & -14.69 & -14.85 & \\
\hline 46 & -21.87 & -23.26 & -58.28 & -25.02 & -32.11 & & -18.59 & -25.90 & -28.55 & 41.02 & -28.52 & & -12.80 & -19.35 & -14.81 & -14.81 & -15.44 & \\
\hline 47 & -24.01 & -24.14 & -38.25 & -27.29 & -28.42 & & -19.10 & -28.55 & -31.07 & -55.13 & -33.46 & & -14.31 & -18.09 & -15.19 & -15.57 & -15.79 & \\
\hline 48 & -27.16 & -25.52 & -45.56 & -32.71 & -32.74 & & -19.85 & -31.82 & -33.84 & -66.47 & -38.00 & & -16.07 & -23.26 & -16.83 & -17.08 & -18.31 & \\
\hline 49 & -32.33 & -27.54 & -53.24 & -39.51 & -38.16 & & -20.74 & -34.97 & -38.50 & -68.11 & 40.58 & & -17.96 & -25.40 & -22.12 & -18.97 & -21.11 & \\
\hline 50 & 41.02 & -30.44 & -61.94 & 49.34 & 45.68 & 0.014 & -21.37 & -36.61 & 46.44 & -70.13 & 43.64 & 0.014 & -20.61 & -29.81 & -19.48 & -21.74 & -22.91 & 0.028 \\
\hline 51 & -48.20 & -33.21 & -69.37 & -61.31 & -53.02 & & -23.89 & 47.57 & -55.13 & -72.77 & 49.84 & & -22.63 & -32.33 & -19.60 & -23.63 & -24.55 & \\
\hline 52 & -56.52 & -37.12 & -71.26 & -67.86 & -58.19 & & -26.03 & -55.89 & -63.20 & -72.90 & -54.50 & & -23.38 & -34.97 & -18.85 & -25.40 & -25.65 & \\
\hline 53 & -67.61 & -43.92 & -72.65 & -71.01 & -63.80 & & -29.68 & -65.34 & -70.13 & -74.66 & -59.95 & & -24.39 & -40.90 & -21.87 & -27.92 & -28.77 & \\
\hline 54 & -71.64 & -51.48 & -78.44 & -72.90 & -68.62 & 0.014 & -34.22 & -70.13 & -72.65 & -78.44 & -63.86 & 0.014 & -27.29 & -47.70 & -23.26 & -32.58 & -32.71 & 0.028 \\
\hline 55 & -74.79 & -62.19 & & -77.94 & -71.64 & & -40.77 & -73.53 & -75.92 & -78.44 & -67.17 & & -29.43 & -55.26 & -24.39 & -35.48 & -36.14 & \\
\hline 56 & -74.16 & -67.23 & & -77.31 & -72.90 & & -47.95 & -72.90 & -74.79 & -75.42 & -67.77 & & -30.69 & -59.04 & -28.04 & -40.90 & -39.67 & \\
\hline 57 & & -75.04 & -74.92 & -75.92 & -75.29 & 0.014 & -59.67 & -76.43 & -75.92 & -76.18 & -72.05 & 0.014 & -32.58 & -68.11 & -31.32 & -44.93 & -44.24 & 0.028 \\
\hline 58 & & -75.04 & -75.29 & -76.68 & -75.67 & & -65.34 & -76.05 & -75.92 & -76.05 & -73.34 & & -33.71 & -69.25 & -34.22 & -43.92 & -45.27 & \\
\hline 59 & & -73.66 & -74.16 & -77.56 & -75.13 & & -67.61 & -75.17 & -77.18 & -76.05 & -74.00 & & -28.42 & -69.37 & -35.73 & -46.19 & 44.93 & \\
\hline 60 & & -74.79 & -75.42 & -77.31 & -75.84 & & -71.64 & -75.80 & -76.05 & -75.04 & -74.63 & & -27.54 & -71.39 & -39.13 & -49.34 & 46.85 & \\
\hline 61 & -75.29 & -73.28 & -75.80 & -76.18 & -75.14 & 0.014 & -71.89 & -75.80 & -76.18 & -76.30 & -75.04 & 0.014 & -29.43 & -72.02 & -41.40 & -52.49 & -48.83 & 0.028 \\
\hline 62 & -75.42 & -74.41 & -75.67 & -75.80 & -75.33 & & -74.16 & -76.68 & -61.56 & -76.05 & -72.11 & & -19.60 & -46.44 & -45.05 & -56.39 & -41.87 & \\
\hline 63 & -75.80 & -74.16 & -76.05 & -75.42 & -75.36 & & -74.79 & -76.68 & -66.60 & -76.18 & -73.56 & & -16.20 & -72.90 & -46.06 & -57.78 & -48.24 & \\
\hline 64 & -74.54 & -74.03 & -76.05 & -75.42 & -75.01 & & -74.16 & -76.30 & -68.74 & -75.29 & -73.62 & & -17.84 & -73.28 & -45.43 & -58.03 & -48.65 & \\
\hline 65 & -75.29 & -74.03 & -75.55 & -75.55 & -75.11 & 0.014 & -74.41 & -75.92 & -76.05 & -75.04 & -75.36 & 0.014 & -21.37 & -73.28 & -47.32 & -61.81 & -50.94 & 0.028 \\
\hline 66 & -76.93 & -76.81 & -76.43 & -76.93 & -76.77 & & -75.29 & -76.93 & -77.06 & -75.92 & -76.30 & & -15.82 & -74.92 & -44.93 & -37.49 & -43.29 & \\
\hline 67 & -75.17 & -75.29 & -75.80 & -76.81 & -75.77 & & -74.79 & -75.55 & -75.29 & -75.55 & -75.29 & & -14.44 & -74.29 & -34.85 & -40.90 & -41.12 & \\
\hline 68 & -77.18 & -75.42 & -75.92 & & -76.18 & & & -76.05 & -75.17 & -75.29 & -75.50 & & -16.96 & -75.92 & -35.86 & 43.67 & 43.10 & \\
\hline 69 & & -75.80 & -76.30 & . & & & & -76.55 & -75.55 & -75.92 & -76.01 & & -19.73 & -75.04 & -41.15 & 47.70 & 45.90 & \\
\hline 70 & & -75.80 & & & & & & -76.55 & -75.42 & -75.67 & -75.88 & & -23.26 & -76.30 & -47.70 & -54.38 & -50.41 & \\
\hline 71 & & -76.05 & -75.55 & & & 0.014 & & -76.18 & -75.42 & & & 0.014 & -26.78 & -75.42 & -55.76 & -51.10 & -52.27 & 0.028 \\
\hline 72 & & -75.55 & -75.17 & & & & & -75.55 & & & & & -26.28 & -75.42 & -61.43 & -58.28 & -55.35 & \\
\hline 73 & & & -75.55 & & & & & -76.30 & & & & & -29.18 & -77.06 & -68.49 & -64.71 & -59.86 & \\
\hline 74 & & & & & & 0.020 & & -75.67 & & & & 0.041 & -32.45 & -74.66 & -67.86 & -65.34 & -60.08 & 0.041 \\
\hline 75 & -71.64 & & & & & & & -76.05 & -76.05 & -75.42 & -75.84 & & -7.88 & -75.80 & -58.66 & -16.45 & -39.70 & \\
\hline
\end{tabular}

(continua). 
Profundidade $0,60 \mathrm{~m}$ (continuação).

\begin{tabular}{|c|c|c|c|c|c|c|c|c|c|c|c|c|c|c|c|c|c|c|}
\hline \multirow[b]{2}{*}{ DAS } & \multicolumn{6}{|c|}{ trat -000} & \multicolumn{6}{|c|}{ trat 0I0 } & \multicolumn{6}{|c|}{ trat III } \\
\hline & rl & 12 & 13 & $\mathrm{r} 4$ & média & $\mathrm{P}+\mathrm{I}$ & I1 & 12 & r3 & $\mathrm{r} 4$ & média & $\mathrm{P}+\mathrm{I}$ & $\mathrm{r} 1$ & 12 & r3 & $\mathrm{r} 4$ & média & $\mathrm{P}+\mathrm{I}$ \\
\hline 76 & -72.40 & & & & & & & -75.80 & -76.05 & -75.80 & -75.88 & & -10.53 & -75.80 & -49.97 & -18.47 & -38.69 & \\
\hline 77 & & & & & & & & -75.42 & -76.30 & -75.42 & -75.71 & & -13.05 & -75.17 & -53.75 & -22.50 & -41.12 & \\
\hline 78 & -75.80 & & & & & 0.020 & -76.05 & -76.68 & -75.92 & -75.80 & -76.11 & 0.041 & -5.49 & -75.80 & -28.17 & -7.88 & -29.34 & 0.041 \\
\hline 79 & -75.80 & & & & & & -19.10 & -76.68 & -71.64 & -75.92 & -60.84 & & -8.26 & -76.05 & -21.11 & -9.77 & -28.80 & \\
\hline 80 & -75.42 & & & & & & -21.49 & -73.28 & -31.32 & -76.05 & -50.54 & & -9.52 & -76.05 & -23.63 & -11.16 & -30.09 & \\
\hline 81 & & & -74.16 & & & & -23.76 & -41.40 & -30.06 & -76.68 & -42.98 & & -10.78 & -76.55 & -26.28 & -11.16 & -31.19 & \\
\hline 82 & & & & & & & -30.06 & -44.55 & -36.23 & & -36.95 & & -12.04 & & -31.45 & -13.18 & -18.89 & \\
\hline 83 & & & & & & & -40.14 & -54.13 & -46.44 & & 46.90 & & -14.06 & & -39.89 & -17.08 & -23.68 & \\
\hline 84 & & & & & & & -51.48 & -61.43 & -56.27 & & -56.39 & & -15.95 & & -50.22 & -19.48 & -28.55 & \\
\hline 85 & & & & & & 0.014 & -59.92 & -67.73 & -62.06 & & -63.24 & 0.028 & -18.09 & & -58.79 & -21.87 & -32.92 & 0.028 \\
\hline 86 & & & & & & & -36.11 & -69.12 & -65.59 & & -56.94 & & 4.23 & -78.95 & -64.71 & -11.29 & -39.79 & \\
\hline 87 & & & & & & & -13.93 & -29.05 & -18.47 & & -20.48 & & -8.01 & -49.59 & -67.61 & -10.78 & -34.00 & \\
\hline 88 & & -75.42 & & -64.96 & & 0.047 & -5.24 & -7.13 & -6.12 & -76.55 & -23.76 & 0.047 & -5.49 & 4.99 & -12.42 & -6.37 & -7.32 & 0.047 \\
\hline 89 & -58.66 & -61.56 & -19.60 & & -46.61 & & -8.01 & -8.64 & -8.39 & -15.70 & -10.18 & & -7.63 & -5.24 & -11.16 & -8.64 & -8.17 & \\
\hline 90 & -66.98 & -16.83 & -34.47 & -36.36 & -38.66 & 0.019 & -7.13 & -7.63 & -7.13 & -9.52 & -7.85 & 0.019 & -7.25 & -6.50 & -9.02 & -8.26 & -7.76 & 0.019 \\
\hline 91 & -16.70 & -8.51 & -24.77 & -39.51 & -22.37 & 0.017 & -6.88 & -7.51 & -7.13 & -8.14 & -7.41 & 0.017 & -7.00 & -6.12 & -8.01 & -8.39 & -7.38 & 0.017 \\
\hline 92 & -10.40 & -4.73 & -6.62 & -24.52 & -11.57 & 0.045 & -4.86 & -5.49 & -5.11 & 4.99 & -5.11 & 0.045 & -4.99 & -3.22 & -5.49 & -8.01 & -5.43 & 0.045 \\
\hline 93 & -13.30 & -7.13 & -6.50 & -6.37 & -8.33 & & -7.76 & -8.01 & -8.01 & -8.01 & -7.95 & & -7.38 & -6.25 & -7.76 & -8.39 & -7.44 & \\
\hline 94 & -16.20 & -9.14 & -8.64 & -6.75 & -10.18 & & -9.40 & -10.15 & -9.77 & -10.28 & -9.90 & & -9.27 & -8.39 & -9.40 & -10.03 & -9.27 & \\
\hline 95 & -18.47 & -11.03 & -10.78 & -8.77 & -12.26 & & -11.41 & -13.55 & -11.41 & -12.80 & -12.29 & & -11.29 & -10.03 & -10.91 & -11.66 & -10.97 & \\
\hline 96 & -13.30 & -12.67 & -12.55 & -11.03 & -12.39 & & -12.80 & -14.06 & -12.80 & -15.82 & -13.87 & & -12.67 & -11.41 & -11.66 & -12.80 & -12.14 & \\
\hline 97 & -15.82 & -15.07 & -14.94 & -13.30 & -14.78 & & -14.94 & -16.83 & -14.44 & -19.98 & -16.55 & & -14.69 & -13.43 & -13.93 & -14.69 & -14.18 & \\
\hline 98 & -19.48 & -17.46 & -17.46 & -15.95 & -17.59 & & -17.46 & -18.72 & -16.45 & -25.78 & -19.60 & & -16.96 & -15.57 & -16.45 & -16.83 & -16.45 & \\
\hline 99 & -24.26 & -20.61 & -20.23 & -18.34 & -20.86 & & -20 & -26.03 & -18.47 & -33.21 & -24.58 & & -19.98 & -18.34 & -20.74 & -19.73 & -19.70 & \\
\hline 100 & -28.93 & -25.15 & -23.13 & -21.87 & -24.77 & 0.023 & -24.39 & -37.62 & -21.24 & -48.33 & -32.90 & 0.044 & -23.51 & -19.85 & -24.01 & -23.76 & -22.78 & 0.044 \\
\hline 101 & -34.34 & -26.03 & -26.66 & -25.02 & -28.01 & & -18.72 & -24.89 & -10.28 & -44.55 & -24.61 & & -9.65 & -11.66 & -16.33 & -22.25 & -14.97 & \\
\hline 102 & -40.77 & -40.39 & -27.67 & -32.20 & -35.26 & & -15.95 & -21.49 & -11.41 & -42.66 & -22.88 & & -11.41 & -13.43 & -16.96 & -21.11 & -15.73 & \\
\hline 103 & -47.70 & -29.43 & -30.06 & -37.87 & -36.27 & & -18.09 & -22.37 & -13.30 & -43.42 & -24.30 & & -13.81 & -16.70 & -19.73 & -21.74 & -18.00 & \\
\hline 104 & -52.74 & -33.21 & -31.70 & -39.64 & -39.32 & & -20.48 & -28.93 & -15.19 & -50.60 & -28.80 & & -16.45 & -19.10 & -23.89 & -23.76 & -20.80 & \\
\hline 105 & -60.05 & -36.36 & -36.36 & 46.31 & -44.77 & & -23.13 & -31.57 & -17.08 & -56.27 & -32.01 & & -18.97 & -22.12 & -28.17 & -26.41 & -23.92 & \\
\hline 106 & -64.08 & -39.38 & -40.14 & -49.59 & -48.30 & 0.020 & -23.76 & -36.74 & -13.68 & -52.74 & -31.73 & 0.041 & -6.12 & -23.13 & -25.52 & -15.32 & -17.52 & 0.041 \\
\hline 107 & -67.86 & -38.88 & -41.40 & -54.76 & -50.72 & 0.031 & -16.20 & -17.59 & -10.15 & -44.42 & -22.09 & 0.031 & -7.38 & -14.31 & -17.96 & -18.97 & -14.66 & 0.031 \\
\hline 108 & -69.88 & -41.40 & 41.90 & -58.91 & -53.02 & & -7.13 & -8.14 & -7.00 & -13.68 & -8.99 & & -6.12 & -6.25 & -9.90 & -9.27 & -7.88 & \\
\hline 109 & -56.52 & -5.87 & -22.75 & -59.67 & -36.20 & 0.038 & -3.22 & -9.14 & -4.73 & -3.73 & -5.21 & 0.038 & -3.60 & -3.10 & -4.86 & -7.38 & -4.73 & 0.038 \\
\hline 110 & -7.51 & -6.88 & -7.76 & -7.38 & -7.38 & & -7.13 & -7.76 & -7.76 & -7.25 & -7.47 & & -7.00 & -6.12 & -7.76 & -7.51 & -7.10 & \\
\hline 111 & -9.77 & -8.89 & -9.27 & -8.01 & -8.99 & & -8.89 & -9.65 & -9.27 & -9.27 & -9.27 & & -8.64 & -7.76 & -9.40 & -9.65 & -8.86 & \\
\hline 112 & -11.66 & -10.28 & -10.91 & -9.90 & -10.69 & & -10.15 & -11.16 & -10.40 & -10.78 & -10.62 & & -10.03 & -9.14 & -10.53 & -10.91 & -10.15 & \\
\hline 113 & -4.86 & -4.48 & -5.11 & -4.10 & -4.64 & 0.055 & -4.86 & -5.36 & -4.23 & 4.73 & 4.80 & 0.055 & 4.86 & -3.47 & -5.74 & -5.87 & 4.99 & 0.055 \\
\hline 114 & -7.38 & -7.13 & -7.51 & -6.12 & -7.03 & & -7.51 & -8.14 & -8.01 & -7.76 & -7.85 & & -7.63 & -6.25 & -8.01 & -8.39 & -7.57 & \\
\hline 115 & -9.02 & -8.77 & -9.27 & -7.76 & -8.70 & & -9.14 & -10.15 & -9.65 & -9.52 & -9.62 & & -9.14 & -7.88 & -9.90 & -9.90 & -9.21 & \\
\hline 116 & -10.28 & -10.40 & -10.78 & -9.02 & -10.12 & & -10.66 & -11.79 & -11.16 & -11.41 & -11.25 & & -10.53 & -9.14 & -11.41 & -11.16 & .56 & \\
\hline 117 & -12.17 & -11.92 & -11.92 & -10.66 & -11.66 & & -11.79 & -13.18 & -12.55 & -13.05 & -12.64 & & -11.92 & -10.66 & -12.67 & -12.80 & -12.01 & \\
\hline 118 & -13.55 & -13.05 & -13.18 & -11.92 & -12.92 & & -12.80 & -14.31 & -13.68 & -15.70 & -14.12 & & -12.80 & -11.79 & -13.68 & -13.81 & -13.02 & \\
\hline 119 & -15.19 & -14.31 & -14.18 & -13.43 & -14.28 & & -14.06 & -15.37 & -14.81 & -16.07 & -15.13 & & -14.06 & -13.18 & -14.94 & -14.94 & -14.28 & \\
\hline 120 & -16.83 & -15.57 & -15.57 & -14.94 & -15.73 & & -15.32 & -17.71 & -16.20 & -18.09 & -16.83 & & -15.32 & -14.31 & -16.83 & -15.82 & -15.57 & \\
\hline 121 & -18.34 & -16.70 & -16.20 & -16.58 & -16.96 & 0.006 & -16.20 & -18.72 & -17.33 & -19.73 & -18.00 & 0.006 & -16.20 & -15.57 & -17.59 & -17.21 & -16.64 & 0.006 \\
\hline 122 & -19.98 & -17.71 & -17.08 & -17.33 & -18.03 & & -17.08 & -19.98 & -18.34 & -20.74 & -19.04 & & -17.21 & -16.33 & -18.59 & -17.96 & -17.52 & \\
\hline 123 & -19.22 & -15.32 & -14.94 & -19.10 & -17.15 & 0.035 & -16.83 & -20.23 & -15.70 & -15.07 & -16.96 & 0.035 & -13.18 & -12.42 & -16.07 & -15.70 & -14.34 & 0.035 \\
\hline 124 & -14.06 & -11.03 & -10.40 & -15.57 & -12.77 & & -11.41 & -13.05 & -10.40 & -13.81 & -12.17 & & -9.52 & -9.27 & -12.80 & -14.69 & -11.57 & \\
\hline 125 & -13.68 & -11.79 & -10.78 & -14.69 & -12.74 & & -11.54 & -13.30 & -11.29 & -15.44 & -12.89 & & -10.03 & -10.28 & -14.56 & -14.44 & -12.33 & \\
\hline 126 & -15.07 & -13.68 & -12.17 & -14.81 & -13.93 & & -12.92 & -14.31 & -12.67 & -17.96 & -14.47 & & -11.29 & -11.92 & -15.95 & -14.69 & -13.46 & \\
\hline 127 & -16.70 & -14.69 & -13.18 & -16.58 & -15.29 & & -13.68 & -15.57 & -13.68 & -19.35 & -15.57 & & -12.29 & -13.05 & -17.46 & -15.57 & -14.59 & \\
\hline 128 & -18.97 & -16.20 & -14.69 & -19.60 & -17.37 & & -15.44 & -17.33 & -15.44 & -22.50 & -17.68 & & -13.43 & -14.94 & -19.48 & -17.21 & -16.26 & \\
\hline 129. & & & & & & 0.008 & & & & & & 0.008 & & & & & & 0.008 \\
\hline 130 & -23.13 & -19.10 & -16.96 & -23.13 & -20.58 & 0.007 & -18.09 & -19.98 & -18.09 & -27.04 & -20.80 & 0.007 & -15.57 & -17.84 & -20.61 & -19.35 & -18.34 & 0.007 \\
\hline 131 & -24.14 & -19.98 & -17.08 & -22.50 & -20.93 & 0.021 & -18.09 & -20.61 & -18.59 & -27.41 & -21.18 & 0.021 & -16.20 & -18.09 & -21.11 & -19.60 & -18.75 & 0.021 \\
\hline 132 & -25.27 & -18.97 & -11.54 & -24.14 & -19.98 & & -17.96 & -17.33 & -12.55 & -20.74 & -17.15 & & -12.29 & -11.29 & -17.33 & -19.73 & -15.16 & \\
\hline 133 & -24.01 & -15.32 & -11.03 & -22.75 & -18.28 & & -14.94 & -14.44 & -11.66 & -18.85 & -14.97 & & -10.91 & -10.66 & -14.44 & -16.70 & -13.18 & \\
\hline 134 & -21.49 & -15.07 & -11.54 & -20.61 & -17.18 & 0.015 & -14.06 & -14.44 & -12.29 & -19.60 & -15.10 & 0.015 & -11.03 & -11.41 & -14.18 & -14.94 & -12.89 & 0.015 \\
\hline 135 & -19.60 & -13.93 & -8.64 & -18.85 & -15.26 & & -12.92 & -12.42 & -13.18 & -17.46 & -14.00 & & -10.15 & -9.14 & -12.80 & -13.68 & -11.44 & \\
\hline 136 & -15.95 & -12.80 & -10.66 & -15.32 & -13.68 & & -11.54 & -12.04 & -10.91 & -15.95 & -12.61 & & -10.03 & -9.27 & -12.04 & -12.42 & -10.94 & \\
\hline 137 & -15.19 & -13.18 & -10.91 & -15.44 & -13.68 & & -11.79 & -12.55 & -12.29 & -17.08 & -13.43 & & -10.15 & -10.03 & -12.42 & -12.29 & -11.22 & \\
\hline 138 & -15.32 & -14.18 & -11.92 & -15.82 & -14.31 & & -12.42 & -13.43 & -12.42 & -17.71 & -14.00 & & -10.91 & -10.91 & -13.05 & -12.80 & -11.92 & \\
\hline 139 & & & & & & 0.008 & & & & & & 0.008 & & & & & & 0.008 \\
\hline 141 & & & & & & 0.020 & & & & & & 0.020 & & & & & & 0.020 \\
\hline 142 & & & & & & 0.025 & & & & & & 0.025 & & & & & & 0.025 \\
\hline 143 & & & & & & 0.015 & & & & & & 0.015 & & & & & & 0.015 \\
\hline 146 & & & & & & 0.043 & & & & & & 0.043 & & & & & & 0.043 \\
\hline 147 & & & & & & 0.070 & & & & & & 0.070 & & & & & & 0.070 \\
\hline
\end{tabular}


Profundidade $0,70 \mathrm{~m}$.

\begin{tabular}{|c|c|c|c|c|c|c|c|c|c|c|c|c|c|c|c|c|c|c|}
\hline \multirow[b]{2}{*}{ DAS } & \multicolumn{6}{|c|}{ trat -000} & \multicolumn{6}{|c|}{ trat $0 \mathrm{IO}$} & \multicolumn{6}{|c|}{ trat III } \\
\hline & $\mathrm{r} 1$ & 12 & r3 & $\mathrm{m}$ & média & $\mathrm{P}+\mathrm{I}$ & r1 & 2 & r3 & $\mathrm{r}$ & média & $\mathrm{P}+\mathrm{I}$ & $\mathrm{r1}$ & r2 & r3 & $\mathrm{r} 4$ & média & $\mathrm{P}+\mathrm{I}$ \\
\hline 0 & & & & & & 0.020 & & & & & & 0.021 & & & & & & 0.021 \\
\hline 1 & & & & & & 0.014 & & & & & & 0.014 & & & & & & 0.014 \\
\hline 2 & & & & & & 0.027 & & & & & & 0.028 & & & & & & 0.028 \\
\hline 4 & & & & & & 0.027 & & & & & & 0.028 & & & & & & 0.028 \\
\hline 5 & & & & & & 0.020 & & & & & & 0.021 & & & & & & 0.021 \\
\hline 7 & & & & & & 0.027 & & & & & & 0.028 & & & & & & 0.028 \\
\hline 8 & & & & & & 0.020 & & & & & & 0.021 & & & & & & 0.021 \\
\hline 9 & & & & & & 0.020 & & & & & & 0.021 & & & & & & 0.021 \\
\hline 13 & & & & & & 0.027 & & & & & & 0.028 & & & & & & 0.028 \\
\hline 16 & & & & & & 0.020 & & & & & & 0.021 & & & & & & 0.021 \\
\hline 17 & -9.28 & -9.15 & -9.78 & -8.27 & -9.12 & & -9.03 & -10.03 & -11.55 & -9.91 & -10.13 & & -9.40 & -9.15 & -8.90 & -11.04 & -9.62 & \\
\hline 18 & -9.66 & -9.66 & -10.16 & -8.02 & -9.37 & 0.014 & -9.40 & -10.41 & -10.92 & -9.78 & -10.13 & 0.014 & -9.53 & -9.53 & -9.15 & -11.17 & -9.85 & 0.014 \\
\hline 19 & -9.28 & -9.66 & -10.29 & -7.89 & -9.28 & & -9.28 & -10.16 & -10.66 & -9.53 & -9.91 & & -9.40 & -9.53 & -8.65 & -11.04 & -9.66 & \\
\hline 20 & -9.53 & -9.53 & -10.41 & -7.89 & -9.34 & 0.019 & -9.40 & -10.54 & -11.04 & -10.16 & -10.29 & 0.020 & -9.66 & -9.78 & -9.03 & -11.17 & -9.91 & 0.020 \\
\hline 21 & -9.66 & -8.52 & -10.03 & -6.88 & -8.77 & 0.011 & -7.89 & -9.03 & -9.91 & -9.28 & -9.03 & 0.011 & -7.89 & -8.90 & -9.40 & -10.16 & -9.09 & 0.011 \\
\hline 22 & -9.53 & -7.64 & -9.03 & -6.88 & -8.27 & & -7.39 & -8.27 & -8.90 & -7.77 & -8.08 & & -7.14 & -7.89 & -9.40 & -9.03 & -8.36 & \\
\hline 23 & -9.53 & -8.77 & -9.28 & -6.51 & -8.52 & 0.027 & -8.14 & -9.28 & -9.28 & -8.90 & -8.90 & 0.028 & -7.89 & -8.52 & -9.40 & -9.66 & -8.87 & 0.028 \\
\hline 24 & -9.53 & -6.38 & -7.39 & -4.99 & -7.07 & & -6.63 & -7.26 & -7.39 & -6.88 & -7.04 & & -6.13 & -6.38 & -7.26 & -8.14 & -6.98 & \\
\hline 25 & -6.51 & -7.39 & -8.40 & -6.00 & -7.07 & & -7.39 & -8.27 & -8.14 & -7.51 & -7.83 & & -7.39 & -7.51 & -7.77 & -8.90 & -7.89 & \\
\hline 26 & -7.64 & -8.65 & -9.40 & -7.14 & -8.21 & & -8.52 & -9.40 & -9.28 & -8.90 & -9.03 & & -8.27 & -8.52 & -8.52 & -9.91 & -8.81 & \\
\hline 27 & -9.53 & -9.78 & -10.54 & -8.14 & -9.50 & & -9.40 & -10.54 & -10.79 & -10.16 & -10.22 & & -9.78 & -9.91 & -9.40 & -11.04 & -10.03 & \\
\hline 28 & -10.03 & -10.16 & -10.66 & -8.65 & -9.88 & 0.024 & -9.78 & -11.17 & -11.17 & -10.54 & -10.66 & 0.024 & -10.03 & -10.29 & -9.78 & -11.29 & -10.35 & 0.024 \\
\hline 29 & -10.29 & -10.29 & -11.17 & -8.65 & -10.10 & 0.027 & -9.91 & -10.79 & -11.29 & -10.79 & -10.70 & 0.028 & -9.78 & -9.66 & -9.91 & -11.67 & -10.25 & 0.028 \\
\hline 30 & -6.76 & -7.01 & -9.40 & -5.88 & -7.26 & 0.027 & -7.51 & -8.02 & -8.65 & -8.27 & -8.11 & 0.028 & -6.88 & -7.26 & -6.88 & -8.77 & -7.45 & 0.028 \\
\hline 31 & -6.38 & -5.88 & -7.01 & -4.36 & -5.91 & & -6.00 & -6.76 & -7.01 & -6.88 & -6.66 & & -5.88 & -5.75 & -6.38 & -7.39 & -6.35 & \\
\hline 32 & -7.64 & -7.51 & -8.14 & & -7.77 & & -7.39 & -8.27 & -8.27 & -7.89 & -7.96 & & -7.26 & -7.26 & -6.88 & -8.52 & -7.48 & \\
\hline 33 & -8.65 & -7.51 & -9.28 & & -8.48 & & -7.89 & -9.40 & -9.15 & -8.52 & -8.74 & & -8.52 & -8.40 & -8.27 & -9.78 & -8.74 & \\
\hline 34 & -9.53 & -9.78 & -10.16 & -7.89 & -9.34 & & -9.28 & -10.41 & -10.54 & -9.53 & -9.94 & & -9.53 & -9.40 & -9.03 & -10.79 & -9.69 & \\
\hline 35 & -10.03 & -10.41 & -11.04 & -8.65 & -10.03 & & -9.78 & -11.42 & -11.42 & -10.66 & -10.82 & & -10.29 & -10.16 & -9.66 & -11.55 & -10.41 & \\
\hline 36 & -10.79 & -11.29 & -11.67 & -9.53 & -10.82 & & -10.66 & -12.05 & -12.30 & -11.55 & -11.64 & & -11.17 & -11.42 & -11.42 & -12.05 & -11.51 & \\
\hline 37 & -11.55 & -12.18 & -12.55 & -10.29 & -11.64 & & -11.29 & -13.18 & -13.18 & -12.05 & -12.43 & & -12.18 & -11.92 & -10.79 & -13.06 & -11.99 & \\
\hline 38 & -12.05 & -12.81 & -13.06 & -11.42 & -12.33 & & -11.67 & -13.69 & -14.07 & -12.93 & -13.09 & & -12.93 & -12.68 & -11.42 & -13.56 & -12.65 & \\
\hline 39 & -12.81 & -13.94 & -13.94 & -12.30 & -13.25 & & -12.30 & -14.44 & -14.95 & -13.69 & -13.85 & & -14.07 & -13.69 & -12.05 & -14.32 & -13.53 & \\
\hline 40 & -13.31 & -15.07 & -14.95 & -13.31 & -14.16 & & -12.93 & -16.08 & -16.08 & -14.57 & -14.92 & & -15.33 & -14.57 & -12.68 & -15.20 & -14.44 & \\
\hline 41 & -13.81 & -15.07 & -16.08 & -13.69 & -14.66 & & -13.56 & -16.71 & -16.71 & -27.17 & -18.54 & & -16.46 & -15.70 & -13.31 & -15.83 & -15.33 & \\
\hline 42 & -14.70 & -17.34 & -17.22 & -15.07 & -16.08 & & -13.94 & -17.85 & -18.35 & -16.08 & -16.55 & & -18.22 & -17.09 & -14.19 & -16.59 & -16.52 & \\
\hline 43 & -15.58 & -18.60 & -18.22 & -16.46 & -17.22 & 0.020 & -14.57 & -18.98 & -19.61 & -17.34 & -17.63 & 0.021 & -18.73 & -18.10 & -14.82 & -17.22 & -17.22 & 0.036 \\
\hline 44 & -15.58 & -18.98 & -19.11 & -16.59 & -17.56 & 0.014 & -15.20 & -19.99 & -20.62 & -18.60 & -18.60 & 0.014 & -19.99 & -19.11 & -15.58 & -17.85 & -18.13 & 0.028 \\
\hline 45 & -17.34 & -19.74 & -20.11 & -21.25 & -19.61 & & -15.83 & -21.25 & -22.13 & -20.87 & -20.02 & & -12.05 & -18.10 & -14.07 & -16.59 & -15.20 & \\
\hline 46 & -18.10 & -20.62 & -22.00 & -21.25 & -20.49 & & -16.46 & -22.00 & -22.89 & -21.25 & -20.65 & & -12.18 & -18.10 & -13.69 & -16.33 & -15.07 & \\
\hline 47 & -19.23 & -21.63 & -24.52 & -23.01 & -22.10 & & -17.09 & -23.01 & -23.39 & -23.01 & -21.63 & & -13.31 & -19.99 & -14.32 & -15.83 & -15.86 & \\
\hline 48 & -20.37 & -22.26 & -28.30 & -26.54 & -24.37 & & -17.59 & -24.02 & -24.52 & -25.78 & -22.98 & & -14.44 & -19.11 & -15.20 & -16.59 & -16.33 & \\
\hline 49 & -22.51 & -23.39 & -33.47 & -30.32 & -27.42 & & -18.10 & -25.53 & -26.16 & -33.47 & -25.82 & & -15.83 & -20.37 & -16.08 & -17.47 & -17.44 & \\
\hline 50 & -25.28 & -25.15 & -33.72 & -35.11 & -29.82 & 0.014 & -19.11 & -27.55 & -28.43 & -39.14 & -28.56 & 0.014 & -17.59 & -22.13 & -16.84 & -18.60 & -18.79 & 0.028 \\
\hline 51 & -28.81 & -21.37 & 48.84 & -41.03 & -35.01 & & -19.86 & -29.69 & -29.82 & -53.25 & -33.16 & & -21.88 & -24.02 & -17.59 & -19.36 & -20.71 & \\
\hline 52 & -33.47 & -28.18 & -59.30 & 47.71 & -42.16 & & -20.87 & -32.21 & -33.47 & -62.95 & -37.38 & & -19.61 & -25.78 & -18.10 & -20.49 & -21.00 & \\
\hline 53 & -43.17 & -31.20 & -68.12 & -57.41 & 49.98 & & -22.89 & -37.00 & 41.91 & -69.13 & -42.73 & & -20.62 & -28.05 & -18.98 & -21.63 & -22.32 & \\
\hline 54 & -52.75 & -35.36 & -70.01 & -63.21 & -55.33 & 0.014 & -26.16 & 42.29 & -48.21 & -69.38 & -46.51 & 0.014 & -22.13 & -31.33 & -20.11 & -22.13 & -23.93 & 0.028 \\
\hline 55 & -64.09 & -39.90 & -71.90 & -75.43 & -62.83 & & -29.06 & -51.11 & -58.54 & -74.42 & -53.28 & & -23.64 & -34.86 & -21.50 & -23.77 & -25.94 & \\
\hline 56 & -67.24 & -43.55 & -71.27 & -71.90 & -63.49 & & -34.73 & -58.42 & -65.22 & -73.79 & -58.04 & & -24.65 & -39.14 & -23.39 & -25.53 & -28.18 & \\
\hline 57 & -69.88 & -59.80 & -72.28 & -74.80 & -69.19 & 0.014 & 44.18 & -70.26 & -74.17 & -75.43 & -66.01 & 0.014 & -26.16 & -47.83 & -26.04 & -28.18 & -32.05 & 0.028 \\
\hline 58 & -71.90 & -60.56 & -72.66 & -74.92 & -70.01 & & -46.70 & -73.66 & -76.18 & -75.43 & -67.99 & & -26.54 & -50.98 & -27.80 & -29.69 & -33.75 & \\
\hline 59 & -71.90 & -63.84 & -72.40 & -73.16 & -70.33 & & -52.37 & -73.66 & -75.68 & -75.43 & -69.29 & & -24.15 & -53.63 & -29.56 & -31.96 & -34.82 & \\
\hline 60 & -71.90 & -69.88 & -73.79 & -74.42 & -72.50 & & -59.93 & -74.42 & -75.68 & -75.68 & -71.43 & & -24.65 & -59.55 & -31.96 & -34.10 & -37.57 & \\
\hline 61 & -71.77 & -70.51 & -73.16 & -73.79 & -72.31 & 0.014 & -65.60 & -74.29 & -76.18 & -76.18 & -73.07 & 0.014 & -26.16 & -61.32 & -34.10 & -37.00 & -39.64 & 0.028 \\
\hline 62 & -71.90 & -72.78 & -73.54 & -72.66 & -72.72 & & -68.50 & -74.42 & -72.53 & -75.05 & -72.62 & & -18.60 & -68.12 & -36.87 & -38.26 & -40.46 & \\
\hline 63 & -71.90 & -73.16 & -73.16 & -73.66 & -72.97 & & -71.27 & -73.92 & -73.16 & -73.79 & -73.03 & & -15.96 & -70.14 & -38.26 & -39.77 & -41.03 & \\
\hline 64 & -71.90 & -73.79 & -72.78 & -73.66 & -73.03 & & -71.27 & -73.16 & -74.04 & -74.42 & -73.22 & & -17.47 & -72.40 & -38.89 & -41.03 & -42.45 & \\
\hline 65 & & -75.30 & -74.55 & -74.55 & -74.80 & 0.014 & -73.79 & -74.92 & -72.66 & -74.29 & -73.92 & 0.014 & -20.62 & -72.03 & -42.04 & -45.69 & 45.09 & 0.028 \\
\hline 66 & -74.55 & -75.30 & -75.43 & -74.80 & -75.02 & & -73.41 & -76.18 & -74.04 & -76.06 & -74.92 & & -16.08 & -72.91 & -37.63 & -47.20 & -43.46 & \\
\hline 67 & -74.67 & -73.79 & -74.17 & -74.29 & -74.23 & & -72.66 & -75.18 & -74.04 & -74.92 & -74.20 & & -14.82 & -71.65 & -38.38 & -47.58 & -43.11 & \\
\hline 68 & -75.43 & -73.79 & -75.30 & & -74.84 & & & -74.92 & -74.17 & -74.80 & -74.63 & & -17.09 & -72.78 & -39.52 & -48.21 & 44.40 & \\
\hline 69 & & -74.04 & -75.05 & & & & & -74.80 & -74.17 & -74.80 & -74.59 & & -19.48 & -71.65 & -43.55 & -49.22 & -45.98 & \\
\hline 70 & & -74.55 & & & & & & -75.30 & -74.29 & -75.30 & -74.97 & & -22.76 & -71.90 & -47.96 & -52.37 & -48.75 & \\
\hline 71 & & -74.80 & -73.54 & & & 0.014 & & -74.92 & -72.78 & & & 0.014 & -25.66 & -72.91 & -50.73 & -53.50 & -50.70 & 0.028 \\
\hline 72 & & -74.92 & -73.66 & & & & & -75.05 & -72.78 & & & & -25.91 & -75.68 & -55.27 & -57.54 & -53.60 & \\
\hline 73 & & & -74.92 & & & & & -74.92 & -74.42 & & & & -27.04 & -76.56 & -61.06 & -61.19 & -56.47 & \\
\hline 74 & & & -74.04 & & & 0.020 & & & -74.42 & & & 0.041 & -30.70 & -74.42 & -61.44 & -63.46 & -57.50 & 0.041 \\
\hline 75 & -72.78 & & -74.55 & & & & & -75.05 & -74.80 & & & & -7.64 & -73.79 & -57.41 & -67.24 & -51.52 & \\
\hline
\end{tabular}

(continua). 
Profundidade $0,70 \mathrm{~m}$ (continuação).

\begin{tabular}{|c|c|c|c|c|c|c|c|c|c|c|c|c|c|c|c|c|c|c|}
\hline \multirow[b]{2}{*}{ DAS } & \multicolumn{6}{|c|}{ trat-000 } & \multicolumn{6}{|c|}{ trat $0 \mathrm{IO}$} & \multicolumn{6}{|c|}{ trat III } \\
\hline & rl & $\mathrm{r} 2$ & r3 & $\mathrm{r} 4$ & média & $\mathrm{P}+\mathrm{I}$ & rl & 2 & r3 & $\mathrm{r} 4$ & média & $\mathrm{P}+\mathrm{I}$ & $\mathrm{r} 1$ & 2 & r3 & $\mathrm{r}$ & média & $\mathrm{P}+\mathrm{I}$ \\
\hline 76 & -74.04 & & -74.29 & & & & & -74.42 & -75.05 & & & & -10.16 & -73.79 & -52.75 & -59.30 & -49.00 & \\
\hline 77 & & & -74.29 & & & & & -74.42 & -73.54 & & & & -12.68 & -74.04 & -54.26 & -51.74 & -48.18 & \\
\hline 78 & -73.54 & & -74.42 & & & 0.020 & & -75.05 & -74.67 & & & 0.041 & -5.25 & -75.43 & -39.77 & -13.06 & -33.38 & 0.041 \\
\hline 79 & -73.41 & & -74.55 & & & & -74.92 & -75.05 & -74.55 & & -74.84 & & -8.14 & -75.55 & -25.03 & -12.68 & -30.35 & \\
\hline 80 & -73.41 & & -74.55 & & & & 46.57 & -75.05 & -74.42 & & -65.35 & & -8.90 & -75.81 & -25.66 & -12.81 & -30.79 & \\
\hline 81 & & & -75.30 & & & & -36.37 & -75.05 & -74.42 & & -61.95 & & -10.16 & -76.06 & -28.43 & -13.69 & -32.08 & \\
\hline 82 & & & & & & & 42.29 & & -74.42 & & & & -11.42 & & -32.21 & -15.83 & -19.82 & \\
\hline 83 & & & & & & & -52.75 & & -74.42 & & & & -13.31 & & -37.88 & -18.35 & -23.18 & \\
\hline 84 & & & & & & & -61.19 & & -74.42 & & & & -14.95 & & 45.06 & -20.62 & -26.88 & \\
\hline 85 & & & & & & 0.014 & -66.23 & & -73.16 & & & 0.028 & -16.71 & & -51.74 & -22.76 & -30.40 & 0.028 \\
\hline 86 & & & & & & & -68.12 & & -74.17 & & & & -4.87 & & -59.30 & -17.22 & -27.13 & \\
\hline 87 & & & & & & & -19.48 & -72.66 & -74.42 & & -55.52 & & -7.26 & & -63.96 & -9.03 & -26.75 & \\
\hline 88 & & -74.55 & -75.43 & -75.05 & & 0.047 & -5.25 & -8.90 & -8.14 & -75.68 & -24.49 & 0.047 & -4.99 & -7.64 & -16.71 & -6.76 & -9.03 & 0.047 \\
\hline 89 & & -70.01 & -41.66 & & & & -3.86 & -8.65 & -8.52 & -76.69 & -24.43 & & -7.01 & -8.14 & -11.67 & -8.40 & -8.81 & \\
\hline 90 & -75.68 & -71.90 & -60.56 & -75.05 & -70.80 & 0.019 & -4.24 & -7.89 & -7.51 & -17.97 & -9.40 & 0.019 & -6.88 & -7.51 & -9.78 & -8.52 & -8.18 & 0.019 \\
\hline 91 & & -15.07 & -65.10 & -73.79 & -51.32 & 0.017 & -4.49 & -7.51 & -7.14 & -12.05 & -7.80 & 0.017 & -6.38 & -6.38 & -8.27 & -8.14 & -7.29 & 0.017 \\
\hline 92 & -5.88 & -4.87 & -7.64 & -74.17 & -23.14 & 0.045 & -3.86 & -5.75 & -5.12 & -8.40 & -5.78 & 0.045 & -4.49 & -4.74 & -5.25 & -6.25 & -5.18 & 0.045 \\
\hline 93 & -7.14 & -6.88 & -7.89 & -6.38 & -7.07 & & -7.39 & -7.64 & -7.89 & -8.52 & -7.86 & & -6.76 & -6.38 & -6.88 & -8.14 & -7.04 & \\
\hline 94 & -9.40 & -8.77 & -9.91 & -7.89 & -8.99 & & -8.52 & -9.53 & -9.78 & -9.28 & -9.28 & & -8.65 & -8.14 & -8.40 & -9.78 & -8.74 & \\
\hline 95 & -11.67 & -11.29 & -12.68 & -10.03 & -11.42 & & -10.66 & -11.55 & -11.29 & -11.67 & -11.29 & & -10.16 & -9.78 & -9.53 & -11.42 & -10.22 & \\
\hline 96 & -11.17 & -11.92 & -14.57 & -11.67 & -12.33 & & -11.92 & -13.18 & -11.04 & -13.31 & -12.37 & & -11.55 & -10.79 & -10.79 & -12.55 & -11.42 & \\
\hline 97 & -15.20 & -14.07 & -17.72 & -15.58 & -15.64 & & -13.44 & -15.58 & -12.93 & -15.83 & -14.44 & & -13.18 & -12.43 & -12.05 & -14.19 & -12.96 & \\
\hline 98 & -19.48 & -16.21 & -22.13 & -19.99 & -19.45 & & -15.33 & -17.47 & -14.19 & -19.74 & -16.68 & & -14.95 & -14.82 & -13.81 & -15.96 & -14.89 & \\
\hline 99 & -24.65 & -18.73 & -28.81 & -27.17 & -24.84 & & -17.47 & -20.24 & -15.83 & -24.52 & -19.52 & & -17.09 & -16.21 & -15.83 & -18.10 & -16.81 & \\
\hline 100 & -34.10 & -22.76 & -37.38 & -40.40 & -33.66 & 0.023 & -19.99 & -26.16 & -20.11 & -31.33 & -24.40 & 0.044 & -19.48 & -20.87 & -18.60 & -21.12 & -20.02 & 0.044 \\
\hline 101 & -37.25 & -22.76 & -38.89 & 40.40 & -34.82 & & -18.98 & -23.89 & -11.17 & -34.23 & -22.07 & & -10.41 & -16.96 & -16.21 & -20.24 & -15.96 & \\
\hline 102 & -49.22 & -24.90 & -42.42 & -47.08 & -40.90 & & -17.09 & -22.00 & -11.17 & -36.62 & -21.72 & & -10.79 & -15.70 & -15.96 & -21.88 & -16.08 & \\
\hline 103 & -57.79 & -26.16 & 46.70 & -55.52 & -46.54 & & -17.72 & -22.26 & -11.67 & -39.14 & -22.70 & & -13.06 & -17.97 & -18.48 & -22.38 & -17.97 & \\
\hline 104 & -63.71 & -30.07 & -52.75 & -60.56 & -51.77 & & -19.74 & -25.28 & -15.20 & -40.40 & -25.15 & & -14.70 & -19.61 & -20.74 & -23.77 & -19.70 & \\
\hline 105 & -67.74 & -32.34 & -58.92 & -66.23 & -56.31 & & -21.50 & -27.17 & -17.47 & -44.94 & -27.77 & & -16.96 & -22.26 & -23.77 & -25.91 & -22.22 & \\
\hline 106 & -68.12 & -35.74 & -63.08 & -66.23 & -58.29 & 0.020 & -23.39 & -27.42 & -17.59 & -45.31 & -28.43 & 0.041 & -6.00 & -24.78 & -25.41 & -19.61 & -18.95 & 0.041 \\
\hline 107 & -71.52 & -32.71 & -59.93 & -68.75 & -58.23 & 0.031 & -18.85 & -23.64 & -11.80 & -45.57 & -24.97 & 0.031 & -7.14 & -20.87 & -26.92 & -21.25 & -19.04 & 0.031 \\
\hline 108 & -72.78 & -35.99 & -61.69 & -69.00 & -59.87 & & -7.89 & -9.66 & -7.51 & -41.41 & -16.62 & & -5.88 & -7.89 & -11.17 & -12.30 & -9.31 & \\
\hline 109 & -72.53 & -4.62 & -60.31 & -68.88 & -51.58 & 0.038 & -3.23 & -10.54 & -5.37 & -3.99 & -5.78 & 0.038 & -3.36 & -3.86 & -4.74 & -5.37 & -4.33 & 0.038 \\
\hline 110 & -10.54 & -6.38 & -8.90 & -17.97 & -10.95 & & -6.88 & -7.39 & -7.39 & -6.88 & -7.14 & & -6.51 & -6.38 & -7.01 & -7.77 & -6.92 & \\
\hline 111 & -9.15 & -8.40 & -10.16 & -7.26 & -8.74 & & -8.65 & -9.28 & -9.15 & -5.12 & -8.05 & & -8.02 & -8.02 & -8.02 & -9.28 & -8.33 & \\
\hline 112 & -11.04 & -9.66 & -11.42 & -7.39 & -9.88 & & -9.66 & -10.66 & -10.54 & -6.38 & -9.31 & & -9.28 & -9.28 & -9.15 & -10.66 & -9.59 & \\
\hline 113 & -8.27 & -4.62 & -6.00 & -7.26 & -6.54 & 0.055 & 4.74 & -5.88 & -5.50 & -6.88 & -5.75 & 0.055 & 4.36 & -4.62 & -5.75 & -6.88 & -5.40 & 0.055 \\
\hline 114 & -8.52 & -6.76 & -7.51 & -7.39 & -7.55 & & -7.26 & -7.77 & -7.77 & -7.01 & -7.45 & & -6.88 & -6.38 & -6.88 & -8.27 & -7.10 & \\
\hline 115 & -9.03 & -8.40 & -9.15 & -7.77 & -8.59 & & -8.90 & -9.66 & -9.40 & -9.03 & -9.25 & & -8.40 & -8.14 & -8.27 & -10.03 & -8.71 & \\
\hline 116 & -10.66 & -9.78 & -10.54 & -7.89 & -9.72 & & -10.03 & -11.29 & -11.04 & -10.66 & -10.76 & & -9.66 & -9.66 & -9.53 & -11.67 & -10.13 & \\
\hline 117 & -12.05 & -11.04 & -11.80 & -8.27 & -10.79 & & -11.29 & -12.93 & -12.18 & -12.05 & -12.11 & & -10.92 & -10.79 & -10.66 & -12.68 & -11.26 & \\
\hline 118 & -13.31 & -12.05 & -12.81 & -9.78 & -11.99 & & -12.43 & -14.32 & -13.31 & -13.31 & -13.34 & & -11.80 & -12.05 & -11.55 & -13.56 & -12.24 & \\
\hline 119 & -14.82 & -13.31 & -13.81 & -10.79 & -13.18 & & -13.18 & -16.21 & -14.44 & -14.57 & -14.60 & & -12.93 & -13.06 & -12.55 & -15.96 & -13.63 & \\
\hline 120 & -16.46 & -14.57 & -14.82 & -13.06 & -14.73 & & -14.32 & -18.22 & -15.58 & -16.33 & -16.11 & & -14.19 & -14.19 & -13.94 & -16.08 & -14.60 & \\
\hline 121 & -17.97 & -15.45 & -15.70 & -14.19 & -15.83 & 0.006 & -15.20 & -19.23 & -16.59 & -17.47 & -17.12 & 0.006 & -14.95 & -15.20 & -14.82 & -17.22 & -15.55 & 0.006 \\
\hline 122 & -18.98 & -16.33 & -16.46 & -14.57 & -16.59 & & -15.96 & -20.37 & -17.22 & -18.73 & -18.07 & & -15.83 & -16.21 & -15.83 & -17.59 & -16.37 & \\
\hline 123 & -19.23 & -17.22 & -16.59 & -17.72 & -17.69 & 0.035 & -16.71 & -21.75 & -17.34 & -16.71 & -18.13 & 0.035 & -15.83 & -16.84 & -15.58 & -14.95 & -15.80 & 0.035 \\
\hline 124 & -17.97 & -12.05 & -12.05 & -14.57 & -14.16 & & -13.06 & -16.71 & -11.80 & -15.33 & -14.22 & & -9.66 & -11.80 & -11.92 & -15.83 & -12.30 & \\
\hline 125 & -16.71 & -11.92 & -12.18 & -15.33 & -14.03 & & -12.55 & -15.45 & -12.18 & -15.96 & -14.03 & & -9.91 & -11.80 & -12.55 & -15.58 & -12.46 & \\
\hline 126 & -17.59 & -13.06 & -12.81 & -16.08 & -14.89 & & -13.18 & -15.96 & -13.18 & -17.85 & -15.04 & & -11.29 & -13.06 & -13.94 & -15.70 & -13.50 & \\
\hline 127 & -18.35 & -13.94 & -13.69 & -16.08 & -15.52 & & -13.94 & -16.84 & -14.19 & -18.85 & -15.96 & & -11.80 & -14.07 & -15.07 & -16.46 & -14.35 & \\
\hline 128 & -20.37 & -15.45 & -15.07 & -15.58 & -16.62 & & -15.20 & -18.48 & -15.45 & -20.87 & -17.50 & & -12.93 & -15.45 & -16.59 & -17.72 & -15.67 & \\
\hline 129 & & & & & & 0.008 & & & & & & 0.008 & & & & & & 0.008 \\
\hline 130 & -23.64 & -17.85 & -16.59 & -21.37 & -19.86 & 0.007 & -17.34 & -20.49 & -17.47 & -24.15 & -19.86 & 0.007 & -15.20 & -17.85 & -18.48 & -19.36 & -17.72 & 0.007 \\
\hline 131 & -23.52 & -18.35 & -16.96 & -21.25 & -20.02 & 0.021 & -17.72 & -20.62 & -17.85 & -24.52 & -20.18 & 0.021 & -15.83 & -18.35 & -18.98 & -19.48 & -18.16 & 0.021 \\
\hline 132 & -24.52 & -17.85 & -15.45 & -22.63 & -20.11 & & -17.97 & -20.11 & -14.82 & -22.89 & -18.95 & & -13.69 & -16.21 & -17.34 & -19.74 & -16.74 & \\
\hline 133 & -25.66 & -15.45 & -13.18 & -23.26 & -19.39 & & -16.59 & -17.47 & -12.81 & -21.12 & -17.00 & & -11.17 & -13.06 & -14.32 & -18.10 & -14.16 & \\
\hline 134 & -25.03 & -14.70 & -13.06 & -25.66 & -19.61 & 0.015 & -15.33 & -16.59 & -12.93 & -20.74 & -16.40 & 0.015 & -11.17 & -12.93 & -14.19 & -15.96 & -13.56 & 0.015 \\
\hline 135 & -23.64 & -13.94 & -9.66 & -22.76 & -17.50 & & -14.57 & -14.95 & -14.82 & -19.61 & -15.99 & & -10.41 & -11.42 & -13.06 & -14.44 & -12.33 & \\
\hline 136 & -21.25 & -12.43 & -11.55 & -21.50 & -16.68 & & -12.81 & -13.56 & -11.67 & -17.97 & -14.00 & & -10.03 & -10.79 & -12.30 & -12.93 & -11.51 & \\
\hline 137 & -19.23 & -13.06 & -11.80 & -20.37 & -16.11 & & -12.68 & -13.94 & -11.92 & -17.85 & -14.10 & & -9.91 & -10.92 & -12.18 & -12.68 & -11.42 & \\
\hline 138 & -18.60 & -13.81 & -12.05 & -18.85 & -15.83 & & -12.93 & -14.57 & -12.55 & -18.22 & -14.57 & & -10.79 & -11.55 & -12.43 & -13.06 & -11.96 & \\
\hline 139 & & & & & & 0.008 & & & & & & 0.008 & & & & & & 0.008 \\
\hline 141 & & & & & & 0.020 & & & & & & 0.020 & & & & & & 0.020 \\
\hline 142 & & & & & & 0.025 & & & & & & 0.025 & & & & & & 0.025 \\
\hline 143 & & & & & & 0.015 & & & & & & 0.015 & & & & & & 0.015 \\
\hline 146 & & & & & & 0.043 & & & & & & 0.043 & & & & & & 0.043 \\
\hline 147 & & & & & & 0.070 & & & & & & 0.070 & & & & & & 0.070 \\
\hline
\end{tabular}


Profundidade $0,80 \mathrm{~m}$.

\begin{tabular}{|c|c|c|c|c|c|c|c|c|c|c|c|c|c|c|c|c|c|c|}
\hline \multirow[b]{2}{*}{ DAS } & \multicolumn{6}{|c|}{ trat -000} & \multicolumn{6}{|c|}{ trat $0 \mathrm{IO}$} & \multicolumn{6}{|c|}{ trat III } \\
\hline & rl & 12 & $\mathrm{r} 3$ & $\mathrm{r4}$ & média & P+I & $\mathrm{rl}$ & 12 & r3 & $\mathrm{r4}$ & média & $\mathrm{P}+\mathrm{I}$ & $\mathrm{rl}$ & 12 & $\mathrm{r} 3$ & $\mathrm{r4}$ & média & $\mathrm{P}+\mathrm{I}$ \\
\hline 0 & & & & & & 0.020 & & & & & & 0.021 & & & & & & 0.021 \\
\hline 1 & & & & & & 0.014 & & & & & & 0.014 & & & & & & 0.014 \\
\hline 2 & & & & & & 0.027 & & & & & & 0.028 & & & & & & 0.028 \\
\hline 4 & & & & & & 0.027 & & & & & & 0.028 & & & & & & 0.028 \\
\hline 5 & & & & & & 0.020 & & & & & & 0.021 & & & & & & 0.021 \\
\hline 7 & & & & & & 0.027 & & & & & & 0.028 & & & & & & 0.028 \\
\hline 8 & & & & & & 0.020 & & & & & & 0.021 & & & & & & 0.021 \\
\hline 9 & & & & & & 0.020 & & & & & & 0.021 & & & & & & 0.021 \\
\hline 13 & & & & & & 0.027 & & & & & & 0.028 & & & & & & 0.028 \\
\hline 16 & & & & & & 0.020 & & & & & & 0.021 & & & & & & 0.021 \\
\hline 17 & -5.63 & -9.66 & -11.18 & -8.40 & -8.72 & & -9.29 & -10.29 & -11.43 & -9.66 & -10.17 & & -9.16 & -9.92 & -8.91 & -10.80 & -9.70 & \\
\hline 18 & -5.88 & -9.79 & -11.30 & -8.53 & -8.88 & 0.014 & -9.41 & -10.42 & -11.43 & -9.54 & -10.20 & 0.014 & -9.41 & -9.92 & -9.03 & -11.30 & -9.92 & 0.014 \\
\hline 19 & -6.01 & -9.92 & -11.43 & -8.40 & -8.94 & & -9.29 & -10.55 & -11.43 & -9.66 & -10.23 & & -9.41 & -9.79 & -8.91 & -11.30 & -9.85 & \\
\hline 20 & -5.76 & -10.17 & -11.43 & -8.53 & -8.97 & 0.019 & -9.41 & -10.55 & -11.93 & -9.92 & -10.45 & 0.020 & -9.54 & -10.04 & -9.16 & -11.30 & -10.01 & 0.020 \\
\hline 21 & -7.02 & -9.54 & -11.43 & -7.90 & -8.97 & 0.011 & -8.53 & -9.66 & -11.30 & -9.29 & -9.70 & 0.011 & -8.53 & -9.41 & -9.16 & -10.92 & -9.51 & 0.011 \\
\hline 22 & -7.65 & -8.28 & -11.05 & -6.64 & -8.40 & & -7.65 & -8.53 & -9.79 & -8.40 & -8.59 & & -7.27 & -8.40 & -9.29 & -9.54 & -8.62 & \\
\hline 23 & -7.65 & -8.78 & -10.92 & -6.77 & -8.53 & 0.027 & -8.15 & -9.29 & -10.29 & -8.66 & -9.10 & 0.028 & -7.90 & -8.66 & -9.29 & -9.54 & -8.85 & 0.028 \\
\hline 24 & -7.65 & -6.77 & -10.04 & -5.51 & -7.49 & & -6.77 & -7.27 & -8.40 & -6.64 & -7.27 & & -6.14 & -6.77 & -7.52 & -8.40 & -7.21 & \\
\hline 25 & -7.65 & -7.65 & -9.79 & -6.39 & -7.87 & & -7.52 & -8.28 & -9.16 & -7.52 & -8.12 & & -7.02 & -7.65 & -7.77 & -8.40 & -7.71 & \\
\hline 26 & -8.28 & -8.78 & -10.42 & -7.40 & -8.72 & & -8.15 & -9.41 & -10.29 & -8.40 & -9.07 & & -9.29 & -8.53 & -8.40 & -9.66 & -8.97 & \\
\hline 27 & -7.52 & -9.92 & -11.30 & -8.40 & -9.29 & & -9.03 & -10.67 & -10.80 & -9.79 & -10.07 & & -9.41 & -9.79 & -8.91 & -10.80 & -9.73 & \\
\hline 28 & -7.77 & -10.29 & -11.43 & -8.78 & -9.57 & 0.024 & -9.41 & -11.05 & -11.43 & -10.04 & -10.48 & 0.024 & -9.66 & -10.17 & -9.41 & -11.30 & -10.14 & 0.024 \\
\hline 29 & -7.65 & -10.42 & -11.93 & -9.41 & -9.85 & 0.027 & -9.66 & -11.18 & -12.31 & -10.29 & -10.86 & 0.028 & -9.92 & -10.42 & -9.66 & -11.68 & -10.42 & 0.028 \\
\hline 30 & -8.40 & -7.65 & -11.68 & -7.65 & -8.85 & 0.027 & -8.15 & -8.66 & -10.55 & -8.53 & -8.97 & 0.028 & -7.40 & -8.15 & -7.90 & -9.79 & -8.31 & 0.028 \\
\hline 31 & -7.27 & -5.88 & -10.04 & 4.75 & -6.99 & & -6.26 & -6.77 & -7.77 & -6.51 & -6.83 & & -5.76 & -6.14 & -6.51 & -7.52 & -6.48 & \\
\hline 32 & -9.03 & -7.40 & -9.92 & & -8.78 & & -7.14 & -8.15 & -9.16 & -7.52 & -7.99 & & -7.02 & -7.27 & -7.27 & -8.40 & -7.49 & \\
\hline 33 & -8.91 & -8.40 & -9.41 & & -8.91 & & -8.15 & -8.03 & -9.66 & -8.40 & -8.56 & & -8.15 & -8.28 & -8.15 & -9.54 & -8.53 & \\
\hline 34 & -9.79 & -9.41 & -10.17 & -8.28 & -9.41 & & -9.03 & -10.29 & -11.43 & -9.29 & -10.01 & & -9.03 & -9.29 & -8.91 & -10.55 & -9.44 & \\
\hline 35 & -10.42 & -10.42 & -11.30 & -9.16 & -10.33 & & -9.41 & -11.18 & -11.81 & -10.04 & -10.61 & & -9.92 & -10.04 & -9.16 & -11.30 & -10.11 & \\
\hline 36 & -10.80 & -11.05 & -11.93 & -9.79 & -10.89 & & -10.29 & -12.81 & -12.56 & -10.92 & -11.65 & & -10.80 & -10.92 & -9.79 & -11.93 & -10.86 & \\
\hline 37 & -10.80 & -11.81 & -12.06 & -10.42 & -11.27 & & -10.67 & -12.81 & -13.44 & -11.43 & -12.09 & & -11.55 & -11.68 & -10.29 & -12.69 & -11.55 & \\
\hline 38 & -11.30 & -12.31 & -12.81 & -11.05 & -11.87 & & -11.05 & -13.44 & -14.33 & -12.31 & -12.78 & & -12.18 & -12.31 & -10.80 & -13.19 & -12.12 & \\
\hline 39 & -11.43 & -13.19 & -13.19 & -11.93 & -12.44 & & -11.55 & -14.33 & -14.96 & -12.94 & -13.44 & & -12.94 & -13.19 & -11.43 & -13.82 & -12.85 & \\
\hline 40 & -11.43 & -13.95 & -13.57 & -12.81 & -12.94 & & -12.18 & -15.21 & -15.71 & -13.70 & -14.20 & & -13.82 & -14.07 & -12.06 & -14.58 & -13.63 & \\
\hline 41 & -11.68 & -14.70 & -13.82 & -13.44 & -13.41 & & -12.56 & -15.84 & -16.97 & -14.58 & -14.99 & & -14.58 & -14.58 & -12.69 & -15.08 & -14.23 & \\
\hline 42 & -11.93 & -15.46 & -13.82 & -14.45 & -13.92 & & -12.81 & -16.72 & -17.73 & -15.33 & -15.65 & & -15.46 & -15.46 & -13.19 & -15.59 & -14.92 & \\
\hline 43 & -12.44 & -16.34 & -14.07 & -15.21 & -14.52 & 0.020 & -13.32 & -17.35 & -18.48 & -16.22 & -16.34 & 0.021 & -16.34 & -16.47 & -13.57 & -16.22 & -15.65 & 0.036 \\
\hline 44 & -13.19 & -16.85 & -14.07 & -16.09 & -15.05 & 0.014 & -13.82 & -18.36 & -18.99 & -17.10 & -17.07 & 0.014 & -17.10 & -16.97 & -13.95 & -16.72 & -16.18 & 0.028 \\
\hline 45 & -13.44 & -17.73 & -15.84 & -17.60 & -16.15 & & -14.33 & -19.37 & -19.87 & -18.48 & -18.01 & & -13.32 & -17.60 & -13.70 & -16.97 & -15.40 & \\
\hline 46 & -13.82 & -18.23 & -15.96 & -18.61 & -16.66 & & -14.70 & -20.00 & -20.88 & -19.24 & -18.70 & & -12.94 & -17.22 & -13.57 & -16.72 & -1 & \\
\hline 47 & -16.34 & -18.99 & -16.34 & -20.37 & -18.01 & & -15.08 & -20.88 & -21.51 & -20.63 & -19.52 & & -12.44 & -17.35 & -13.95 & -16.22 & -14.99 & \\
\hline 48 & -17.22 & -19.62 & -16.72 & -23.15 & -19.18 & & -15.46 & -21.63 & -22.39 & -21.89 & -20.34 & & -13.82 & -17.60 & -14.33 & -16.47 & -15.55 & \\
\hline 49 & -18.23 & -20.25 & -17.35 & -25.92 & -20.44 & & -16.09 & -22.64 & -23.65 & -23.65 & -21.51 & & -14.83 & -18.23 & -14.83 & -16.97 & -16.22 & \\
\hline 50 & -18.61 & -21.13 & -18.61 & -27.18 & -21.38 & 0.014 & -16.47 & -24.03 & -24.41 & -25.92 & -22.71 & 0.014 & -15.96 & -18.99 & -15.46 & -17.60 & -17.00 & 0.028 \\
\hline 51 & -16.59 & -22.01 & -18.99 & -24.91 & -20.63 & & -16.97 & -25.29 & -26.42 & -29.19 & -24.47 & & -17.10 & -20.12 & -15.96 & -17.98 & -17.79 & \\
\hline 52 & -19.24 & -23.15 & -19.87 & 45.70 & -26.99 & & -17.60 & -27.18 & -28.44 & -33.48 & -26.67 & & -17.60 & -20.88 & -16.59 & -18.74 & -18 & \\
\hline 53 & -21.76 & -24.66 & -21.38 & -57.67 & -31.37 & & -18.61 & -30.20 & -32.60 & -41.54 & -30.74 & & -18.23 & -21.89 & -17.10 & -19.37 & -19.15 & \\
\hline 54 & -24.28 & -26.80 & -24.28 & -63.47 & -34.71 & 0.014 & -19.87 & -35.24 & -37.51 & -52.00 & -36.16 & 0.014 & -18.74 & -23.02 & -17.85 & -20.00 & -19.90 & 0.028 \\
\hline 55 & -25.54 & -29.32 & -26.80 & -71.40 & -38.27 & & -21.13 & 42.42 & 40.41 & -62.71 & -41.67 & & -19.87 & -24.28 & -18.86 & -21.00 & -21.00 & \\
\hline 56 & -21.76 & -33.10 & -26.42 & -70.90 & -38.05 & & -22.77 & -57.04 & 45.07 & -60.06 & 46.24 & & -20.25 & -26.17 & -19.87 & -21.76 & -22.01 & \\
\hline 57 & -23.90 & 40.28 & -33.86 & -73.80 & -42.96 & 0.014 & -26.80 & -72.41 & -56.66 & -72.92 & -57.20 & 0.014 & -21.26 & -28.06 & -21.51 & -23.02 & -23.46 & 0.028 \\
\hline 58 & -26.04 & 45.95 & -35.62 & -73.67 & -45.32 & & -28.31 & -70.90 & -56.28 & -73.80 & -57.32 & & -21.76 & -29.70 & -22.64 & -23.90 & -24.50 & \\
\hline 59 & -26.17 & -52.25 & -39.90 & -72.16 & 47.62 & & -32.85 & -70.90 & -56.79 & -71.66 & -58.05 & & -21.38 & -31.08 & -23.65 & -24.91 & -2 & \\
\hline 60 & -29.95 & -62.46 & 48.85 & -74.05 & -53.83 & & & -72.16 & -64.47 & -73.42 & -70.02 & & -21.76 & -33.10 & -25.54 & -25.92 & -26.58 & \\
\hline 61 & -30.08 & -67.88 & -58.68 & -72.79 & -57.36 & 0.014 & & -72.16 & -67.75 & -72.54 & -70.82 & 0.014 & -22.39 & -34.86 & -26.93 & -27.30 & -27.87 & 0.028 \\
\hline 62 & -33.10 & -70.52 & -65.36 & -72.54 & -60.38 & & & -74.05 & -69.64 & -72.79 & -72.16 & & -20.50 & -36.88 & -28.69 & -28.31 & -28.60 & \\
\hline 63 & -34.36 & -70.52 & -69.89 & -72.16 & -61.73 & & & -74.18 & -70.65 & -73.42 & -72.75 & & -17.98 & -39.40 & -30.58 & -29.32 & -29.32 & \\
\hline 64 & & -70.02 & -70.90 & -72.66 & -71.19 & & & -74.05 & -70.27 & -73.67 & -72.66 & & -17.98 & 41.16 & -31.84 & -30.33 & -30.33 & \\
\hline 65 & -77.07 & -71.40 & -73.67 & -73.17 & -73.83 & 0.014 & & -73.92 & -72.16 & -73.29 & -73.13 & 0.014 & -19.62 & -45.20 & -34.61 & -31.97 & -32.85 & 0.028 \\
\hline 66 & & -73.04 & -72.41 & -74.55 & -73.34 & & & -75.18 & -73.17 & -74.55 & -74.30 & & -18.86 & 48.60 & -29.95 & -33.35 & -32.69 & \\
\hline 67 & & -71.78 & -70.52 & -73.29 & -71.87 & & & -73.92 & -71.66 & -74.05 & -73 & & -16.59 & -50.36 & -37.51 & -34.49 & -34.74 & \\
\hline 68 & & -73.04 & -70.90 & & & & & -73.80 & -71.66 & -73.55 & -73.00 & & -17.35 & -52.88 & -39.15 & -35.75 & & \\
\hline 69 & & -73.04 & -73.17 & & & & & -73.92 & -71.66 & -73.42 & -73.00 & & -19.24 & -55.78 & 40.03 & -37.13 & & \\
\hline 70 & & -75.18 & -73.67 & & & & & -74.68 & -72.16 & -73.92 & -73.59 & & -21.51 & -60.57 & $\mathbf{4 4 . 4 4}$ & 40.03 & 41.64 & \\
\hline 71 & & -74.93 & -72.16 & & & 0.014 & & -74.43 & -70.90 & & & 0.014 & -23.02 & -64.60 & 47.59 & 41.29 & 44.13 & 0.028 \\
\hline 72 & & -73.42 & -74.05 & & & & & -74.55 & -74.05 & & & & -23.90 & -69.39 & 49.48 & 43.81 & 46.65 & \\
\hline 73 & & & -74.55 & & & & & -74.18 & & & & & -24.91 & -72.79 & -53.01 & 46.58 & 49.32 & \\
\hline 74 & & & -72.66 & & & 0.020 & & & -72.16 & & & 0.041 & -27.18 & -70.02 & -53.89 & -51.37 & -50.61 & 0. \\
\hline 75 & & & -73.67 & & & & & -73.67 & -74.05 & -73.80 & -73.84 & & -8.28 & -71.15 & -58.68 & -55.28 & -48.35 & \\
\hline
\end{tabular}

(continua). 
Profundidade $0,80 \mathrm{~m}$ (continuação).

\begin{tabular}{|c|c|c|c|c|c|c|c|c|c|c|c|c|c|c|c|c|c|c|}
\hline \multirow[b]{2}{*}{ DAS } & \multicolumn{6}{|c|}{ trat -000} & \multicolumn{6}{|c|}{ trat $0 \mathrm{IO}$} & \multicolumn{6}{|c|}{ trat III } \\
\hline & r1 & 12 & $\mathrm{r} 3$ & $\mathrm{r} 4$ & média & $\mathrm{P}+\mathrm{I}$ & rl & 12 & $\mathrm{r} 3$ & $\mathrm{r} 4$ & média & $\mathrm{P}+\mathrm{I}$ & r1 & 12 & r3 & $\mathrm{r} 4$ & média & $\mathrm{P}+\mathrm{I}$ \\
\hline 76 & & & -73.29 & & & & & -73.42 & -74.05 & -74.43 & -73.97 & & -10.17 & & -60.82 & -56.41 & -42.47 & \\
\hline 77 & & & -72.79 & & & & & -73.04 & -72.54 & -73.42 & -73.00 & & -12.69 & & -61.70 & -55.78 & -43.39 & \\
\hline 78 & & & -72.92 & & & 0.020 & & -74.05 & -73.80 & -73.42 & -73.76 & 0.041 & -5.00 & & -63.84 & -17.85 & -28.90 & 0.041 \\
\hline 79 & & & -73.29 & & & & & -74.05 & -74.05 & -73.55 & -73.88 & & -7.27 & & -61.32 & -16.34 & -28.31 & \\
\hline 80 & & & -73.29 & & & & & -74.05 & -73.67 & -73.55 & -73.76 & & -8.78 & & -52.13 & -15.84 & -25.58 & \\
\hline 81 & & & -73.42 & & & & & -74.43 & -74.30 & -74.05 & -74.26 & & -9.92 & & -49.48 & -16.09 & -25.16 & \\
\hline 82 & & & & & & & & & & & & & -11.30 & & 48.47 & -17.73 & -25.83 & \\
\hline 83 & & & & & & & & & & & & & -12.94 & & -52.25 & -20.00 & -28.40 & \\
\hline 84 & & & & & & & & & & & & & -14.58 & & -57.04 & -22.39 & -31.34 & \\
\hline 85 & & & & & & 0.014 & & & & & & 0.028 & -16.22 & & -62.58 & -24.91 & -34.57 & 0.028 \\
\hline 86 & & & & & & & & & & & & & -5.00 & & -66.87 & -24.66 & -32.18 & \\
\hline 87 & & & & & & & & -73.42 & -73.42 & & & & -7.14 & & -69.39 & -21.76 & -32.76 & \\
\hline 88 & & -73.80 & -73.42 & -73.42 & -73.55 & 0.047 & -3.74 & -74.05 & -74.30 & -73.42 & -56.38 & 0.047 & -4.88 & -7.14 & -71.53 & -6.89 & -22.61 & 0.047 \\
\hline 89 & & -70.90 & & & & & -6.77 & -9.29 & -10.42 & -65.86 & -23.08 & & -6.64 & -9.03 & -21.00 & -8.15 & -11.21 & \\
\hline 90 & & -72.79 & & -71.91 & & 0.019 & -7.14 & -8.78 & -8.91 & -68.63 & -23.37 & 0.019 & -6.89 & -8.28 & -15.21 & -8.28 & -9.66 & 0.019 \\
\hline 91 & & -73.42 & & -72.16 & & 0.017 & -6.51 & -7.77 & -7.77 & -16.72 & -9.70 & 0.017 & -6.51 & -7.02 & -9.66 & -7.40 & -7.65 & 0.017 \\
\hline 92 & -32.72 & -5.88 & -72.66 & -71.78 & -45.76 & 0.045 & -4.25 & -6.01 & -5.63 & -5.13 & -5.25 & 0.045 & -4.50 & -4.37 & -5.25 & -6.14 & -5.07 & 0.045 \\
\hline 93 & -10.42 & -6.89 & -72.54 & -6.51 & -24.09 & & -6.64 & -7.14 & -7.90 & -7.14 & -7.21 & & -6.64 & -6.39 & -6.51 & -7.90 & -6.86 & \\
\hline 94 & -10.17 & -8.91 & -19.87 & -8.03 & -11.74 & & -8.03 & -9.16 & -10.04 & -9.16 & -9.10 & & -8.66 & -8.15 & -7.77 & -9.54 & -8.53 & \\
\hline 95 & -11.93 & -10.80 & -19.24 & -9.79 & -12.94 & & -9.79 & -11.05 & -11.68 & -10.92 & -10.86 & & -10.29 & -9.92 & -9.16 & -11.05 & -10.11 & \\
\hline 96 & -11.93 & -12.06 & -20.12 & -11.30 & -13.85 & & -10.55 & -12.56 & -12.31 & -13.44 & -12.22 & & -11.68 & -11.30 & -9.92 & -12.18 & -11.27 & \\
\hline 97 & -13.70 & -13.19 & -24.28 & -13.95 & -16.28 & & -11.68 & -14.70 & -13.70 & -16.85 & -14.23 & & -13.32 & -12.94 & -11.18 & -13.57 & -12.75 & \\
\hline 98 & -16.47 & -16.09 & -30.33 & -17.10 & -20.00 & & -12.56 & -16.34 & -15.33 & -21.89 & -16.53 & & -14.83 & -14.70 & $-12,69$ & -15.08 & -14.33 & \\
\hline 99 & -18.61 & -18.74 & -39.65 & -22.39 & -24.85 & & -14.20 & -18.86 & -17.10 & -30.33 & -20.12 & & -17.10 & -16.72 & -14.33 & -16.85 & -16.25 & \\
\hline 100 & -22.14 & -24.03 & -54.77 & -32.97 & -33.48 & 0.023 & -16.59 & -25.16 & -19.24 & -55.28 & -29.07 & 0.044 & -20.12 & -17.73 & -16.97 & -19.24 & -18.52 & 0.044 \\
\hline 101 & -24.66 & -24.03 & -54.77 & -32.47 & -33.98 & & -16.85 & -22.64 & -16.97 & -50.49 & -26.74 & & -15.59 & -21.13 & -17.60 & -19.37 & -18.42 & \\
\hline 102 & -30.45 & -25.92 & -60.19 & 40.53 & -39.27 & & -16.34 & -23.27 & -15.08 & -57.29 & -28.00 & & -13.82 & -20.50 & -17.48 & -21.76 & -18.39 & \\
\hline 103 & -35.62 & -26.42 & -64.85 & -48.22 & -43.78 & & -16.22 & -22.14 & -15.46 & -61.32 & -28.78 & & -15.21 & -21.13 & -18.86 & -22.77 & -19.49 & \\
\hline 104 & -43.05 & -30.58 & -65.23 & -62.71 & -50.39 & & -17.35 & -28.31 & -16.47 & -65.23 & -31.84 & & -17.98 & -23.27 & -20.50 & -23.15 & -21.22 & \\
\hline 105 & -51.75 & -32.85 & -69.51 & -66.49 & -55.15 & & -18.61 & -29.07 & -18.36 & -67.62 & -33.42 & & -18.74 & -24.03 & -22.77 & -25.79 & -22.83 & \\
\hline 106 & -54.27 & -35.49 & -71.53 & -66.49 & -56.95 & 0.020 & -19.74 & -36.63 & -18.86 & -66.99 & -35.56 & 0.041 & -6.64 & -26.42 & -25.29 & -20.25 & -19.65 & 0.041 \\
\hline 107 & -54.52 & -31.08 & -73.42 & -68.13 & -56.79 & 0.031 & -18.99 & -24.66 & -15.33 & -68.38 & -31.84 & 0.031 & -7.52 & -26.55 & -24.78 & 1.80 & -14.26 & 0.031 \\
\hline 108 & -56.66 & -34.49 & -72.66 & -66.74 & -57.64 & & -9.79 & -14.45 & -9.03 & -68.38 & -25.41 & & -6.51 & -12.69 & -17.48 & -19.87 & -14.14 & \\
\hline 109 & -56.41 & -7.27 & -72.54 & -66.11 & -50.58 & 0.038 & -4.12 & -12.81 & -7.52 & -4.12 & -7.14 & 0.038 & -3.49 & -7.52 & 4.50 & -6.39 & -5.47 & 0.038 \\
\hline 110 & -11.43 & -6.51 & -70.90 & -53.51 & -35.59 & & -6.64 & -7.40 & -7.65 & -6.64 & -7.08 & & -6.39 & -6.14 & -6.89 & -7.65 & -6.77 & \\
\hline 111 & -12.44 & -8.40 & -23.90 & -14.20 & -14.74 & & -8.15 & -9.54 & -6.89 & -8.53 & -8.28 & & -8.40 & -1.60 & -7.90 & -7.14 & -6.26 & \\
\hline 112 & -14.07 & -9.92 & -20.88 & -7.27 & -13.03 & & -9.29 & -10.67 & -9.92 & -8.91 & -9.70 & & -9.66 & -1.60 & -8.03 & -7.90 & -6.80 & \\
\hline 113 & -7.65 & -5.13 & -14.07 & -5.38 & -8.06 & 0.055 & -5.38 & -6.26 & -10.42 & -5.38 & -6.86 & 0.055 & -3.87 & -2.61 & -5.88 & -8.28 & -5.16 & 0.055 \\
\hline 114 & -7.52 & -6.77 & -9.79 & -5.51 & -7.40 & & -6.77 & -7.65 & -10.80 & -6.77 & -7.99 & & -6.77 & -3.36 & -6.64 & -8.40 & -6.29 & \\
\hline 115 & -9.41 & -8.66 & -10.42 & -7.27 & -8.94 & & -8.40 & -10.04 & -9.79 & -8.53 & -9.19 & & -8.66 & -5.76 & -7.90 & -8.53 & -7.71 & \\
\hline 116 & -10.80 & -10.17 & -11.43 & -8.66 & -10.26 & & -9.54 & -12.31 & -11.18 & -10.17 & -10.80 & & -10.04 & -11.30 & -9.03 & -11.05 & -10.36 & \\
\hline 117 & -12.31 & -11.55 & -13.57 & -10.04 & -11.87 & & -10.55 & -13.57 & -12.56 & -11.68 & -12.09 & & -11.05 & -12.94 & -10.17 & -12.06 & -11.55 & \\
\hline 118 & -13.57 & -12.69 & -13.07 & -10.80 & -12.53 & & -11.43 & -15.46 & -13.57 & -12.81 & -13.32 & & -12.18 & -13.82 & -10.80 & -12.94 & -12.44 & \\
\hline 119 & -15.46 & -13.82 & -13.70 & -12.31 & -13.82 & & -12.31 & -17.10 & -14.70 & -14.07 & -14.55 & & -13.32 & -15.08 & -11.93 & -14.07 & -13.60 & \\
\hline 120 & -16.72 & -15.46 & -14.20 & -13.57 & -14.99 & & -13.57 & -20.75 & -15.46 & -15.59 & -16.34 & & -15.08 & -16.34 & -12.94 & -15.21 & -14.89 & \\
\hline 121 & -18.23 & -16.22 & -15.08 & -14.83 & -16.09 & 0.006 & -14.07 & -22.26 & -16.34 & -16.72 & -17.35 & 0.006 & -14.83 & -17.73 & -13.82 & -15.84 & -15.55 & 0.006 \\
\hline 122 & -18.86 & -16.97 & -15.46 & -16.09 & -16.85 & & -14.83 & -24.41 & -16.34 & -17.73 & -18.33 & & -15.71 & -18.48 & -14.33 & -16.72 & -16.31 & \\
\hline 123 & -20.25 & -18.23 & -15.96 & -17.48 & -17.98 & 0.035 & -15.46 & -26.30 & -16.97 & -16.22 & -18.74 & 0.035 & -15.46 & -19.87 & -15.33 & -14.70 & -16.34 & 0.035 \\
\hline 124 & -20.63 & -16.09 & -15.33 & -18.23 & -17.57 & & -14.83 & -22.14 & -12.94 & -16.59 & -16.63 & & -12.44 & -15.96 & -13.07 & -15.46 & -14.23 & \\
\hline 125 & -21.13 & -15.08 & -14.70 & -18.86 & -17.44 & & -14.07 & -19.11 & -13.32 & -16.85 & -15.84 & & -12.31 & -14.70 & -13.32 & -16.47 & -14.20 & \\
\hline 126 & -21.76 & -14.83 & -14.83 & -18.99 & -17.60 & & -14.07 & -17.98 & -14.07 & -18.48 & -16.15 & & -12.31 & -15.46 & -14.20 & -16.59 & -14.64 & \\
\hline 127 & -21.38 & -15.84 & -14.96 & -19.37 & -17.89 & & -14.20 & -18.99 & -13.95 & -18.99 & -16.53 & & -13.07 & -16.47 & -14.70 & -16.72 & -15.24 & \\
\hline 128 & -23.27 & -17.73 & -15.84 & -20.75 & -19.40 & & -15.33 & -21.00 & -16.09 & -20.63 & -18.26 & & -14.20 & -17.85 & -16.22 & -17.48 & -16.44 & \\
\hline 129 & & & & & & 0.008 & & & & & & 0.008 & & & & & & 0.008 \\
\hline 130 & -25.04 & -18.61 & -16.59 & -23.27 & -20.88 & 0.007 & 9 & -21.00 & -18.23 & -23.15 & & 0.007 & -16.09 & -19.11 & -17.98 & -19.24 & -18.11 & 0.007 \\
\hline 131 & -23.90 & -19.62 & -16.59 & -23.40 & -20.88 & 0.021 & -16.47 & -20.88 & -16.47 & -23.52 & -19.33 & 0.021 & -16.34 & -19.87 & -17.48 & -19.24 & -18.23 & 0.021 \\
\hline 132 & -24.78 & -19.74 & -16.72 & -24.53 & -21.45 & & -16.72 & -21.51 & -16.22 & -23.02 & -19.37 & & -15.96 & -19.62 & -17.10 & -19.37 & -18.01 & \\
\hline 133 & -25.79 & -18.74 & -16.22 & -25.79 & -21.63 & & -16.72 & -20.25 & -14.33 & -22.64 & -18.48 & & -13.82 & -16.97 & -15.59 & -18.99 & -16.34 & \\
\hline 134 & -26.04 & -17.35 & -15.71 & -26.42 & -21.38 & 0.015 & -16.22 & -18.48 & -14.45 & -21.76 & -17.73 & 0.015 & -12.81 & -15.59 & -14.83 & -17.10 & -15.08 & 0.015 \\
\hline 135 & -26.04 & -17.10 & -11.18 & -26.55 & -20.22 & & -15.46 & -17.22 & -14.58 & -20.88 & -17.04 & & -12.18 & -14.58 & -13.70 & -15.84 & -14.07 & \\
\hline 136 & -24.66 & -15.46 & -14.20 & -25.79 & -20.03 & & -13.95 & -15.46 & -12.56 & -19.49 & -15.37 & & -11.18 & -12.69 & -12.56 & -15.46 & -12.97 & \\
\hline 137 & -24.03 & -14.83 & -13.82 & -25.04 & -19.43 & & -13.57 & -14.96 & -13.44 & -18.99 & -15.24 & & -11.18 & -12.44 & -12.31 & -13.57 & -12.37 & \\
\hline 138 & -23.40 & -15.21 & -13.70 & -23.90 & -19.05 & & -13.57 & -15.21 & -14.45 & -18.61 & -15.46 & & -11.43 & -12.69 & -12.94 & -13.44 & -12.63 & \\
\hline 139 & & & & & & 0.008 & & & & & & 0.008 & & & & & & 0.008 \\
\hline 141 & & & & & & 0.020 & & & & & & 0.020 & & & & & & 0.020 \\
\hline 142 & & & & & & 0.025 & & & & & & 0.025 & & & & & & 0.025 \\
\hline 143 & & & & & & 0.015 & & & & & & 0.015 & & & & & & 0.015 \\
\hline 146 & & & & & & 0.043 & & & & & & 0.043 & & & & & & 0.043 \\
\hline 147 & & & & & & 0.070 & & & & & & 0.070 & & & & & & 0.070 \\
\hline
\end{tabular}


Profundidade $0,90 \mathrm{~m}$.

\begin{tabular}{|c|c|c|c|c|c|c|c|c|c|c|c|c|c|c|c|c|c|c|}
\hline \multirow[b]{2}{*}{ DAS } & \multicolumn{6}{|c|}{ trat -000} & \multicolumn{6}{|c|}{ trat $0 \mathrm{IO}$} & \multicolumn{6}{|c|}{ trat III } \\
\hline & $\mathrm{r} 1$ & 12 & 13 & $\mathrm{r} 4$ & média & $\mathrm{P}+\mathrm{I}$ & r1 & $\sqrt{2}$ & $\mathrm{r} 3$ & $\mathrm{r} 4$ & média & $\mathrm{P}+\mathrm{I}$ & rl & r2 & r3 & $\mathrm{r} 4$ & média & $\mathrm{P}+\mathrm{I}$ \\
\hline 0 & & & & & & 0.020 & & & & & & 0.021 & & & & & & 0.021 \\
\hline 1 & & & & & & 0.014 & & & & & & 0.014 & & & & & & 0.014 \\
\hline 2 & & & & & & 0.027 & & & & & & 0.028 & & & & & & 0.028 \\
\hline 4 & & & & & & 0.027 & & & & & & 0.028 & & & & & & 0.028 \\
\hline 5 & & & & & & 0.020 & & & & & & 0.021 & & & & & & 0.021 \\
\hline 7 & & & & & & 0.027 & & & & & & 0.028 & & & & & & 0.028 \\
\hline 8 & & & & & & 0.020 & & & & & & 0.021 & & & & & & 0.021 \\
\hline 9 & & & & & & 0.020 & & & & & & 0.021 & & & & & & 0.021 \\
\hline 13 & & & & & & 0.027 & & & & & & 0.028 & & & & & & 0.028 \\
\hline 16 & & & & & & 0.020 & & & & & & 0,021 & & & & & & 0.021 \\
\hline 17 & -7.78 & -10.30 & -8.54 & -8.79 & -8.85 & & -7.66 & -10.81 & -10.93 & -10.05 & -9.86 & & -9.55 & -9.92 & -8.66 & -10.81 & -9.74 & \\
\hline 18 & -4.13 & -10.55 & -8.92 & -8.54 & -8.03 & 0.014 & -9.17 & -10.68 & -11.06 & -9.92 & -10.21 & 0.014 & -9.55 & -10.18 & -8.66 & -11.31 & -9.92 & 0.014 \\
\hline 19 & -3.88 & -10.68 & -8.92 & -9.04 & -8.13 & & -9.04 & -11.06 & -11.18 & -10.43 & -10.43 & & -9.80 & -10.30 & -8.54 & -11.31 & -9.99 & \\
\hline 20 & -6.27 & -10.55 & -9.04 & -9.17 & -8.76 & 0.019 & -9.29 & -11.06 & -11.31 & -10.30 & -10.49 & 0.020 & -9.80 & -10.30 & -8.54 & -11.31 & -9.99 & 0.020 \\
\hline 21 & -6.52 & -10.55 & -8.79 & -8.79 & -8.66 & 0.011 & -8.66 & -10.68 & -11.18 & -10.05 & -10.14 & 0.011 & -9.67 & -10.18 & -8.79 & -11.06 & -9.92 & 0.011 \\
\hline 22 & -6.65 & -9.67 & -7.91 & -7.53 & -7.94 & & -7.91 & -9.67 & -10.05 & -9.42 & -9.26 & & -8.03 & -9.04 & -8.79 & -9.80 & -8.92 & \\
\hline 23 & -7.53 & -9.42 & -8.03 & -7.28 & -8.07 & 0.027 & -8.16 & -9.67 & -9.80 & -9.17 & -9.20 & 0.028 & -8.16 & -9.04 & -8.79 & -9.80 & -8.95 & 0.028 \\
\hline 24 & -7.53 & -7.91 & -6.52 & -6.27 & -7.06 & & -7.03 & -8.16 & -8.41 & -7.66 & -7.81 & & -6.65 & -7.53 & -7.53 & -8.79 & -7.62 & \\
\hline 25 & -7.40 & -8.29 & -7.15 & -6.65 & -7.37 & & -7.28 & -8.66 & -8.66 & -8.03 & -8.16 & & -7.28 & -7.91 & -7.40 & -9.04 & -7.91 & \\
\hline 26 & -7.91 & -9.17 & -8.03 & -7.40 & -8.13 & & -7.78 & -9.55 & -9.67 & -8.66 & -8.92 & & -8.03 & -8.66 & -7.91 & -9.80 & -8.60 & \\
\hline 27 & -9.80 & -10.18 & -9.04 & -8.66 & -9.42 & & -8.54 & -10.81 & -10.81 & -10.05 & -10.05 & & -9.42 & -10.05 & -8.66 & -10.93 & -9.77 & \\
\hline 28 & -10.05 & -10.55 & -9.29 & -9.04 & -9.74 & 0.024 & -9.04 & -11.18 & -11.18 & -10.30 & -10.43 & 0.024 & -9.67 & -10.30 & -8.92 & -11.18 & -10.02 & 0.024 \\
\hline 29 & -10.55 & -11.18 & -9.67 & -9.42 & -10.21 & 0.027 & -9.42 & -11.56 & -11.69 & -10.68 & -10.84 & 0.028 & -10.05 & -10.55 & -9.17 & -11.69 & -10.37 & 0.028 \\
\hline 30 & -8.41 & -9.29 & -8.79 & -8.29 & -8.70 & 0.027 & -8.66 & -10.05 & -10.43 & -10.05 & -9.80 & 0.028 & -8.41 & -9.29 & -8.03 & -10.55 & -9.07 & 0.028 \\
\hline 31 & -6.90 & -6.65 & -6.65 & -4.88 & -6.27 & & -6.52 & -7.40 & -8.03 & -7.91 & -7.47 & & -6.27 & -6.90 & -6.27 & -8.03 & -6.87 & \\
\hline 32 & -7.78 & -7.66 & -7.03 & & -7.49 & & -7.91 & -8.41 & -8.66 & -8.16 & -8.29 & & -7.15 & -7.40 & -6.77 & -8.66 & -7.50 & \\
\hline 33 & -8.66 & -8.54 & -7.91 & & -8.37 & & -7.78 & -9.29 & -9.67 & -9.04 & -8.95 & & -7.53 & -7.91 & -7.28 & -9.55 & -8.07 & \\
\hline 34 & -9.42 & -9.80 & -8.79 & -8.16 & -9.04 & & -8.54 & -10.43 & -10.55 & -9.67 & -9.80 & & -9.17 & -9.42 & -8.16 & -10.43 & -9.29 & \\
\hline 35 & -10.05 & -10.55 & -9.42 & -8.92 & -9.74 & & -9.04 & -11.18 & -11.31 & -10.55 & -10.52 & & -9.92 & -10.18 & -8.66 & -11.06 & -9.96 & \\
\hline 36 & -10.68 & -11.31 & -10.05 & -9.67 & -10.43 & & -9.67 & -11.94 & -11.94 & -11.18 & -11.18 & & -10.43 & -10.93 & -9.17 & -11.69 & -10.55 & \\
\hline 37 & -11.18 & -11.94 & -10.55 & -10.43 & -11.03 & & -10.05 & -12.82 & -12.82 & -11.56 & -11.81 & & -11.31 & -11.56 & -9.67 & -12.44 & -11.25 & \\
\hline 38 & -11.56 & -12.57 & -11.18 & -10.93 & -11.56 & & -10.43 & -13.33 & -13.20 & -12.32 & -12.32 & & -11.81 & -12.19 & -10.05 & -12.95 & -11.75 & \\
\hline 39 & -12.19 & -13.20 & -11.69 & -11.56 & -12.16 & & -10.93 & -14.08 & -13.96 & -12.82 & -12.95 & & -12.44 & -12.82 & -10.55 & -13.45 & -12.32 & \\
\hline 40 & -12.70 & -13.96 & -12.44 & -12.32 & -12.85 & & -11.31 & -14.59 & -14.59 & -13.58 & -13.52 & & -13.33 & -13.58 & -11.18 & -14.08 & -13.04 & \\
\hline 41 & -13.20 & -14.21 & -12.95 & -12.95 & -13.33 & & -11.81 & -15.34 & -14.96 & -14.21 & -14.08 & & -13.96 & -13.96 & -11.56 & -14.33 & $-13,45$ & \\
\hline 42 & -13.70 & -15.09 & -13.83 & -13.70 & -14.08 & & -12.07 & -15.85 & -15.59 & -14.59 & -14.52 & & -14.59 & -14.33 & -11.94 & -15.09 & -13.99 & \\
\hline 43 & -14.21 & -15.47 & -14.59 & -14.33 & -14.65 & 0.020 & -12.44 & -16.48 & -16.48 & -15.22 & -15.15 & 0.021 & -15.47 & -15.22 & -12.44 & -15.59 & -14.68 & 0.036 \\
\hline 44 & -14.59 & -15.97 & -15.22 & -14.96 & -15.18 & 0.014 & -12.82 & -17.23 & -16.48 & -15.34 & -15.47 & 0.014 & -15.59 & -15.59 & -12.82 & -15.97 & -15.00 & 0.028 \\
\hline 45 & -15.22 & -16.60 & -15.97 & -15.72 & -15.88 & & -13.07 & -17.99 & -17.48 & -16.98 & -16.38 & & -14.46 & -16.73 & -12.95 & -16.48 & -15.15 & \\
\hline 46 & -15.47 & -17.23 & -16.73 & -16.35 & -16.44 & & -13.58 & -18.49 & -17.61 & -17.48 & -16.79 & & -13.70 & -16.85 & -13.07 & -16.60 & -15.06 & \\
\hline 47 & -16.10 & -17.74 & -17.61 & -16.60 & -17.01 & & -14.08 & -19.25 & -19.00 & -17.86 & -17.55 & & -13.33 & -16.35 & -11.69 & -16.35 & -14.43 & \\
\hline 48 & -16.73 & -18.11 & -23.66 & -18.11 & -19.15 & & -14.21 & -19.88 & -19.63 & -18.87 & -18.15 & & -13.70 & -16.98 & -11.81 & -16.48 & & \\
\hline 49 & -17.61 & -18.87 & -20.13 & -18.87 & -18.87 & & -14.46 & -20.51 & -20.38 & -20.13 & -18.87 & & -14.46 & -16.98 & -11.94 & -16.60 & -15.00 & \\
\hline 50 & -18.49 & -19.37 & -22.02 & -20.26 & -20.04 & 0.014 & -14.96 & -21.39 & -21.64 & -23.28 & -20.32 & 0.014 & -15.22 & -16.85 & -12.57 & -17.11 & -15.44 & 0.028 \\
\hline 51 & -19.50 & -20.13 & -24.92 & -21.77 & -21.58 & & -15.34 & -22.27 & -22.52 & -21.26 & -20.35 & & -15.85 & -16.98 & -14.46 & -17.48 & -16.19 & \\
\hline 52 & -20.76 & -20.76 & -27.82 & -23.66 & -23.25 & & -15.72 & -23.53 & -24.04 & -24.54 & -21.96 & & -16.48 & -17.99 & -14.46 & -17.86 & -16.70 & \\
\hline 53 & -23.28 & & -32.86 & -26.56 & -27.57 & & -16.35 & -25.04 & -26.81 & -32.48 & -25.17 & & -16.98 & -19.25 & -14.46 & -18.62 & -17.33 & \\
\hline 54 & -27.06 & -22.65 & 41.55 & -31.85 & -30.78 & 0.014 & -16.98 & -28.07 & -31.22 & -39.91 & -29.04 & 0.014 & -17.48 & -20.26 & -14.96 & -19.25 & -17.99 & 0.028 \\
\hline 55 & -31.47 & -23.03 & -51.00 & -36.51 & -35.50 & & -17.86 & -30.34 & -34.62 & -53.65 & -34.12 & & -17.99 & -20.51 & -16.98 & -19.75 & -18.81 & \\
\hline 56 & -38.78 & -27.06 & -60.45 & -45.71 & -43.00 & & -18.87 & -35.12 & 43.94 & -62.84 & -40.20 & & -13.20 & -22.40 & -17.74 & -20.51 & -18.46 & \\
\hline 57 & -50.62 & -34.37 & -72.17 & -59.69 & -54.21 & 0.014 & -20.38 & -46.09 & -59.95 & -67.38 & -48.45 & 0.014 & -11.81 & -23.15 & -19.00 & -21.52 & -18.87 & 0.028 \\
\hline 58 & -51.38 & -37.77 & -73.93 & -61.71 & -56.20 & & -20.13 & -48.48 & -60.07 & -70.53 & -49.80 & & -12.57 & -23.03 & -19.50 & -22.02 & -19.28 & \\
\hline 59 & -57.68 & -47.85 & -71.16 & -63.98 & -60.17 & & -22.90 & -54.78 & -60.07 & -70.91 & -52.17 & & -12.57 & -25.17 & -20.51 & -23.03 & -20.32 & \\
\hline 60 & -63.10 & -57.30 & -72.42 & -69.27 & -65.52 & & -25.17 & -61.71 & -68.01 & -71.03 & -56.48 & & -15.09 & -27.06 & -21.39 & -23.66 & -21.80 & \\
\hline 61 & -66.62 & -65.11 & -71.79 & -69.27 & -68.20 & 0.014 & -28.57 & -67.38 & -69.27 & -71.29 & -59.13 & 0.014 & -12.70 & -28.32 & -22.90 & -25.17 & -22.27 & 0.028 \\
\hline 62 & -69.90 & -69.52 & -71.54 & -72.42 & -70.85 & & -31.72 & -71.16 & -71.16 & -67.76 & -60.45 & & -20.13 & -25.93 & -23.78 & -25.55 & -23.85 & \\
\hline 63 & -69.90 & -70.53 & -71.16 & -72.42 & -71.00 & & -35.63 & -71.54 & -72.17 & -72.42 & -62.94 & & -19.25 & -27.06 & -24.92 & -26.18 & -24.35 & \\
\hline 64 & -70.53 & -69.90 & -70.91 & -72.17 & -70.88 & & & -71.54 & -72.17 & -72.80 & -72.17 & & -19.50 & -27.94 & -25.80 & -26.68 & -24.98 & \\
\hline 65 & -63.47 & -68.26 & -71.92 & -72.17 & -68.96 & 0.014 & & -72.92 & -71.03 & -72.92 & -72.29 & 0.014 & -18.62 & -29.45 & -27.56 & -28.45 & -26.02 & 0.028 \\
\hline 66 & -73.81 & -78.72 & -73.05 & -73.43 & -74.75 & & & -74.18 & -72.80 & -74.56 & -73.85 & & -19.37 & -32.35 & -26.30 & -29.20 & -26.81 & \\
\hline 67 & -73.55 & -72.67 & -71.79 & -71.92 & -72.48 & & & -72.92 & -72.92 & -72.67 & -72.84 & & -18.49 & -34.37 & -30.46 & -30.84 & -28.54 & \\
\hline 68 & -73.55 & -72.55 & -71.79 & & -72.63 & & & -73.05 & -73.05 & -74.06 & -73.39 & & -18.24 & -37.77 & -33.23 & -31.47 & -30.18 & \\
\hline 69 & & -73.55 & -72.17 & . & & & & -72.67 & -73.05 & -73.43 & -73.05 & & -18.49 & -39.91 & -33.74 & -32.86 & -31.25 & \\
\hline 70 & & -73.43 & -72.67 & & & & & -73.05 & -73.68 & -73.55 & -73.43 & & -19.88 & -43.31 & -36.26 & -35.88 & -33.83 & \\
\hline 71 & -73.43 & -73.55 & -71.16 & & -72.71 & 0.014 & & -73.18 & -72.42 & & & 0.014 & -21.01 & -43.44 & -37.77 & -36.76 & -34.75 & 0.028 \\
\hline 72 & -73.05 & -73.43 & -72.42 & & -72.97 & & & -73.05 & -72.42 & & & & -22.02 & -46.84 & -41.30 & -39.41 & -37.39 & \\
\hline 73 & -74.31 & & -73.68 & & & & & -73.43 & -74.56 & & & & -23.03 & -52.89 & 45.83 & -39.28 & -40.26 & \\
\hline 74 & -72.04 & & -71.54 & & & 0.020 & & -73.05 & -71.16 & & & 0.041 & -20.76 & -56.04 & -49.11 & -48.48 & -43.60 & 0.041 \\
\hline 75 & -73.43 & & -72.55 & & & & & -72.92 & -72.92 & -72.17 & -72.67 & & -7.28 & -63.47 & -51.63 & -50.12 & -43.13 & \\
\hline
\end{tabular}

(continua). 
Profundidade $0,90 \mathrm{~m}$ (continuação).

\begin{tabular}{|c|c|c|c|c|c|c|c|c|c|c|c|c|c|c|c|c|c|c|}
\hline \multirow[b]{2}{*}{ DAS } & \multicolumn{6}{|c|}{ trat -000} & \multicolumn{6}{|c|}{ trat 0I0 } & \multicolumn{6}{|c|}{ trat III } \\
\hline & $\mathrm{r} 1$ & 12 & r3 & $r 4$ & média & $\mathrm{P}+\mathrm{I}$ & $\mathrm{rl}$ & 12 & r3 & $\mathrm{r} 4$ & média & $\mathrm{P}+\mathrm{I}$ & r1 & 12 & r3 & $\mathrm{r} 4$ & média & $\mathrm{P}+\mathrm{I}$ \\
\hline 76 & & & -72.29 & & & & & -72.42 & -72.42 & -71.79 & -72.21 & & -11.06 & -64.86 & -54.40 & 49.74 & -45.02 & \\
\hline 77 & & & -72.04 & & & & & -72.17 & -71.16 & -71.54 & -71.62 & & -12.82 & -66.12 & -56.80 & -51.00 & -46.68 & \\
\hline 78 & -72.92 & & -72.04 & & & 0.020 & & -73.18 & -71.16 & -71.79 & -72.04 & 0.041 & -5.14 & -66.50 & -62.21 & -42.31 & 44.04 & 0.041 \\
\hline 79 & -72.67 & & -72.80 & & & & & -73.43 & -72.55 & -70.91 & -72.29 & & -7.15 & -69.40 & -64.48 & -34.49 & -43.88 & \\
\hline 80 & -72.80 & & -72.80 & & & & & -73.18 & -72.42 & -71.16 & -72.25 & & -8.79 & -69.27 & -65.24 & -26.93 & -42.56 & \\
\hline 81 & & & -73.43 & & & & & -73.55 & -72.92 & -71.54 & -72.67 & & -9.92 & -68.64 & -66.12 & -24.41 & -42.27 & \\
\hline 82 & & & & & & & & & & & & & -11.18 & & -63.98 & -24.16 & -33.11 & \\
\hline 83 & & & & & & & & & & & & & -12.32 & & -64.23 & -26.56 & -34.37 & \\
\hline 84 & & & & & & & & & & & . & & -13.83 & & -64.73 & -28.70 & -35.75 & \\
\hline 85 & & & & & & 0.014 & & & & & & 0.028 & -15.22 & & -68.64 & -30.84 & -38.23 & 0.028 \\
\hline 86 & & & & & & & & & & & & & -5.26 & & -69.90 & -32.60 & -35.92 & \\
\hline 87 & & & & & & & & -72.67 & -69.90 & & & & -6.90 & & -69.65 & -32.98 & -36.51 & \\
\hline 88 & & -72.29 & -72.29 & -72.67 & -72.42 & 0.047 & -7.66 & -73.43 & -70.66 & -72.80 & -56.13 & 0.047 & -4.51 & -63.10 & -70.40 & -8.92 & -36.73 & 0.047 \\
\hline 89 & & -71.79 & & & & & -7.15 & -13.83 & -11.56 & -66.88 & -24.86 & & -6.40 & -9.67 & -64.86 & -8.41 & -22.34 & \\
\hline 90 & & -73.43 & & & & 0.019 & -7.53 & -11.18 & -11.18 & -69.65 & -24.89 & 0.019 & -6.90 & -9.42 & -45.20 & -8.54 & -17.52 & 0.019 \\
\hline 91 & & & & & & 0.017 & -7.03 & -9.04 & -7.91 & -69.77 & -23.44 & 0.017 & -6.77 & -9.04 & -15.72 & -8.16 & -9.92 & 0.017 \\
\hline 92 & -73.18 & -72.29 & -72.42 & -65.74 & -70.91 & 0.045 & -4.63 & -6.65 & -5.26 & -14.46 & -7.75 & 0.045 & -4.13 & -8.92 & -6.65 & -6.65 & -6.59 & 0.045 \\
\hline 93 & -7.91 & -9.92 & -72.17 & -13.70 & -25.93 & & -5.89 & -7.28 & -7.15 & -12.95 & -8.32 & & -6.40 & -6.02 & -6.40 & -7.78 & -6.65 & \\
\hline 94 & -8.16 & -10.05 & -10.30 & -3.75 & -8.07 & & -7.28 & -9.04 & -8.79 & -10.93 & -9.01 & & -7.91 & -6.14 & -7.15 & -9.42 & -7.66 & \\
\hline 95 & -10.05 & -11.69 & -10.68 & -17.36 & -12.44 & & -9.17 & -10.68 & -10.30 & -11.44 & -10.40 & & -9.55 & -6.40 & -8.41 & -10.93 & -8.82 & \\
\hline 96 & -12.57 & -12.44 & -13.33 & -11.81 & -12.54 & & -9.92 & -11.94 & -11.56 & -13.58 & -11.75 & & -10.68 & -6.65 & -9.29 & -12.19 & -9.70 & \\
\hline 97 & -14.84 & -14.46 & -16.48 & -15.09 & -15.22 & & -10.93 & -13.58 & -12.95 & -16.48 & -13.48 & & -12.19 & -8.79 & -10.30 & -13.58 & -11.22 & \\
\hline 98 & -17.11 & -16.35 & -21.14 & -17.74 & -18.08 & & -11.56 & -15.22 & -14.46 & -20.76 & -15.50 & & -13.58 & -10.81 & -11.56 & -15.09 & -12.76 & \\
\hline 99 & -19.88 & -18.87 & -26.81 & -22.65 & -22.05 & & -12.57 & -16.98 & -15.97 & -27.94 & -18.37 & & -14.84 & -11.31 & -12.95 & -16.98 & -14.02 & \\
\hline 100 & -23.28 & -24.54 & -34.62 & -31.97 & -28.60 & 0.023 & -14.21 & -19.50 & -18.37 & 44.57 & -24.16 & 0.044 & -12.70 & -14.71 & -14.59 & -19.50 & -15.37 & 0.044 \\
\hline 101 & -27.19 & -24.54 & -39.79 & -35.88 & -31.85 & & -14.59 & -19.50 & -17.36 & 44.83 & -24.07 & & -11.94 & -15.85 & -15.97 & -20.13 & -15.97 & \\
\hline 102 & -31.72 & -26.05 & 46.46 & 42.43 & -36.67 & & -14.84 & -20.38 & -15.47 & -51.00 & -25.42 & & -15.72 & -16.85 & -16.73 & -22.27 & -17.89 & \\
\hline 103 & -36.89 & -26.93 & -53.90 & 49.49 & 41.80 & & -14.84 & -20.51 & -15.59 & -56.80 & -26.93 & & -11.31 & -19.50 & -17.61 & -23.28 & -17.93 & \\
\hline 104 & -42.81 & -38.78 & -56.42 & -61.46 & 49.87 & & -15.72 & -21.39 & -16.85 & -64.23 & -29.55 & & -15.72 & -21.14 & -18.74 & -24.92 & -20.13 & \\
\hline 105 & -50.24 & -43.94 & -62.84 & -66.12 & -55.79 & & -16.48 & -22.52 & -18.11 & -67.76 & -31.22 & & -12.57 & -24.29 & -20.13 & -26.43 & -20.85 & \\
\hline 106 & -56.67 & -51.00 & -66.12 & -68.01 & -60.45 & 0.020 & -17.36 & -24.41 & -18.87 & -69.77 & -32.60 & 0.041 & -7.03 & -29.20 & -21.77 & -27.69 & -21.42 & 0.041 \\
\hline 107 & -57.55 & -32.48 & -69.14 & -69.65 & -57.21 & 0.031 & -17.23 & -23.15 & -16.10 & -71.79 & -32.07 & 0.031 & -7.78 & -28.95 & -22.02 & -26.05 & -21.20 & 0.031 \\
\hline 108 & -61.71 & -39.66 & -68.77 & -69.02 & -59.79 & & -13.70 & -20.13 & -9.29 & -71.54 & -28.67 & & -6.27 & -26.18 & -22.27 & -26.56 & -20.32 & \\
\hline 109 & -61.08 & -40.42 & -68.64 & -68.89 & -59.76 & 0.038 & -5.14 & -11.94 & -6.90 & -12.07 & -9.01 & 0.038 & -3.50 & -12.70 & -6.90 & -8.03 & -7.78 & 0.038 \\
\hline 110 & -11.06 & -8.16 & -68.64 & -67.88 & -38.94 & & -6.27 & -7.28 & -6.90 & -8.92 & -7.34 & & -6.40 & -6.40 & -6.90 & -7.78 & -6.87 & \\
\hline 111 & -12.32 & -9.42 & -10.68 & -39.66 & -18.02 & & -7.66 & -8.79 & -8.54 & -9.42 & -8.60 & & -7.91 & 4.00 & -7.40 & -9.04 & -7.09 & \\
\hline 112 & -14.08 & -10.68 & -11.31 & -26.93 & -15.75 & & -8.79 & -10.05 & -9.67 & -9.42 & -9.48 & & -9.04 & -5.26 & -7.40 & -9.80 & -7.88 & \\
\hline 113 & -7.91 & -6.40 & -5.39 & -10.68 & -7.59 & 0.055 & -5.51 & -7.53 & -6.27 & -10.43 & -7.44 & 0.055 & -4.88 & -5.89 & -6.52 & -7.40 & -6.18 & 0.055 \\
\hline 114 & -7.15 & -7.28 & -6.02 & -6.65 & -6.77 & & -6.52 & -7.53 & -7.15 & -10.68 & -7.97 & & -6.40 & -6.02 & -6.27 & -7.91 & -6.65 & \\
\hline 115 & -8.92 & -9.29 & -7.78 & -7.53 & -8.38 & & -8.16 & -9.17 & -8.79 & -9.04 & -8.79 & & -8.16 & -8.16 & -7.40 & -9.55 & -8.32 & \\
\hline 116 & -10.55 & -10.93 & -9.17 & -9.04 & -9.92 & & -9.17 & -10.81 & -10.05 & -10.43 & -10.11 & & -9.55 & -9.42 & -8.41 & -10.81 & -9.55 & \\
\hline 117 & -11.81 & -11.94 & -10.30 & -10.30 & -11.09 & & -10.05 & -11.94 & -11.18 & -11.94 & -11.28 & & -10.68 & -7.53 & -9.42 & -11.69 & -9.83 & \\
\hline 118 & -13.20 & -13.20 & -11.31 & -11.31 & -12.26 & & -10.68 & -13.07 & -12.32 & -13.33 & -12.35 & & -11.81 & -8.66 & -10.18 & -12.95 & -10.90 & \\
\hline 119 & -14.71 & -14.46 & -12.32 & -12.57 & -13.52 & & -11.56 & -14.33 & -12.95 & -14.46 & -13.33 & & -12.70 & -10.68 & -10.93 & -13.70 & -12.00 & \\
\hline 120 & -15.72 & -17.86 & -13.33 & -14.33 & -15.31 & & -12.82 & -15.97 & -13.83 & -16.98 & -14.90 & & -14.46 & -14.46 & -11.94 & -14.84 & -13.92 & \\
\hline 121 & -17.11 & -18.24 & -14.21 & -15.59 & -16.29 & 0.006 & -13.20 & -16.73 & -14.59 & -17.23 & -15.44 & 0.006 & -14.84 & -15.59 & -12.70 & -15.47 & -14.65 & 0.006 \\
\hline 122 & -17.99 & -19.25 & -14.71 & -16.73 & -17.17 & & -13.83 & -17.48 & -15.22 & -17.99 & -16.13 & & -15.72 & -16.48 & -13.33 & -16.10 & -15.41 & \\
\hline 123 & -19.12 & -20.76 & -15.22 & -17.74 & -18.21 & 0.035 & -14.46 & -18.11 & -15.72 & -18.37 & -16.67 & 0.035 & -15.72 & -17.61 & -14.08 & -16.22 & -15.91 & 0.035 \\
\hline 124 & -19.63 & -22.90 & -12.44 & -18.87 & -18.46 & & -15.09 & -18.37 & -14.33 & -19.12 & -16.73 & & -14.59 & -14.96 & -13.70 & -16.98 & -15.06 & \\
\hline 125 & -19.88 & -20.38 & -12.07 & -20.00 & -18.08 & & -14.33 & -17.48 & -13.45 & -19.37 & -16.16 & & -13.96 & -15.09 & -13.70 & -16.85 & -14.90 & \\
\hline 126 & -20.26 & -17.99 & -12.57 & -20.89 & -17.93 & & -14.08 & -17.36 & -13.58 & -19.88 & -16.22 & & -13.83 & -15.97 & -13.83 & -16.85 & -15.12 & \\
\hline 127 & -20.26 & -19.88 & -13.07 & -21.39 & -18.65 & & -14.08 & -17.61 & -13.83 & -20.26 & -16.44 & & -14.21 & -16.98 & -14.08 & -16.98 & -15.56 & \\
\hline 128 & -23.91 & -21.14 & -14.46 & -22.78 & -20.57 & & -14.96 & -18.49 & -14.84 & -22.02 & -17.58 & & -15.47 & -19.75 & -14.96 & -17.61 & -16.95 & \\
\hline 129 & & & & & & 0.008 & & & & & & 0.008 & & & & & & 0.008 \\
\hline 130 & -23.41 & -19.75 & -15.85 & -25.30 & -21.08 & 0.007 & -15.59 & -19.50 & -16.10 & -22.65 & -18.46 & 0.007 & -16.10 & -21.01 & -15.97 & -18.62 & -17.93 & 0.007 \\
\hline 131 & -23.28 & -22.90 & -15.59 & -25.42 & -21.80 & 0.021 & -15.72 & -19.50 & -16.22 & -23.03 & -18.62 & 0.021 & -13.58 & -21.14 & -16.10 & -18.74 & -17.39 & 0.021 \\
\hline 132 & -24.04 & -22.90 & -15.47 & -26.30 & -22.18 & & -15.72 & -19.88 & -15.97 & -23.15 & -18.68 & & -13.70 & -21.64 & -16.10 & -18.87 & -17.58 & \\
\hline 133 & -24.54 & -23.03 & -13.45 & -27.31 & -22.08 & & -16.10 & -19.88 & -14.84 & -23.41 & -18.56 & & -13.33 & -20.38 & -15.59 & -18.74 & -17.01 & \\
\hline 134 & -25.04 & -21.01 & -15.34 & -15.47 & -19.22 & 0.015 & -15.72 & -19.50 & -14.46 & -22.90 & -18.15 & 0.015 & -14.59 & -18.11 & -14.84 & -17.74 & -16.32 & 0.015 \\
\hline 135 & -24.79 & -20.38 & -13.83 & -28.32 & -21.83 & & -15.22 & -18.24 & -11.56 & -22.40 & -16.85 & & -13.83 & -16.73 & -13.96 & -16.60 & -15.28 & \\
\hline 136 & -24.29 & -19.88 & -10.81 & -28.45 & -20.85 & & -14.71 & -17.23 & -12.82 & -21.89 & -16.67 & & -11.31 & -14.84 & -12.95 & -15.22 & -13.58 & \\
\hline 137 & -23.91 & -17.86 & -10.93 & -28.95 & -20.41 & & -14.08 & -16.35 & -12.57 & -20.89 & -15.97 & & -12.57 & -13.96 & -12.57 & -14.46 & -13.39 & \\
\hline 138 & -22.78 & -17.23 & -11.31 & -28.57 & -19.97 & & -13.83 & -15.97 & -12.82 & -20.26 & -15.72 & & -13.45 & -13.70 & -12.44 & -14.08 & -13.42 & \\
\hline 139 & & & & & & 0.008 & & & & & & 0.008 & & & & & & 0.008 \\
\hline 141 & & & & & & 0.020 & & & & & & 0.020 & & & & & & 0.020 \\
\hline 142 & & & & & & 0.025 & & & & & & 0.025 & & & & & & 0.025 \\
\hline 143 & & & & & & 0.015 & & & & & & 0.015 & & & & & & 0.015 \\
\hline 146 & & & & & & 0.043 & & & & & & 0.043 & & & & & & 0.043 \\
\hline 147 & & & & & & 0.070 & & & & & & 0.070 & & & & & & 0.070 \\
\hline
\end{tabular}


Profundidade $1,00 \mathrm{~m}$.

\begin{tabular}{|c|c|c|c|c|c|c|c|c|c|c|c|c|c|c|c|c|c|c|}
\hline \multirow[b]{2}{*}{ DAS } & \multicolumn{6}{|c|}{ trat -000} & \multicolumn{6}{|c|}{ trat $0 \mathrm{IO}$} & \multicolumn{6}{|c|}{ trat III } \\
\hline & $\mathrm{r} 1$ & 12 & r3 & $\mathrm{r} 4$ & média & $\mathrm{P}+\mathrm{I}$ & $\mathrm{rl}$ & 12 & $r^{3}$ & $\mathrm{r} 4$ & média & $\mathrm{P}+\mathrm{I}$ & $\mathrm{rl}$ & 12 & r3 & $\mathrm{r} 4$ & média & $\mathrm{P}+\mathrm{I}$ \\
\hline 0 & & & & & & 0.020 & & & & & & 0.021 & & & & & & 0.021 \\
\hline 1 & & & & & & 0.014 & & & & & & 0.014 & & & & & & 0.014 \\
\hline 2 & & & & & & 0.027 & & & & & & 0.028 & & & & & & 0.028 \\
\hline 4 & & & & & & 0.027 & & & & & & 0.028 & & & & & & 0.028 \\
\hline 5 & & & & & & 0.020 & & & & & & 0.021 & & & & & & 0.021 \\
\hline 7 & & & & & & 0.027 & & & & & & 0.028 & & & & & & 0.028 \\
\hline 8 & & & & & & 0.020 & & & & & & 0.021 & & & & & & .021 \\
\hline 9 & & & & & & 0.020 & & & & & & 0.021 & & & & & & 0.021 \\
\hline 13 & & & & & & 0.027 & & & & & & 0.028 & & & & & & 0.028 \\
\hline 16 & & & & & & 0.020 & & & & & & 0.021 & & & & & & 0.021 \\
\hline 17 & -9.55 & -10.18 & -8.92 & -9.18 & -9.46 & & -8.92 & -10.69 & -10.81 & -9.55 & -10.00 & & -10.06 & -9.93 & -9.55 & -11.32 & -10.22 & \\
\hline 18 & -9.55 & -10.18 & -9.05 & -9.43 & -9.55 & 0.014 & -9.05 & -10.81 & -10.94 & -10.18 & -10.25 & 0.014 & -10.06 & -9.93 & -8.55 & -11.44 & -10.00 & 0.014 \\
\hline 19 & -9.68 & -10.44 & -9.30 & -9.55 & -9.74 & & -9.05 & -10.94 & -11.07 & -10.06 & -10.28 & & -9.93 & -10.18 & -8.42 & -11.32 & -9.96 & \\
\hline 20 & -9.68 & -10.44 & -9.30 & -9.43 & -9.71 & 0.019 & -9.18 & -8.42 & -11.19 & -10.06 & -9.71 & 0.020 & -10.06 & -10.31 & -8.42 & -11.57 & -10.09 & 0.020 \\
\hline 21 & -9.93 & -10.44 & -9.30 & -9.30 & -9.74 & 0.011 & -8.92 & -10.81 & -11.19 & -10.18 & -10.28 & 0.011 & -9.93 & -10.18 & -8.67 & -11.44 & -10.06 & 0.011 \\
\hline 22 & -9.93 & -9.68 & -8.67 & -8.29 & -9.14 & & -8.17 & -9.81 & -10.31 & -9.30 & -9.40 & & -8.42 & -9.43 & -8.80 & -11.32 & -9.49 & \\
\hline 23 & -9.81 & -9.43 & -8.55 & -7.79 & -8.89 & 0.027 & -8.04 & -9.68 & -10.06 & -9.18 & -9.24 & 0.028 & -8.42 & -9.18 & -8.67 & -11.32 & -9.40 & 0.028 \\
\hline 24 & -9.81 & -8.17 & -7.54 & -7.03 & -8.14 & & -7.29 & -8.55 & -9.05 & -7.79 & -8.17 & & -6.91 & -8.04 & -8.04 & -11.19 & -8.55 & \\
\hline 25 & -8.29 & -7.92 & -7.41 & -6.91 & -7.63 & & -7.16 & -8.67 & -8.80 & -8.04 & -8.17 & & -7.29 & -7.79 & -8.04 & -9.18 & -8.07 & \\
\hline 26 & -8.04 & -8.92 & -8.17 & -7.66 & -8.20 & & -7.54 & -9.43 & -9.55 & -8.55 & -8.77 & & -8.29 & -8.55 & -7.79 & -9.93 & -8.64 & \\
\hline 27 & -9.55 & -9.93 & -9.30 & -8.80 & -9.40 & & -8.42 & -10.69 & -10.18 & -9.81 & -9.77 & & -9.05 & -9.81 & -8.55 & -11.19 & -9.65 & \\
\hline 28 & -9.68 & -10.31 & -9.43 & -9.05 & -9.62 & 0.024 & -8.80 & -10.94 & -10.94 & -10.06 & -10.18 & 0.024 & -9.55 & -10.06 & -8.80 & -11.44 & -9.96 & 0.024 \\
\hline 29 & -9.93 & -10.81 & -9.68 & -9.55 & -10.00 & 0.027 & -9.05 & -10.81 & -11.44 & -10.44 & -10.44 & 0.028 & -10.31 & -10.44 & -9.05 & -11.57 & -10.34 & 0.028 \\
\hline 30 & -8.92 & -9.81 & -9.55 & -9.30 & -9.40 & 0.027 & -8.92 & -10.56 & -11.07 & -10.31 & -10.22 & 0.028 & -9.18 & -9.81 & -8.42 & -11.82 & -9.81 & 0.028 \\
\hline 31 & -6.53 & -6.91 & -7.79 & -6.40 & -6.91 & & -7.54 & -7.79 & -8.42 & -8.55 & -8.07 & & -6.78 & -7.41 & -6.91 & -9.55 & -7.66 & \\
\hline 32 & -7.41 & -7.54 & -7.66 & & -7.54 & & -7.29 & -8.42 & -8.80 & -8.29 & -8.20 & & -7.41 & -7.66 & -6.91 & -9.55 & -7.88 & \\
\hline 33 & -8.17 & -8.42 & -7.29 & & -7.96 & & -7.66 & -9.18 & -9.68 & -8.67 & -8.80 & & -8.04 & -7.79 & -7.41 & -9.55 & -8.20 & \\
\hline 34 & -9.05 & -9.43 & -8.92 & -7.92 & -8.83 & & -8.17 & -10.06 & -10.31 & -9.55 & -9.52 & & -9.30 & -9.18 & -8.17 & -10.31 & -9.24 & \\
\hline 35 & -9.68 & -10.18 & -9.43 & -9.05 & -9.59 & & -8.67 & -10.94 & -11.07 & -10.06 & -10.18 & & -9.81 & -9.81 & -8.55 & -10.94 & -9.77 & \\
\hline 36 & -10.31 & -10.81 & -9.93 & -9.81 & -10.22 & & -9.30 & -11.32 & -11.70 & -10.69 & -10.75 & & -10.44 & -10.56 & -9.05 & -11.82 & -10.47 & \\
\hline 37 & -10.69 & -11.57 & -10.31 & -10.31 & -10.72 & & -9.68 & -12.33 & -12.20 & -11.32 & -11.38 & & -11.32 & -11.07 & -9.43 & -12.45 & -11.07 & \\
\hline 38 & -10.94 & -11.95 & -10.81 & -10.94 & -11.16 & & -9.93 & -12.96 & -12.70 & -11.82 & -11.85 & & -11.57 & -11.70 & -9.81 & -12.83 & -11.48 & \\
\hline 39 & -11.44 & -12.70 & -11.19 & -11.44 & -11.70 & & -10.31 & -13.71 & -13.21 & -12.45 & -12.42 & & -12.33 & -12.33 & -10.18 & -13.21 & -12.01 & \\
\hline 40 & -11.95 & -13.33 & -11.70 & -12.20 & -12.29 & & -10.69 & -14.34 & -13.84 & -13.08 & -12.99 & & -13.21 & -13.08 & -10.56 & -13.71 & -12.64 & \\
\hline 41 & -12.33 & -13.71 & -12.20 & -12.33 & -12.64 & & -11.07 & -14.72 & -14.34 & -13.59 & -13.43 & & -13.59 & -13.59 & -10.94 & -14.09 & -13.05 & \\
\hline 42 & -12.70 & -14.34 & -12.70 & -13.08 & -13.21 & & -11.32 & -15.22 & -14.85 & -14.09 & -13.87 & & -14.09 & -14.22 & -11.32 & -14.59 & -13.55 & \\
\hline 43 & -12.96 & -14.85 & -13.21 & -13.59 & -13.65 & 0.020 & -11.70 & -15.98 & -15.22 & -14.72 & -14.41 & 0.021 & -14.47 & -14.85 & -11.82 & -15.10 & -14.06 & 0.036 \\
\hline 44 & -13.21 & -15.35 & -13.59 & -14.22 & -14.09 & 0.014 & -12.07 & -16.36 & -15.73 & -15.35 & -14.88 & 0.014 & -15.10 & -15.35 & -12.20 & -15.48 & -14.53 & 0.028 \\
\hline 45 & -13.71 & -15.73 & -14.09 & -14.97 & -14.63 & & -12.20 & -16.99 & -16.23 & -16.11 & -15.38 & & -14.72 & -15.98 & -12.45 & -15.85 & -14.75 & \\
\hline 46 & -14.09 & -16.48 & -14.47 & -15.35 & -15.10 & & -12.70 & -17.37 & -16.61 & -16.74 & -15.85 & & -14.22 & -16.11 & -12.58 & -16.11 & -14.75 & \\
\hline 47 & -14.34 & -16.86 & -14.47 & -15.85 & -15.38 & & -12.96 & -18.00 & -17.11 & -17.62 & -16.42 & & -13.71 & -16.23 & -12.70 & -16.11 & -14.69 & \\
\hline 48 & -14.72 & -17.24 & -15.60 & -16.48 & -16.01 & & -13.33 & -18.37 & -17.37 & -18.25 & -16.83 & & -13.71 & -16.36 & -12.70 & -15.98 & -14.69 & \\
\hline 49 & -15.10 & -17.87 & -16.23 & -16.99 & -16.55 & & -13.46 & -18.88 & -17.74 & -19.13 & -17.30 & & -14.22 & -16.61 & -12.96 & -15.98 & -14.94 & \\
\hline 50 & -15.60 & -18.25 & -16.99 & -18.00 & -17.21 & 0.014 & -13.84 & -19.51 & -18.25 & -20.39 & -18.00 & 0.014 & -14.85 & -17.11 & -13.21 & -16.23 & -15.35 & 0.028 \\
\hline 51 & -16.36 & -18.75 & -17.74 & -18.50 & -17.84 & & -14.22 & -20.14 & -18.88 & -21.52 & -18.69 & & -15.22 & -17.87 & -13.46 & -16.23 & -15.70 & \\
\hline 52 & -16.99 & -19.38 & -19.00 & -19.76 & -18.78 & & -14.47 & -20.77 & -18.75 & -23.04 & -19.26 & & -15.73 & -18.12 & -13.84 & -16.99 & -16.17 & \\
\hline 53 & -18.00 & & -20.77 & -21.02 & -19.93 & & -14.97 & -21.65 & -20.26 & -25.43 & -20.58 & & -16.36 & -18.75 & -14.09 & -17.37 & -16.64 & \\
\hline 54 & -19.26 & -21.02 & -23.29 & -22.66 & -21.56 & 0.014 & -15.60 & -22.91 & -21.65 & -28.71 & -22.22 & 0.014 & -16.48 & -19.13 & -14.72 & -17.87 & -17.05 & 0.028 \\
\hline 55 & -21.02 & -22.03 & -25.43 & -23.79 & -23.07 & & -15.98 & -24.42 & -22.91 & -31.73 & -23.76 & & -16.74 & -19.89 & -15.10 & -18.00 & -17.43 & \\
\hline 56 & -23.16 & -23.54 & -26.94 & -27.19 & -25.21 & & -16.61 & -26.06 & -25.05 & -36.77 & -26.12 & & -17.49 & -20.39 & -15.73 & -18.25 & -17.96 & \\
\hline 57 & -26.56 & -25.43 & -34.50 & -29.21 & -28.93 & 0.014 & -17.49 & -28.96 & -28.58 & 44.08 & -29.78 & 0.014 & -18.00 & -21.27 & -16.74 & -18.88 & -18.72 & 0.028 \\
\hline 58 & -27.95 & -27.57 & -37.78 & -33.49 & -31.70 & & -18.25 & -31.10 & -30.47 & -50.76 & -32.64 & & -18.37 & -21.78 & -17.11 & -19.00 & -19.07 & \\
\hline 59 & -30.72 & -29.97 & -42.57 & -37.27 & -35.13 & & -19.13 & -32.61 & -33.24 & -55.29 & -35.07 & & -18.63 & -22.41 & -17.87 & -19.76 & -19.67 & \\
\hline 60 & -34.88 & -34.25 & -52.52 & 46.85 & 42.13 & & -20.01 & -36.14 & -39.92 & -64.24 & 40.08 & & -19.00 & -23.16 & -18.63 & -20.52 & -20.33 & \\
\hline 61 & -40.55 & -39.79 & -61.21 & -52.39 & -48.49 & 0.014 & -21.52 & 40.17 & -50.38 & -74.19 & -46.57 & 0.014 & -19.13 & -23.54 & -19.76 & -21.15 & -20.89 & 0.028 \\
\hline 62 & -46.22 & 44.20 & -74.19 & -60.08 & -56.17 & & -23.04 & 44.08 & -53.40 & -69.40 & 47.48 & & -19.13 & -24.55 & -20.52 & -20.77 & -21.24 & \\
\hline 63 & -51.89 & -51.64 & -69.28 & -66.88 & -59.92 & & -24.67 & -47.86 & -59.45 & -69.28 & -50.32 & & -19.13 & -25.43 & -21.65 & -21.65 & -21.97 & \\
\hline 64 & -55.29 & -56.68 & -68.90 & -71.67 & -63.14 & & & -51.64 & -64.36 & -69.03 & -61.68 & & -18.75 & -26.06 & -22.28 & -22.28 & -22.34 & \\
\hline 65 & -70.29 & -70.03 & -70.16 & -69.66 & -70.03 & 0.014 & & -71.92 & -66.25 & -69.53 & -69.24 & 0.014 & -19.13 & -26.94 & -24.04 & -22.03 & -23.04 & 0.028 \\
\hline 66 & -67.39 & -69.78 & -71.04 & -72.05 & -70.07 & & & -68.27 & -68.27 & -71.67 & -69.40 & & -19.63 & -27.95 & -24.80 & -23.16 & -23.89 & \\
\hline 67 & -66.76 & -69.03 & -69.66 & -71.29 & -69.18 & & & -65.50 & -68.77 & -70.29 & -68.19 & & -18.88 & -28.83 & -26.56 & -23.16 & -24.36 & \\
\hline 68 & -67.39 & -70.29 & -70.03 & -70.03 & -69.44 & & & -67.77 & -68.90 & -71.17 & -69 . & & -18.75 & -29.59 & -28.45 & -24.55 & -25.34 & \\
\hline 69 & -67.64 & -72.43 & -70.79 & -71.42 & -70.57 & & & -68.65 & -69.15 & -71.04 & -69.61 & & -18.88 & -30.85 & -30.47 & -25.43 & -26.41 & \\
\hline 70 & -71.42 & -72.55 & -71.04 & -71.67 & -71.67 & & & -69.03 & -71.42 & -72.43 & -70.96 & & -19.89 & -32.99 & -33.87 & -24.80 & -27.89 & \\
\hline 71 & -72.05 & -72.30 & -70.03 & -71.92 & -71.58 & 0.014 & & -71.42 & -70.29 & & & 0.014 & -20.26 & -34.50 & -36.14 & -24.55 & -28.86 & 0.028 \\
\hline 72 & -71.42 & -71.42 & -70.16 & -72.43 & -71.36 & & & -72.05 & -70.16 & & & & -21.27 & -36.39 & -39.29 & -26.94 & -30.97 & \\
\hline 73 & -72.68 & & -72.68 & -72.68 & -72.68 & & & -72.43 & -73.56 & & & & -22.03 & -39.16 & 44.46 & -29.08 & -33.68 & \\
\hline 74 & -70.41 & & -71.42 & & & 0.020 & & -70.16 & -73.31 & & & 0.041 & -22.91 & -43.45 & -53.15 & -29.21 & -37.18 & 0.041 \\
\hline 75 & & & -71.80 & & & & & -71.92 & -71.92 & -71.17 & -71.67 & & -12.70 & -46.98 & -59.83 & -27.32 & -36.71 & \\
\hline
\end{tabular}

(continua) 
Profundidade 1,00 m (continuação).

\begin{tabular}{|c|c|c|c|c|c|c|c|c|c|c|c|c|c|c|c|c|c|c|}
\hline \multirow[b]{2}{*}{ DAS } & \multicolumn{6}{|c|}{ trat -000} & \multicolumn{6}{|c|}{ trat $0 \mathrm{IO}$} & \multicolumn{6}{|c|}{ trat III } \\
\hline & r1 & 12 & r3 & $\mathrm{r} 4$ & média & $\mathrm{P}+\mathrm{I}$ & $\mathrm{rl}$ & 12 & r3 & $\mathrm{r} 4$ & média & $\mathrm{P}+\mathrm{I}$ & r1 & 12 & r3 & $\mathrm{r} 4$ & média & $\mathrm{P}+\mathrm{I}$ \\
\hline 76 & & & -71.42 & & & & & -71.67 & -71.42 & -71.42 & -71.50 & & -13.08 & -49.24 & -63.61 & -30.09 & -39.01 & \\
\hline 77 & & & -71.04 & & & & & -71.42 & -70.66 & -70.16 & -70.75 & & -14.59 & -51.26 & -65.12 & -31.10 & -40.52 & \\
\hline 78 & -71.55 & & -71.55 & & & 0.020 & & -71.92 & -71.29 & -70.41 & -71.21 & 0.041 & -5.27 & -53.65 & -68.40 & -32.99 & -40.08 & 0.041 \\
\hline 79 & -71.67 & & -71.80 & & & & & -72.05 & -71.92 & -66.76 & -70.24 & & -7.54 & -55.67 & -70.16 & -34.12 & 41.87 & \\
\hline 80 & -71.67 & & -71.80 & & & & & -72.30 & -72.05 & -67.89 & -70.75 & & -8.92 & -54.41 & -70.03 & -34.75 & -42.03 & \\
\hline 81 & & & -72.43 & & & & & -72.68 & -72.43 & -70.66 & -71.92 & & -9.93 & -51.89 & -70.54 & -33.87 & -41.56 & \\
\hline 82 & & & & & & & & & & & & & -11.32 & & -69.03 & -20.64 & -33.66 & \\
\hline 83 & & & & & & & & & & & & & -12.83 & & -68.52 & -31.10 & -37.48 & \\
\hline 84 & & & & & & & & & & & & & -14.72 & & -68.52 & -29.46 & -37.57 & \\
\hline 85 & & & & & & 0.014 & & & & & & 0.028 & -15.35 & & -72.05 & -25.43 & -37.61 & 0.028 \\
\hline 86 & & & & & & & & & & & & & -6.91 & & -72.68 & -28.33 & -35.97 & \\
\hline 87 & & & & & & & & -70.79 & -72.43 & & & & -7.66 & & -71.42 & -29.84 & -36.31 & \\
\hline 88 & & -71.92 & -71.67 & -71.04 & -71.55 & 0.047 & -72.30 & -71.42 & -72.18 & -69.53 & -71.36 & 0.047 & 4.89 & -54.41 & -72.55 & -27.32 & -39.79 & 0.047 \\
\hline 89 & & -70.16 & & & & & -8.67 & -22.41 & -39.54 & -69.91 & -35.13 & & -6.28 & -22.91 & -66.63 & -9.30 & -26.28 & \\
\hline 90 & & -72.43 & & & & 0.019 & -8.55 & -13.46 & -15.98 & -71.42 & -27.35 & 0.019 & -7.03 & -13.46 & -71.92 & -9.43 & -25.46 & 0.019 \\
\hline 91 & & & & & & 0.017 & -7.79 & -9.81 & -10.44 & -70.79 & -24.71 & 0.017 & -6.66 & -9.18 & -72.05 & -9.43 & -24.33 & 0.017 \\
\hline 92 & -67.51 & -72.30 & -72.30 & -71.55 & -70.92 & 0.045 & 4.89 & -7.16 & -6.40 & -71.04 & -22.37 & 0.045 & 4.51 & -6.28 & -8.80 & -7.79 & -6.85 & 0.045 \\
\hline 93 & -59.07 & -11.44 & -72.18 & -71.42 & -53.53 & & -6.53 & -6.91 & -7.29 & -11.57 & -8.07 & & -5.90 & -6.15 & -7.41 & -7.79 & -6.81 & \\
\hline 94 & -17.74 & -11.19 & -17.87 & -70.16 & -29.24 & & -7.79 & -8.67 & -9.05 & -11.19 & -9.18 & & -7.79 & -7.79 & -7.41 & -9.43 & -8.11 & \\
\hline 95 & -19.38 & -11.19 & -14.72 & -38.03 & -20.83 & & -8.67 & -10.06 & -10.31 & -12.70 & -10.44 & & -9.30 & -9.30 & -8.29 & -10.69 & -9.40 & \\
\hline 96 & -14.72 & -9.05 & -14.34 & -14.22 & -13.08 & & -9.30 & -10.94 & -11.57 & -12.83 & -11.16 & & -10.31 & -10.56 & -8.92 & -11.82 & -10.40 & \\
\hline 97 & -17.24 & -14.22 & -18.25 & -17.11 & -16.70 & & -10.06 & -12.58 & -11.95 & -16.48 & -12.77 & & -11.82 & -12.20 & -10.06 & -12.96 & -11.76 & \\
\hline 98 & -20.01 & -16.23 & -20.52 & -20.26 & -19.26 & & -10.56 & -13.71 & -14.34 & -19.63 & -14.56 & & -12.96 & -13.84 & -11.07 & -14.22 & -13.02 & \\
\hline 99 & -23.92 & -19.26 & -24.80 & -24.67 & -23.16 & & -11.32 & -15.35 & -15.98 & -24.30 & -16.74 & & -14.72 & -15.98 & -12.20 & -15.60 & -14.63 & \\
\hline 100 & -30.47 & -25.05 & -29.71 & -32.11 & -29.34 & 0.023 & -12.45 & -17.62 & -18.50 & -33.37 & -20.48 & 0.044 & -16.61 & -18.63 & -13.59 & -17.24 & -16.52 & 0.044 \\
\hline 101 & -32.86 & -25.05 & -34.63 & -32.99 & -31.38 & & -13.21 & -17.74 & -16.11 & -34.00 & -20.26 & & -17.74 & -20.26 & -14.85 & -18.50 & -17.84 & \\
\hline 102 & -39.54 & -25.81 & -39.54 & -38.66 & -35.89 & & -13.71 & -18.63 & -16.23 & -38.41 & -21.74 & & -17.74 & -22.53 & -15.98 & -19.76 & -19.00 & \\
\hline 103 & 45.34 & -26.69 & 44.71 & 46.47 & 40.80 & & -13.84 & -19.13 & -16.11 & 41.81 & -22.72 & & -18.12 & -24.17 & -16.74 & -20.77 & -19.95 & \\
\hline 104 & -54.66 & 40.05 & 47.73 & -55.04 & 49.37 & & -14.47 & -20.14 & -16.48 & -56.05 & -26.78 & & -18.37 & -26.31 & -17.49 & -21.78 & -20.99 & \\
\hline 105 & -62.35 & 45.09 & -52.77 & -61.09 & -55.32 & & -14.97 & -21.40 & -18.00 & -62.22 & -29.15 & & & -30.47 & -18.88 & -23.04 & -24.13 & \\
\hline 106 & -65.37 & -51.13 & -55.42 & -62.85 & -58.69 & 0.020 & -15.73 & -22.66 & -17.74 & -64.49 & -30.16 & 0.041 & -8.04 & -33.49 & -20.39 & -21.65 & -20.89 & 0.041 \\
\hline 107 & -67.89 & -32.11 & -59.07 & -65.25 & -56.08 & 0.031 & -15.73 & -21.78 & -17.62 & -72.05 & -31.79 & 0.031 & -9.43 & -32.11 & -20.64 & -24.17 & -21.59 & 0.031 \\
\hline 108 & -67.01 & -40.55 & -61.72 & -66.38 & -58.91 & & -15.60 & -20.64 & -11.95 & -72.05 & -30.06 & & -8.80 & -35.01 & -21.65 & -25.18 & -22.66 & \\
\hline 109 & -67.01 & 41.81 & -63.48 & -68.27 & -60.14 & 0.038 & -8.55 & -12.83 & -9.68 & -60.33 & -22.85 & 0.038 & 4.77 & -21.52 & -6.78 & -15.73 & -12.20 & 0.038 \\
\hline 110 & -21.27 & -9.55 & -63.61 & -67.39 & 40.46 & & -6.15 & -7.54 & -6.91 & -10.56 & -7.79 & & -6.03 & -7.41 & -7.29 & $=8.80$ & -7.38 & \\
\hline 111 & -18.63 & -9.30 & -24.80 & -65.12 & -29.46 & & -7.41 & -8.67 & -7.16 & -11.32 & -8.64 & & -7.66 & -7.79 & -7.16 & -9.30 & -7.98 & \\
\hline 112 & -18.88 & -10.31 & -18.88 & -67.89 & -28.99 & & -8.17 & -9.68 & -8.42 & -11.82 & -9.52 & & -8.80 & -8.80 & -7.79 & -10.31 & -8.92 & \\
\hline 113 & -16.23 & -7.29 & -10.69 & -16.99 & -12.80 & 0.055 & -6.03 & -7.92 & -8.17 & -8.29 & -7.60 & 0.055 & -5.65 & -7.41 & -7.03 & -8.42 & -7.13 & 0.055 \\
\hline 114 & -8.04 & -6.78 & -7.03 & -10.56 & -8.11 & & -6.40 & -7.16 & -8.42 & -7.16 & -7.29 & & -6.03 & -6.53 & -6.40 & -8.04 & -6.75 & \\
\hline 115 & -9.30 & -8.42 & -7.79 & -9.43 & -8.74 & & -7.79 & -8.92 & -8.80 & -8.80 & -8.58 & & -8.04 & -7.92 & -7.16 & -9.43 & -8.14 & \\
\hline 116 & -11.07 & -10.06 & -9.05 & -9.81 & -10.00 & & -8.67 & -10.44 & -10.18 & -10.18 & -9.87 & & -9.55 & -8.80 & -8.17 & -10.69 & -9.30 & \\
\hline 117 & -11.82 & -11.32 & -9.81 & -10.94 & -10.97 & & -9.30 & -11.57 & -11.07 & -11.19 & -10.78 & & -10.44 & -10.94 & -9.05 & -11.57 & -10.50 & \\
\hline 118 & -13.33 & -12.58 & -10.81 & -12.20 & -12.23 & & -10.06 & -12.83 & -11.95 & -12.20 & -11.76 & & -11.57 & -12.07 & -9.81 & -12.58 & -11.51 & \\
\hline 119 & -14.72 & -13.96 & -11.57 & -13.59 & -13.46 & & -10.69 & -13.96 & -12.83 & -13.08 & -12.64 & & -12.83 & -13.46 & -10.69 & -13.33 & -12.58 & \\
\hline 120 & -15.98 & -17.11 & -12.33 & -15.85 & -15.32 & & -11.32 & -15.35 & -13.46 & -14.34 & -13.62 & & -14.09 & -15.35 & -11.57 & -14.34 & -13.84 & \\
\hline 121 & -16.99 & -17.24 & -13.08 & -17.11 & -16.11 & 0.006 & -11.95 & -16.23 & -14.22 & -14.97 & -14.34 & 0.006 & -14.97 & -16.48 & -12.07 & -14.97 & -14.63 & 0.006 \\
\hline 122 & -17.74 & -17.87 & -13.71 & -18.00 & -16.83 & & -12.45 & -17.11 & -14.72 & -15.73 & -15.00 & & -15.60 & -17.49 & -12.70 & -15.35 & -15.29 & \\
\hline 123 & -18.63 & -19.89 & -14.22 & -19.00 & -17.93 & 0.035 & -13.08 & -18.00 & -15.22 & -16.36 & -15.67 & 0.035 & -16.23 & -18.88 & -13.33 & -15.98 & -16.11 & 0.035 \\
\hline 124 & -19.38 & -22.91 & -13.59 & -20.14 & -19.00 & & -13.59 & -18.88 & -14.59 & -17.37 & -16.11 & & -16.48 & -21.40 & -13.46 & -16.61 & -16.99 & \\
\hline 125 & -19.89 & -21.65 & -12.70 & -21.40 & -18.91 & & -13.71 & -18.63 & -14.59 & -17.74 & -16.17 & & -15.85 & -22.15 & -13.46 & -16.74 & -17.05 & \\
\hline 126 & -20.01 & -18.63 & -12.96 & -23.16 & -18.69 & & -13.46 & -18.37 & -14.47 & -30.72 & -19.26 & & -15.98 & -23.04 & -13.59 & -16.61 & -17.30 & \\
\hline 127 & -20.14 & -20.26 & -12.96 & -23.41 & -19.19 & & -13.21 & -18.88 & -14.47 & -18.37 & -16.23 & & -15.85 & -23.92 & -13.71 & -16.86 & & \\
\hline 128 & -21.27 & -21.78 & -14.22 & -25.93 & -20.80 & & -13.71 & -19.26 & -14.97 & -19.26 & -16.80 & & -16.74 & -25.56 & -14.22 & -17.24 & -18.44 & \\
\hline 129 & & & & & & 0.008 & & & & & & 0.008 & & & & & & 0. \\
\hline 130 & -22.53 & -20.77 & -15.35 & -15.85 & -18.63 & 0.007 & -14.22 & -19.26 & -15.98 & -20.39 & & 0.007 & -18.00 & -24.17 & & -18.00 & & 0.007 \\
\hline 131 & -22.28 & -24.17 & -14.72 & -27.32 & -22.12 & 0.021 & -14.34 & -19.26 & -15.98 & -20.52 & -17.52 & 0.021 & -17.24 & -24.17 & -14.85 & -18.12 & -18.59 & 0.021 \\
\hline 132 & -22.78 & -23.29 & -14.97 & -27.82 & -22.22 & & -14.47 & -19.51 & -15.98 & -20.52 & -17.62 & & -17.37 & -24.30 & -14.85 & -18.25 & -18.69 & \\
\hline 133 & -23.29 & -23.04 & -14.34 & -28.83 & -22.37 & & -14.85 & -19.63 & -15.48 & -21.02 & & & & -23.41 & -14.72 & -18.25 & & \\
\hline 134 & -23.67 & -21.15 & -13.46 & -29.59 & -21.97 & 0.015 & -14.72 & -19.38 & -14.97 & -21.27 & -17.59 & 0.015 & -15.85 & -21.27 & -14.47 & -17.74 & -17.33 & 0.015 \\
\hline 135 & -23.67 & -20.64 & -10.94 & -29.97 & -21.30 & & -14.72 & -18.63 & -14.47 & -20.77 & -17.15 & & -14.72 & -19.38 & -13.71 & -17.11 & -16.23 & \\
\hline 136 & -23.54 & -19.89 & -12.07 & -29.84 & -21.34 & & -14.22 & -17.87 & -13.96 & -20.77 & & & & -17.49 & & -16.23 & & \\
\hline 137 & -23.67 & -18.00 & -11.70 & -30.97 & -21.08 & & -13.96 & -17.24 & -13.71 & -20.52 & -16.36 & & -12.96 & -15.98 & -12.33 & -15.35 & & \\
\hline 138 & -23.16 & -17.37 & -11.70 & -30.85 & -20.77 & & -13.46 & -16.74 & -13.46 & -20.01 & -15.92 & & -12.96 & -14.97 & -11.95 & -14.97 & -13.71 & \\
\hline 139 & & & & & & 0.008 & & & & & & 0.008 & & & & & & 0.008 \\
\hline 141 & & & & & & 0.020 & & & & & & 0.020 & & & & & & 0.020 \\
\hline 142 & & & & & & 0.025 & & & & & & 0.025 & & & & & & 0.025 \\
\hline 143 & & & & & & 0.015 & & & & & & 0.013 & & & & & & 0.015 \\
\hline 146 & & & & & & 0.043 & & & & & & 0.043 & & & & & & 0.043 \\
\hline 147 & & & & & & 0.070 & & & & & & 0.070 & & & & & & 0.070 \\
\hline
\end{tabular}




\section{APÊNDICE 2}

Gráficos mostrando a variabilidade em termos de desvio padrão e o valor médio diário do potencial mátrico $\left(\phi_{\mathrm{m}}\right)$, em $\mathrm{kPa}$, e mostrando os volumes de água de irrigação e precipitação (P+I), em $\mathrm{m}^{3} / \mathrm{m}^{2}$, em função do tempo (DAS), dias após a semeadura.

Obs.: as barras no eixo inferior indicam os volumes de água e as barras no centro do gráfico indicam dois desvios padrão, um abaixo e um acima da média, que está ao centro. 


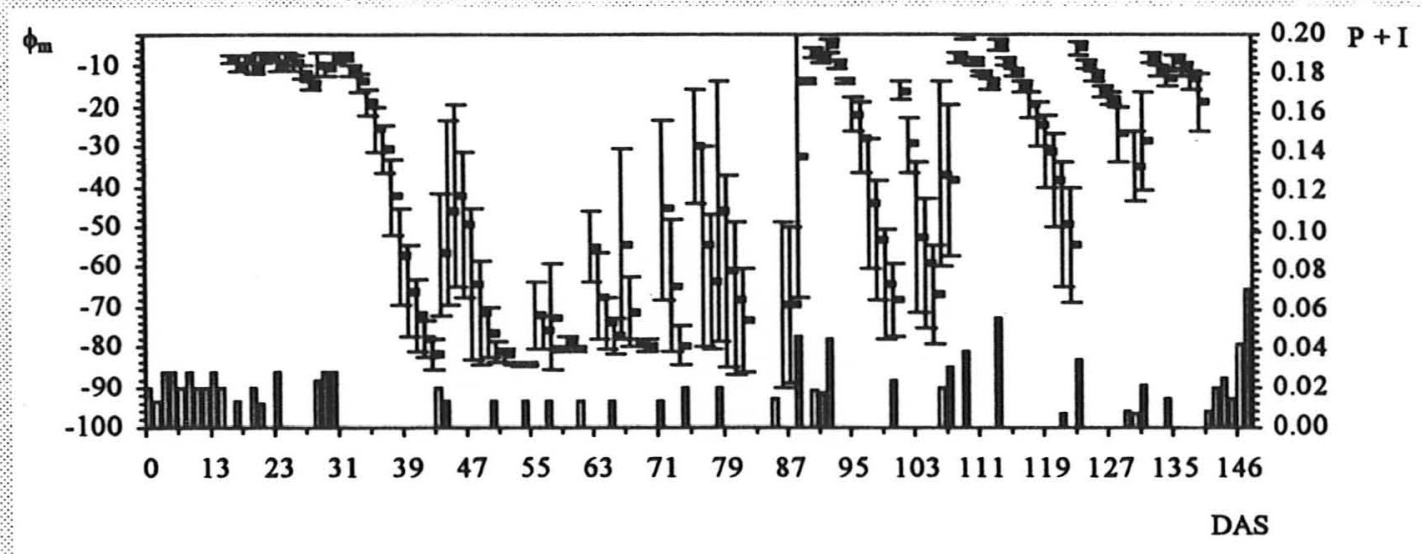

Tratamento tr000

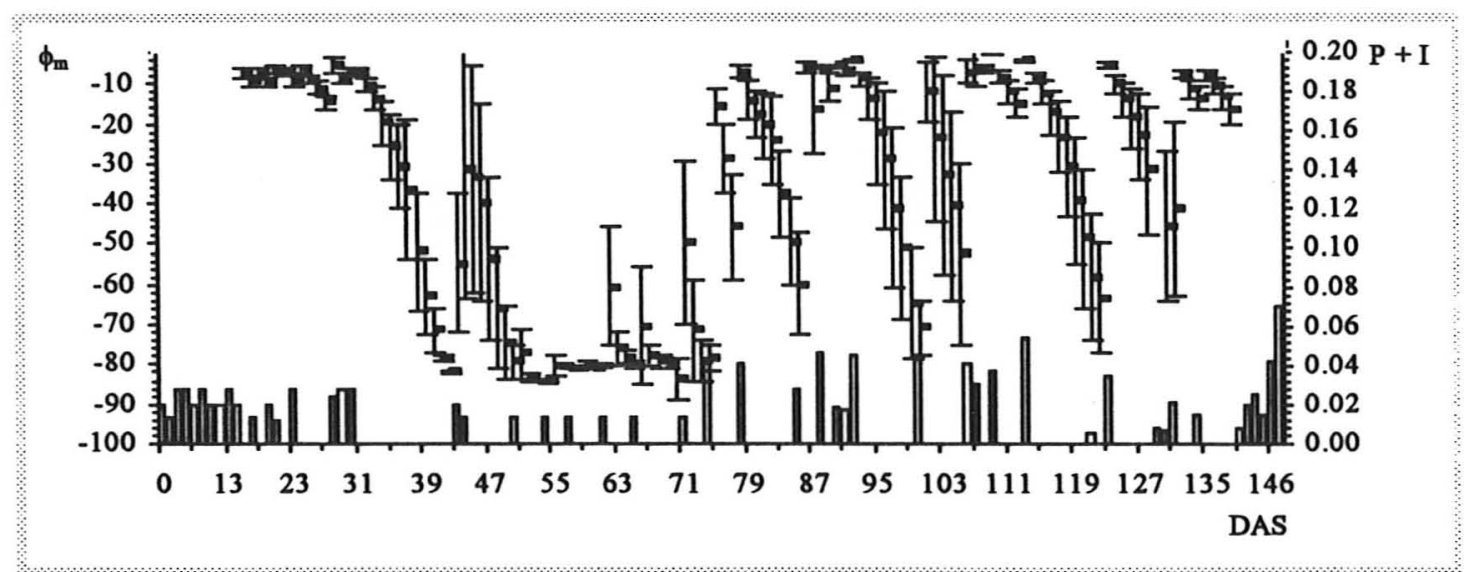

Tratamento tr0I0

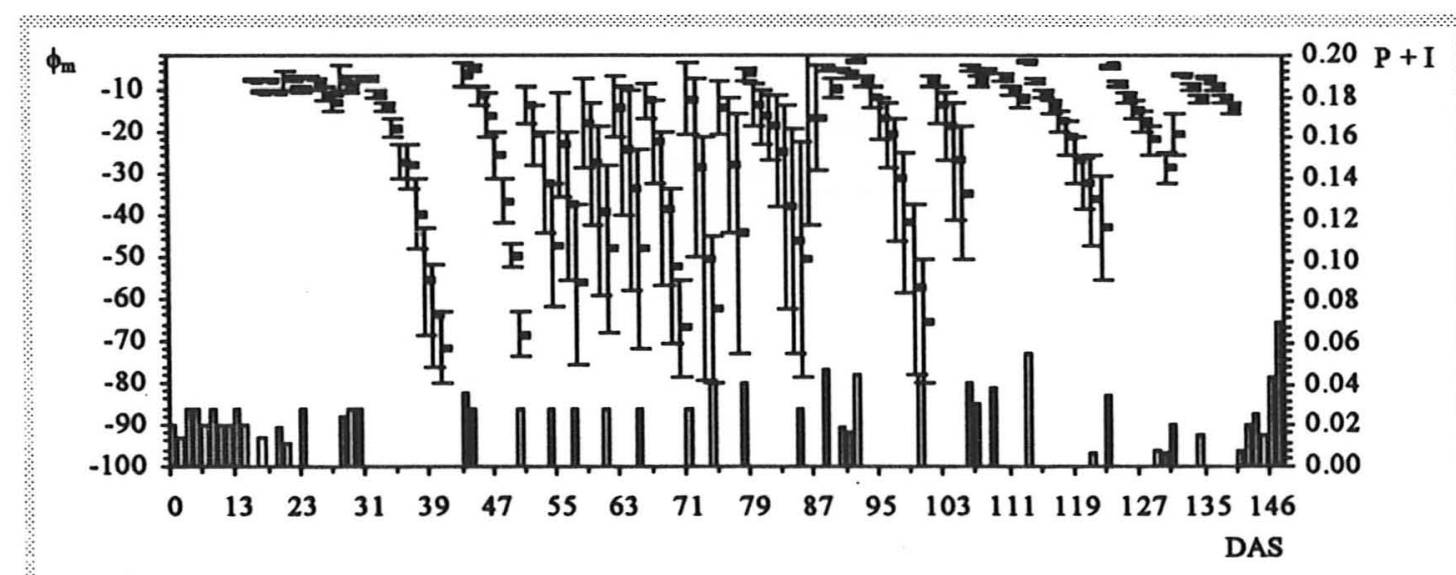




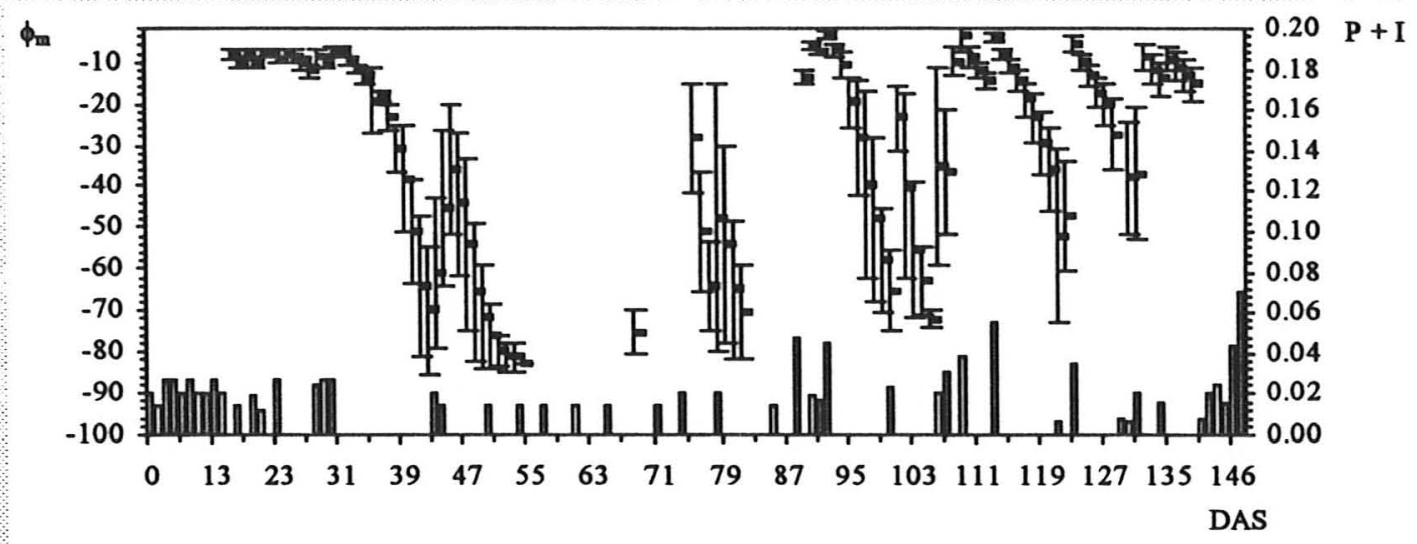

Tratamento tro00

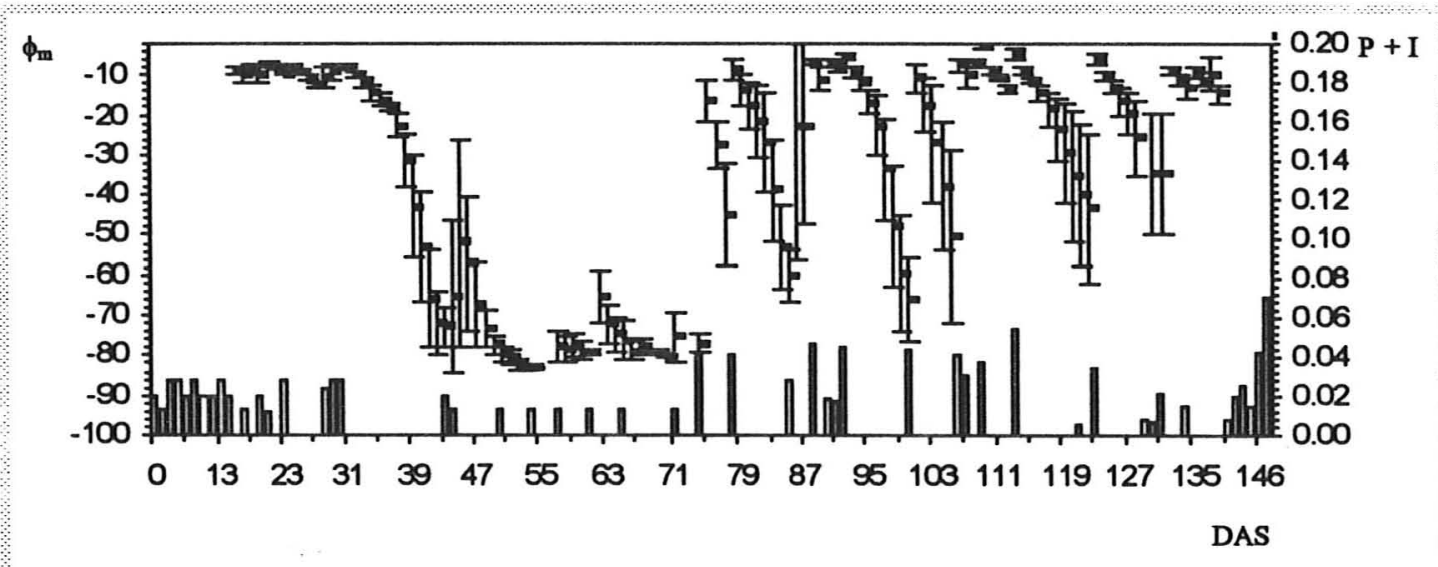

Tratamento troI0

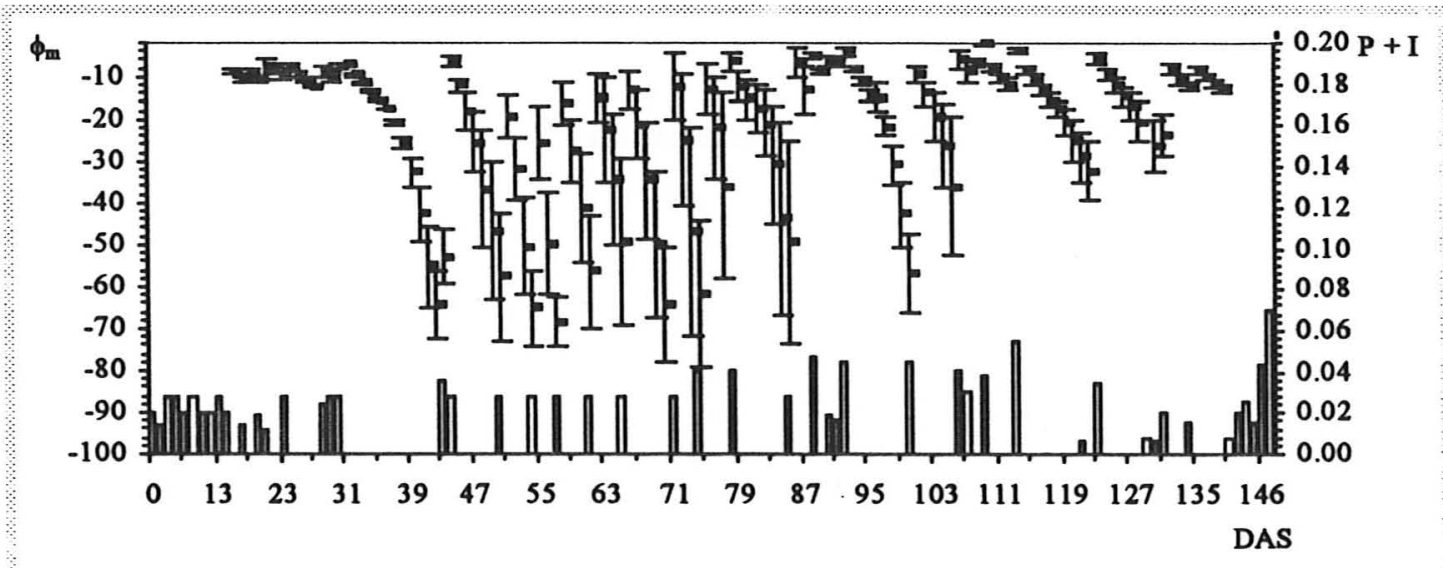

Tratamento trIII

PROFUNDIDADE $0,20 \mathrm{~m}$. 


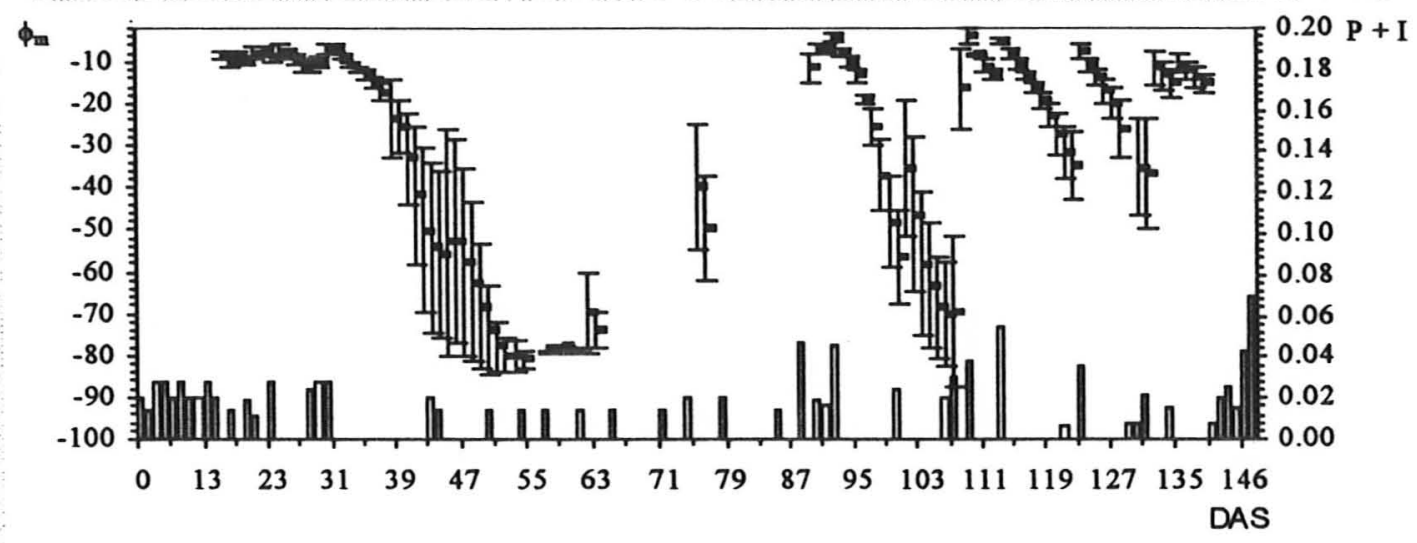

Tratamento tro00

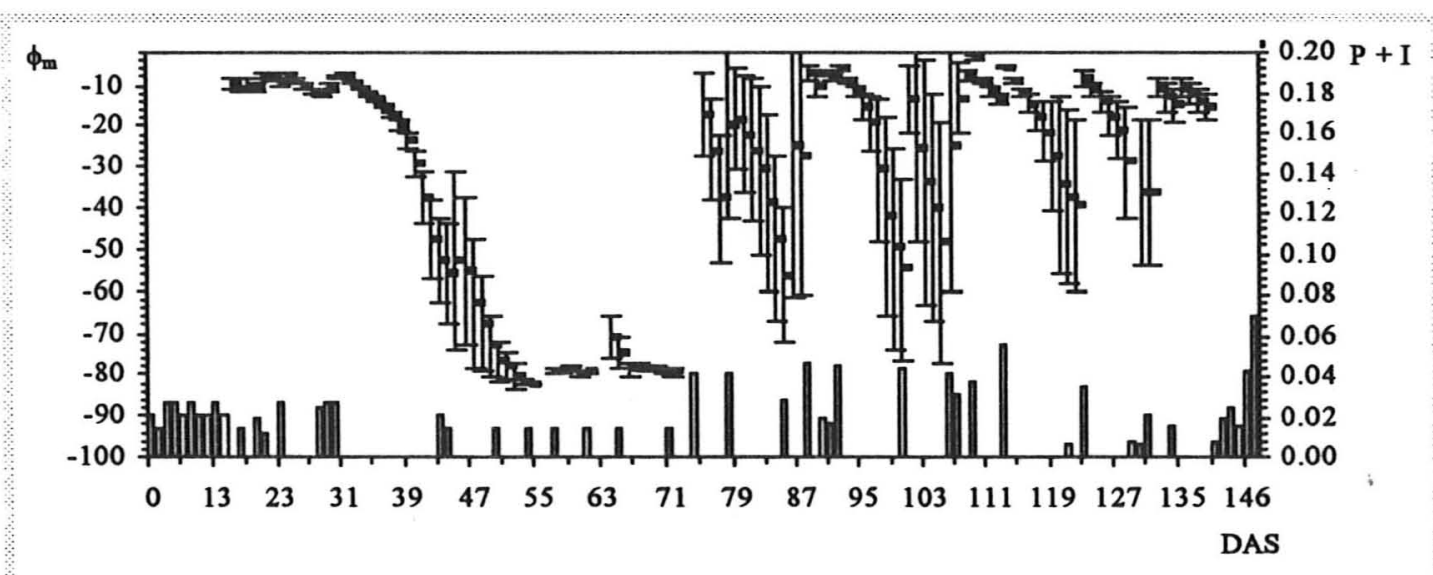

Tratamento troI0

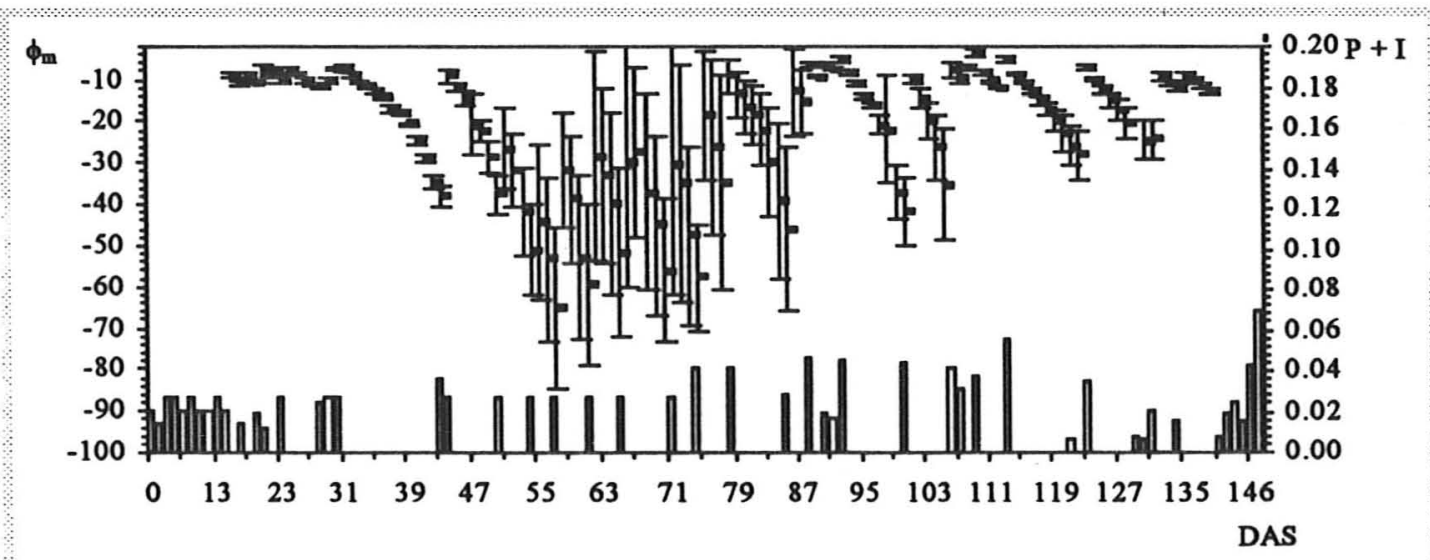

Tratamento trIII

PROFUNDIDADE $0,30 \mathrm{~m}$. 


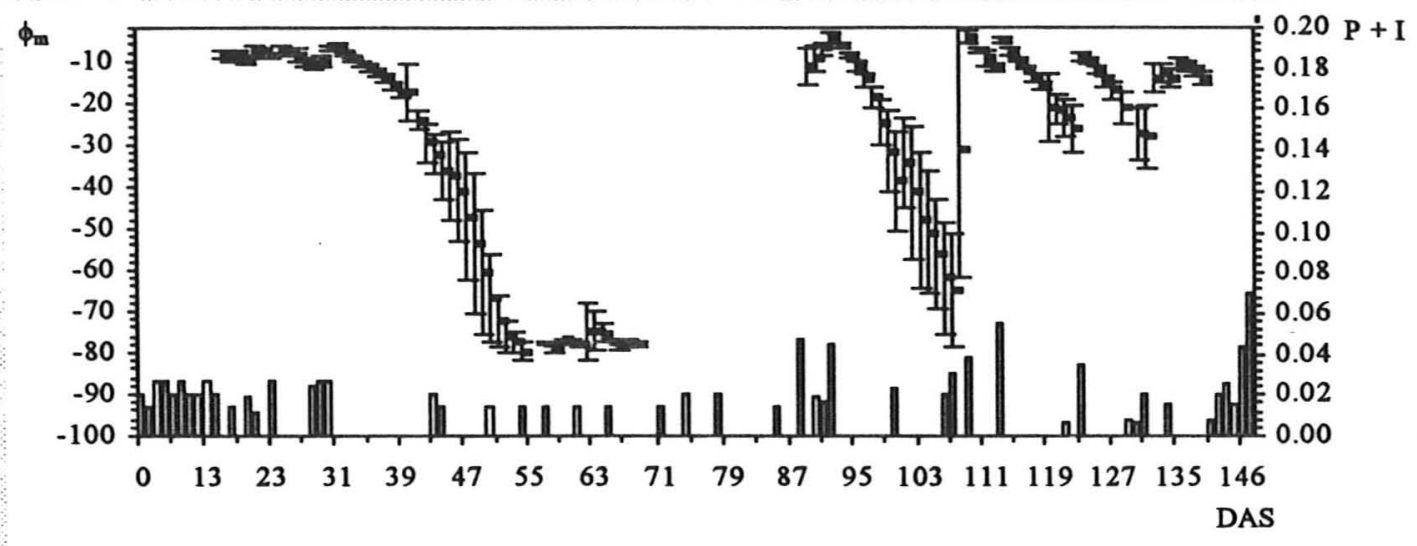

\section{Tratamento tr000}

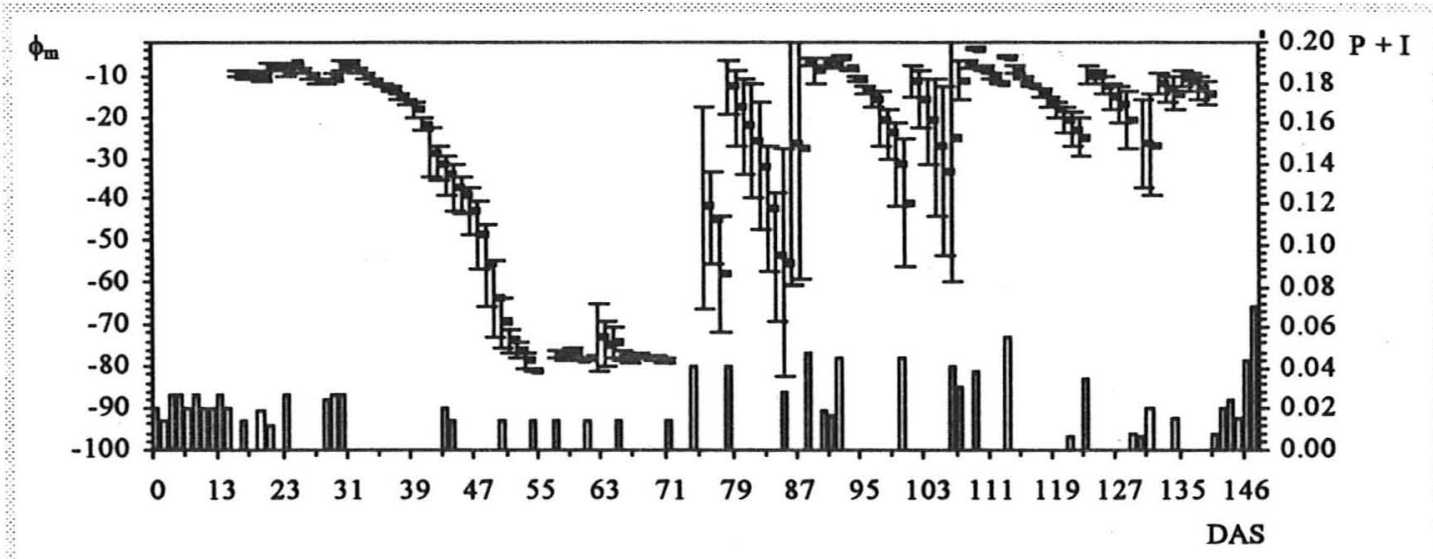

Tratamento troI0

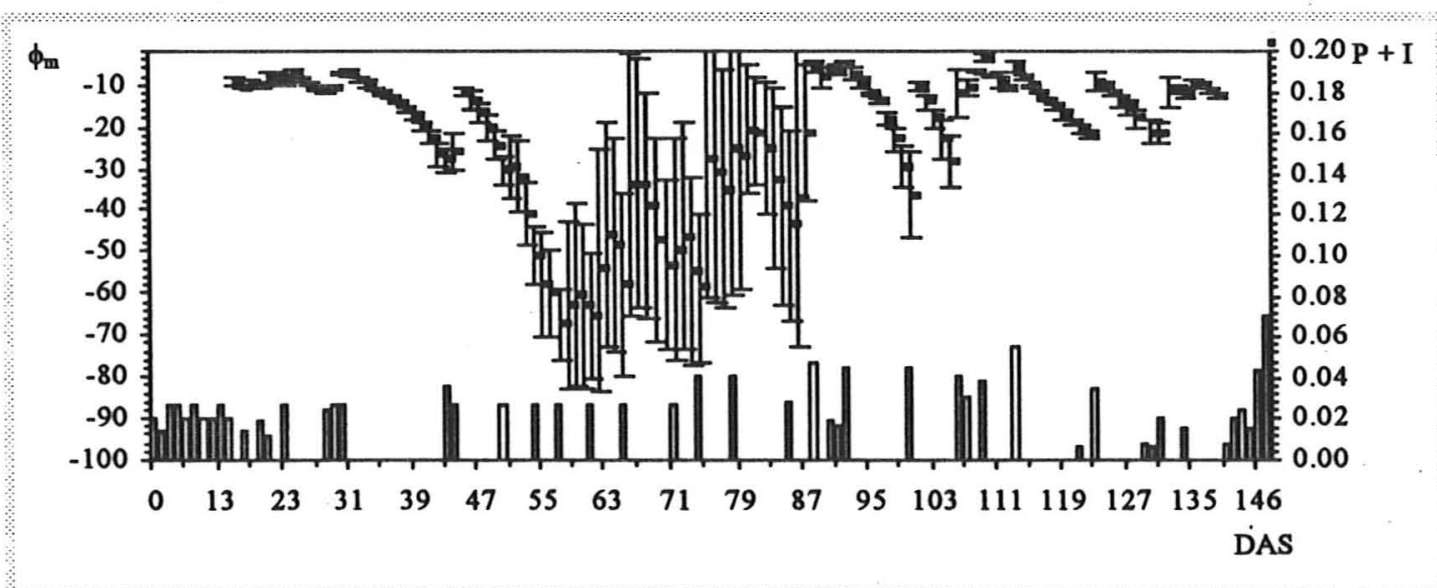

Tratamento trIII

PROFUNDIDADE $0,40 \mathrm{~m}$. 


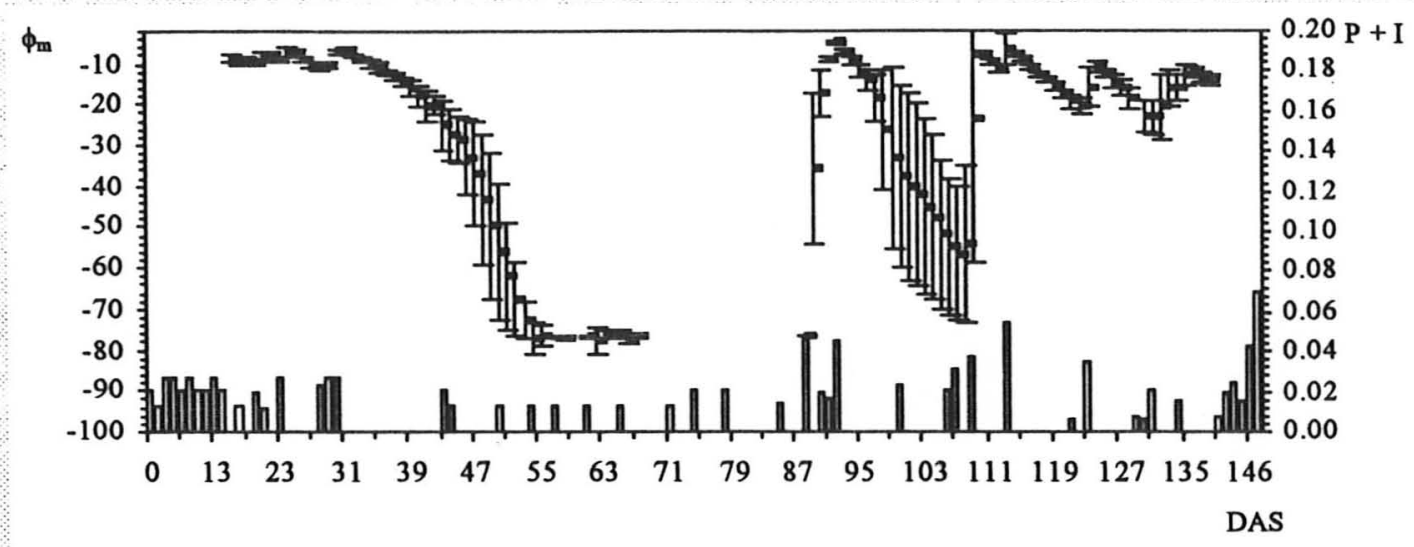

Tratamento tr000

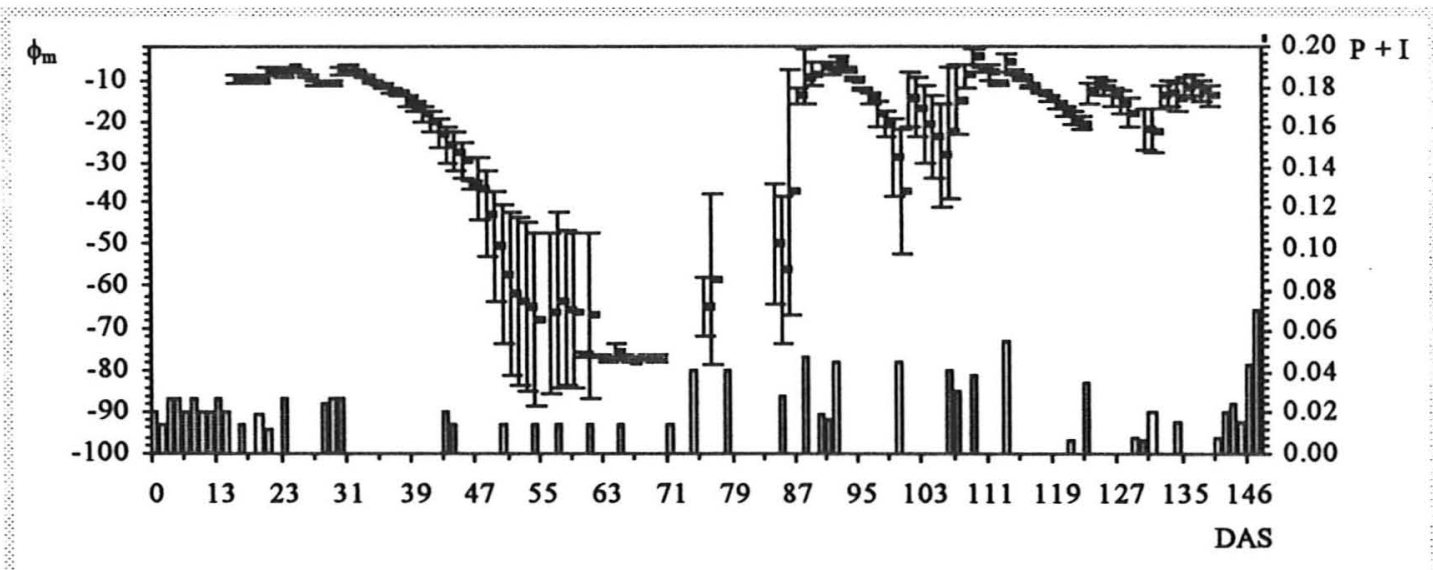

Tratamento tr0I0

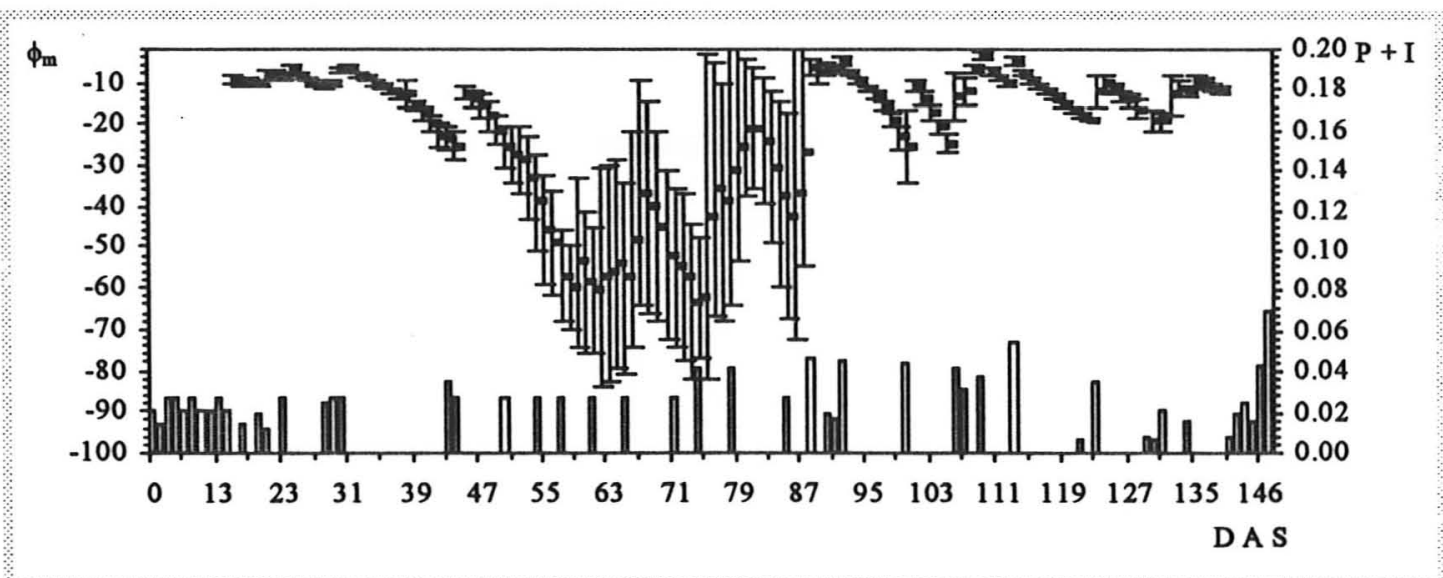

Tratamento trIII

PROFUNDIDADE $0,50 \mathrm{~m}$. 


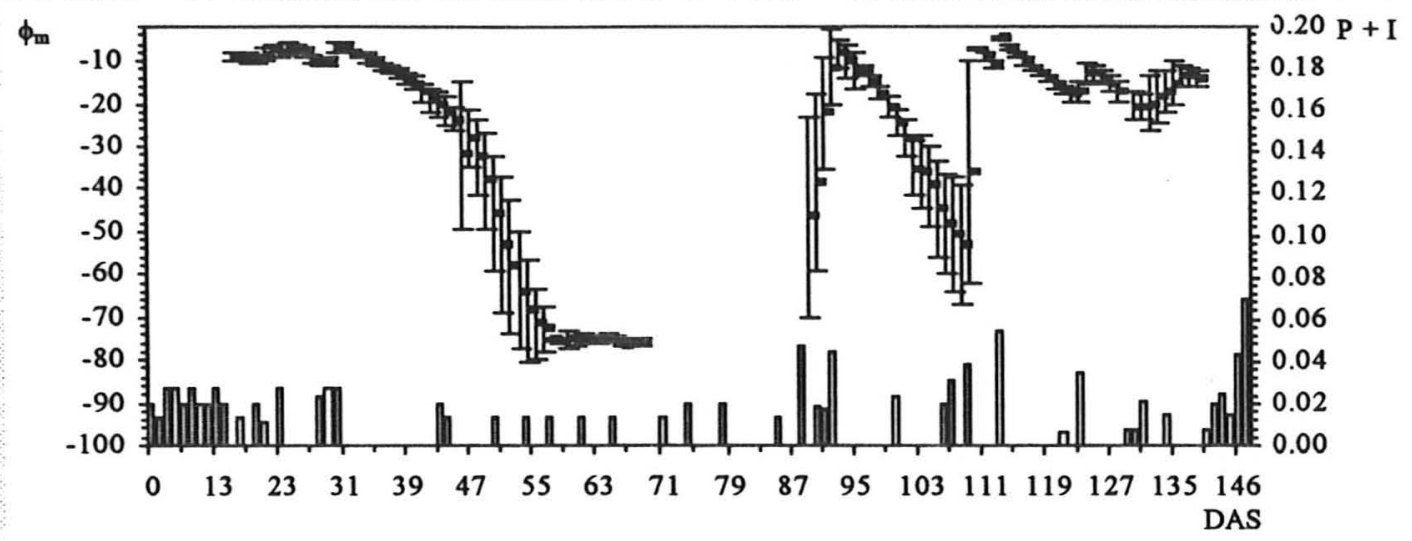

Tratamento tr000

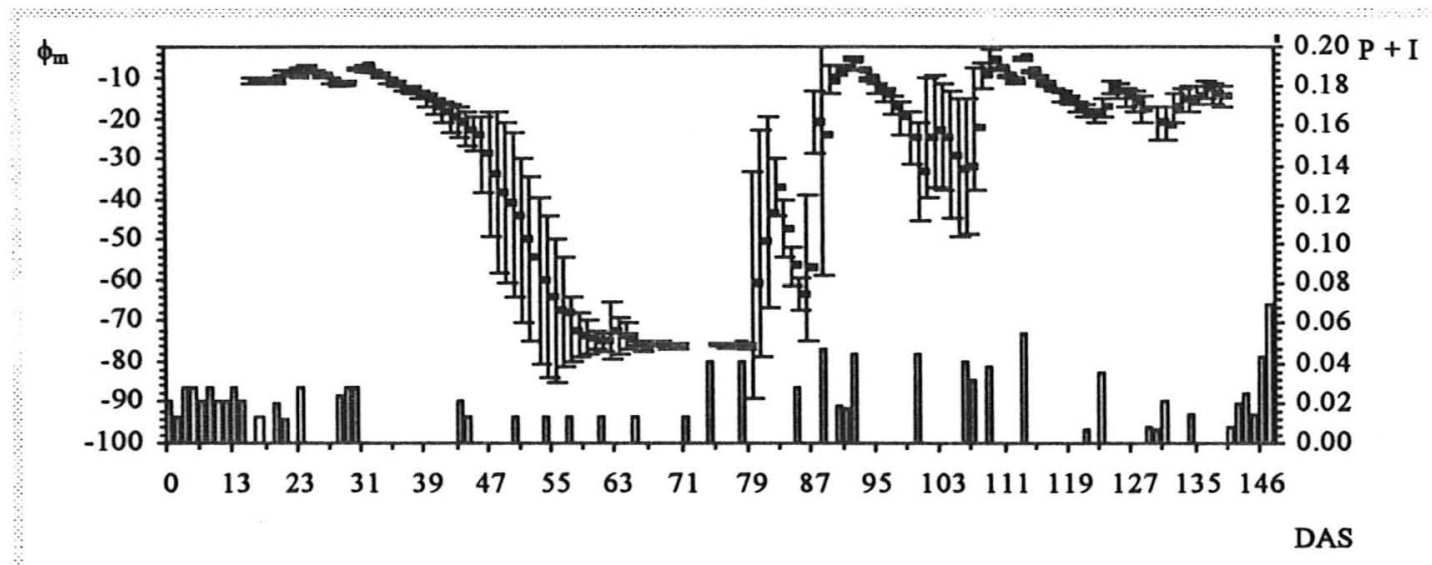

Tratamento troI0

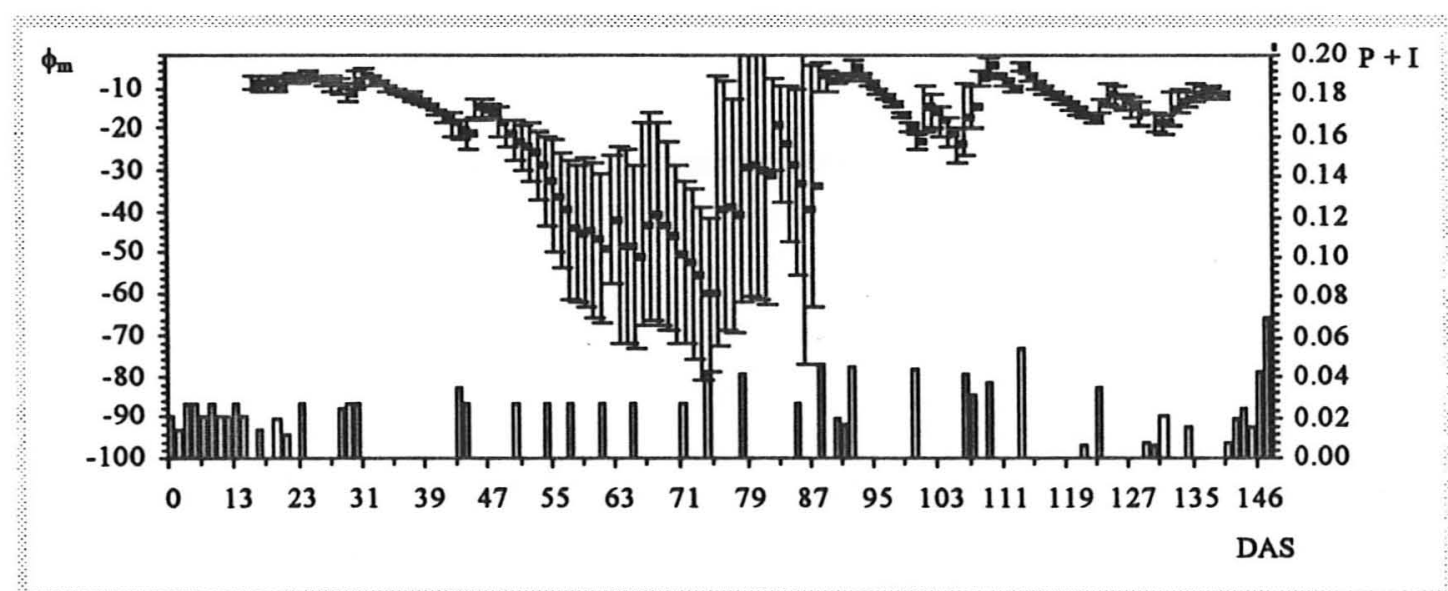

Tratamento trIII

PROFUNDIDADE $0,60 \mathrm{~m}$. 


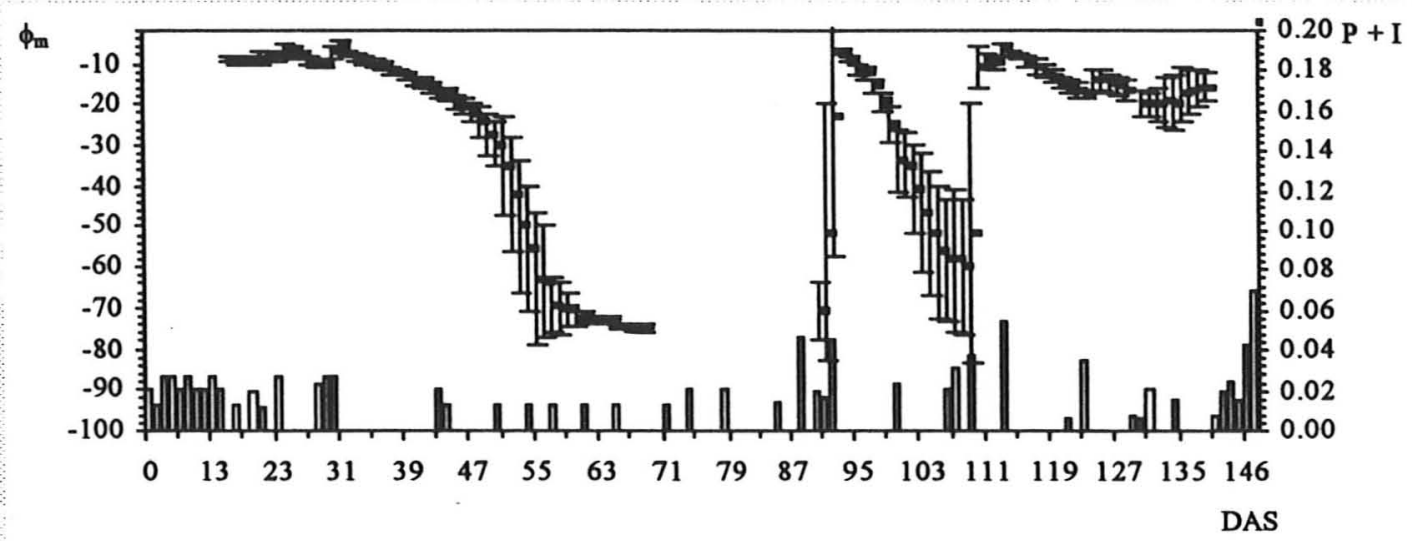

Tratamento tr000

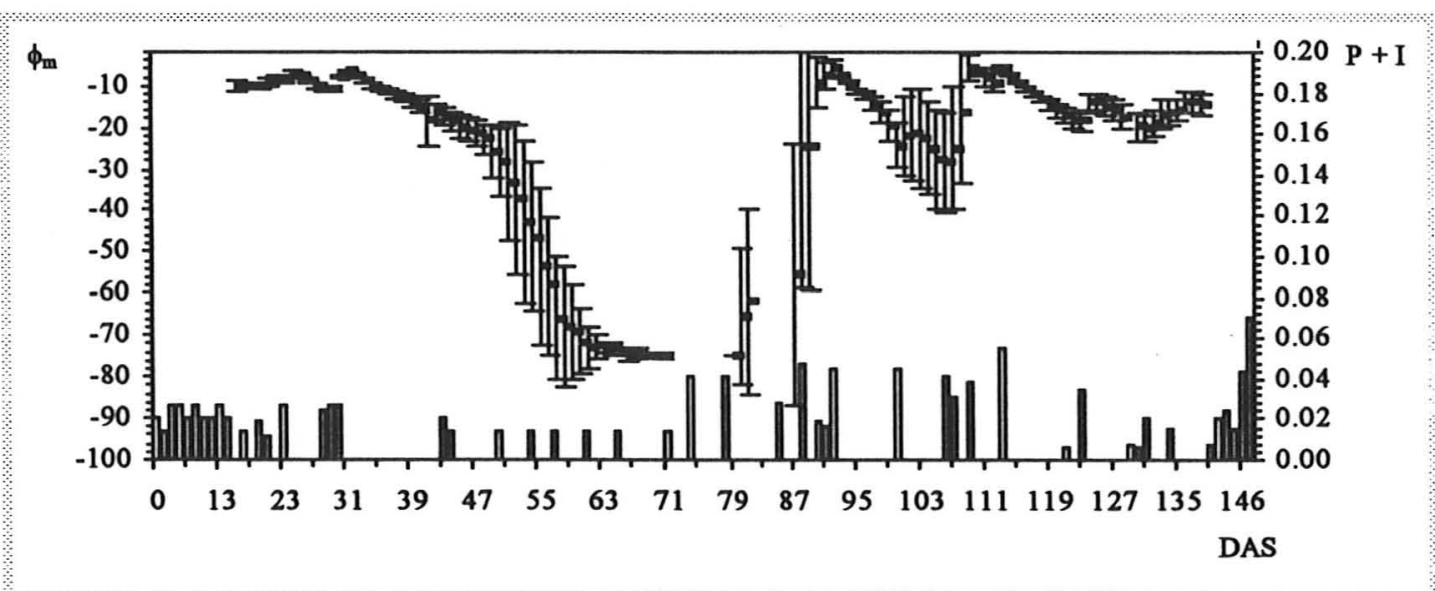

Tratamento troI0

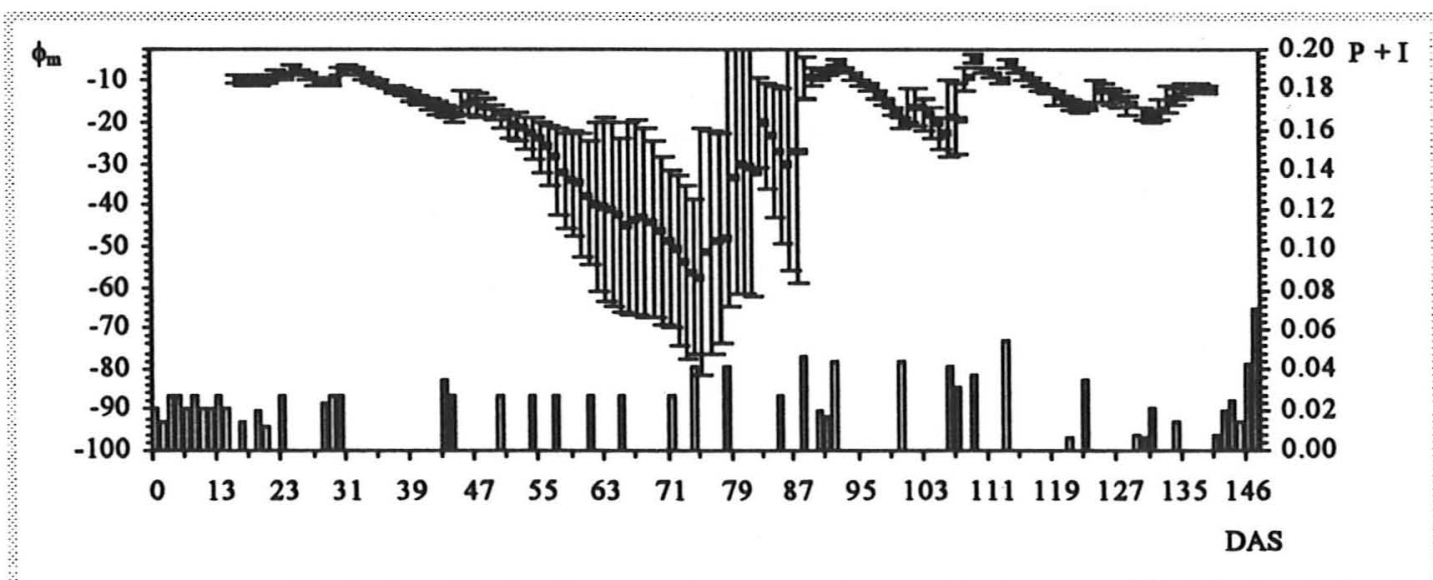

Tratamento trIII

PROFUNDIDADE $0,70 \mathrm{~m}$. 


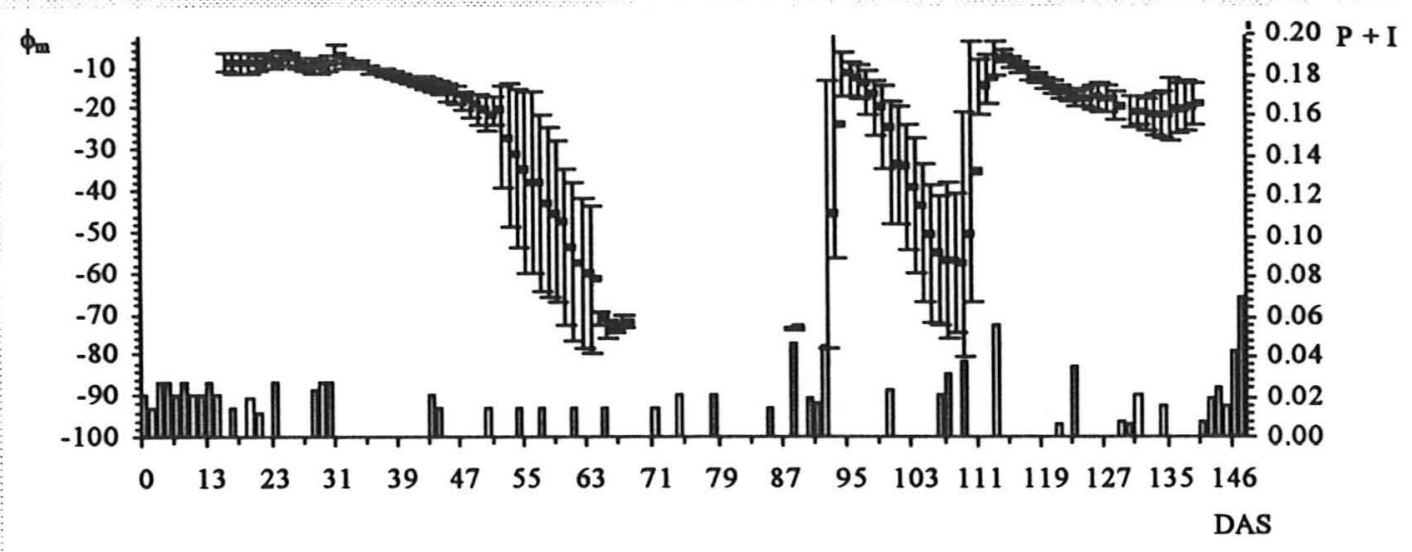

\section{Tratamento tr000}

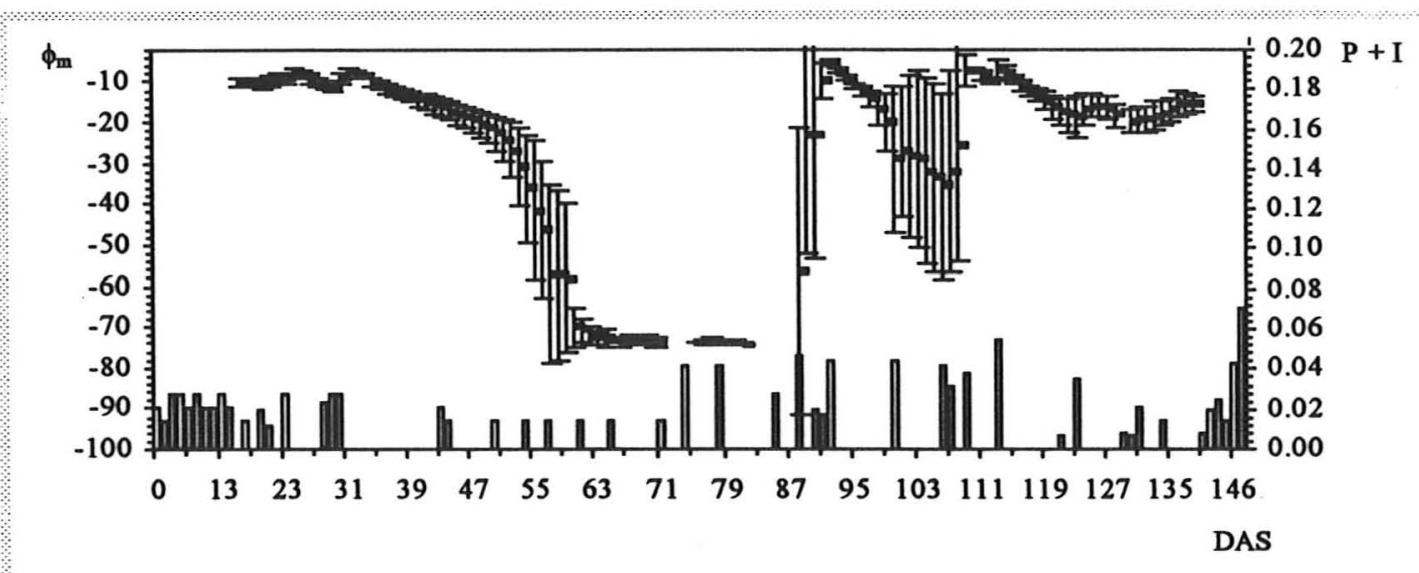

Tratamento troI0

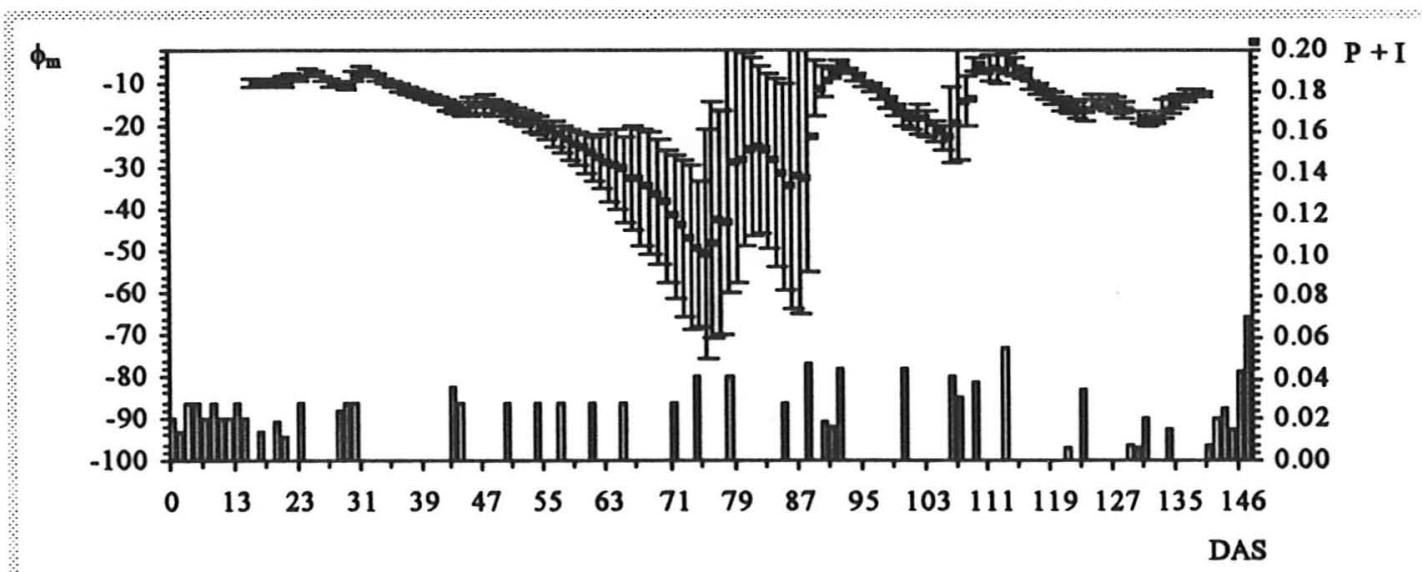

Tratamento trIII

PROFUNDIDADE $0,80 \mathrm{~m}$. 


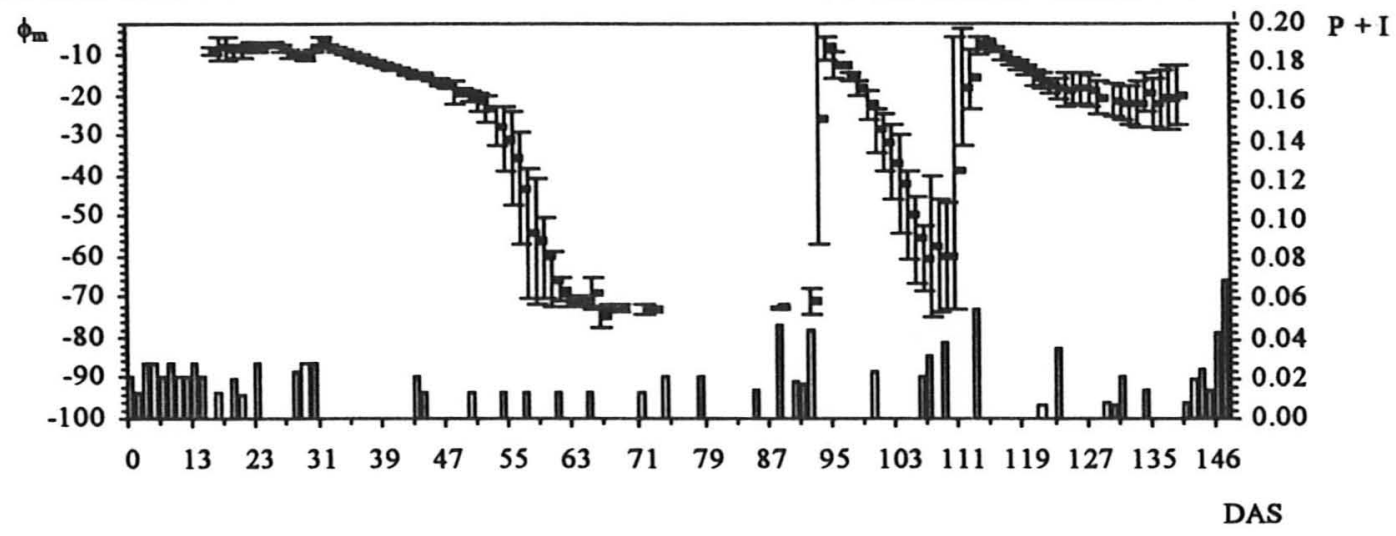

\section{Tratamento tr000}

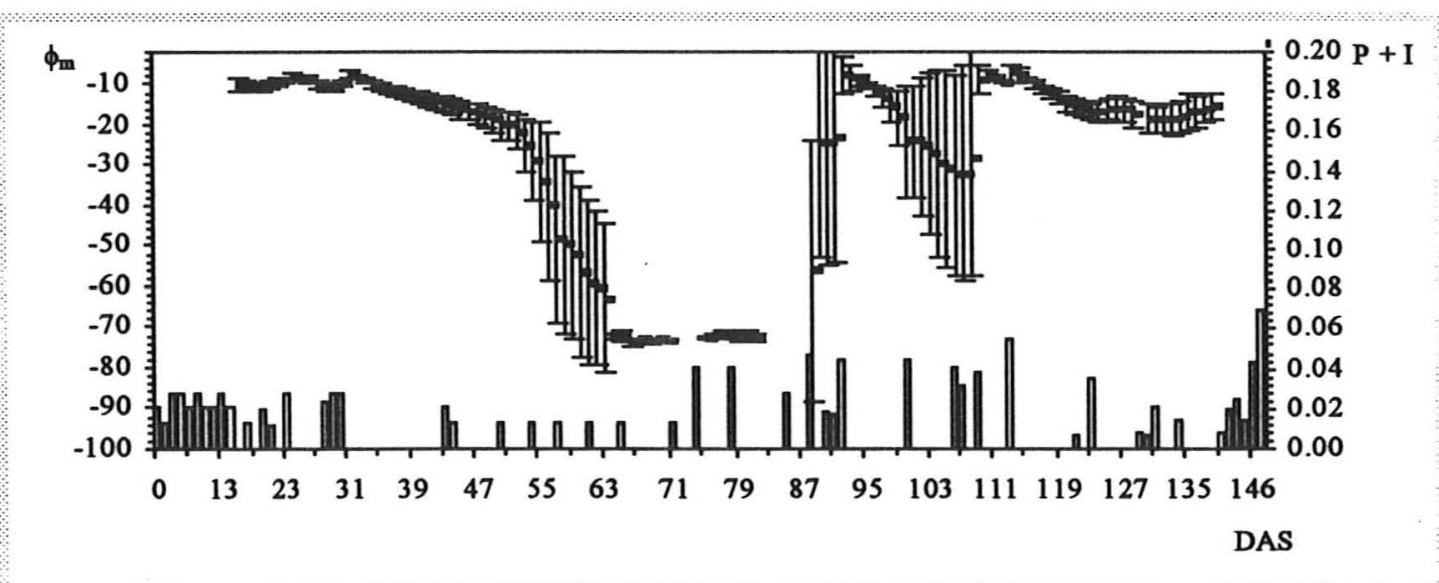

Tratamento troI0

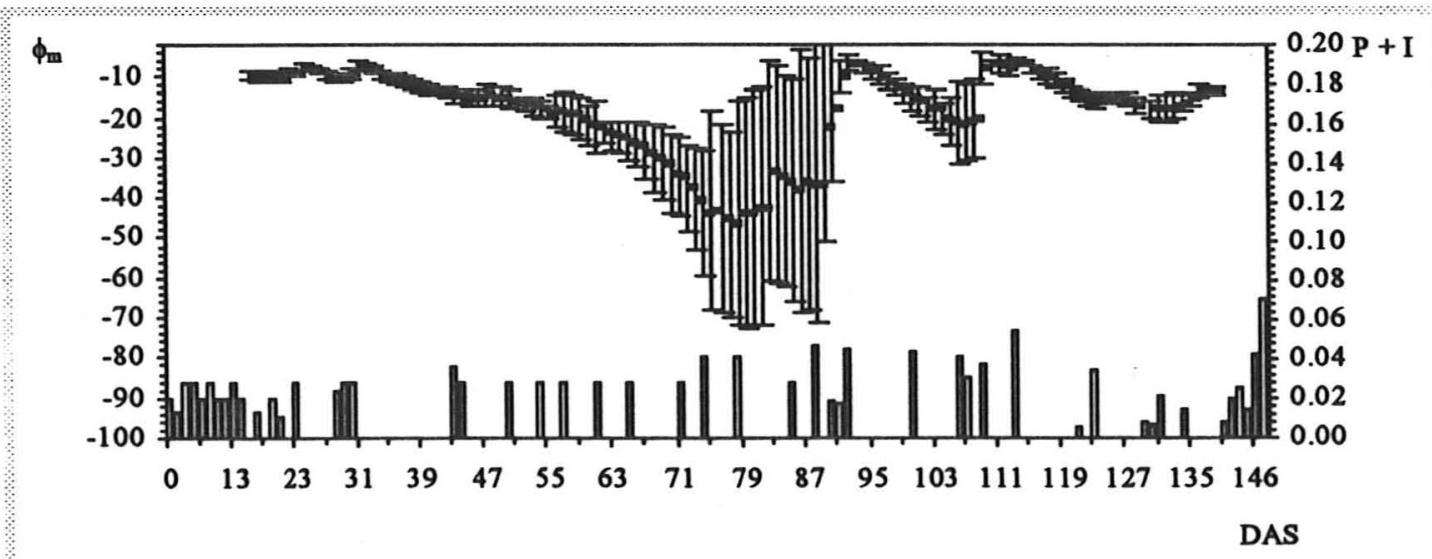

Tratamento trIII

PROFUNDIDADE $0,90 \mathrm{~m}$. 


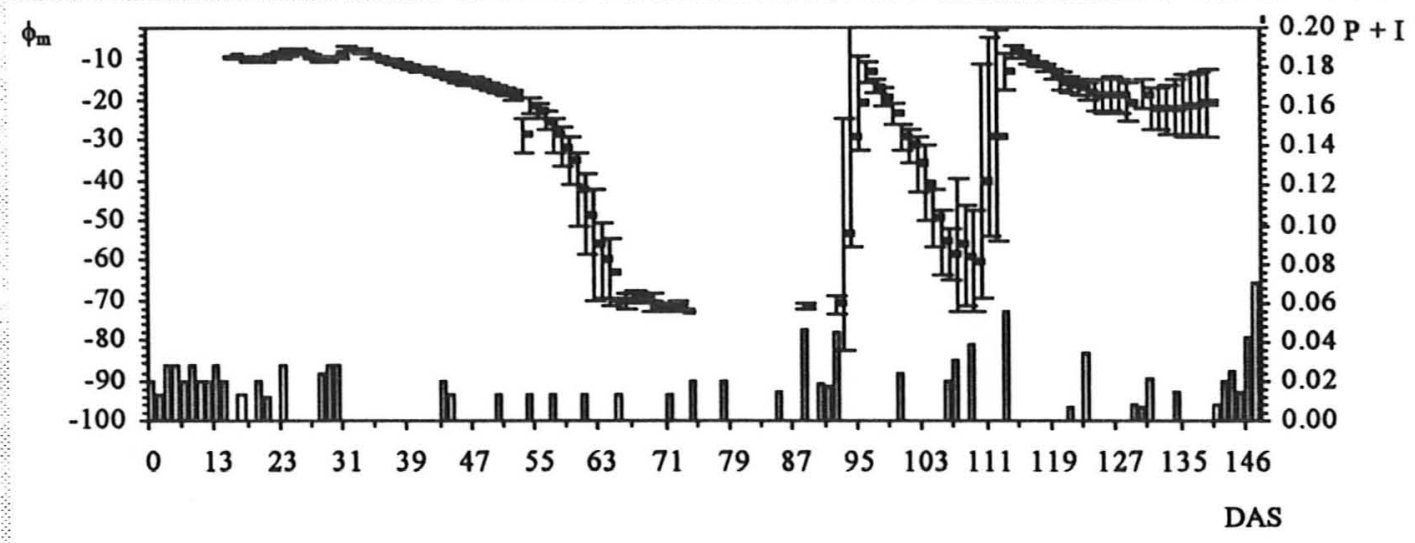

\section{Tratamento tr000}

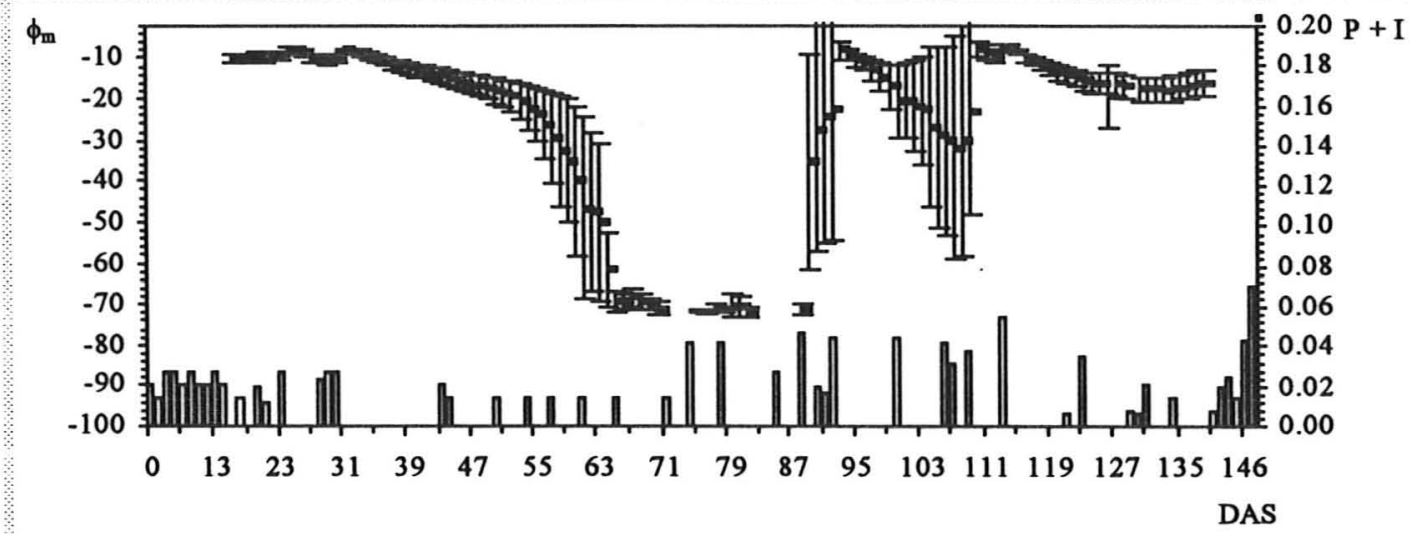

Tratamento troI0

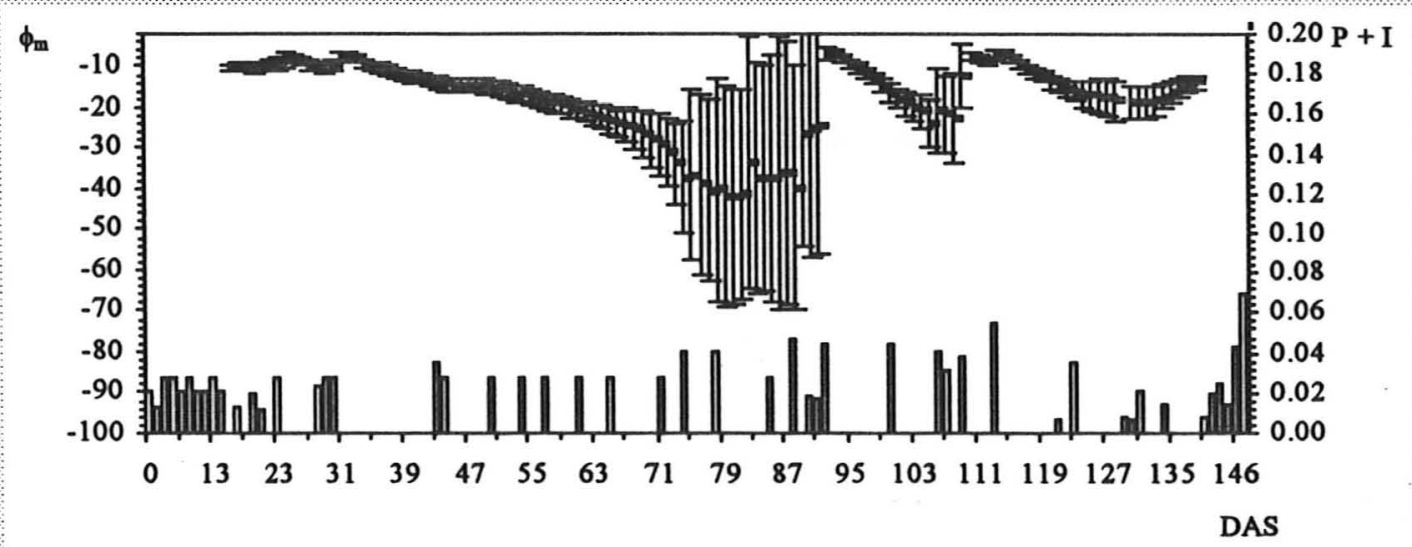

Tratamento trIII

PROFUNDIDADE $1,00 \mathrm{~m}$. 


\section{APÊNDICE 3}

Gráficos mostrando a variabilidade do potencial mátrico em termos de desvio padrão (dp) em função do valor médio diário desse potencial mátrico $\left(\phi_{\mathrm{m}}\right)$, em $\mathrm{kPa}$. 


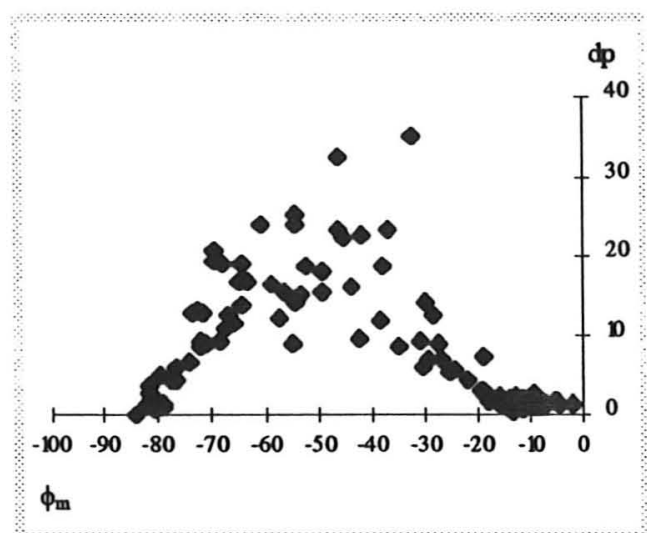

Tratamento tro00.

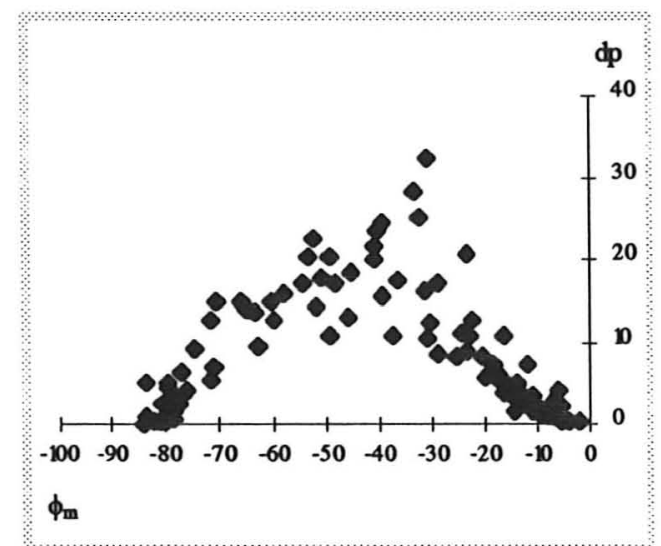

Tratamento troI0.

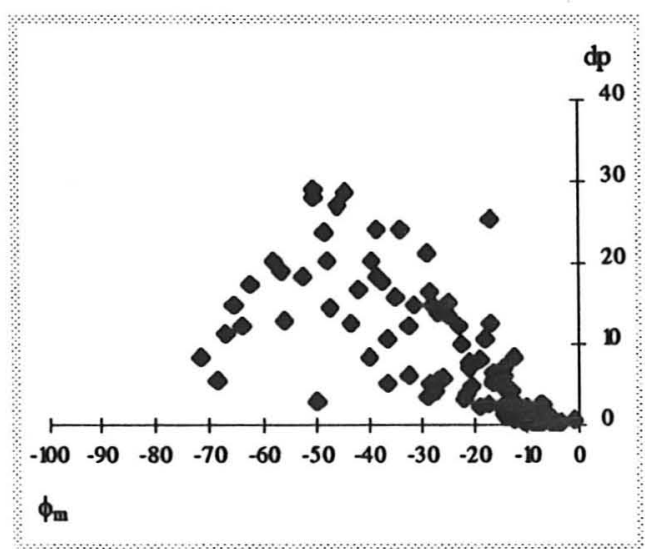

Tratamento trIII.

PROFUNDIDADE $0,10 \mathrm{~m}$.

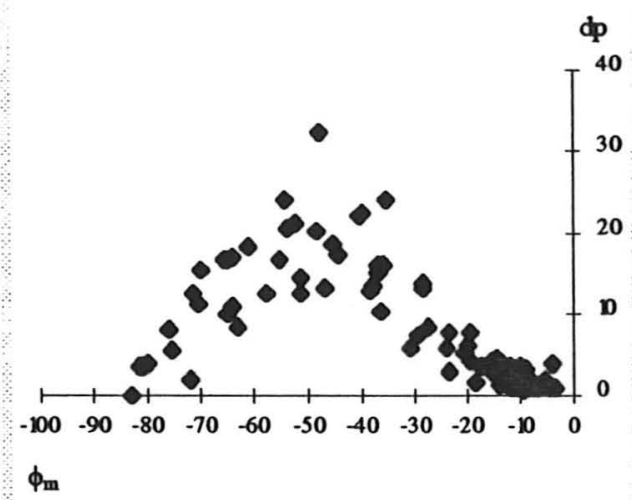

Tratamento tr000.

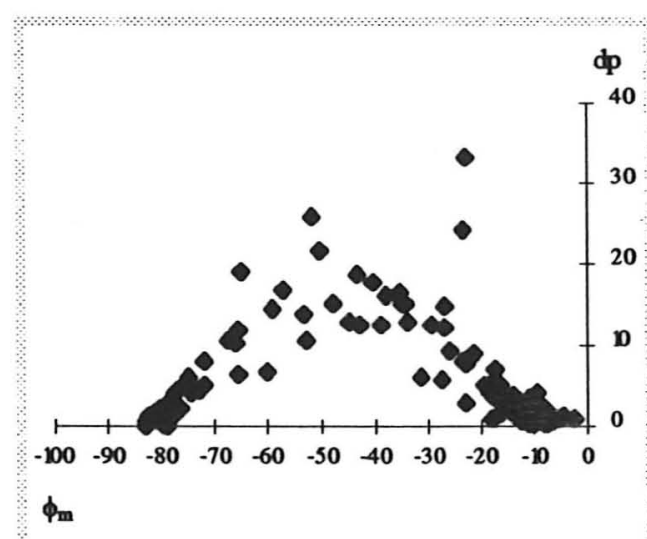

Tratamento troI0.

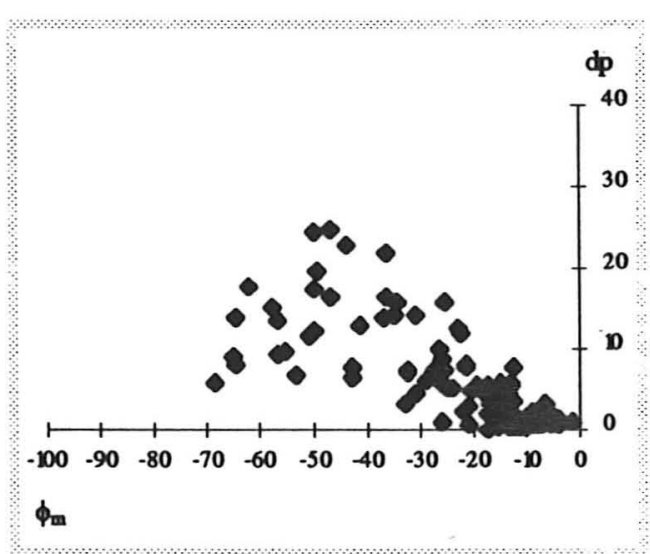

Tratamento trIII.

PROFUNDIDADE $0,20 \mathrm{~m}$. 


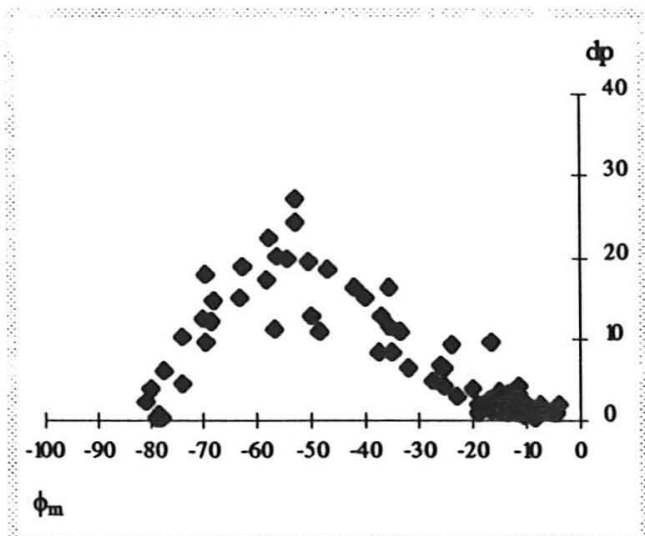

Tratamento tro00.

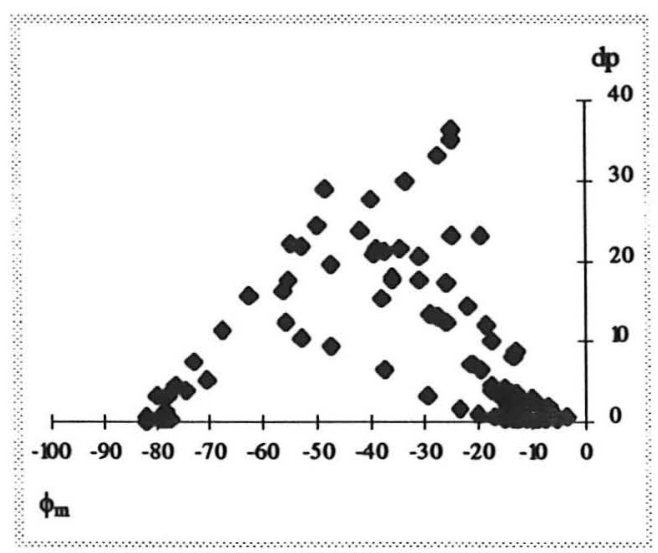

Tratamento troI0.

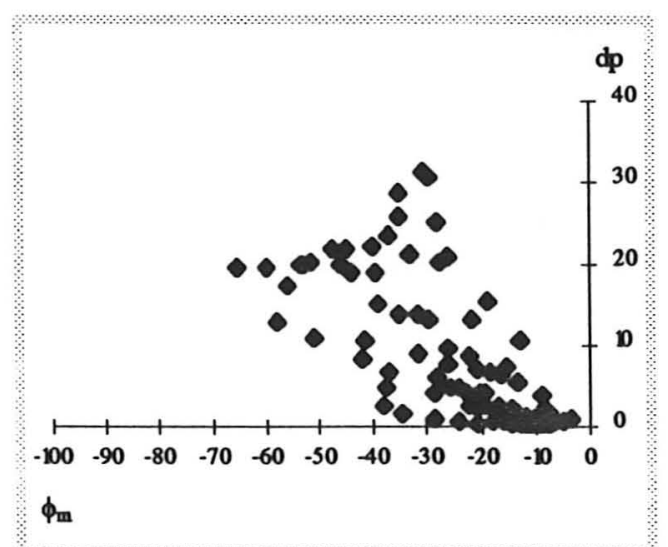

Tratamento trIII.

PROFUNDIDADE $0,30 \mathrm{~m}$.

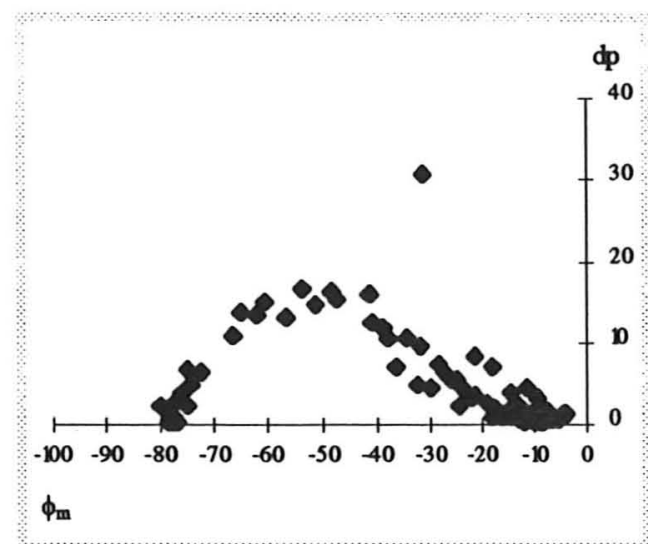

Tratamento tr000.

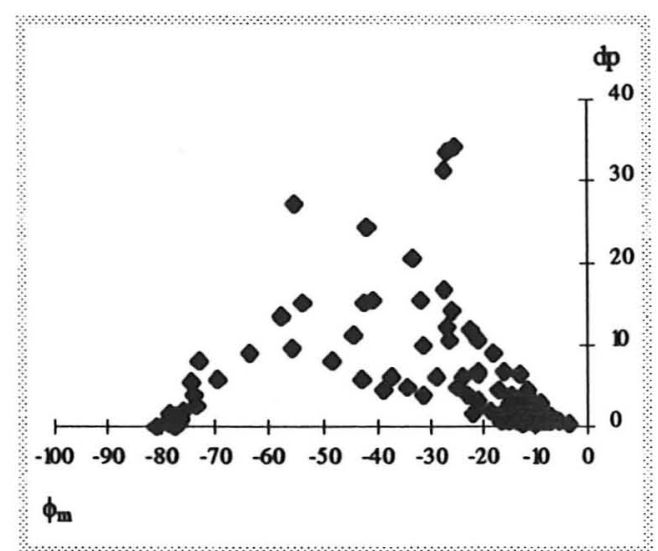

Tratamento troI0.

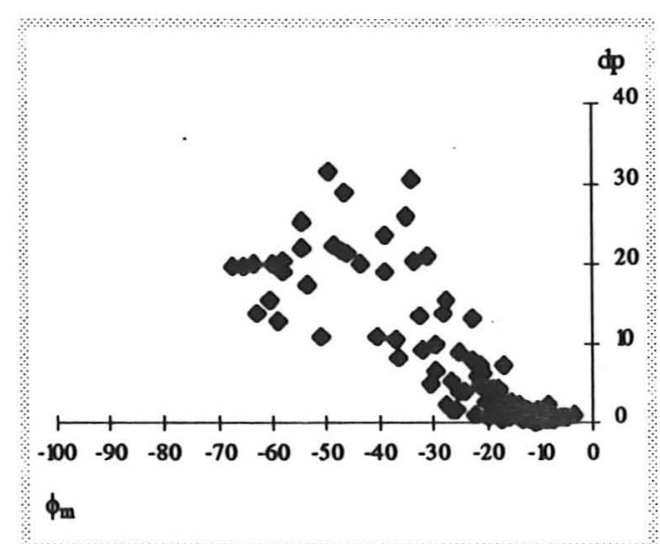

Tratamento trIII.

PROFUNDIDADE $0,40 \mathrm{~m}$. 


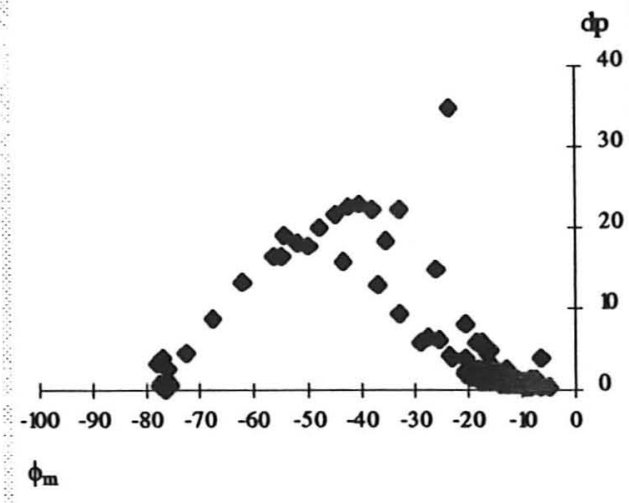

Tratamento tr000.

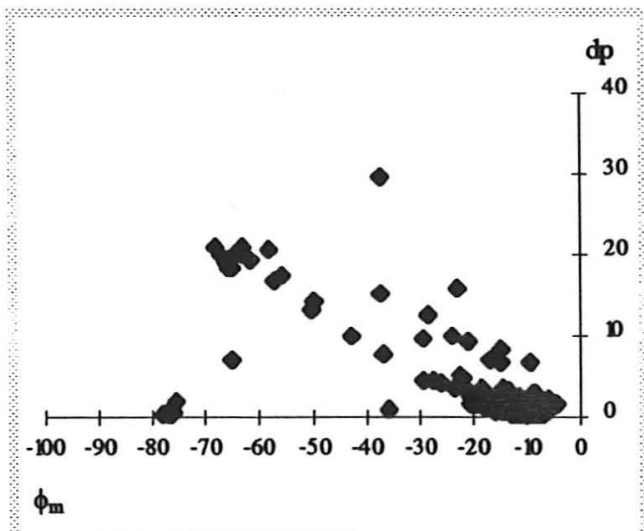

Tratamento trOI0.

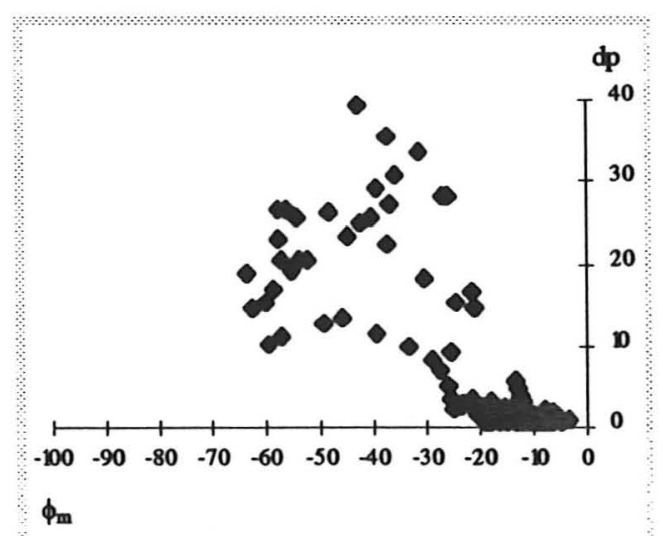

Tratamento trIII.

PROFUNDIDADE $0,50 \mathrm{~m}$.

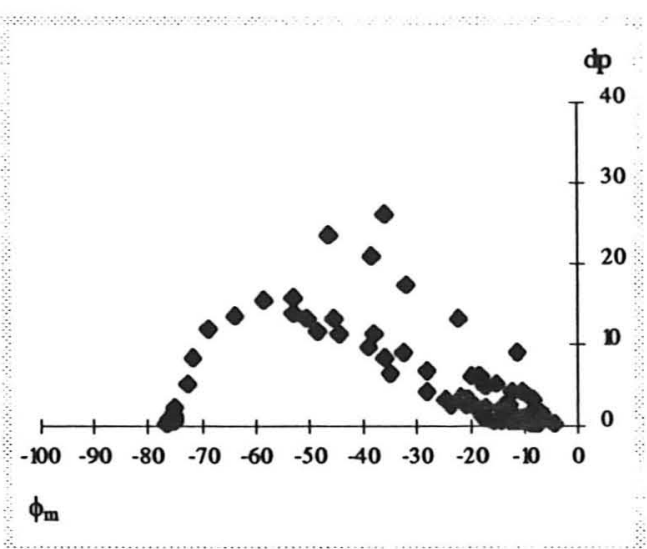

Tratamento tr000.

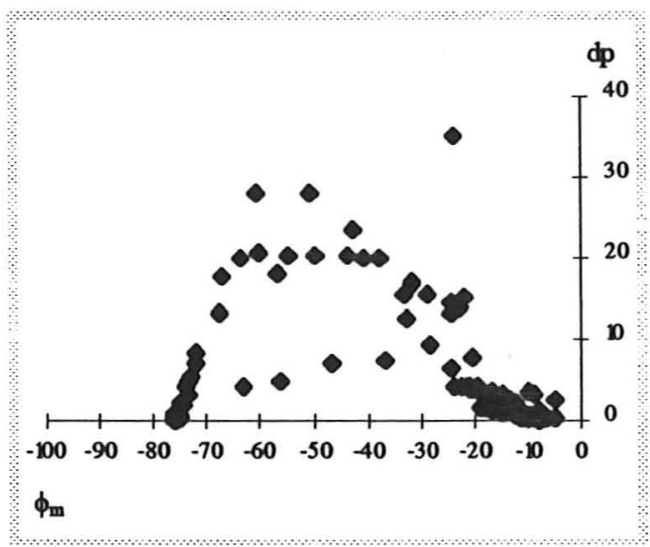

Tratamento troI0.

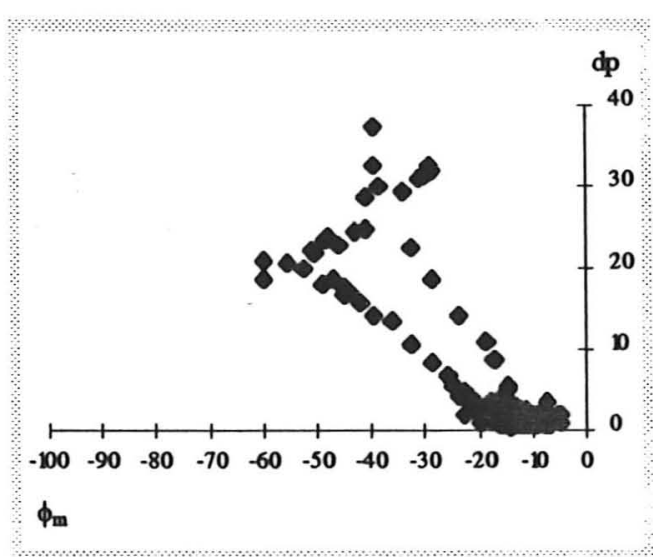

Tratamento trIII.

PROFUNDIDADE $0,60 \mathrm{~m}$. 


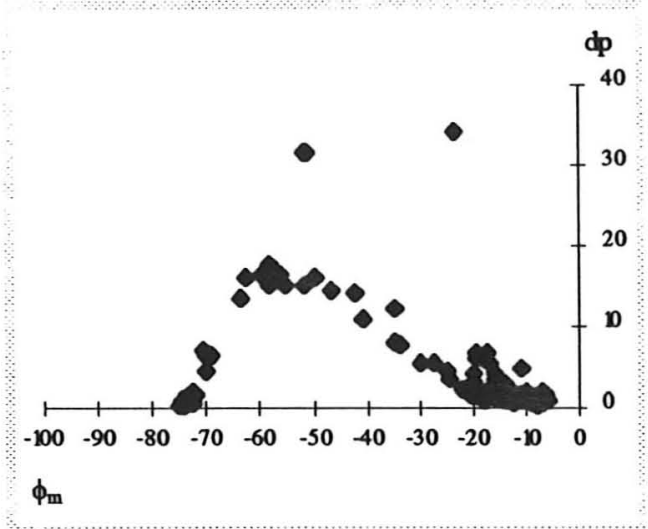

Tratamento tr000.

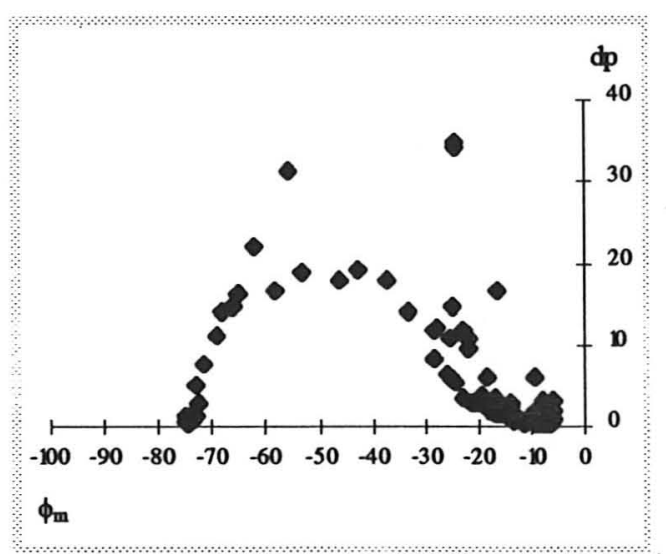

Tratamento troI0.

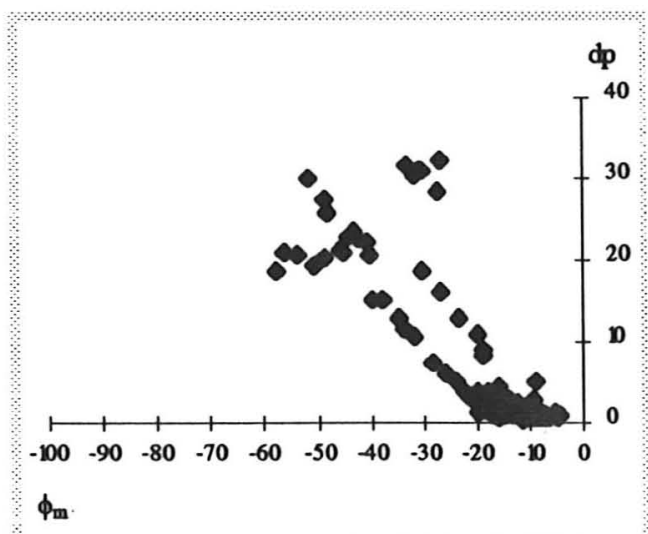

Tratamento trIII.

PROFUNDIDADE $0,70 \mathrm{~m}$.

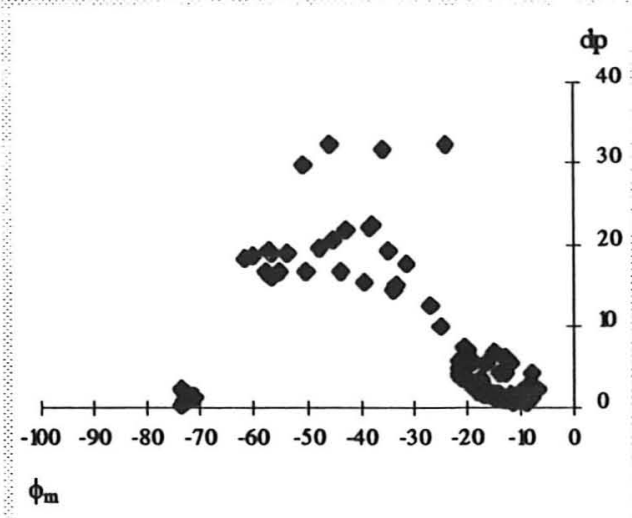

Tratamento tr000.

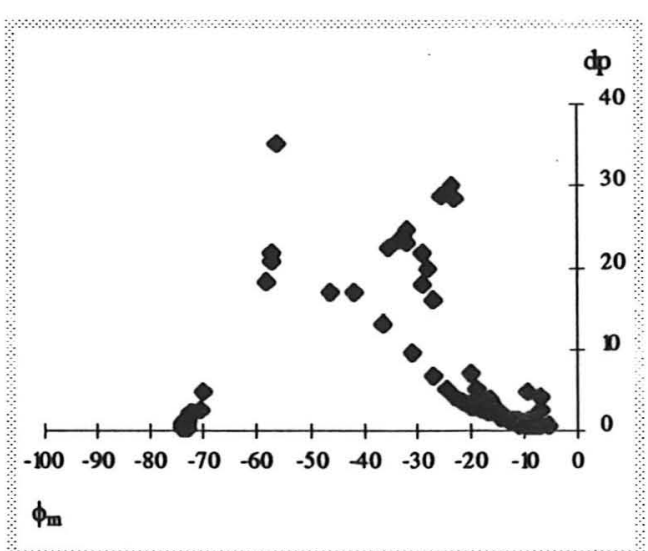

Tratamento tr0I0.

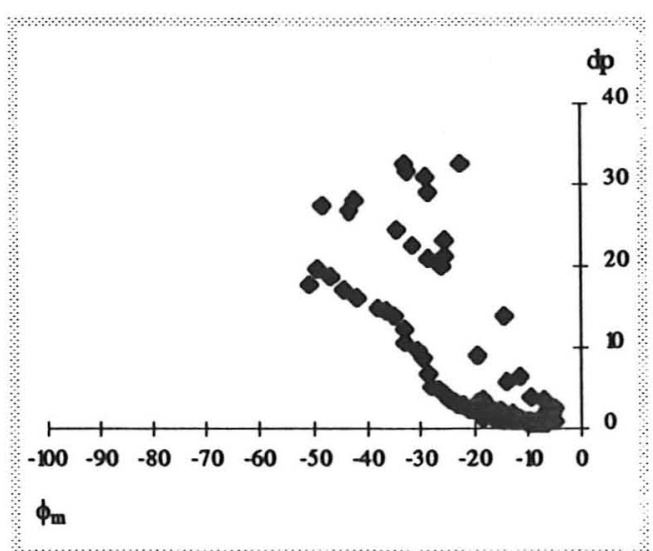

Tratamento trIII.

PROFUNDIDADE $0,80 \mathrm{~m}$. 


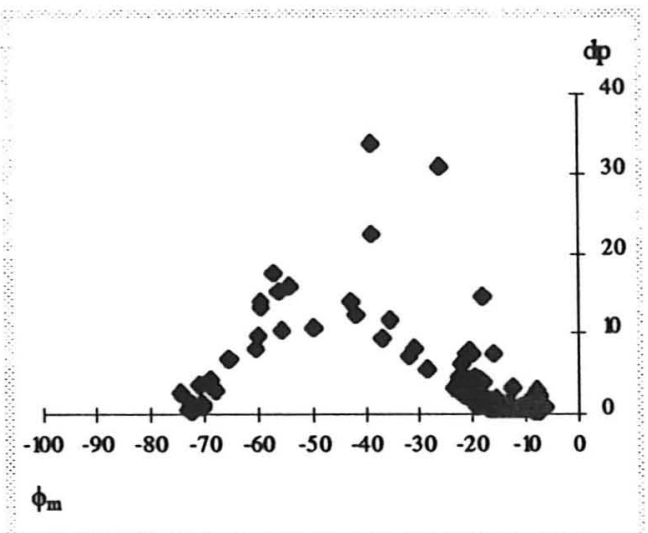

Tratamento tro00.

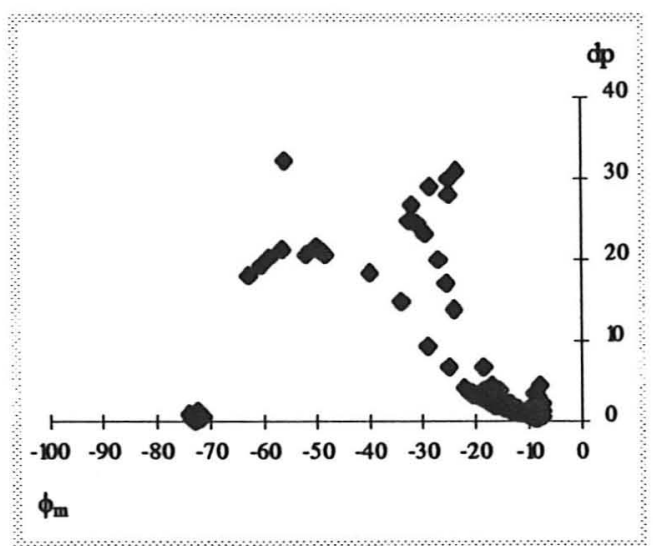

Tratamento troI0.

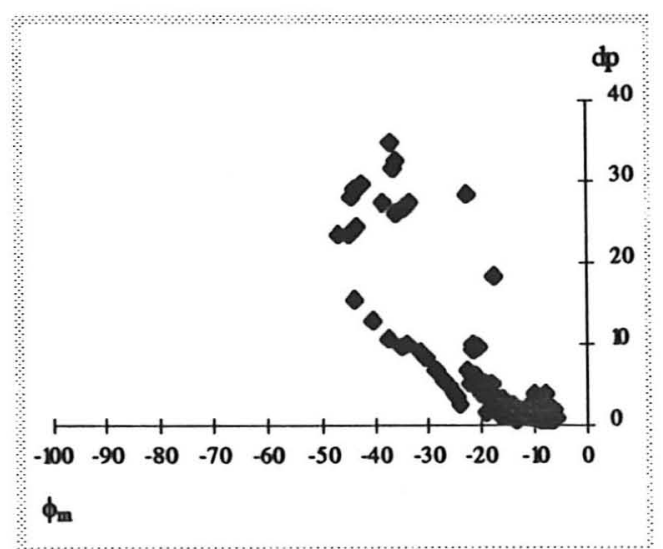

Tratamento trIII.

PROFUNDIDADE $0,90 \mathrm{~m}$.

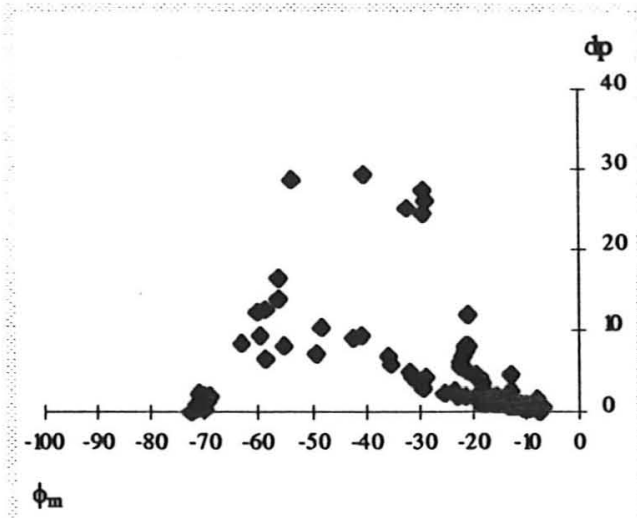

Tratamento tr000.

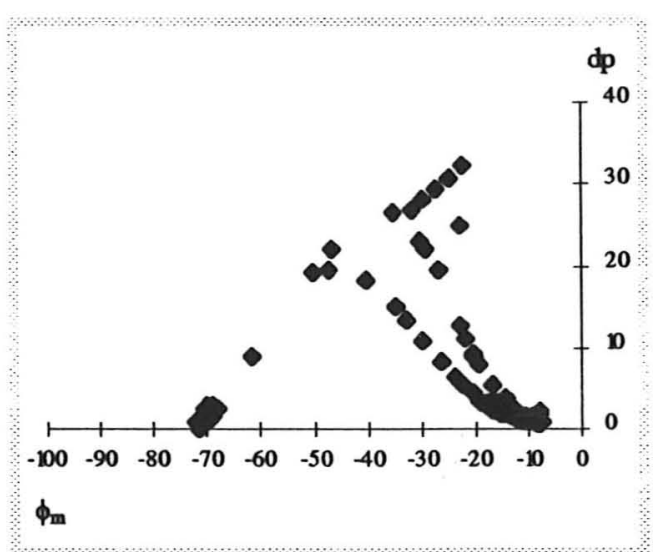

Tratamento tr0I0.

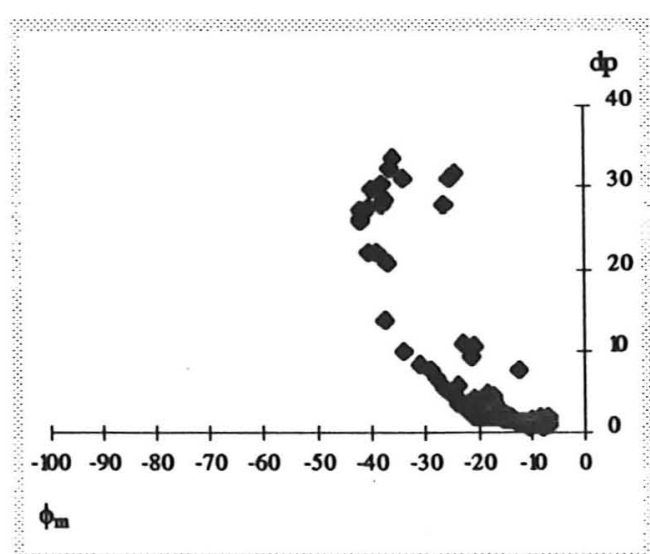

Tratamento trIII.

PROFUNDIDADE $1,00 \mathrm{~m}$. 


\section{APÊNDICE 4}

Contagem relativa de nêutrons lentos para cada repetição(r1, r2, r3 e r4) e sua média por tratamento, e as quantidades estimadas de água das chuvas ou aplicadas nas irrigações, em $\mathrm{m}^{3} / \mathrm{m}^{2}$, em função do tempo (DAS), em dias após a semeadura, para cada profundidade estudada. 
Profundidade $0,20 \mathrm{~m}$.

\begin{tabular}{|c|c|c|c|c|c|c|c|c|c|c|c|c|c|c|c|c|c|c|}
\hline \multirow[b]{2}{*}{ DAS } & \multicolumn{4}{|c|}{ tro } & \multicolumn{4}{|c|}{ tr1 } & \multicolumn{4}{|c|}{ to 2} & \multicolumn{4}{|c|}{ trbs } & \multirow{2}{*}{$\frac{\mathrm{t} 2}{\mathrm{r} 3 \mathrm{p}}$} & \multirow[b]{2}{*}{$\mathrm{P}+\mathrm{I}$} \\
\hline & $\mathrm{rl}$ & 12 & $\mathrm{r} 3$ & média & $\mathrm{rl}$ & 12 & $\mathrm{r} 3$ & média & $\mathrm{rl}$ & 12 & r3 & média & r1 & $\mathrm{r} 2$ & r3 & média & & \\
\hline 23 & 1.577 & 1.533 & 1.653 & 1.588 & 1.903 & 1.610 & 1.655 & 1.723 & 1.649 & 1.775 & & & 1.764 & 1.541 & 1.454 & 1.587 & $1.6+3$ & \\
\hline 25 & 1.511 & 1.495 & 1.624 & 1.543 & 1.630 & 1.550 & 1.651 & 1.610 & 1.673 & 1.774 & & & 1.776 & 1.514 & 1.416 & 1.568 & 1.619 & \\
\hline 27 & 1.375 & 1.393 & 1.542 & 1.437 & 1.572 & 1.404 & 1.530 & 1.502 & 1.490 & 1.708 & & & 1.695 & 1.461 & 1.358 & 1.505 & 1.565 & \\
\hline 30 & 1.237 & 1.253 & 1.413 & 1.301 & 1.466 & 1.327 & 1.417 & 1.403 & 1.380 & 1.606 & 1.553 & 1.513 & 1.658 & 1.392 & 1.300 & 1.450 & 1.486 & \\
\hline 32 & 1.175 & 1.236 & 1.350 & 1.253 & 1.423 & 1.288 & 1.372 & 1.361 & 1.312 & 1.559 & 1.493 & 1.454 & 1.614 & 1.351 & 1.267 & 1.410 & & \\
\hline 34 & 1.139 & 1.196 & 1.302 & 1.212 & 1.414 & 1.294 & 1.364 & 1.357 & 1.317 & 1.536 & 1.472 & 1.441 & 1.624 & 1.331 & 1.247 & 1.401 & & 0.0005 \\
\hline 35 & & & & & & & & & & & & & & & & & & 0.0006 \\
\hline 37 & & & & & & & & & & & & & & & & & & 0.0266 \\
\hline 38 & 1.557 & 1.527 & 1.602 & 1.562 & 1.525 & 1.588 & 1.623 & 1.579 & 1.333 & 1.640 & 1.552 & 1.508 & 1.698 & 1.524 & 1.689 & 1.637 & & \\
\hline 41 & 1.380 & 1.304 & 1.431 & 1.371 & 1.444 & 1.440 & 1.501 & 1.462 & 1.303 & 1.588 & 1.433 & 1.441 & 1.682 & 1.520 & 1.391 & 1.531 & 1.415 & \\
\hline 4 & 1.118 & 1.169 & 1.258 & 1.182 & 1.358 & 1.252 & 1.322 & 1.311 & 1.198 & 1.370 & 1.312 & 1.293 & 1.616 & 1.424 & 1.337 & 1.459 & 1.282 & 0.0266 \\
\hline 46 & 1.495 & 1.353 & 1.537 & 1.462 & 1.395 & 1.506 & 1.609 & 1.503 & 1.344 & 1.622 & 1.460 & 1.475 & 1.732 & 1.531 & 1.454 & 1.572 & 1.405 & \\
\hline 47 & & & & & & & & & & & & & & & & & & 0.0038 \\
\hline 48 & 1.360 & 1.200 & 1.366 & 1.308 & 1.337 & 1.330 & 1.468 & 1.379 & 1.275 & 1.485 & 1.389 & 1.383 & 1.676 & 1.478 & 1.388 & 1.514 & 1.351 & \\
\hline 50 & & & & & & & & & & & & & & & & & & 0.0266 \\
\hline 51 & 1.574 & 1.405 & 1.484 & 1.488 & 1.570 & 1.566 & 1.662 & 1.599 & 1.621 & 1.604 & 1.601 & 1.609 & 1.778 & 1.597 & 1.570 & 1.648 & 1.522 & 0.0006 \\
\hline 53 & 1.411 & 1.280 & 1.376 & 1.356 & 1.487 & 1.405 & 1.502 & 1.465 & 1.469 & 1.509 & 1.491 & 1.490 & 1.749 & 1.539 & 1.463 & 1.584 & 1.457 & \\
\hline 54 & & & & & & & & & & & & & & & & & & 0.0055 \\
\hline 55 & 1.345 & 1.231 & 1.325 & 1.301 & 1.429 & 1.342 & 1.422 & 1.398 & 1.367 & 1.442 & 1.409 & 1.406 & 1.724 & 1.528 & 1.469 & 1.574 & 1.404 & 0.0002 \\
\hline 56 & & & & & & & & & & & & & & & & & & 0.0023 \\
\hline 58 & 1.239 & 1.199 & 1.301 & 1.246 & 1.397 & 1.306 & 1.354 & 1.352 & 1.265 & 1.432 & 1.373 & 1.357 & 1.720 & 1.489 & 1.416 & 1.542 & 1.345 & 0.0099 \\
\hline 60 & 1.283 & 1.188 & 1.313 & 1.261 & 1.404 & 1.339 & 1.381 & 1.374 & 1.273 & 1.460 & 1.415 & 1.382 & 1.728 & 1.503 & 1.432 & 1.554 & 1.359 & 0.0245 \\
\hline 61 & & & & & & & & & & & & & & & & & & 0.0366 \\
\hline 62 & 1.600 & 1.580 & 1.638 & 1.606 & 1.736 & 1.666 & 1.790 & 1.731 & 1.706 & 1.631 & 1.675 & 1.671 & 1.794 & 1.628 & 1.577 & 1.666 & 1.611 & 0.0191 \\
\hline 64 & & & & & & & & & & & & & & & & & & 0.0010 \\
\hline 65 & 1.529 & 1.438 & 1.542 & 1.503 & 1.661 & 1.563 & 1.634 & 1.619 & 1.614 & 1.690 & 1.562 & 1.622 & 1.762 & 1.577 & 1.507 & 1.615 & 1.584 & 0.0029 \\
\hline 66 & & & & & & & & & & & & & & & & & & 0.0053 \\
\hline 67 & 1.473 & 1.379 & 1.484 & 1.445 & 1.629 & 1.534 & 1.598 & 1.587 & 1.530 & 1.641 & 1.594 & 1.588 & 1.760 & 1.570 & 1.491 & 1.607 & 1.577 & \\
\hline 69 & 1.311 & 1.294 & 1.351 & 1.319 & 1.521 & 1.389 & 1.443 & 1.451 & 1.383 & 1.526 & 1.457 & 1.455 & 1.674 & 1.449 & 1.426 & 1.516 & 1.439 & 0.0375 \\
\hline 70 & & & & & & & & & & & & & & & & & & 0.0002 \\
\hline 71 & & & & & & & & & & & & & & & & & & 0.0007 \\
\hline 72 & 1.470 & 1.419 & 1.518 & 1.469 & 1.612 & 1.519 & 1.605 & 1.579 & 1.570 & 1.607 & 1.594 & 1.590 & 1.702 & 1.488 & 1.479 & 1.557 & 1.534 & \\
\hline 74 & 1.436 & 1.349 & 1.474 & 1.420 & 1.593 & 1.459 & 1.548 & 1.533 & 1.506 & 1.586 & 1.558 & 1.550 & 1.712 & 1.458 & 1.458 & 1.543 & 1.505 & 0.0042 \\
\hline 76 & 1.392 & 1.306 & 1.395 & 1.364 & 1.531 & 1.416 & 1.474 & 1.474 & 1.395 & 1.533 & 1.496 & 1.475 & 1.655 & 1.403 & 1.409 & 1.489 & 1.464 & \\
\hline 77 & & & & & & & & & & & & & & & & & & 0.0488 \\
\hline 78 & & & & & & & & & & & & & & & & & & 0.0231 \\
\hline 79 & 1.627 & 1.621 & 1.653 & 1.633 & 1.747 & 1.688 & 1.744 & 1.726 & 1.727 & 1.726 & 1.709 & 1.721 & 1.795 & 1.566 & 1.592 & 1.651 & 1.667 & 0.0020 \\
\hline 80 & & & & & & & & & & & & & . & & & & & 0.0216 \\
\hline 81 & 1.654 & 1.639 & 1.671 & 1.655 & 1.784 & 1.712 & 1.771 & 1.756 & 1.748 & 1.717 & 1.741 & 1.735 & 1.782 & 1.560 & 1.586 & 1.643 & 1.674 & \\
\hline 82 & & & & & & & & & & & & & & & & & & 0.0083 \\
\hline 83 & 1.658 & 1.562 & 1.659 & 1.626 & 1.733 & 1.671 & 1.732 & 1.712 & 1.728 & 1.683 & 1.700 & 1.704 & 1.759 & 1.527 & 1.533 & 1.606 & 1.621 & 0.0387 \\
\hline 85 & 1.607 & 1.563 & 1.632 & 1.601 & 1.722 & 1.647 & 1.688 & 1.686 & 1.657 & 1.721 & 1.688 & 1.688 & 1.747 & 1.540 & 1.501 & 1.596 & 1.655 & \\
\hline 87 & 1.510 & 1.484 & 1.572 & 1.522 & 1.666 & 1.569 & 1.631 & 1.622 & 1.641 & 1.660 & 1.655 & 1.652 & 1.720 & 1.502 & 1.459 & 1.560 & 1.571 & \\
\hline 89 & 1.428 & 1.385 & 1.464 & 1.426 & 1.591 & 1.482 & 1.563 & 1.545 & 1.581 & 1.570 & 1.589 & 1.580 & 1.680 & 1.474 & 1.418 & 1.524 & 1.514 & \\
\hline 92 & 1.374 & 1.317 & 1.370 & 1.354 & 1.501 & 1.408 & 1.472 & 1.461 & 1.468 & 1.515 & 1.501 & 1.494 & 1.593 & 1.419 & 1.373 & 1.461 & 1.480 & 0.0072 \\
\hline 93 & & & & & & & & & & & & & & & & & & 0.0440 \\
\hline 94 & 1.595 & 1.547 & 1.596 & 1.579 & 1.709 & 1.607 & 1.667 & 1.661 & 1.650 & 1.635 & 1.647 & 1.644 & 1.596 & 1.477 & 1.455 & 1.509 & 1.602 & 0.0076 \\
\hline 96 & 1.567 & 1.527 & 1.604 & 1.566 & 1.718 & 1.605 & 1.652 & 1.658 & 1.673 & 1.648 & 1.653 & 1.658 & 1.641 & 1.497 & 1.388 & 1.509 & 1.611 & \\
\hline 100 & & & & & & & & & & & & & & & & & & 0.0170 \\
\hline 101 & 1.650 & 1.423 & 1.592 & 1.555 & 1.670 & 1.622 & 1.690 & 1.661 & 1.716 & 1.645 & 1.654 & 1.672 & 1.564 & 1.478 & 1.331 & 1.458 & 1.609 & 0.0026 \\
\hline 103 & 1.585 & 1.400 & 1.524 & 1.503 & 1.615 & 1.559 & 1.635 & 1.603 & 1.638 & 1.599 & 1.584 & 1.607 & 1.520 & 1.464 & 1.249 & 1.411 & 1.556 & \\
\hline 105 & 1.430 & 1.305 & 1.424 & 1.386 & 1.488 & 1.434 & 1.497 & 1.473 & 1.443 & 1.494 & 1.477 & 1.471 & 1.452 & 1.380 & 1.192 & 1.341 & 1.442 & \\
\hline 107 & 1.316 & 1.261 & 1.355 & 1.311 & 1.439 & 1.363 & 1.416 & 1.406 & 1.338 & 1.438 & 1.406 & 1.394 & 1.438 & 1.317 & 1.168 & 1.308 & 1.405 & \\
\hline 109 & 1.249 & 1.218 & 1.341 & 1.269 & 1.403 & 1.325 & 1.365 & 1.364 & 1.314 & 1.409 & 1.403 & 1.375 & 1.436 & 1.282 & 1.134 & 1.284 & 1.369 & \\
\hline 111 & & & & & & & & & & & & & & & & & & 0.0067 \\
\hline 112 & 1.673 & 1.625 & 1.687 & 1.662 & 1.791 & 1.703 & 1.732 & 1.742 & 1.749 & 1.704 & 1.732 & 1.728 & 1.742 & 1.441 & 1.362 & 1.515 & 1.678 & 0.0364 \\
\hline 113 & & & & & & & & & & & & & & & & & & 0.0230 \\
\hline 114 & 1.571 & 1.553 & 1.624 & 1.583 & 1.711 & 1.658 & 1.677 & 1.682 & 1.660 & 1.675 & 1.686 & 1.674 & 1.696 & 1.410 & 1.319 & 1.475 & 1.613 & \\
\hline 116 & & & & & & & & & & & & & & & & & & 0.0654 \\
\hline 117 & & & & & & & & & & & & & & & & & & 0.0384 \\
\hline 121 & 1.687 & 1.674 & 1.740 & 1.700 & 1.797 & 1.732 & 1.808 & 1.779 & 1.792 & 1.735 & 1.773 & 1.767 & 1.779 & 1.570 & 1.487 & 1.612 & & 0.0312 \\
\hline
\end{tabular}


Profundidade $0,30 \mathrm{~m}$.

\begin{tabular}{|c|c|c|c|c|c|c|c|c|c|c|c|c|c|c|c|c|c|c|}
\hline \multirow[b]{2}{*}{ DAS } & \multicolumn{4}{|c|}{ tro } & \multicolumn{4}{|c|}{ tr 1} & \multicolumn{4}{|c|}{ tr2 } & \multicolumn{4}{|c|}{ trbs } & \multirow{2}{*}{$\frac{\mathrm{tr} 2}{\mathrm{r} 3-\mathrm{p}}$} & \multirow[b]{2}{*}{$\mathrm{P}+\mathrm{I}$} \\
\hline & rl & 12 & r3 & média & $\mathrm{r} 1$ & 12 & r3 & média & rl & 12 & r3 & média & $\mathrm{rl}$ & 12 & r3 & média & & \\
\hline 23 & 1.832 & 1.739 & 1.787 & 1.786 & 1.901 & 1.820 & 1.833 & 1.851 & 1.739 & 1.927 & & & 1.956 & 1.640 & 1.671 & 1.756 & 1.869 & \\
\hline 25 & 1.835 & 1.735 & 1.766 & 1.779 & 1.888 & 1.830 & 1.816 & 1.844 & 1.734 & 1.932 & & & 1.823 & 1.654 & 1.617 & 1.698 & 1.861 & \\
\hline 27 & 1.728 & 1.689 & 1.700 & 1.706 & 1.852 & 1.772 & 1.741 & 1.788 & 1.706 & 1.897 & & & 1.811 & 1.602 & 1.587 & 1.667 & 1.812 & \\
\hline 30 & 1.681 & 1.638 & 1.675 & 1.665 & 1.806 & 1.705 & 1.687 & 1.733 & 1.631 & 1.857 & 1.809 & 1.766 & 1.803 & 1.591 & 1.575 & 1.656 & 1.786 & \\
\hline 32 & 1.594 & 1.557 & 1.599 & 1.583 & 1.757 & 1.669 & 1.653 & 1.693 & 1.574 & 1.816 & 1.731 & 1.707 & 1.752 & 1.592 & 1.554 & 1.633 & & \\
\hline 34 & 1.585 & 1.528 & 1.577 & 1.563 & 1.737 & 1.671 & 1.649 & 1.685 & 1.546 & 1.795 & 1.721 & 1.688 & 1.766 & 1.553 & 1.571 & 1.630 & & 0.0005 \\
\hline 35 & & & & & & & & & & & & & & & & & & 0.0006 \\
\hline 37 & & & & & & & & & & & & & & & & & & 0.0266 \\
\hline 38 & 1.793 & 1.635 & 1.692 & 1.706 & 1.729 & 1.765 & 1.641 & 1.712 & 1.507 & 1.813 & 1.702 & 1.674 & 1.740 & 1.646 & 1.624 & 1.670 & & \\
\hline 41 & 1.718 & 1.521 & 1.603 & 1.614 & 1.728 & 1.673 & 1.637 & 1.679 & 1.471 & 1.765 & 1.704 & 1.647 & 1.750 & 1.625 & 1.611 & 1.662 & 1.633 & \\
\hline 44 & 1.538 & 1.469 & 1.503 & 1.503 & 1.621 & 1.579 & 1.540 & 1.580 & 1.408 & 1.621 & 1.558 & 1.529 & 1.719 & 1.577 & 1.605 & 1.634 & 1.538 & 0.0266 \\
\hline 46 & 1.742 & 1.474 & 1.661 & 1.626 & 1.686 & 1.626 & 1.759 & 1.690 & 1.395 & 1.753 & 1.621 & 1.590 & 1.801 & 1.676 & 1.868 & 1.782 & 1.527 & \\
\hline 47 & & & & & & & & & & & & & & & & & & 0.0038 \\
\hline 48 & 1.664 & 1.436 & 1.540 & 1.547 & 1.635 & 1.563 & 1.627 & 1.608 & 1.383 & 1.677 & 1.555 & 1.538 & 1.755 & 1.597 & 1.586 & 1.646 & 1.497 & \\
\hline 50 & & & & & & & & & & & & & & & & & & 0.0266 \\
\hline 51 & 1.767 & 1.526 & 1.627 & 1.640 & 1.675 & 1.672 & 1.685 & 1.677 & 1.495 & 1.712 & 1.687 & 1.632 & 1.829 & 1.678 & 1.693 & 1.734 & 1.613 & 0.0006 \\
\hline 53 & 1.658 & 1.502 & 1.563 & 1.574 & 1.711 & 1.644 & 1.637 & 1.664 & 1.486 & 1.691 & 1.659 & 1.612 & 1.831 & 1.671 & 1.658 & 1.720 & 1.597 & \\
\hline 54 & & & & & & & & & & & & & & & & & & 0.0055 \\
\hline 55 & 1.610 & 1.470 & 1.516 & 1.532 & 1.674 & 1.609 & 1.563 & 1.616 & 1.464 & 1.680 & 1.627 & 1.591 & 1.802 & 1.642 & 1.622 & 1.689 & 1.571 & 0.0002 \\
\hline 56 & & & & & & & & & & & & & & & & & & 0.0023 \\
\hline 58 & 1.595 & 1.483 & 1.490 & 1.523 & 1.661 & 1.573 & 1.530 & 1.588 & 1.443 & 1.655 & 1.613 & 1.570 & 1.807 & 1.620 & 1.643 & 1.690 & 1.549 & 0.0099 \\
\hline 60 & 1.588 & 1.477 & 1.531 & 1.532 & 1.666 & 1.575 & 1.528 & 1.590 & 1.419 & 1.662 & 1.584 & 1.555 & 1.795 & 1.620 & 1.658 & 1.691 & 1.563 & 0.0245 \\
\hline 61 & & & & & & & & & & & & & & & & & & 0.0366 \\
\hline 62 & 1.786 & 1.658 & 1.734 & 1.726 & 1.931 & 1.812 & 1.819 & 1.854 & 1.775 & 1.860 & 1.820 & 1.818 & 1.825 & 1.734 & 1.721 & 1.760 & 1.745 & 0.0191 \\
\hline 64 & & & & & & & & & & & & & & & & & & 0.0010 \\
\hline 65 & 1.795 & 1.671 & 1.705 & 1.724 & 1.905 & 1.775 & 1.768 & 1.816 & 1.719 & 1.850 & 1.814 & 1.794 & 1.833 & 1.671 & 1.710 & 1.738 & 1.766 & 0.0029 \\
\hline 66 & & & & & & & & & & & & & & & & & & 0.0053 \\
\hline 67 & 1.753 & 1.598 & 1.668 & 1.673 & 1.885 & 1.745 & 1.720 & 1.784 & 1.668 & 1.817 & 1.788 & 1.758 & 1.811 & 1.659 & 1.678 & 1.716 & 1.763 & \\
\hline 69 & 1.641 & 1.536 & 1.569 & 1.582 & 1.808 & 1.638 & 1.611 & 1.686 & 1.571 & 1.713 & 1.685 & 1.656 & 1.774 & 1.618 & 1.648 & 1.680 & 1.654 & 0.0375 \\
\hline 70 & & & & & & & & & & & & & & & & & & 0.0002 \\
\hline 71 & & & & & & & & & & & & & & & & & & 0.0007 \\
\hline 72 & 1.745 & 1.564 & 1.650 & 1.653 & 1.825 & 1.728 & 1.704 & 1.752 & 1.666 & 1.786 & 1.745 & 1.732 & 1.762 & 1.626 & 1.665 & 1.684 & 1.723 & \\
\hline 74 & 1.719 & 1.562 & 1.635 & 1.639 & 1.869 & 1.716 & 1.682 & 1.756 & 1.614 & 1.774 & 1.725 & 1.704 & 1.794 & 1.597 & 1.668 & 1.686 & 1.708 & 0.0042 \\
\hline 76 & 1.703 & 1.520 & 1.600 & 1.608 & 1.835 & 1.668 & 1.621 & 1.708 & 1.550 & 1.752 & 1.697 & 1.666 & 1.789 & 1.578 & 1.647 & 1.671 & 1.668 & \\
\hline 77 & & & & & & & & & & & & & & & & & & 0.0488 \\
\hline 78 & & & & & & & & & & & & & & & & & & 0.0231 \\
\hline 79 & 1.805 & 1.770 & 1.791 & 1.789 & 1.938 & 1.847 & 1.860 & 1.882 & 1.790 & 1.863 & 1.864 & 1.839 & 1.859 & 1.653 & 1.709 & 1.740 & 1.818 & 0.0020 \\
\hline 80 & & & & & & & & & & & & & & & & & & 0.0216 \\
\hline 81 & 1.825 & 1.749 & 1.784 & 1.786 & 1.955 & 1.848 & 1.823 & 1.875 & 1.798 & 1.860 & 1.858 & 1.839 & 1.847 & 1.634 & 1.709 & 1.730 & 1.819 & \\
\hline 82 & & & & & & & & & & & & & & & & & & 0.0083 \\
\hline 83 & 1.789 & 1.662 & 1.760 & 1.737 & 1.922 & 1.812 & 1.792 & 1.842 & 1.754 & 1.838 & 1.825 & 1.805 & 1.805 & 1.635 & 1.686 & 1.709 & 1.769 & 0.0387 \\
\hline 85 & 1.798 & 1.725 & 1.772 & 1.765 & 1.899 & 1.800 & 1.824 & 1.841 & 1.733 & 1.850 & 1.822 & 1.802 & 1.802 & 1.661 & 1.698 & 1.720 & 1.792 & \\
\hline 87 & 1.757 & 1.672 & 1.704 & 1.711 & 1.900 & 1.754 & 1.765 & 1.806 & 1.697 & 1.801 & 1.796 & 1.765 & 1.807 & 1.659 & 1.675 & 1.713 & 1.770 & \\
\hline 89 & 1.736 & 1.644 & 1.633 & 1.671 & 1.858 & 1.698 & 1.714 & 1.757 & 1.660 & 1.770 & 1.762 & 1.731 & 1.789 & 1.638 & 1.649 & 1.692 & 1.735 & \\
\hline 92 & 1.680 & 1.571 & 1.609 & 1.620 & 1.769 & 1.634 & 1.631 & 1.678 & 1.572 & 1.720 & 1.682 & 1.658 & 1.768 & 1.632 & 1.632 & 1.677 & 1.652 & 0.0072 \\
\hline 93 & & & & & & & & & & & & & & & & & & 0.0440 \\
\hline 94 & 1.758 & 1.678 & 1.724 & 1.720 & 1.870 & 1.741 & 1.750 & 1.787 & 1.712 & 1.766 & 1.756 & 1.745 & 1.678 & 1.566 & 1.570 & 1.605 & 1.720 & 0.0076 \\
\hline 96 & 1.777 & 1.675 & 1.750 & 1.734 & 1.924 & 1.780 & 1.760 & 1.821 & 1.730 & 1.808 & 1.803 & 1.780 & 1.742 & 1.654 & 1.583 & 1.660 & 1.754 & \\
\hline 100 & & & & & & & & & & & & & & & & & & 0.0170 \\
\hline 101 & 1.783 & 1.605 & 1.702 & 1.697 & 1.837 & 1.719 & 1.761 & 1.772 & 1.645 & 1.752 & 1.746 & 1.714 & 1.674 & 1.616 & 1.483 & 1.591 & 1.682 & 0.0026 \\
\hline 103 & 1.697 & 1.531 & 1.655 & 1.635 & 1.796 & 1.690 & 1.710 & 1.732 & 1.626 & 1.736 & 1.713 & 1.692 & 1.665 & 1.592 & 1.453 & 1.570 & 1.694 & \\
\hline 105 & 1.696 & 1.535 & 1.594 & 1.608 & 1.770 & 1.641 & 1.627 & 1.679 & 1.532 & 1.680 & 1.663 & 1.625 & 1.604 & 1.558 & 1.405 & 1.522 & 1.625 & \\
\hline 107 & 1.647 & 1.500 & 1.547 & 1.565 & 1.688 & 1.613 & 1.567 & 1.623 & 1.484 & 1.650 & 1.635 & 1.590 & 1.577 & 1.528 & 1.421 & 1.509 & 1.583 & \\
\hline 109 & 1.618 & 1.503 & 1.552 & 1.558 & 1.687 & 1.603 & 1.545 & 1.612 & 1.474 & 1.681 & 1.604 & 1.586 & 1.565 & 1.518 & 1.415 & 1.499 & 1.562 & \\
\hline 111 & & & & & & & & & & & & & & & & & & 0.0067 \\
\hline 112 & 1.811 & 1.728 & 1.798 & 1.779 & 1.957 & 1.861 & 1.858 & 1.892 & 1.790 & 1.846 & 1.861 & 1.832 & 1.820 & 1.538 & 1.451 & 1.603 & 1.802 & 0.0364 \\
\hline 113 & & & & & & & & & & & & & & & & & & 0.0230 \\
\hline 114 & 1.788 & 1.701 & 1.742 & 1.744 & 1.907 & 1.799 & 1.789 & 1.832 & 1.700 & 1.850 & 1.820 & 1.790 & 1.773 & 1.546 & 1.474 & 1.598 & 1.779 & \\
\hline 116 & & & & & & & & & & & & & & & & & & 0.0654 \\
\hline 117 & & & & & & & & & & & & & & & & & & 0.0384 \\
\hline 121 & 1.846 & 1.790 & 1.840 & 1.825 & 1.959 & 1.863 & 1.869 & 1.897 & 1.827 & 1.902 & 1.875 & 1.868 & 1.831 & 1.673 & 1.629 & 1.712 & & 0.0312 \\
\hline
\end{tabular}


Profundidade $0,40 \mathrm{~m}$.

\begin{tabular}{|c|c|c|c|c|c|c|c|c|c|c|c|c|c|c|c|c|c|c|}
\hline \multirow[b]{2}{*}{ DAS } & \multicolumn{4}{|c|}{ tro } & \multicolumn{4}{|c|}{ tr1 } & \multicolumn{4}{|c|}{$t 2$} & \multicolumn{4}{|c|}{ tribs } & \multirow{2}{*}{$\begin{array}{l}\mathrm{t} 2 \\
\mathrm{r} 3-\mathrm{p}\end{array}$} & \multirow[b]{2}{*}{$\mathrm{P}+\mathrm{I}$} \\
\hline & r1 & 12 & $\mathrm{r3}$ & média & $\mathrm{rl}$ & 12 & r3 & média & $\mathrm{rl}$ & 2 & r3 & média & $\mathrm{rl}$ & 2 & $\mathrm{r} 3$ & média & & \\
\hline 23 & 1.899 & 1.857 & 1.872 & 1.876 & 1.878 & 1.966 & 1.863 & 1.902 & 1.779 & 1.811 & & & 1.656 & 1.981 & 1.721 & 1.786 & 1.857 & \\
\hline 25 & 1.917 & 1.884 & 1.874 & 1.892 & 1.903 & 1.575 & 1.857 & 1.778 & 1.792 & 2.024 & & & 1.843 & 1.681 & 1.725 & 1.750 & 1.889 & \\
\hline 27 & 1.865 & 1.855 & 1.828 & 1.850 & 1.872 & 1.926 & 1.838 & 1.879 & 1.727 & 1.987 & & & 1.791 & 1.652 & 1.720 & 1.721 & 1.800 & \\
\hline 30 & 1.838 & 1.823 & 1.817 & 1.826 & 1.857 & 1.902 & 1.804 & 1.854 & 1.720 & 1.947 & 1.886 & 1.851 & 1.806 & 1.663 & 1.722 & 1.730 & 1.831 & \\
\hline 32 & 1.783 & 1.749 & 1.805 & 1.779 & 1.822 & 1.853 & 1.748 & 1.808 & 1.676 & 1.958 & 1.833 & 1.822 & 1.760 & 1.652 & 1.711 & 1.708 & & \\
\hline 34 & 1.758 & 1.754 & 1.793 & 1.769 & 1.801 & 1.875 & 1.742 & 1.806 & 1.687 & 1.938 & 1.823 & 1.816 & 1.808 & 1.652 & 1.715 & 1.725 & & 0.0005 \\
\hline 35 & & & & & & & & & & & & & & & & & & 0.0006 \\
\hline 37 & & & & & & & & & & & & & & & & & & 0.0266 \\
\hline 38 & 1.899 & 1.706 & 1.795 & 1.800 & 1.768 & 1.853 & 1.689 & 1.770 & 1.613 & 1.930 & 1.817 & 1.787 & 1.754 & 1.733 & 1.725 & 1.737 & & \\
\hline 41 & 1.852 & 1.709 & 1.771 & 1.777 & 1.744 & 1.839 & 1.682 & 1.755 & 1.593 & 1.908 & 1.800 & 1.767 & 1.762 & 1.685 & 1.745 & 1.731 & 1.721 & \\
\hline 44 & 1.708 & 1.631 & 1.653 & 1.664 & 1.675 & 1.745 & 1.552 & 1.657 & 1.540 & 1.798 & 1.732 & 1.690 & 1.742 & 1.665 & 1.695 & 1.701 & 1.602 & 0.0266 \\
\hline 46 & 1.840 & 1.631 & 1.745 & 1.739 & 1.691 & 1.775 & 1.759 & 1.741 & 1.532 & 1.867 & 1.728 & 1.709 & 1.800 & 1.719 & 1.754 & 1.758 & 1.607 & \\
\hline 47 & & & & & & & & & & & & & & & & & & 0.0038 \\
\hline 48 & 1.756 & 1.607 & 1.666 & 1.676 & 1.656 & 1.730 & 1.672 & 1.686 & 1.476 & 1.777 & 1.678 & 1.643 & 1.755 & 1.670 & 1.707 & 1.711 & 1.568 & \\
\hline 50 & & & & & & & & & & & & & & & & & & 0.0266 \\
\hline 51 & 1.819 & 1.641 & 1.708 & 1.723 & 1.710 & 1.777 & 1.691 & 1.726 & 1.574 & 1.804 & 1.731 & 1.703 & 1.815 & 1.717 & 1.835 & 1.789 & 1.655 & 0.0006 \\
\hline 53 & 1.787 & 1.656 & 1.686 & 1.710 & 1.697 & 1.756 & 1.661 & 1.705 & 1.552 & 1.822 & 1.717 & 1.697 & 1.805 & 1.730 & 1.813 & 1.782 & 1.637 & \\
\hline 54 & & & & & & & & & & & & & & & & & & 0.0055 \\
\hline 55 & 1.736 & 1.655 & 1.662 & 1.684 & 1.700 & 1.747 & 1.619 & 1.689 & 1.532 & 1.788 & 1.710 & 1.677 & 1.806 & 1.723 & 1.795 & 1.775 & 1.615 & 0.0002 \\
\hline 56 & & & & & & & & & & & & & & & & & & 0.0023 \\
\hline 58 & 1.706 & 1.631 & 1.650 & 1.662 & 1.707 & 1.711 & 1.589 & 1.669 & 1.541 & 1.792 & 1.685 & 1.673 & 1.789 & 1.694 & 1.804 & 1.762 & 1.616 & 0.0099 \\
\hline 60 & 1.690 & 1.658 & 1.656 & 1.668 & 1.678 & 1.732 & 1.600 & 1.670 & 1.527 & 1.789 & 1.674 & 1.664 & 1.799 & 1.708 & 1.772 & 1.760 & 1.603 & 0.0245 \\
\hline 61 & & & & & & & & & & & & & & & & & & 0.0366 \\
\hline 62 & 1.873 & 1.749 & 1.890 & 1.837 & 1.923 & 1.958 & 1.863 & 1.915 & 1.825 & 1.954 & 1.911 & 1.897 & 1.848 & 1.785 & 1.862 & 1.832 & 1.804 & 0.0191 \\
\hline 64 & & & & & & & & & & & & & & & & & & 0.0010 \\
\hline 65 & 1.873 & 1.791 & 1.848 & 1.837 & 1.929 & 1.916 & 1.816 & 1.887 & 1.779 & 1.961 & 1.873 & 1.871 & 1.839 & 1.751 & 1.840 & 1.810 & 1.811 & 0.0029 \\
\hline 66 & & & & & & & & & & & & & & & & & & 0.0053 \\
\hline 67 & 1.871 & 1.775 & 1.811 & 1.819 & 1.910 & 1.925 & 1.759 & 1.865 & 1.736 & 1.917 & 1.839 & 1.831 & 1.828 & 1.756 & 1.815 & 1.800 & 1.804 & \\
\hline 69 & 1.783 & 1.673 & 1.708 & 1.721 & 1.859 & 1.833 & 1.665 & 1.785 & 1.660 & 1.802 & 1.765 & 1.743 & 1.781 & 1.706 & 1.748 & 1.745 & 1.720 & 0.0375 \\
\hline 70 & & & & & & & & & & & & & & & & & & 0.0002 \\
\hline 71 & & & & & & & & & & & & & & & & & & 0.0007 \\
\hline 72 & 1.840 & 1.710 & 1.801 & 1.784 & 1.890 & 1.868 & 1.766 & 1.842 & 1.690 & 1.918 & 1.817 & 1.808 & 1.779 & 1.704 & 1.786 & 1.756 & 1.764 & \\
\hline 74 & 1.831 & 1.735 & 1.779 & 1.782 & 1.879 & 1.853 & 1.742 & 1.824 & 1.700 & 1.899 & 1.828 & 1.809 & 1.795 & 1.722 & 1.807 & 1.775 & 1.768 & 0.0042 \\
\hline 76 & 1.793 & 1.707 & 1.737 & 1.746 & 1.883 & 1.851 & 1.710 & 1.814 & 1.645 & 1.863 & 1.803 & 1.770 & 1.801 & 1.702 & 1.811 & 1.771 & 1.739 & \\
\hline 77 & & & & & & & & & & & & & & & & & & 0.0488 \\
\hline 78 & & & & & & & & & & & & & & & & & & 0.0231 \\
\hline 79 & 1.902 & 1.845 & 1.893 & 1.880 & 1.979 & 1.952 & 1.884 & 1.938 & 1.834 & 1.994 & 1.919 & 1.916 & 1.827 & 1.716 & 1.857 & 1.800 & 1.842 & 0.0020 \\
\hline 80 & & & & & & & & & & & & & & & & & & 0.0216 \\
\hline 81 & 1.906 & 1.871 & 1.886 & 1.888 & 1.983 & 1.981 & 1.885 & 1.950 & 1.836 & 1.991 & 1.917 & 1.915 & 1.808 & 1.720 & 1.837 & 1.788 & 1.845 & \\
\hline 82 & & & & & & & & & & & & & & & & & & 0.0083 \\
\hline 83 & 1.890 & 1.824 & 1.841 & 1.852 & 1.929 & 1.925 & 1.822 & 1.892 & 1.774 & 1.949 & 1.884 & 1.869 & 1.825 & 1.709 & 1.807 & 1.780 & 1.811 & 0.0387 \\
\hline 85 & 1.869 & 1.862 & 1.865 & 1.865 & 1.961 & 1.931 & 1.851 & 1.914 & 1.789 & 1.966 & 1.866 & 1.874 & 1.814 & 1.716 & 1.821 & 1.784 & 1.820 & \\
\hline 87 & 1.855 & 1.844 & 1.833 & 1.844 & 1.925 & 1.892 & 1.807 & 1.875 & 1.756 & 1.947 & 1.822 & 1.842 & 1.805 & 1.728 & 1.811 & 1.781 & 1.783 & \\
\hline 89 & 1.847 & 1.822 & 1.774 & 1.814 & 1.924 & 1.859 & 1.761 & 1.848 & 1.705 & 1.900 & 1.821 & 1.809 & 1.817 & 1.727 & 1.805 & 1.783 & 1.753 & \\
\hline 92 & 1.783 & 1.755 & 1.747 & 1.762 & 1.877 & 1.805 & 1.701 & 1.794 & 1.651 & 1.843 & 1.787 & 1.760 & 1.769 & 1.739 & 1.775 & 1.761 & 1.707 & 0.0072 \\
\hline 93 & & & & & & & & & & & & & & & & & & 0.0440 \\
\hline 94 & 1.816 & 1.800 & 1.818 & 1.811 & 1.888 & 1.895 & 1.806 & 1.863 & 1.754 & 1.890 & 1.833 & 1.826 & 1.710 & 1.642 & 1.695 & 1.682 & 1.764 & 0.0076 \\
\hline 96 & 1.866 & 1.845 & 1.842 & 1.851 & 1.927 & 1.898 & 1.821 & 1.882 & 1.797 & 1.929 & 1.879 & 1.869 & 1.746 & 1.708 & 1.761 & 1.738 & 1.825 & \\
\hline 100 & & & & & & & & & & & & & & & & & & 0.0170 \\
\hline 101 & 1.849 & 1.775 & 1.799 & 1.808 & 1.863 & 1.837 & 1.765 & 1.821 & 1.687 & 1.855 & 1.803 & 1.782 & 1.717 & 1.698 & 1.667 & 1.694 & 1.742 & 0.0026 \\
\hline 103 & 1.828 & 1.769 & 1.751 & 1.782 & 1.857 & 1.840 & 1.747 & 1.815 & 1.664 & 1.821 & 1.772 & 1.752 & 1.703 & 1.698 & 1.739 & 1.713 & 1.749 & \\
\hline 105 & 1.788 & 1.711 & 1.708 & 1.736 & 1.799 & 1.786 & 1.670 & 1.752 & 1.610 & 1.798 & 1.728 & 1.712 & 1.665 & 1.695 & 1.593 & 1.651 & 1.689 & \\
\hline 107 & 1.752 & 1.680 & 1.672 & 1.701 & 1.739 & 1.758 & 1.630 & 1.709 & 1.582 & 1.774 & 1.679 & 1.679 & 1.633 & 1.672 & 1.604 & 1.636 & 1.664 & \\
\hline 109 & 1.740 & 1.704 & 1.701 & 1.715 & 1.735 & 1.779 & 1.604 & 1.706 & 1.578 & 1.788 & 1.679 & 1.681 & 1.648 & 1.667 & 1.612 & 1.642 & 1.637 & \\
\hline 111 & & & & & & & & & & & & & & & & & & 0.0067 \\
\hline 112 & 1.909 & 1.869 & 1.979 & 1.919 & 1.970 & 1.958 & 1.890 & 1.939 & 1.849 & 1.973 & 1.913 & 1.912 & 1.822 & 1.669 & 1.632 & 1.708 & 1.856 & 0.0364 \\
\hline 113 & & & & & & & & & & & & & & & & & & 0.0230 \\
\hline 114 & 1.892 & 1.819 & 1.879 & 1.864 & 1.933 & 1.921 & 1.854 & 1.902 & 1.763 & 1.938 & 1.881 & 1.861 & 1.807 & 1.644 & 1.612 & 1.688 & 1.821 & \\
\hline 116 & & & & & & & & & & & & & & & & & & 0.0654 \\
\hline 117 & & & & & & & & & & & & & & & & & & 0.0384 \\
\hline 121 & 1.932 & 1.935 & 1.936 & 1.934 & 1.990 & 1.982 & 1.922 & 1.965 & 1.875 & 1.993 & 1.937 & 1.935 & 1.850 & 1.744 & 1.741 & 1.778 & & 0.0312 \\
\hline
\end{tabular}


Profundidade $0,50 \mathrm{~m}$.

\begin{tabular}{|c|c|c|c|c|c|c|c|c|c|c|c|c|c|c|c|c|c|c|}
\hline \multirow[b]{2}{*}{ DAS } & \multicolumn{4}{|c|}{ tro } & \multicolumn{4}{|c|}{ tr1 } & \multicolumn{4}{|c|}{ tr 2} & \multicolumn{4}{|c|}{ trbs } & \multirow{2}{*}{$\frac{\mathrm{t} 2}{\mathrm{r} 2}$} & \multirow[b]{2}{*}{ P+I } \\
\hline & rl & 12 & r3 & média & $\mathrm{r} 1$ & 12 & r3 & média & $\mathrm{rl}$ & 12 & $r 3$ & média & r1 & 12 & r3 & média & & \\
\hline 23 & 1.948 & 1.911 & 1.900 & 1.920 & 1.837 & 1.966 & 1.885 & 1.896 & 1.877 & 2.027 & & & 1.853 & 1.701 & 1.761 & 1.772 & 1.868 & \\
\hline 25 & 1.924 & 1.925 & 1.922 & 1.924 & 1.857 & 1.983 & 1.894 & 1.911 & 1.900 & 2.047 & & & 1.881 & 1.741 & 1.742 & 1.788 & 1.889 & \\
\hline 27 & 1.930 & 1.879 & 1.857 & 1.889 & 1.810 & 1.945 & 1.837 & 1.864 & 1.853 & 2.016 & & & 1.830 & 1.706 & 1.752 & 1.762 & 1.874 & \\
\hline 30 & 1.928 & 1.879 & 1.883 & 1.896 & 1.828 & 1.940 & 1.817 & 1.862 & 1.823 & 2.006 & 1.897 & 1.909 & 1.810 & 1.714 & 1.767 & 1.763 & 1.837 & \\
\hline 32 & 1.887 & 1.834 & 1.819 & 1.846 & 1.800 & 1.926 & 1.785 & 1.837 & 1.812 & 1.971 & 1.891 & 1.892 & 1.797 & 1.736 & 1.738 & 1.757 & & \\
\hline 34 & 1.883 & 1.867 & 1.855 & 1.868 & 1.796 & 1.936 & 1.802 & 1.845 & 1.819 & 2.016 & 1.893 & 1.909 & 1.831 & 1.732 & 1.738 & 1.767 & & 0.0005 \\
\hline 35 & & & & & & & & & & & & & & & & & & 0.0006 \\
\hline 37 & & & & & & & & & & & & & & & & & & 0.0266 \\
\hline 38 & 1.903 & 1.808 & 1.832 & 1.848 & 1.775 & 1.891 & 1.784 & 1.817 & 1.796 & 1.980 & 1.870 & 1.882 & 1.789 & 1.737 & 1.758 & 1.761 & & \\
\hline 41 & 1.897 & 1.799 & 1.814 & 1.837 & 1.746 & 1.883 & 1.753 & 1.794 & 1.766 & 1.993 & 1.851 & 1.870 & 1.793 & 1.747 & 1.783 & 1.774 & 1.782 & \\
\hline 4 & 1.844 & 1.733 & 1.735 & 1.771 & 1.698 & 1.836 & 1.714 & 1.749 & 1.698 & 1.858 & 1.781 & 1.779 & 1.740 & 1.734 & 1.754 & 1.743 & 1.724 & 0.0266 \\
\hline 46 & 1.902 & 1.731 & 1.780 & 1.804 & 1.686 & 1.792 & 1.741 & 1.740 & 1.688 & 1.911 & 1.785 & 1.795 & 1.832 & 1.781 & 1.790 & 1.801 & 1.704 & \\
\hline 47 & & & & & & & & & & & & & & & & & & 0.0038 \\
\hline 48 & 1.802 & 1.686 & 1.707 & 1.732 & 1.649 & 1.737 & 1.700 & 1.695 & 1.645 & 1.831 & 1.726 & 1.734 & 1.764 & 1.723 & 1.742 & 1.743 & 1.626 & \\
\hline 50 & & & & & & & & & & & & & & & & & & 0.0266 \\
\hline 51 & 1.862 & 1.711 & 1.744 & 1.772 & 1.677 & 1.785 & 1.693 & 1.718 & 1.685 & 1.854 & 1.765 & 1.768 & 1.820 & 1.773 & 1.898 & 1.830 & 1.705 & 0.0006 \\
\hline 53 & 1.851 & 1.721 & 1.740 & 1.770 & 1.676 & 1.798 & 1.698 & 1.724 & 1.668 & 1.877 & 1.766 & 1.770 & 1.839 & 1.807 & 1.876 & 1.841 & 1.676 & \\
\hline 54 & & & & & & & & & & & & & & & & & & 0.0055 \\
\hline 55 & 1.833 & 1.708 & 1.717 & 1.753 & 1.683 & 1.785 & 1.691 & 1.720 & 1.656 & 1.837 & 1.753 & 1.749 & 1.809 & 1.775 & 1.840 & 1.808 & 1.636 & 0.0002 \\
\hline 56 & & & & & & & & & & & & & & & & & & 0.0023 \\
\hline 58 & 1.786 & 1.693 & 1.700 & 1.727 & 1.678 & 1.763 & 1.634 & 1.692 & 1.664 & 1.841 & 1.688 & 1.731 & 1.808 & 1.802 & 1.859 & 1.823 & 1.656 & .0099 \\
\hline 60 & 1.753 & 1.692 & 1.713 & 1.720 & 1.686 & 1.744 & 1.629 & 1.686 & 1.653 & 1.807 & 1.692 & 1.717 & 1.809 & 1.794 & 1.842 & 1.815 & 1.666 & 0.0245 \\
\hline 61 & & & & & & & & & & & & & & & & & & 0.0366 \\
\hline 62 & 1.947 & 1.770 & 1.908 & 1.875 & 1.924 & 2.036 & 1.889 & 1.950 & 1.884 & 1.980 & 1.918 & 1.927 & 1.879 & 1.853 & 1.913 & 1.882 & 1.847 & 0.0191 \\
\hline 64 & & & & & & & & & & & & & & & & & & 0.0010 \\
\hline 65 & 1.942 & 1.837 & 1.893 & 1.891 & 1.928 & 1.959 & 1.854 & 1.914 & 1.881 & 1.990 & 1.848 & 1.906 & 1.848 & 1.877 & 1.888 & 1.871 & 1.857 & 0.0029 \\
\hline 66 & & & & & & & & & & & & & & & & & & 0.0053 \\
\hline 67 & 1.893 & 1.836 & 1.840 & 1.856 & 1.898 & 1.954 & 1.812 & 1.888 & 1.864 & 1.969 & 1.901 & 1.912 & 1.855 & 1.875 & 1.891 & 1.874 & 1.818 & \\
\hline 69 & 1.864 & 1.759 & 1.766 & 1.796 & 1.845 & 1.869 & 1.710 & 1.808 & 1.787 & 1.878 & 1.842 & 1.836 & 1.808 & 1.797 & 1.838 & 1.814 & 1.761 & 0.0375 \\
\hline 70 & & & & & & & & & & & & & & & & & & 0.0002 \\
\hline 71 & & & & & & & & & & & & & & & & & & 0.0007 \\
\hline 72 & 1.864 & 1.782 & 1.819 & 1.822 & 1.875 & 1.917 & 1.786 & 1.859 & 1.680 & 1.926 & 1.875 & 1.827 & 1.796 & 1.804 & 1.868 & 1.822 & 1.809 & \\
\hline 74 & 1.896 & 1.791 & 1.829 & 1.839 & 1.909 & 1.922 & 1.755 & 1.862 & 1.805 & 1.925 & 1.864 & 1.865 & 1.817 & 1.847 & 1.863 & 1.842 & 1.828 & 0.0042 \\
\hline 76 & 1.877 & 1.813 & 1.787 & 1.825 & 1.885 & 1.873 & 1.721 & 1.826 & 1.821 & 1.893 & 1.856 & 1.857 & 1.793 & 1.820 & 1.881 & 1.831 & 1.821 & \\
\hline 77 & & & & & & & & & & & & & & & & & & 0.0488 \\
\hline 78 & & & & & & & & & & & & & & & & & & 0.0231 \\
\hline 79 & 1.958 & 1.899 & 1.943 & 1.933 & 1.979 & 2.001 & 1.920 & 1.967 & 1.913 & 2.010 & 1.946 & 1.956 & 1.824 & 1.854 & 1.911 & 1.863 & 1.915 & 0.0020 \\
\hline 80 & & & & & & & & & & & & & & & & & & 0.0216 \\
\hline 81 & 1.983 & 1.923 & 1.946 & 1.950 & 1.960 & 1.988 & 1.909 & 1.952 & 1.926 & 2.015 & 1.939 & 1.960 & 1.821 & 1.810 & 1.894 & 1.842 & 1.896 & \\
\hline 82 & & & & & & & & & & & & & & & & & & 0.0083 \\
\hline 83 & 1.929 & 1.885 & 1.891 & 1.902 & 1.917 & 1.957 & 1.859 & 1.911 & 1.893 & 1.993 & 1.920 & 1.935 & 1.815 & 1.789 & 1.879 & 1.828 & 1.837 & 0.0387 \\
\hline 85 & 1.913 & 1.927 & 1.904 & 1.915 & 1.922 & 1.976 & 1.865 & 1.921 & 1.895 & 2.009 & 1.932 & 1.945 & 1.822 & 1.813 & 1.878 & 1.838 & 1.847 & \\
\hline 87 & 1.921 & 1.903 & 1.891 & 1.905 & 1.921 & 1.908 & 1.864 & 1.898 & 1.854 & 1.955 & 1.899 & 1.903 & 1.832 & 1.817 & 1.862 & 1.837 & 1.823 & \\
\hline 89 & 1.895 & 1.893 & 1.857 & 1.881 & 1.923 & 1.908 & 1.796 & 1.876 & 1.826 & 1.972 & 1.877 & 1.891 & 1.841 & 1.810 & 1.884 & 1.845 & 1.815 & \\
\hline 92 & 1.884 & 1.876 & 1.826 & 1.862 & 1.897 & 1.862 & 1.731 & 1.830 & 1.783 & 1.895 & 1.845 & 1.841 & 1.818 & 1.818 & 1.866 & 1.834 & 1.771 & 0.0072 \\
\hline 93 & & & & & & & & & & & & & & & & & & 0.0440 \\
\hline 94 & 1.876 & 1.856 & 1.864 & 1.865 & 1.860 & 1.901 & 1.821 & 1.861 & 1.847 & 1.931 & 1.843 & 1.874 & 1.722 & 1.743 & 1.786 & 1.750 & 1.817 & 0.0076 \\
\hline 96 & 1.920 & 1.912 & 1.909 & 1.913 & 1.920 & 1.929 & 1.868 & 1.906 & 1.871 & 1.999 & 1.908 & 1.926 & 1.810 & 1.823 & 1.845 & 1.826 & 1.850 & \\
\hline 100 & & & & & & & & & & & & & & & & & & 0.0170 \\
\hline 101 & 1.886 & 1.879 & 1.836 & 1.867 & 1.897 & 1.874 & 1.770 & 1.847 & 1.806 & 1.885 & 1.837 & 1.843 & 1.761 & 1.828 & 1.803 & 1.797 & 1.775 & 0.0026 \\
\hline 103 & 1.876 & 1.851 & 1.808 & 1.845 & 1.864 & 1.837 & 1.772 & 1.824 & 1.804 & 1.868 & 1.810 & 1.827 & 1.747 & 1.817 & 1.770 & 1.778 & 1.766 & \\
\hline 105 & 1.844 & 1.817 & 1.770 & 1.810 & 1.813 & 1.822 & 1.698 & 1.778 & 1.731 & 1.791 & 1.722 & 1.748 & 1.738 & 1.797 & 1.688 & 1.741 & 1.724 & \\
\hline 107 & 1.805 & 1.784 & 1.735 & 1.775 & 1.769 & 1.802 & 1.647 & 1.740 & 1.701 & 1.819 & 1.694 & 1.738 & 1.726 & 1.769 & 1.709 & 1.735 & 1.705 & \\
\hline 109 & 1.812 & 1.785 & 1.746 & 1.781 & 1.791 & 1.786 & 1.634 & 1.737 & 1.695 & 1.813 & 1.715 & 1.741 & 1.712 & 1.774 & 1.691 & 1.726 & 1.691 & \\
\hline 111 & & & & & & & & & & & & & & & & & & 0.0067 \\
\hline 112 & 1.951 & 1.906 & 1.939 & 1.932 & 1.960 & 2.011 & 1.898 & 1.956 & 1.893 & 2.009 & 1.931 & 1.944 & 1.862 & 1.761 & 1.728 & 1.784 & 1.877 & 0.0364 \\
\hline 113 & & & & & & & & & & & & & & & & & & 0.0230 \\
\hline 114 & 1.936 & 1.880 & 1.903 & 1.906 & 1.955 & 1.942 & 1.876 & 1.924 & 1.862 & 1.922 & 1.901 & 1.895 & 1.840 & 1.760 & 1.701 & 1.767 & 1.852 & \\
\hline 116 & & & & & & & & & & & & & & & & & & 0.0654 \\
\hline 117 & & & & & & & & & & & & & & & & & & 0.0384 \\
\hline 121 & 1.959 & 1.973 & 1.939 & 1.957 & 1.996 & 2.019 & 1.950 & 1.988 & 1.970 & 2.065 & 1.970 & 2.002 & 1.895 & 1.865 & 1.774 & 1.845 & & 0.0312 \\
\hline
\end{tabular}


Profundidade $0,60 \mathrm{~m}$.

\begin{tabular}{|c|c|c|c|c|c|c|c|c|c|c|c|c|c|c|c|c|c|c|}
\hline \multirow[b]{2}{*}{ DAS } & \multicolumn{4}{|c|}{ tro } & \multicolumn{4}{|c|}{ trl } & \multicolumn{4}{|c|}{ tr2 } & \multicolumn{4}{|c|}{ trbs } & \multirow{2}{*}{$\frac{t 2}{r 3-p}$} & \multirow[b]{2}{*}{$\mathrm{P}+\mathrm{I}$} \\
\hline & $\mathrm{r} 1$ & 12 & 13 & média & rl & 12 & $\mathrm{r} 3$ & média & r1 & 12 & r3 & média & rl & 12 & r3 & média & & \\
\hline 23 & 1.978 & 1.824 & 1.893 & 1.898 & 1.694 & 1.921 & 1.914 & 1.843 & 1.899 & 2.009 & & & 1.889 & 1.721 & 1.759 & 1.790 & 1.707 & \\
\hline 25 & 1.985 & 1.830 & 1.881 & 1.899 & 1.722 & 1.937 & 1.907 & 1.855 & 1.930 & 2.034 & & & 1.894 & 1.742 & 1.788 & 1.808 & 1.709 & \\
\hline 27 & 1.951 & 1.809 & 1.865 & 1.875 & 1.680 & 1.862 & 1.853 & 1.798 & 1.885 & 2.004 & & & 1.866 & 1.721 & 1.734 & 1.774 & 1.691 & \\
\hline 30 & 1.928 & 1.808 & 1.850 & 1.862 & 1.706 & 1.864 & 1.870 & 1.813 & 1.854 & 2.011 & 1.941 & 1.935 & 1.867 & 1.739 & 1.796 & 1.801 & 1.697 & \\
\hline 32 & 1.921 & 1.797 & 1.828 & 1.849 & 1.680 & 1.840 & 1.813 & 1.777 & 1.839 & 1.978 & 1.924 & 1.913 & 1.842 & 1.718 & 1.775 & 1.778 & & \\
\hline 34 & 1.927 & 1.821 & 1.870 & 1.872 & 1.695 & 1.853 & 1.837 & 1.795 & 1.860 & 1.987 & 1.918 & 1.922 & 1.878 & 1.733 & 1.790 & 1.800 & & 0.0005 \\
\hline 35 & & & & & & & & & & & & & & & & & & 0.0006 \\
\hline 37 & & & & & & & & & & & & & & & & & & 0.0266 \\
\hline 38 & 1.956 & 1.783 & 1.828 & 1.856 & 1.686 & 1.827 & 1.808 & 1.774 & 1.847 & 1.985 & 1.871 & 1.901 & 1.784 & 1.748 & 1.800 & 1.777 & & \\
\hline 41 & 1.931 & 1.769 & 1.800 & 1.834 & 1.671 & 1.821 & 1.773 & 1.755 & 1.832 & 1.963 & 1.873 & 1.889 & 1.827 & 1.746 & 1.788 & 1.787 & 1.645 & \\
\hline 44 & 1.882 & 1.705 & 1.742 & 1.776 & 1.602 & 1.777 & 1.734 & 1.704 & 1.795 & 1.855 & 1.844 & 1.832 & 1.809 & 1.746 & 1.786 & 1.780 & 1.605 & 0.0266 \\
\hline 46 & 1.964 & 1.707 & 1.765 & 1.812 & 1.610 & 1.755 & 1.751 & 1.705 & 1.783 & 1.879 & 1.829 & 1.830 & 1.833 & 1.748 & 1.809 & 1.797 & 1.581 & \\
\hline 47 & & & & & & & & & & & & & & & & & & 0.0038 \\
\hline 48 & 1.873 & 1.642 & 1.716 & 1.744 & 1.572 & 1.683 & 1.686 & 1.647 & 1.690 & 1.803 & 1.752 & 1.748 & 1.801 & 1.705 & & 1.753 & 1.520 & \\
\hline 50 & & & & & & & & & & & & & & & & & & 0.0266 \\
\hline 51 & 1.895 & 1.701 & 1.732 & 1.776 & 1.599 & 1.715 & 1.727 & 1.680 & 1.758 & 1.813 & 1.802 & 1.791 & 1.846 & 1.778 & 1.906 & 1.843 & 1.517 & 0.0006 \\
\hline 53 & 1.913 & 1.691 & 1.715 & 1.773 & 1.613 & 1.711 & 1.735 & 1.686 & 1.736 & 1.825 & 1.800 & 1.787 & 1.837 & 1.778 & 1.922 & 1.846 & 1.532 & \\
\hline 54 & & & & & & & & & & & & & & & & & & 0.0055 \\
\hline 55 & 1.859 & 1.691 & 1.701 & 1.750 & 1.596 & 1.702 & 1.733 & 1.677 & 1.726 & 1.808 & 1.778 & 1.771 & 1.822 & 1.805 & 1.889 & 1.839 & 1.489 & 0.0002 \\
\hline 56 & & & & & & & & & & & & & & & & & & 0.0023 \\
\hline 58 & 1.832 & 1.670 & 1.691 & 1.731 & 1.599 & 1.688 & 1.685 & 1.657 & 1.716 & 1.772 & 1.738 & 1.742 & 1.845 & 1.794 & 1.876 & 1.838 & 1.475 & 0.0099 \\
\hline 60 & 1.806 & 1.668 & 1.678 & 1.717 & 1.613 & 1.676 & 1.672 & 1.654 & 1.726 & 1.780 & 1.710 & 1.738 & 1.821 & 1.796 & 1.896 & 1.838 & 1.473 & 0.0245 \\
\hline 61 & & & & & & & & & & & & & & & & & & 0.0366 \\
\hline 62 & 1.955 & 1.682 & 1.900 & 1.846 & 1.851 & 1.901 & 1.873 & 1.875 & 1.919 & 1.945 & 1.935 & 1.933 & 1.907 & 1.848 & 1.962 & 1.906 & 1.665 & 0.0191 \\
\hline 64 & & & & & & & & & & & & & & & & & & 0.0010 \\
\hline 65 & 1.981 & 1.785 & 1.870 & 1.879 & 1.869 & 1.885 & 1.863 & 1.872 & 1.957 & 1.978 & 1.958 & 1.965 & 1.901 & 1.892 & 1.945 & 1.913 & 1.681 & 0.0029 \\
\hline 66 & & & & & & & & & & & & & & & & & & 0.0053 \\
\hline 67 & 1.952 & 1.772 & 1.847 & 1.857 & 1.845 & 1.855 & 1.840 & 1.847 & 1.942 & 1.922 & 1.931 & 1.931 & 1.890 & 1.876 & 1.942 & 1.903 & 1.649 & \\
\hline 69 & 1.837 & 1.732 & 1.763 & 1.777 & 1.770 & 1.789 & 1.744 & 1.768 & 1.853 & 1.873 & 1.856 & 1.861 & 1.831 & 1.819 & 1.903 & 1.851 & 1.631 & 0.0375 \\
\hline 70 & & & & & & & & & & & & & & & & & & 0.0002 \\
\hline 71 & & & & & & & & & & & & & & & & & & 0.0007 \\
\hline$n$ & 1.926 & 1.734 & 1.806 & 1.822 & 1.818 & 1.852 & 1.815 & 1.828 & 1.866 & 1.889 & 1.902 & 1.886 & 1.833 & 1.807 & 1.904 & 1.848 & 1.651 & \\
\hline 74 & 1.950 & 1.754 & 1.808 & 1.837 & 1.848 & 1.837 & 1.814 & 1.833 & 1.877 & 1.903 & 1.888 & 1.889 & 1.869 & 1.855 & 1.940 & 1.888 & 1.654 & 0.0042 \\
\hline 76 & 1.897 & 1.755 & 1.780 & 1.811 & 1.815 & 1.824 & 1.761 & 1.800 & 1.880 & 1.888 & 1.873 & 1.880 & 1.886 & 1.845 & 1.948 & 1.893 & 1.620 & \\
\hline 77 & & & & & & & & & & & & & & & & & & 0.0488 \\
\hline 78 & & & & & & & & & & & & & & & & & & 0.0231 \\
\hline 79 & 1.998 & 1.864 & 1.907 & 1.923 & 1.951 & 1.953 & 1.966 & 1.957 & 1.961 & 1.983 & 2.004 & 1.983 & 1.860 & 1.863 & 1.950 & 1.891 & 1.732 & 0.0020 \\
\hline 80 & & & & & & & & & & & & & & & & & & 0.0216 \\
\hline 81 & 1.995 & 1.887 & 1.934 & 1.939 & 1.937 & 1.965 & 1.946 & 1.949 & 1.990 & 1.996 & 1.986 & 1.991 & 1.861 & 1.819 & 1.948 & 1.876 & 1.719 & \\
\hline 82 & & & & & & & & & & & & & & & & & & 0.0083 \\
\hline 83 & 1.950 & 1.848 & 1.880 & 1.893 & 1.884 & 1.893 & 1.874 & 1.883 & 1.930 & 1.959 & 1.936 & 1.942 & 1.783 & 1.825 & 1.918 & 1.842 & 1.672 & 0.0387 \\
\hline 85 & 1.959 & 1.901 & 1.860 & 1.907 & 1.898 & 1.905 & 1.915 & 1.906 & 1.956 & 1.977 & 1.966 & 1.966 & 1.861 & 1.838 & 1.944 & 1.881 & 1.671 & \\
\hline 87 & 1.934 & 1.884 & 1.862 & 1.893 & 1.882 & 1.862 & 1.870 & 1.871 & 1.908 & 1.941 & 1.912 & 1.921 & 1.848 & 1.838 & 1.921 & 1.869 & 1.679 & \\
\hline 89 & 1.927 & 1.873 & 1.835 & 1.878 & 1.878 & 1.857 & 1.850 & 1.862 & 1.897 & 1.944 & 1.892 & 1.911 & 1.866 & 1.840 & 1.939 & 1.882 & 1.669 & \\
\hline 92 & 1.901 & 1.845 & 1.835 & 1.860 & 1.813 & 1.819 & 1.794 & 1.809 & 1.850 & 1.879 & 1.850 & 1.859 & 1.860 & 1.857 & 1.924 & 1.881 & 1.601 & 0.0072 \\
\hline 93 & & & & & & & & & & & & & & & & & & 0.0440 \\
\hline 94 & 1.902 & 1.856 & 1.830 & 1.863 & 1.850 & 1.847 & 1.839 & 1.845 & 1.876 & 1.917 & 1.891 & 1.895 & 1.799 & 1.768 & 1.811 & 1.793 & 1.626 & 0.0076 \\
\hline 96 & 1.965 & 1.909 & 1.892 & 1.922 & 1.897 & 1.892 & 1.897 & 1.895 & 1.923 & 1.969 & 1.934 & 1.942 & 1.863 & 1.823 & 1.882 & 1.856 & 1.671 & \\
\hline 100 & & & & & & & & & & & & & & & & & & 0.0170 \\
\hline 101 & 1.929 & 1.859 & 1.853 & 1.880 & 1.835 & 1.813 & 1.817 & 1.822 & 1.868 & 1.874 & 1.852 & 1.865 & 1.820 & 1.816 & 1.875 & 1.837 & 1.640 & 0.0026 \\
\hline 103 & 1.911 & 1.851 & 1.813 & 1.858 & 1.830 & 1.790 & 1.800 & 1.807 & 1.854 & 1.862 & 1.818 & 1.845 & 1.832 & 1.825 & 1.877 & 1.844 & 1.591 & \\
\hline 105 & 1.888 & 1.803 & 1.766 & 1.819 & 1.792 & 1.777 & 1.736 & 1.768 & 1.787 & 1.771 & 1.773 & 1.777 & 1.790 & 1.814 & 1.777 & 1.793 & 1.572 & \\
\hline 107 & 1.846 & 1.750 & 1.742 & 1.779 & 1.750 & 1.731 & 1.709 & 1.730 & 1.779 & 1.753 & 1.737 & 1.756 & 1.796 & 1.793 & 1.780 & 1.790 & 1.519 & \\
\hline 109 & 1.836 & 1.784 & 1.754 & 1.792 & 1.738 & 1.720 & 1.701 & 1.720 & 1.769 & 1.754 & 1.727 & 1.750 & 1.799 & 1.813 & 1.786 & 1.800 & 1.511 & \\
\hline 111 & & & & & & & & & & & & & & & & & & 0.0067 \\
\hline 112 & 1.967 & 1.873 & 1.940 & 1.927 & 1.895 & 1.923 & 1.902 & 1.906 & 1.888 & 1.935 & 1.962 & 1.928 & 1.867 & 1.801 & 1.796 & 1.821 & 1.684 & 0.0364 \\
\hline 113 & & & & & & & & & & & & & & & & & & 0.0230 \\
\hline 114 & 1.948 & 1.862 & 1.892 & 1.900 & 1.853 & 1.882 & 1.871 & 1.869 & 1.895 & 1.912 & 1.922 & 1.910 & 1.862 & 1.790 & 1.768 & 1.807 & 1.628 & \\
\hline 116 & & & & & & & & & & & & & & & & & & 0.0654 \\
\hline 117 & & & & & & & & & & & & & & & & & & 0.0384 \\
\hline 121 & 2.013 & 1.963 & 1.930 & 1.969 & 1.953 & 1.953 & 1.972 & 1.959 & 1.990 & 2.000 & 2.000 & 1.997 & 1.898 & 1.861 & 1.810 & 1.857 & & 0.0312 \\
\hline
\end{tabular}


Profundidade $0,70 \mathrm{~m}$.

\begin{tabular}{|c|c|c|c|c|c|c|c|c|c|c|c|c|c|c|c|c|c|c|}
\hline \multirow[b]{2}{*}{ DAS } & \multicolumn{4}{|c|}{ tro } & \multicolumn{4}{|c|}{ tr 1} & \multicolumn{4}{|c|}{ tr2 } & \multicolumn{4}{|c|}{ trbs } & \multirow{2}{*}{$\frac{t+2}{r 3-p}$} & \multirow[b]{2}{*}{$\mathrm{P}+\mathrm{I}$} \\
\hline & $\mathrm{rl}$ & 12 & r3 & média & $\mathrm{rl}$ & 12 & r3 & média & $\mathrm{r} 1$ & 12 & r3 & média & $\mathrm{rl}$ & 12 & $\mathrm{r} 3$ & média & & \\
\hline 23 & 1.872 & 1.686 & 1.862 & 1.807 & 1.606 & 1.830 & 1.873 & 1.769 & 1.738 & 1.938 & & & 1.850 & 1.770 & 1.770 & 1.796 & 1.242 & \\
\hline 25 & 1.907 & 1.692 & 1.865 & 1.821 & 1.598 & 1.827 & 1.900 & 1.775 & 1.786 & 1.962 & & & 1.877 & 1.775 & 1.823 & 1.825 & 1.208 & \\
\hline 27 & 1.852 & 1.688 & 1.851 & 1.797 & 1.593 & 1.800 & 1.860 & 1.751 & 1.745 & 1.925 & & & 1.857 & 1.769 & 1.786 & 1.804 & 1.115 & \\
\hline 30 & 1.875 & 1.727 & 1.847 & 1.816 & 1.607 & 1.803 & 1.864 & 1.758 & 1.766 & 1.938 & 1.895 & 1.866 & 1.869 & 1.775 & 1.781 & 1.809 & 1.155 & \\
\hline 32 & 1.841 & 1.697 & 1.825 & 1.788 & 1.594 & 1.777 & 1.839 & 1.736 & 1.748 & 1.919 & 1.865 & 1.844 & 1.850 & 1.769 & 1.802 & 1.807 & & \\
\hline 34 & 1.894 & 1.732 & 1.830 & 1.818 & 1.610 & 1.736 & 1.853 & 1.733 & 1.769 & 1.909 & 1.890 & 1.856 & 1.856 & 1.796 & 1.839 & 1.830 & & 0.0005 \\
\hline 35 & & & & & & & & & & & & & & & & & & 1.0006 \\
\hline 37 & & & & & & & & & & & & & & & & & & .0266 \\
\hline 38 & 1.883 & 1.703 & 1.819 & 1.802 & 1.602 & 1.758 & 1.830 & 1.730 & 1.673 & 1.920 & 1.867 & 1.820 & 1.858 & 1.766 & 1.819 & 1.814 & & \\
\hline 41 & 1.880 & 1.719 & 1.801 & 1.800 & 1.602 & 1.749 & 1.800 & 1.717 & 1.746 & 1.897 & 1.814 & 1.819 & 1.857 & 1.782 & 1.730 & 1.790 & 1.138 & \\
\hline 44 & 1.817 & 1.677 & 1.711 & 1.735 & 1.595 & 1.732 & 1.770 & 1.699 & 1.713 & 1.897 & 1.841 & 1.817 & 1.818 & 1.752 & 1.776 & 1.782 & 1.095 & 0.0266 \\
\hline 46 & 1.897 & 1.654 & 1.751 & 1.767 & 1.555 & 1.705 & 1.776 & 1.678 & 1.711 & 1.851 & 1.799 & 1.787 & 1.845 & 1.781 & 1.821 & 1.816 & 1.119 & \\
\hline 47 & & & & & & & & & & & & & & & & & & .0038 \\
\hline 48 & 1.816 & 1.596 & 1.692 & 1.701 & 1.518 & 1.632 & 1.730 & 1.626 & 1.638 & 1.788 & 1.741 & 1.722 & 1.787 & 1.723 & 1.766 & 1.759 & 1.058 & \\
\hline 50 & & & & & & & & & & & & & & & & & & .0266 \\
\hline 51 & 1.887 & 1.639 & 1.721 & 1.74 & 1.548 & 1.669 & 1.769 & 1.662 & 1.684 & 1.799 & 1.784 & 1.755 & 1.838 & 1.795 & 1.865 & 1.833 & 1.044 & .0006 \\
\hline 53 & 1.867 & 1.632 & 1.743 & 1.747 & 1.558 & 1.657 & 1.751 & 1.655 & 1.689 & 1.760 & 1.761 & 1.736 & 1.844 & 1.798 & 1.912 & 1.851 & 1.060 & \\
\hline 54 & & & & & & & & & & & & & & & & & & 0.0055 \\
\hline 55 & 1.869 & 1.628 & 1.723 & 1.740 & 1.544 & 1.607 & 1.734 & 1.629 & 1.689 & 1.738 & 1.752 & 1.727 & 1.839 & 1.803 & 1.928 & 1.857 & 1.053 & .0002 \\
\hline 56 & & & & & & & & & & & & & & & & & & .0023 \\
\hline 58 & 1.841 & 1.630 & 1.691 & 1.721 & 1.545 & 1.621 & 1.722 & 1.629 & 1.681 & 1.745 & 1.741 & 1.722 & 1.846 & 1.807 & 1.905 & 1.853 & 1.020 & .0099 \\
\hline 60 & 1.806 & 1.620 & 1.684 & 1.703 & 1.550 & 1.576 & 1.709 & 1.612 & 1.685 & 1.738 & 1.724 & 1.715 & 1.812 & 1.827 & 1.910 & 1.850 & 1.020 & .0245 \\
\hline 61 & & & & & & & & & & & & & & & & & & .0366 \\
\hline 62 & 1.909 & 1.651 & 1.902 & 1.821 & 1.875 & 1.857 & 1.868 & 1.867 & 1.789 & 1.835 & 1.885 & 1.836 & 1.902 & 1.827 & 1.973 & 1.900 & 1.157 & .0191 \\
\hline 64 & & & & & & & & & & & & & & & & & & .0010 \\
\hline 65 & 1.939 & 1.727 & 1.889 & 1.852 & 1.834 & 1.825 & 1.884 & 1.848 & 1.886 & 1.885 & 1.911 & 1.894 & 1.902 & 1.882 & 1.980 & 1.921 & 1.179 & .0029 \\
\hline 66 & & & & & & & & & & & & & & & & & & 0.0053 \\
\hline 67 & 1.926 & 1.732 & 1.854 & 1.838 & 1.789 & 1.787 & 1.845 & 1.807 & 1.855 & 1.863 & 1.903 & 1.874 & 1.910 & 1.886 & 1.974 & 1.923 & 1.142 & \\
\hline 69 & 1.851 & 1.699 & 1.796 & 1.782 & 1.746 & 1.728 & 1.802 & 1.758 & 1.797 & 1.809 & 1.806 & 1.804 & 1.874 & 1.836 & 1.910 & 1.873 & 1.098 & 0.0375 \\
\hline 70 & & & & & & & & & & & & & & & & & & .0002 \\
\hline 71 & & & & & & & & & & & & & & & & & & .0007 \\
\hline 72 & 1.895 & 1.684 & 1.815 & 1.798 & 1.789 & 1.780 & 1.801 & 1.790 & 1.800 & 1.815 & 1.865 & 1.827 & 1.850 & 1.860 & 1.933 & 1.881 & 1.157 & \\
\hline 74 & 1.878 & 1.705 & 1.809 & 1.797 & 1.805 & 1.782 & 1.825 & 1.804 & 1.825 & 1.834 & 1.860 & 1.840 & 1.887 & 1.888 & 1.955 & 1.910 & 1.155 & 0.0042 \\
\hline 76 & 1.871 & 1.708 & 1.780 & 1.787 & 1.801 & 1.757 & 1.777 & 1.778 & 1.819 & 1.828 & 1.861 & 1.836 & 1.882 & 1.884 & 1.969 & 1.912 & 1.106 & \\
\hline 77 & & & & & & & & & & & & & & & & & & .0488 \\
\hline 78 & & & & & & & & & & & & & & & & & & 31 \\
\hline 79 & 1.961 & 1.803 & 1.940 & 1.901 & 1.896 & 1.891 & 1.931 & 1.906 & 1.902 & 1.906 & 1.941 & 1.917 & 1.862 & 1.881 & 1.962 & 1.902 & 1.187 & 20 \\
\hline 80 & & & & & & & & & & & & & & & & & & .0216 \\
\hline 81 & 1.966 & 1.828 & 1.925 & 1.906 & 1.904 & 1.895 & 1.954 & 1.918 & 1.919 & 1.884 & 1.968 & 1.924 & 1.866 & 1.860 & 1.961 & 1.896 & 1.195 & \\
\hline 82 & & & & & & & & & & & & & & & & & & 83 \\
\hline 83 & 919 & 1.819 & 1.878 & 1.872 & .857 & .828 & 1.889 & 1.858 & 1.869 & 1.886 & 1.901 & 1.885 & 1.863 & 1.822 & 60 & 1.882 & 1.099 & .0387 \\
\hline 85 & 1.926 & 1.877 & 1.896 & 1.899 & 1.861 & 1.816 & 1.907 & 1.861 & 1.901 & 1.901 & 1.896 & 1.899 & 1.845 & 1.835 & 1.938 & 1.87 & 1.166 & \\
\hline 87 & 1.905 & 1.834 & 1.867 & 1.869 & 1.840 & 1.798 & 1.886 & 1.841 & 1.872 & 1.881 & 1.884 & 1.879 & 1.849 & 1.843 & 1.947 & 1.880 & 1.135 & \\
\hline 89 & 1.896 & 1.836 & 1.845 & 1.859 & 1.824 & 1.789 & 1.851 & 1.821 & 1.861 & 1.871 & 1.841 & 1.857 & 1.844 & 1.836 & 1.938 & 1.873 & 1.152 & \\
\hline 92 & 1.874 & 1.813 & 1.815 & 1.834 & 1.808 & 1.784 & 1.826 & 1.806 & 1.829 & 1.843 & 1.839 & 1.837 & 1.870 & 1.881 & 1.944 & 1.898 & 1.118 & 0.0072 \\
\hline 93 & & & & & & & & & & & & & & & & & & .0440 \\
\hline 94 & 1.872 & 1.826 & 1.833 & 1.844 & 1.821 & 1.795 & 1.849 & 1.822 & 1.859 & 1.841 & 1.825 & 1.842 & 1.779 & 1.779 & 1.875 & 1.811 & 1.121 & 0.0076 \\
\hline 96 & 1.925 & 1.858 & 1.863 & 1.882 & 1.853 & 1.818 & 1.903 & 1.858 & 1.892 & 1.891 & 1.893 & 1.892 & 1.872 & 1.856 & 1.934 & 1.887 & 1.142 & \\
\hline 100 & & & & & & & & & & & & & & & & & & 0.0170 \\
\hline 101 & 1.886 & 1.834 & 1.820 & 1.847 & 1.807 & 1.760 & 1.823 & 1.796 & 1.834 & 1.825 & 1.828 & 1.829 & 1.845 & 1.849 & 1.914 & 1.869 & 1.080 & 0.0026 \\
\hline 103 & 1.867 & 1.819 & 1.837 & 1.841 & 1.785 & 1.740 & 1.818 & 1.781 & 1.817 & 1.789 & 1.802 & 1.803 & 1.854 & 1.858 & 1.923 & 1.878 & 1.107 & \\
\hline 105 & 1.835 & 1.796 & 1.766 & 1.799 & 1.750 & 1.726 & 1.761 & 1.746 & 1.759 & 1.739 & 1.743 & 1.747 & 1.811 & 1.852 & 1.826 & 1.830 & 1.080 & \\
\hline 107 & 1.811 & 1.753 & 1.767 & 1.777 & 1.718 & 1.677 & 1.738 & 1.711 & 1.730 & 1.693 & 1.713 & 1.712 & 1.796 & 1.828 & 1.826 & 1.817 & 1.042 & \\
\hline 109 & 1.819 & 1.776 & 1.760 & 1.785 & 1.704 & 1.700 & 1.724 & 1.709 & 1.716 & 1.705 & 1.690 & 1.704 & 1.830 & 1.851 & 1.866 & 1.849 & 1.052 & \\
\hline 111 & & & & & & & & & & & & & & & & & & 0.0067 \\
\hline 112 & 1.886 & 1.791 & 1.927 & 1.868 & 1.854 & 1.828 & 1.807 & 1.830 & 1.770 & 1.806 & 1.881 & 1.819 & 1.890 & 1.832 & 1.855 & 1.859 & 1.137 & 0.0364 \\
\hline 113 & & & & & & & & & & & & & & & & & & 0.0230 \\
\hline 114 & 1.869 & 1.798 & 1.898 & 1.855 & 1.808 & 1.798 & 1.825 & 1.810 & 1.756 & 1.803 & 1.862 & 1.807 & 1.861 & 1.839 & 1.832 & 1.844 & 1.159 & \\
\hline 116 & & & & & & & & & & & & & & & & & & 0.0654 \\
\hline 117 & & & & & & & & & & & & & & & & & & 0.0384 \\
\hline 121 & 1.964 & 1.921 & 1.913 & 1.932 & 1.921 & 1.794 & 1.962 & 1.892 & 1.948 & 1.957 & 1.939 & 1.948 & 1.916 & 1.867 & 1.830 & 1.871 & & 0.0312 \\
\hline
\end{tabular}


Profundidade $0,80 \mathrm{~m}$.

\begin{tabular}{|c|c|c|c|c|c|c|c|c|c|c|c|c|c|c|c|c|c|c|}
\hline \multirow[b]{2}{*}{ DAS } & \multicolumn{4}{|c|}{ tro } & \multicolumn{4}{|c|}{ tr1 } & \multicolumn{4}{|c|}{ tr2 } & \multicolumn{4}{|c|}{ tros } & \multirow{2}{*}{$\frac{\mathrm{t} 2}{\mathrm{r} 3-\mathrm{p}}$} & \multirow[b]{2}{*}{$\mathrm{P}+\mathrm{I}$} \\
\hline & $\mathrm{rl}$ & 12 & $\mathrm{r} 3$ & média & $\mathrm{rl}$ & 12 & $\mathrm{r} 3$ & média & $\mathrm{rl}$ & 12 & $\mathrm{r} 3$ & média & r1 & 12 & r3 & média & & \\
\hline 23 & 1.741 & 1.594 & 1.804 & 1.713 & 1.517 & 1.732 & 1.761 & 1.670 & 1.671 & 1.858 & & & 1.800 & 1.779 & 1.734 & 1.771 & 1.002 & \\
\hline 25 & 1.778 & 1.623 & 1.853 & 1.751 & 1.521 & 1.739 & 1.797 & 1.686 & 1.683 & 1.863 & & & 1.801 & 1.781 & 1.749 & 1.777 & 1.021 & \\
\hline 27 & 1.780 & 1.603 & 1.817 & 1.733 & 1.527 & 1.700 & 1.762 & 1.663 & 1.670 & 1.838 & & & 1.806 & 1.770 & 1.738 & 1.771 & 1.006 & \\
\hline 30 & 1.772 & 1.600 & 1.816 & 1.729 & 1.546 & 1.676 & 1.756 & 1.659 & 1.681 & 1.825 & 1.791 & 1.763 & 1.784 & 1.797 & 1.758 & 1.780 & 0.984 & \\
\hline 32 & 1.750 & 1.607 & 1.781 & 1.713 & 1.517 & 1.672 & 1.777 & 1.655 & 1.671 & 1.835 & 1.755 & 1.754 & 1.767 & 1.771 & 1.751 & 1.763 & & \\
\hline 34 & 1.808 & 1.635 & 1.808 & 1.750 & 1.559 & 1.680 & 1.771 & 1.670 & 1.691 & 1.878 & 1.756 & 1.775 & 1.787 & 1.788 & 1.780 & 1.785 & & 0.0005 \\
\hline 35 & & & & & & & & & & & & & & & & & & 0.0006 \\
\hline 37 & & & & & & & & & & & & & & & & & & 0.0266 \\
\hline 38 & 1.801 & 1.639 & 1.996 & 1.812 & 1.562 & 1.681 & 1.749 & 1.664 & 1.692 & 1.803 & 1.752 & 1.749 & 1.784 & 1.786 & 1.780 & 1.783 & & \\
\hline 41 & 1.803 & 1.660 & 1.773 & 1.745 & 1.557 & 1.664 & 1.757 & 1.659 & 1.685 & 1.823 & 1.726 & 1.745 & 1.789 & 1.786 & 1.761 & 1.779 & 0.951 & \\
\hline 44 & 1.760 & 1.624 & 1.688 & 1.691 & 1.522 & 1.631 & 1.721 & 1.625 & 1.657 & 1.790 & 1.712 & 1.720 & 1.737 & 1.768 & 1.779 & 1.762 & 0.958 & 0.0266 \\
\hline 46 & 1.819 & 1.623 & 1.691 & 1.711 & 1.531 & 1.625 & 1.717 & 1.624 & 1.656 & 1.768 & 1.731 & 1.718 & 1.773 & 1.752 & 1.772 & 1.766 & 0.938 & \\
\hline 47 & & & & & & & & & & & & & & & & & & 0.0038 \\
\hline 48 & 1.748 & 1.558 & 1.679 & 1.662 & 1.497 & 1.564 & 1.668 & 1.576 & 1.609 & 1.723 & 1.645 & 1.659 & 1.711 & 1.706 & 1.738 & 1.718 & 0.914 & \\
\hline 50 & & & & & & & & & & & & & & & & & & 0.0266 \\
\hline 51 & 1.800 & 1.592 & 1.698 & 1.696 & 1.525 & 1.597 & 1.730 & 1.617 & 1.659 & 1.746 & 1.679 & 1.695 & 1.762 & 1.787 & 1.800 & 1.783 & 0.941 & 0.0006 \\
\hline 53 & 1.820 & 1.599 & 1.704 & 1.708 & 1.525 & 1.576 & 1.704 & 1.602 & 1.659 & 1.714 & 1.695 & 1.689 & 1.789 & 1.784 & 1.838 & 1.804 & 0.936 & \\
\hline 54 & & & & & & & & & & & & & & & & & & 0.0055 \\
\hline 55 & 1.781 & 1.580 & 1.712 & 1.691 & 1.508 & 1.561 & 1.697 & 1.589 & 1.638 & 1.690 & 1.671 & 1.666 & 1.765 & 1.793 & 1.819 & 1.793 & 0.924 & 0.0002 \\
\hline 56 & 0.000 & 0.000 & 0.000 & 0.000 & 0.000 & 0.000 & 0.000 & 0.000 & 0.000 & 0.000 & 0.000 & 0.000 & 0.000 & 0.000 & 0.000 & 0.000 & & 0.0023 \\
\hline 58 & 1.769 & 1.571 & 1.685 & 1.675 & 1.494 & 1.537 & 1.677 & 1.569 & 1.628 & 1.663 & 1.658 & 1.650 & 1.752 & 1.784 & 1.847 & 1.794 & 0.906 & 0.0099 \\
\hline 60 & 1.767 & 1.583 & 1.673 & 1.674 & 1.520 & 1.511 & 1.662 & 1.564 & 1.614 & 1.679 & 1.644 & 1.645 & 1.759 & 1.795 & 1.859 & 1.804 & 0.914 & 0.0245 \\
\hline 61 & & & & & & & & & & & & & & & & & & 0.0366 \\
\hline 62 & 1.860 & 1.554 & 1.856 & 1.756 & 1.664 & 1.723 & 1.782 & 1.723 & 1.671 & 1.718 & 1.736 & 1.709 & 1.846 & 1.790 & 1.943 & 1.860 & 0.976 & 0.0191 \\
\hline 64 & & & & & & & & & & & & & & & & & & 0.0010 \\
\hline 65 & 1.893 & 1.674 & 1.846 & 1.804 & 1.767 & 1.728 & 1.837 & 1.777 & 1.836 & 1.787 & 1.796 & 1.806 & 1.873 & 1.841 & 1.940 & 1.885 & 0.989 & 0.0029 \\
\hline 66 & & & & & & & & & & & & & & & & & & 0.0053 \\
\hline 67 & 1.869 & 1.653 & 1.824 & 1.782 & 1.729 & 1.704 & 1.789 & 1.741 & 1.830 & 1.770 & 1.775 & 1.792 & 1.861 & 1.830 & 1.957 & 1.883 & 0.980 & \\
\hline 69 & 1.806 & 1.642 & 1.750 & 1.733 & 1.684 & 1.653 & 1.738 & 1.692 & 1.763 & 1.714 & 1.722 & 1.733 & 1.790 & 1.810 & 1.864 & 1.821 & 0.950 & 0.0375 \\
\hline 70 & & & & & & & & & & & & & & & & & & 0.0002 \\
\hline 71 & & & & & & & & & & & & & & & & & & 0.0007 \\
\hline 72 & 1.813 & 1.621 & 1.764 & 1.733 & 1.735 & 1.668 & 1.736 & 1.713 & 1.780 & 1.732 & 1.742 & 1.751 & 1.797 & 1.790 & 1.899 & 1.828 & 0.972 & \\
\hline 74 & 1.846 & 1.651 & 1.778 & 1.758 & 1.751 & 1.672 & 1.747 & 1.723 & 1.789 & 1.758 & 1.756 & 1.767 & 1.839 & 1.840 & 1.919 & 1.866 & 0.981 & 0.0042 \\
\hline 76 & 1.831 & 1.658 & 1.746 & 1.745 & 1.714 & 1.671 & 1.758 & 1.714 & 1.790 & 1.741 & 1.754 & 1.762 & 1.813 & 1.842 & 1.929 & 1.861 & 0.957 & \\
\hline 77 & & & & & & & & & & & & & & & & & & 0.0488 \\
\hline 78 & & & & & & & & & & & & & & & & & & 0.0231 \\
\hline 79 & 1.938 & 1.711 & 1.893 & 1.847 & 1.879 & 1.805 & 1.858 & 1.847 & 1.848 & 1.803 & 1.847 & 1.833 & 1.807 & 1.852 & 1.925 & 1.862 & 1.026 & 0.0020 \\
\hline 80 & & & & & & & & & & & & & & & & & & 0.0216 \\
\hline 81 & 1.921 & 1.764 & 1.908 & 1.864 & 1.851 & 1.814 & 1.876 & 1.847 & 1.923 & 1.819 & 1.862 & 1.868 & 1.800 & 1.867 & 1.906 & 1.858 & 1.014 & \\
\hline 82 & & & & & & & & & & & & & & & & & & 0.0083 \\
\hline 83 & 1.897 & 1.762 & 1.862 & 1.840 & 1.850 & 1.730 & 1.818 & 1.799 & 1.848 & 1.811 & 1.801 & 1.820 & 1.776 & 1.840 & 1.888 & 1.835 & 1.005 & 0.0387 \\
\hline 85 & 1.895 & 1.821 & 1.900 & 1.872 & 1.804 & 1.734 & 1.846 & 1.795 & 1.898 & 1.847 & 1.805 & 1.850 & 1.772 & 1.830 & 1.888 & 1.830 & 0.992 & \\
\hline 87 & 1.863 & 1.803 & 1.848 & 1.838 & 1.785 & 1.712 & 1.834 & 1.777 & 1.843 & 1.830 & 1.762 & 1.812 & 1.781 & 1.813 & 1.883 & 1.826 & 0.968 & \\
\hline 89 & 1.845 & 1.802 & 1.826 & 1.824 & 1.771 & 1.688 & 1.780 & 1.746 & 1.765 & 1.816 & 1.765 & 1.782 & 1.814 & 1.833 & 1.900 & 1.849 & 0.979 & \\
\hline 92 & 1.840 & 1.793 & 1.810 & 1.815 & 1.696 & 1.670 & 1.774 & 1.713 & 1.818 & 1.773 & 1.741 & 1.778 & 1.821 & 1.851 & 1.892 & 1.855 & 0.969 & 0.0072 \\
\hline 93 & & & & & & & & & & & & & & & & & & 0.0440 \\
\hline 94 & 1.829 & 1.776 & 1.828 & 1.811 & 1.782 & 1.694 & 1.794 & 1.757 & 1.832 & 1.754 & 1.722 & 1.769 & 1.737 & 1.777 & 1.810 & 1.775 & 0.974 & 0.0076 \\
\hline 96 & 1.880 & 1.823 & 1.865 & 1.856 & 1.819 & 1.731 & 1.810 & 1.787 & 1.859 & 1.822 & 1.773 & 1.818 & 1.786 & 1.826 & 1.885 & 1.832 & 0.992 & \\
\hline 100 & & & & & & & & & & & & & & & & & & 0.0170 \\
\hline 101 & 1.806 & 1.775 & 1.840 & 1.807 & 1.734 & 1.667 & 1.767 & 1.72 & 1.804 & 1.736 & 1.724 & 1.755 & 1.787 & 1.861 & 1.881 & 1.843 & 0.963 & 0.0026 \\
\hline 103 & 1.803 & 1.787 & 1.823 & 1.804 & 1.742 & 1.659 & 1.762 & 1.721 & 1.797 & 1.731 & 1.719 & 1.749 & 1.801 & 1.839 & 1.868 & 1.836 & 0.967 & \\
\hline 105 & 1.770 & 1.770 & 1.776 & 1.772 & 1.718 & 1.626 & 1.703 & 1.682 & 1.761 & 1.676 & 1.658 & 1.698 & 1.779 & 1.806 & 1.831 & 1.805 & 0.926 & \\
\hline 107 & 1.744 & 1.723 & 1.762 & 1.743 & 1.692 & 1.613 & 1.667 & 1.657 & 1.710 & 1.646 & 1.619 & 1.659 & 1.770 & 1.819 & 1.797 & 1.795 & 0.918 & \\
\hline 109 & 1.772 & 1.728 & 1.762 & 1.754 & 1.697 & 1.647 & 1.666 & 1.670 & 1.704 & 1.647 & 1.622 & 1.657 & 1.770 & 1.839 & 1.822 & 1.810 & 0.902 & \\
\hline 111 & & & & & & & & & & & & & & & & & & 0.0067 \\
\hline 112 & 1.779 & 1.734 & 1.900 & 1.804 & 1.742 & 1.689 & 1.680 & 1.703 & 1.691 & 1.690 & 1.713 & 1.698 & 1.805 & 1.828 & 1.813 & 1.815 & 0.974 & 0.0364 \\
\hline 113 & & & & & & & & & & & & & & & & & & 0.0230 \\
\hline 114 & 1.790 & 1.735 & 1.870 & 1.799 & 1.746 & 1.701 & 1.696 & 1.714 & 1.719 & 1.693 & 1.703 & 1.705 & 1.829 & 1.818 & 1.817 & 1.821 & 0.954 & \\
\hline 116 & & & & & & & & & & & & & & & & & & 0.0654 \\
\hline 117 & & & & & & & & & & & & & & & & & & 0.0384 \\
\hline 121 & 1.922 & 1.879 & 1.932 & 1.911 & 1.883 & 1.806 & 1.900 & 1.863 & 1.937 & 1.891 & 1.877 & 1.902 & 1.867 & 1.831 & 1.789 & 1.829 & & 0.0312 \\
\hline
\end{tabular}


Profundidade $0,90 \mathrm{~m}$.

\begin{tabular}{|c|c|c|c|c|c|c|c|c|c|c|c|c|c|c|c|c|c|c|}
\hline \multirow[b]{2}{*}{ DAS } & \multicolumn{4}{|c|}{ tro } & \multicolumn{4}{|c|}{ tr1 } & \multicolumn{4}{|c|}{ tr 2} & \multicolumn{4}{|c|}{ trbs } & \multirow{2}{*}{$\frac{\mathrm{t} 2 \mathrm{2}}{\mathrm{t} 3-\mathrm{p}}$} & \multirow[b]{2}{*}{$\mathrm{P}+\mathrm{I}$} \\
\hline & r1 & 12 & $\mathrm{r} 3$ & média & $\mathrm{r} 1$ & 12 & $r^{3}$ & média & r1 & 12 & r3 & média & $\mathrm{r} 1$ & $\mathrm{r} 2$ & r3 & média & & \\
\hline 23 & 1.579 & 1.529 & 1.670 & 1.593 & 1.465 & 1.551 & 1.558 & 1.525 & 1.614 & 1.785 & & & 1.772 & 1.751 & 1.686 & 1.736 & 1.169 & \\
\hline 25 & 1.622 & 1.555 & 1.807 & 1.661 & 1.499 & 1.556 & 1.608 & 1.554 & 1.615 & 1.797 & & & 1.767 & 1.764 & 1.705 & 1.745 & 1.172 & \\
\hline 27 & 1.638 & 1.526 & 1.753 & 1.639 & 1.462 & 1.531 & 1.595 & 1.529 & 1.600 & 1.783 & & & 1.759 & 1.751 & 1.672 & 1.727 & 1.224 & \\
\hline 30 & 1.657 & 1.547 & 1.740 & 1.648 & 1.481 & 1.529 & 1.595 & 1.535 & 1.618 & 1.767 & 1.757 & 1.714 & 1.756 & 1.765 & 1.705 & 1.742 & 1.138 & \\
\hline 32 & 1.627 & 1.525 & 1.755 & 1.636 & 1.469 & 1.507 & 1.619 & 1.532 & 1.603 & 1.779 & 1.682 & 1.688 & 1.771 & 1.757 & 1.701 & 1.743 & & \\
\hline 34 & 1.676 & 1.555 & 1.764 & 1.665 & 1.487 & 1.528 & 1.610 & 1.542 & 1.609 & 1.787 & 1.711 & 1.702 & 1.759 & 1.798 & 1.717 & 1.758 & & 0.0005 \\
\hline 35 & & & & & & & & & & & & & & & & & & 0.0006 \\
\hline 37 & & & & & & & & & & & & & & & & & & 0.0266 \\
\hline 38 & 1.674 & 1.572 & 1.736 & 1.661 & 1.501 & 1.494 & 1.609 & 1.535 & 1.618 & 1.760 & 1.698 & 1.692 & 1.772 & 1.760 & 1.725 & 1.752 & & \\
\hline 41 & 1.680 & 1.572 & 1.743 & 1.665 & 1.495 & 1.504 & 1.609 & 1.536 & 1.632 & 1.766 & 1.700 & 1.699 & 1.747 & 1.766 & 1.716 & 1.743 & 1.096 & \\
\hline 44 & 1.653 & 1.561 & 1.632 & 1.616 & 1.484 & 1.481 & 1.589 & 1.518 & 1.609 & 1.722 & 1.669 & 1.667 & 1.760 & 1.737 & 1.703 & 1.734 & 1.123 & 0.0266 \\
\hline 46 & 1.699 & 1.553 & 1.684 & 1.645 & 1.458 & 1.482 & 1.573 & 1.504 & 1.605 & 1.715 & 1.679 & 1.666 & 1.759 & 1.762 & 1.728 & 1.750 & 1.082 & \\
\hline 47 & & & & & & & & & & & & & & & & & & 0.0038 \\
\hline 48 & 1.662 & 1.509 & 1.642 & 1.604 & 1.432 & 1.476 & 1.524 & 1.477 & 1.560 & 1.649 & 1.607 & 1.605 & 1.708 & 1.692 & 1.684 & 1.695 & 1.065 & \\
\hline 50 & & & & & & & & & & & & & & & & & & 0.0266 \\
\hline 51 & 1.726 & 1.550 & 1.660 & 1.645 & 1.474 & 1.455 & 1.589 & 1.506 & 1.613 & 1.673 & 1.656 & 1.647 & 1.763 & 1.755 & 1.751 & 1.756 & 1.069 & 0.0006 \\
\hline 53 & 1.722 & 1.531 & 1.669 & 1.641 & 1.477 & 1.437 & 1.559 & 1.491 & 1.606 & 1.674 & 1.628 & 1.636 & 1.783 & 1.792 & 1.782 & 1.786 & 1.083 & \\
\hline 54 & & & & & & & & & & & & & & & & & & 0.0055 \\
\hline 55 & 1.701 & 1.525 & 1.654 & 1.627 & 1.444 & 1.450 & 1.555 & 1.483 & 1.590 & 1.626 & 1.640 & 1.619 & 1.750 & 1.759 & 1.787 & 1.765 & 1.119 & 0.0002 \\
\hline 56 & & & & & & & & & & & & & & & & & & 0.0023 \\
\hline 58 & 1.697 & 1.535 & 1.629 & 1.620 & 1.470 & 1.423 & 1.557 & 1.483 & 1.578 & 1.615 & 1.614 & 1.602 & 1.752 & 1.760 & 1.795 & 1.769 & 1.084 & 0.0099 \\
\hline 60 & 1.680 & 1.511 & 1.600 & 1.597 & 1.459 & 1.397 & 1.554 & 1.470 & 1.574 & 1.621 & 1.618 & 1.604 & 1.762 & 1.769 & 1.777 & 1.770 & 1.073 & 0.0245 \\
\hline 61 & & & & & & & & & & & & & & & & & & 0.0366 \\
\hline 62 & 1.745 & 1.503 & 1.802 & 1.684 & 1.511 & 1.543 & 1.634 & 1.563 & 1.582 & 1.620 & 1.611 & 1.604 & 1.821 & 1.764 & 1.907 & 1.831 & 1.098 & 0.0191 \\
\hline 64 & & & & & & & & & & & & & & & & & & 0.0010 \\
\hline 65 & 1.820 & 1.585 & 1.815 & 1.740 & 1.691 & 1.577 & 1.684 & 1.651 & 1.755 & 1.702 & 1.719 & 1.725 & 1.850 & 1.779 & 1.898 & 1.843 & 1.176 & 0.0029 \\
\hline 66 & & & & & & & & & & & & & & & & & & 0.0053 \\
\hline 67 & 1.784 & 1.592 & 1.780 & 1.719 & 1.677 & 1.569 & 1.633 & 1.626 & 1.713 & 1.692 & 1.728 & 1.711 & 1.816 & 1.795 & 1.883 & 1.832 & 1.144 & \\
\hline 69 & 1.742 & 1.520 & 1.723 & 1.662 & 1.624 & 1.491 & 1.617 & 1.577 & 1.708 & 1.665 & 1.654 & 1.676 & 1.781 & 1.763 & 1.814 & 1.786 & 1.120 & 0.0375 \\
\hline 70 & & & & & & & & & & & & & & & & & & 0.0002 \\
\hline 71 & & & & & & & & & & & & & & & & & & 0.0007 \\
\hline 72 & 1.765 & 1.557 & 1.712 & 1.678 & 1.637 & 1.505 & 1.582 & 1.575 & 1.835 & 1.658 & 1.654 & 1.715 & 1.790 & 1.766 & 1.824 & 1.793 & 1.092 & \\
\hline 74 & 1.772 & 1.595 & 1.727 & 1.698 & 1.661 & 1.503 & 1.604 & 1.590 & 1.718 & 1.687 & 1.692 & 1.699 & 1.829 & 1.815 & 1.874 & 1.839 & 1.134 & 0.0042 \\
\hline 76 & 1.754 & 1.595 & 1.734 & 1.694 & 1.683 & 1.505 & 1.595 & 1.594 & 1.688 & 1.679 & 1.686 & 1.684 & 1.811 & 1.806 & 1.869 & 1.829 & 1.119 & \\
\hline 77 & & & & & & & & & & & & & & & & & & 0.0488 \\
\hline 78 & & & & & & & & & & & & & & & & & & 0.0231 \\
\hline 79 & 1.893 & 1.597 & 1.868 & 1.786 & 1.772 & 1.657 & 1.662 & 1.697 & 1.792 & 1.718 & 1.772 & 1.761 & 1.811 & 1.805 & 1.841 & 1.819 & 1.204 & 0.0020 \\
\hline 80 & & & & & & & & & & & & & & & & & & 0.0216 \\
\hline 81 & 1.875 & 1.645 & 1.880 & 1.800 & 1.765 & 1.674 & 1.735 & 1.724 & 1.808 & 1.715 & 1.790 & 1.771 & 1.786 & 1.795 & 1.855 & 1.812 & 1.221 & \\
\hline 82 & & & & & & & & & & & & & & & & & & 0.0083 \\
\hline 83 & 1.815 & 1.675 & 1.840 & 1.777 & 1.754 & 1.602 & 1.691 & 1.682 & 1.810 & 1.741 & 1.748 & 1.767 & 1.795 & 1.806 & 1.846 & 1.816 & 1.165 & 0.0387 \\
\hline 85 & 1.819 & 1.771 & 1.832 & 1.807 & 1.746 & 1.609 & 1.701 & 1.686 & 1.830 & 1.810 & 1.743 & 1.794 & 1.789 & 1.781 & 1.827 & 1.799 & 1.162 & \\
\hline 87 & 1.794 & 1.725 & 1.814 & 1.778 & 1.720 & 1.573 & 1.651 & 1.648 & 1.791 & 1.771 & 1.718 & 1.760 & 1.791 & 1.774 & 1.832 & 1.799 & 1.158 & \\
\hline 89 & 1.762 & 1.726 & 1.799 & 1.763 & 1.702 & 1.572 & 1.652 & 1.642 & 1.784 & 1.768 & 1.680 & 1.744 & 1.790 & 1.793 & 1.837 & 1.807 & 1.141 & \\
\hline 92 & 1.767 & 1.717 & 1.770 & 1.751 & 1.691 & 1.536 & 1.653 & 1.627 & 1.758 & 1.709 & 1.676 & 1.714 & 1.802 & 1.807 & 1.847 & 1.819 & 1.121 & 0.0072 \\
\hline 93 & & & & & & & & & & & & & & & & & & 0.0440 \\
\hline 94 & 1.725 & 1.677 & 1.809 & 1.737 & 1.695 & 1.541 & 1.648 & 1.628 & 1.814 & 1.712 & 1.680 & 1.735 & 1.718 & 1.717 & 1.750 & 1.728 & 1.149 & 0.0076 \\
\hline 96 & 1.784 & 1.749 & 1.823 & 1.785 & 1.721 & 1.575 & 1.674 & 1.656 & 1.787 & 1.737 & 1.735 & 1.753 & 1.800 & 1.792 & 1.829 & 1.807 & 1.178 & \\
\hline 100 & & & & & & & & & & & & & & & & & & 0.0170 \\
\hline 101 & 1.743 & 1.702 & 1.782 & 1.742 & 1.678 & 1.541 & 1.646 & 1.622 & 1.742 & 1.707 & 1.678 & 1.709 & 1.788 & 1.809 & 1.826 & 1.808 & 1.142 & 0.0026 \\
\hline 103 & 1.759 & 1.703 & 1.769 & 1.744 & 1.691 & 1.533 & 1.611 & 1.612 & 1.765 & 1.673 & 1.662 & 1.700 & 1.780 & 1.807 & 1.818 & 1.801 & 1.114 & \\
\hline 105 & 1.689 & 1.702 & 1.747 & 1.713 & 1.639 & 1.497 & 1.602 & 1.579 & 1.722 & 1.643 & 1.623 & 1.663 & 1.770 & 1.798 & 1.806 & 1.791 & 1.106 & \\
\hline 107 & 1.703 & 1.663 & 1.709 & 1.692 & 1.619 & 1.470 & 1.563 & 1.551 & 1.669 & 1.628 & 1.587 & 1.628 & 1.761 & 1.766 & 1.773 & 1.767 & 1.093 & \\
\hline 109 & 1.712 & 1.690 & 1.728 & 1.710 & 1.630 & 1.487 & 1.492 & 1.536 & 1.661 & 1.622 & 1.592 & 1.625 & 1.772 & 1.788 & 1.787 & 1.782 & 1.115 & \\
\hline 111 & & & & & & & & & & & & & & & & & & 0.0067 \\
\hline 112 & 1.696 & 1.672 & 1.848 & 1.739 & 1.654 & 1.501 & 1.537 & 1.564 & 1.634 & 1.635 & 1.639 & 1.636 & 1.781 & 1.777 & 1.753 & 1.770 & 1.155 & 0.0364 \\
\hline 113 & & & & & & & & & & & & & & & & & & 0.0230 \\
\hline 114 & 1.681 & 1.657 & 1.799 & 1.712 & 1.721 & 1.527 & 1.568 & 1.605 & 1.642 & 1.605 & 1.619 & 1.622 & 1.777 & 1.788 & 1.773 & 1.779 & 1.121 & \\
\hline 116 & & & & & & & & & & & & & & & & & & 0.0654 \\
\hline 117 & & & & & & & & & & & & & & & & & & 0.0384 \\
\hline 121 & 1.857 & 1.798 & 1.878 & 1.845 & 1.786 & 1.660 & 1.757 & 1.734 & 1.863 & 1.812 & 1.783 & 1.820 & 1.859 & 1.796 & 1.747 & 1.801 & & 0.0312 \\
\hline
\end{tabular}


Profundidade $1,00 \mathrm{~m}$.

\begin{tabular}{|c|c|c|c|c|c|c|c|c|c|c|c|c|c|c|c|c|c|c|}
\hline \multirow[b]{2}{*}{ DAS } & \multicolumn{4}{|c|}{ tro } & \multicolumn{4}{|c|}{ tr1 } & \multicolumn{4}{|c|}{ tr2 } & \multicolumn{4}{|c|}{ trbs } & \multirow{2}{*}{$\frac{\mathrm{t} 2 \mathrm{2}}{\mathrm{r} 3-\mathrm{p}}$} & \multirow[b]{2}{*}{$\mathrm{P}+\mathrm{I}$} \\
\hline & r1 & 12 & $\mathrm{r} 3$ & média & $\mathrm{r} 1$ & 12 & r3 & média & $r 1$ & 12 & $\mathrm{r} 3$ & média & $\mathrm{r1}$ & 2 & $\mathrm{r} 3$ & média & & \\
\hline 23 & 1.529 & 1.510 & 1.625 & 1.555 & 1.474 & 1.487 & 1.511 & 1.491 & 1.562 & 1.689 & & & 1.753 & 1.621 & 1.643 & 1.672 & $\cdot 1.527$ & \\
\hline 25 & 1.566 & 1.530 & 1.684 & 1.593 & 1.470 & 1.512 & 1.557 & 1.513 & 1.610 & 1.722 & & & 1.751 & 1.655 & 1.653 & 1.686 & 1.517 & \\
\hline 27 & 1.551 & 1.504 & 1.652 & 1.569 & 1.462 & 1.491 & 1.539 & 1.498 & 1.580 & 1.700 & & & 1.748 & 1.628 & 1.638 & 1.671 & 1.495 & \\
\hline 30 & 1.590 & 1.516 & 1.645 & 1.584 & 1.468 & 1.479 & 1.560 & 1.502 & 1.591 & 1.695 & 1.745 & 1.677 & 1.728 & 1.623 & 1.647 & 1.666 & 1.483 & \\
\hline 32 & 1.586 & 1.496 & 1.639 & 1.574 & 1.454 & 1.480 & 1.559 & 1.497 & 1.574 & 1.680 & 1.627 & 1.627 & 1.732 & 1.611 & 1.645 & 1.663 & & \\
\hline 34 & 1.620 & 1.537 & 1.656 & 1.605 & 1.468 & 1.484 & 1.562 & 1.505 & 1.564 & 1.680 & 1.689 & 1.644 & 1.752 & 1.624 & 1.671 & 1.682 & & 0.0005 \\
\hline 35 & & & & & & & & & & & & & & & & & & 0.0006 \\
\hline 37 & & & & & & & & & & & & & & & & & & 0.0266 \\
\hline 38 & 1.596 & 1.549 & 1.640 & 1.595 & 1.477 & 1.471 & 1.581 & 1.510 & 1.581 & 1.695 & 1.683 & 1.653 & 1.763 & 1.619 & 1.654 & 1.679 & & \\
\hline 41 & 1.639 & 1.550 & 1.628 & 1.606 & 1.491 & 1.501 & 1.563 & 1.518 & 1.582 & 1.668 & 1.682 & 1.644 & 1.722 & 1.643 & 1.645 & 1.670 & 1.464 & \\
\hline 44 & 1.604 & 1.530 & 1.570 & 1.568 & 1.468 & 1.472 & 1.567 & 1.503 & 1.579 & 1.667 & 1.635 & 1.627 & 1.725 & 1.616 & 1.665 & 1.668 & 1.431 & 0.0266 \\
\hline 46 & 1.623 & 1.508 & 1.567 & 1.566 & 1.471 & 1.457 & 1.553 & 1.494 & 1.551 & 1.658 & 1.623 & 1.611 & 1.741 & 1.633 & 1.709 & 1.695 & 1.448 & \\
\hline 47 & & & & & & & & & & & & & & & & & & 0.0038 \\
\hline 48 & 1.529 & 1.462 & 1.543 & 1.511 & 1.439 & 1.420 & 1.504 & 1.454 & 1.516 & 1.607 & 1.577 & 1.567 & 1.695 & 1.560 & 1.632 & 1.629 & 1.405 & \\
\hline 50 & & & & & & & & & & & & & & & & & & 0.0266 \\
\hline 51 & 1.657 & 1.545 & 1.573 & 1.592 & 1.457 & 1.455 & 1.540 & 1.484 & 1.574 & 1.641 & 1.620 & 1.612 & 1.746 & 1.624 & 1.721 & 1.697 & 1.449 & 0.0006 \\
\hline 53 & 1.686 & 1.545 & 1.567 & 1.599 & 1.474 & 1.455 & 1.546 & 1.492 & 1.568 & 1.636 & 1.611 & 1.605 & 1.735 & 1.615 & 1.732 & 1.694 & 1.432 & \\
\hline 54 & & & & & & & & & & & & & & & & & & 0.0055 \\
\hline 55 & 1.638 & 1.533 & 1.580 & 1.583 & 1.455 & 1.430 & 1.525 & 1.470 & 1.547 & 1.619 & 1.617 & 1.594 & 1.751 & 1.615 & 1.716 & 1.694 & 1.449 & 0.0002 \\
\hline 56 & & & & & & & & & & & & & & & & & & 0.0023 \\
\hline 58 & 1.644 & 1.513 & 1.548 & 1.568 & 1.457 & 1.430 & 1.516 & 1.468 & 1.565 & 1.578 & 1.584 & 1.576 & 1.748 & 1.617 & 1.691 & 1.685 & 1.439 & 0.0099 \\
\hline 60 & 1.629 & 1.488 & 1.568 & 1.562 & 1.453 & 1.412 & 1.521 & 1.462 & 1.563 & 1.586 & 1.580 & 1.576 & 1.743 & 1.608 & 1.714 & 1.688 & 1.430 & 0.0245 \\
\hline 61 & & & & & & & & & & & & & & & & & & 0.0366 \\
\hline 62 & 1.665 & 1.488 & 1.639 & 1.597 & 1.481 & 1.712 & 1.599 & 1.597 & 1.540 & 1.585 & 1.580 & 1.569 & 1.781 & 1.591 & 1.829 & 1.733 & 1.444 & 0.0191 \\
\hline 64 & & & & & & & & & & & & & & & & & & 0.0010 \\
\hline 65 & 1.775 & 1.532 & 1.707 & 1.672 & 1.633 & 1.582 & 1.637 & 1.617 & 1.661 & 1.627 & 1.681 & 1.656 & 1.813 & 1.614 & 1.806 & 1.744 & 1.502 & 0.0029 \\
\hline 66 & & & & & & & & & & & & & & & & & & 0.0053 \\
\hline 67 & 1.765 & 1.548 & 1.686 & $1.666^{\circ}$ & 1.628 & 1.553 & 1.624 & 1.602 & 1.669 & 1.626 & 1.671 & 1.656 & 1.799 & 1.633 & 1.790 & 1.740 & 1.496 & \\
\hline 69 & 1.689 & 1.522 & 1.632 & 1.614 & 1.578 & 1.483 & 1.565 & 1.542 & 1.623 & 1.596 & 1.614 & 1.611 & 1.756 & 1.585 & 1.772 & 1.704 & 1.420 & 0.0375 \\
\hline 70 & & & & & & & & & & & & & & & & & & 0.0002 \\
\hline 71 & & & & & & & & & & & & & & & & & & 0.0007 \\
\hline 72 & 1.707 & 1.520 & 1.612 & 1.613 & 1.615 & 1.496 & 1.557 & 1.556 & 1.617 & 1.601 & 1.607 & 1.608 & 1.768 & 1.597 & 1.754 & 1.706 & 1.437 & \\
\hline 74 & 1.723 & 1.556 & 1.607 & 1.629 & 1.619 & 1.497 & 1.575 & 1.564 & 1.657 & 1.624 & 1.626 & 1.635 & 1.773 & 1.640 & 1.794 & 1.735 & 1.478 & 0.0042 \\
\hline 76 & 1.714 & 1.538 & 1.609 & 1.621 & 1.622 & 1.506 & 1.552 & 1.560 & 1.643 & 1.616 & 1.642 & 1.634 & 1.782 & 1.636 & 1.779 & 1.732 & 1.461 & \\
\hline 77 & & & & & & & & & & & & & & & & & & 0.0488 \\
\hline 78 & & & & & & & & & & & & & & & & & & 0.0231 \\
\hline 79 & 1.805 & 1.570 & 1.728 & 1.701 & 1.739 & 1.606 & 1.616 & 1.654 & 1.716 & 1.617 & 1.735 & 1.689 & 1.783 & 1.645 & 1.777 & 1.735 & 1.562 & 0.0020 \\
\hline 80 & & & & & & & & & & & & & & & & & & 0.0216 \\
\hline 81 & 1.804 & 1.570 & 1.772 & 1.715 & 1.720 & 1.639 & 1.679 & 1.680 & 1.763 & 1.627 & 1.747 & 1.713 & 1.743 & 1.643 & 1.770 & 1.718 & 1.583 & \\
\hline 82 & & & & & & & & & & & & & & & & & & 0.0083 \\
\hline 83 & 1.776 & 1.630 & 1.735 & 1.713 & 1.708 & 1.604 & 1.639 & 1.650 & 1.746 & 1.660 & 1.709 & 1.705 & 1.777 & 1.653 & 1.756 & 1.729 & 1.529 & 0.0387 \\
\hline 85 & 1.777 & 1.727 & 1.724 & 1.743 & 1.724 & 1.614 & 1.691 & 1.677 & 1.824 & 1.740 & 1.703 & 1.756 & 1.744 & 1.634 & 1.746 & 1.708 & 1.530 & \\
\hline 87 & 1.762 & 1.684 & 1.718 & 1.721 & 1.666 & 1.565 & 1.660 & 1.630 & 1.765 & 1.693 & 1.683 & 1.713 & 1.745 & 1.633 & 1.758 & 1.712 & 1.490 & \\
\hline 89 & 1.750 & 1.697 & 1.713 & 1.720 & 1.662 & 1.548 & 1.654 & 1.621 & 1.771 & 1.701 & 1.681 & 1.718 & 1.751 & 1.633 & 1.770 & 1.718 & 1.485 & \\
\hline 92 & 1.737 & 1.694 & 1.684 & 1.705 & 1.679 & 1.558 & 1.606 & 1.614 & 1.738 & 1.671 & 1.650 & 1.686 & 1.774 & 1.642 & 1.742 & 1.719 & 1.466 & 0.0072 \\
\hline 93 & & & & & & & & & & & & & & & & & & 0.0440 \\
\hline 94 & 1.682 & 1.656 & 1.709 & 1.682 & 1.636 & 1.538 & 1.607 & 1.594 & 1.707 & 1.604 & 1.643 & 1.651 & 1.709 & 1.648 & 1.681 & 1.679 & 1.498 & 0.0076 \\
\hline 96 & 1.731 & 1.708 & 1.723 & 1.721 & 1.674 & 1.570 & 1.674 & 1.639 & 1.763 & 1.672 & 1.681 & 1.705 & 1.762 & 1.640 & 1.758 & 1.720 & 1.524 & \\
\hline 100 & & & & & & & & & & & & & & & & & & 0.0170 \\
\hline 101 & 1.688 & 1.683 & 1.677 & 1.683 & 1.654 & 1.531 & 1.636 & 1.607 & 1.731 & 1.640 & 1.635 & 1.669 & 1.757 & 1.650 & 1.745 & 1.717 & 1.478 & 0.0026 \\
\hline 103 & 1.694 & 1.688 & 1.686 & 1.690 & 1.647 & 1.544 & 1.594 & 1.595 & 1.715 & 1.652 & 1.632 & 1.667 & 1.772 & 1.646 & 1.744 & 1.721 & 1.468 & \\
\hline 105 & 1.612 & 1.651 & 1.631 & 1.631 & 1.612 & 1.512 & 1.577 & 1.567 & 1.682 & 1.598 & 1.603 & 1.628 & 1.742 & 1.624 & 1.730 & 1.699 & 1.438 & \\
\hline 107 & 1.655 & 1.651 & 1.626 & 1.644 & 1.615 & 1.490 & 1.552 & 1.552 & 1.636 & 1.588 & 1.579 & 1.601 & 1.727 & 1.604 & 1.701 & 1.677 & 1.436 & \\
\hline 109 & 1.673 & 1.641 & 1.607 & 1.640 & 1.627 & 1.490 & 1.531 & 1.550 & 1.651 & 1.584 & 1.569 & 1.601 & 1.763 & 1.608 & 1.723 & 1.698 & 1.455 & \\
\hline 111 & & & & & & & & & & & & & & & & & & 0.0067 \\
\hline 112 & 1.665 & 1.637 & 1.710 & 1.671 & 1.627 & 1.495 & 1.525 & 1.549 & 1.621 & 1.601 & 1.601 & 1.608 & 1.781 & 1.634 & 1.706 & 1.707 & 1.461 & 0.0364 \\
\hline 113 & & & & & & & & & & & & & & & & & & 0.0230 \\
\hline 114 & 1.653 & 1.637 & 1.697 & 1.662 & 1.621 & 1.531 & 1.517 & 1.556 & 1.609 & 1.577 & 1.563 & 1.583 & 1.786 & 1.656 & 1.702 & 1.715 & 1.477 & \\
\hline 116 & & & & & & & & & & & & & & & & & & 0.0654 \\
\hline 117 & & & & & & & & & & & & & & & & & & 0.0384 \\
\hline 121 & 1.802 & 1.759 & 1.799 & 1.786 & 1.732 & 1.673 & 1.730 & 1.712 & 1.823 & 1.741 & 1.745 & 1.770 & 1.837 & 1.619 & 1.682 & 1.712 & & 0.0312 \\
\hline
\end{tabular}


Profundidade $1,10 \mathrm{~m}$.

\begin{tabular}{|c|c|c|c|c|c|c|c|c|c|c|c|c|c|c|c|c|c|c|}
\hline \multirow[b]{2}{*}{ DAS } & \multicolumn{4}{|c|}{ tro } & \multicolumn{4}{|c|}{ tr1 } & \multicolumn{4}{|c|}{$t=2$} & \multicolumn{4}{|c|}{ trbs } & \multirow{2}{*}{$\frac{t+2}{r 3-p}$} & \multirow[b]{2}{*}{ P+I } \\
\hline & $\mathrm{rl}$ & 12 & $\mathrm{r} 3$ & média & $\mathrm{rl}$ & 12 & $\mathrm{r}^{3}$ & média & $\mathrm{rl}$ & 12 & $\mathrm{r} 3$ & média & $\mathrm{r} 1$ & 12 & $r^{3}$ & média & & \\
\hline 23 & 1.531 & 1.533 & 1.615 & 1.560 & 1.437 & 1.464 & 1.520 & 1.474 & 1.532 & 1.659 & & & 1.674 & 1.510 & 1.582 & 1.589 & 1.560 & \\
\hline 25 & 1.532 & 1.545 & 1.662 & 1.580 & 1.445 & 1.488 & 1.549 & 1.494 & 1.563 & 1.703 & & & 1.706 & 1.508 & 1.604 & 1.606 & 1.557 & \\
\hline 27 & 1.512 & 1.508 & 1.632 & 1.551 & 1.427 & 1.468 & 1.512 & 1.469 & 1.517 & 1.643 & & & 1.683 & 1.492 & 1.587 & 1.587 & 1.500 & \\
\hline 30 & 1.555 & 1.550 & 1.635 & 1.580 & 1.437 & 1.499 & 1.535 & 1.490 & 1.546 & 1.673 & 1.706 & 1.642 & 1.692 & 1.482 & 1.606 & 1.593 & 1.519 & \\
\hline 32 & 1.514 & 1.505 & 1.604 & 1.541 & 1.406 & 1.478 & 1.516 & 1.467 & 1.522 & 1.653 & 1.617 & 1.597 & 1.703 & 1.479 & 1.618 & 1.600 & & \\
\hline 34 & 1.550 & 1.555 & 1.627 & 1.577 & 1.459 & 1.524 & 1.577 & 1.520 & 1.549 & 1.680 & 1.630 & 1.620 & 1.722 & 1.490 & 1.623 & 1.611 & & 0.0005 \\
\hline 35 & & & & & & & & & & & & & & & & & & 0.0006 \\
\hline 37 & & & & & & & & & & & & & & & & & & 0.0266 \\
\hline 38 & 1.563 & 1.547 & 1.660 & 1.590 & 1.449 & 1.501 & 1.554 & 1.501 & 1.554 & 1.658 & 1.627 & 1.613 & 1.686 & 1.513 & 1.602 & 1.600 & & \\
\hline 41 & 1.560 & 1.554 & 1.627 & 1.580 & 1.458 & 1.501 & 1.551 & 1.504 & 1.558 & 1.654 & 1.625 & 1.612 & 1.704 & 1.480 & 1.634 & 1.606 & 1.505 & \\
\hline 44 & 1.551 & 1.554 & 1.595 & 1.567 & 1.409 & 1.495 & 1.534 & 1.479 & 1.523 & 1.648 & 1.602 & 1.591 & 1.667 & 1.462 & 1.611 & 1.580 & 1.496 & 0.0266 \\
\hline 46 & 1.567 & 1.515 & 1.583 & 1.555 & 1.430 & 1.485 & 1.528 & 1.481 & 1.545 & 1.631 & 1.600 & 1.592 & 1.692 & 1.465 & 1.671 & 1.609 & 1.515 & \\
\hline 47 & & & & & & & & & & & & & & & & & & 0.0038 \\
\hline 48 & 1.487 & 1.497 & 1.547 & 1.510 & 1.412 & 1.440 & 1.500 & 1.451 & 1.498 & 1.574 & 1.537 & 1.537 & 1.652 & 1.433 & 1.612 & 1.566 & 1.443 & \\
\hline 50 & & & & & & & & & & & & & & & & & & 0.0266 \\
\hline 51 & 1.579 & 1.542 & 1.600 & 1.574 & 1.437 & 1.497 & 1.533 & 1.489 & 1.540 & 1.724 & 1.588 & 1.617 & 1.695 & 1.479 & 1.655 & 1.610 & 1.523 & 0.0006 \\
\hline 53 & 1.585 & 1.550 & 1.571 & 1.568 & 1.439 & 1.500 & 1.514 & 1.484 & 1.528 & 1.623 & 1.589 & 1.580 & 1.702 & 1.485 & 1.684 & 1.624 & 1.475 & \\
\hline 54 & & & & & & & & & & & & & & & & & & 0.0055 \\
\hline 55 & 1.589 & 1.536 & 1.589 & 1.571 & 1.430 & 1.469 & 1.532 & 1.477 & 1.531 & 1.554 & 1.576 & 1.554 & 1.710 & 1.485 & 1.656 & 1.617 & 1.477 & 0.0002 \\
\hline 56 & & & & & & & & & & & & & & & & & & 0.0023 \\
\hline 58 & 1.614 & 1.527 & 1.554 & 1.565 & 1.432 & 1.458 & 1.523 & 1.471 & 1.543 & 1.623 & 1.578 & 1.581 & 1.706 & 1.476 & 1.645 & 1.609 & 1.454 & 0.0099 \\
\hline 60 & 1.596 & 1.527 & 1.565 & 1.563 & 1.423 & 1.455 & 1.496 & 1.458 & 1.524 & 1.603 & 1.569 & 1.565 & 1.708 & 1.473 & 1.638 & 1.606 & 1.480 & 0.0245 \\
\hline 61 & & & & & & & & & & & & & & & & & & 0.0366 \\
\hline 62 & 1.595 & 1.532 & 1.570 & 1.566 & 1.435 & 1.516 & 1.507 & 1.486 & 1.513 & 1.597 & 1.558 & 1.556 & 1.765 & 1.486 & 1.717 & 1.656 & 1.464 & 0.0191 \\
\hline 64 & & & & & & & & & & & & & & & & & & 0.0010 \\
\hline 65 & 1.703 & 1.537 & 1.675 & 1.638 & 1.565 & 1.588 & 1.619 & 1.591 & 1.600 & 1.635 & 1.632 & 1.622 & 1.750 & 1.503 & 1.762 & 1.67 & 1.497 & 0.0029 \\
\hline 66 & & & & & & & & & & & & & & & & & & 0.0053 \\
\hline 67 & 1.681 & 1.551 & 1.673 & 1.635 & 1.551 & 1.562 & 1.602 & 1.572 & 1.602 & 1.618 & 1.625 & 1.615 & 1.751 & 1.501 & 1.750 & 1.668 & 1.492 & \\
\hline 69 & 1.644 & 1.516 & 1.602 & 1.587 & 1.490 & 1.517 & 1.575 & 1.527 & 1.558 & 1.588 & 1.570 & 1.572 & 1.717 & 1.468 & 1.667 & 1.617 & 1.466 & 0.0375 \\
\hline 70 & & & & & & & & & & & & & & & & & & 0.0002 \\
\hline 71 & & & & & & & & & & & & & & & & & & 0.0007 \\
\hline 72 & 1.631 & 1.534 & 1.597 & 1.587 & 1.535 & 1.518 & 1.549 & 1.534 & 1.573 & 1.582 & 1.583 & 1.579 & 1.721 & 1.463 & 1.680 & 1.621 & 1.470 & \\
\hline 74 & 1.667 & 1.559 & 1.610 & 1.612 & 1.556 & 1.532 & 1.579 & 1.556 & 1.591 & 1.619 & 1.617 & 1.609 & 1.744 & 1.471 & 1.707 & 1.641 & 1.493 & 0.0042 \\
\hline 76 & 1.662 & 1.551 & 1.611 & 1.608 & 1.565 & 1.533 & 1.557 & 1.552 & 1.592 & 1.602 & 1.602 & 1.599 & 1.755 & 1.503 & 1.711 & 1.657 & 1.493 & \\
\hline 77 & & & & & & & & & & & & & & & & & & 0.0488 \\
\hline 78 & & & & & & & & & & & & & & & & & & 0.0231 \\
\hline 79 & 1.729 & 1.556 & 1.696 & 1.660 & 1.637 & 1.598 & 1.590 & 1.609 & 1.643 & 1.632 & 1.653 & 1.643 & 1.747 & 1.511 & 1.699 & 1.652 & 1.576 & 0.0020 \\
\hline 80 & & & & & & & & & & & & & & & & & & 0.0216 \\
\hline 81 & 1.720 & 1.596 & 1.717 & 1.677 & 1.621 & 1.649 & 1.617 & 1.629 & 1.690 & 1.642 & 1.718 & 1.683 & 1.767 & 1.504 & 1.685 & 1.652 & 1.604 & \\
\hline 82 & & & & & & & & & & & & & & & & & & 0.0083 \\
\hline 83 & 1.701 & 1.632 & 1.707 & 1.680 & 1.633 & 1.623 & 1.622 & 1.626 & 1.692 & 1.659 & 1.684 & 1.678 & 1.705 & 1.484 & 1.666 & 1.619 & 1.539 & 0.0387 \\
\hline 85 & 1.713 & 1.698 & 1.721 & 1.710 & 1.642 & 1.647 & 1.704 & 1.664 & 1.755 & 1.695 & 1.688 & 1.713 & 1.737 & 1.502 & 1.685 & 1.642 & 1.564 & \\
\hline 87 & 1.707 & 1.699 & 1.703 & 1.703 & 1.616 & 1.625 & 1.636 & 1.626 & 1.712 & 1.674 & 1.662 & 1.682 & 1.719 & 1.484 & 1.673 & 1.626 & 1.550 & \\
\hline 89 & 1.706 & 1.700 & 1.705 & 1.703 & 1.626 & 1.607 & 1.644 & 1.626 & 1.705 & 1.669 & 1.662 & 1.679 & 1.725 & 1.491 & 1.675 & 1.630 & 1.550 & \\
\hline 92 & 1.674 & 1.689 & 1.663 & 1.676 & 1.563 & 1.665 & 1.635 & 1.621 & 1.720 & 1.664 & 1.649 & 1.678 & 1.748 & 1.515 & 1.679 & 1.648 & 1.503 & 0.0072 \\
\hline 93 & & & & & & & & & & & & & & & & & & 0.0440 \\
\hline 94 & 1.623 & 1.630 & 1.659 & 1.638 & 1.556 & 1.570 & 1.588 & 1.571 & 1.624 & 1.619 & 1.606 & 1.616 & 1.659 & 1.435 & 1.638 & 1.577 & 1.502 & 0.0076 \\
\hline 96 & 1.676 & 1.719 & 1.723 & 1.706 & 1.591 & 1.618 & 1.615 & 1.608 & 1.705 & 1.674 & 1.662 & 1.680 & 1.725 & 1.485 & 1.689 & 1.633 & 1.539 & \\
\hline 100 & & & & & & & & & & & & & & & & & & 0.0170 \\
\hline 101 & 1.679 & 1.689 & 1.673 & 1.681 & 1.575 & 1.578 & 1.599 & 1.584 & 1.659 & 1.633 & 1.613 & 1.635 & 1.716 & 1.512 & 1.668 & 1.632 & 1.514 & 0.0026 \\
\hline 103 & 1.668 & 1.696 & 1.678 & 1.681 & 1.590 & 1.590 & 1.603 & 1.594 & 1.748 & 1.619 & 1.613 & 1.660 & 1.725 & 1.530 & 1.651 & 1.635 & 1.517 & \\
\hline 105 & 1.650 & 1.656 & 1.651 & 1.652 & 1.587 & 1.557 & 1.574 & 1.573 & 1.645 & 1.613 & 1.577 & 1.612 & 1.707 & 1.496 & 1.656 & 1.620 & 1.482 & \\
\hline 107 & 1.613 & 1.641 & 1.643 & 1.632 & 1.544 & 1.556 & 1.550 & 1.550 & 1.623 & 1.584 & 1.570 & 1.592 & 1.706 & 1.469 & 1.648 & 1.608 & 1.467 & \\
\hline 109 & 1.640 & 1.656 & 1.640 & 1.646 & 1.567 & 1.544 & 1.554 & 1.555 & 1.602 & 1.608 & 1.551 & 1.587 & 1.711 & 1.500 & 1.648 & 1.619 & 1.460 & \\
\hline 111 & & & & & & & & & & & & & & & & & & 0.0067 \\
\hline 112 & 1.634 & 1.652 & 1.652 & 1.646 & 1.531 & 1.546 & 1.533 & 1.537 & 1.598 & 1.606 & 1.586 & 1.597 & 1.724 & 1.521 & 1.627 & 1.624 & 1.464 & 0.0364 \\
\hline 113 & & & & & & & & & & & & & & & & & & 0.0230 \\
\hline 114 & 1.614 & 1.652 & 1.670 & 1.645 & 1.551 & 1.558 & 1.532 & 1.347 & 1.595 & 1.564 & 1.539 & 1.566 & 1.718 & 1.492 & 1.632 & 1.614 & 1.454 & \\
\hline 116 & & & & & & & & & & & & & & & & & & 0.0654 \\
\hline 117 & & & & & & & & & & & & & & & & & & 0.0384 \\
\hline 121 & 1.752 & 1.771 & 1.779 & 1.768 & 1.663 & 1.692 & 1.717 & 1.691 & 1.755 & 1.734 & 1.709 & 1.733 & 1.721 & 1.495 & 1.645 & 1.620 & & 0.0312 \\
\hline
\end{tabular}


Profundidade $1,20 \mathrm{~m}$.

\begin{tabular}{|c|c|c|c|c|c|c|c|c|c|c|c|c|c|c|c|c|c|c|}
\hline \multirow[b]{2}{*}{ DAS } & \multicolumn{4}{|c|}{ tro } & \multicolumn{4}{|c|}{ tr1 } & \multicolumn{4}{|c|}{$\operatorname{tr} 2$} & \multicolumn{4}{|c|}{ trbs } & \multirow{2}{*}{$\frac{t 2}{r 3-p}$} & \multirow[b]{2}{*}{$\mathrm{P}+\mathrm{I}$} \\
\hline & r1 & 12 & r3 & média & rl & 12 & r3 & média & r1 & 12 & r3 & média & $\mathrm{r} 1$ & $\mathrm{r} 2$ & r3 & média & & \\
\hline 23 & 1.523 & 1.663 & 1.622 & 1.602 & 1.413 & 1.439 & 1.609 & 1.487 & 1.552 & 1.674 & & & 1.670 & 1.460 & 1.575 & 1.568 & 1.461 & \\
\hline 25 & 1.532 & 1.692 & 1.634 & 1.619 & 1.415 & 1.466 & 1.646 & 1.509 & 1.567 & 1.699 & & & 1.700 & 1.457 & 1.592 & 1.583 & 1.461 & \\
\hline 27 & 1.496 & 1.663 & 1.607 & 1.589 & 1.426 & 1.466 & 1.604 & 1.499 & 1.573 & 1.665 & & & 1.670 & 1.439 & 1.560 & 1.556 & 1.431 & \\
\hline 30 & 1.517 & 1.680 & 1.637 & 1.612 & 1.407 & 1.453 & 1.624 & 1.495 & 1.563 & 1.685 & 1.707 & 1.651 & 1.688 & 1.436 & 1.578 & 1.568 & 1.419 & \\
\hline 32 & 1.511 & 1.673 & 1.601 & 1.595 & 1.416 & 1.451 & 1.607 & 1.492 & 1.532 & 1.651 & 1.623 & 1.602 & 1.681 & 1.445 & 1.613 & 1.580 & & \\
\hline 34 & 1.542 & 1.682 & 1.634 & 1.619 & 1.411 & 1.479 & 1.639 & 1.510 & 1.565 & 1.666 & 1.633 & 1.621 & 1.677 & 1.467 & 1.609 & 1.584 & & 0.0005 \\
\hline 35 & & & & & & & & & & & & & & & & & & 0.0006 \\
\hline 37 & & & & & & & & & & & & & & & & & & 0.0266 \\
\hline 38 & 1.532 & 1.699 & 1.633 & 1.622 & 1.412 & 1.482 & 1.635 & 1.510 & 1.559 & 1.674 & 1.625 & 1.619 & 1.683 & 1.457 & 1.623 & 1.587 & & \\
\hline 41 & 1.551 & 1.686 & 1.634 & 1.623 & 1.426 & 1.479 & 1.642 & 1.515 & 1.556 & 1.670 & 1.633 & 1.620 & 1.684 & 1.452 & 1.612 & 1.583 & 1.396 & \\
\hline 44 & 1.520 & 1.680 & 1.590 & 1.597 & 1.420 & 1.471 & 1.616 & 1.502 & 1.541 & 1.674 & 1.613 & 1.609 & 1.680 & 1.454 & 1.586 & 1.573 & 1.407 & 0.0266 \\
\hline 46 & 1.545 & 1.665 & 1.617 & 1.609 & 1.406 & 1.490 & 1.597 & 1.498 & 1.554 & 1.651 & 1.599 & 1.601 & 1.676 & 1.434 & 1.658 & 1.589 & 1.392 & \\
\hline 47 & & & & & & & & & & & & & & & & & & 0.0038 \\
\hline 48 & 1.446 & 1.614 & 1.551 & 1.537 & 1.371 & 1.427 & 1.567 & 1.455 & 1.490 & 1.666 & 1.548 & 1.568 & 1.653 & 1.382 & 1.611 & 1.549 & 1.324 & \\
\hline 50 & & & & & & & & & & & & & & & & & & 0.0266 \\
\hline 51 & 1.560 & 1.694 & 1.610 & 1.621 & 1.398 & 1.475 & 1.624 & 1.499 & 1.555 & 1.659 & 1.602 & 1.605 & 1.697 & 1.456 & 1.653 & 1.602 & 1.381 & 0.0006 \\
\hline 53 & 1.564 & 1.681 & 1.611 & 1.618 & 1.426 & 1.491 & 1.606 & 1.508 & 1.534 & 1.634 & 1.601 & 1.590 & 1.687 & 1.438 & 1.654 & 1.593 & 1.378 & \\
\hline 54 & & & & & & & & & & & & & & & & & & 0.0055 \\
\hline 55 & 1.540 & 1.694 & 1.615 & 1.616 & 1.387 & 1.474 & 1.618 & 1.493 & 1.540 & 1.618 & 1.578 & 1.578 & 1.684 & 1.438 & 1.662 & 1.595 & 1.375 & 0.0002 \\
\hline 56 & & & & & & & & & & & & & & & & & & 0.0023 \\
\hline 58 & 1.547 & 1.684 & 1.581 & 1.604 & 1.411 & 1.462 & 1.602 & 1.492 & 1.548 & 1.636 & 1.576 & 1.587 & 1.685 & 1.445 & 1.644 & 1.591 & 1.365 & 0.0099 \\
\hline 60 & 1.566 & 1.662 & 1.570 & 1.599 & 1.384 & 1.478 & 1.607 & 1.490 & 1.540 & 1.634 & 1.579 & 1.584 & 1.684 & 1.448 & 1.626 & 1.586 & 1.368 & 0.0245 \\
\hline 61 & & & & & & & & & & & & & & & & & & 0.0366 \\
\hline 62 & 1.579 & 1.679 & 1.579 & 1.613 & 1.384 & 1.499 & 1.598 & 1.494 & 1.526 & 1.608 & 1.572 & 1.569 & 1.749 & 1.435 & 1.624 & 1.602 & 1.366 & 0.0191 \\
\hline 64 & & & & & & & & & & & & & & & & & & 0.0010 \\
\hline 65 & 1.644 & 1.704 & 1.662 & 1.670 & 1.485 & 1.560 & 1.701 & 1.582 & 1.590 & 1.662 & 1.617 & 1.623 & 1.728 & 1.463 & 1.684 & 1.625 & 1.396 & 0.0029 \\
\hline 66 & & & & & & & & & & & & & & & & & & 0.0053 \\
\hline 67 & 1.641 & 1.687 & 1.641 & 1.656 & 1.489 & 1.541 & 1.673 & 1.568 & 1.614 & 1.657 & 1.594 & 1.622 & 1.732 & 1.442 & 1.687 & 1.620 & 1.385 & \\
\hline 69 & 1.589 & 1.658 & 1.616 & 1.621 & 1.445 & 1.502 & 1.614 & 1.520 & 1.541 & 1.620 & 1.573 & 1.578 & 1.684 & 1.421 & 1.648 & 1.584 & 1.374 & 0.0375 \\
\hline 70 & & & & & & & & & & & & & & & & & & 0.0002 \\
\hline 71 & & & & & & & & & & & & & & & & & & 0.0007 \\
\hline 72 & 1.603 & 1.643 & 1.601 & 1.616 & 1.468 & 1.499 & 1.632 & 1.533 & 1.561 & 1.605 & 1.563 & 1.576 & 1.695 & 1.428 & 1.621 & 1.582 & 1.372 & \\
\hline 74 & 1.628 & 1.699 & 1.611 & 1.646 & 1.475 & 1.542 & 1.653 & 1.557 & 1.582 & 1.620 & 1.608 & 1.603 & 1.725 & 1.448 & 1.650 & 1.607 & 1.384 & 0.0042 \\
\hline 76 & 1.614 & 1.706 & 1.621 & 1.647 & 1.499 & 1.521 & 1.643 & 1.554 & 1.594 & 1.628 & 1.599 & 1.607 & 1.725 & 1.450 & 1.675 & 1.617 & 1.384 & \\
\hline 77 & & & & & & & & & & & & & & & & & & 0.0488 \\
\hline 78 & & & & & & & & & & & & & & & & & & 0.0231 \\
\hline 79 & 1.689 & 1.713 & 1.671 & 1.691 & 1.540 & 1.544 & 1.641 & 1.575 & 1.613 & 1.645 & 1.655 & 1.638 & 1.748 & 1.458 & 1.679 & 1.628 & 1.440 & 0.0020 \\
\hline 80 & & & & & & & & & & & & & & & & & & 0.0216 \\
\hline 81 & 1.701 & 1.692 & 1.705 & 1.699 & 1.572 & 1.626 & 1.682 & 1.627 & 1.662 & 1.655 & 1.702 & 1.673 & 1.735 & 1.449 & 1.634 & 1.606 & 1.462 & \\
\hline 82 & & & & & & & & & & & & & & & & & & 0.0083 \\
\hline 83 & 1.682 & 1.740 & 1.704 & 1.709 & 1.581 & 1.613 & 1.674 & 1.623 & 1.676 & 1.665 & 1.678 & 1.673 & 1.703 & 1.445 & 1.651 & 1.599 & 1.461 & 0.0387 \\
\hline 85 & 1.734 & 1.813 & 1.774 & 1.774 & 1.619 & 1.671 & 1.825 & 1.705 & 1.719 & 1.719 & 1.703 & 1.714 & 1.723 & 1.472 & 1.664 & 1.620 & 1.484 & \\
\hline 87 & 1.662 & 1.827 & 1.710 & 1.733 & 1.573 & 1.635 & 1.764 & 1.657 & 1.705 & 1.692 & 1.673 & 1.690 & 1.745 & 1.445 & 1.616 & 1.602 & 1.429 & \\
\hline 89 & 1.687 & 1.820 & 1.713 & 1.740 & 1.573 & 1.634 & 1.740 & 1.649 & 1.692 & 1.690 & 1.675 & 1.686 & 1.722 & 1.474 & 1.654 & 1.616 & 1.441 & \\
\hline 92 & 1.673 & 1.800 & 1.707 & 1.726 & 1.556 & 1.605 & 1.713 & 1.625 & 1.692 & 1.685 & 1.625 & 1.667 & 1.723 & 1.455 & 1.659 & 1.612 & 1.408 & 0.0072 \\
\hline 93 & & & & & & & & & & & & & & & & & & 0.0440 \\
\hline 94 & 1.591 & 1.751 & 1.635 & 1.659 & 1.513 & 1.533 & 1.686 & 1.577 & 1.619 & 1.624 & 1.618 & 1.621 & 1.663 & 1.410 & 1.585 & 1.553 & 1.414 & 0.0076 \\
\hline 96 & 1.656 & 1.826 & 1.702 & 1.728 & 1.555 & 1.600 & 1.750 & 1.635 & 1.682 & 1.676 & 1.646 & 1.668 & 1.707 & 1.469 & 1.636 & 1.604 & 1.382 & \\
\hline 100 & & & & & & & & & & & & & & & & & & 0.0170 \\
\hline 101 & 1.653 & 1.819 & 1.680 & 1.717 & 1.563 & 1.598 & 1.702 & 1.621 & 1.661 & 1.662 & 1.625 & 1.649 & 1.726 & 1.456 & 1.630 & 1.604 & 1.401 & 0.0026 \\
\hline 103 & 1.652 & 1.811 & 1.662 & 1.708 & 1.529 & 1.596 & 1.716 & 1.614 & 1.668 & 1.671 & 1.609 & 1.649 & 1.737 & 1.456 & 1.638 & 1.610 & 1.414 & \\
\hline 105 & 1.637 & 1.809 & 1.653 & 1.699 & 1.513 & 1.578 & 1.679 & 1.590 & 1.643 & 1.635 & 1.594 & 1.624 & 1.705 & 1.473 & 1.613 & 1.597 & 1.389 & \\
\hline 107 & 1.610 & 1.804 & 1.624 & 1.679 & 1.517 & 1.536 & 1.650 & 1.567 & 1.615 & 1.619 & 1.578 & 1.604 & 1.700 & 1.460 & 1.630 & 1.597 & 1.369 & \\
\hline 109 & 1.601 & 1.783 & 1.653 & 1.679 & 1.517 & 1.545 & 1.671 & 1.578 & 1.630 & 1.611 & 1.583 & 1.608 & 1.729 & 1.462 & 1.617 & 1.603 & 1.373 & \\
\hline 111 & & & & & & & & & & & & & & & & & & 0.0067 \\
\hline 112 & 1.617 & 1.799 & 1.652 & 1.689 & 1.509 & 1.551 & 1.653 & 1.571 & 1.609 & 1.589 & 1.572 & 1.590 & 1.706 & 1.487 & 1.627 & 1.607 & 1.367 & 0.0364 \\
\hline 113 & & & & & & & & & & & & & & & & & & 0.0230 \\
\hline 114 & 1.594 & 1.798 & 1.662 & 1.685 & 1.504 & 1.551 & 1.662 & 1.572 & 1.590 & 1.617 & 1.555 & 1.587 & 1.721 & 1.460 & 1.623 & 1.601 & 1.378 & \\
\hline 116 & & & & & & & & & & & & & & & & & & 0.0654 \\
\hline 117 & & & & & & & & & & & & & & & & & & 0.0384 \\
\hline 121 & 1.729 & 1.931 & 1.769 & 1.809 & 1.619 & 1.674 & 1.855 & 1.716 & 1.761 & 1.736 & 1.705 & 1.734 & 1.773 & 1.479 & 1.606 & 1.620 & & 0.0312 \\
\hline
\end{tabular}




\section{APÊNDICE 5}

Gráficos mostrando a variabilidade em termos de desvio padrão e o valor médio diário da contagem relativa de nêutrons lentos (CR), e mostrando os volumes de água de irrigação e precipitação $(P+I), e m \mathrm{~m}^{3} / \mathrm{m}^{2}$, em função do tempo (DAS), dias após a semeadura.

Obs.: as barras no eixo inferior indicam os volumes de água e as barras no centro do gráfico indicam dois desvios padrão, um abaixo e um acima da média, que está ao centro. 


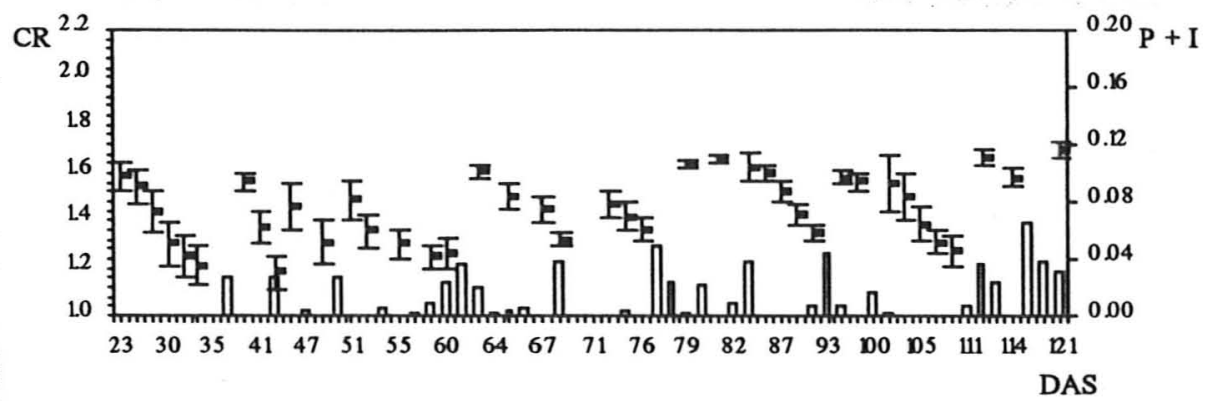

Tratamento tr0.

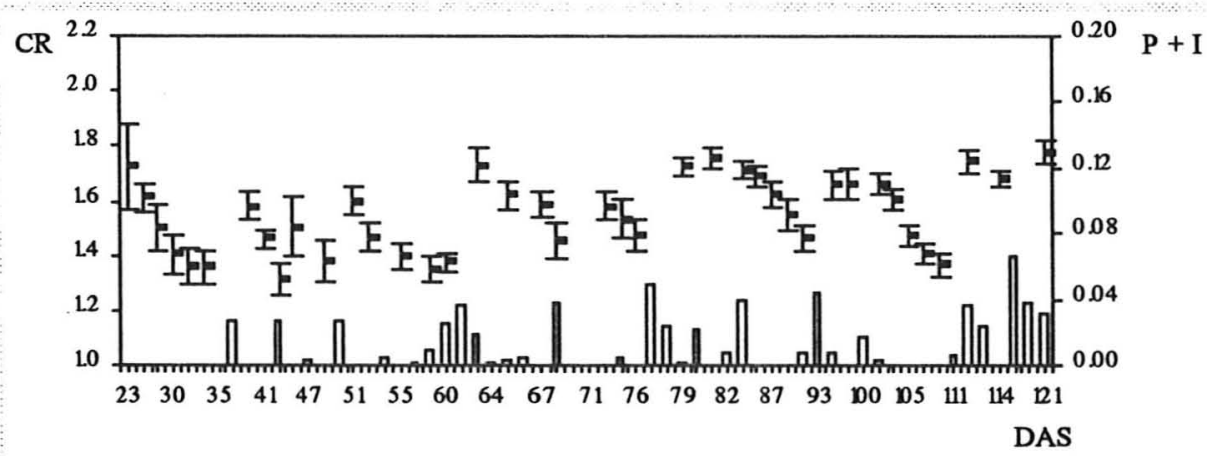

\section{Tratamento tr1.}

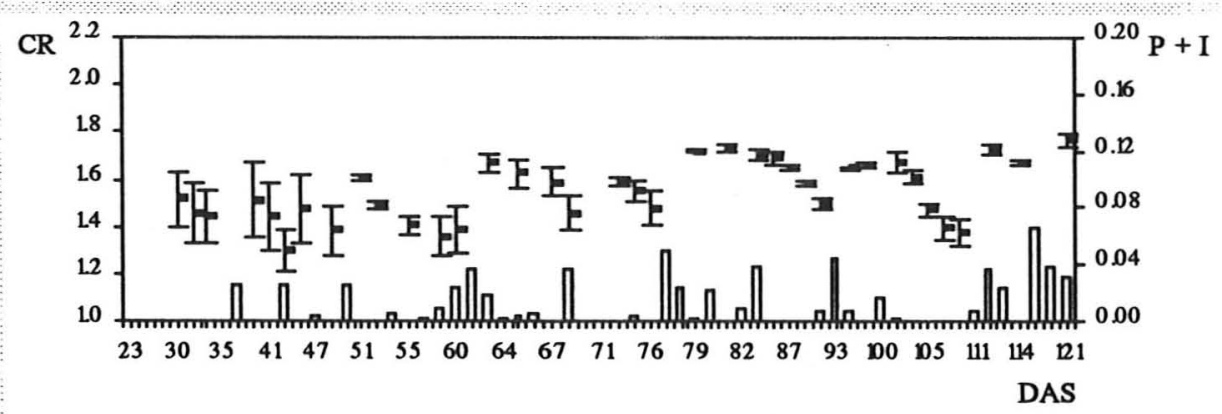

Tratamento tr2.

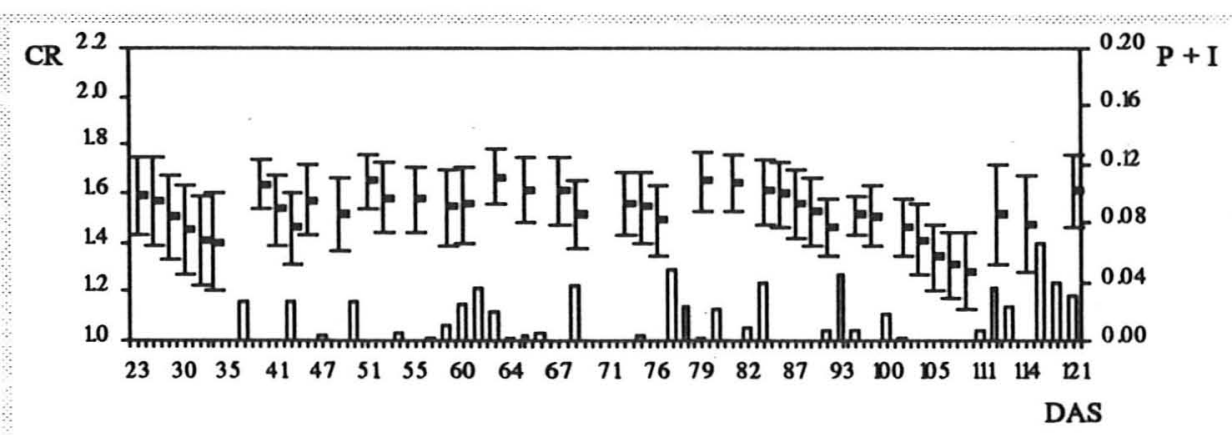

Tratamento trbs.

PROFUNDIDADE $0,20 \mathrm{~m}$. 


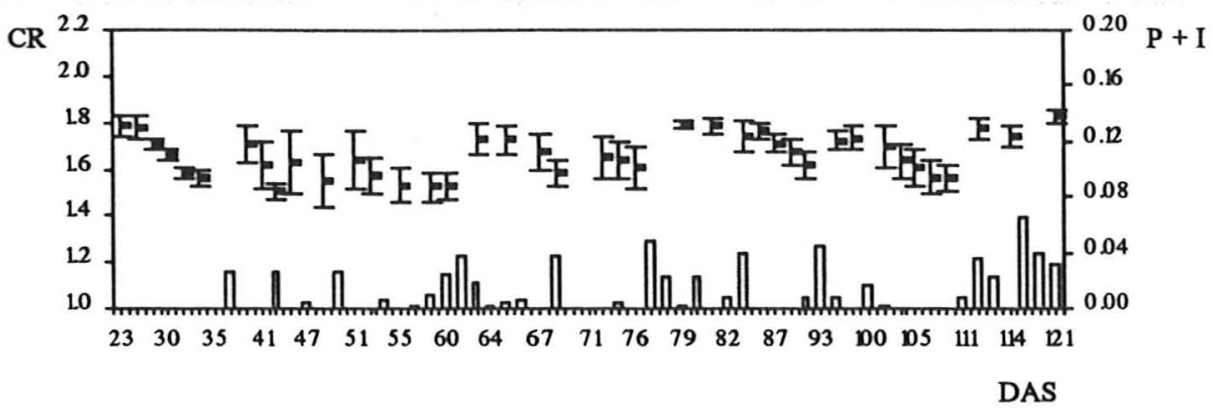

Tratamento tro.

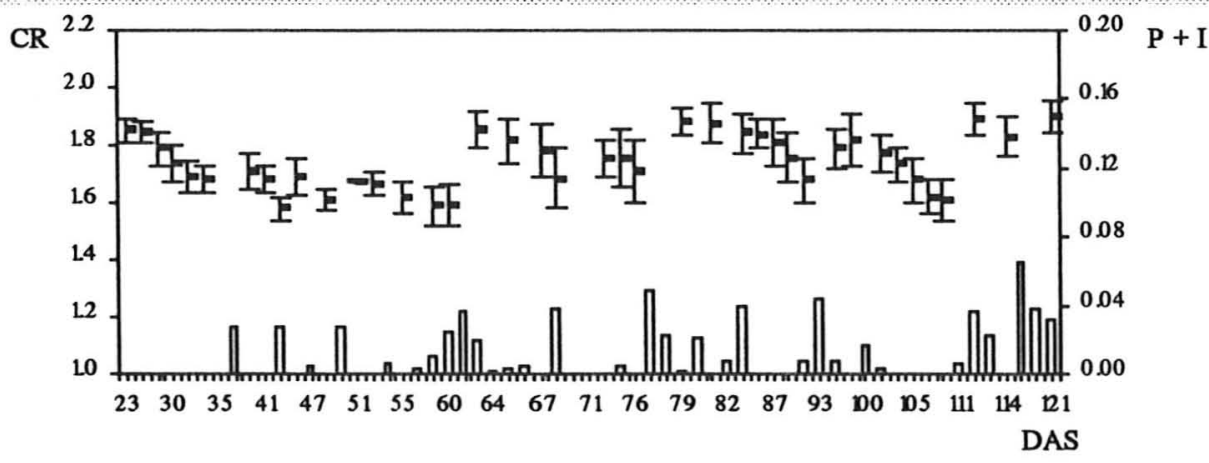

Tratamento trl.

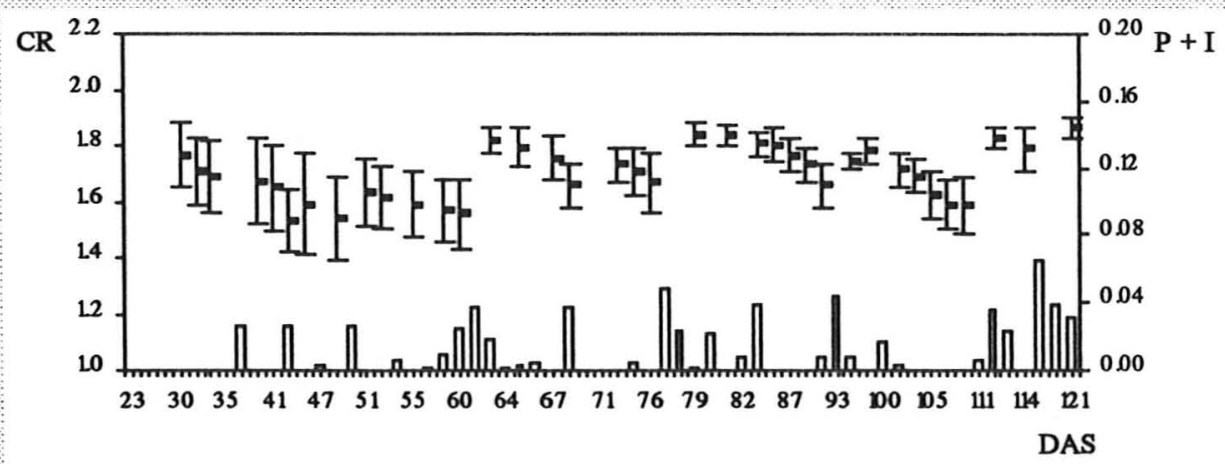

Tratamento tr2.

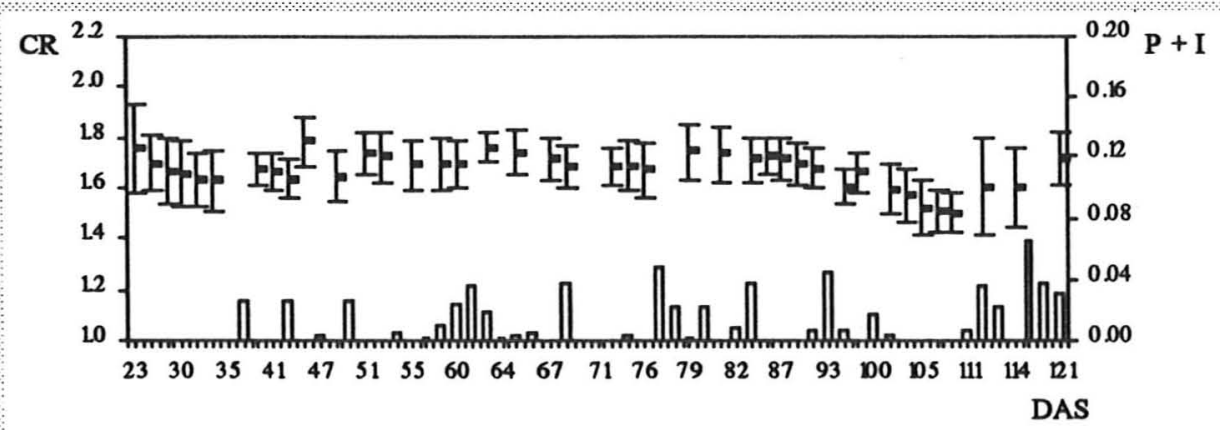

Tratamento trbs.

PROFUNDIDADE $0,30 \mathrm{~m}$. 


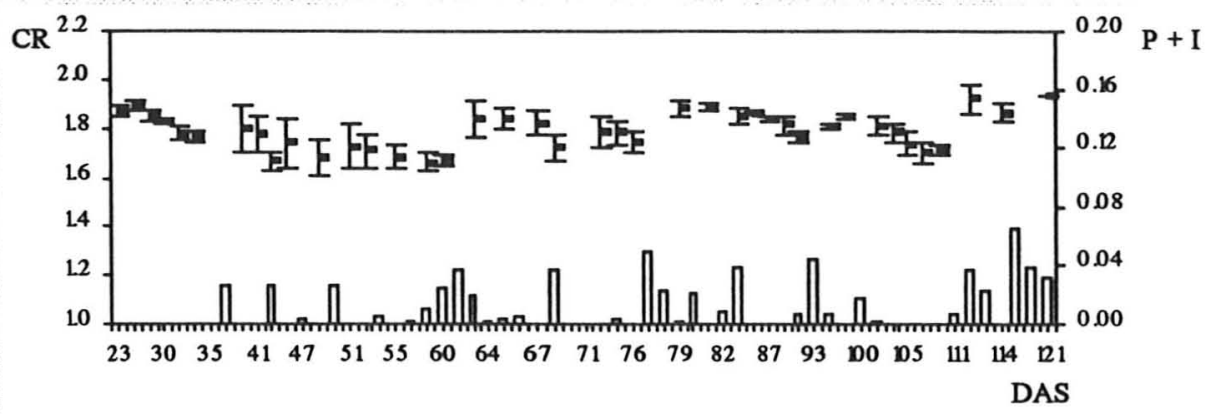

Tratamento tr0.

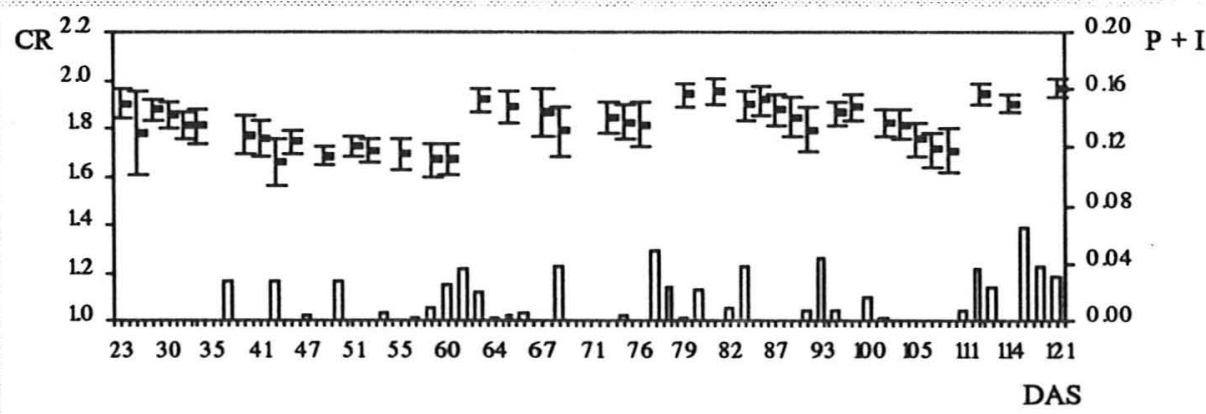

Tratamento trl.

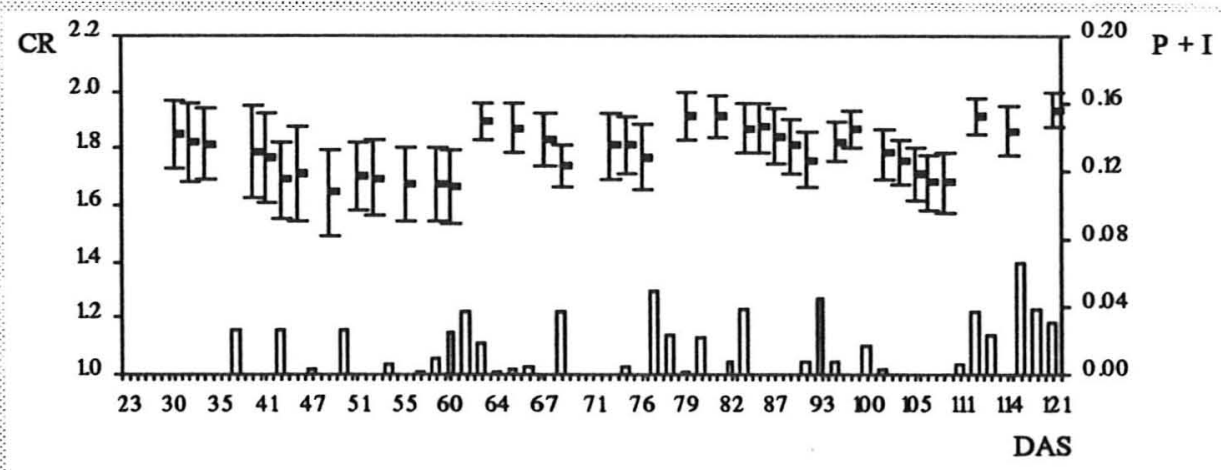

Tratamento tr2.

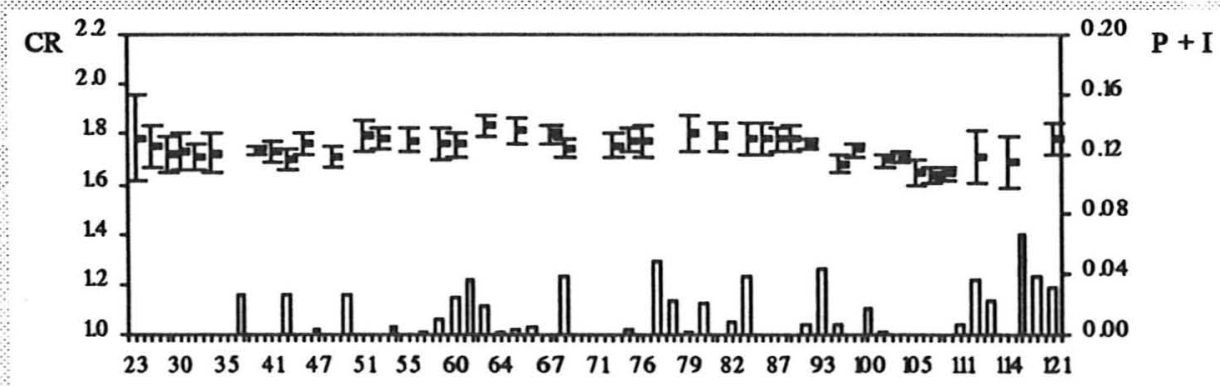

DAS

Tratamento trbs. 


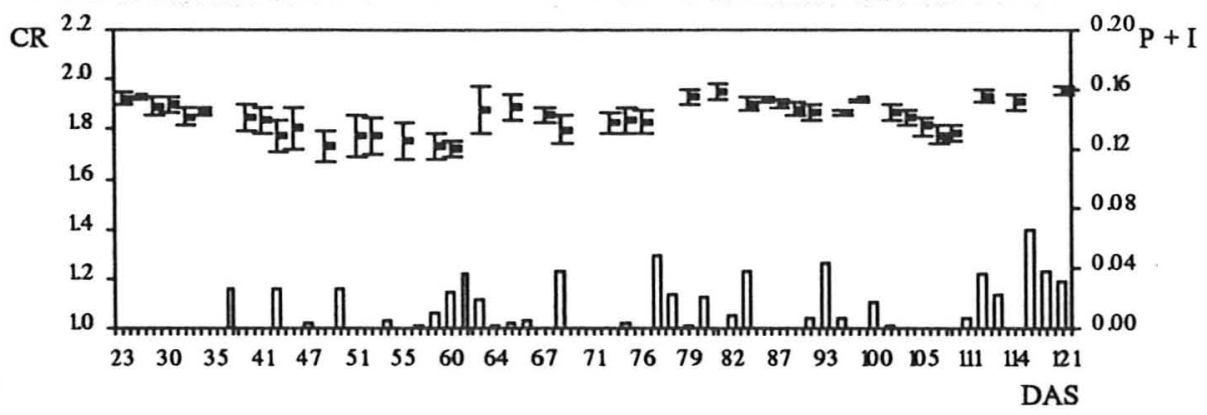

Tratamento tro.

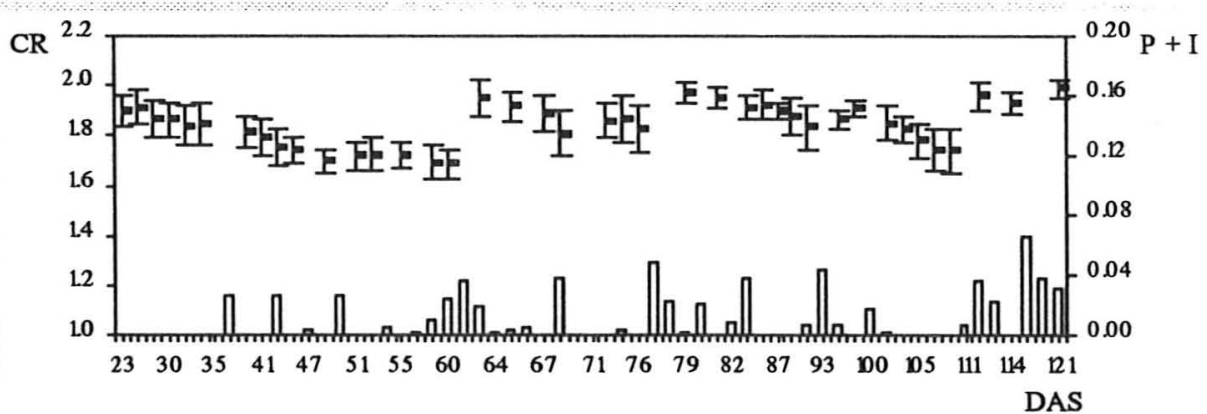

Tratamento tr1.

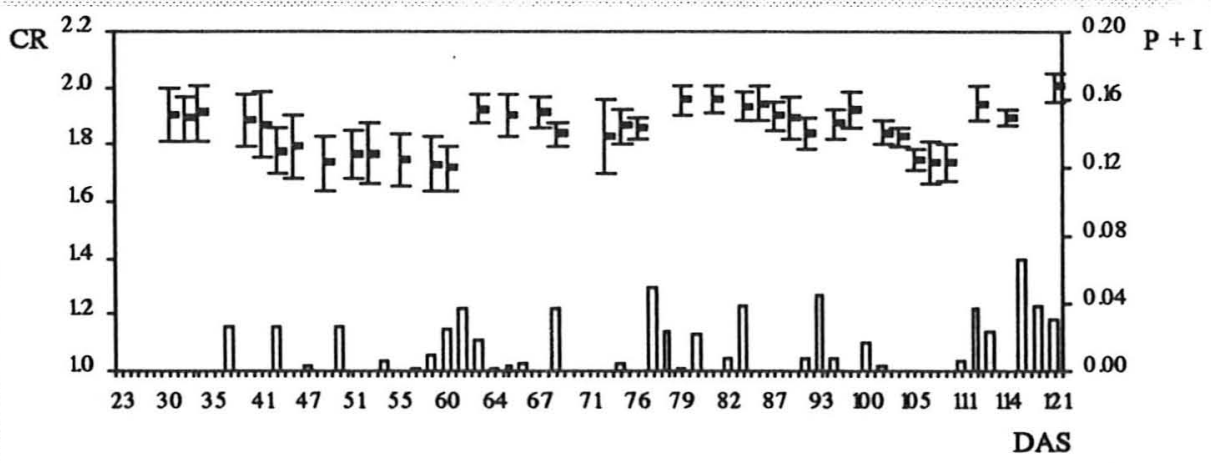

Tratamento tr2.

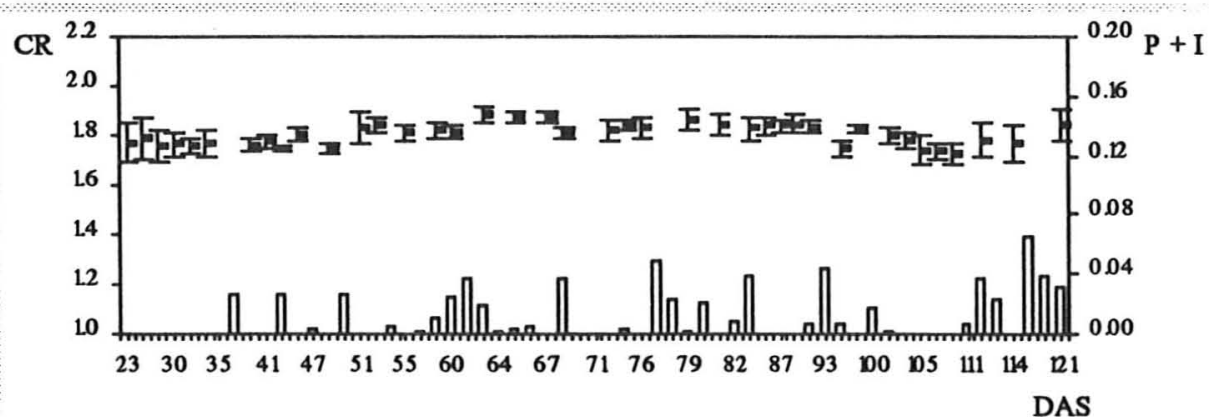

Tratamento trbs.

PROFUNDIDADE $0,50 \mathrm{~m}$. 


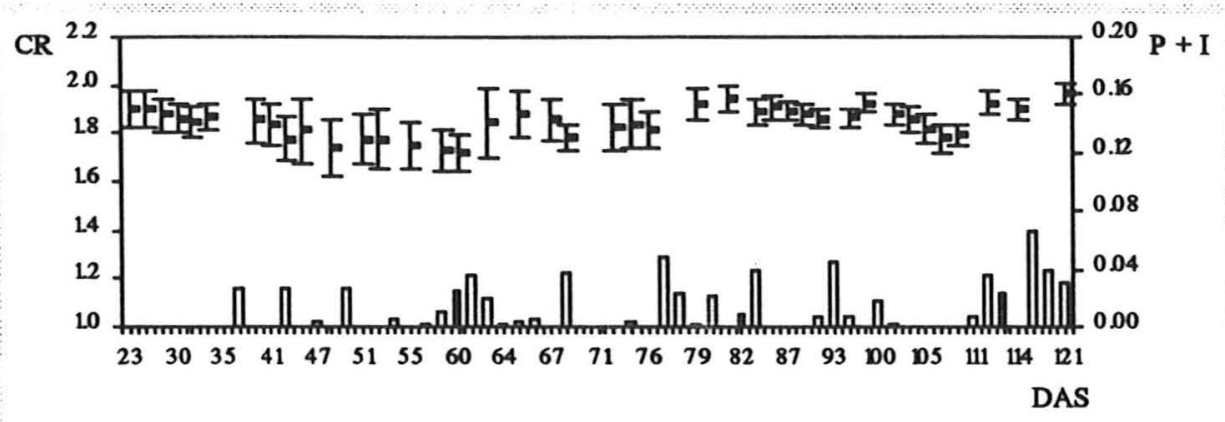

Tratamento tro.

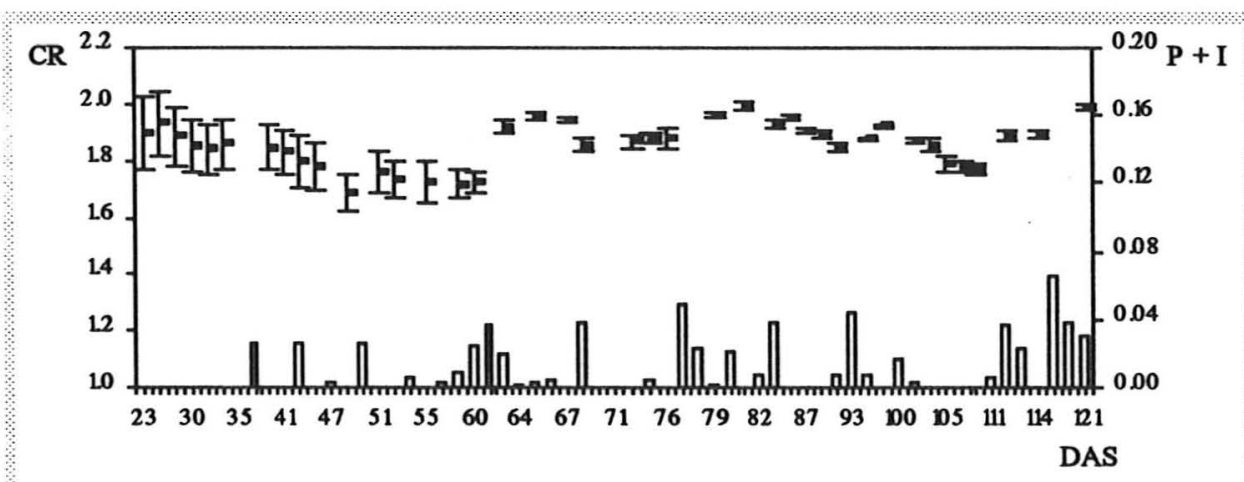

\section{Tratamento tr1.}

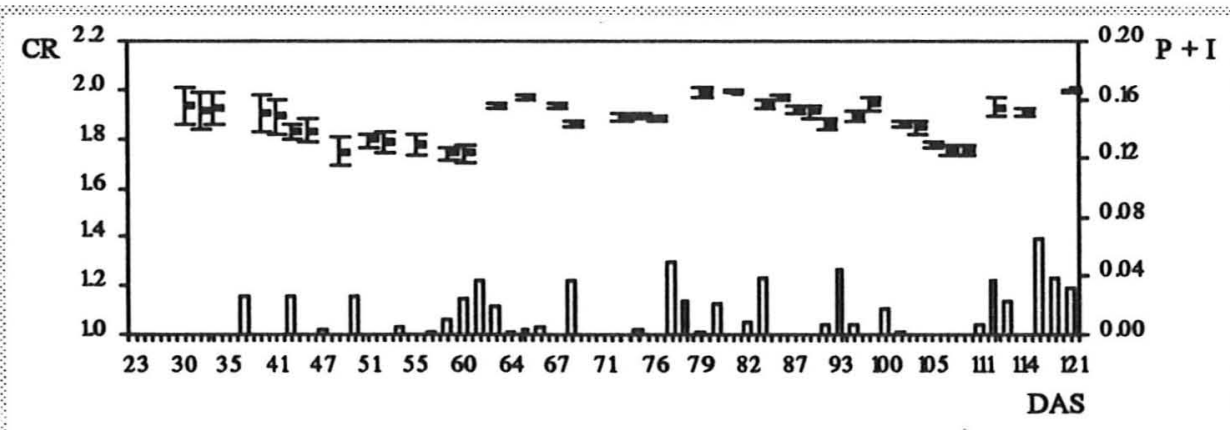

\section{Tratamento tr2.}

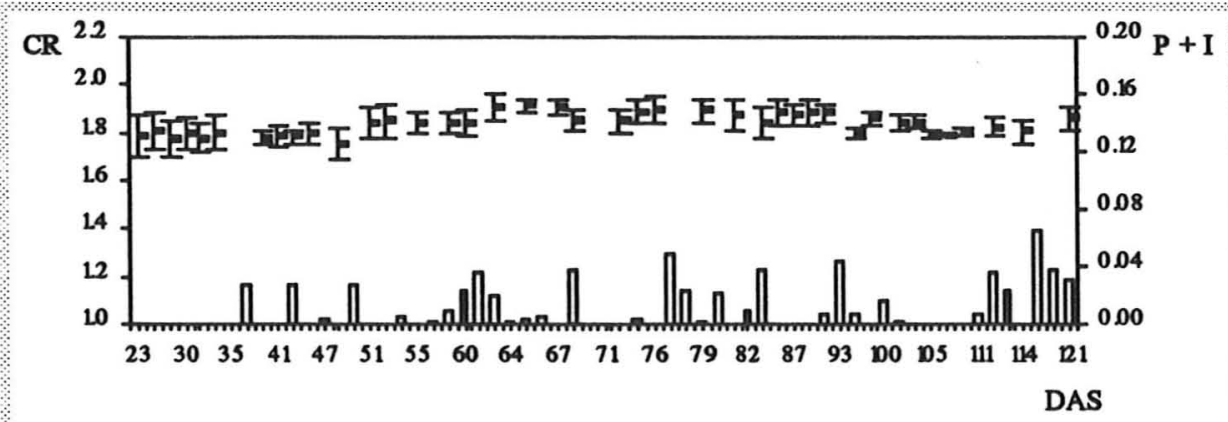

Tratamento trbs.

PROFUNDIDADE $0,60 \mathrm{~m}$. 


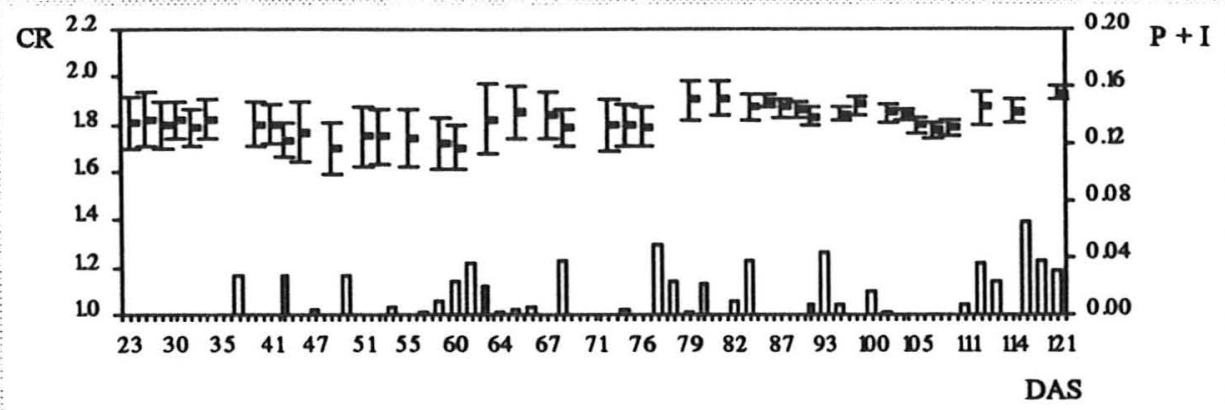

\section{Tratamento tro.}

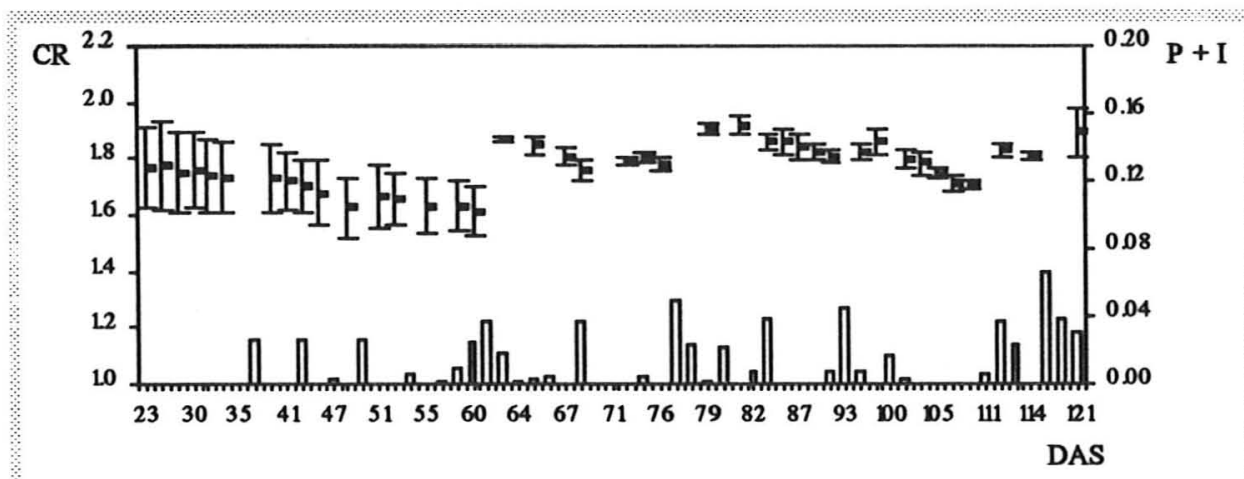

Tratamento trl.

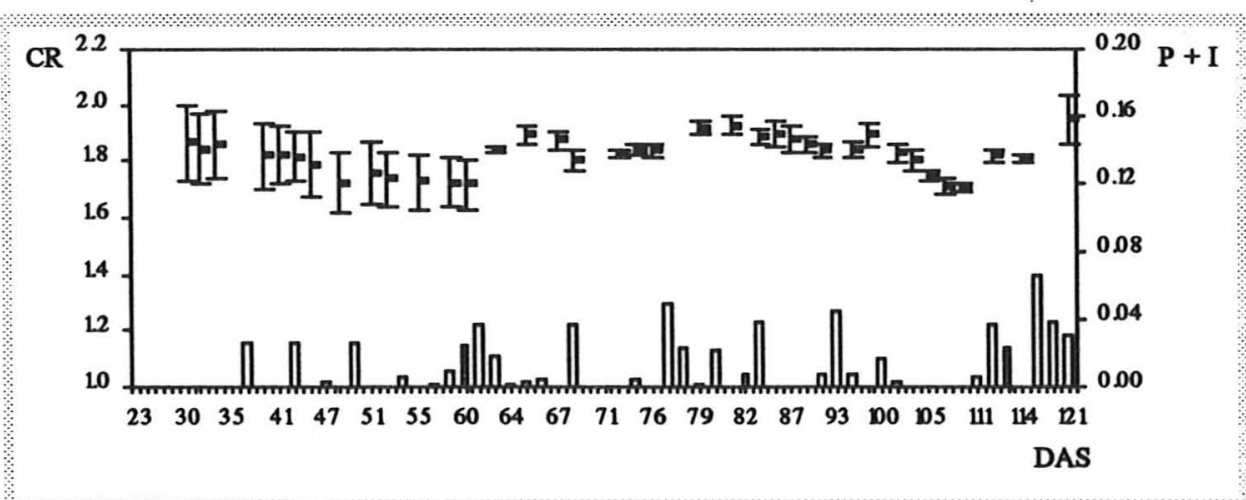

Tratamento tr2.

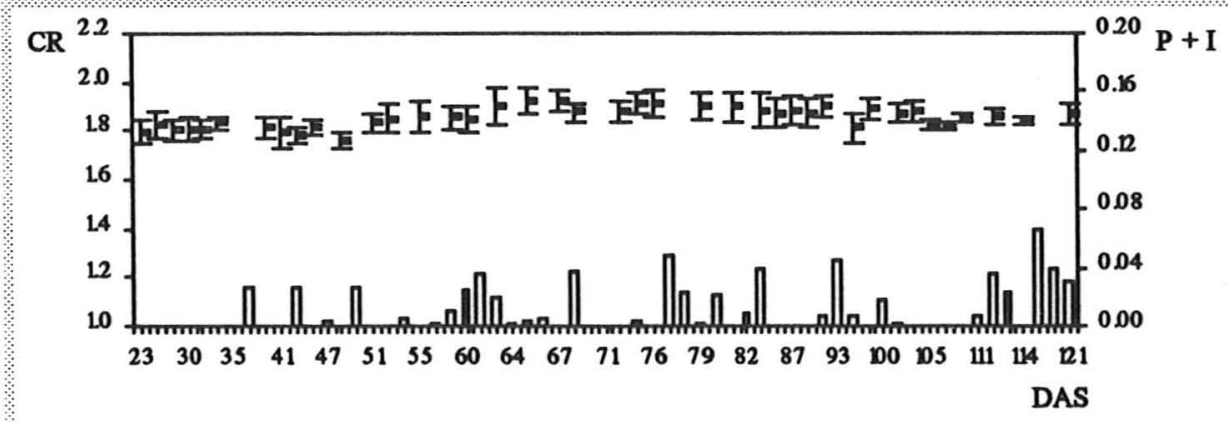

Tratamento trbs.

PROFUNDIDADE $0,70 \mathrm{~m}$. 


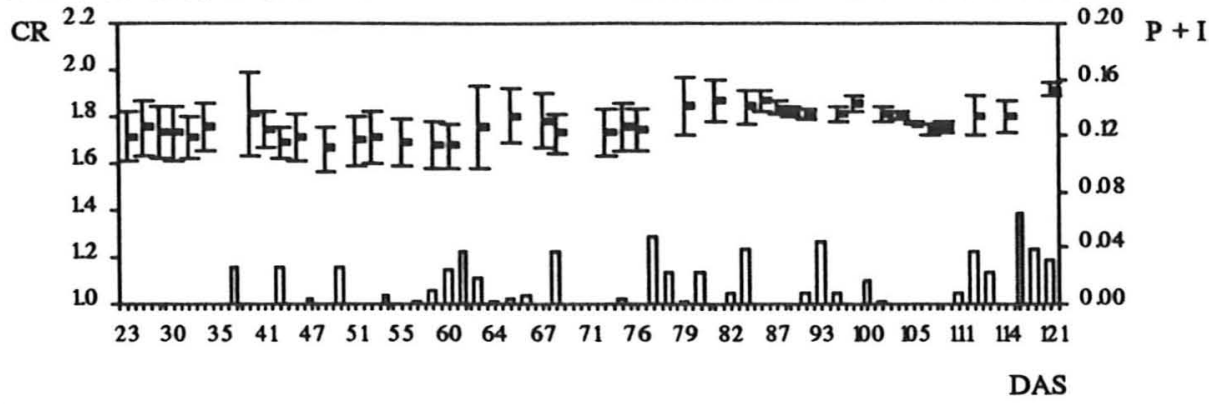

Tratamento tro.

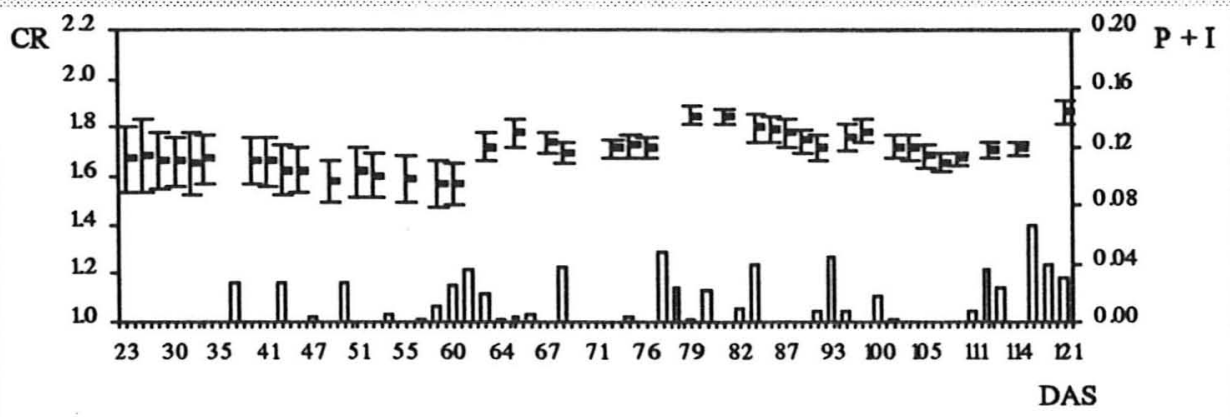

Tratamento tr1.

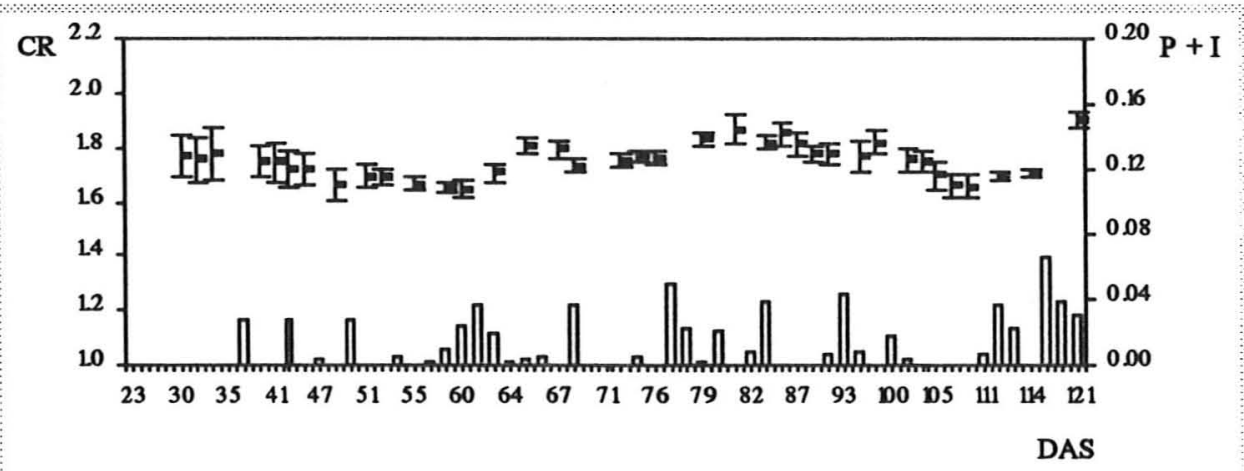

Tratamento tr2.

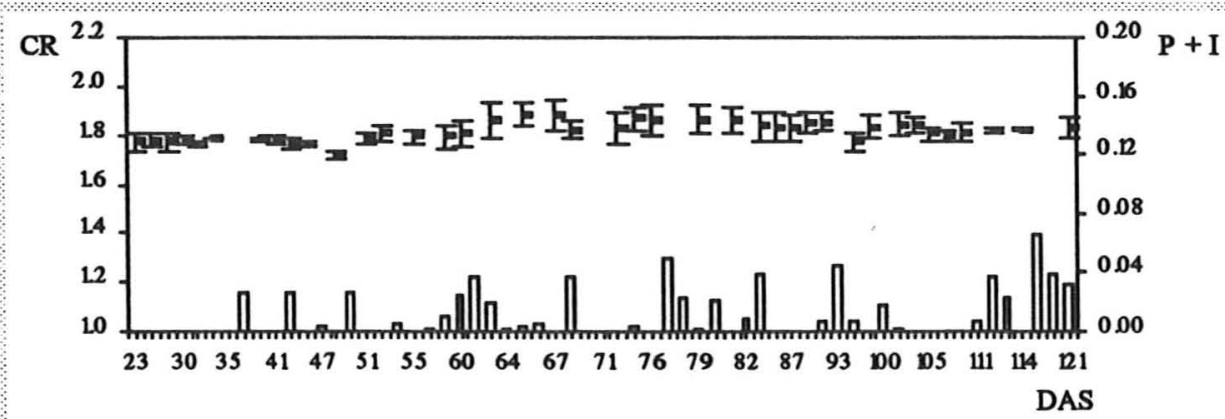

Tratamento trbs.

PROFUNDIDADE $0,80 \mathrm{~m}$. 


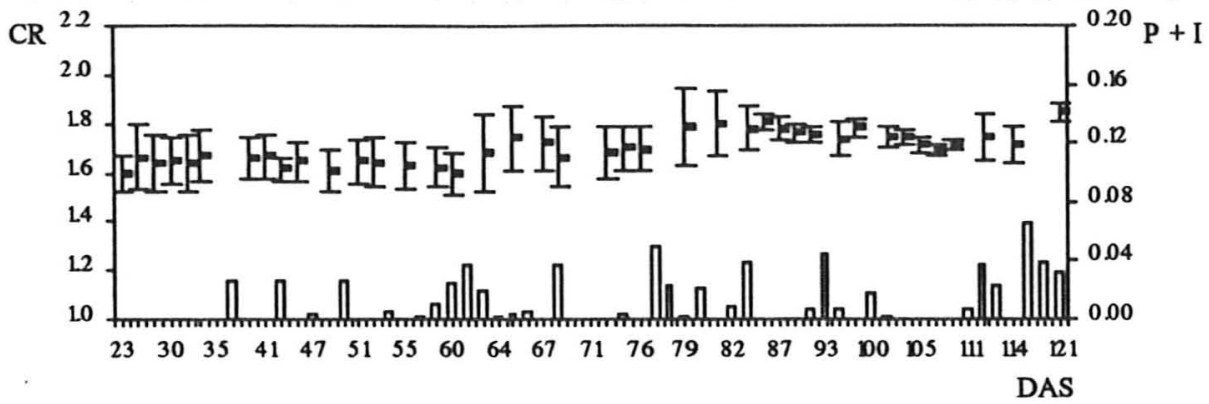

Tratamento tro.

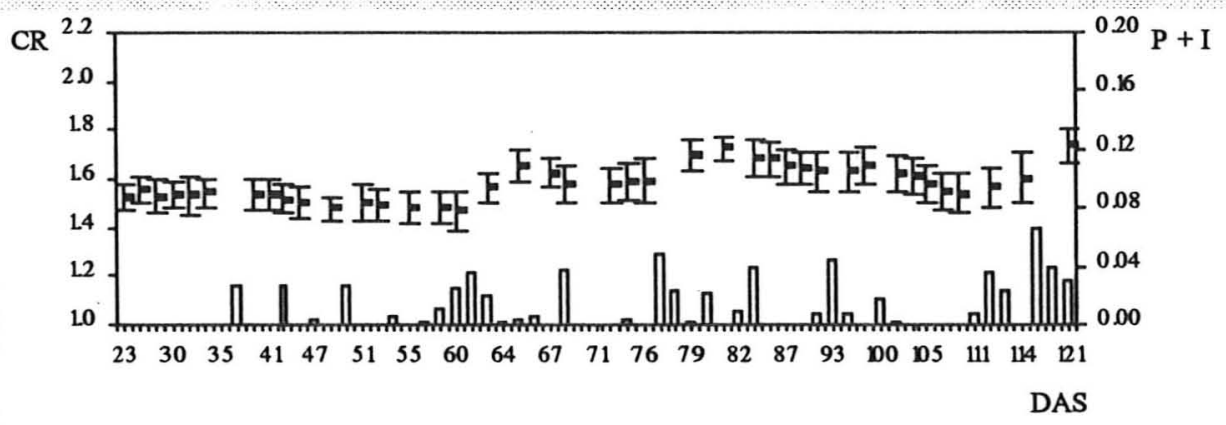

Tratamento tr1.

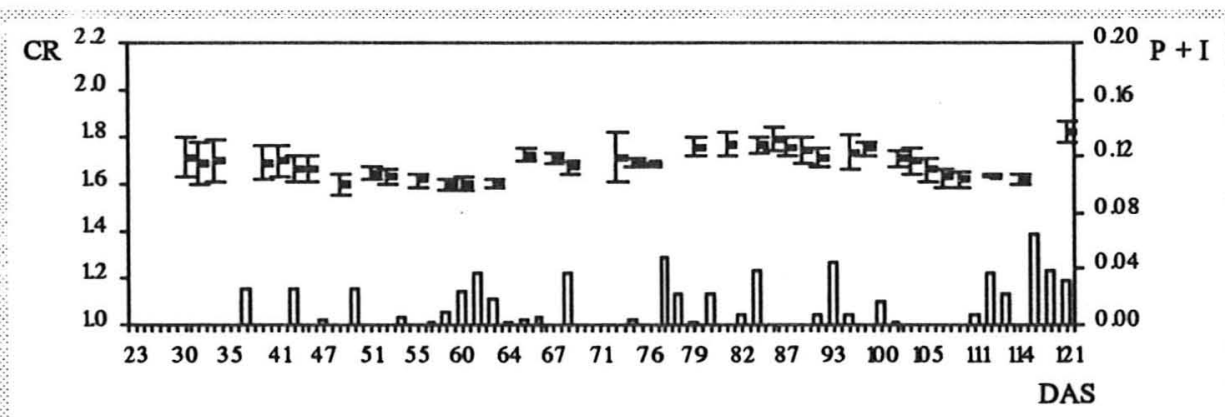

Tratamento tr2.

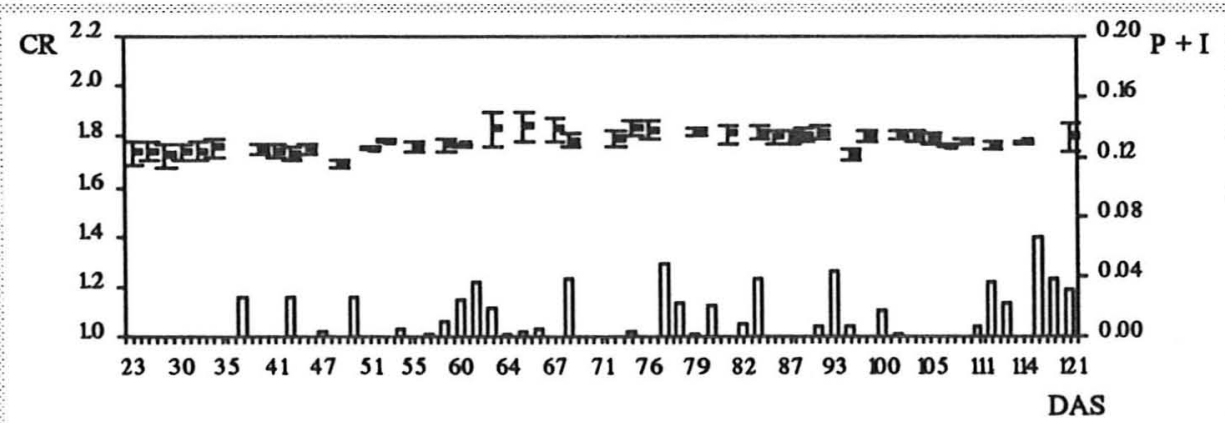

Tratamento trbs.

PROFUNDIDADE $0,90 \mathrm{~m}$. 


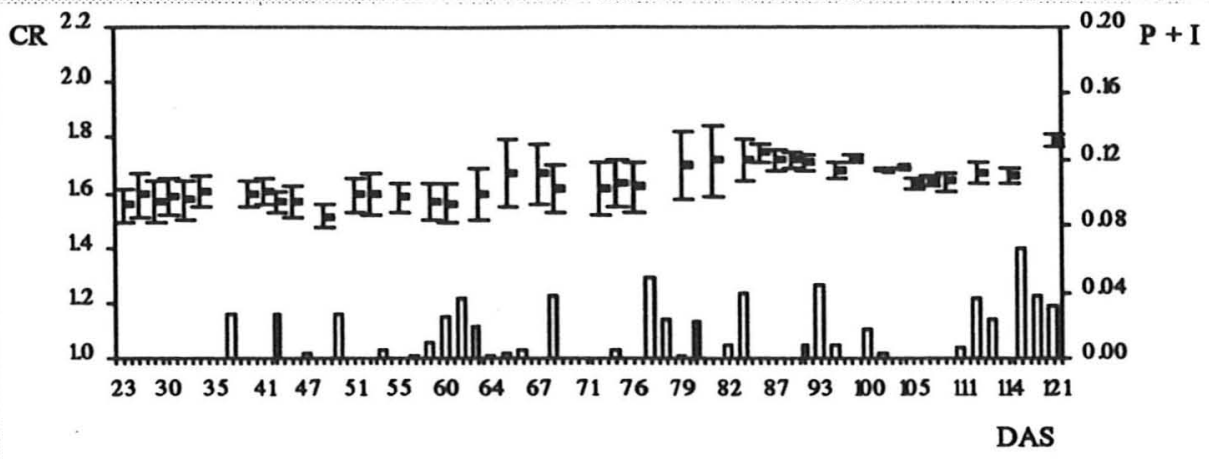

Tratamento tro.

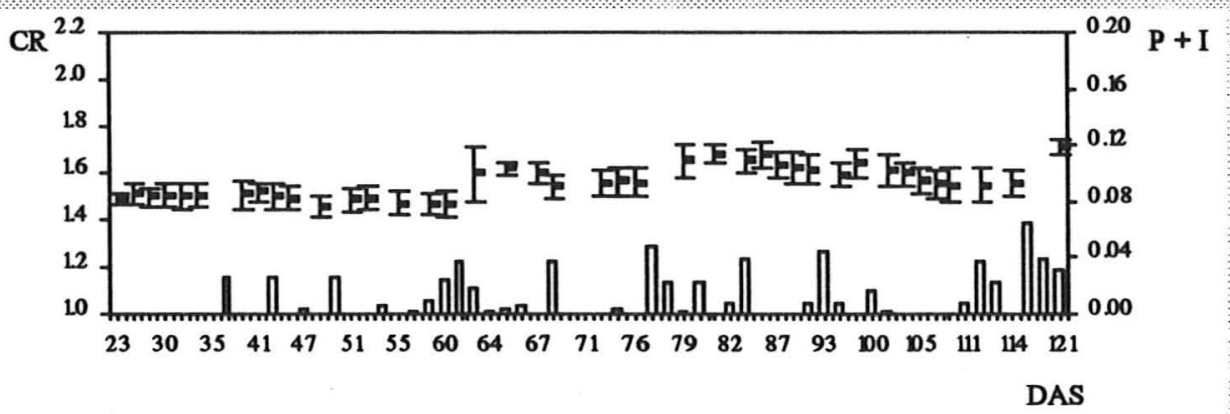

\section{Tratamento tr1.}

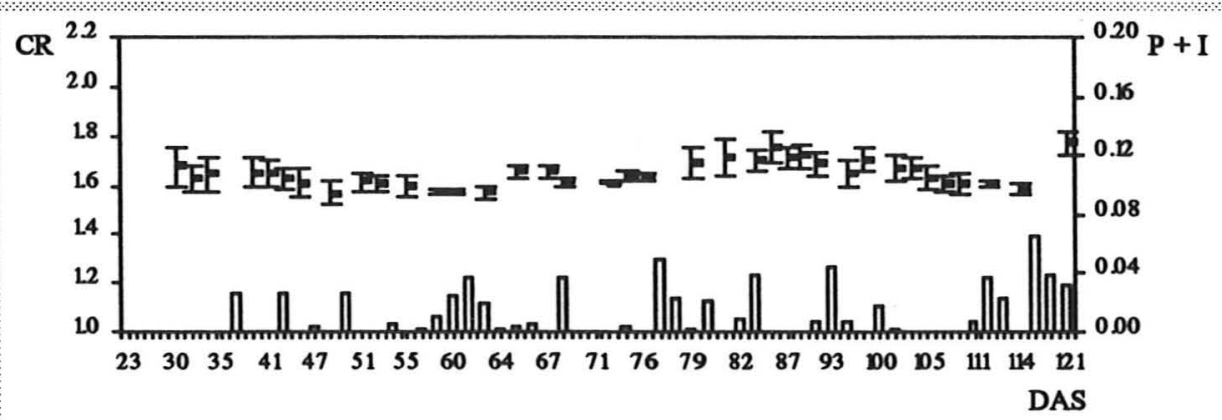

\section{Tratamento tr2.}

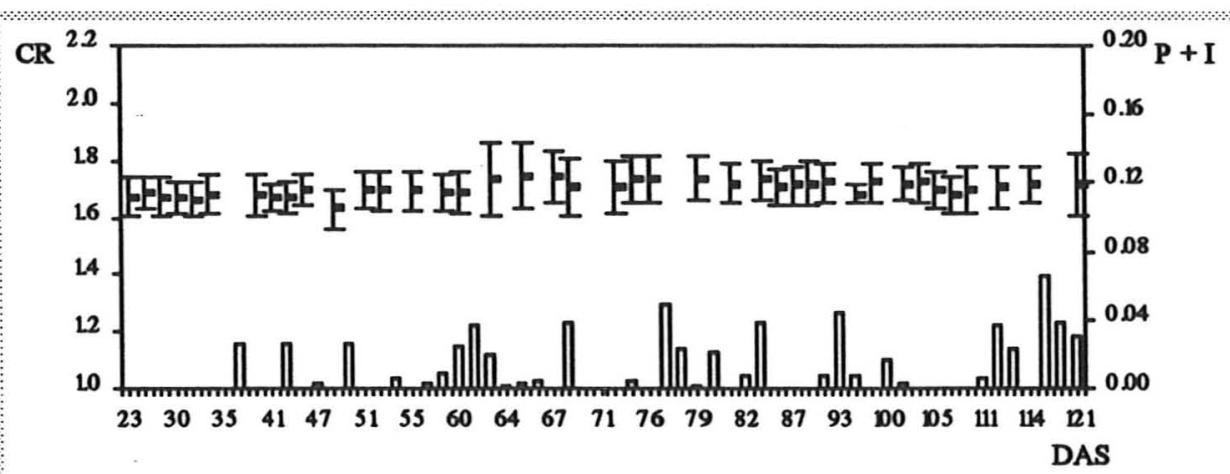

Tratamento trbs.

PROFUNDIDADE $1,00 \mathrm{~m}$. 


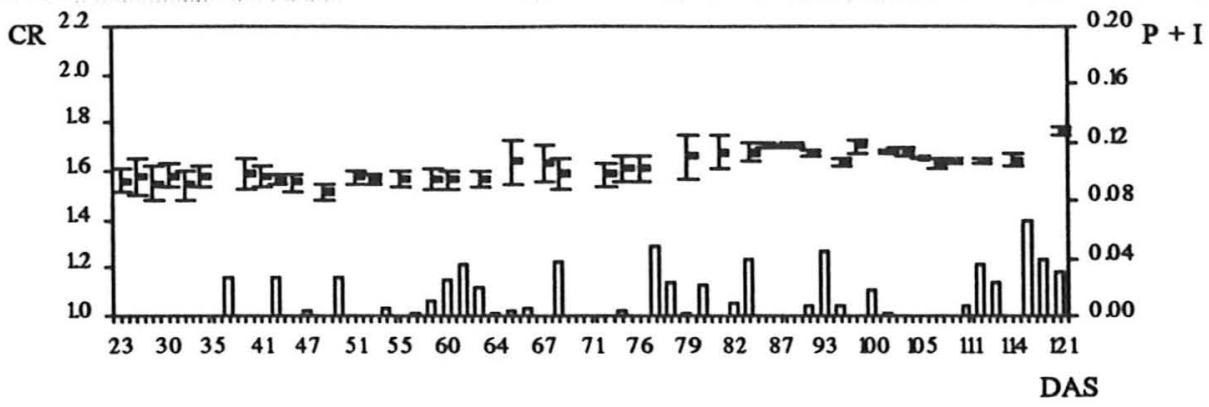

Tratamento tro.

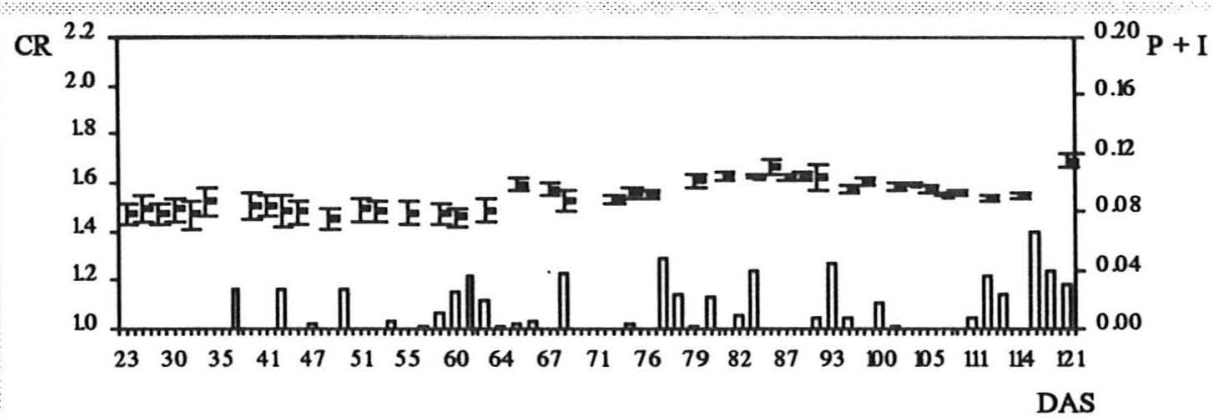

\section{Tratamento tr1.}

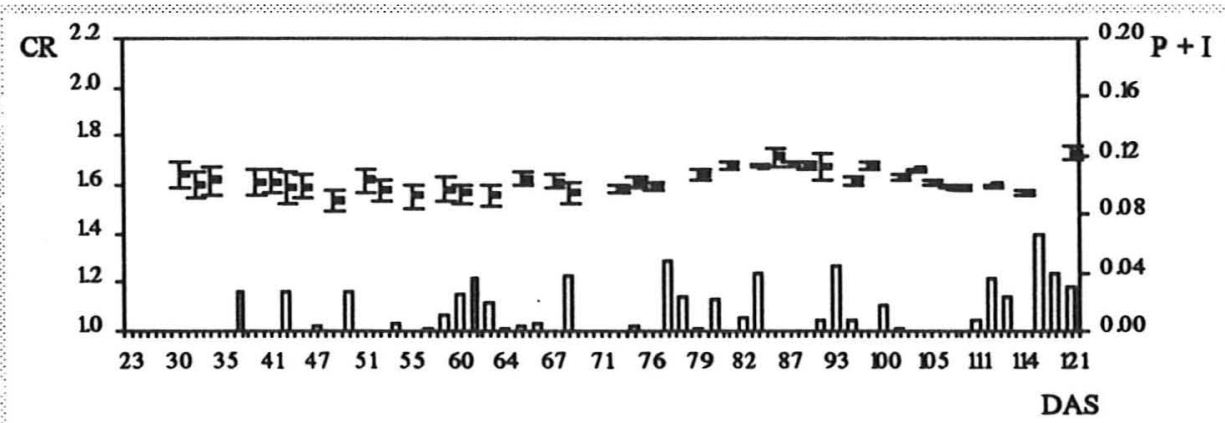

\section{Tratamento tr2.}

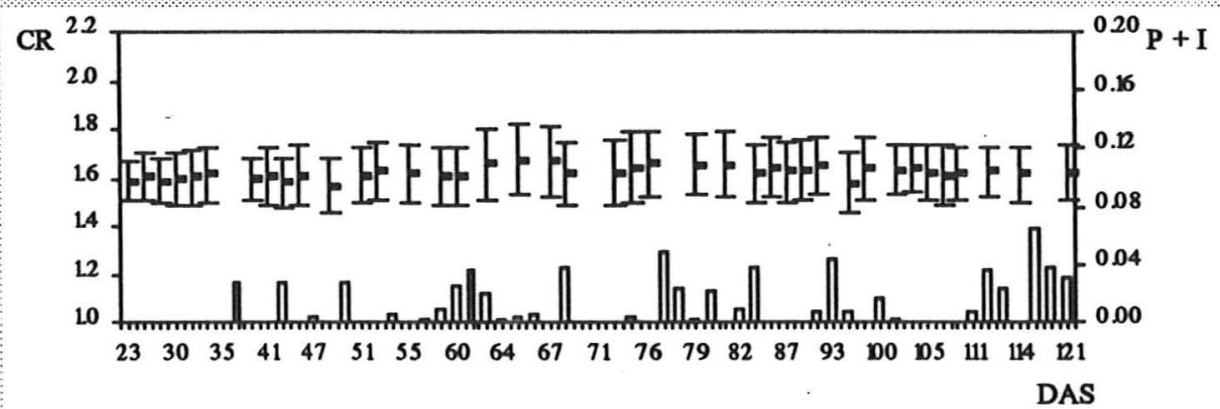

Tratamento trbs.

PROFUNDIDADE $1,10 \mathrm{~m}$. 


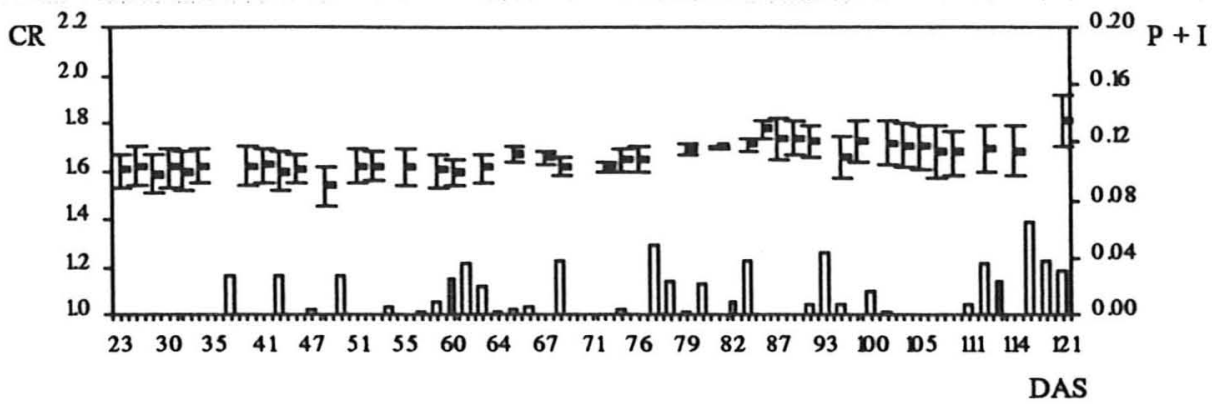

\section{Tratamento tr0.}

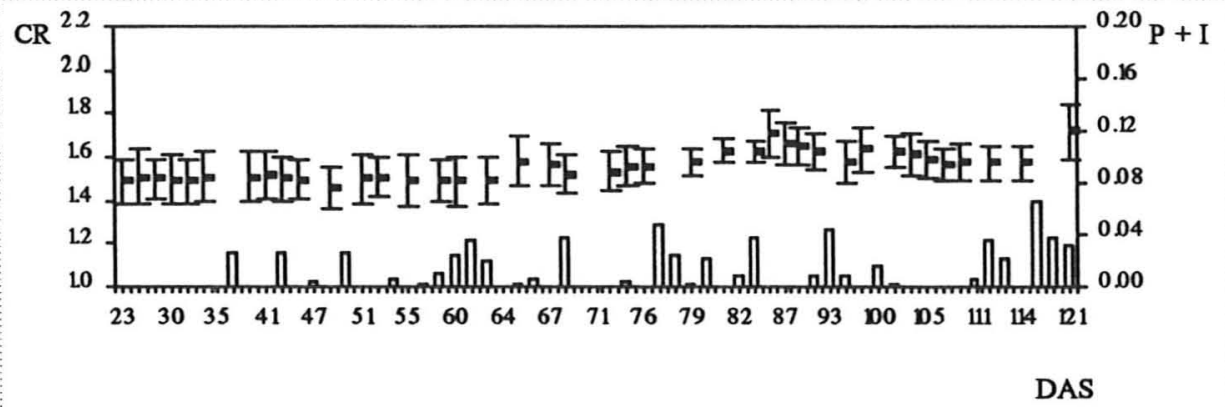

\section{Tratamento tr1.}

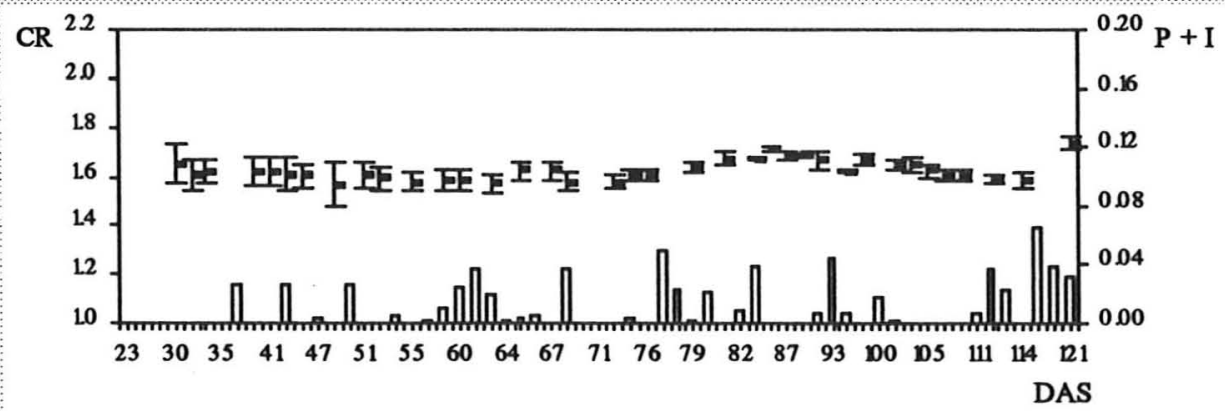

\section{Tratamento tr2.}

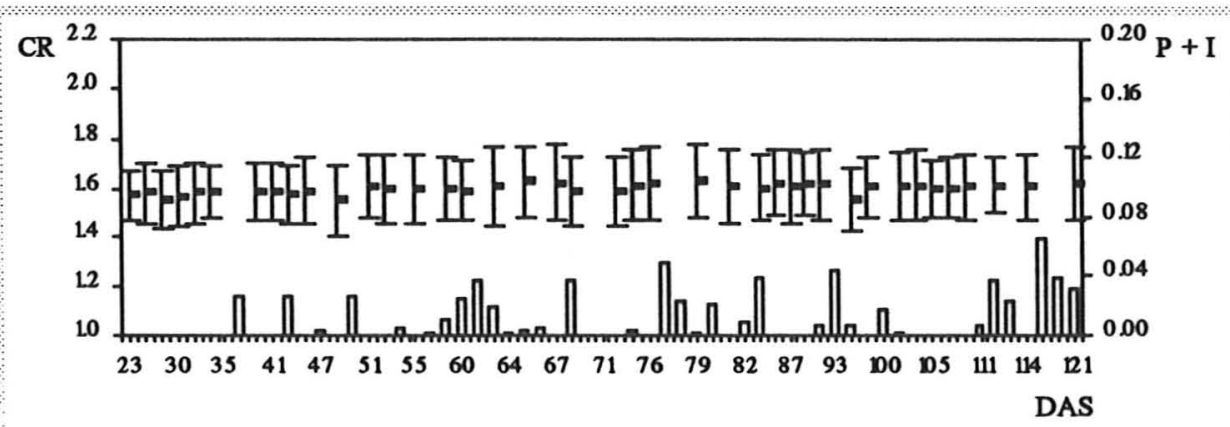

Tratamento trbs.

PROFUNDIDADE $1,20 \mathrm{~m}$. 


\section{APÊNDICE 6}

Gráficos mostrando a variabilidade da contagem relativa de nêutrons lentos em termos de desvio padrão (dp) em função do valor médio diário dessa contagem relativa (CR). 


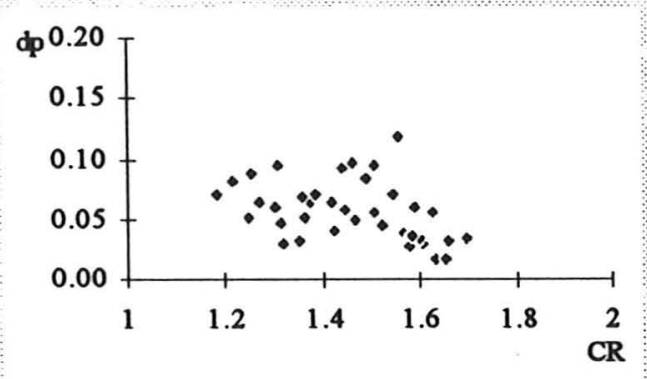

Tratamento tr0

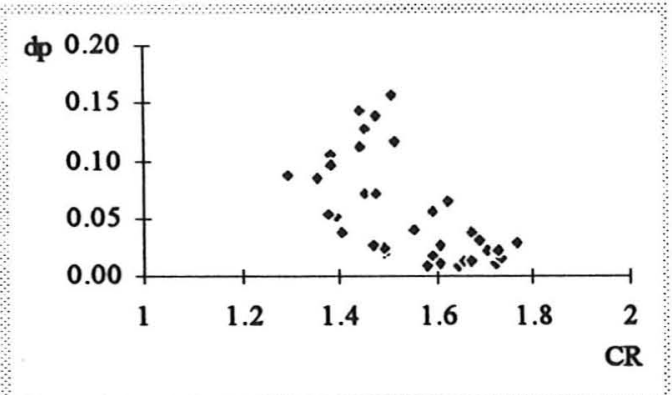

Tratamento tr2

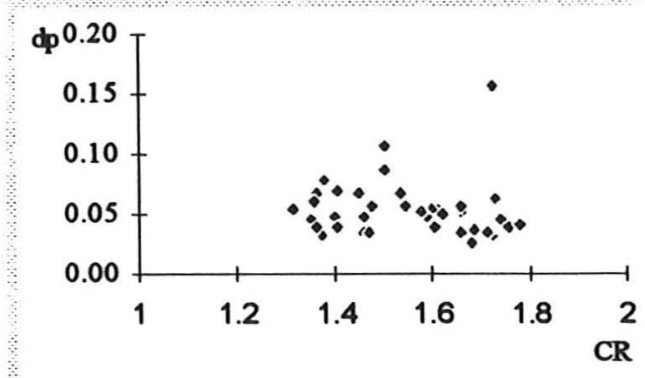

Tratamento tr1

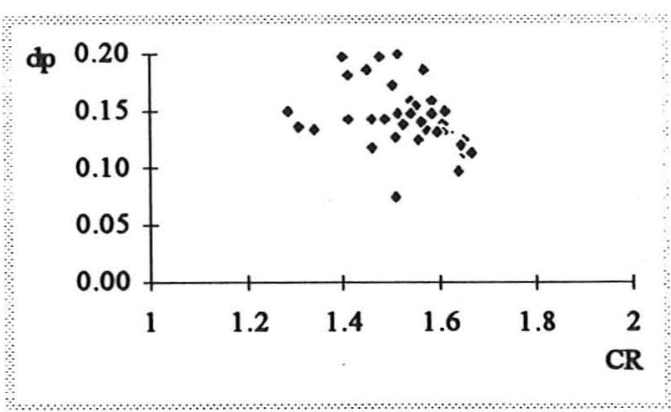

Tratamento trbs

PROFUNDIDADE 0,20 m

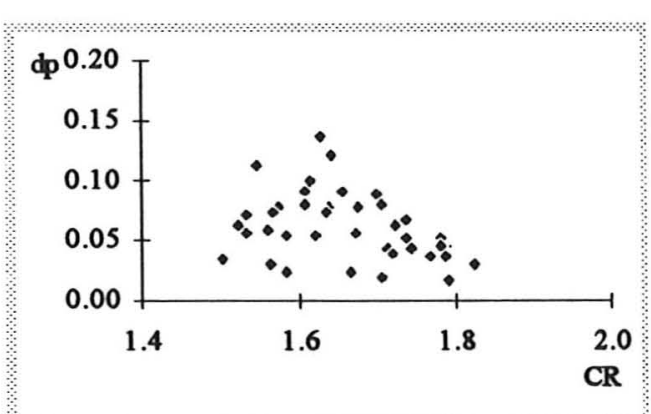

Tratamento tro

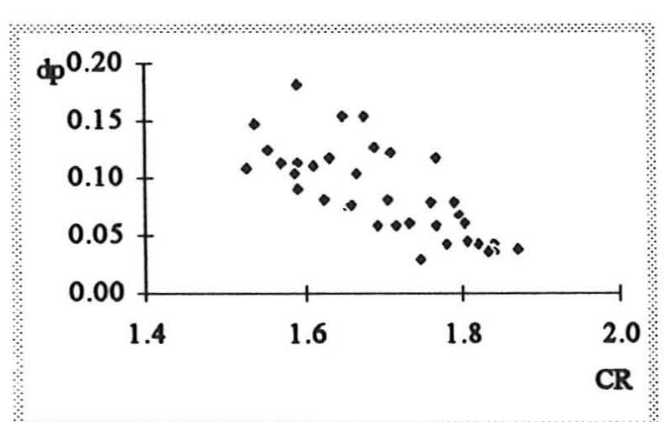

Tratamento tr2

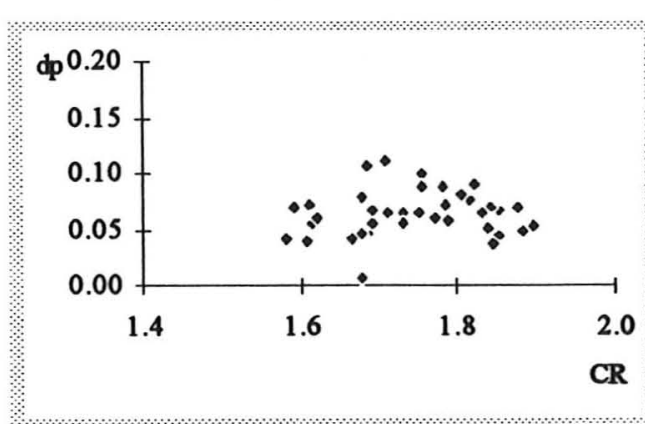

Tratamento trl

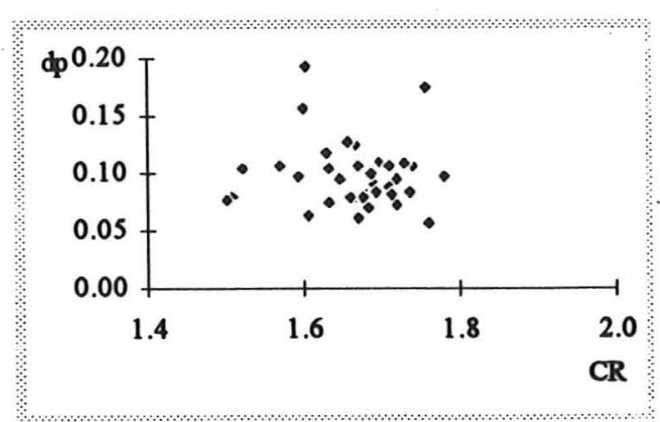

Tratamento trbs 


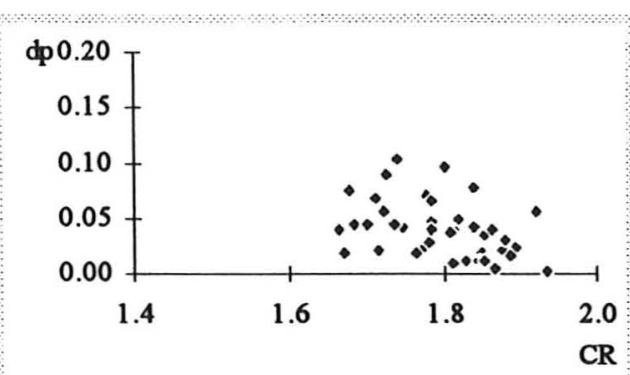

Tratamento tr0

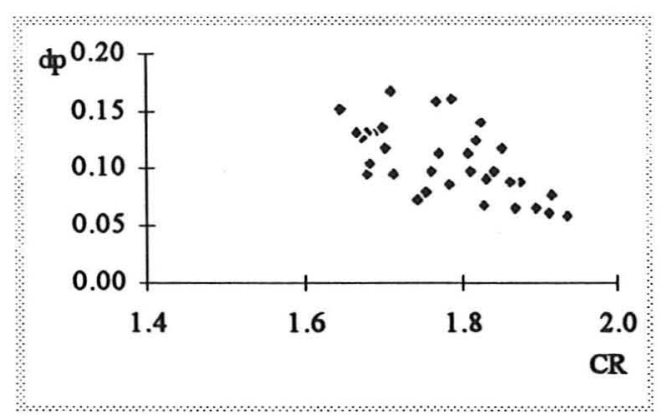

Tratamento tr2

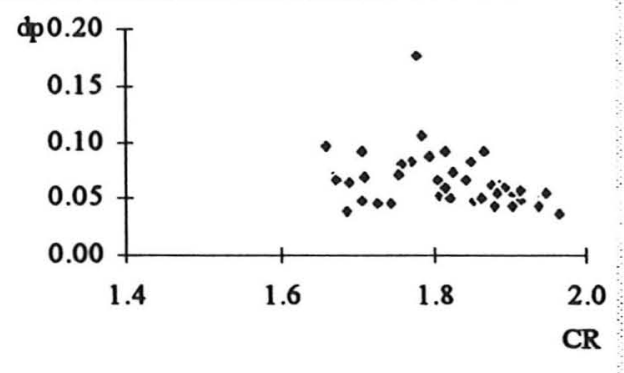

Tratamento tr1

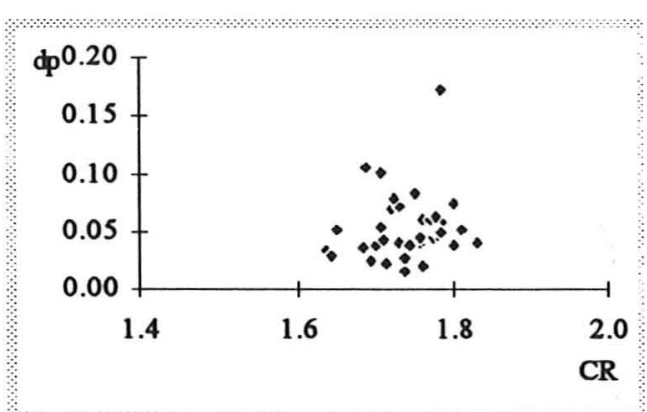

Tratamento trbs

PROFUNDIDADE $0,40 \mathrm{~m}$.

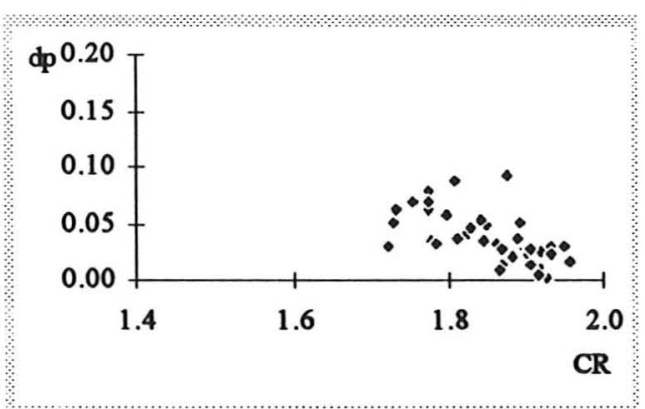

Tratamento tro

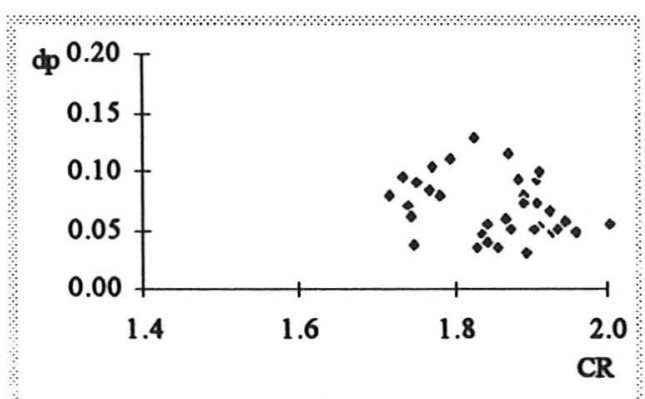

Tratamento tr2

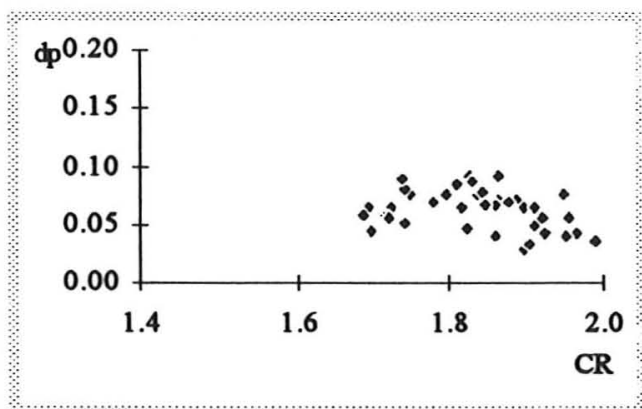

Tratamento tr1

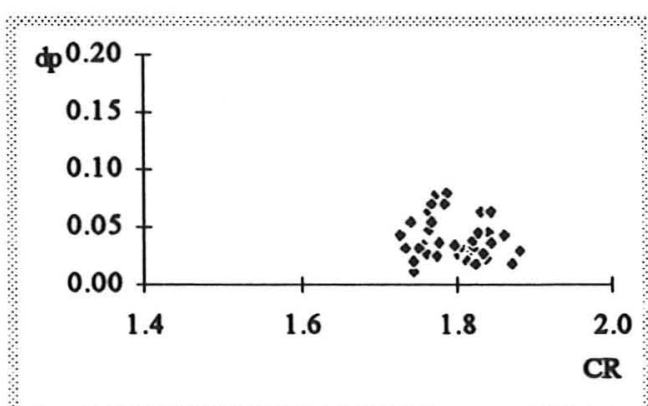

\section{Tratamento trbs}

PROFUNDIDADE $0,50 \mathrm{~m}$. 


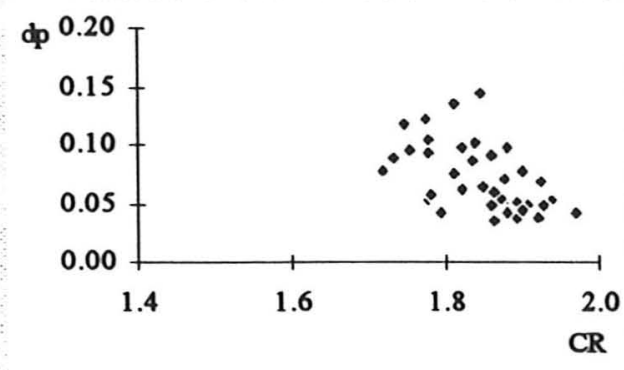

Tratamento tro

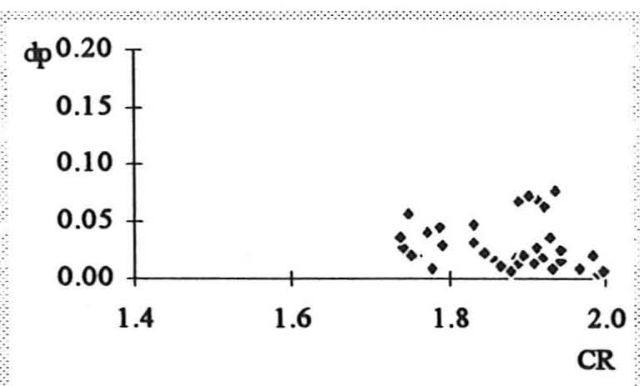

Tratamento tr2

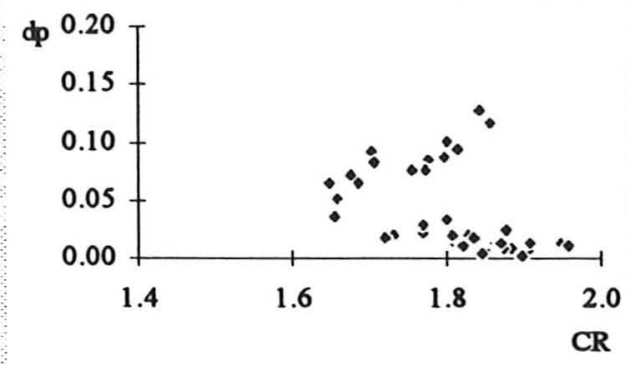

Tratamento tr1

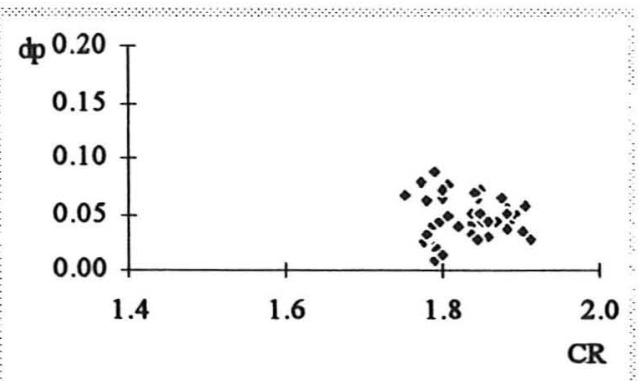

Tratamento trbs

PROFUNDIDADE $0,60 \mathrm{~m}$.

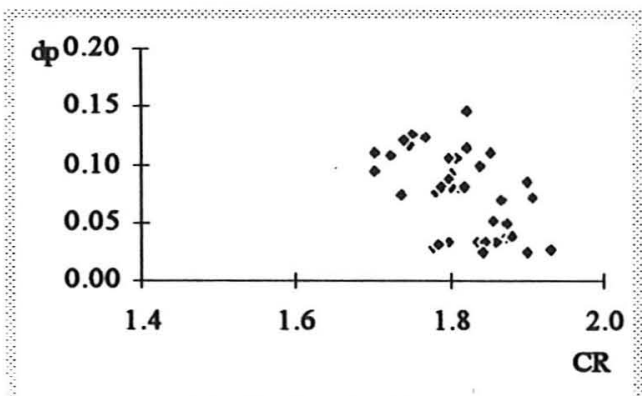

Tratamento tro

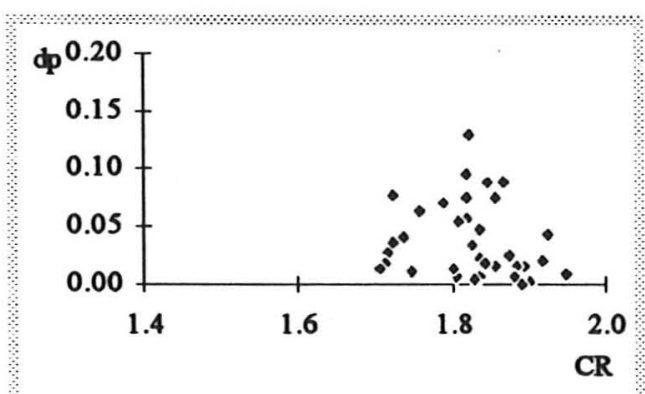

Tratamento tr2

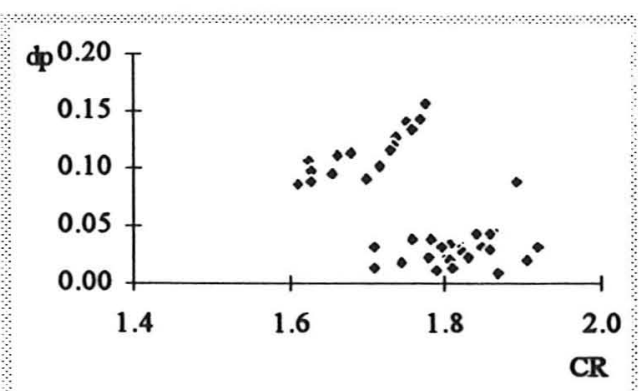

Tratamento tr1

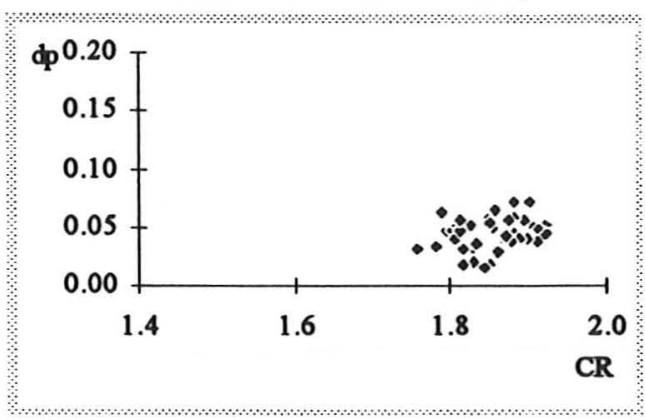

Tratamento trbs

PROFUNDIDADE $0,70 \mathrm{~m}$. 


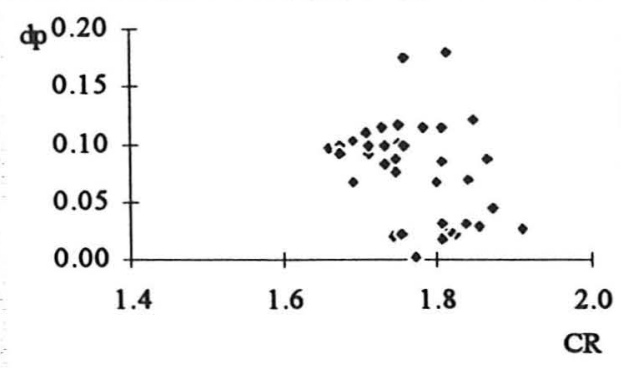

Tratamento tro

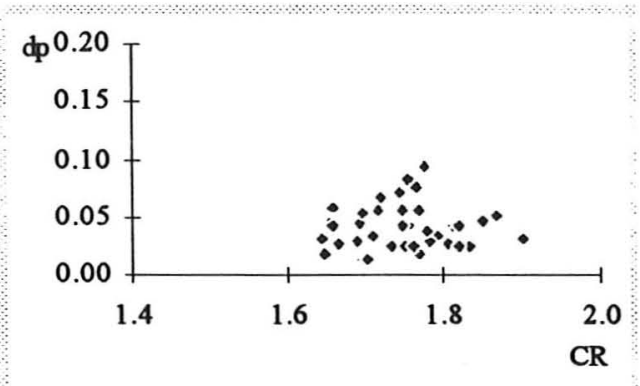

Tratamento tr2

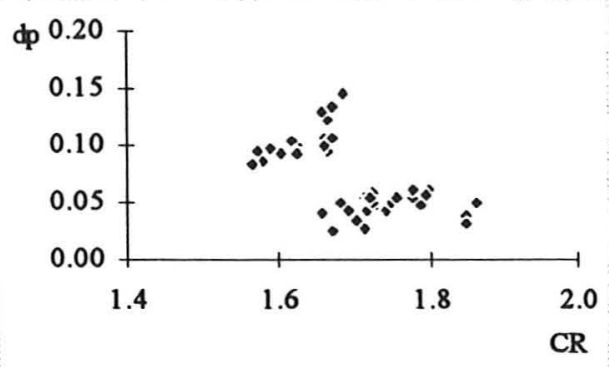

Tratamento tr1

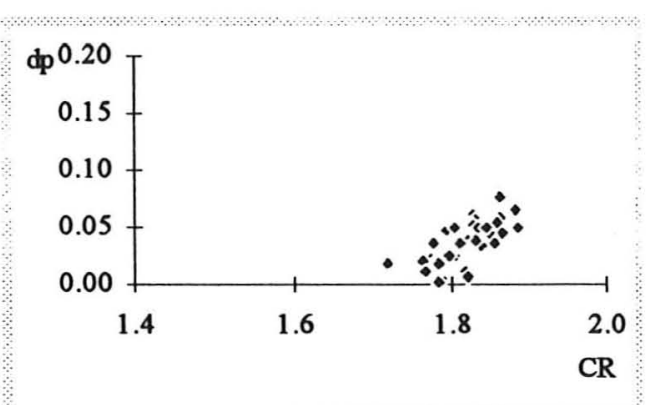

Tratamento trbs

PROFUNDIDADE $0,80 \mathrm{~m}$.

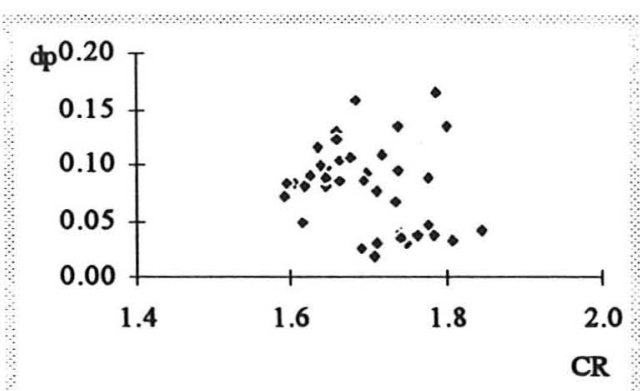

Tratamento tro

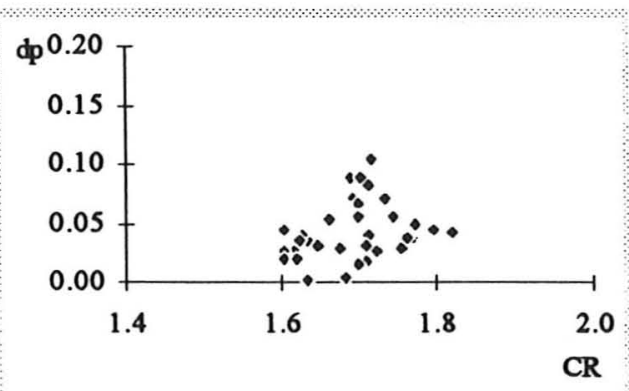

Tratamento tr2

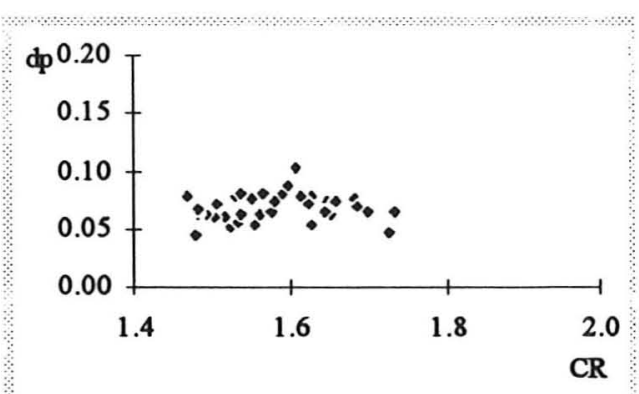

Tratamento tr1

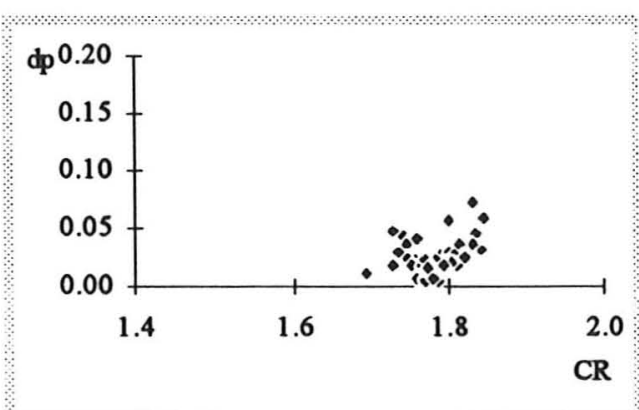

Tratamento trbs

PROFUNDIDADE $0,90 \mathrm{~m}$. 


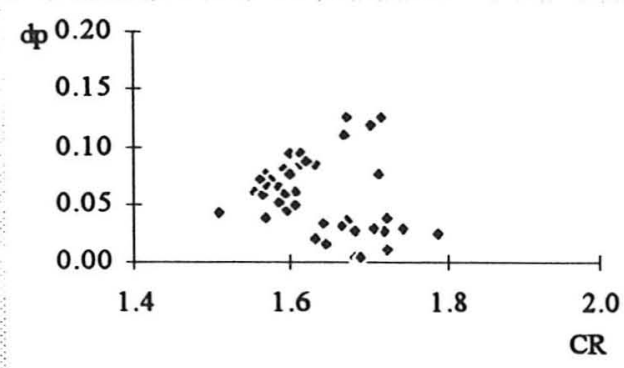

Tratamento tro

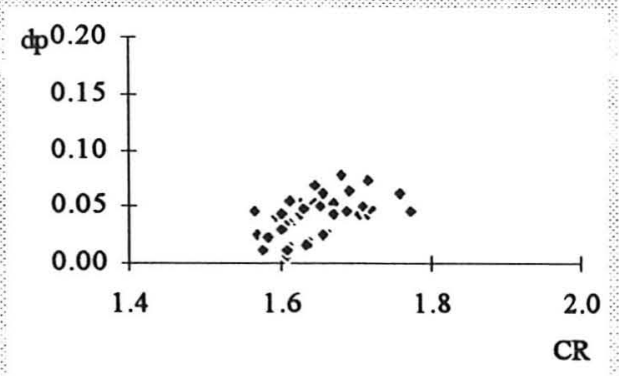

Tratamento tr2

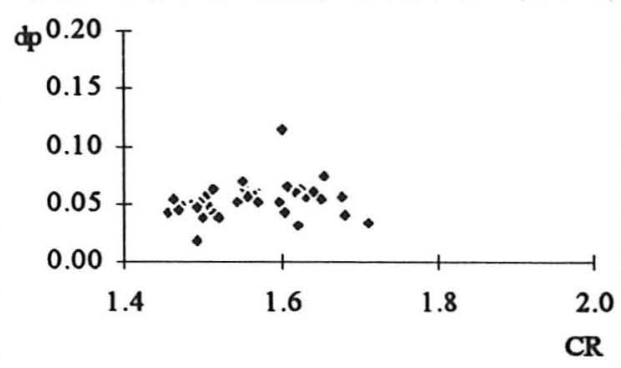

Tratamento tr1

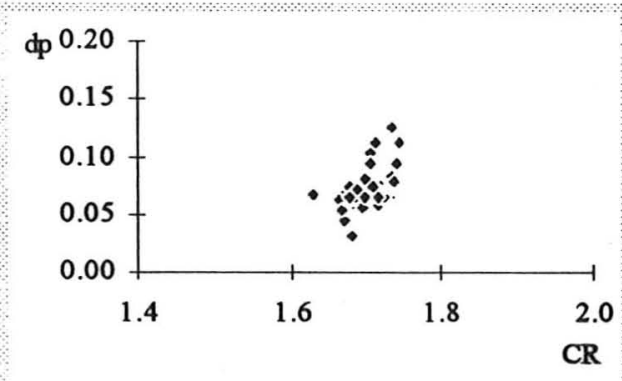

Tratamento trbs

PROFUNDIDADE $1,00 \mathrm{~m}$.

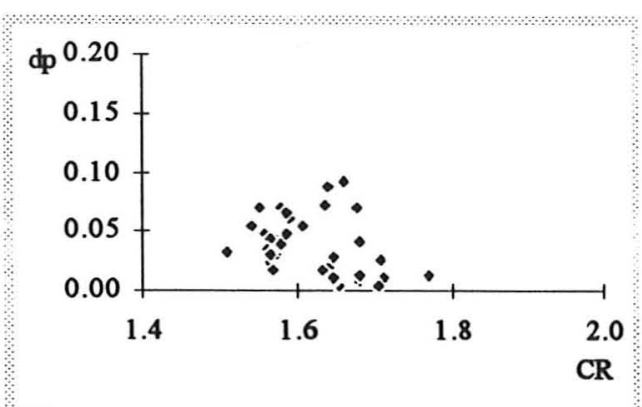

Tratamento tro

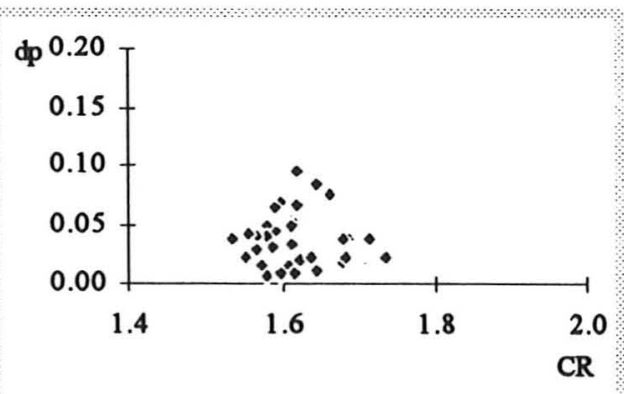

Tratamento tr2

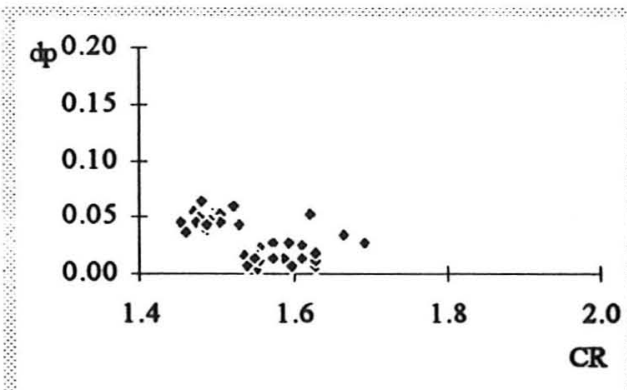

Tratamento trl

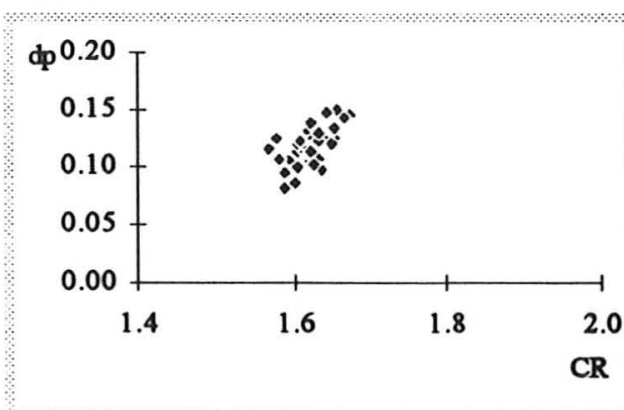

Tratamento trbs 


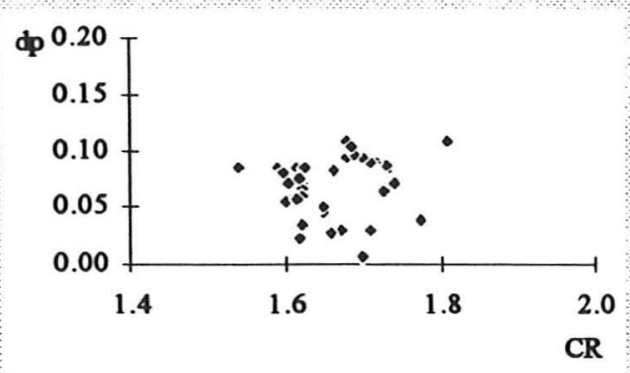

Tratamento tro

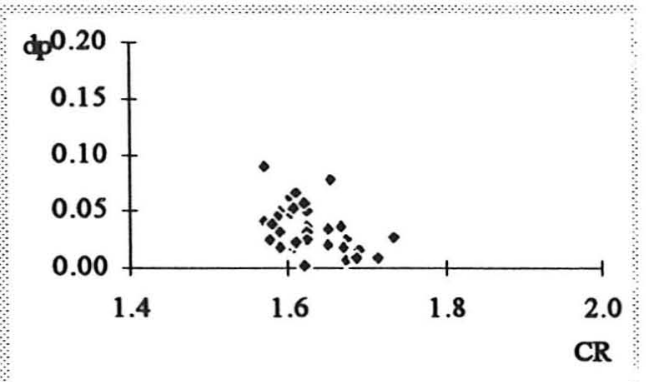

Tratamento tr2

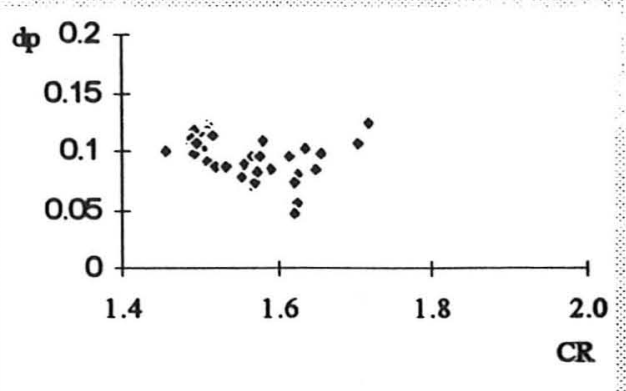

Tratamento tr1

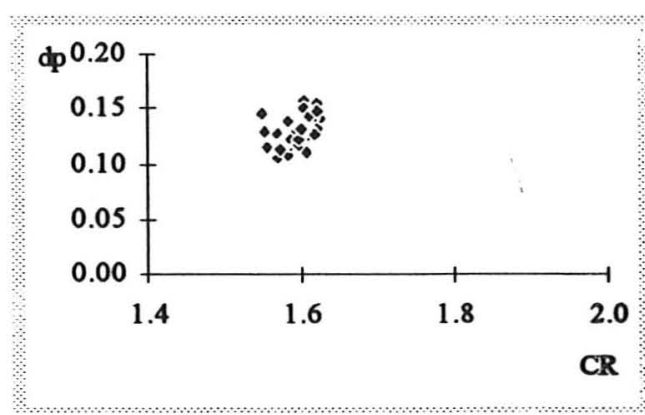

Tratamento trbs

PROFUNDIDADE $1,20 \mathrm{~m}$. 